\title{
Methods for Estimating Magnitude and Frequency of Floods in the Southwestern United States
}

By BLAKEMORE E. THOMAS, H.W. HJALMARSON, and S.D. WALTEMEYER

U.S. GEOLOGICAL SURVEY

Open-File Report 93-419

Prepared in cooperation with the

COLORADO DEPARTMENT OF HIGHWAYS,

ARIZONA DEPARTMENT OF TRANSPORTATION,

CALIFORNIA DEPARTMENT OF TRANSPORTATION, IDAHO DEPARTMENT OF TRANSPORTATION, NEVADA DEPARTMENT OF TRANSPORTATION, NEW MEXICO STATE HIGHWAY AND TRANSPORTATION DEPARTMENT, OREGON DEPARTMENT OF TRANSPORTATION, TEXAS DEPARTMENT OF TRANSPORTATION, and UTAH DEPARTMENT OF TRANSPORTATION

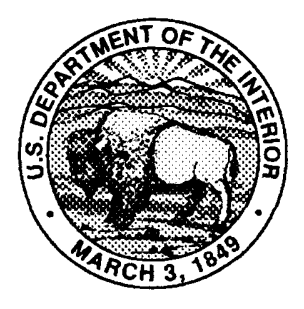




\title{
U.S. DEPARTMENT OF THE INTERIOR BRUCE BABBITT, Secretary
}

\author{
U.S. GEOLOGICAL SURVEY \\ Gordon P. Eaton, Director
}

For additional information write to:

District Chief

U.S. Geological Survey Water Resources Division 375 South Euclid Avenue Tucson, AZ 85719-6644
Copies of this report can be purchased from:

U.S. Geological Survey Earth Science Information Center Open-File Reports Section Box 25286, MS 517

Denver Federal Center Denver, CO 80225 


\section{CONTENTS}

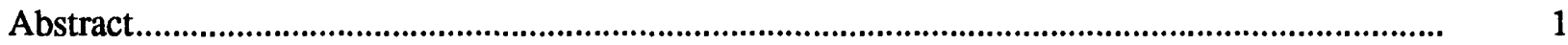

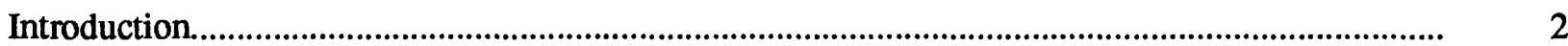

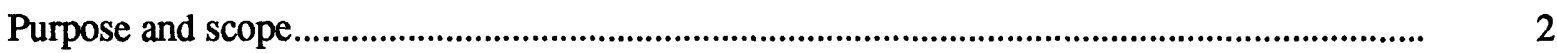

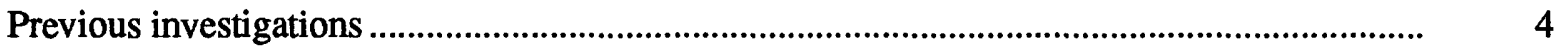

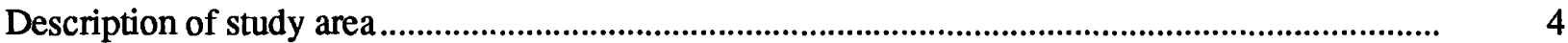

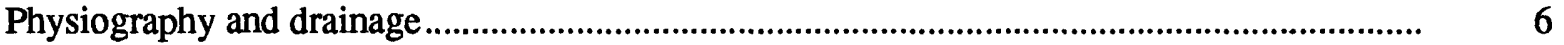

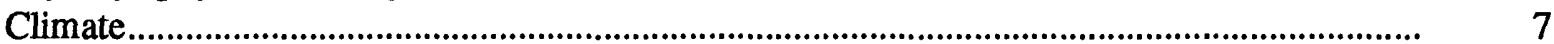

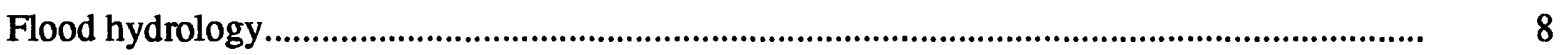

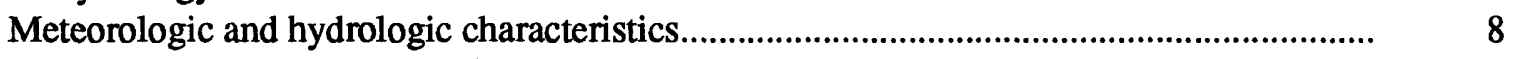

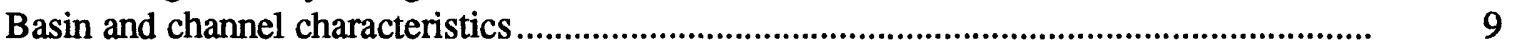

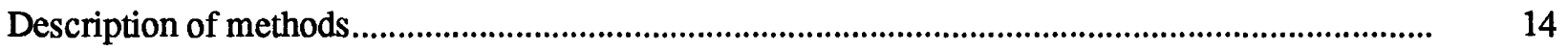

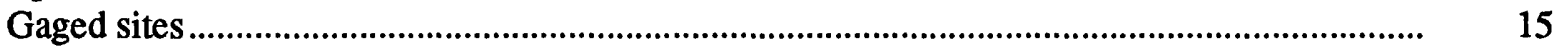

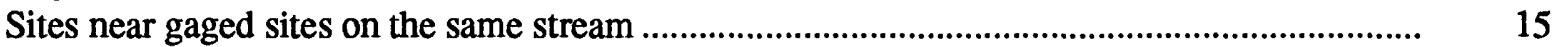

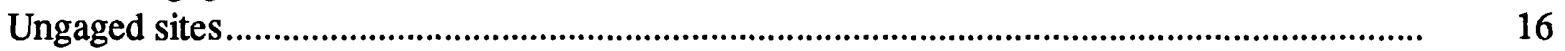

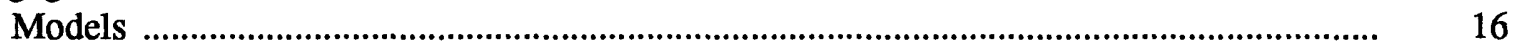

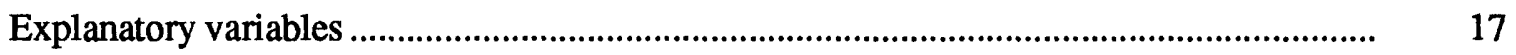

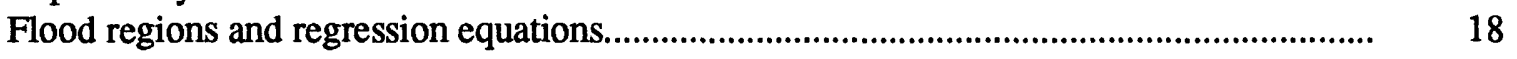

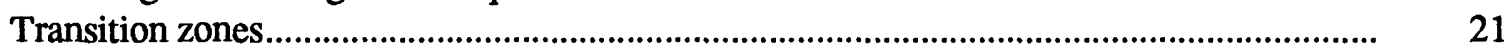

Excluded streams and distributary-flow areas ............................................................. 22

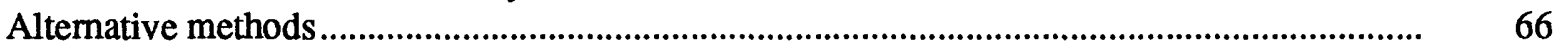

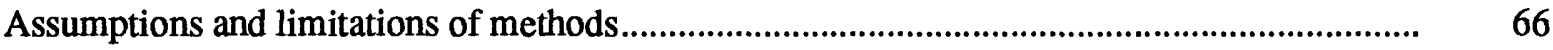

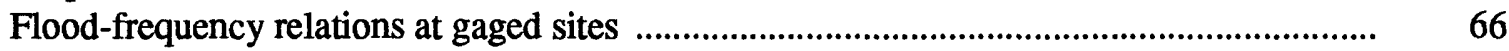

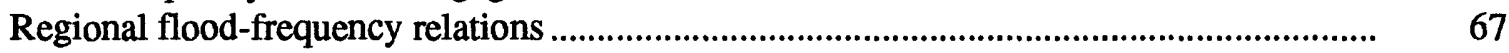

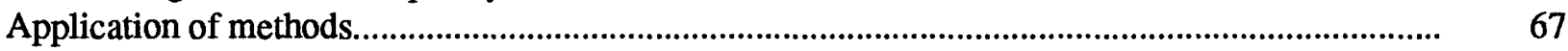

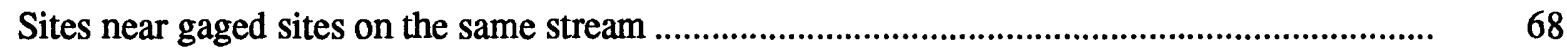

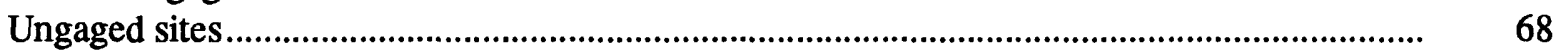

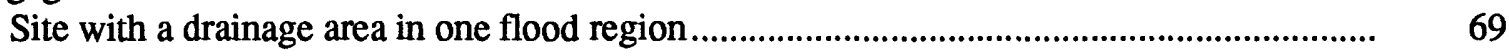

Site with a drainage area in two low- to middle-elevation flood regions........................... 70

Low- to middle-elevation site near the high-elevation flood region .................................... 70

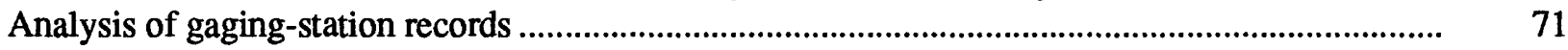

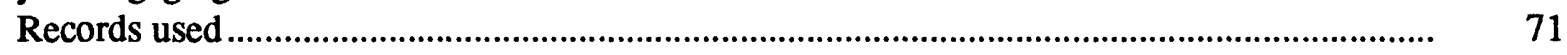

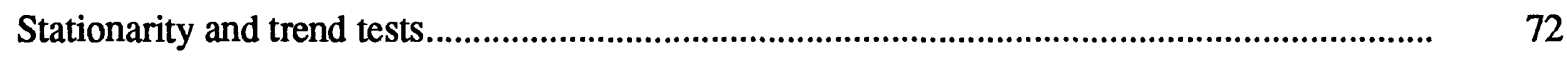

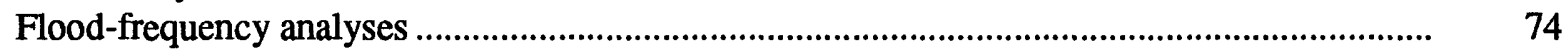

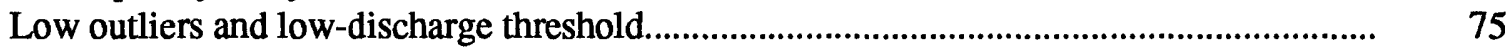

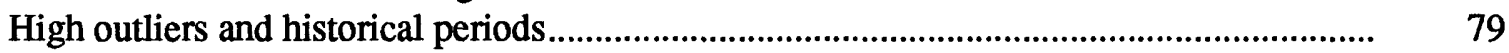

Sharp breaks or discontinuities in plotted peaks .......................................................... $\quad 82$

Gaged sites with inadequate samples or non-log-Pearson Type III distribution.................. $\quad 85$

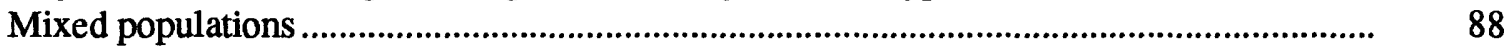

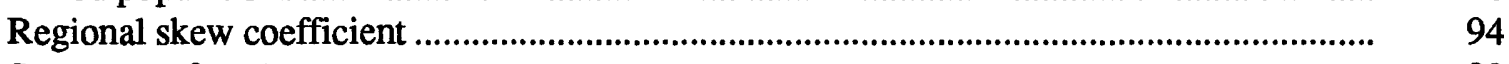

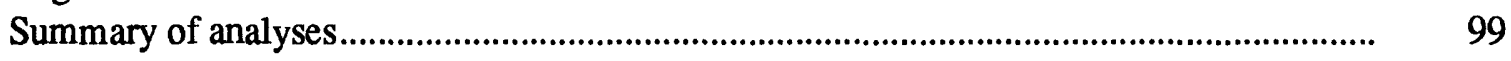

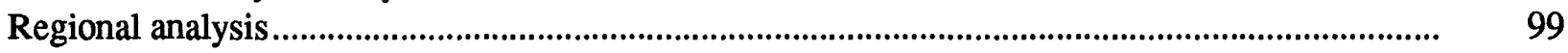

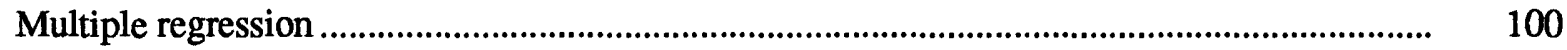

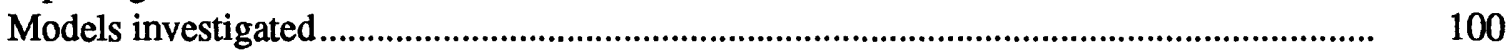

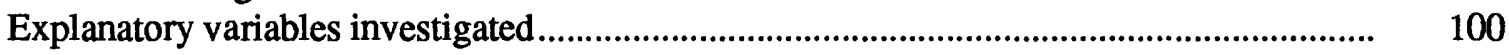

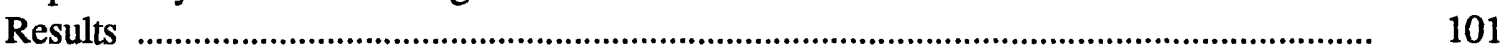

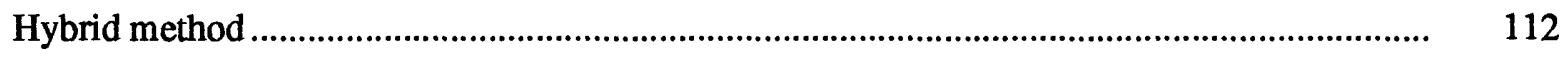

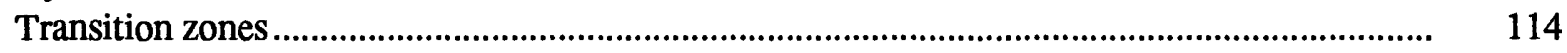




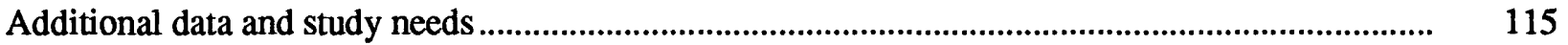

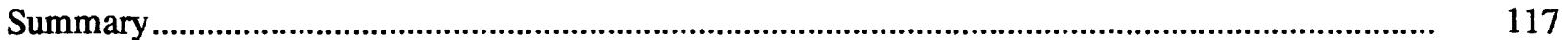

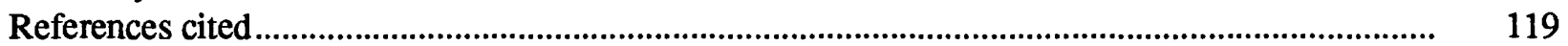

Basin, climatic, and flood characteristics for streamflow-gaging stations in the southwestern United States.

\section{FIGURES}

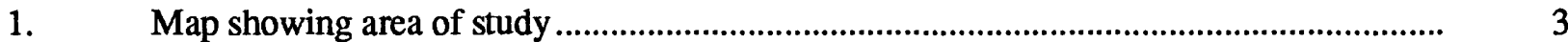

2. Map showing physiographic provinces in the study area ........................................... 5

3-4. Graphs showing relation between:

3. Latitude and the maximum unit peak discharge of record at gaged sites in the southwestern United States

4. Site elevation, latitude, and maximum unit peak discharge of record at gaged sites in the southwestern United States.

5. Graph showing estimated elevation threshold for large floods caused by thunderstorms in the southwestern United States.

6-16. Maps showing flood regions in:

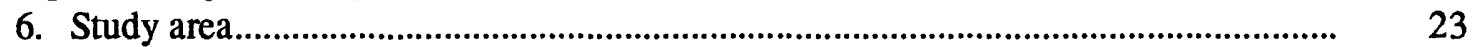

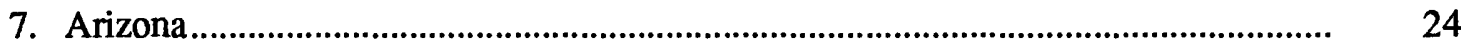

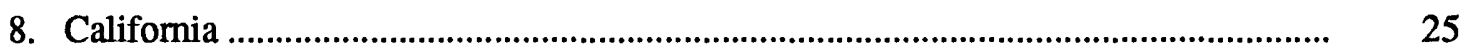

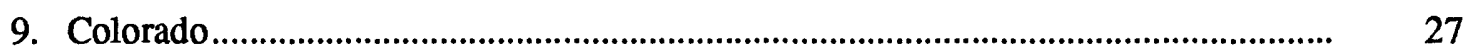

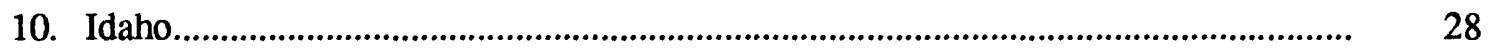

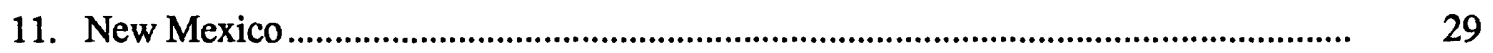

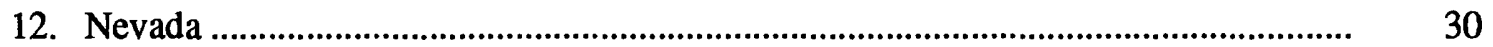

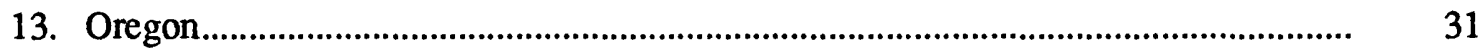

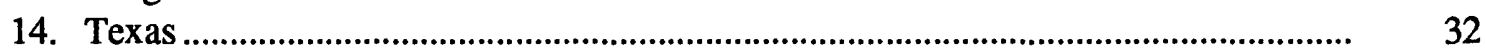

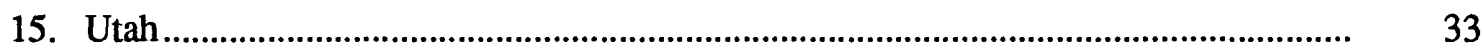

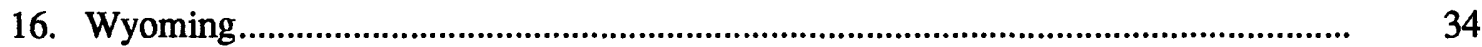

17-23. Graphs showing:
17. Relation between maximum peak discharge of record and drainage area for gaged sites in the study area.................................................................... $\quad 35$

18. Joint distribution of mean annual precipitation and drainage area for gaged sites in High-Elevation Region 1 ....................................................... $\quad 36$

19. Relations between 100-year peak discharge and drainage area and plot of maximum peak discharge of record and drainage area for gaged sites in High-Elevation Region 1

20. Joint distribution of mean basin elevation and drainage area for gaged sites in the Northwest Region 2 .

21. Relations between 100-year peak discharge and drainage area and plot of maximum peak discharge of record and drainage area for gaged sites in the Northwest Region 2

22. Joint distribution of mean annual precipitation and drainage area for gaged sites in the South-Central Idaho Region 3

23. Relations between 100-year peak discharge and drainage area and plot of maximum peak discharge of record and drainage area for gaged sites in the South-Central Idaho Region 3 
24-41. Graphs showing:

24. Joint distribution of mean basin elevation and drainage area for gaged sites in the Northeast Region 4

25. Relations between 100-year peak discharge and drainage area and plot of maximum peak discharge of record and drainage area for gaged sites in the Northeast Region 4

26. Joint distribution of latitude and drainage area for gaged sites in the Eastern Sierras Region 5

27. Joint distribution of mean basin elevation and drainage area for gaged sites in the Eastern Sierras Region 5.

28. Relations between 100-year peak discharge and drainage area and plot of maximum peak discharge of record and drainage area for gaged sites in the Eastern Sierras Region 5.

29. Joint distribution of mean basin elevation and drainage area for gaged sites in the Northem Great Basin Region 6.

30. Relations between 100-year peak discharge and drainage area and plot of maximum peak discharge of record and drainage area for gaged sites in the Northern Great Basin Region 6

31. Joint distribution of mean basin elevation and drainage area for gaged sites in the South-Central Utah Region 7.

32. Relations between 100-year peak discharge and drainage area and plot of maximum peak discharge of record and drainage area for gaged sites in the South-Central Utah Region 7.

33. Joint distribution of mean basin elevation and drainage area for gaged sites in the Four Corners Region 8.

34. Relations between 100-year peak discharge and drainage area and plot of maximum peak discharge of record and drainage area for gaged sites in the Four Corners Region 8

35. Joint distribution of mean basin elevation and drainage area for gaged sites in the Western Colorado Region 9.

36. Relations between 100-year peak discharge and drainage area and plot of maximum peak discharge of record and drainage area for gaged sites in the Western Colorado Region 9.

37. Relations between 100-year peak discharge and drainage area and plot of maximum peak discharge of record and drainage area for gaged sites in the Southern Great Basin Region 10

38. Joint distribution of mean annual evaporation and drainage area for gaged sites in the Northeastern Arizona Region 11.

39. Relations between 100-year peak discharge and drainage area and plot of maximum peak discharge of record and drainage area for gaged sites in the Northeastern Arizona Region 11

40. Joint distribution of mean basin elevation and drainage area for gaged sites in the Central Arizona Region 12

41. Relations between 100-year peak discharge and drainage area and plot of maximum peak discharge of record and drainage area for gaged sites in the Central Arizona Region 12 
42-49. Graphs showing:

42. Relations between 100-year peak discharge and drainage area and plot of maximum peak discharge of record and drainage area for gaged sites in the Southern Arizona Region 13

43. Joint distribution of mean basin elevation and drainage area for gaged sites in the Upper Gila Basin Region 14

44. Relations between 100-year peak discharge and drainage area and plot of maximum peak discharge of record and drainage area for gaged sites in the Upper Gila Basin Region 14

45. Joint distribution of longitude and drainage area for gaged sites in the Upper Rio Grande Basin Region 15.

46. Joint distribution of mean basin elevation and drainage area for gaged sites in the Upper Rio Grande Basin Region 15.

47. Relations between 100-year peak discharge and drainage area and plot of maximum peak discharge of record and drainage area for gaged sites in the Upper Rio Grande Basin Region 15

48. Joint distribution of mean annual evaporation and drainage area for gaged sites in the Southeast Region 16

49. Relations between 100-year peak discharge and drainage area and plot of maximum peak discharge of record and drainage area for gaged sites in the Southeast Region 16

50-51. Maps showing:

50. Gaging stations used in this study.

51. Gaging stations with an applied low-discharge threshold

52-53. Graphs showing flood-frequency relations for:

52. Santa Cruz River near Lochiel, Arizona (09480000)

53. New River near Glendale, Arizona (09513910)

54. Map showing gaging stations with a high outlier

55. Graph showing examples of gaging-station records with sharp breaks or discontinuities in their plotted peaks

56. Map showing gaging stations with sharp breaks or discontinuities in their plotted peaks

57. Graph showing examples of plotted peaks for gaging stations with samples that are inadequate to define a flood-frequency relation.

58. Map showing gaging stations with samples that are inadequate to define a flood-frequency relation.

59. Graph showing elevation zone for mixed population of floods caused by thunderstorms and snowmelt in the southwestern United States.

60. Map showing gaging stations with an analysis for a mixed population of floods caused by thunderstorms and snowmelt

61-63. Graphs showing flood-frequency relations for:

61. South Fork of Rock Creek near Hanna, Utah (09278000).......................................... 93

62. Big Creek near Randolf, Utah (10023000) ........................................................... 93

63. Mill Creek near Moab, Utah (09184000)................................................................... 94 
64-66. Graphs showing relation between:

64. 100-year peak discharge and drainage area for Southern Arizona Region 13............ 104

65. Logarithm of 100-year peak discharge and drainage area for

Southern Arizona Region 13

66. 100-year peak discharge and drainage area for the northern, middle, and southern parts of the study area.

\section{TABLES}

1. Areas of study of previous regional flood-frequency investigations

2. Relation between season of occurrence of annual peak discharges and latitude in the southwestern United States.

3. Magnitude of maximum unit-peak discharge of record compared to latitude and proportions of peaks caused by thunderstorms in the southwestern United States.......

4. Summary of selected characteristics of flood regions in the southwestern United States

5-9. Generalized least-squares regression equations for estimating regional flood-frequency relations for the:

5. High-Elevation Region 1.

6. Northwest Region 2 ...................................................................................

7. South-Central Idaho Region 3 …………………………...................................... 40

8. Northeast Region 4................................................................................. 42

9. Eastern Sierras Region 5 ................................................................................

10. Hybrid equations for estimating regional flood-frequency relations for the Northern Great Basin Region 6.

11-13. Generalized least-squares regression equations for estimating regional flood-frequency relations for the:

11. South-Central Utah Region 7 .............................................................................

12. Four Comers Region 8 ……........................................................................ 50

13. Western Colorado Region 9 .............................................................................. 52

14-15. Hybrid equations for estimating regional flood-frequency relations for the:

14. Southern Great Basin Region 10 ........................................................................ 54

15. Northeastem Arizona Region 11 ....................................................................... 55

16-19. Generalized least-squares regression equations for estimating regional flood-frequency relations for the:

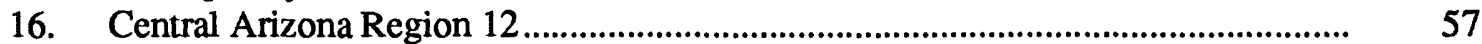

17. Southern Arizona Region 13 ........................................................................ 59

18. Upper Gila Basin Region 14 ........................................................................ 60

19. Upper Rio Grande Basin Region 15 ................................................................... 63

20. Hybrid equations for estimating regional flood-frequency relations for Southeast Region 16.............................................................................................. 64

21. Drainage area and years of systematic record at gaging stations in the southwestern United States.........................................................................................

22. Significance of trends over time in annual peak discharges for gaging stations with at least 30 years of record in the southwestern United States................... $\quad 74$

23. Summary of characteristics of station flood-frequency relations in the southwestern United States. 
24. Characteristics of station flood-frequency relations compared to basin and climatic characteristics in the southwestern United States.

25. Percentage of gaging stations with undefined flood-frequency relations compared to basin and climatic characteristics in the southwestern United States

26. Summary of analyses of mixed-population flood records in the southwestern United States

27. Correlation matrix with 100-year peak discharge and explanatory variables for the southwestern United States

28. Stepwise ordinary least-squares regression of T-year discharge and basin and climatic characteristics for the entire low- to middle-elevation study area

29. Summary of estimated prediction errors of generalized least-squares regional models.

30. Summary of residuals from low- to middle-elevation regional models, high-elevation model, and composite model for gaged sites in a transition zone

\section{CONVERSION FACTORS}

\begin{tabular}{lcl}
\hline Multiply & By & To obtain \\
\hline inch (in.) & 25.40 & millimeter \\
foot (ft) & 0.3048 & meter \\
square mile $\left(\mathrm{mi}^{2}\right)$ & 2.590 & square kilometer \\
cubic foot per second $\left(\mathrm{ft}^{3} / \mathrm{s}\right)$ & 0.02832 & cubic meter per second \\
cubic foot per second per square mile & 0.01093 & $\begin{array}{c}\text { cubic meter per second per square } \\
{\left[\left(\mathrm{ft}^{3} / \mathrm{s}\right) / \mathrm{mi}^{2}\right]}\end{array}$ \\
\end{tabular}

Air temperatures are given in degrees Fahrenheit $\left({ }^{\circ} \mathrm{F}\right)$, which can be converted to degrees Celsius $\left({ }^{\circ} \mathrm{C}\right)$ by the following equation:

$$
{ }^{\circ} \mathrm{C}=5 / 9\left({ }^{\circ} \mathrm{F}\right)-32
$$

\section{VERTICAL DATUM}

Sea level: In this report "sea level" refers to the National Geodetic Vertical Datum of 1929 -A geodetic datum derived from a general adjustment of the first-order level nets of the United States and Canada, formerly called "Sea Level Datum of 1929." 


\title{
Methods for Estimating Magnitude and Frequency of Floods in the Southwestern United States
}

\author{
By Blakemore E. Thomas, H.W. Hjalmarson, and S.D. Waltemeyer
}

\begin{abstract}
Equations for estimating 2-, 5-, 10-, 25-, 50-, and 100-year peak discharges at ungaged sites in the southwestern United States were developed using generalized least-squares multiple-regression techniques and a hybrid method that was developed in this study. The equations are applicable to unregulated streams that drain basins of less than about 200 square miles. Drainage area, mean basin elevation, mean annual precipitation, mean annual evaporation, latitude, and longitude are the basin and climatic characteristics used in the equations. The study area was divided into 16 flood regions; Region 1 is a high-elevation region that includes the entire study area.
\end{abstract}

Floods in the northern latitudes of the study area generally are much smaller than floods in the southern latitudes. Typical unit peak discharges of record range from 316 cubic feet per second per square mile for sites between $29^{\circ}$ and $37^{\circ}$ latitude to 26 cubic feet per second per square mile for sites between $41^{\circ}$ and $45^{\circ}$ latitude. An elevation threshold exists in the study area above which large floods caused by thunderstorms are unlikely to occur. For sites between $29^{\circ}$ and $41^{\circ}$ latitude, the elevation threshold is approximately 7,500 feet. For sites between $41^{\circ}$ and $45^{\circ}$ latitude, the elevation threshold decreases in a northward direction at a rate of about 300 feet for each degree of latitude.

Detailed flood-frequency analyses were made of more than 1,300 gaging stations with a combined 40,000 station years of annual peak discharges through water year 1986. The log-Pearson Type III distribution and the method of moments were used to define flood-frequency relations. A low-discharge threshold was applied to about one-half of the sites to adjust the relations for low outliers. With few exceptions, the use of the low-discharge threshold resulted in markedly better-appearing fits between the computed relations and the plotted annual peak discharges. After all adjustments were made, 80 percent of the gaging stations were judged to have adequate fits of the computed relations to the plotted data. The individual flood-frequency relations were judged to be unreliable for the remaining 20 percent of the stations because of extremely poor fits of the computed relations to the data, and these relations were not used in the generalized least-squares regional-regression analysis. Most of the stations with unreliable relations were from extremely arid areas with 43 percent of the stations having no flow for more than 25 percent of the years of record. A new regional flood-frequency method, which is named the hybrid method, was developed for those more arid regions.

An analysis of regional skew coefficient was made for the study area. The methods of attempting to define the variation in skew by geographic areas or by regression with basin and 
climatic characteristics all failed to improve on a mean of zero for the sample. The regional skew used in the study, therefore, was the mean of zero with an associated error equal to the sample variance of $0.31 \log$ units.

Generalized least-squares regression was used to define the regression models in 12 regions where sufficient data allowed a reasonable regional model to be developed using the flood-frequency relations at gaged sites. Four regions had more than 30 percent of the gaged sites with no defined relations; thus the regression method was not used because of the large amount of missing information. The hybrid method was used in those four regions because individual fitted flood-frequency relations are not required and data from all gaging stations in a region can be used. Average standard error of prediction of the generalized least-squares regional models for 12 regions ranged from 39 to 95 percent for the 100-year peak discharge, and only three of those models have errors of greater than 70 percent. The estimated average standard error of the hybrid models for four regions, which was computed differently than generalized least-squares errors, ranged from 0.44 to $1.8 \mathrm{log}$ units for the 100-year peak discharge.

\section{INTRODUCTION}

Flood-frequency information is needed for the cost-effective design of bridges, culverts, dams, and embankments and for the management of flood plains. In this study, methods were developed by the U.S. Geological Survey for estimating magnitude and frequency of floods of streams in basins of less than about $200 \mathrm{mi}^{2}$ in the arid southwestern United States. The reliable estimation of flood-frequency relations for both gaged and ungaged streams that drain these arid basins is complex because rainfall is variable in time and space and the physiography of the drainage basins is extremely variable. The development of accurate flood-frequency relations at gaged sites is unlikely in some areas because of the variability of annual peak discharges and short records. At some sites, most years have no flow. At other sites, commonly used probability distributions do not appear to fit the plot of annual peak discharges.

The understanding of the flood characteristics of streams in arid lands is improved because of the regional perspective of this study. A large data base of streamflow-gaging-station records was evaluated for most of the southwestern United States. The study was done in cooperation with the Departments of Transportation of nine States-Colorado, Arizona, California, Idaho, Nevada, New Mexico, Oregon, Texas, and Utah.

\section{Purpose and Scope}

This report describes the results of a study to develop reliable methods for estimating magnitude and frequency of floods for gaged and ungaged streams in the southwestern United States and to improve the understanding of flood hydrology in the southwestern United States. The large study area, which encompasses most of the arid lands of the southwestern United States, provided an opportunity to examine truly regional relations. Current and new methods for estimating regional flood-frequency relations and associated errors were investigated. The study area includes all of Arizona, Nevada, and Utah, and parts of California, Colorado, Idaho, New Mexico, Oregon, Texas, and Wyoming (fig. 1).

The data examined in the study include sites with drainage areas of less than $2,000 \mathrm{mi}^{2}$ and mean annual precipitation of less than 68 in. The focus of the study, however, was on drainage areas of less than about $200 \mathrm{mi}^{2}$ and arid areas with less than 20 in. of mean annual precipitation. The series of annual peak discharges for sites used in this study are unaffected by regulation, and the individual sites have at least 10 years of record through water year 1986.

The basic regional method used in this study is an information-transfer method in which floodfrequency relations determined at gaged sites are transferred to ungaged sites using multiple- 


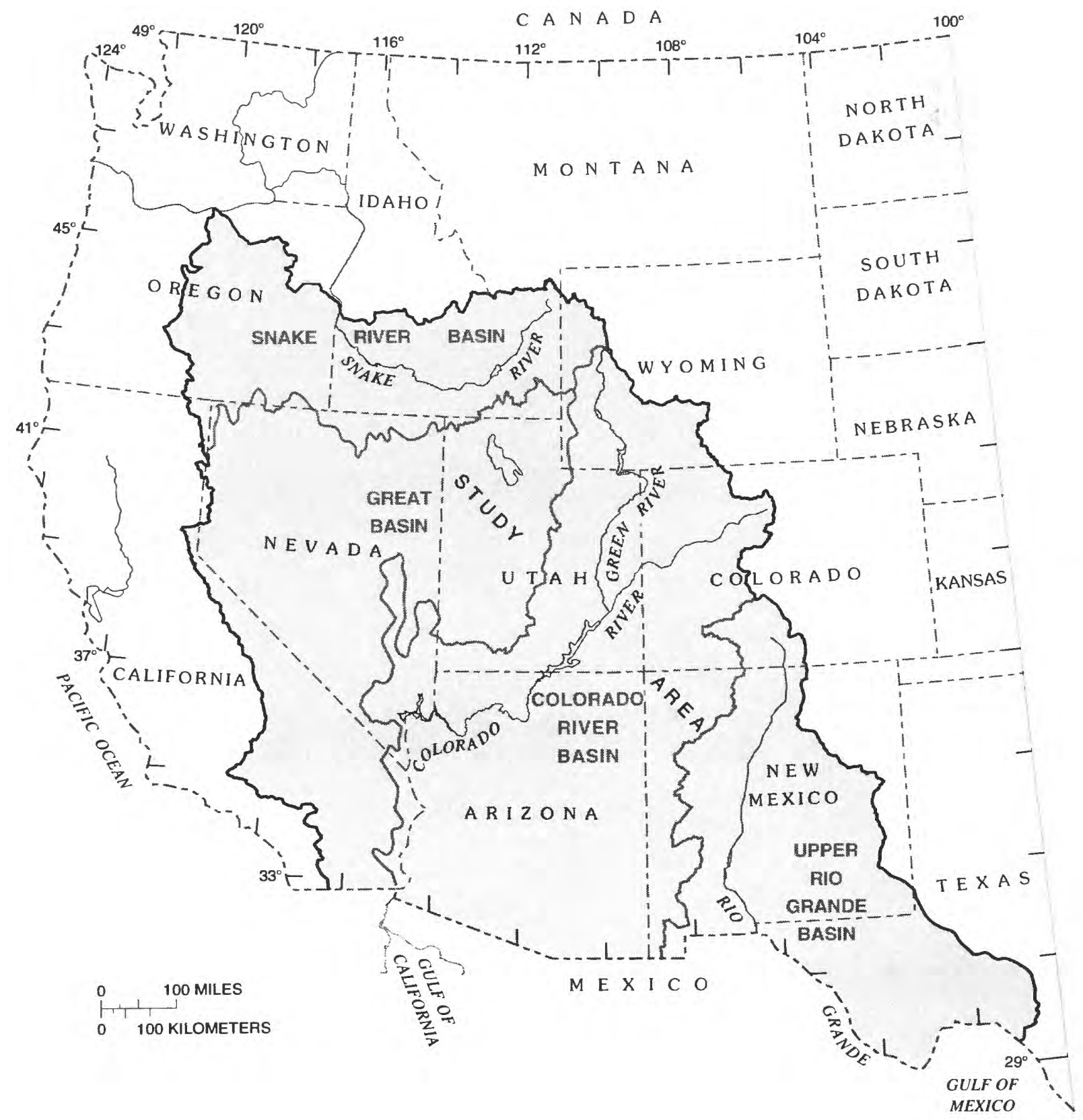

Figure 1. Area of study (shaded). 
regression techniques. Flood-frequency relations were determined at gaged sites using guidelines recommended by the Interagency Advisory Committee on Water Data (1982). Ordinary and generalized least-squares multiple-regression analyses were used to relate the gaged-site flood-frequency relations to basin and climatic characteristics.

During this study, a new method of estimating regional flood-frequency relations was developed (Hjalmarson and Thomas, 1992). The new method, named the hybrid method, combines elements of the station-year method and multiple-regression analysis. Individual flood-frequency relations are not used in the new method, thus the method is useful for extremely arid areas where development of reliable flood-frequency relations at gaged sites is difficult.

This regional study offers several advantages compared with previous State-wide regional studies. The large data base of more than 1,300 gaged sites with about 40,000 station years of annual maximum peaks can decrease the time-sampling error of flood estimates, which can be a problem with small data sets in the southwestern United States. Some of the recent regional studies developed for single States have large differences in the estimated flood-frequency relations at State boundaries. These different estimates of flood magnitudes at State boundaries were removed in this study. Regional relations that were derived from the large data base with a large range of values are potentially more reliable than relations derived from smaller data bases and can be used with less extrapolation for ungaged streams. The data base for this study is in a section entitled "Basin, Climatic, and Flood Characteristics for Streamflow-Gaging Stations," at the end of this report and hereafter will be referred to as the data section.

A goal of this study was to define regional flood-frequency relations with a standard error of prediction of less than approximately 50 percent. This goal was accomplished for some regions of the study area. For the more arid regions in particular, this goal was impossible to accomplish and errors in excess of 100 percent could not be reduced.
The first sections of this report serve as a design guide for engineers and hydrologists interested in estimating the magnitude and frequency of floods. Maps of the States are used to show flood regions because most users of the method are State oriented. These design guide sections include the design methods, the accuracy of the estimated regional relations, examples of the design methods, and maps and (or) discussions of nonapplication areas within the study area.

\section{Previous Investigations}

Many investigations have been done on regional flood-frequency relations in the study area (table 1). Five regional studies of river basins were done using the index-flood method. Benson (1964) was one of the first investigators to use the multiple-regression method.

The multiple-regression method with basin and climatic characteristics as explanatory variables has been used to develop regional flood-frequency relations in the 10 individual States in the study area. Studies for six individual States have used measurements of channel geometry as a predictor of regional flood-frequency relations. An additional channel-geometry study of the western United States included the entire study area (Hedman and Osterkamp, 1982). During the past decade, studies were done using paleoflood hydrologic techniques to extend streamflow records for hundreds or thousands of years (Kochel, 1980; Baker, 1984; Ely and Baker, 1985; Baker and others, 1987; O'Connor, Fuller, and Baker, 1986; O'Connor, Webb, and Baker, 1986; Fuller, 1987; Partridge and Baker, 1987; Roberts, 1987; and Webb and others, 1988).

\section{DESCRIPTION OF STUDY AREA}

The study area is about $600,000 \mathrm{mi}^{2}$ and includes all or parts of ten States-Arizona, California, Colorado, Idaho, Nevada, New Mexico, Oregon, Texas, Utah, and Wyoming. The area is bounded by the Rocky Mountains on the east, the northern slopes of the Snake River basin on the north, the Cascade-Sierra Mountains on the west, and the international border with Mexico on the south (figs. 1 and 2). 


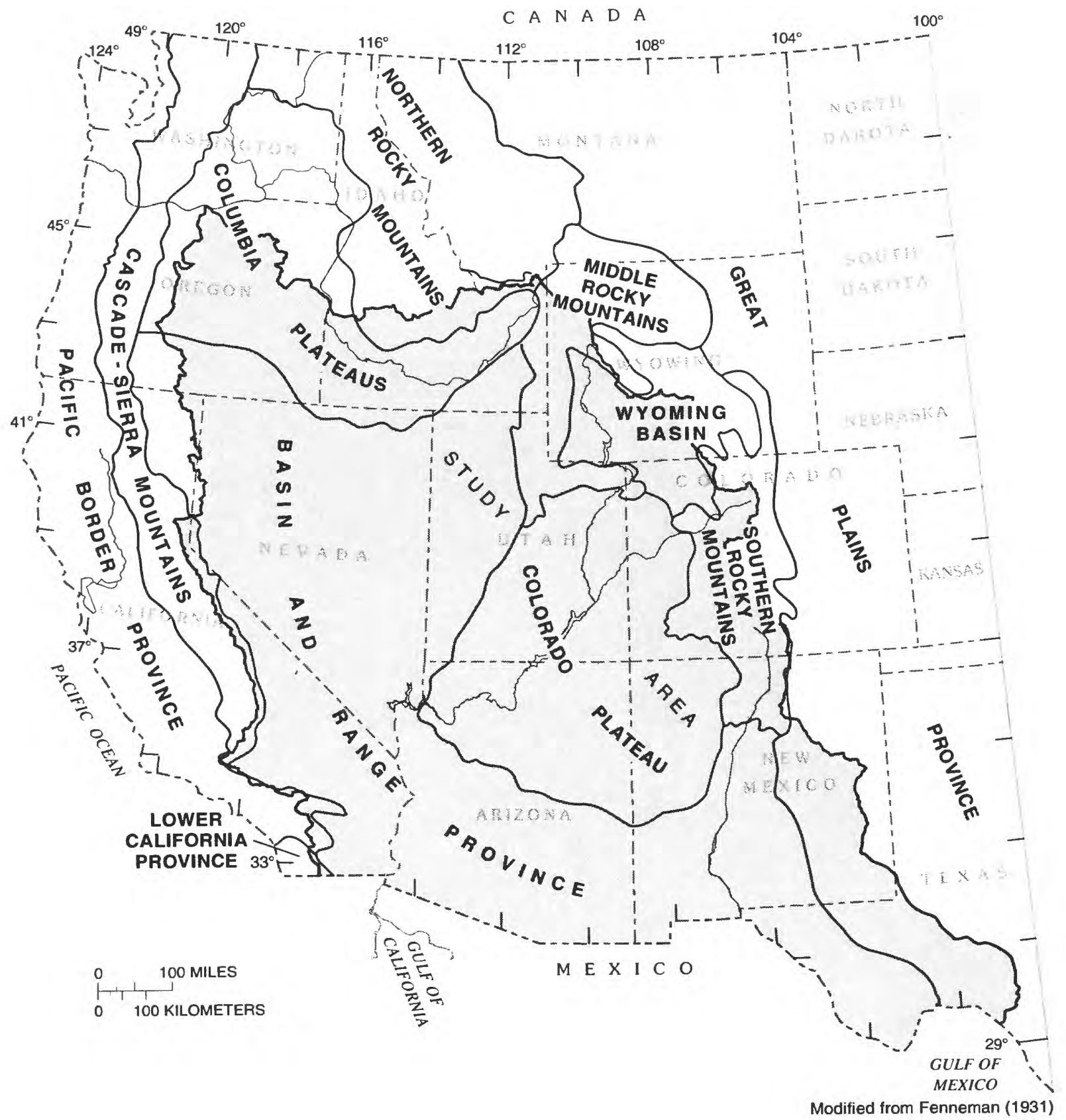

Figure 2. Physiographic provinces in the study area. 
Table 1. Areas of study of previous regional flood-frequency investigations

\begin{tabular}{|c|c|c|c|}
\hline \multirow{2}{*}{ State } & \multirow{2}{*}{ Index-flood method } & \multicolumn{2}{|c|}{ Multiple-regression method } \\
\hline & & Basin and cllmate & Channel geometry \\
\hline Arizona & $\begin{array}{l}\text { Patterson and Somers } \\
(1966)\end{array}$ & $\begin{array}{l}\text { Roeske (1978) } \\
\text { Boughton and Renard (1984) } \\
\text { Eychaner (1984) }\end{array}$ & No data \\
\hline California & $\begin{array}{l}\text { Butler and others (1966) } \\
\text { Patterson and Somers } \\
\text { (1966) }\end{array}$ & Wannanen and Crippen (1977) & No data \\
\hline Colorado & $\begin{array}{l}\text { Patterson and Somers } \\
\text { (1966) }\end{array}$ & $\begin{array}{l}\text { McCain and Jarrett (1976) } \\
\text { Kircher and others (1985) }\end{array}$ & Hedman and others (1972) \\
\hline Idaho & Thomas and others (1963) & $\begin{array}{l}\text { Thomas and others (1973) } \\
\text { Riggs and Harenburg (1976) } \\
\text { Kjelstrom and Moffatt } \\
\text { (1981) }\end{array}$ & $\begin{array}{l}\text { Riggs and Harenburg (1976) } \\
\text { Harrenburg (1980) }\end{array}$ \\
\hline Nevada & $\begin{array}{l}\text { Butler and others (1966) } \\
\text { Patterson and Somers } \\
\text { (1966) }\end{array}$ & Moore (1976) & Moore (1974) \\
\hline $\begin{array}{l}\text { New } \\
\text { Mexico }\end{array}$ & $\begin{array}{l}\text { Patterson (1965) } \\
\text { Patterson and Somers } \\
\text { (1966) }\end{array}$ & $\begin{array}{l}\text { Scott (1971) } \\
\text { Thomas and Gold (1982) } \\
\text { Hejl (1984) } \\
\text { Waltemeyer (1986) }\end{array}$ & Scott and Kunkler (1976) \\
\hline Oregon & $\begin{array}{l}\text { Thomas and others (1963) } \\
\text { Hulsing and Kallio (1964) } \\
\text { Butler and others (1966) }\end{array}$ & Harris and Hubbard (1982) & No data \\
\hline Texas & Patterson (1965) & $\begin{array}{l}\text { Massey and Schroeder (1977) } \\
\text { Schroeder and Massey (1977) }\end{array}$ & No data \\
\hline Utah & $\begin{array}{l}\text { Patterson and Somers } \\
\text { (1966) } \\
\text { Butler and others (1966) }\end{array}$ & $\begin{array}{l}\text { Butler and Cruff (1971) } \\
\text { Eychaner (1976) } \\
\text { Thomas and Lindskov (1983) } \\
\text { Christenson and others (1985) }\end{array}$ & Fields (1975) \\
\hline Wyoming & $\begin{array}{l}\text { Patterson and Somers } \\
\text { (1966) } \\
\text { Butler and others (1966) }\end{array}$ & $\begin{array}{l}\text { Lowham (1976) } \\
\text { Craig and Rankl (1978) } \\
\text { Lowham (1988) }\end{array}$ & Lowham (1988) \\
\hline $\begin{array}{l}\text { Multiple } \\
\text { States }\end{array}$ & & Benson (1964) & Hedman and Osterkamp (1982) \\
\hline
\end{tabular}

\section{Physiography and Drainage}

The topography varies between high rugged mountains and flat continuous plains. The elevation of the crestline of the Cascade-Sierra Mountains to the west and the Rocky Mountains to the east is commonly more than $10,000 \mathrm{ft}$; some peaks are more than $12,000 \mathrm{ft}$. In the interior part of the area, isolated mountains are separated by arid desert plains. Most of the mountain ranges trend north and northwest and commonly rise a few thousand feet above the adjacent alluvial plains. A large plateau was incised by the Colorado and Green Rivers in southeastern Utah, northeastern Arizona, and northwestern New Mexico. 
Fenneman (1931) provided a detailed description of the physiographic provinces in the study area (fig. 2). The northern, middle, and southern Rocky Mountains in the northern and eastern parts of the study area are high complex mountainous areas separated by lower basins or valleys. The Wyoming basin province in southwestern Wyoming lies between the southern and middle provinces of the Rocky Mountains. The major landform of the Wyoming basin is an elevated plain or plateau with some isolated low mountains scattered throughout the basin.

The Colorado Plateau province in the central part of the study area has nearly horizontal sedimentary rocks, generally high elevations of 5,000 to $11,000 \mathrm{ft}$, and many canyons and escarpments. Landforms include plains, plateaus, pediments, and isolated mountains.

The Basin and Range province in the western and southern part of the study area has mostly isolated block mountains separated by aggraded desert plains. The mountains commonly rise abruptly from the valley floors and have piedmont plains that extend downward to neighboring basin floors. Several large flat desert areas are interspersed between the mountains, and some are old lake bottoms that have not been covered with water for hundreds of years. Many of the piedmont plains contain distributary-flow areas that are composed of material deposited by mountain-front runoff.

The Cascade-Sierra Mountains province, which forms the west boundary of the study area, consists of volcanic mountains in Oregon and northern California and a block mountain range in eastern California. The Columbia Plateaus province in the northwestern part of the area mainly has nearly horizontal sheets of lava with a flat or rolling surface and some broad alluvial terraces and valleys interspersed throughout the area.

Major drainage basins in the study area include the entire Colorado River basin, the upper Rio Grande River basin, interior drainage of streams in the Great Basin, and part of the Snake River basin (fig. 1). The large rivers originate in high-elevation mountainous areas where precipitation is abundant and pass through arid desert areas on the way to the oceans or playas.

Most of the streams in the study area flow only in direct response to rainfall or snowmelt. In the northern latitudes and at the higher elevations where the climate is cooler and more humid, most of the streams flow continuously. Streams in alluvial valleys and base-level plains are perennial or intermittent where the stream receives ground-water outflow. Small streams in the southern latitudes commonly flow only a few hours during a year (Hjalmarson, 1991).

\section{Climate}

An arid or semiarid climate in the middle latitudes exists where potential evaporation from the soil surface and from vegetation exceeds the average annual precipitation (Trewartha, 1954, p. 267). About 90 percent of the study area is arid or semiarid and has a mean annual precipitation of less than $20 \mathrm{in.}$. In addition to the generally meager precipitation, the climate of the study area is characterized by extreme variations in precipitation and temperature. Mean annual precipitation ranges from more than 50 in. in the Cascade-Sierra Mountains in California to less than $3 \mathrm{in}$. in the deserts of southwestern Arizona and southeastern California. Temperatures range from about $110^{\circ} \mathrm{F}$ in the southwestern deserts in the summer to below $0^{\circ} \mathrm{F}$ in the northern latitudes and mountains in the winter. Precipitation in the study area is variable temporally and spatially. As a general rule, the relative variability of annual precipitation increases with decreasing annual amounts (Trewartha, 1954, p. 269). In some extremely arid parts of the study area, the mean annual precipitation has been exceeded by the rainfall from one or two summer thunderstorms.

Climate in the study area generally is influenced by latitude, elevation, and orographic effects. In the desert lowlands of the southern part of the study area, the climate is hot and dry. The high valleys of the north are cooler and also dry. Elevation has a complex effect on climate. On a small scale, annual precipitation increases and mean temperature decreases with increased 
elevation. Thus, throughout the study area, the climate can range from humid to arid within a few miles between mountains and adjacent valleys. On a larger scale, large elevation differences that are consistent over large areas cause an orographic effect on the climate. Areas on the leeward side of major mountain ranges such as the Cascade-Sierra Mountains of Oregon and California receive small quantities of precipitation. Areas on the windward side of land masses that intercept prevailing wind movement, such as the southern edge of the Colorado Plateau in central Arizona, receive large quantities of precipitation.

\section{Flood Hydrology}

Floods have been assigned many definitions on the basis of quantity and expected frequency of streamflow, relation of flow to the geometry of the stream channel, and possible damage to property. Thus, a flood can be any flow event that is large, that overtops the natural or artificial banks of a stream, or that results in loss of life or damage to property.

\section{Meteorologic and Hydrologic Characteristics}

Floods in the study area can be generated by several processes. High rates of rainfall that exceed infiltration capacity of the soils can cause rapid runoff and floods. Rapid melting of a snowpack as a result of high temperatures or rainfall on a snowpack also can cause floods. A unique combination of accumulation of snowpack, melting of the snowpack, freezing of the melted snow and ground, and then rainfall has caused large floods in northern Nevada and southern Idaho. Nearly all streams in the study area have a mixed population of floods. A mixed population is defined as an aggregation of floods that are caused by two or more distinct and generally independent hydrometeorologic conditions such as snowmelt and rainfall. Populations of floods in the study area are those caused by snowmelt; rainfall from thunderstorms, midlatitude cyclonic storms, upper-level low-pressure systems, and tropical cyclones; and rainfall on snow. The distribution of the populations of floods is related to distance from moisture sources and elevation.
Much of the moisture in the study area comes from the Pacific Ocean and the Gulfs of California and Mexico (fig. 1). In the northern part of the study area, moisture comes from all three sources, and midlatitude cyclonic storms and upper-level low pressure systems that move from west to east during October through May are the most frequent weather systems. Rainfall or snow and subsequent snowmelt from those weather systems cause most of the larger floods. In the southern part of the study area, the Gulf of Mexico and Gulf of California are the primary moisture sources, and rainfall from summer thunderstorms causes most of the larger floods. Elevation also influences the type of precipitation; snow commonly falls in the high elevations, and rain commonly falls in low elevations. Snow can occur in most of the study area; however, most of the accumulation of snow is at high elevations and in the northern latitudes. Because of a cooler climate, more floods from snowmelt occur at lower elevations in the northern latitudes than in the southern latitudes.

A general picture of the areal distribution of populations of floods in the study area can be seen by examining the season of occurrence of annual peak discharges. Each population of floods usually occurs during a particular season, therefore, the populations can be placed into three groups-peaks that occur in the spring, summer, or fall and winter. Snowmelt causes floods in the spring, and thunderstorms cause floods in the summer. Midlatitude cyclonic storms, upper-level low-pressure systems, and tropical cyclones result in floods in fall or winter.

The season of occurrence of annual peak discharges in the study area primarily is related to latitude (table 2). For sites between $29^{\circ}$ and $37^{\circ}$ latitude, the average gaging-station record has 14 percent of its peaks in the spring, 60 percent in the summer, and 26 percent in the winter. Thus, most of the annual peaks in the southern part of the study area are caused by summer thunderstorms. An average site between $41^{\circ}$ and $45^{\circ}$ latitude has only 6 percent of its annual peaks occur in the summer. Spring peaks (snowmelt) have the opposite relation to latitude; the percentage increases from 14 percent in the south to 70 percent in the north. The percentage of winter peaks (rainfall from cyclonic 
Table 2. Relation between season of occurrence of annual peak discharges and latitude in the southwestern United States

\begin{tabular}{cc|c|c}
\hline & \multicolumn{3}{c}{$\begin{array}{c}\text { Average percentage of peak dlscharges } \\
\text { In gaglng-statlon records }\end{array}$} \\
\cline { 2 - 4 } Latitude, in & Spring & Summer & Fall-winter \\
\cline { 2 - 4 } & Aprll-June & $\begin{array}{c}\text { July- } \\
\text { September }\end{array}$ & $\begin{array}{c}\text { October- } \\
\text { March }\end{array}$ \\
\cline { 2 - 4 } & 14 & 60 & 26 \\
$37-39$ & 49 & 38 & 13 \\
$39-41$ & 62 & 22 & 16 \\
$41-45$ & 70 & 6 & 24 \\
\hline
\end{tabular}

storms, upper-level lows, and tropical cyclones) is about 25 percent in the south and north, and only 13 to 16 percent in the middle part of the study area. The lower percentage of winter peaks in the middle part of the area may be related to the cold winters in the midlatitudes and to the orographic effect of the high elevations of the Cascade-Sierra Mountains between $35^{\circ}$ and $41^{\circ}$ latitude, which acts as a barrier to the winter systems.

Summer thunderstorms generally result in the largest unit-peak discharges in the study area. To examine the magnitude and distribution of thunderstorm-caused peaks, the maximum peak discharge of record for all gaged sites was divided by its drainage area, and that value, called unit-peak discharge, was compared to site characteristics. All unit-peak discharges greater than $100\left(\mathrm{ft}^{3} / \mathrm{s}\right) / \mathrm{mi}^{2}$ were caused by rainfall except for one site in Idaho that had a discharge of $130\left(\mathrm{ft}^{3} / \mathrm{s}\right) / \mathrm{mi}^{2}$ caused by snowmelt. Summer thunderstorms caused about 90 percent of the maximum unit peaks greater than 100 $\left(\mathrm{ft}^{3} / \mathrm{s}\right) / \mathrm{mi}^{2}$. The remainder of the maximum unit peaks greater than $100\left(\mathrm{ft}^{3} / \mathrm{s}\right) / \mathrm{mi}^{2}$ were caused by rainfall from other types of storms.

The magnitude of the unit peaks decreases in a northward direction with a significant decrease at $41^{\circ}$ latitude (fig. 3 ). In the southern part of the study area (between $29^{\circ}$ and $37^{\circ}$ latitude), where 63 percent of the maximum peaks were caused by summer thunderstorms, the average maximum unit peak discharge of record is $316\left(\mathrm{ft}^{3} / \mathrm{s}\right) / \mathrm{mi}^{2}$ (table 3$)$. In the northern part of the study area (between $41^{\circ}$ and $45^{\circ}$ latitude), the average maximum unit peak of record is $26\left(\mathrm{ft}^{3} / \mathrm{s}\right) / \mathrm{mi}^{2}$ and only 9 percent of those peaks were caused by summer thunderstorms.
Typical peak discharges for major floods in the southern latitudes are nearly 10 times greater than peak discharges for major floods in the northern latitudes.

Jarrett (1987) and Tunnell (1991) determined that large floods caused by thunderstorms are unlikely to occur above an elevation threshold. The physical basis of this threshold probably is related to factors that include available energy and moisture in the atmosphere for the convective process and a generally abundant cover of vegetation in high elevations below the timber line that enhances infiltration of rainfall and thereby reduces runoff.

The elevation threshold of large floods that result from thunderstorms was investigated for this study by comparing the relation between the maximum unit peak discharge of record and site elevation. The relations discovered in this study agree with relations presented by Jarrett (1987). For sites between $29^{\circ}$ and $41^{\circ}$ latitude, the elevation threshold for large floods caused by thunderstorms is about 7,500 ft (fig. 4). For sites between $41^{\circ}$ and $45^{\circ}$ latitude, the estimated elevation threshold decreases in a northward direction at a rate of about $300 \mathrm{ft}$ for each degree of latitude (fig. 5), and the general magnitude of unit peaks is much smaller than for sites south of $41^{\circ}$ latitude (fig. 4).

\section{Basin and Channel Characteristics}

When runoff from rainfall or snowmelt begins, drainage-basin and stream-channel characteristics affect the quantity and rate of runoff. Drainage-basin and stream-channel characteristics that influence flood runoff are vegetation, topography and orographic influences, topography and stream channels, and distributary-flow areas.

Vegetation.-Most of the study area is sparsely covered with vegetation because of the arid climate. A dense cover of vegetation exists only in the high elevations of the mountains where precipitation is abundant. Most of the low-elevation areas are sparsely covered with shrubs and grasses with large areas of sagebrush in the north and creosote bush in the south. At intermediate elevations, juniper and pinyon woodland is 


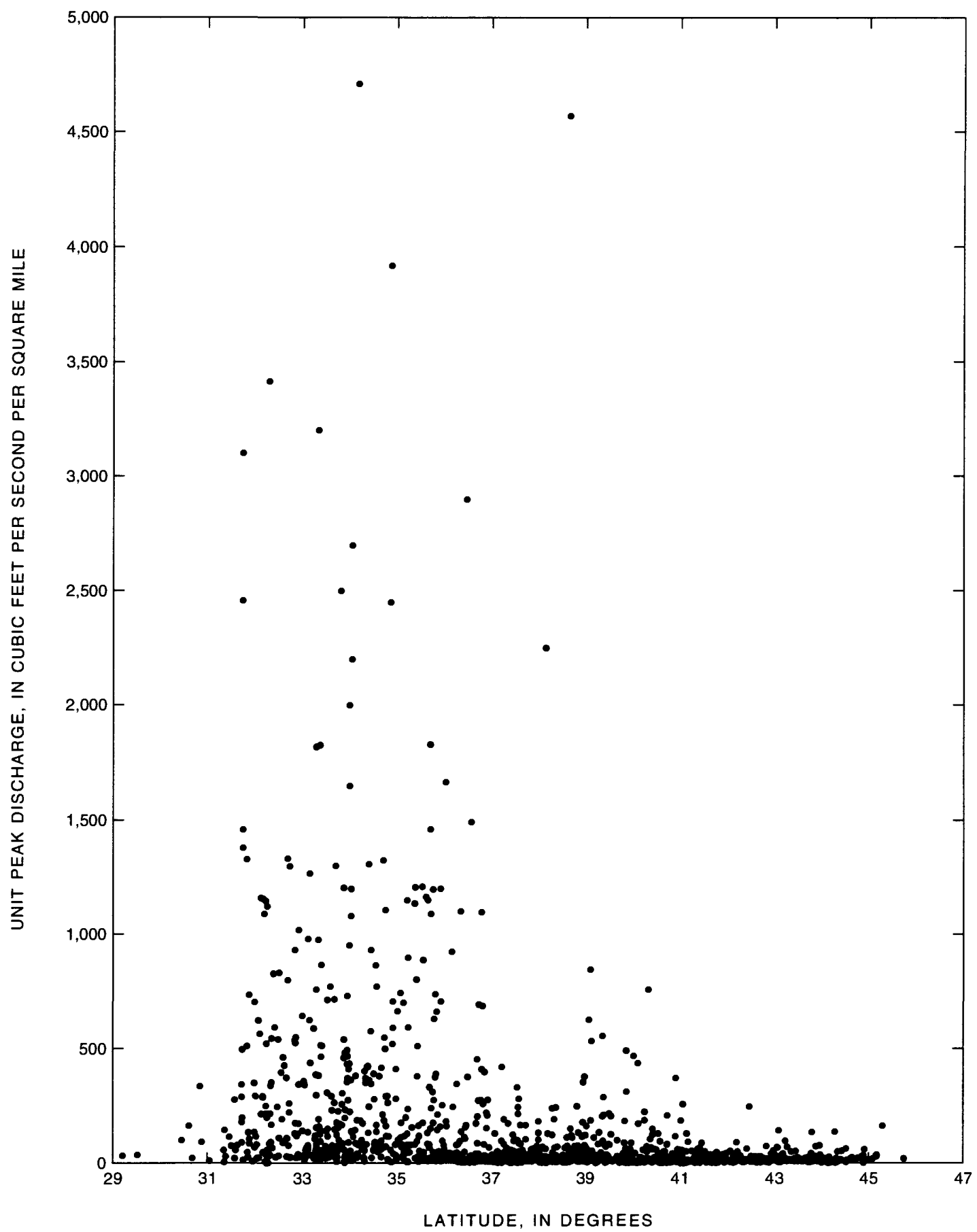

Figure 3. Relation between latitude and the maximum unit peak discharge of record at gaged sites in the southwestern United States. 
Table 3. Magnitude of maximum unit-peak discharge of record compared to latitude and proportions of peaks caused by thunderstorms in the southwestern United States

\begin{tabular}{|c|c|c|c|c|}
\hline \multirow[b]{2}{*}{$\begin{array}{l}\text { Latitude, in } \\
\text { degrees }\end{array}$} & \multirow[b]{2}{*}{ Number of sites } & \multicolumn{3}{|c|}{ Average } \\
\hline & & $\begin{array}{c}\text { Maximum unit peak } \\
\text { discharge of record, } \\
\text { in cublc feet per } \\
\text { second per square } \\
\text { mile }\end{array}$ & $\begin{array}{l}\text { Percentage of } \\
\text { maximum peaks of } \\
\text { record caused by } \\
\text { summer } \\
\text { thunderstorms }\end{array}$ & $\begin{array}{l}\text { Percentage of entire } \\
\text { record with peaks } \\
\text { caused by summer } \\
\text { thunderstorms }\end{array}$ \\
\hline $29-37$ & 559 & 316 & 63 & 60 \\
\hline $37-39$ & 256 & 66 & 47 & 38 \\
\hline $39-41$ & 226 & 61 & 34 & 22 \\
\hline $41-45$ & 282 & 26 & 9 & 6 \\
\hline
\end{tabular}

common in the isolated mountains of Nevada and in large areas of Utah, Colorado, Arizona, and New Mexico. Forests of pine and fir trees are common in the higher elevations of the mountains.

Topography and orographic influences.Mountains with high topographic relief influence the quantity and distribution of precipitation and runoff. As moisture moves into the study area from the north, west, or south, mountains act as barriers and cause an uneven areal distribution of precipitation. Along the windward side of mountains, moving air masses drop much of their moisture as the air is forced to ascend over the mountains. In contrast, on the leeward sides of mountains, air masses usually descend, temperatures increase, and precipitation decreases. In the study area, areas of increased precipitation and heavy runoff on windward sides of mountains occur in central Arizona, central New Mexico, east-central Utah, and southwestern Colorado. Areas of decreased precipitation and smaller runoff on leeward sides of mountains occur in most of Nevada, western Utah, and northeastern Arizona.

Topography and stream channels.-The conveyance properties of stream channels are related to the slope of the channel, material constituting the bed and banks of the channel, geometry of the channel, shape and width of the natural flood plain, and the topography of the area through which the stream is flowing. The topography of the study area can be grouped into three broad categories in which the streams have similar conveyance properties. These categories are (1) mountains, (2) piedmont plains, and (3) base-level plains, plateaus, or alluvial valleys. Burkham (1988) described flood hazards for a similar classification of topography for streams in the Great Basin in California, Idaho, Nevada, Oregon, Utah, and Wyoming.

Mountainous areas typically have V-shaped valleys that are well drained and composed mostly of bedrock and colluvium. The stream channels are typically steep, scoured, and rocky. The flood plain is narrow or nonexistent. The system of stream channels in the mountains is tributary, and the peak discharge of large floods typically increases as the drainage area increases. Another physiographic region with similar properties of mountain streams is the canyonland areas of the Colorado Plateau (fig. 2) where the channels are deeply incised into the surrounding bedrock.

Piedmont plains are transition areas between mountains and base-level plains or plateaus. The upper elevation limit of a piedmont plain is commonly at a sharp decrease in the slope of land surface at a mountain front. A piedmont plain consists of pediments, alluvial fans, or old-fan remnants. A pediment is an erosional surface cut on rock and usually covered with a thin layer of alluvium. The upper elevation limit of a pediment is 


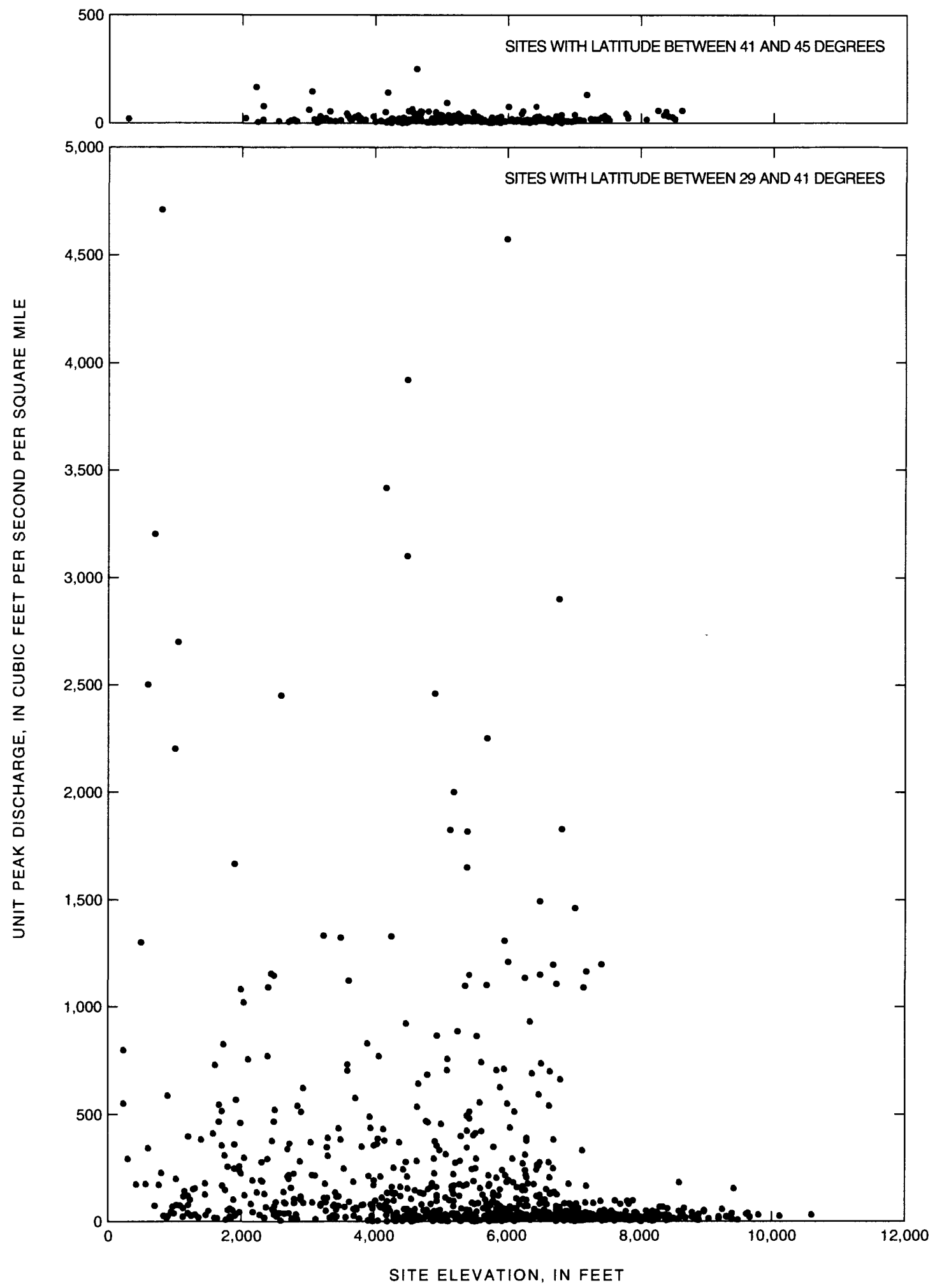

Figure 4. Relation between site elevation, latitude, and maximum unit peak discharge of record at gaged sites in the southwestern United States. 


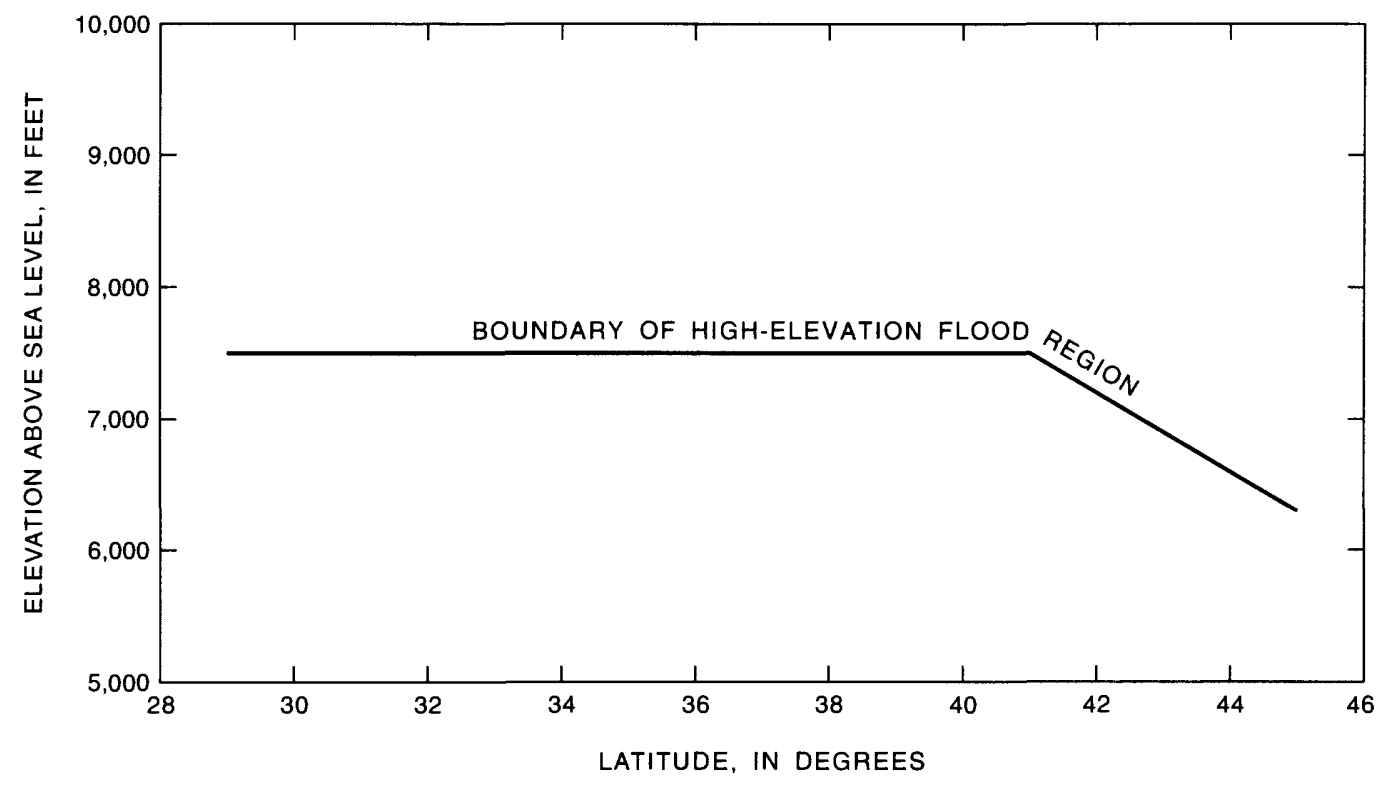

Figure 5. Estimated elevation threshold for large floods caused by thunderstorms in the southwestern United States.

commonly at the mountain front. Alluvial fans are composed of material deposited by streams emerging from mountains or pediments, thus the upper elevation limit of alluvial fans may be at the mountain front or at the lower part of a pediment. Alluvial fans are active where stream deposition is common and stream systems are distributary. Alluvial fans are inactive where stream deposition is less common and most stream systems are tributary. Thus, active fans are mostly depositional surfaces, and inactive fans are mostly erosional surfaces.

Floodflow on pediments commonly is confined to tributary channels separated by stable ridges that are above the level of large floods. Floodflow on active alluvial fans commonly is unconfined in a distributary system of small channels separated by low and unstable ridges that are often overtopped during large floods. The size and location of channels on active fans can change during flooding. In contrast, floodflow on old-fan remnants commonly is confined to a tributary system of incised channels.

Typical streams in base-level plains, plateaus, or alluvial valleys have a defined main channel with an adjacent flood plain. During large floods, floodwater may spill over the banks of the main channel onto the flood plain. Flood plains are commonly wide, flat, and covered with riparian vegetation or agricultural crops. These characteristics can cause the peak discharge of large floods to decrease or attenuate, mostly because the floodflow is temporarily stored in the wide, flat, and hydraulically rough flood plains. Some streams in plains, plateaus, or alluvial valleys have small main channels, and most of the floodflow of medium and large floods spreads over wide and flat flood plains. For these streams, the peak discharge of large floods can decrease in the downstream direction even where there is a large increase in drainage area. Other streams may have enlarged channels because of lateral erosion of the channel banks and (or) downcutting of the channel bed. Some of these entrenched channels can convey large floods within the confines of vertical banks.

In a few parts of the study area, streams in base-level plains, plateaus, or alluvial valleys flow through areas of highly permeable geologic material such as limestone, basalt, or sandy alluvial bed material. Large proportional losses of flow to infiltration can occur during the small to medium 
floods. Most of these areas are localized except for much of the Snake River basin in Idaho (fig. 1), which is a large area of permeable volcanic material. In the Snake River basin, many streams originate in the surrounding mountains and flow onto a flat plain where the water rapidly infiltrates into the ground.

Distributary-flow areas.-Throughout the study area, but especially in Nevada, western Utah, southeastem Califormia, and southem and western Arizona, distributary-flow areas can have a large effect on the flood characteristics of streams. The magnitude of peak discharges leaving a basin can be significantly reduced in basins with distributary-flow areas. A distributary-flow area, which includes active alluvial fans, commonly occurs on piedmont plains downslope from mountains. A distributary-flow area contains a primary diffluence where floodflow in a single channel separates into two or more channels. The channels commonly remain separated and have terraces. In many distributary-flow areas, the channels divide and join over wide areas and the erratic flow paths appear to occur randomly over much of the land surface (Hjalmarson and Kemna, 1991).

In the arid southwestern United States, some of the flood-peak attenuation shown by comparison of flood-frequency relations for sites on the same stream is related to the presence of distributary-flow areas in the intervening drainage area. An example is Brawley Wash in southem Arizona, in which the 100 -year peak discharge decreases from 24,100 to $20,000 \mathrm{ft}^{3} / \mathrm{s}$ between streamflow-gaging stations 09486800 and 09487000 (see data section, flood region 13). Altar Wash (station 09486800) is a tributary to Brawley Wash (station 09487000). The gross drainage area for these two sites increases from 463 to $776 \mathrm{mi}^{2}$. A large percentage of the potential intervening runoff from the mountains and pediments must traverse many distributary-flow areas. The floodflow divides and combines many times and spreads laterally over the permeable soil. Even during large floods, most of the peak discharge in the distributary-flow areas can be lost to infiltration or attenuation.
During this study, a few streamflow-gaging sites that appeared to have unusually small quantities of peak discharge for the size of drainage area were examined and found to be on distributary stream channels. During floodflow, some of the flow was bypassing the gaged sites in other distributary channels. At two sites, some of the flow appeared to leave the drainage basin upstream from the site and enter an adjacent drainage system. Sites with known distributary flow that could bypass the gaging station were excluded from this study.

Distributary-flow areas can be identified on standard 7.5-minute series of USGS topographic maps, which provide much of the information needed to delineate distributary-flow areas. Bifurcating intermittent stream symbols on maps depict distributary-flow areas. Small wash or intermittent stream symbols that end abruptly in an area with smooth contours also may depict distributary flow. Broad areas of piedmont that are marked with the sand symbol (stippled pattem) may depict aggrading areas and possibly distributary flow. Relative drainage texture domains depicted by contour-crenulation counts (small rounded upslope projection of a contour line) provide excellent clues to the type of landform and potential distributary-flow areas (Hjalmarson and Kemna, 1991). The drainage texture (spacing of the more low-order drainage channels) of active areas of distributary flow normally is uniform in the upslope direction. Smooth contours that are straight and parallel (or slightly convex pointing downstream in plan view) indicate mild relief that may result from distributary flow. Contours with relatively large and narrow crenulations may reveal remnants of old inactive fans.

\section{DESCRIPTION OF METHODS}

Methods developed for this study to estimate flood-peak discharge for various recurrence intervals are for gaged and ungaged natural flow streams. A study site will fit into one of three categories-(1) a gaged site, (2) a site near a gaged site on the same stream, or (3) an ungaged site. The methods and their limitations are explained in this section, and step-by-step procedures and examples 
of using the methods are given in the section entitled "Application of Methods."

\section{Gaged Sites}

Flood-frequency relations for gaged sites can be estimated using the relations defined in this study. In the data section at the end of the report, the top line for each station in the peak-discharge columns is the peak discharge from the station flood-frequency relation. The bottom line is a weighted estimate of the peak discharge based on the station flood-frequency relation and the regional relation. Regional regression equations are discussed in the section entitled "Ungaged Sites."

Weighted estimates are considered to be the best estimates of flood frequency at a gaged site and are used to reduce the time-sampling error that may occur in a station flood-frequency estimate. The time-sampling error is the error caused by having a sample of floods that is not representative of the population of floods. Usually, the time-sampling error is decreased as the length of record at a gaged site is increased. A station with a short period of record may have a large time-sampling error because the short period of record may not represent the full range of potential floods at the site. At short-record sites, the observed period of record at a station has the possibility of falling within a wet or dry period, and a preponderance of unusually small or large floods may yield a significantly unrepresentative computed flood-frequency relation. The weighted estimate of flood frequency should be a better indicator of the true values because the regression estimate is an average of the flood histories of many gaging stations over a long period of time.

The weighting procedure used in this study weights the station flood frequency and the regression estimate of flood frequency by the years of record at the station and the equivalent years of record of the regression estimate (Sauer, 1974). The equivalent years of record are an expression of the accuracy of the regression relation. Thus, in a weighted estimate, the flood-frequency relation for a station with a long period of record will be given greater weight than that for a station with a short period of record. Equivalent years of record for each regression estimate were estimated using a procedure described by Hardison (1971). The following equation was used for the weighted estimate (Sauer, 1974):

$$
Q_{T(w)}=\frac{Q_{T(s)} N+Q_{T(r)} E}{N+E},
$$

where

$$
\begin{aligned}
Q_{T(w)}= & \text { weighted discharge, in cubic feet per } \\
& \text { second, for T-year recurrence interval; } \\
Q_{T(s)}= & \text { station value of the discharge, in cubic } \\
& \text { feet per second, for T-year recurrence } \\
& \text { interval; } \\
Q_{T(r)}= & \text { regression value of the discharge, in } \\
& \text { cubic feet per second, for T-year } \\
& \text { recurrence interval; } \\
N= & \text { number of years of station data used to } \\
& \text { compute } Q_{T(s) ;} \text { and } \\
E= & \text { equivalent years of record for } Q_{T(r) .} .
\end{aligned}
$$

\section{Sites Near Gaged Sites on the Same Stream}

Flood-frequency relations at sites near gaged sites on the same stream can be estimated using a ratio of drainage area for the ungaged and gaged sites. The drainage-area ratio should be approximately between 0.5 and 1.5 . Characteristics of the ungaged and gaged drainage basins need to be examined. The method for ungaged sites should be used if a large tributary stream is between the ungaged and gaged sites and the tributary basin has much different topography, geology, vegetation, and other characteristics that may affect flood magnitudes. If the basins have similar characteristics and meet the drainage-area ratio requirement, peak discharges can be computed by the following equation:

$$
Q_{T(u)}=Q_{T(g)}\left(A_{u} / A_{g}\right)^{x},
$$

where

$$
\begin{aligned}
Q_{T(u)}= & \text { peak discharge, in cubic feet per } \\
& \text { second, at ungaged site for T-year } \\
& \text { recurrence interval; }
\end{aligned}
$$


$Q_{T(g)}=$ weighted peak discharge, in cubic feet per second, at gaged site for T-year recurrence interval;

$A_{u}=$ drainage area, in square miles, at ungaged site;

$A_{g}=$ drainage area, in square miles, at gaged site; and

$x=$ exponent for each flood region as follows:

\begin{tabular}{|c|c|c|}
\hline \multicolumn{2}{|l|}{ Flood region } & \multirow{2}{*}{ Exponent $x$} \\
\hline Name & Number & \\
\hline High Elevation ............................ & 1 & 0.8 \\
\hline 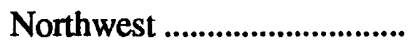 & 2 & .7 \\
\hline South-Central Idaho................ & 3 & .7 \\
\hline 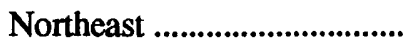 & 4 & .7 \\
\hline 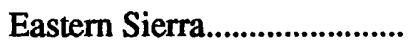 & 5 & .8 \\
\hline Northern Great Basin............. & 6 & .6 \\
\hline South-Central Utah ............... & 7 & .5 \\
\hline 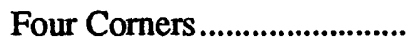 & 8 & .4 \\
\hline Western Colorado ................... & 9 & .5 \\
\hline Southern Great Basin............. & 10 & .6 \\
\hline Northeastern Arizona............. & 11 & 6 \\
\hline Central Arizona & 12 & .6 \\
\hline Southern Arizona..................... & 13 & .5 \\
\hline Upper Gila Basin ..................... & 14 & .5 \\
\hline Upper Rio Grande Basin ..... & 15 & .5 \\
\hline 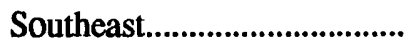 & 16 & .4 \\
\hline
\end{tabular}

The exponent was determined by regressing the six T-year discharges $(T=2,5,10,25,50,100)$ on the drainage area for each flood region and taking the average of the drainage-area exponent for the six equations. In addition to the ratio method for sites near gaged sites, if a study site is between two gaged sites, the peak discharge may be estimated by interpolation between values for the two gaged sites with allowance for major tributaries.

\section{Ungaged Sites}

Flood-frequency relations at ungaged sites can be estimated using the regional models developed in this study. The models are regression equations that use basin and climatic characteristics as explanatory variables. The regional regression analysis is discussed in the section entitled "Regional Analysis."

\section{Models}

Three models were used in this study to express the relation between peak discharge and basin and climatic characteristics. The most common relation is in the multiplicative form:

$$
Q_{T}=a A^{b} B^{c} .
$$

The following linear relation is obtained by logarithmic transformation:

$$
\log Q_{T}=\log a+b \log A+c \log B+\ldots,
$$

where

$$
\begin{aligned}
Q_{T}= & \text { peak discharge, in cubic feet per } \\
& \text { second, for T-year recurrence } \\
& \text { interval, }
\end{aligned}
$$

$$
\begin{aligned}
A \text { and } B & =\text { explanatory variables, and } \\
a, b, c & =\text { regression coefficients. }
\end{aligned}
$$

Throughout the study area, drainage area is the most significant explanatory variable and is used as the first explanatory variable in all regional models. In a few parts of the study area, however, the relation between the logarithm of $Q_{T}$ and the logarithm of drainage area is not linear as is expressed in equation 3B. In those areas, therefore, another model was used in which drainage area is transformed to produce a linear relation. The following equations perform that function:

$$
Q_{T}=10^{\left(a+b A R E A^{x}\right)} B^{c},
$$

or the logarithmic transformation: 


$$
Q_{T}=a+b A R E A^{x}+c \log B+\ldots,
$$

where

$$
\begin{aligned}
A R E A= & \text { drainage area, } \\
B \quad= & \text { other basin or climatic characteristic, } \\
& \text { and } \\
x \quad= & \text { exponent for } A R E A \text { for which the } \\
& \text { relation is made linear. }
\end{aligned}
$$

The third model used in the study is another method of accounting for a nonlinear relation. In this case, the nonlinear relation is between the residual from the $Q_{T}$ and $A R E A$ relation and a second explanatory variable. The following equations were used to transform the second explanatory variable to yield a linear equation:

$$
Q_{T}=a A R E A^{b}(B-d)^{c},
$$

or the logarithmic transformation:

$$
\log Q_{T}=\log a+b \log A R E A+c \log (B-d)+\ldots,
$$

where

$$
\begin{aligned}
d= & \text { a constant, which is less than the } \\
& \text { minimum value of } B \text {, for which the } \\
& \text { relation is made linear. }
\end{aligned}
$$

\section{Explanatory Variables}

For purposes of this report, six basin and climatic characteristics are referred to as explanatory variables and are used as terms in the model equations. Additional explanatory variables that are described in the section entitled "Explanatory Variables Investigated" were considered but were not used. The six explanatory variables that were used are shown for each site in the data section. The abbreviation for each variable and method of measuring the variable are as follows.
1. AREA is the drainage area, in square miles, and is determined by planimetering the contributing drainage area on the largest scale topographic map available.

2. ELEV is the mean basin elevation, in feet above sea level and is determined by placing a transparent grid over the drainage-basin area, which is drawn on the largest scale topographic map available. The elevations of a minimum of 20 equally spaced points are determined, and the average of the points is taken. As many as 100 points may be needed for large basins.

3. PREC is the mean annual precipitation, in inches, and is determined by placing a transparent grid over an isohyetal map of mean annual precipitation. The drainagearea boundary is drawn on the map, the mean annual precipitation is determined at each grid intersection, and the values are averaged for the basin.

A single source of isohyetal maps is not available. To use the regression equations in this report, the mean annual precipitation should be determined using the isohyetal maps that were used to determine the values for most of the gaging stations in this study. These maps are referred to as normal-annual precipitation maps, have a large scale (1:500,000), and were developed from data collected during 1931 to 1960 (U.S. Weather Bureau, 1963). If these maps are not available, the most recent and largest scale maps available should be used.

The original isohyetal maps that were used to determine mean annual precipitation for some of the gaging stations are in the "Climates of the States" series of the U.S. Weather Bureau (1959-61). These page-size maps were developed from data from about 1955 to 1960 . These maps can be used only if larger-scale maps are not available.

4. EVAP is the mean annual free water-surface evaporation, in inches, and was determined for gaged sites by linear interpolation between the isolines of map 3 from 
Farnsworth and others (1982). The value used for the regression equations was the value at the gaged-site location; therefore, in the application of the regression equations, the study-site location should be used. To use the methods in this report, EVAP should be estimated for the study site by linear interpolation between the isolines of EVAP shown in figs. 7, 11, and 14.

5. LAT is the latitude of the gaged site, in decimal degrees, and is determined using the largest scale topographic map available. The value used for the regression equations was the value at the gaged-site location; therefore, in the application of the regression equations, the study-site location should be used. Decimal degrees are the minutes and seconds of the latitude converted to a decimal.

6. LONG is the longitude of the gaged site, in decimal degrees, and is determined using the largest scale topographic map available. The value used for the regression equations was the value at the gaged-site location; therefore, in the application of the regression equations, the study-site location should be used. Decimal degrees are the minutes and seconds of the longitude converted to a decimal.

\section{Flood Regions and Regression Equations}

A single regression model for the entire study area does not adequately explain the variation in flood characteristics. The standard errors of estimate for $\mathrm{T}$-year discharges were more than 100 percent for all attempted single models. In addition, these single models were biased in certain parts of the study area. The study area, therefore, was divided into 16 flood regions, and separate regression equations were developed for each region. Use of the 16 flood regions removes some of the variability in the system that is not explained by available explanatory variables and thus makes the subsequent equations simpler and more accurate. The flood regions were delineated on the basis of the magnitudes of floods, meteorologic cause of floods (snowmelt, summer thunderstorms, or cyclonic rainfall), elevation of the sites, and geographic pattems in residuals from the regression analysis. A consistent geographic pattern in residuals from a single study-wide relation was not discerned; therefore, an explanatory variable that could define the study-wide geographic variation could not be developed.

The first major stratification for the study area was for a high-elevation region that extends throughout the entire study area. The lower boundary of the region corresponds to an estimated elevation threshold for large floods caused by thunderstorms (fig. 5). The elevation of the study site is used to determine if the site fits in the high-elevation region. The remaining 15 flood regions consist of low- to middle-elevation sites (table 4 and figs. 6-16) where nearly all boundaries are drainage divides. The exceptions are the boundary between Regions 6 and 10 , which is at $37^{\circ}$ latitude, and part of the boundary between Region 8 and Regions 6 and 7 in southern Utah.

Information about the 16 flood regions includes the number of gaging stations, time of year of peak discharges, and an index to the many tables and figures that describe the regions (table 4). The number of gaging-station records used for most flood regions is less than the number of available gaging-station records within the region (table 4 and figs. 17-49). Flood-frequency relations could not be defined for some sites because the data were unreliable or because a three-parameter distribution did not appear to adequately fit the plot of annual peaks in the records. Also, a few outlier stations were deleted from the regression analysis, and some sites had missing values for explanatory variables and thus were not used. The deleted outliers may be different from the majority of sites by random chance, or occasionally their basin or channel characteristics are much different from the majority of sites. For Regions $6,10,11$, and 16 where the hybrid method was used, data for all available gaging stations were used (table 4).

The regression equations developed for estimating regional flood-frequency relations (tables 5-20) are applicable for sites with characteristics that fall within the range of explanatory variables for the gaged sites that were used to develop the equations. Plots of the 
explanatory variables used for the regional equations were prepared for each flood region. Figure numbers for the plots are listed in table 4. The plots depict a cloud of common values. The regression equations are applicable to sites with characteristics that fall within this cloud of common values. The predictive errors of the equations increase with distance from the mean values of the explanatory variables, and errors are unknown and probably are quite large beyond the cloud of common values.

The regression equations are most applicable to sites with drainage areas of less than about 200 $\mathrm{mi}^{2}$. Gaged sites used in the analysis were selected to ensure a reliable sample to define regional relations for basins of up to about $200 \mathrm{mi}^{2}$. Basins between $200 \mathrm{mi}^{2}$ and the limits of the cloud of common values for each region were used to better define the relation between peak discharge and drainage area for the small basins. The regression equations are for basins of less than $200 \mathrm{mi}^{2}$; judicious use of the equations should be made for basins between $200 \mathrm{mi}^{2}$ and the limits of the cloud of common values.

The peak discharges estimated from the regional models can be compared to the relations between the maximum peak discharge of record and drainage area for gaged sites in each flood region and for the entire study area (fig. 17). Figure numbers of the relations for each flood region are listed in table 4. All available gaged sites in a region are shown on these plots. Three relations are drawn on most plots for the flood regions-an envelope curve for maximum peak discharge of record for the gaging stations used in the entire study area, the relation between the 100 -year peak discharge and drainage area for the entire low-to middle-elevation study area (Regions 2-16), and the relation between the 100-year peak discharge and drainage area computed for the region. For regional relations with multiple variables, the 100 -year peak-discharge relations are for mean values of the variables used in addition to drainage area. Effects of these additional variables are not accounted for in the regional relations between the 100 -year peak discharge and drainage area; therefore, the plots of these regression lines may not appear to fit the data.
The envelope curve for the entire study area (fig. 17) is a measure of the maximum potential floodflow at gaged sites in the southwestern United States. The envelope curves for each flood region are similar measures for each region. The curves are based on data at the gaged sites used in this study and do not include miscellaneous data collected at ungaged sites or data at gaged sites with less than 10 years of record. A few extreme floods at ungaged sites in the study area are above the envelope curves and may have been debris flows. Thus, the envelope curves represent only the data used for the statistical analysis.

The plots of maximum peak discharge of record for gaging stations in the study area were compared to three other envelope curves of maximum measured peak discharges. The envelope curve for this study, however, is based on gaging-station records of 10 or more years, and the three other envelope curves are based on measured peak discharges from all available records. Costa (1987) developed an envelope curve for maximum rainfall-runoff floods measured in the United States. The envelope curve for data in this study (fig. 17) is about 40 percent of the magnitude of the curve in Costa (1987) for drainage basins of less than about $100 \mathrm{mi}^{2}$. For the larger drainage areas, the envelope curve in this study is only about 20 percent of the magnitude of the curve in Costa (1987). Crippen and Bue (1977) developed envelope curves for 17 regions of the United States. Regions 14 and 16 in Crippen and Bue (1977) are entirely inside the study area of this report. Flood regions 7,8 , and 11 of this study are comparable to Crippen and Bue's region 14 (1977; see Colorado Plateau, fig. 2, this report), and flood regions 6,10 , $12,13,14$, and 16 are comparable to Crippen and Bue's region 16 (1977; see Basin and Range, fig. 2, this report). For region 14 of Crippen and Bue (1977), the curve for the applicable data in this study has a similar magnitude as the curve for region 14. The magnitude of the curve for region 16 in Crippen and Bue (1977) is similar to the magnitude of the curve in Costa (1987). The curve for the applicable data in this study and the curve for region 16 in Crippen and Bue (1977), therefore, have the same relation as described for this study and Costa (1987). 


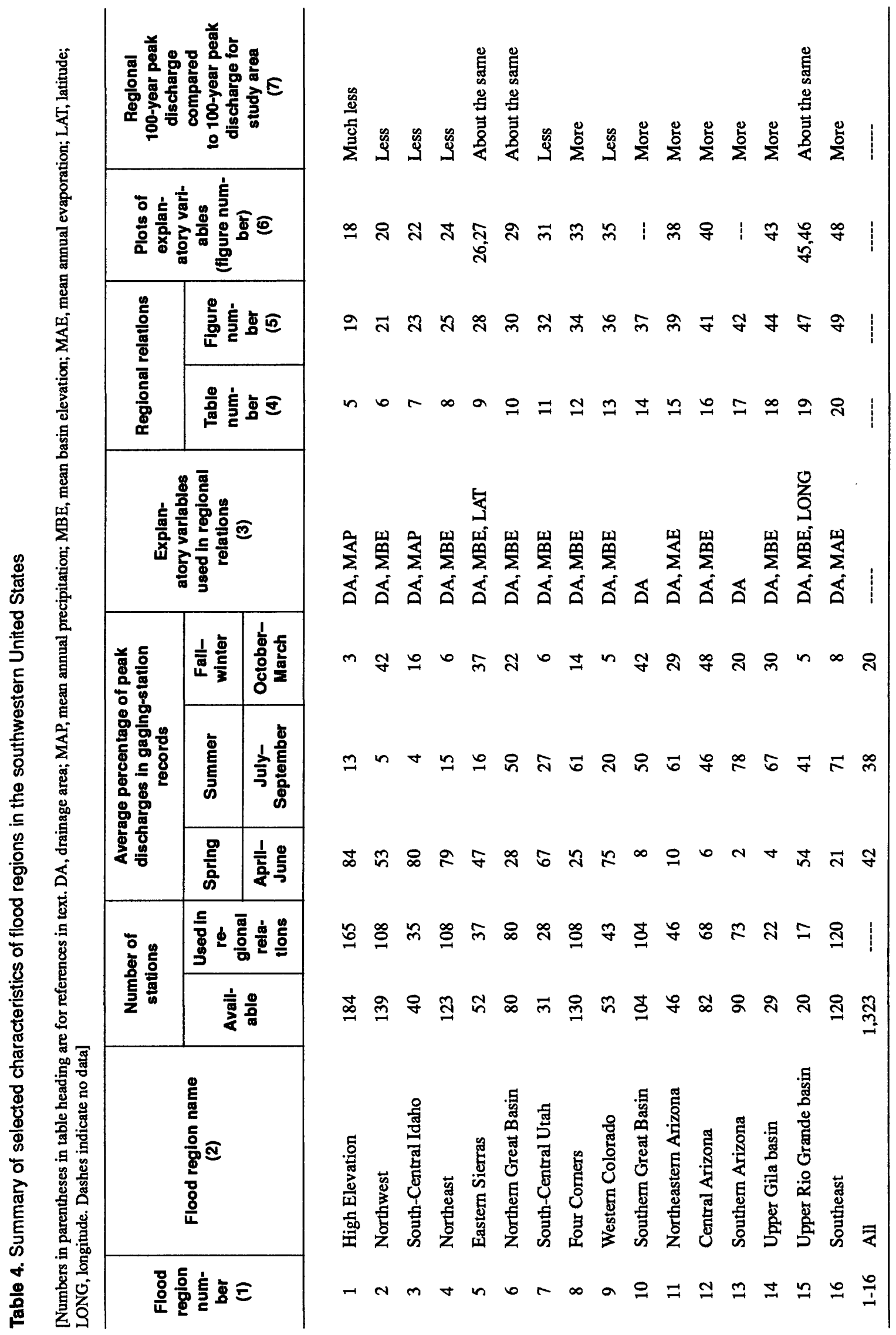




\section{Transition Zones}

At most ungaged sites in the study area, flood-frequency relations can be estimated using the single set of equations for the flood region in which the site is located. When a site is near a regional boundary, however, a weighted estimate of peak discharge may be more appropriate. Computed peak discharges from the equations of two adjacent regions may be quite different for a site near a boundary. The method of dividing the study area into flood regions requires distinct boundaries, but the boundaries do not necessarily imply a distinct change in flood characteristics. Instead of the distinct boundaries, transition zones can be used to provide smooth transitions across boundaries.

Two transition zones are defined in this report where methods are provided to estimate weighted flood-frequency relations-(1) sites with a drainage area in two low-to middle-elevation regions and (2) sites in a low-to middle-elevation flood region with an elevation that is near the boundary of the high-elevation region. A third transition zone is where a site is near a regional boundary, but the drainage area is entirely in one region. Characteristics of the drainage basin of the study site may need to be compared with the general characteristics of the adjacent flood regions. If the site is similar to both regions, a straight average of computed peak discharges from both regions may be appropriate.

Weighted flood-frequency relations should be used when the drainage area of the study site is in two low- to middle-elevation regions. The peak discharge should be computed using the equations for both regions. The basin and climatic characteristics for the entire basin should be used in the computations for both regions. A weighted peak discharge is then computed using the percentage of the drainage area in each region. The following equation should be used:

$$
Q_{T(w)}=\frac{Q_{T(a)} A R E A_{(a)}+Q_{T(b)} A R E A_{(b)}}{A R E A},
$$

where

$$
\begin{aligned}
& Q_{T(w)}= \text { weighted discharge, in cubic feet } \\
& \text { per second, for T-year recurrence } \\
& \text { interval; } \\
& Q_{T(a)}= \text { discharge for region (a), in cubic } \\
& \text { feet per second, for T-year } \\
& \text { recurrence interval; } \\
& Q_{T(b)}= \text { discharge for region (b), in cubic } \\
& \text { feet per second, for T-year } \\
& \text { recurrence interval; } \\
& A R E A_{(a)}= \text { drainage area in region (a), in } \\
& \text { square miles; } \\
& A R E A_{(b)}= \text { drainage area in region (b), in } \\
& \text { square miles; and } \\
& A R E A= \text { total drainage area in both regions, } \\
& \text { in square miles. }
\end{aligned}
$$
$Q_{T(b)}=$ discharge for region (b), in cubic feet per second, for T-year recurrence interval;

Weighted flood-frequency relations should be used for sites in a low- to middle-elevation flood region when the elevation of the study site is near the boundary of the high-elevation region. A transition zone is defined as a zone of elevation that starts at the boundary of the high-elevation region and extends 700 feet below that boundary (fig. 5). South of $41^{\circ}$ latitude, all study sites with an elevation between 6,800 and $7,500 \mathrm{ft}$ are in the transition zone. North of $41^{\circ}$ latitude, the zone is at progressively lower elevations as the latitude increases (fig. 5). In the transition zone, discharge should be computed using the equation for the lowto middle-elevation region in which the site is located and by using the equation for the high-elevation region. The characteristics of the entire basin should be used in both computations, and then a weighted discharge should be computed on the basis of the study-site elevation as:

$$
Q_{T(w)}=Q_{T(l)} \frac{B-E}{700}+Q_{T(h)}\left(1-\frac{B-E}{700}\right),
$$

where

$\begin{aligned} Q_{T(w)}= & \text { weighted discharge, in cubic feet per } \\ & \text { second, for T-year recurrence interval; }\end{aligned}$ 


$$
\begin{aligned}
Q_{T(l)}= & \text { discharge from the low- to middle- } \\
& \text { elevation region for T-year recurrence } \\
& \text { interval; } \\
Q_{T(h)=} & \text { discharge from the high-elevation } \\
& \text { region for T-year recurrence interval; } \\
E= & \text { elevation of the study site, in feet; and } \\
B= & \text { elevation of the lower boundary of the } \\
& \text { high-elevation region, in feet (fig. 5). }
\end{aligned}
$$

The weighted discharges are thus close to the lowto middle-elevation models near the lower part of the transition zone and close to the high-elevation model near the upper part of the transition zone.

\section{Excluded Streams and Distributary-Flow Areas}

Regional flood-frequency relations that are based on a large sample of flood peaks and explanatory variables are assumed to represent most of the streams in the study area. A few streams, however, have variables that are not represented, and regional relations should not be used for these streams. Streams that may not be represented by the regional relations include (1) streams with basin and climatic characteristics that are outside the range of explanatory variables, (2) streams in basins that have large areas of highly permeable rocks, (3) ungaged streams in some regions that have less base flow than nearby gaged streams, (4) streams with channel characteristics that cause a large quantity of floodflow attenuation, and (5) streams that are part of a system of distributary channels or streams that have a drainage that includes large distributary-flow areas.

Streams that have basin characteristics that are outside the range of explanatory variables for the gaged sites used to develop the regional relations are not represented by the regional flood-frequency relations. Also, some potentially important basin characteristics are not defined. For example, surficial geology is an important characteristic that affects floodflow, but it is not included specifically as an explanatory variable in the regional relations.
The regional relations reflect some large regional differences in geologic conditions, but local effects of surficial geology may not be reflected.

Drainage basins that have large areas of highly permeable rocks are not represented in the regional relations. Only a few stations used in the relations were in basins draining highly permeable rocks such as limestone or volcanic rocks. Large amounts of floodflow can be lost along stream channels that traverse these areas. The quantity of water lost to infiltration appears to vary from stream reach to stream reach, and regional relations of peak discharge for such streams cannot be defined using available explanatory variables. The Snake River plain in Idaho is an example of a large continuous area for which regional relations were not developed (fig. 10).

For some regions, the sample of gaged streams may be biased because streams that are gaged tend to be those that have more base flow. In the arid west, the network of streamflow-gaging stations was established because of water-supply needs and issues, and flood issues were and continue to be of secondary concern. In some regions, such as central Arizona, most of the gaged sites are on streams that have a large base flow in basins that have a similar aspect. These gaged basins may have storm characteristics, such as orographic effects, that are different from nearby ungaged basins with a different aspect. In places, the sample of gaged sites used for this study was defined by water-supply needs, and the sample may not represent flood characteristics for nearby ungaged streams.

Streams with channel characteristics that cause a large amount of floodflow attenuation are not represented in the regional relations. Such streams may have small channels and large, hydraulically rough flood plains. Drainage basins that have large distributary-flow areas are not represented in the regional relations. The magnitude of peak discharges leaving a basin can be significantly reduced in areas with distributary flow. 

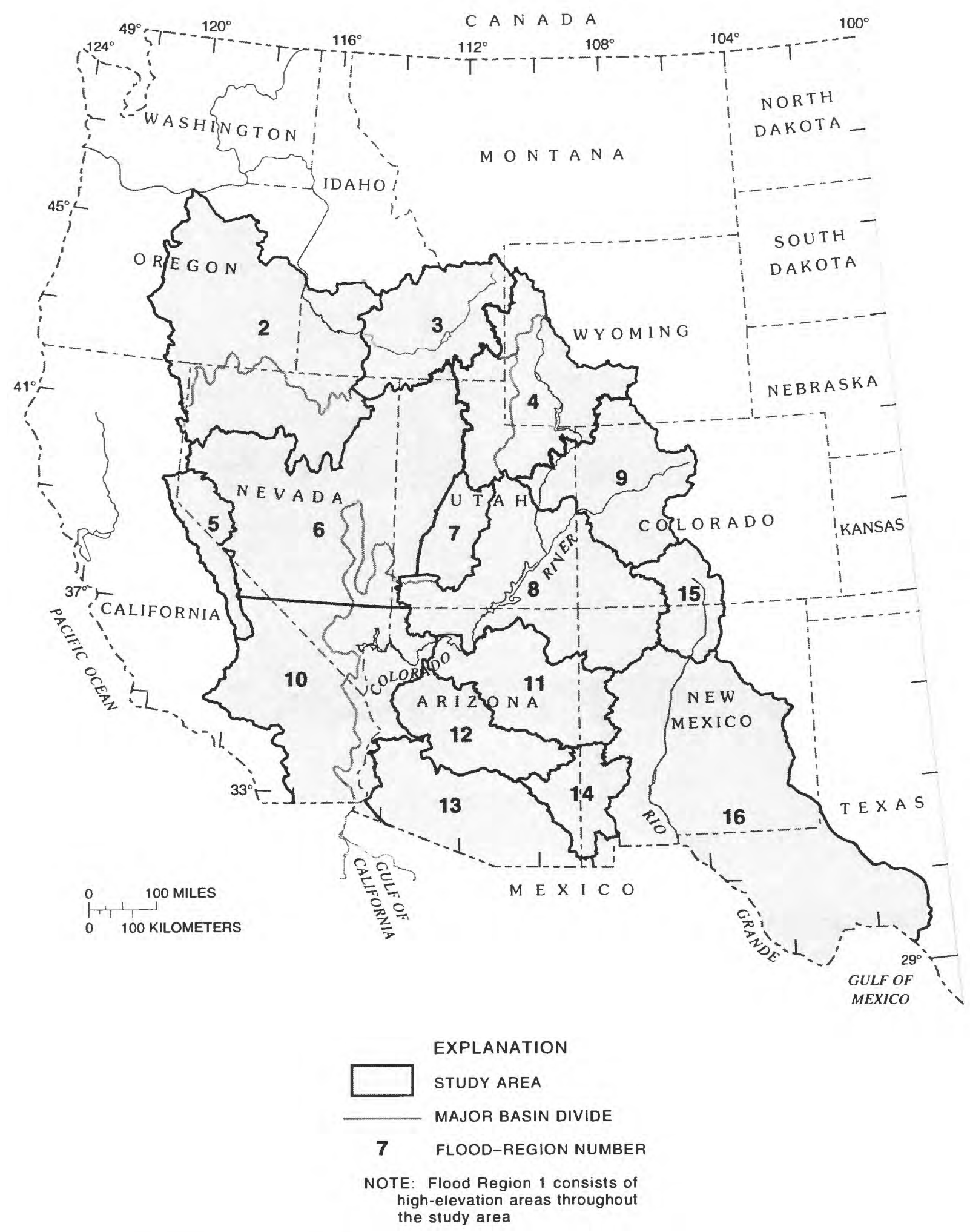

Figure 6. Flood regions in the study area. 


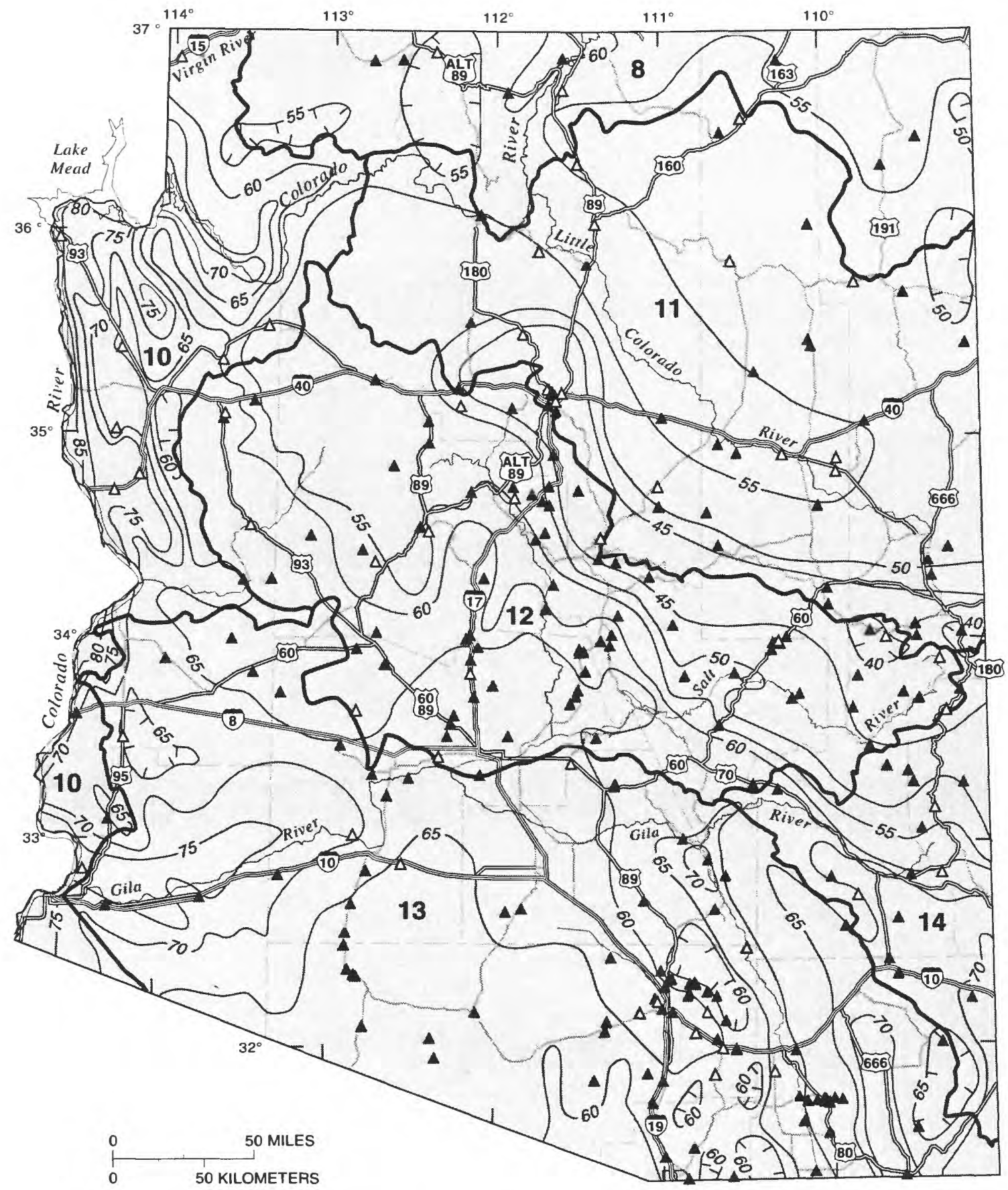

EXPLANATION
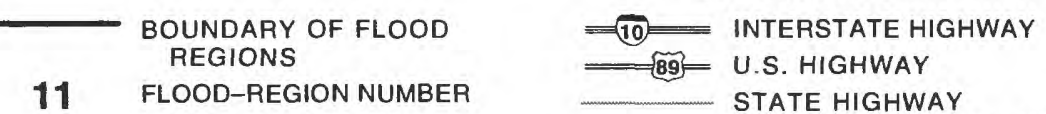

STREAMFLOW-GAGING STATION

A Station relation defined

$-60-$ LINE OF EQUAL FREE WATER-

$\Delta$ Station relation undefined SURFACE EVAPORATIONInterval 5 inches (Farnsworth and others, 1982)

Figure 7. Flood regions in Arizona. 


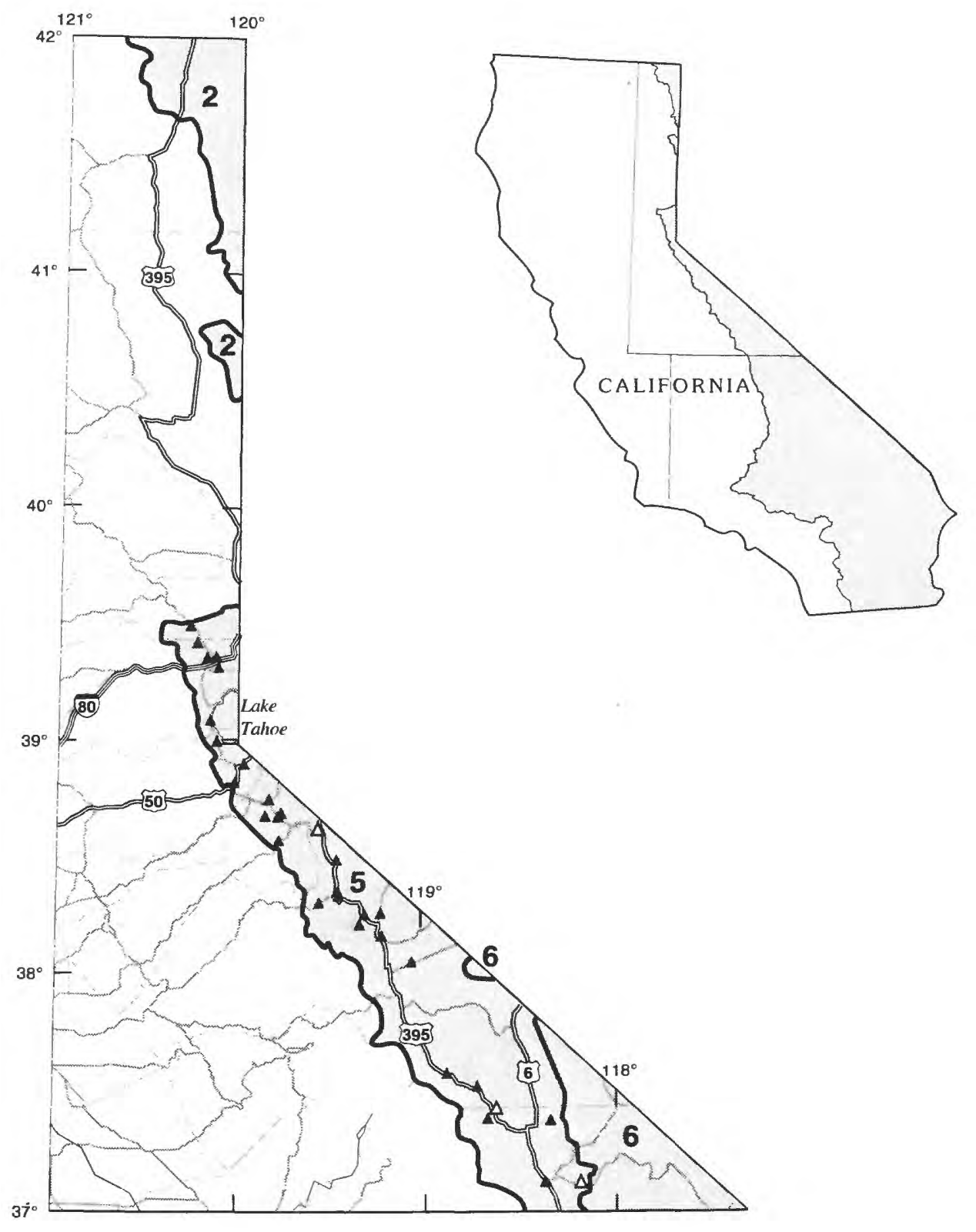

BOUNDARY OF FLOOD

EXPLANATION

REGIONS

\begin{aligned}$=80= &$ INTERSTATE HIGHWAY \\ \hline $50= &$ U.S. HIGHWAY \\ & STATE HIGHWAY \end{aligned}

STREAMFLOW-GAGING STATION

A Station relation defined

$\Delta$ Station relation undefined

Figure 8. Flood regions in California. 


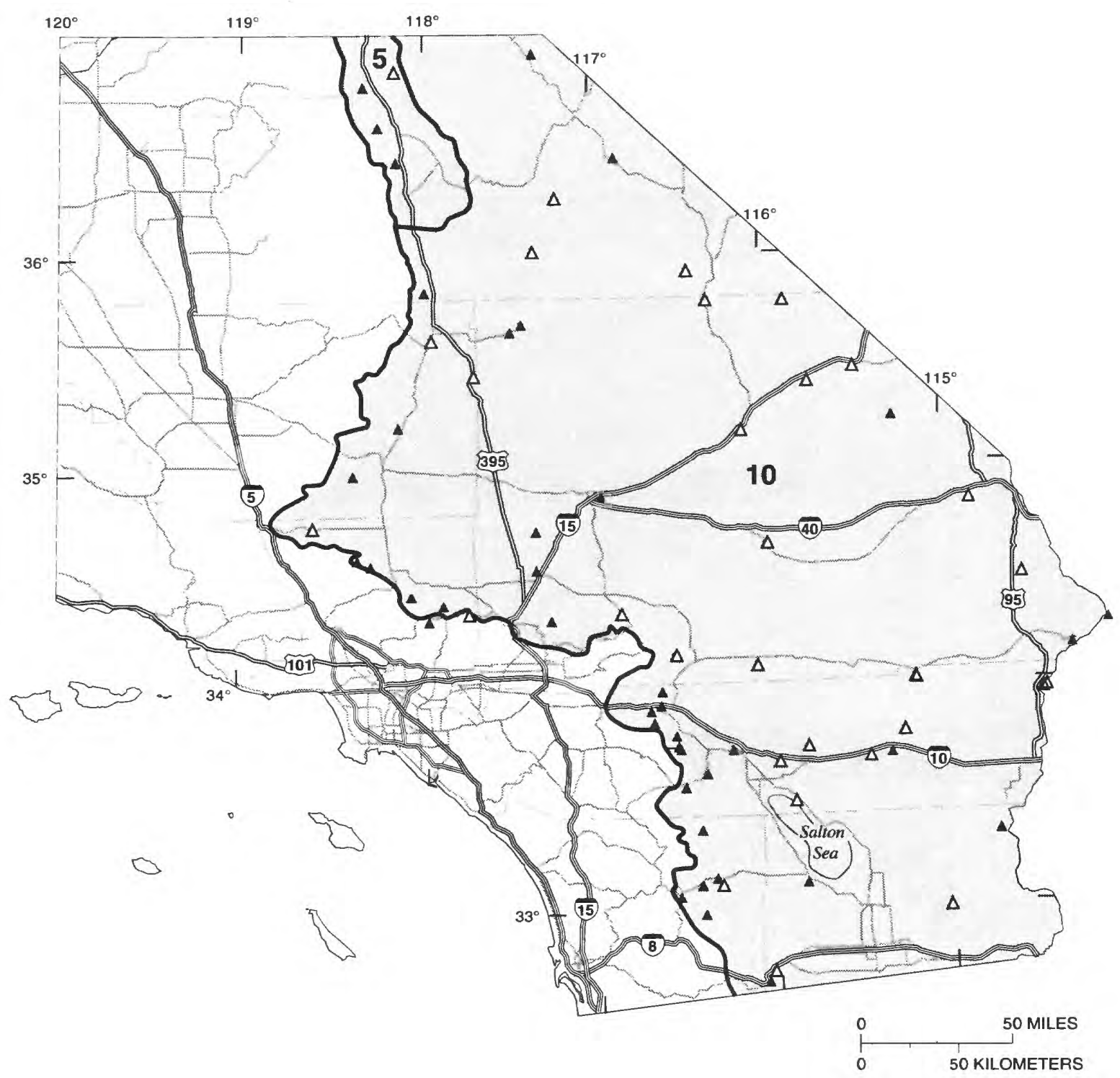

Figure 8. Continued. 

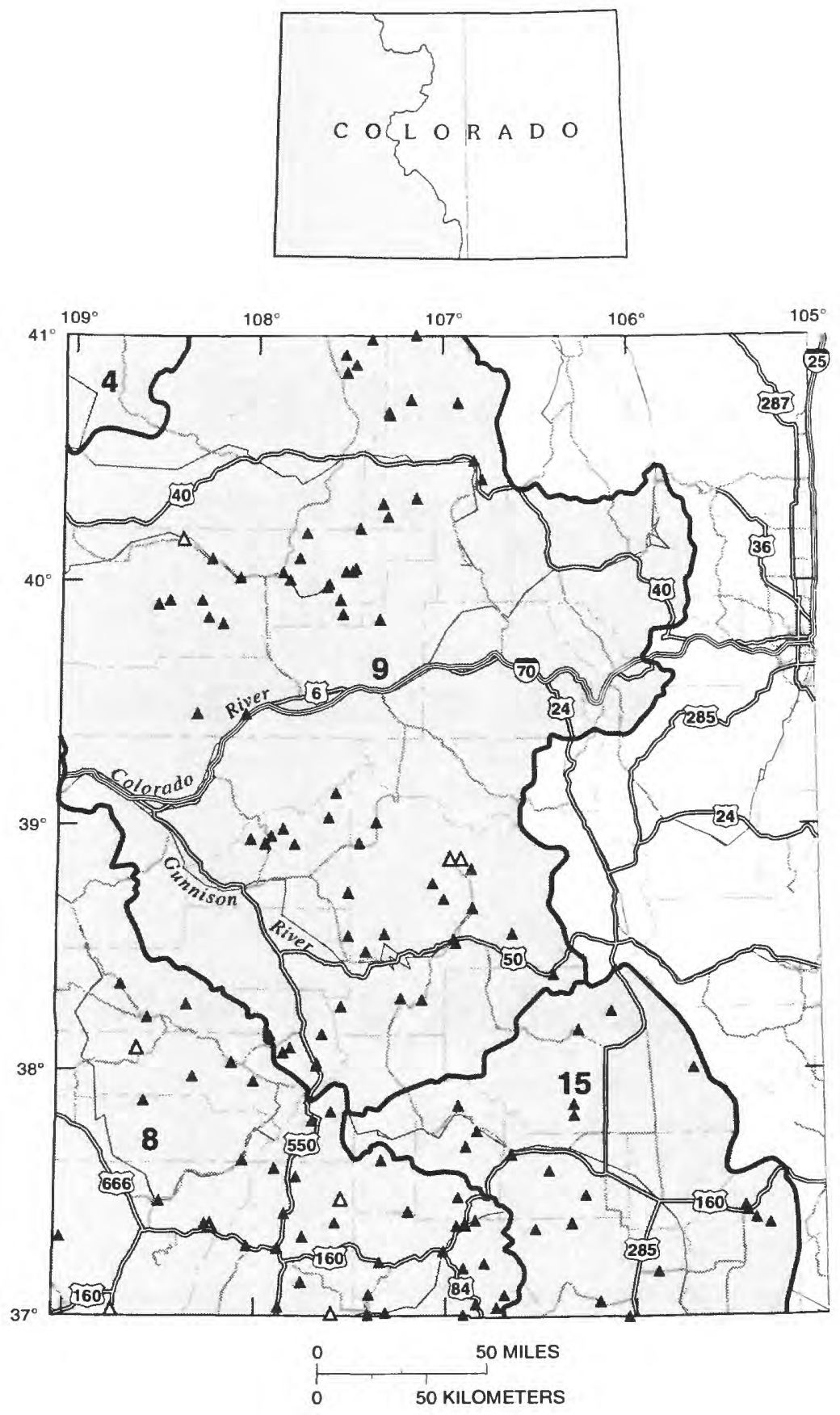

BOUNDARY OF FLOOD REGIONS

9 FLOOD-REGION NUMBER

EXPLANATION

$\begin{aligned}=70 \equiv & =\text { INTERSTATE HIGHWAY } \\ & =\text { U.S. HIGHWAY } \\ & \text { STATE HIGHWAY }\end{aligned}$

STREAMFLOW-GAGING STATION

- Station relation defined

$\Delta$ Station relation undefined

Figure 9. Flood regions in Colorado. 

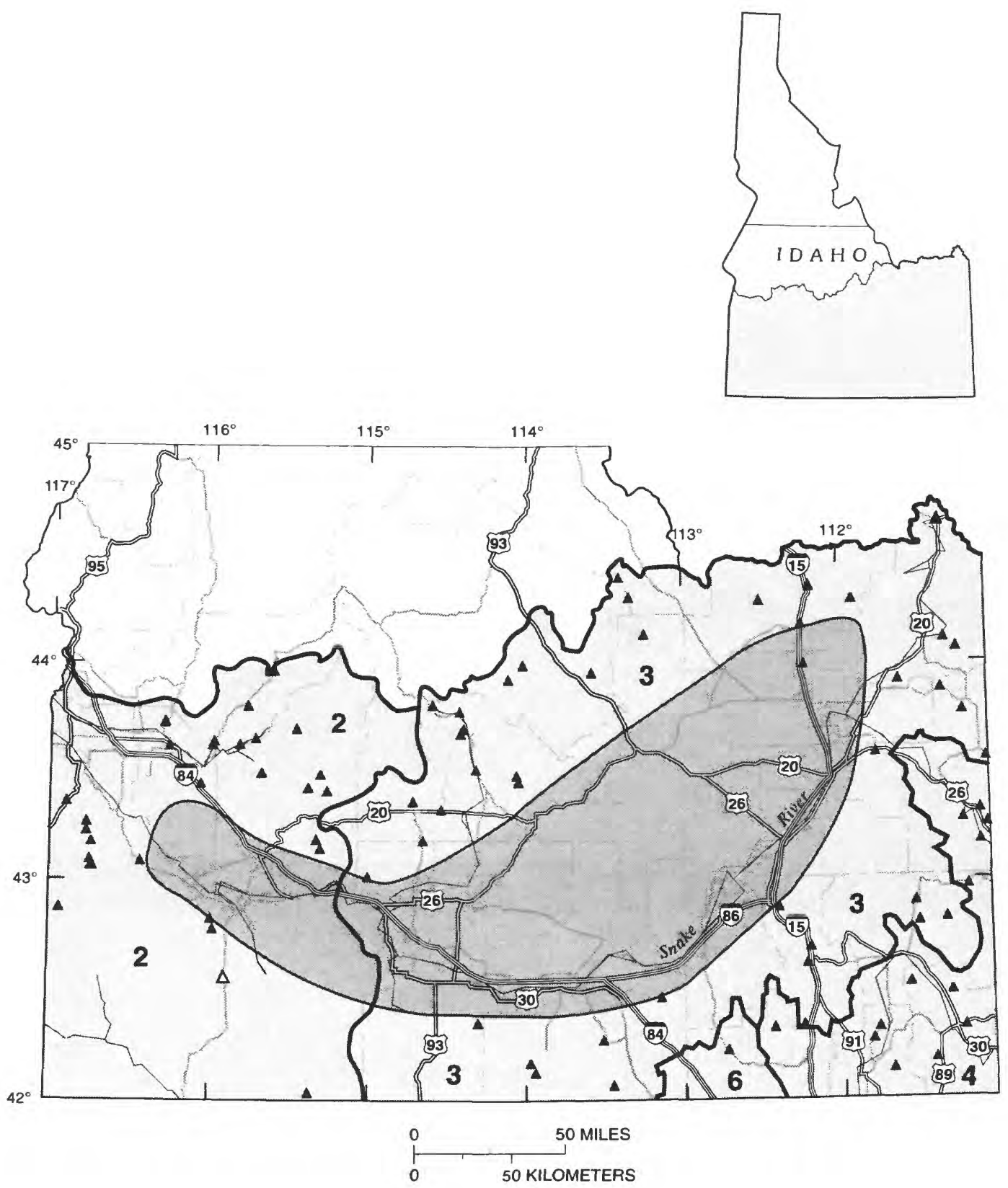

EXPLANATION

SNAKE RIVER PLAIN-FIOOd frequency undefined BOUNDARY OF FLOOD REGIONS

3 FLOOD-REGION NUMBER

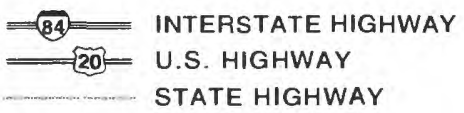

STATE HIGHWAY
STREAMFLOW-GAGING STATION

- Station relation defined

$\Delta$ Station relation undefined

Figure 10. Flood regions in Idaho. 


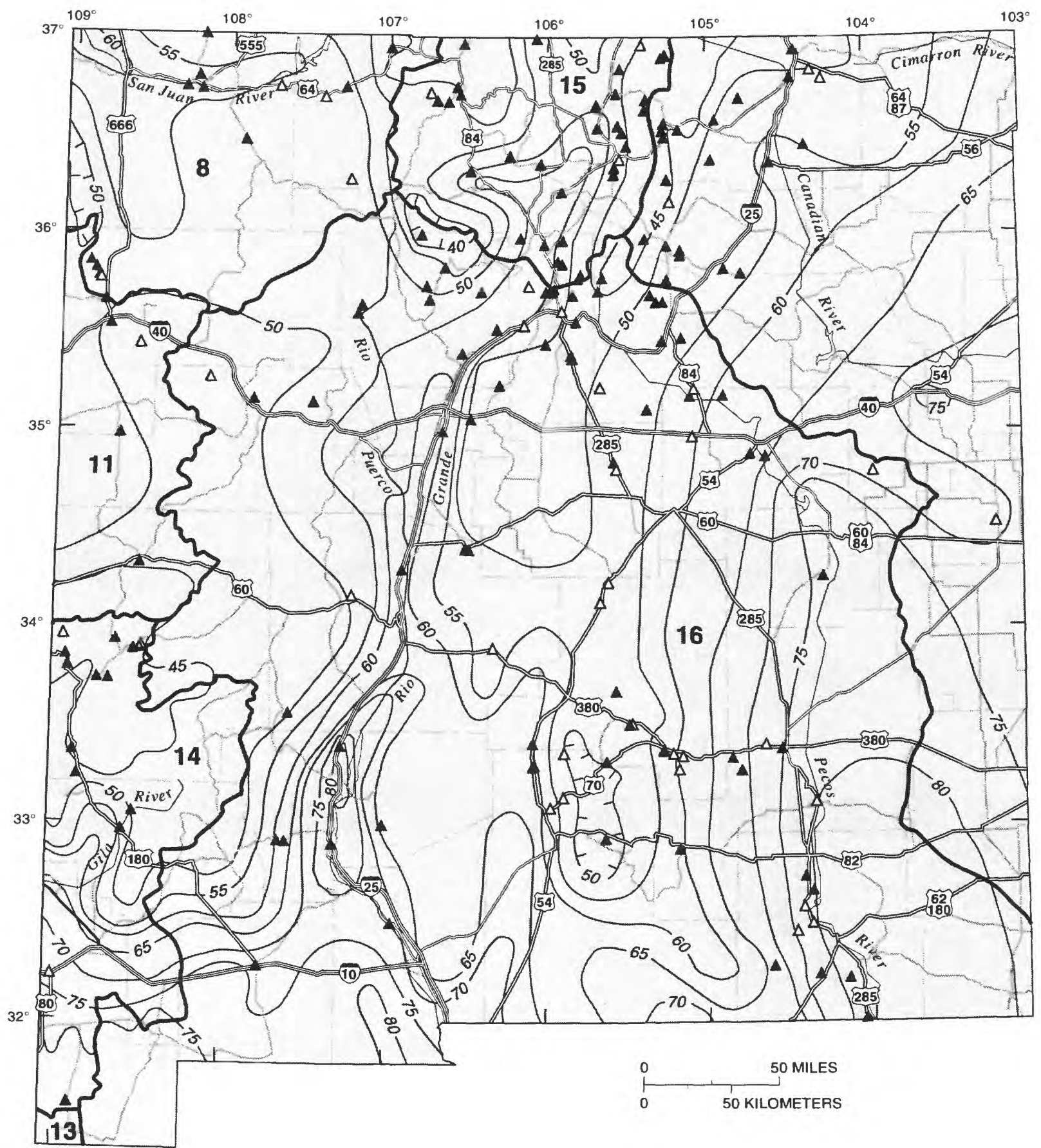

EXPLANATION

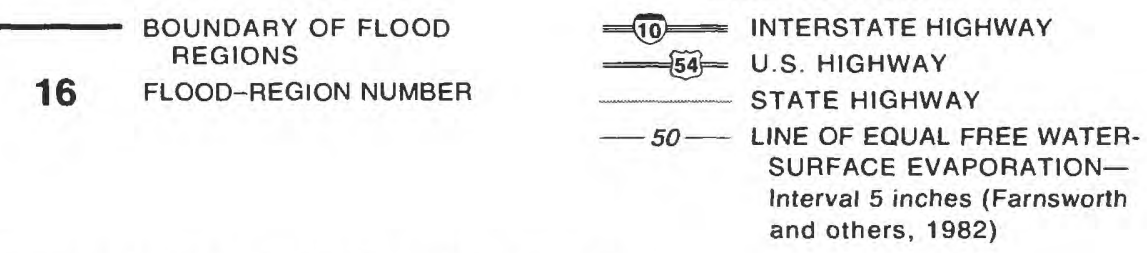

STREAMFLOW-GAGING STATION

- Station relation defined

$\Delta$ Station relation undefined

Figure 11. Flood regions in New Mexico. 


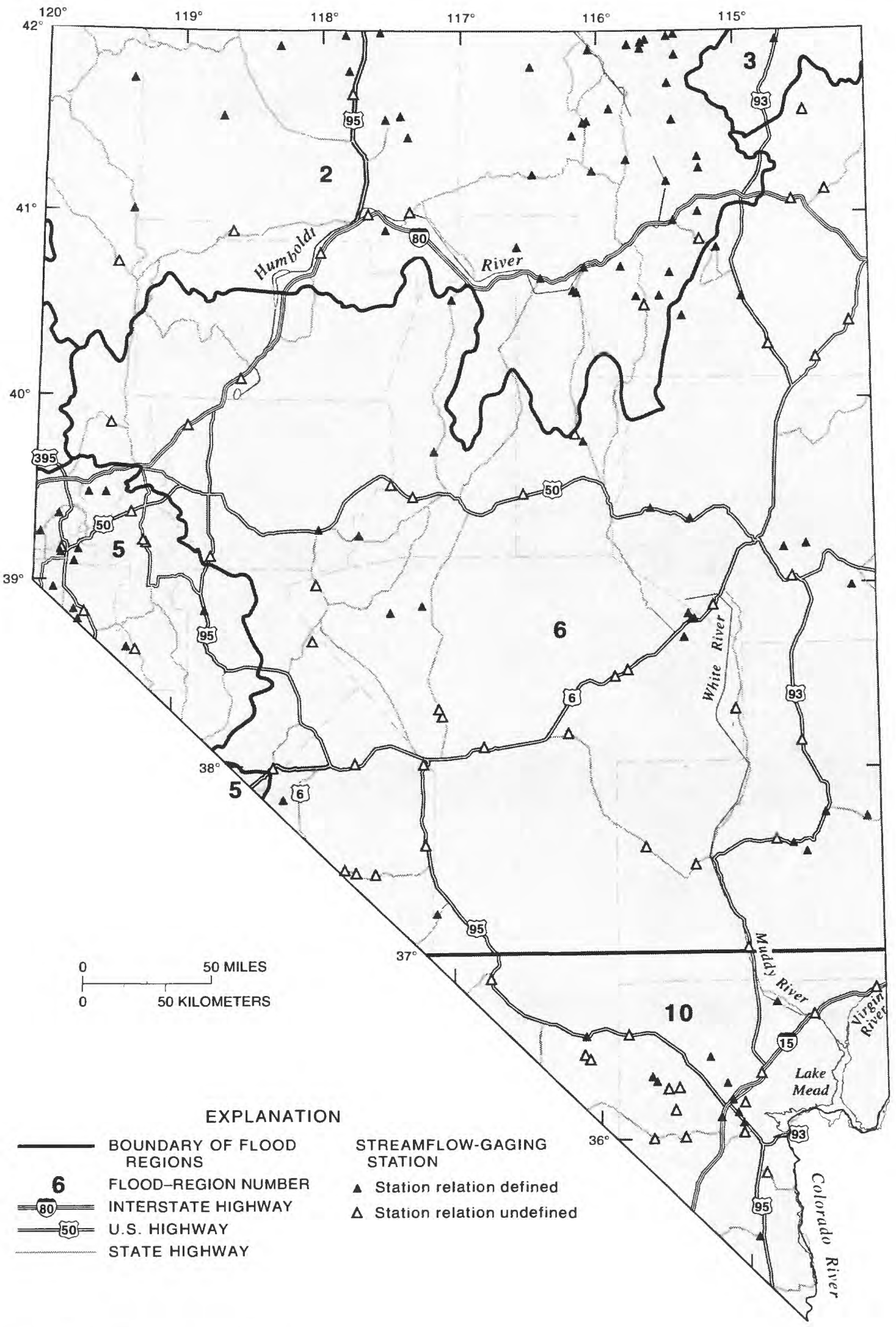

Figure 12. Flood regions in Nevada. 

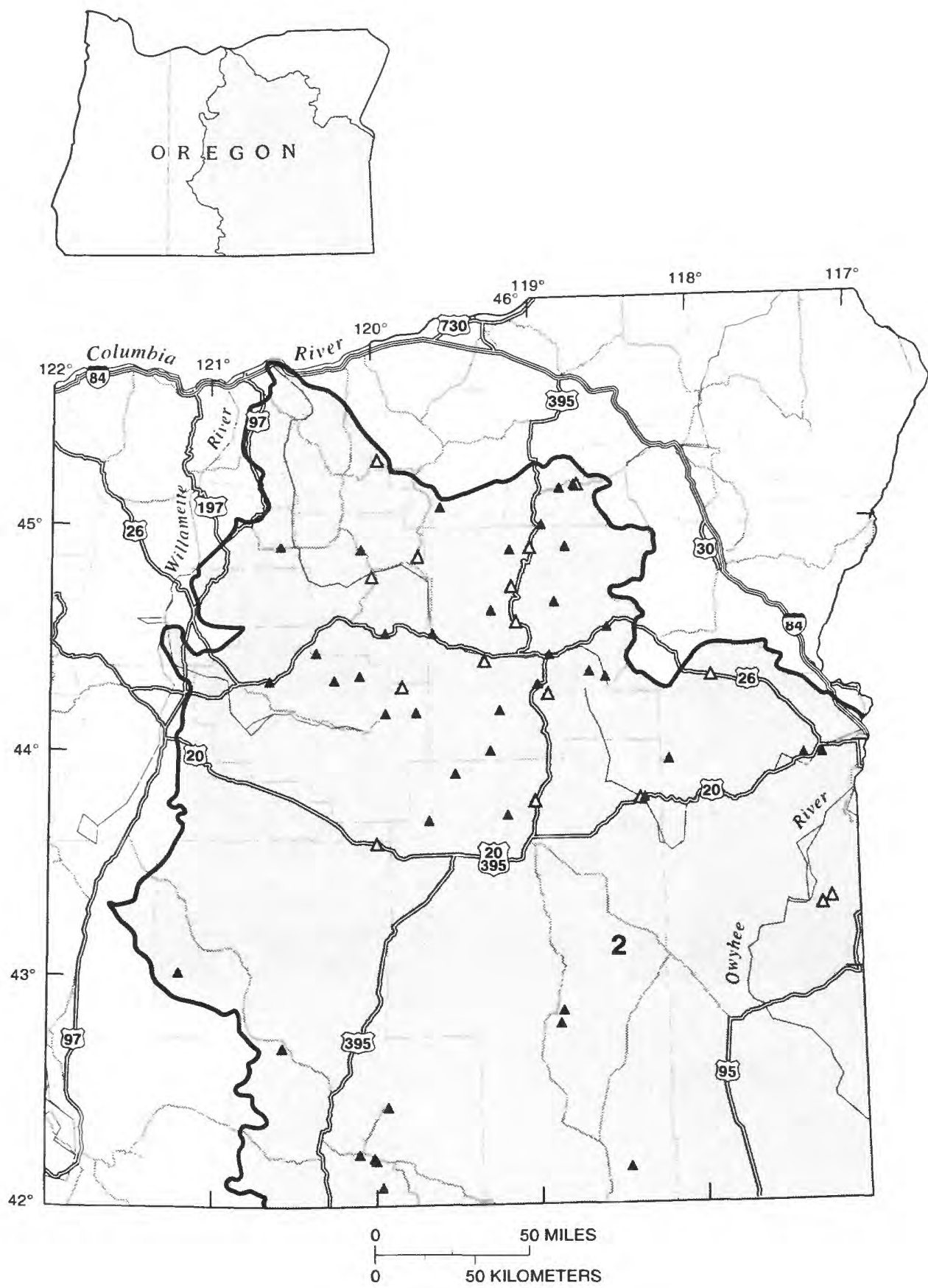

BOUNDARY OF FLOOD REGIONS

2

\section{EXPLANATION}

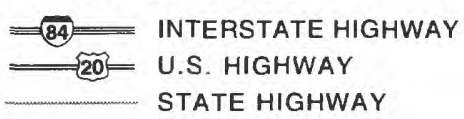

STREAMFLOW-GAGING STATION

- Station relation defined

$\Delta$ Station relation undefined

Figure 13. Flood regions in Oregon. 


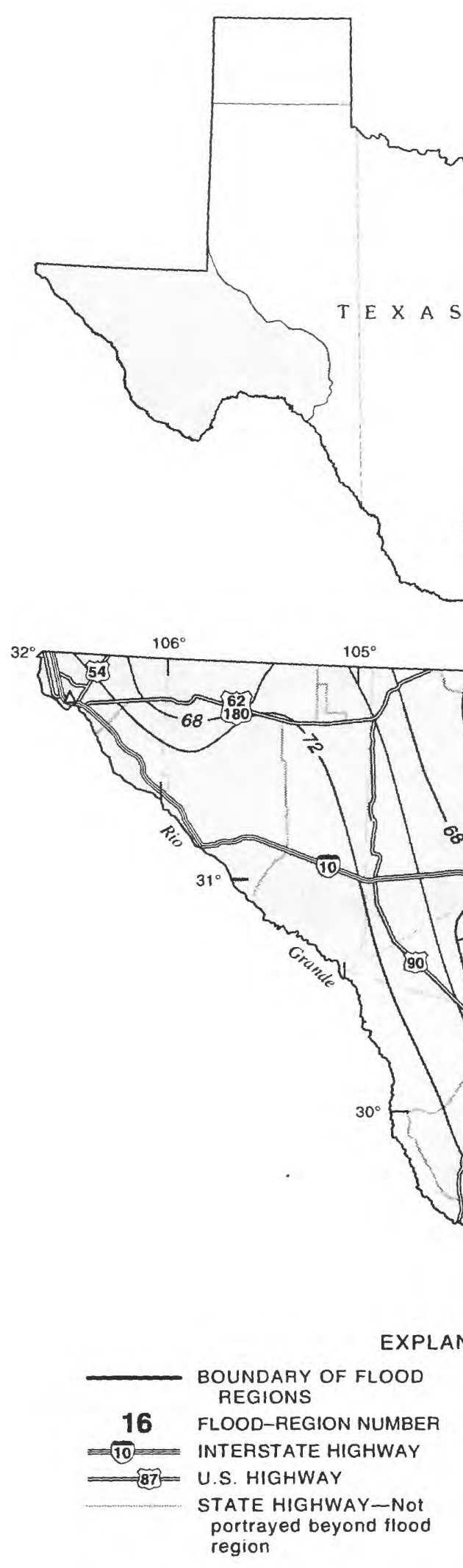

$35^{\circ} 103^{\circ} \quad 102^{\circ}-101^{\circ}-100^{\circ}$
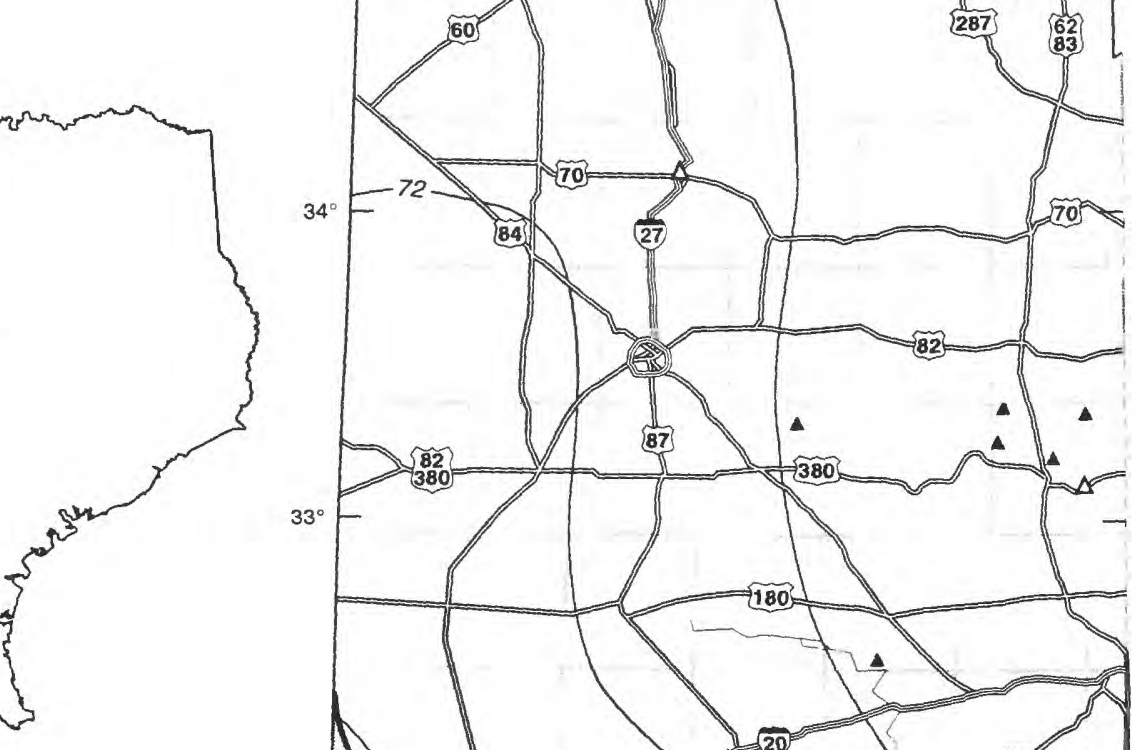


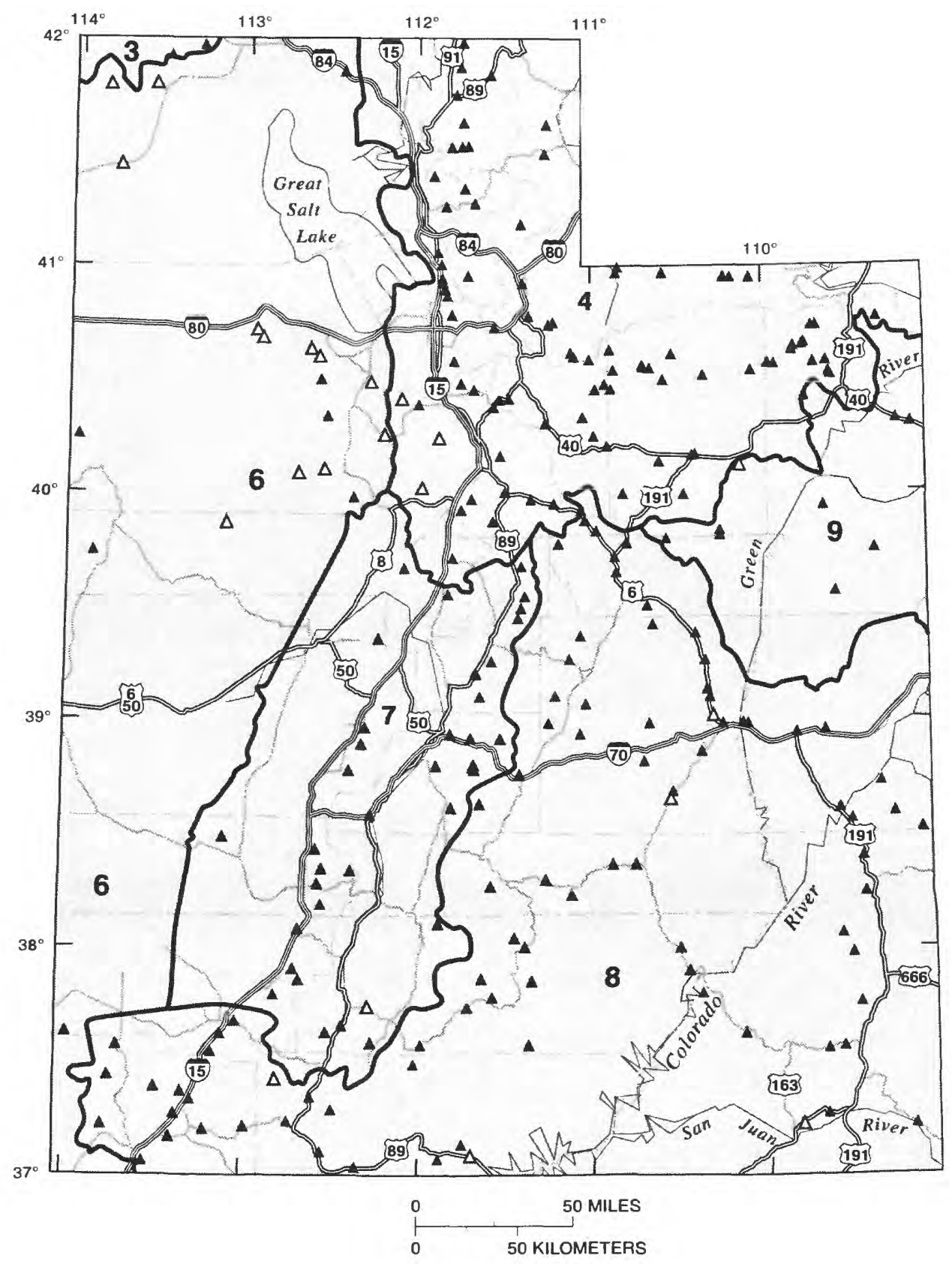

BOUNDARY OF FLOOD REGIONS

7 FLOOD-REGION NUMBER
EXPLANATION

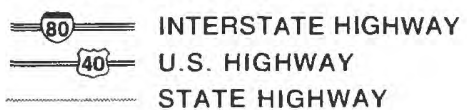

STREAMFLOW-GAGING STATION

- Station relation defined

$\Delta$ Station relation undefined

Figure 15. Flood regions in Utah. 

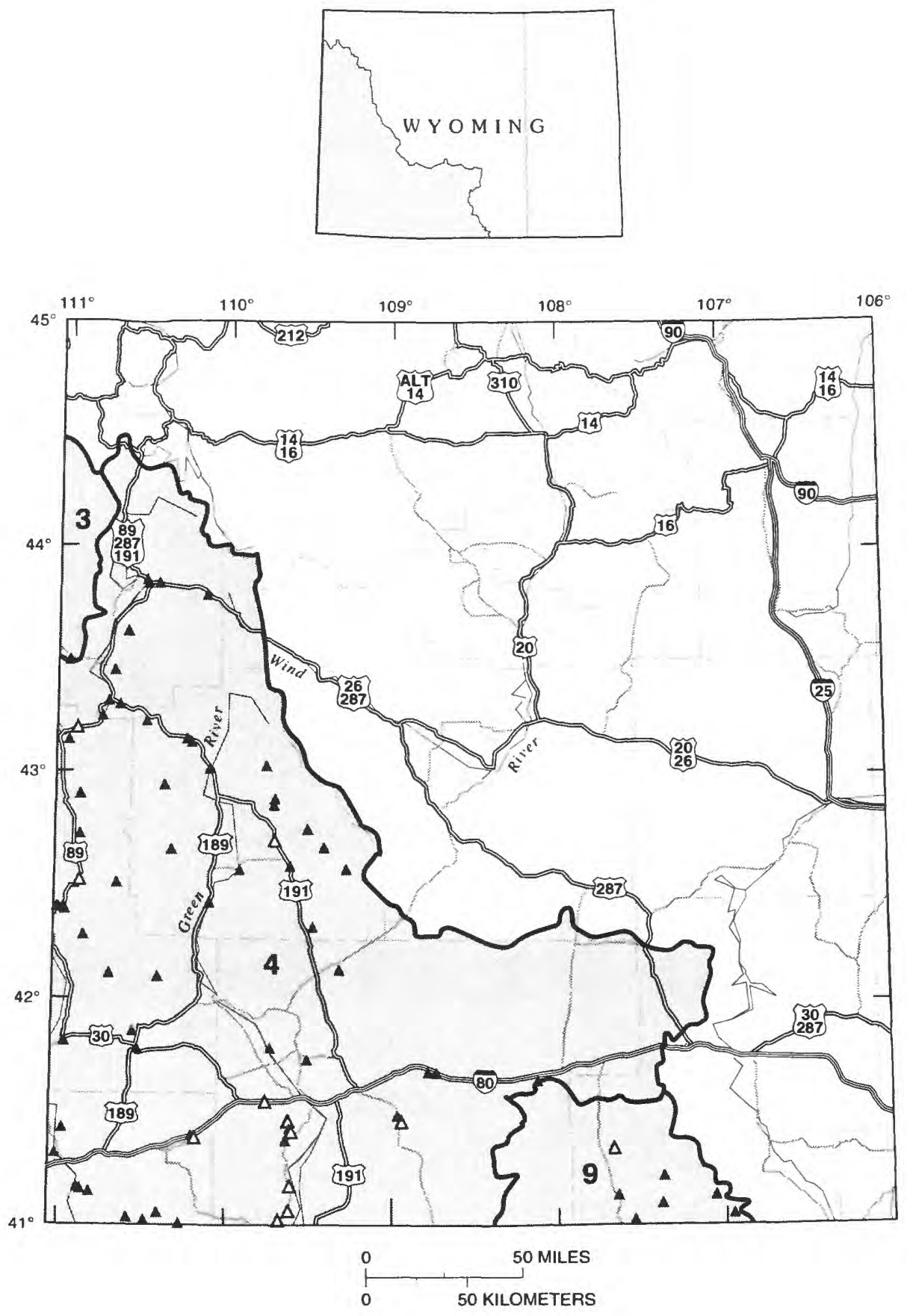

BOUNDARY OF FLOOD REGIONS

4 FLOOD-REGION NUMBER

EXPLANATION

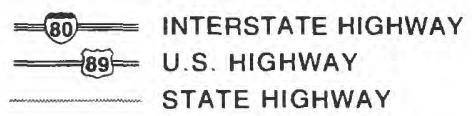

STREAMFLOW-GAGING STATION

A Station relation defined

$\Delta$ Station relation undefined

Figure 16. Flood regions in Wyoming. 


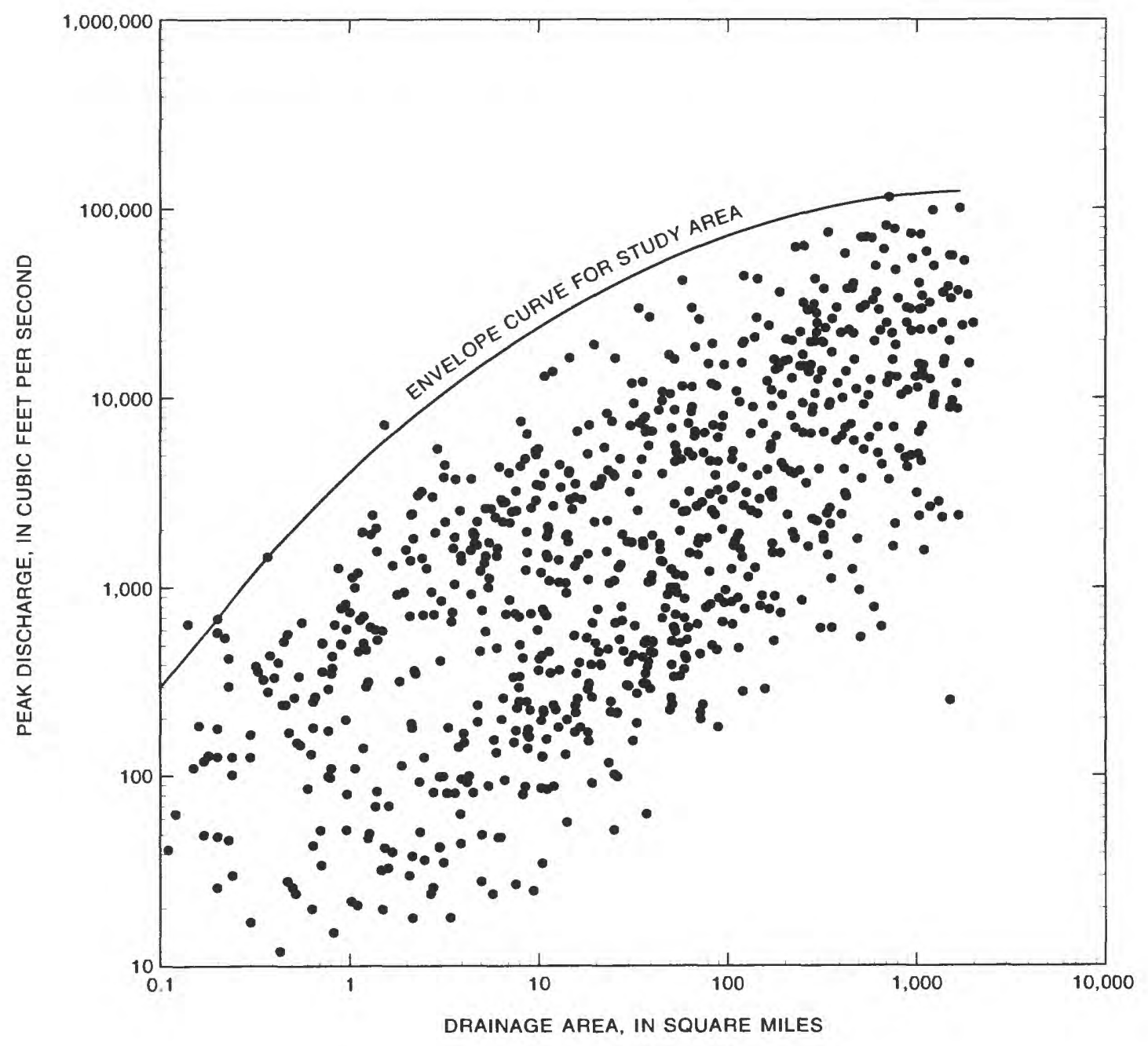

Figure 17. Relation between maximum peak discharge of record and drainage area for gaged sites in the study area. 


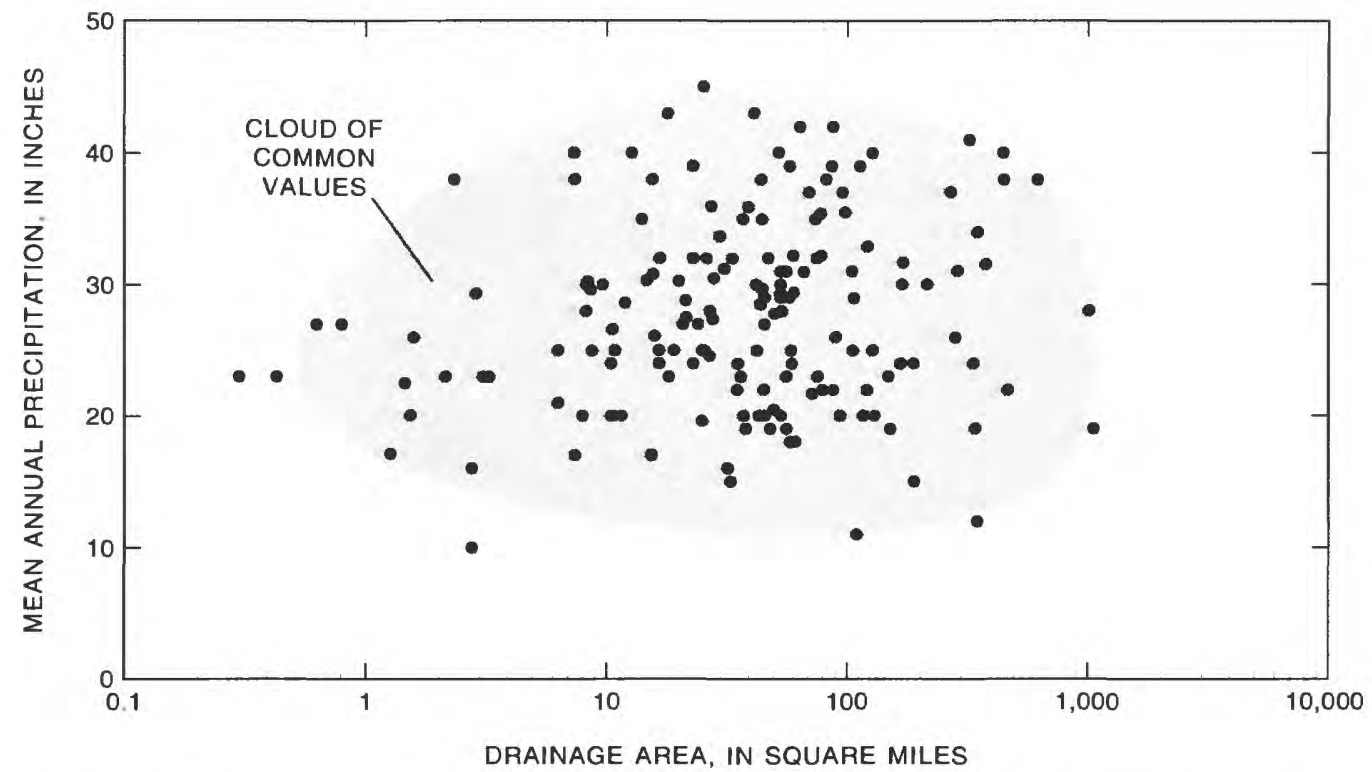

Figure 18. Joint distribution of mean annual precipitation and drainage area for gaged sites in the High-Elevation Region 1.

Table 5. Generalized least-squares regression equations for estimating regional flood-frequency relations for the High-Elevation Region 1

Equation: Q, peak discharge, in cubic feet per second; AREA, drainage area, in square miles; and PREC, mean annual precipitation, in inches. Data were based on 165 stations. Average number of years of systematic record is 28.

\begin{tabular}{cccc}
\hline $\begin{array}{c}\text { Recurrence } \\
\text { interval, in years }\end{array}$ & Equation & $\begin{array}{c}\text { Average } \\
\text { standard error of } \\
\text { prediction, in } \\
\text { percent }\end{array}$ & $\begin{array}{c}\text { Equivalent } \\
\text { years of } \\
\text { record }\end{array}$ \\
\hline 2 & $Q=0.124 \mathrm{AREA}^{0.845} \mathrm{PREC}^{1.44}$ & 59 & 0.16 \\
5 & $Q=0.629 \mathrm{AREA}^{0.807} \mathrm{PREC}^{1.12}$ & 52 & .62 \\
10 & $Q=1.43 \mathrm{AREA}^{0.786} \mathrm{PREC}^{0.958}$ & 48 & 1.34 \\
25 & $Q=3.08 \mathrm{AREA}^{0.768} \mathrm{PREC}^{0.811}$ & 46 & 2.50 \\
50 & $Q=4.75 \mathrm{AREA}^{0.758} \mathrm{PREC}^{0.732}$ & 46 & 3.37 \\
100 & $Q=6.78 \mathrm{AREA}^{0.750} \mathrm{PREC}^{0.668}$ & 46 & 4.19 \\
\hline
\end{tabular}




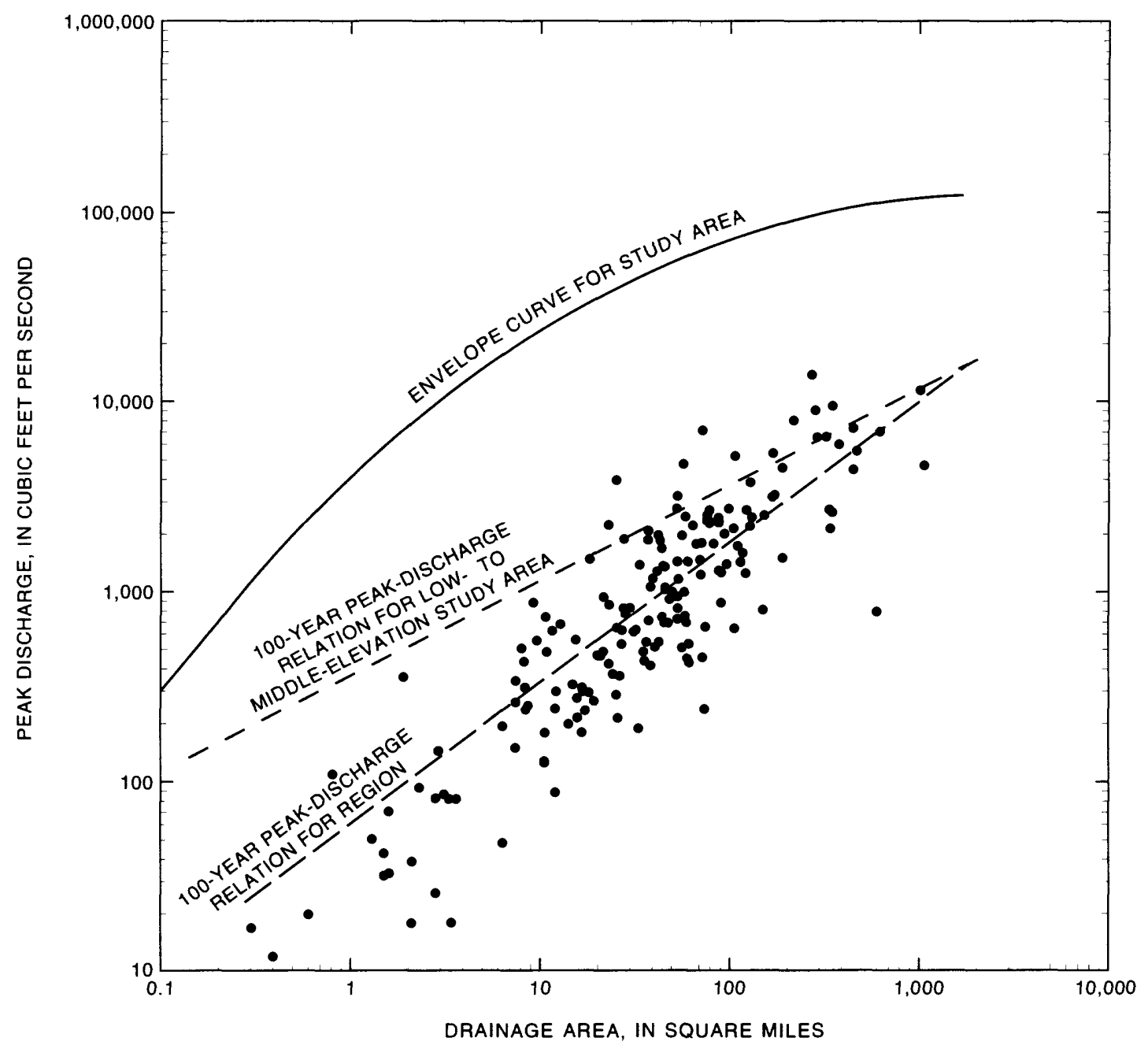

Figure 19. Relations between 100-year peak discharge and drainage area and plot of maximum peak discharge of record and drainage area for gaged sites in the High Elevation Region 1. 


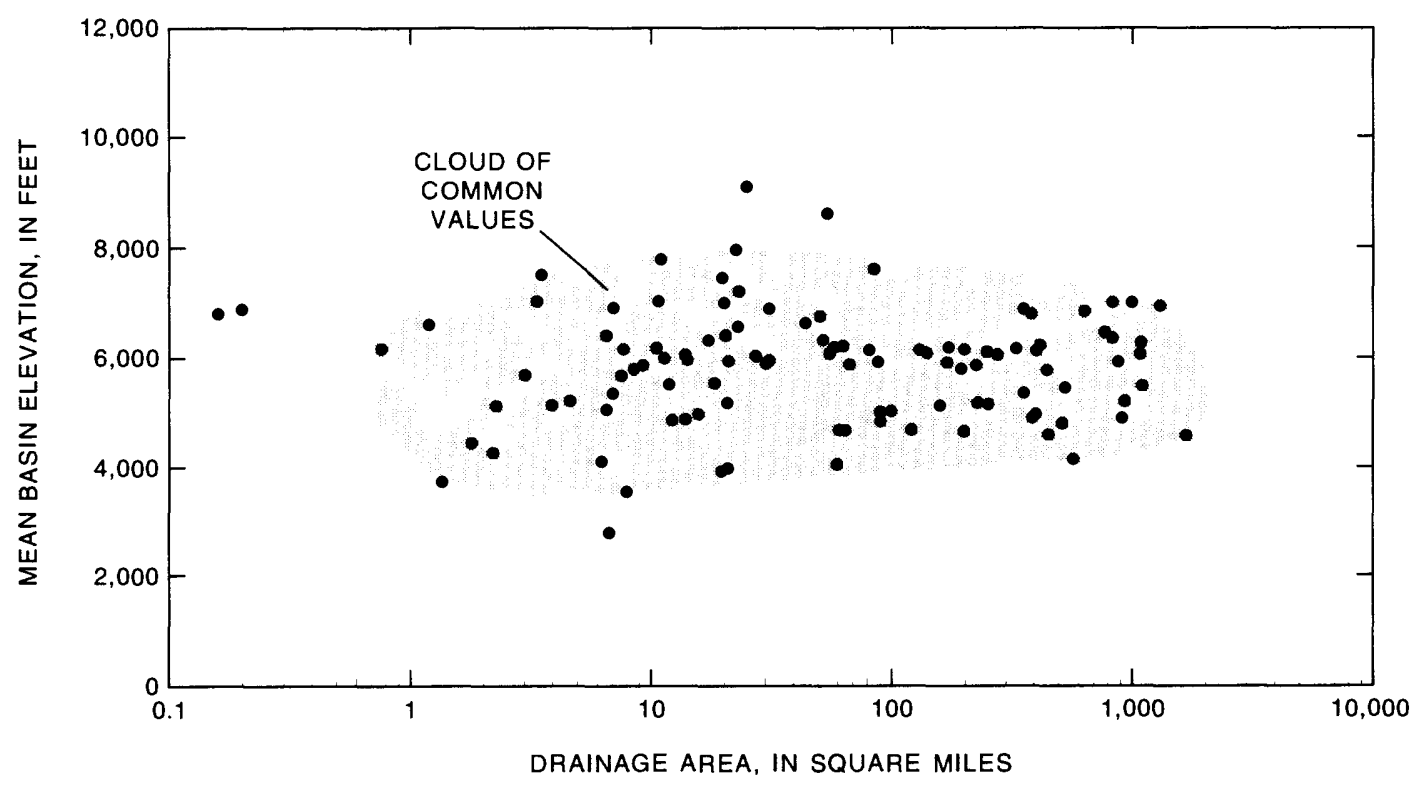

Figure 20. Joint distribution of mean basin elevation and drainage area for gaged sites in the Northwest Region 2.

Table 6. Generalized least-squares regression equations for estimating regional flood-frequency relations for the Northwest Region 2

Equation: $Q$, peak discharge, in cubic feet per second; AREA, drainage area, in square miles; and ELEV, mean basin elevation, in feet. Data were based on 108 stations. Average number of years of systematic record is 26.

\begin{tabular}{cccc}
\hline $\begin{array}{c}\text { Recurrence } \\
\text { Interval, in years }\end{array}$ & Equation & $\begin{array}{c}\text { Average } \\
\text { standard error of } \\
\text { prediction, in } \\
\text { percent }\end{array}$ & $\begin{array}{c}\text { Equivalent } \\
\text { years of } \\
\text { record }\end{array}$ \\
\hline 2 & $Q=13.1 \mathrm{AREA}^{0.713}$ & 72 & 0.96 \\
5 & $Q=22.4 \mathrm{AREA}^{0.723}$ & 66 & 1.80 \\
10 & $Q=55.7 \mathrm{AREA}^{0.727}\left(\mathrm{ELEV}^{-1,000)^{-0.353}}\right.$ & 61 & 3.07 \\
25 & $Q=84.7 \mathrm{AREA}^{0.737}(\mathrm{ELEV} / 1,000)^{-0.438}$ & 61 & 4.64 \\
50 & $Q=113 \mathrm{AREA}^{0.746}(\mathrm{ELEV} / 1,000)^{-0.511}$ & 64 & 5.47 \\
100 & $Q=148 \mathrm{AREA}^{0.752}(\mathrm{ELEV} / 1,000)^{-0.584}$ & 68 & 6.05 \\
\hline
\end{tabular}




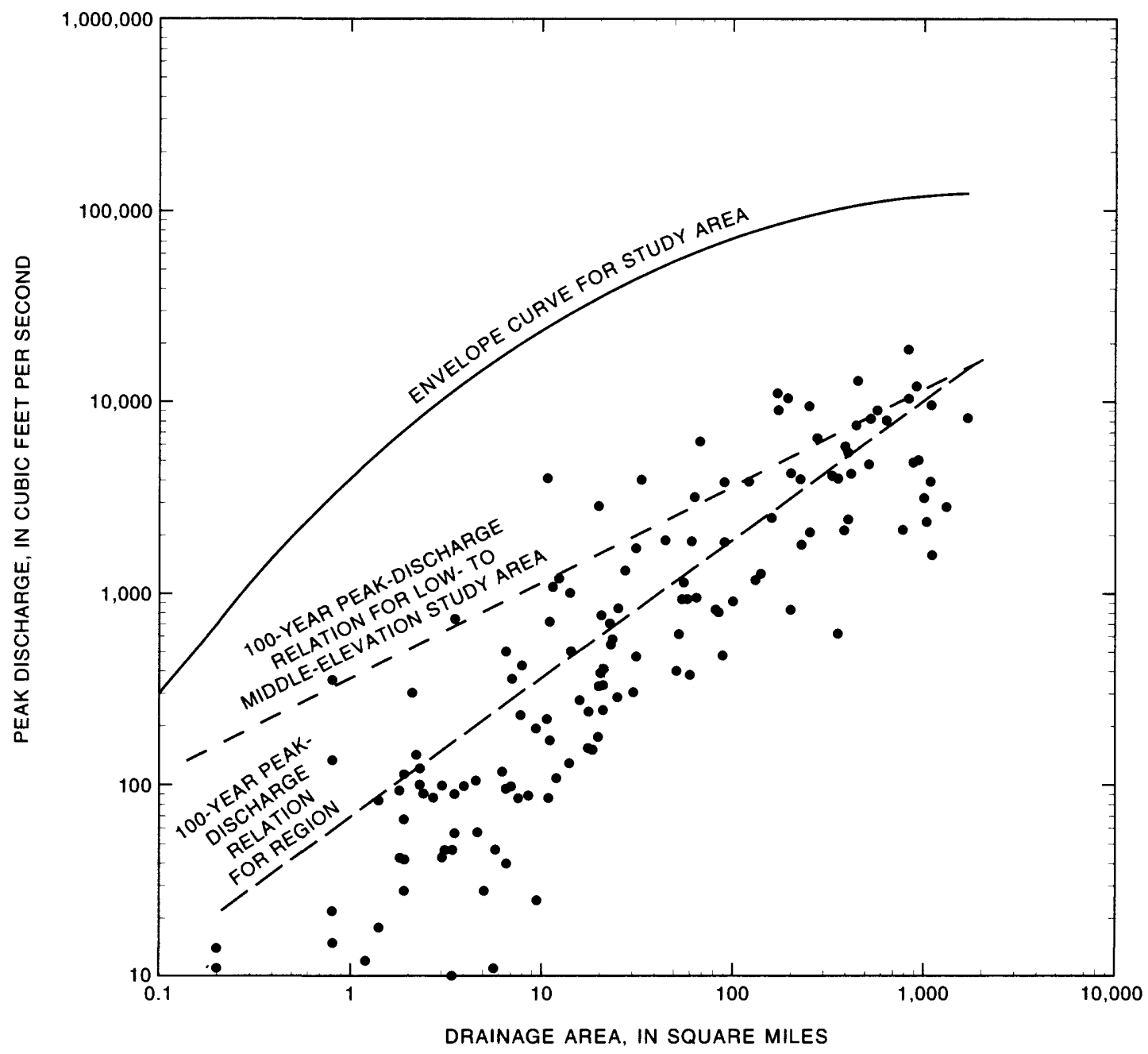

Figure 21. Relations between 100-year peak discharge and drainage area and plot of maximum peak discharge of record and drainage area for gaged sites in the Northwest Region 2. 


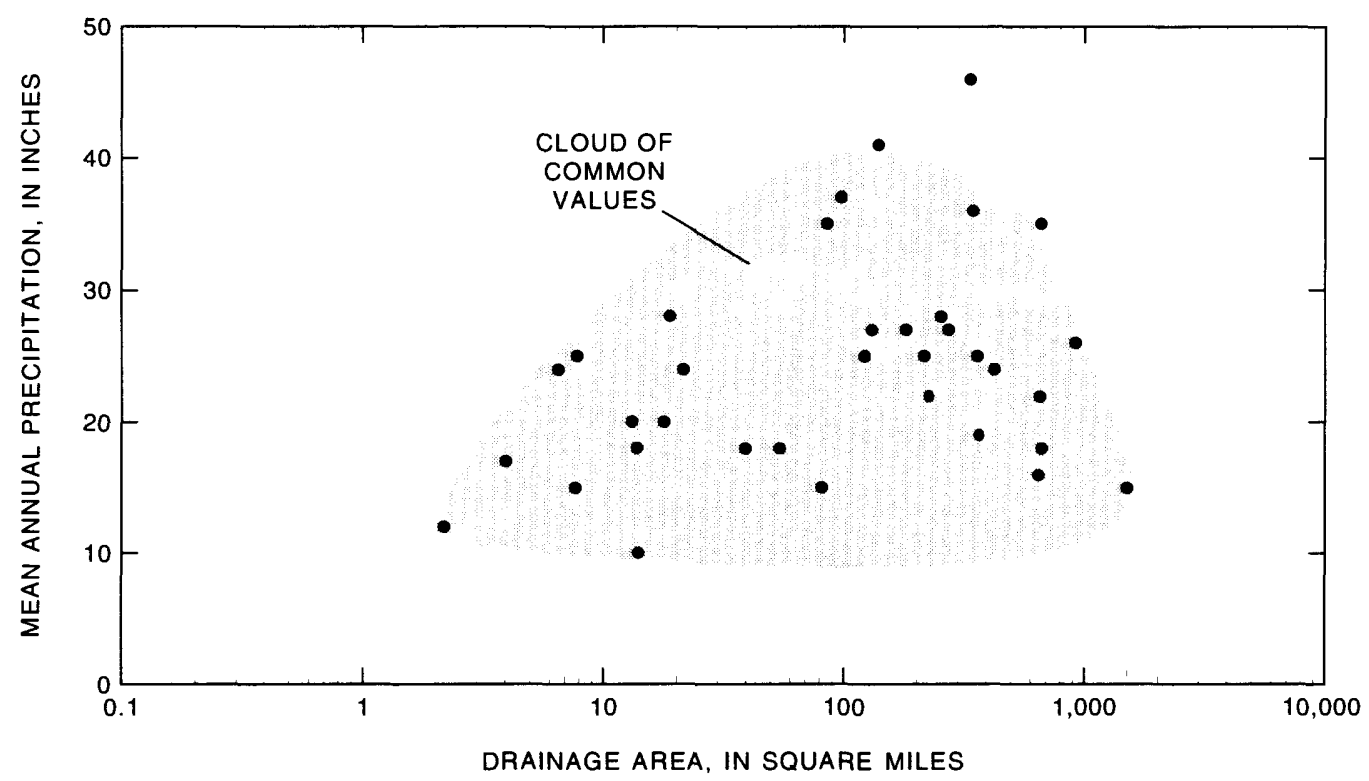

Figure 22. Joint distribution of mean annual precipitation and drainage area for gaged sites in the South-Central Idaho Region 3.

Table 7. Generalized least-squares regression equations for estimating regional flood-frequency relations for the South-Central Idaho Region 3

Equation: $Q$, peak discharge, in cubic feet per second; AREA, drainage area, in square miles; and PREC, mean annual precipitation, in inches. Data were based on 35 stations. Average number of years of systematic record is 32 .

\begin{tabular}{cccc}
\hline $\begin{array}{c}\text { Recurrence } \\
\text { interval, in years }\end{array}$ & Equatlon & $\begin{array}{c}\text { Average } \\
\text { standard error of } \\
\text { prediction, in } \\
\text { percent }\end{array}$ & $\begin{array}{c}\text { Equivalent } \\
\text { years of } \\
\text { record }\end{array}$ \\
\hline 2 & $Q=0.444 \mathrm{AREA}^{0.649} \mathrm{PREC}^{1.15}$ & 86 & 0.29 \\
5 & $Q=1.21 \mathrm{AREA}^{0.639} \mathrm{PREC}^{0.995}$ & 83 & .49 \\
10 & $Q=1.99 \mathrm{AREA}^{0.633} \mathrm{PREC}^{0.924}$ & 80 & .77 \\
25 & $Q=3.37 \mathrm{AREA}^{0.627} \mathrm{PREC}^{0.849}$ & 78 & 1.23 \\
50 & $Q=4.70 \mathrm{AREA}^{0.625} \mathrm{PREC}^{0.802}$ & 77 & 1.57 \\
100 & $Q=6.42 \mathrm{AREA}^{0.621} \mathrm{PREC}^{0.757}$ & 78 & 1.92 \\
\hline
\end{tabular}




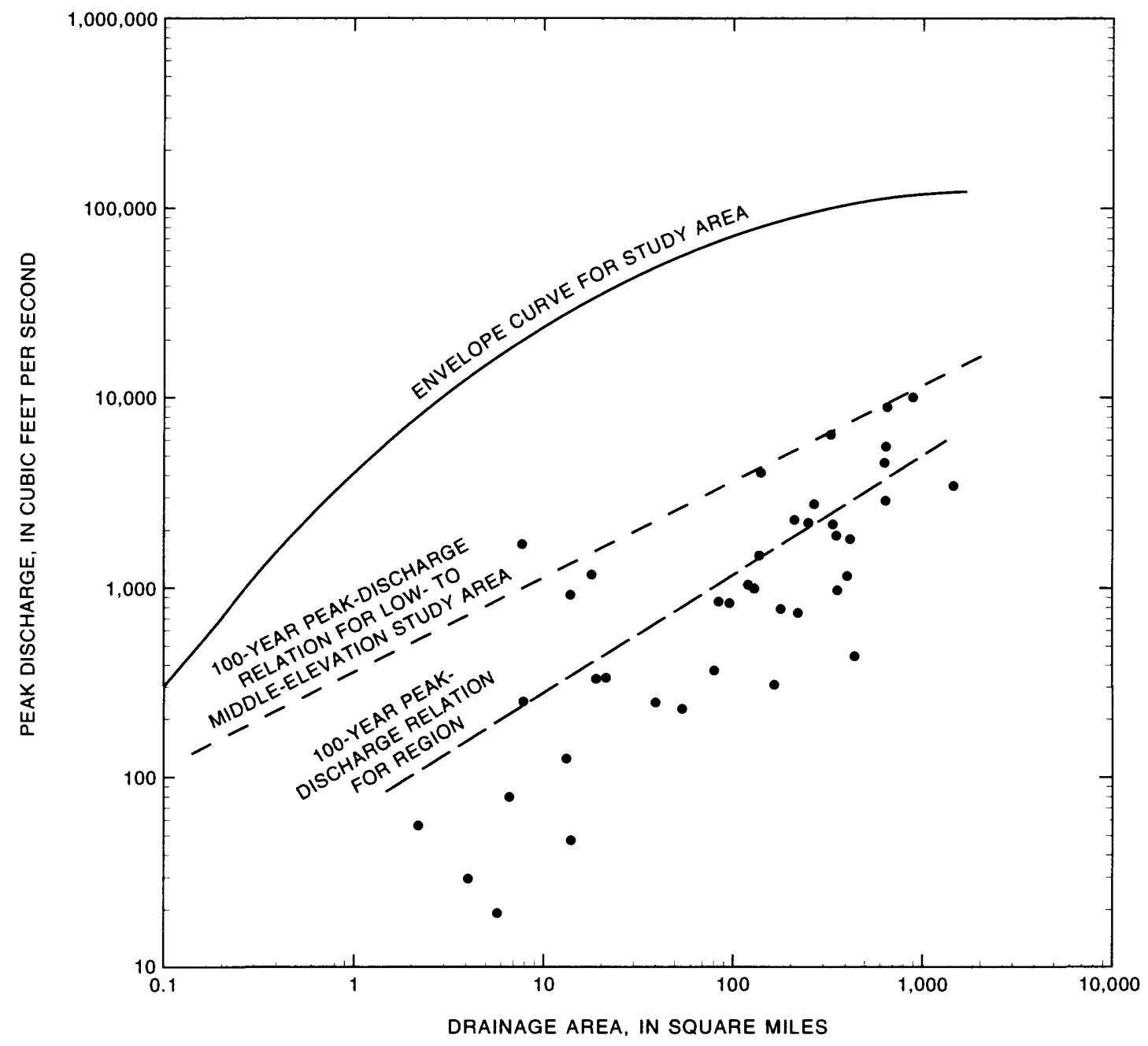

Figure 23. Relations between 100-year peak discharge and drainage area and plot of maximum peak discharge of record and drainage area for gaged sites in the South-Central Idaho Region 3. 


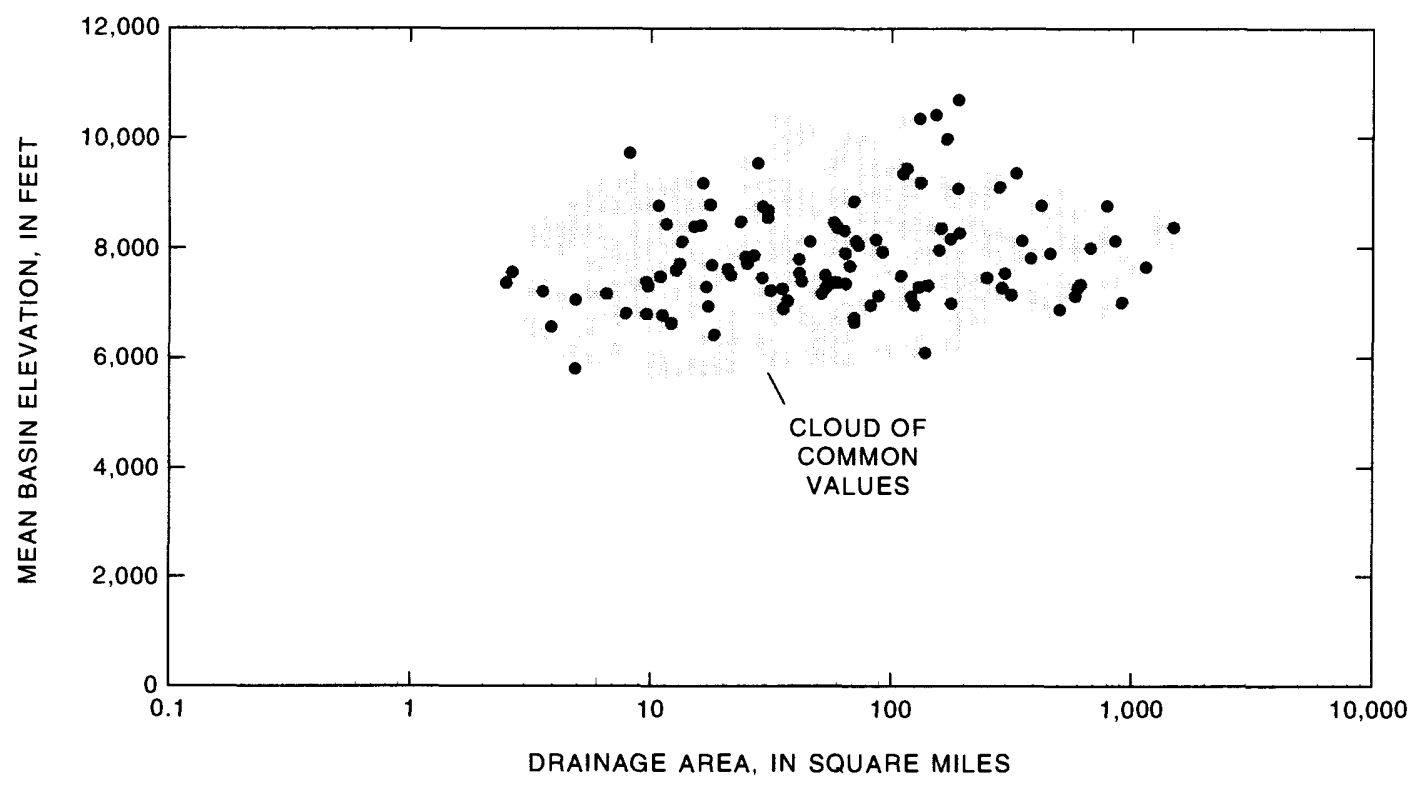

Figure 24. Joint distribution of mean basin elevation and drainage area for gaged sites in the Northeast Region 4.

Table 8. Generalized least-squares regression equations for estimating regional flood-frequency relations for the Northeast Region 4

Equation: $Q$, peak discharge, in cubic feet per second; AREA, drainage area, in square miles; and ELEV, mean basin elevation, in feet. Data were based on 108 stations. Average number of years of systematic record is 28.

\begin{tabular}{cccc}
\hline $\begin{array}{c}\text { Recurrence } \\
\text { interval, in } \\
\text { years }\end{array}$ & Equation & $\begin{array}{c}\text { Average } \\
\text { standard error } \\
\text { of prediction, in } \\
\text { percent }\end{array}$ & $\begin{array}{c}\text { Equivalent } \\
\text { years of } \\
\text { record }\end{array}$ \\
\hline 2 & $Q=0.0405 \mathrm{AREA}^{0.701}(\mathrm{ELEV} / 1,000)^{2.91}$ & 64 & 0.39 \\
5 & $Q=0.408 \mathrm{AREA}^{0.683}(\mathrm{ELEV} / 1,000)^{2.05}$ & 57 & .95 \\
10 & $Q=1.26 \mathrm{AREA}^{0.674}(\mathrm{ELEV} / 1,000)^{1.64}$ & 53 & 1.76 \\
25 & $Q=3.74 \mathrm{AREA}^{0.667}(\mathrm{ELEV} / 1,000)^{1.24}$ & 51 & 3.02 \\
50 & $Q=7.04 \mathrm{AREA}^{0.664}(\mathrm{ELEV} / 1,000)^{1.02}$ & 52 & 3.89 \\
100 & $Q=11.8 \mathrm{AREA}^{0.662}(\mathrm{ELEV} / 1,000)^{0.835}$ & 53 & 4.65 \\
\hline
\end{tabular}




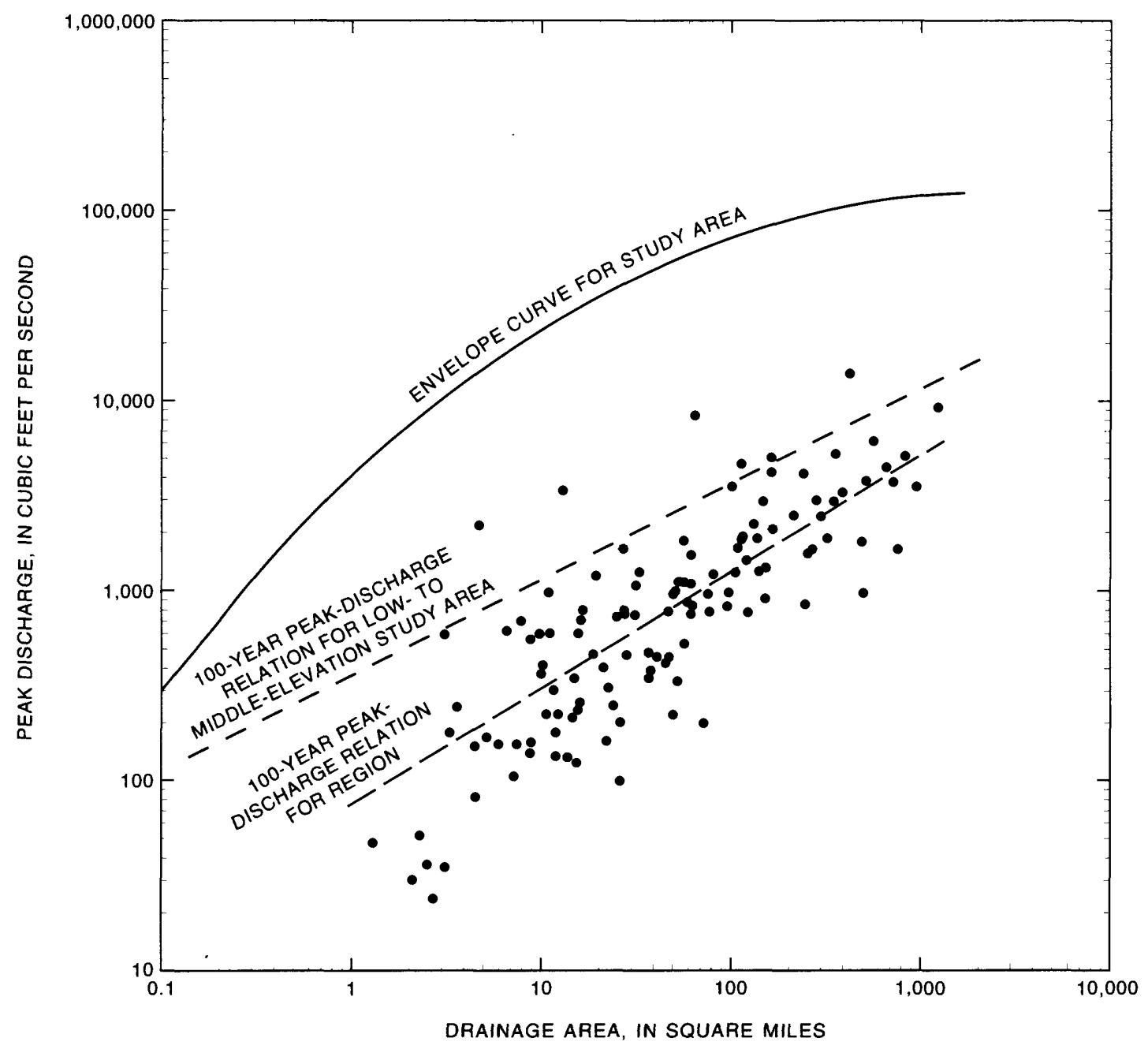

Figure 25. Relations between 100-year peak discharge and drainage area and plot of maximum peak discharge of record and drainage area for gaged sites in the Northeast Region 4. 


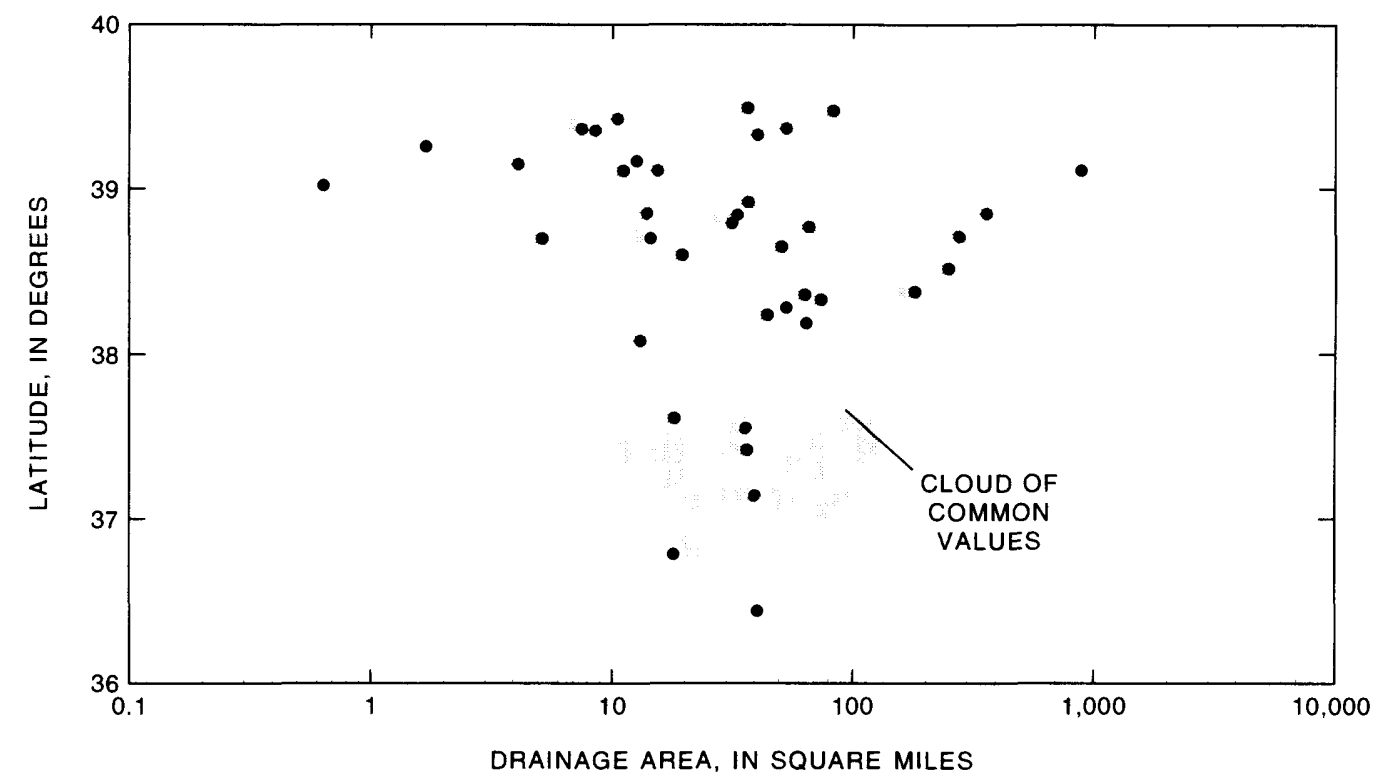

Figure 26. Joint distribution of latitude and drainage area for gaged sites in the Eastern Sierras Region 5.

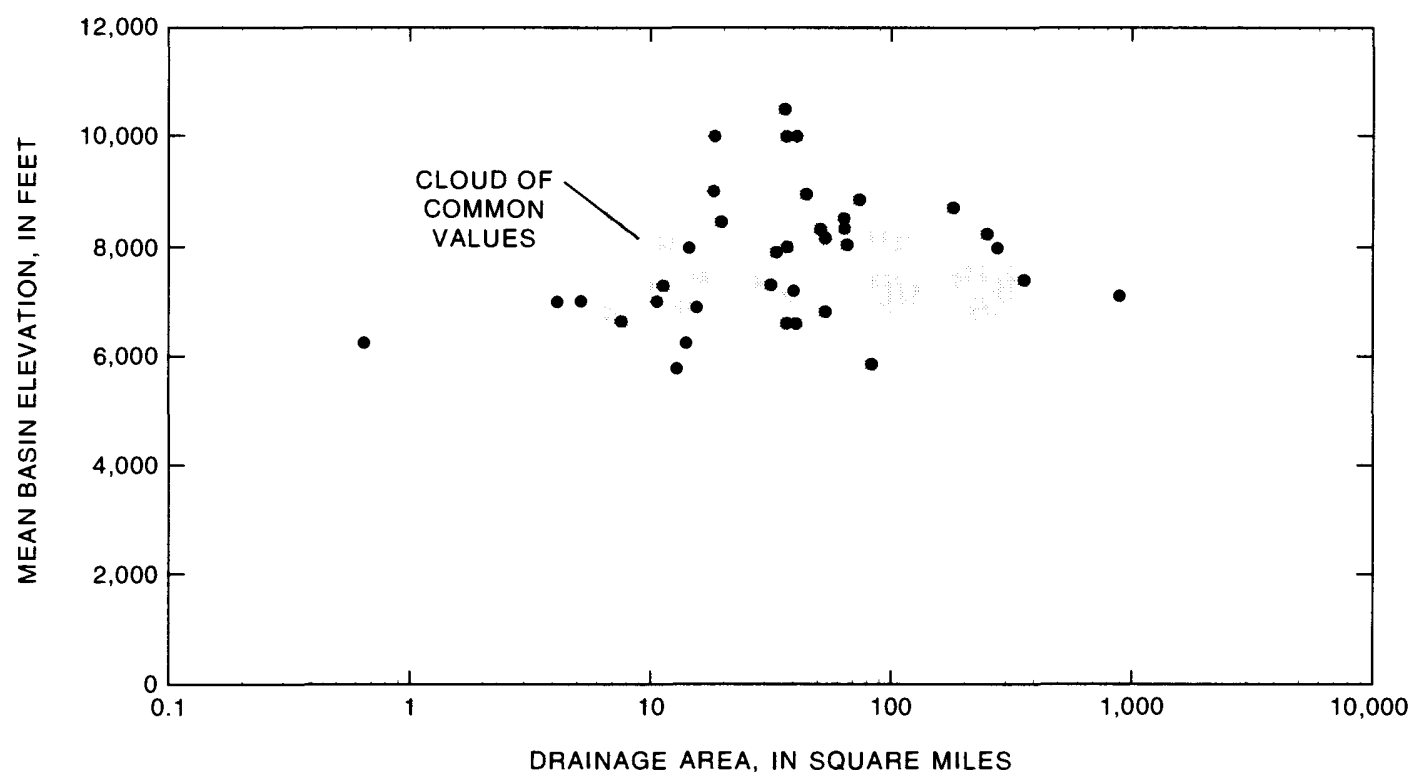

Figure 27. Joint distribution of mean basin elevation and drainage area for gaged sites in the Eastern Sierras Region 5. 


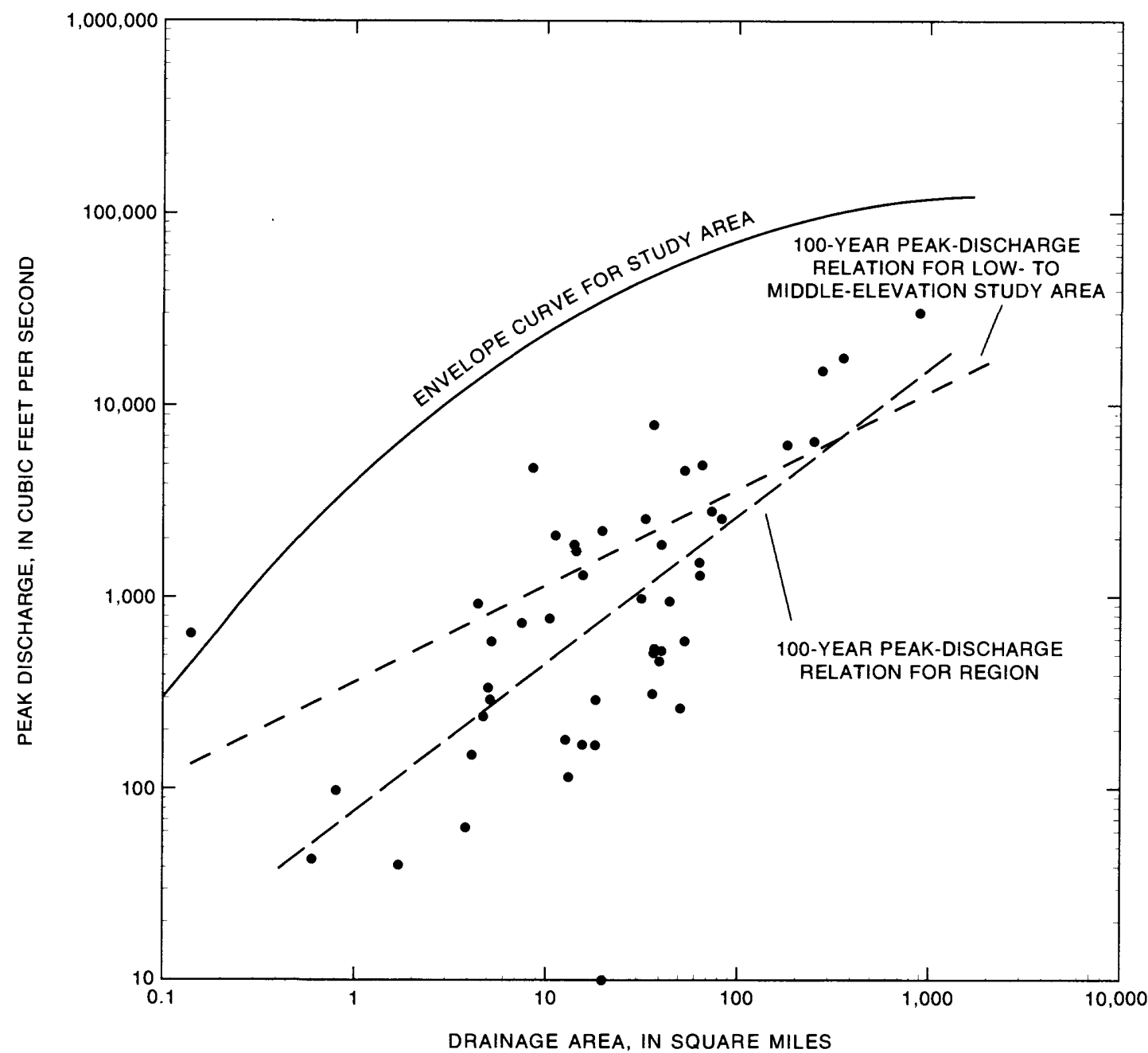

Figure 28. Relations between 100-year peak discharge and drainage area and plot of maximum peak discharge of record and drainage area for gaged sites in the Eastern Sierras Region 5.

Table 9. Generalized least-squares regression equations for estimating regional flood-frequency relations for the Eastern Sierras Region 5

Equation: Q, peak discharge, in cubic feet per second; AREA, drainage area, in square miles; ELEV, mean basin elevation, in feet; and LAT, latitude of site, in decimal degrees. Data were based on 37 stations. Average number of years of systematic record is 31 .

\begin{tabular}{cccc}
\hline $\begin{array}{c}\text { Recurrence } \\
\text { Interval, In years }\end{array}$ & Equatlon & $\begin{array}{c}\text { Average } \\
\text { standarderror of } \\
\text { prediction, in } \\
\text { percent }\end{array}$ & $\begin{array}{c}\text { Equivalent } \\
\text { years of } \\
\text { record }\end{array}$ \\
\hline 2 & $Q=0.0333 \mathrm{AREA}^{0.853}(\mathrm{ELEV} / 1,000)^{2.68}[(\mathrm{LAT}-28) / 10]^{4.1}$ & 135 & 0.21 \\
5 & $Q=2.42 \mathrm{AREA}^{0.823}\left(\mathrm{ELEV}^{4} 1,000\right)^{1.01}[(\mathrm{LAT}-28) / 10]^{4.1}$ & 101 & .73 \\
10 & $Q^{4}=28.0 \mathrm{AREA}^{0.826}[(\mathrm{LAT}-28) / 10]^{4.3}$ & 84 & 1.69 \\
25 & $Q=426 \mathrm{AREA}^{0.812}\left(\mathrm{ELEV}^{4}, 000\right)^{-1.10}[(\mathrm{LAT}-28) / 10]^{4.3}$ & 87 & 2.62 \\
50 & $Q=2,030 \mathrm{AREA}^{0.798}(\mathrm{ELEV} / 1,000)^{-1.71}[(\mathrm{LAT}-28) / 10]^{4.4}$ & 91 & 3.26 \\
100 & $Q=7,000 \mathrm{AREA}^{0.782}(\mathrm{ELEV} / 1,000)^{-2.18}[(\mathrm{LAT}-28) / 10]^{4.6}$ & 95 & 3.80 \\
\hline
\end{tabular}




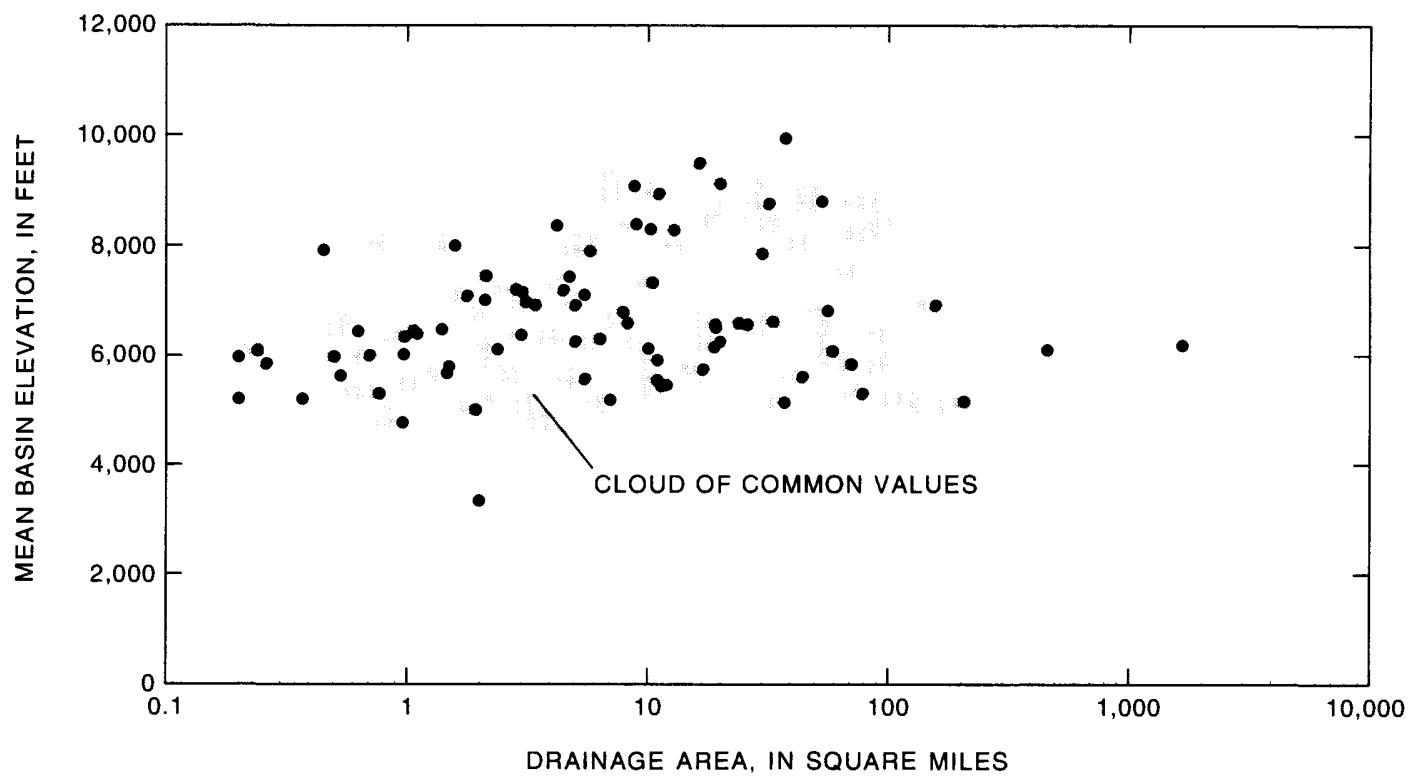

Figure 29. Joint distribution of mean basin elevation and drainage area for gaged sites in the Northern Great Basin Region 6.

Table 10. Hybrid equations for estimating regional flood-frequency relations for the Northern Great Basin Region 6 Equation: $Q$, peak discharge, in cubic feet per second; AREA, drainage area, in square miles; and ELEV, mean basin elevation, in feet. Data were based on 80 stations. Dashes indicate no data. Average number of years of systematic record is 19.

Estimated average standard error of regression for the hybrid method includes much of the within-station residual variance and therefore is not comparable to standard error of estimate from an ordinary least-squares regression. See section entitled "Hybrid Method" for explanation of error.

\begin{tabular}{cccc}
\hline $\begin{array}{c}\text { Recurrence } \\
\text { Interval, In years }\end{array}$ & Equatlon & $\begin{array}{c}\text { Estimated } \\
\text { average } \\
\text { standard error of } \\
\text { regression, in } \\
\text { log units }\end{array}$ & $\begin{array}{c}\text { Equlvalent } \\
\text { years of } \\
\text { record }\end{array}$ \\
\hline 2 & $Q=0$ & - & -- \\
5 & $Q=32 \mathrm{AREA}^{0.80}(\mathrm{ELEV} / 1,000)^{-0.66}$ & 1.47 & 0.233 \\
10 & $Q=590 \mathrm{AREA}^{0.62}(\mathrm{ELEV} / 1,000)^{-1.6}$ & 1.12 & .748 \\
25 & $Q=3,200 \mathrm{AREA}^{0.62}(\mathrm{ELEV} / 1,000)^{-2.1}$ & .796 & 2.52 \\
50 & $Q=5,300 \mathrm{AREA}^{0.64}(\mathrm{ELEV} / 1,000)^{-2.1}$ & 1.10 & 1.75 \\
100 & $Q=20,000 \mathrm{AREA}^{0.51}(\mathrm{ELEV} / 1,000)^{-2.3}$ & 1.84 & .794 \\
\hline
\end{tabular}




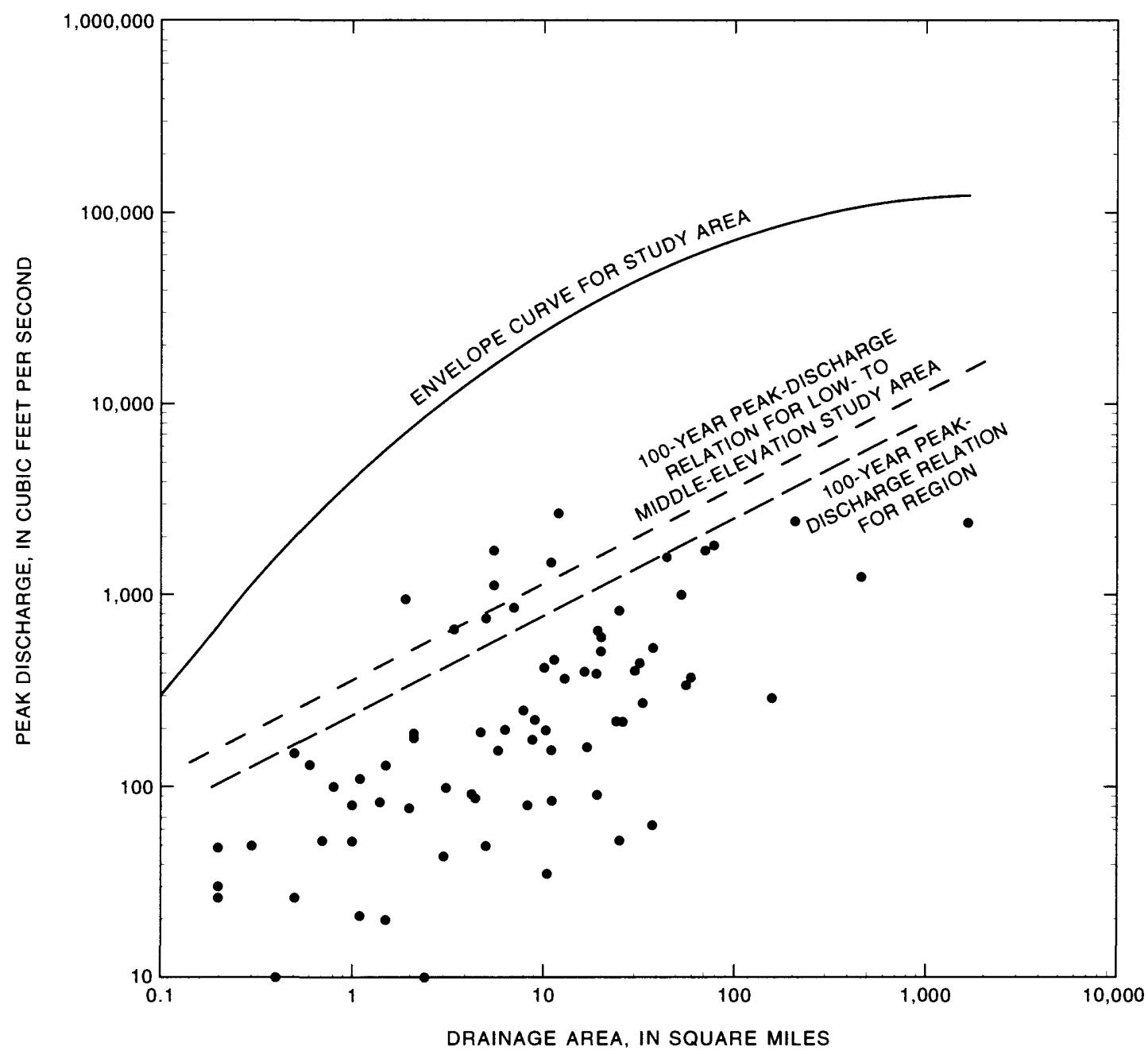

Figure 30. Relations between 100-year peak discharge and drainage area and plot of maximum peak discharge of record and drainage area for gaged sites in the Northern Great Basin Region 6. 


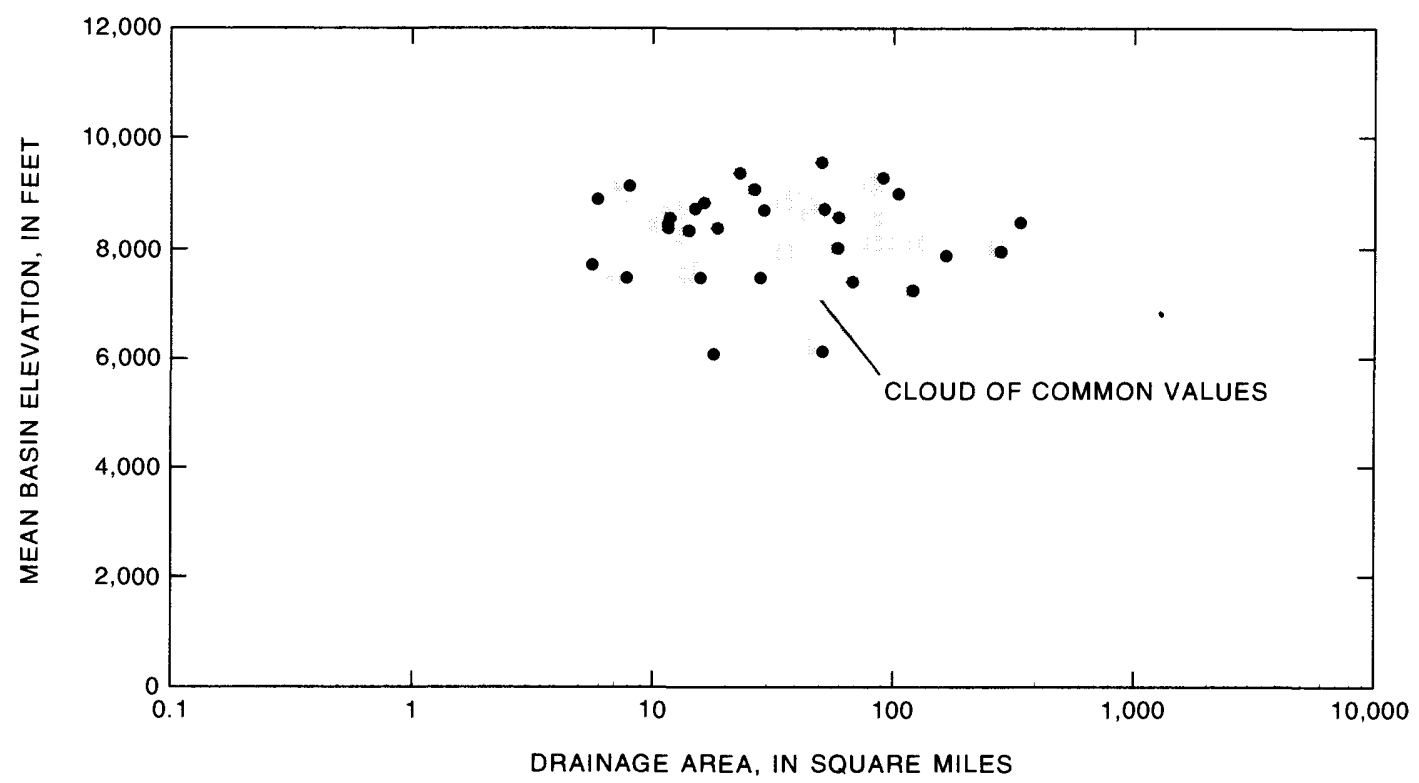

Figure 31. Joint distribution of mean basin elevation and drainage area for gaged sites in the South-Central Utah Region 7.

Table 11. Generalized least-squares regression equations for estimating regional flood-frequency relations for the South-Central Utah Region 7

Equation: Q, peak discharge, in cubic feet per second; AREA, drainage area, in square miles; and ELEV, mean basin elevation, in feet. Data were based on 28 stations. Average number of years of systematic record is 23 .

\begin{tabular}{cccc}
\hline $\begin{array}{c}\text { Recurrence } \\
\text { interval, in years }\end{array}$ & Equation & $\begin{array}{c}\text { Average } \\
\text { standard error of } \\
\text { predlction, in } \\
\text { percent }\end{array}$ & $\begin{array}{c}\text { Equivalent } \\
\text { years of } \\
\text { record }\end{array}$ \\
\hline 2 & $Q=0.0150 \mathrm{AREA}^{0.697}(\mathrm{ELEV} / 1,000)^{3.16}$ & 56 & 0.25 \\
5 & $Q=0.306 \mathrm{AREA}^{0.590}(\mathrm{ELEV} / 1,000)^{2.22}$ & 45 & 1.56 \\
10 & $Q=1.25 \mathrm{AREA}^{0.526}\left(\mathrm{ELEV}^{2.11,000}\right)^{1.83}$ & 45 & 3.07 \\
25 & $Q=122 \mathrm{AREA}^{0.440}$ & 49 & 4.60 \\
50 & $Q=183 \mathrm{AREA}^{0.390}$ & 53 & 5.27 \\
100 & $Q=264 \mathrm{AREA}^{0.344}$ & 59 & 5.68 \\
\hline
\end{tabular}




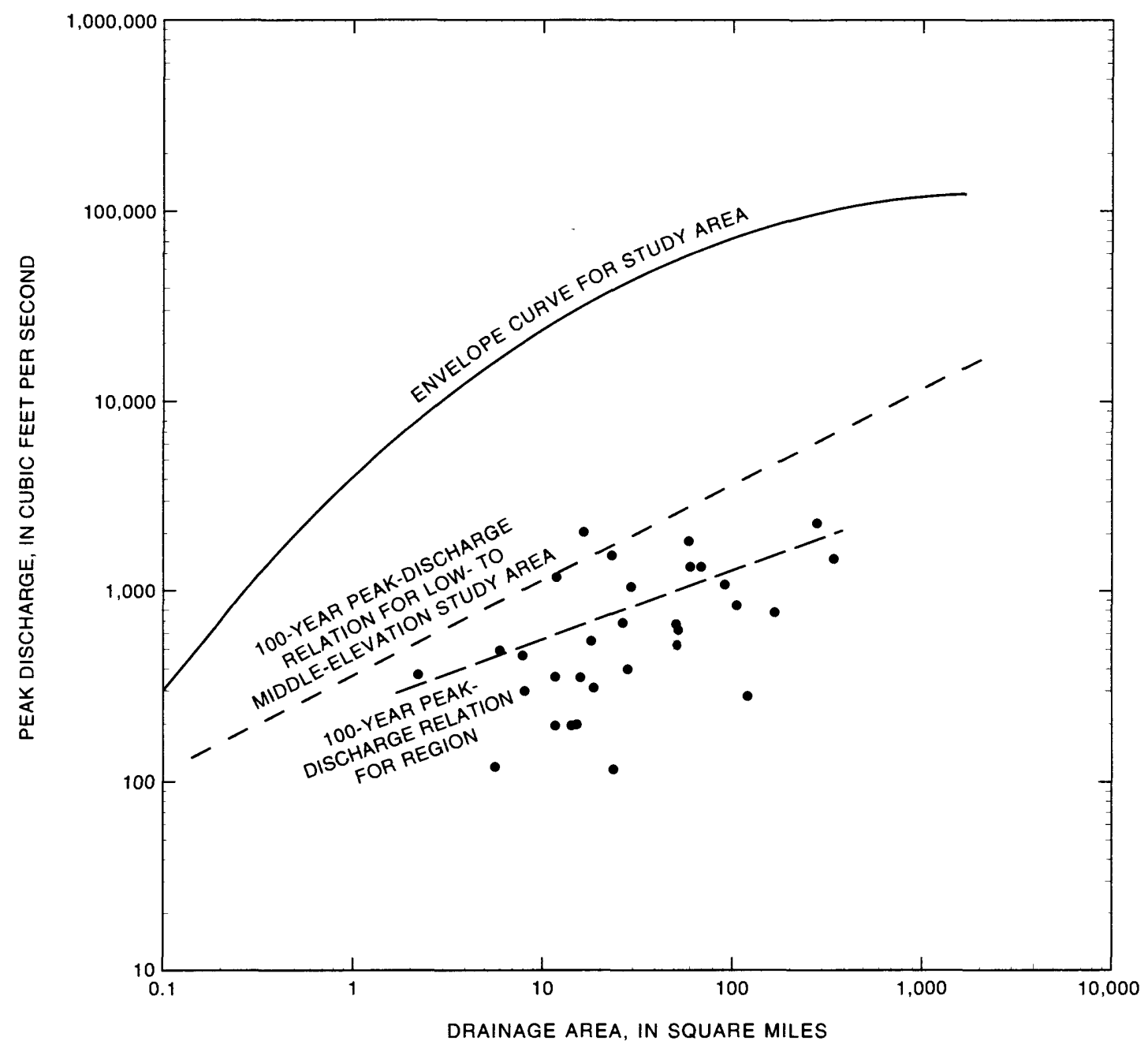

Figure 32. Relations between 100-year peak discharge and drainage area and plot of maximum peak discharge of record and drainage area for gaged sites in the South-Central Utah Region 7. 


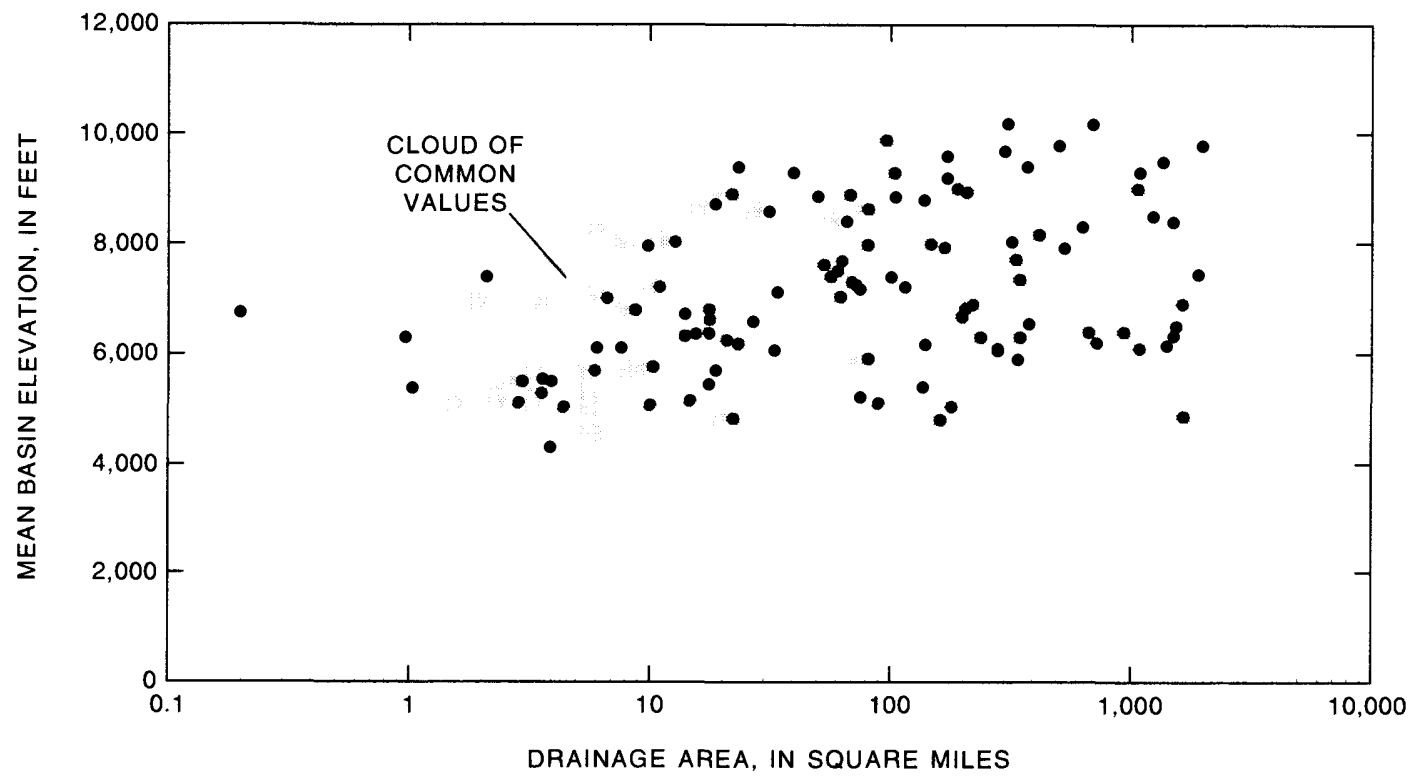

Figure 33. Joint distribution of mean basin elevation and drainage area for gaged sites in the Four Corners Region 8.

Table 12. Generalized least-squares regression equations for estimating regional flood-frequency relations for the Four Corners Region 8

Equation: Q, peak discharge, in cubic feet per second; AREA, drainage area, in square miles; and ELEV, mean basin elevation, in feet. Data were based on 108 stations. Average number of years of systematic record is 27.

\begin{tabular}{cccc}
\hline $\begin{array}{c}\text { Recurrence } \\
\text { Interval, in years }\end{array}$ & Equation & $\begin{array}{c}\text { Average } \\
\text { standard error of } \\
\text { predictlon, in } \\
\text { percent }\end{array}$ & $\begin{array}{c}\text { Equivalent } \\
\text { years of } \\
\text { record }\end{array}$ \\
\hline 2 & $Q=598 \mathrm{AREA}^{0.501}(\mathrm{ELEV} / 1,000)^{-1.02}$ & 72 & 0.37 \\
5 & $Q=2,620 \mathrm{AREA}^{0.449}(\mathrm{ELEV} / 1,000)^{-1.28}$ & 62 & 1.35 \\
10 & $Q=5,310 \mathrm{AREA}^{0.425}(\mathrm{ELEV} / 1,000)^{-1.40}$ & 57 & 2.88 \\
25 & $Q=10,500 \mathrm{AREA}^{0.403}(\mathrm{ELEV} / 1,000)^{-1.49}$ & 54 & 5.45 \\
50 & $Q=16,000 \mathrm{AREA}^{0.390}(\mathrm{ELEV} / 1,000)^{-1.54}$ & 53 & 7.45 \\
100 & $Q=23,300 \mathrm{AREA}^{0.377}(\mathrm{ELEV} / 1,000)^{-1.59}$ & 53 & 9.28 \\
\hline
\end{tabular}




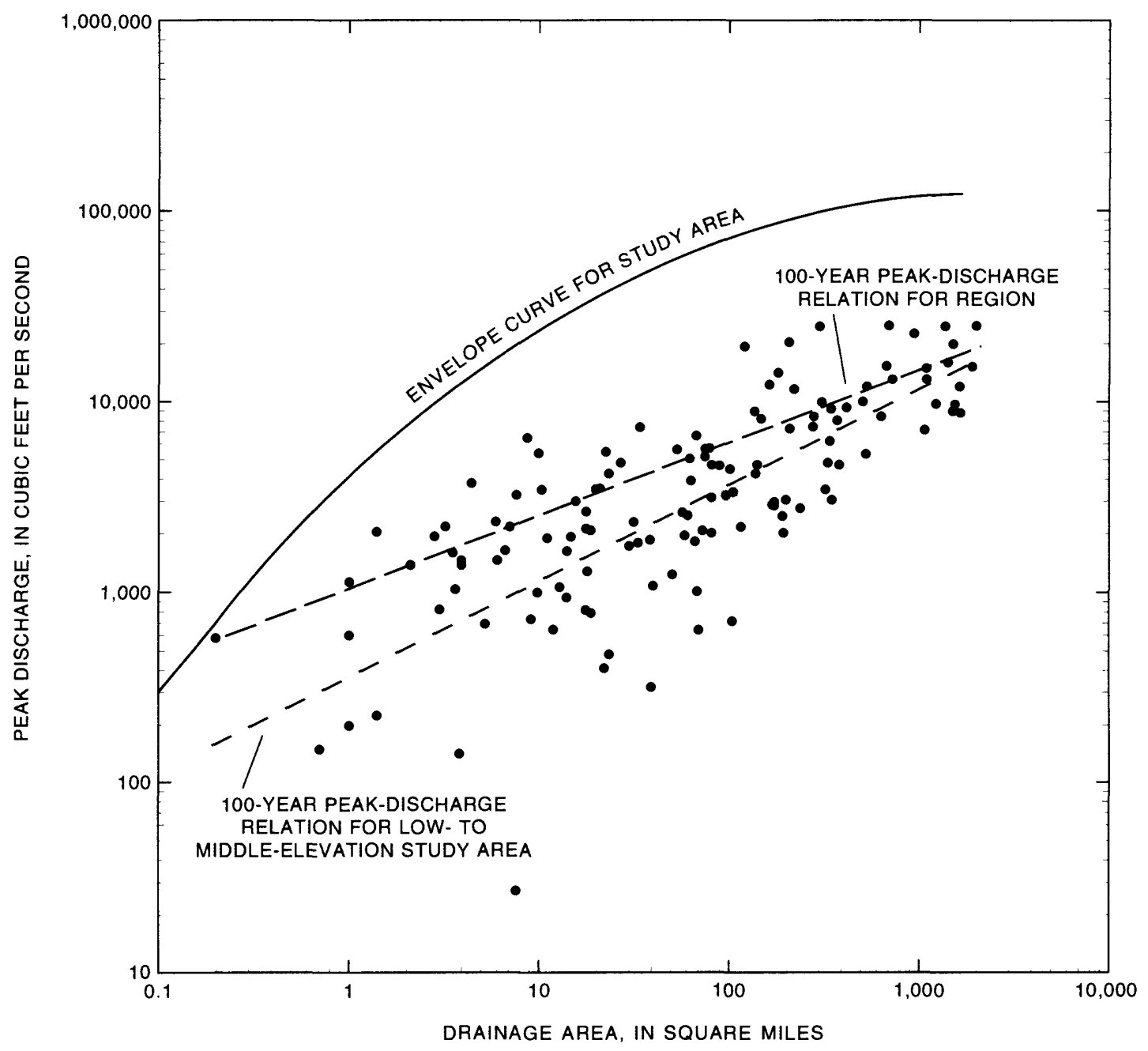

Figure 34. Relations between 100-year peak discharge and drainage area and plot of maximum peak discharge of record and drainage area for gaged sites in the Four Corners Region 8. 


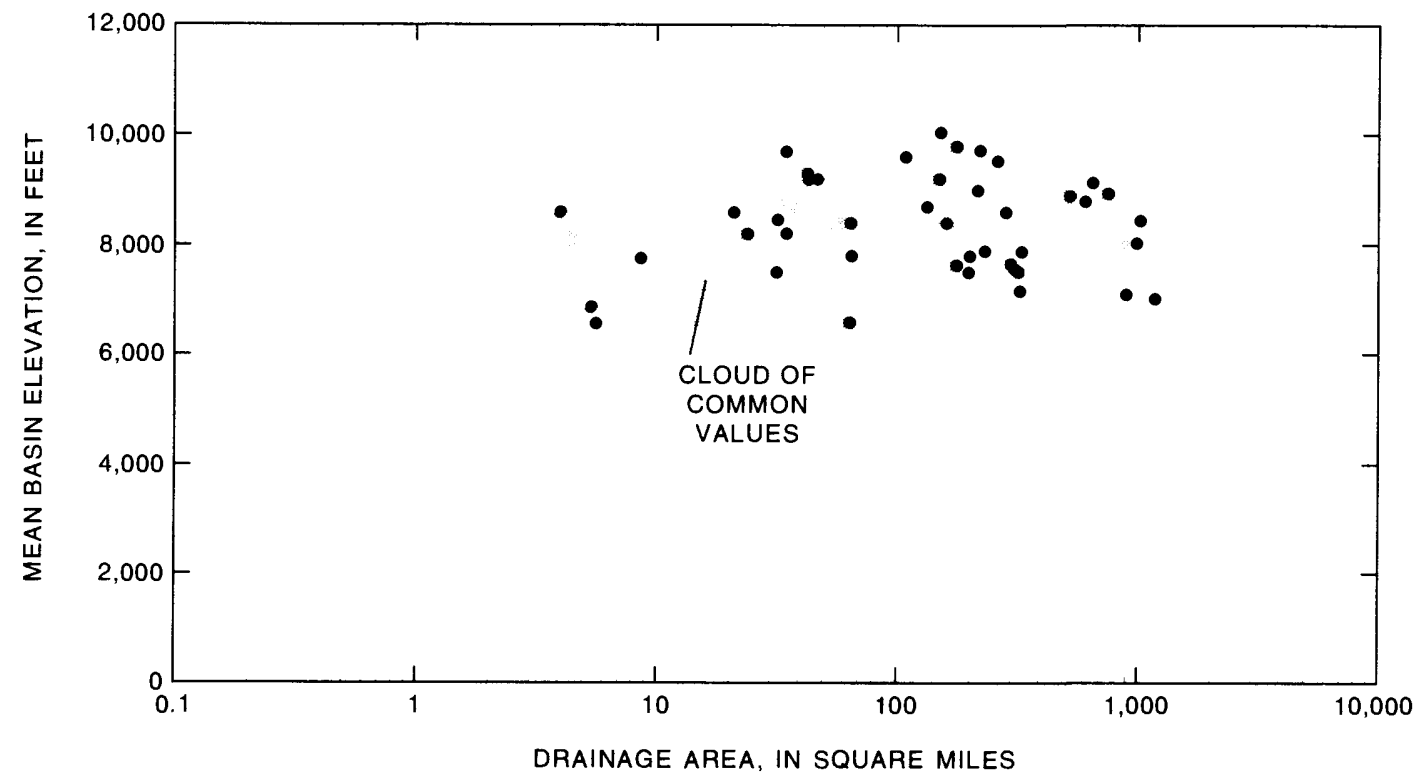

Figure 35. Joint distribution of mean basin elevation and drainage area for gaged sites in the Western Colorado Region 9.

Table 13. Generalized least-squares regression equations for estimating regional flood-frequency relations for the Western Colorado Region 9

Equation: $Q$, peak discharge, in cubic feet per second; AREA, drainage area, in square miles; and ELEV, mean basin elevation, in feet. Data were based on 43 stations. Average number of years of systematic record is 28.

\begin{tabular}{cccc}
\hline $\begin{array}{c}\text { Recurrence } \\
\text { interval, in } \\
\text { years }\end{array}$ & Equation & $\begin{array}{c}\text { Average } \\
\text { standard error } \\
\text { of prediction, in } \\
\text { percent }\end{array}$ & $\begin{array}{c}\text { Equivalent } \\
\text { years of } \\
\text { record }\end{array}$ \\
\hline 2 & $Q=0.0204 \mathrm{AREA}^{0.606}(\mathrm{ELEV} / 1,000)^{3.5}$ & 68 & 0.14 \\
5 & $Q=0.181 \mathrm{AREA}^{0.515}(\mathrm{ELEV} / 1,000)^{2.9}$ & 55 & .77 \\
10 & $Q=1.18 \mathrm{AREA}^{0.488}\left(\mathrm{ELEV}^{2.1,000}\right)^{2.2}$ & 52 & 1.70 \\
25 & $Q=18.2 \mathrm{AREA}^{0.465}\left(\mathrm{ELEV}^{2} /, 000\right)^{1.1}$ & 53 & 2.81 \\
50 & $Q=248 \mathrm{AREA}^{0.449}$ & 57 & 3.36 \\
100 & $Q=292 \mathrm{AREA}^{0.444}$ & 59 & 3.94 \\
\hline
\end{tabular}




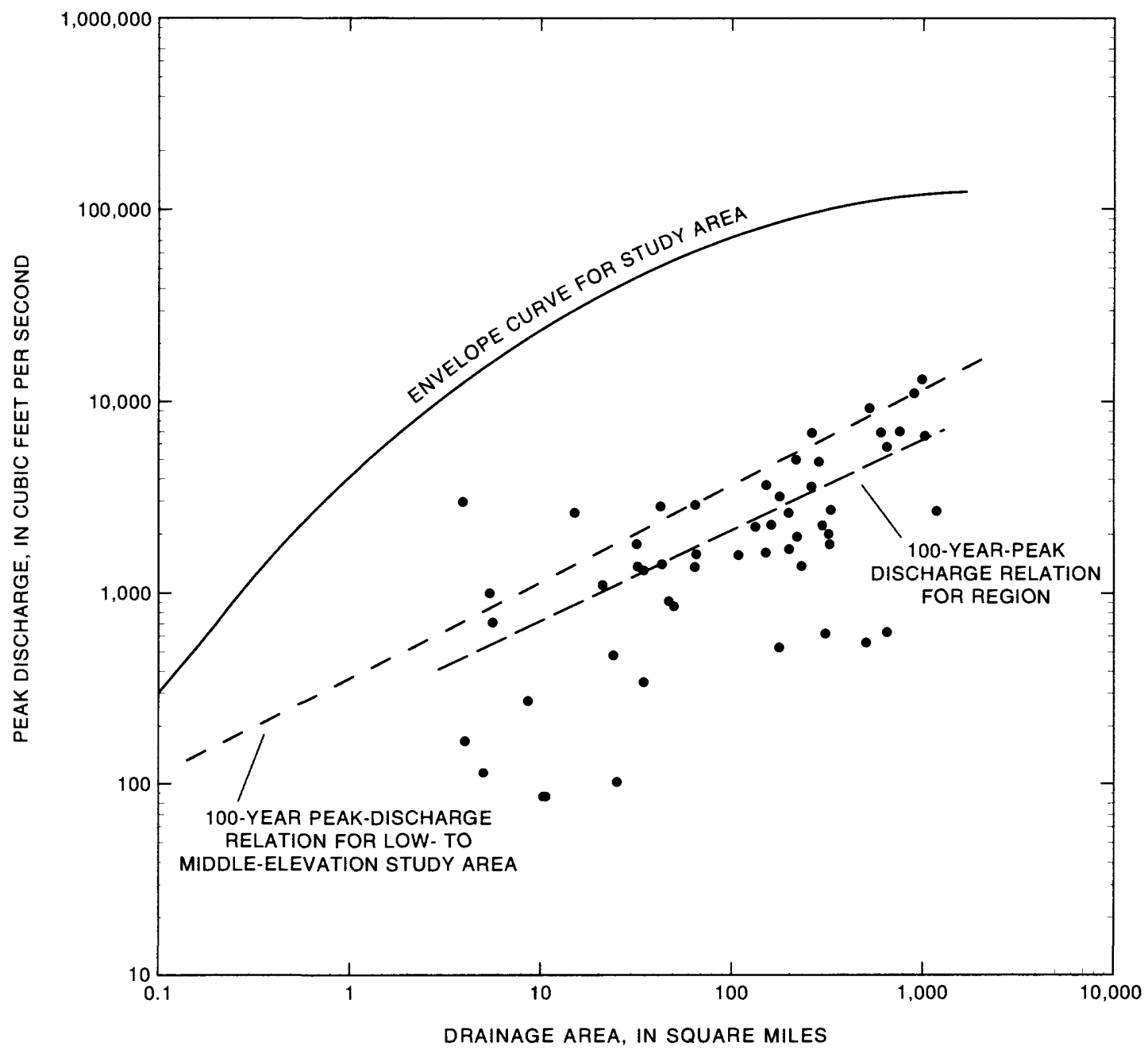

Figure 36. Relations between 100-year peak discharge and drainage area and plot of maximum peak discharge of record and drainage area for gaged sites in the Western Colorado Region 9. 


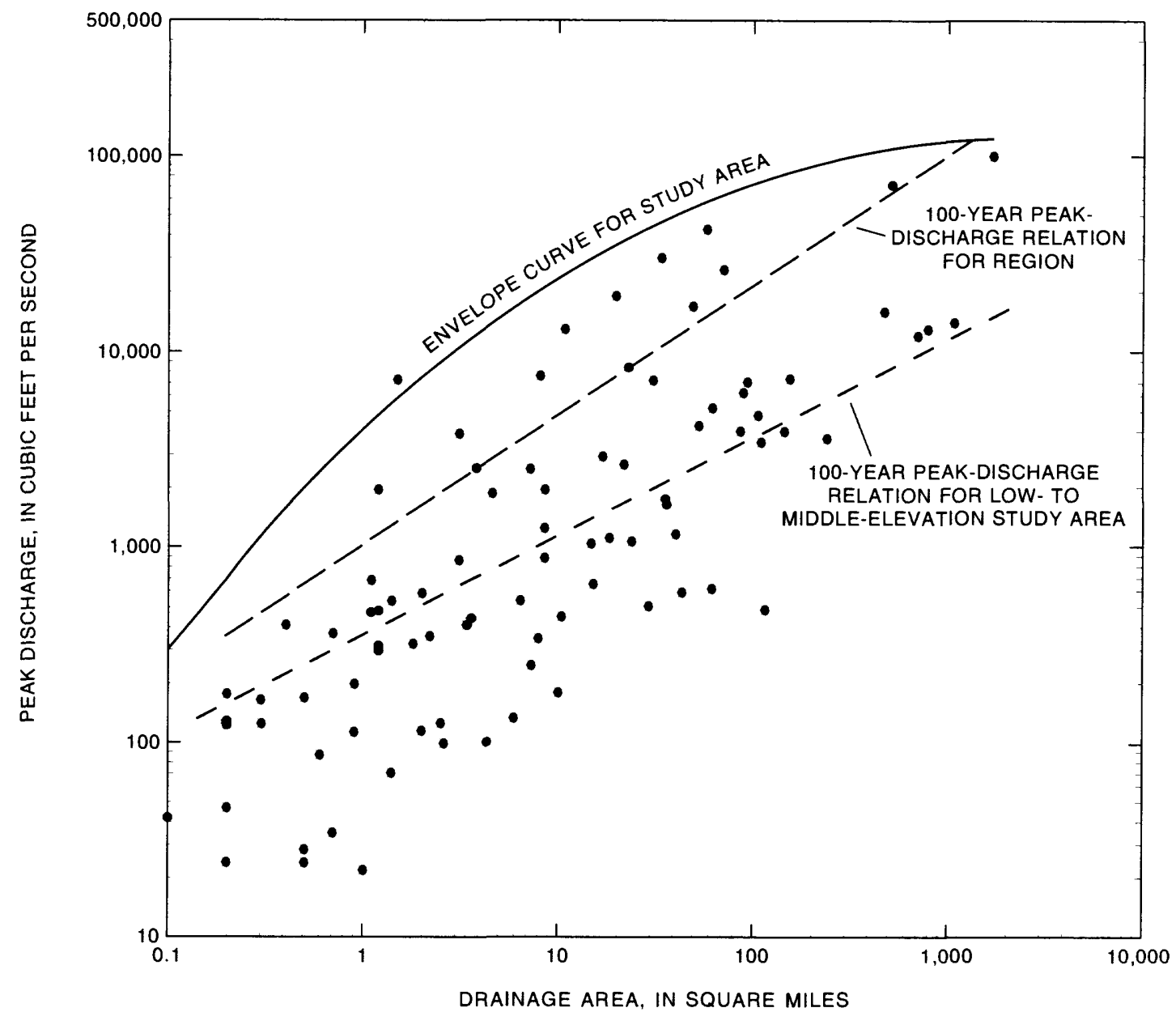

Figure 37. Relations between 100-year peak discharge and drainage area and plot of maximum peak discharge of record and drainage area for gaged sites in the Southern Great Basin Region 10.

Table 14. Hybrid equations for estimating regional flood-frequency relations for the Southern Great Basin Region 10 Equation: Q, peak discharge, in cubic feet per second; and AREA, drainage area, in square miles. Data were based on 104 stations. Average number of years of systematic record is 21 .

Estimated average standard error of regression for the hybrid method includes much of the within-station residual variance and therefore is not comparable to standard error of estimate from an ordinary least-squares regression. See section entitled "Hybrid Method" for explanation of error.

\begin{tabular}{cccc}
\hline $\begin{array}{c}\text { Recurrence } \\
\text { Interval, In years }\end{array}$ & Equation & $\begin{array}{c}\text { Estimated } \\
\text { average } \\
\text { standard error of } \\
\text { regression, in } \\
\text { log unlts }\end{array}$ & $\begin{array}{c}\text { Equivalent } \\
\text { years of } \\
\text { record }\end{array}$ \\
\hline 2 & $Q=12$ AREA $^{0.58}$ & 1.14 & 0.618 \\
5 & $Q=85$ AREA $^{0.59}$ & .602 & 3.13 \\
10 & $Q=$ 200AREA $^{0.62}$ & .675 & 3.45 \\
25 & $Q=400$ AREA $^{0.65}$ & .949 & 2.49 \\
50 & $Q=590$ AREA $^{0.67}$ & .928 & 3.22 \\
100 & $Q=850$ AREA $^{0.69}$ & 1.23 & 2.22 \\
\hline
\end{tabular}




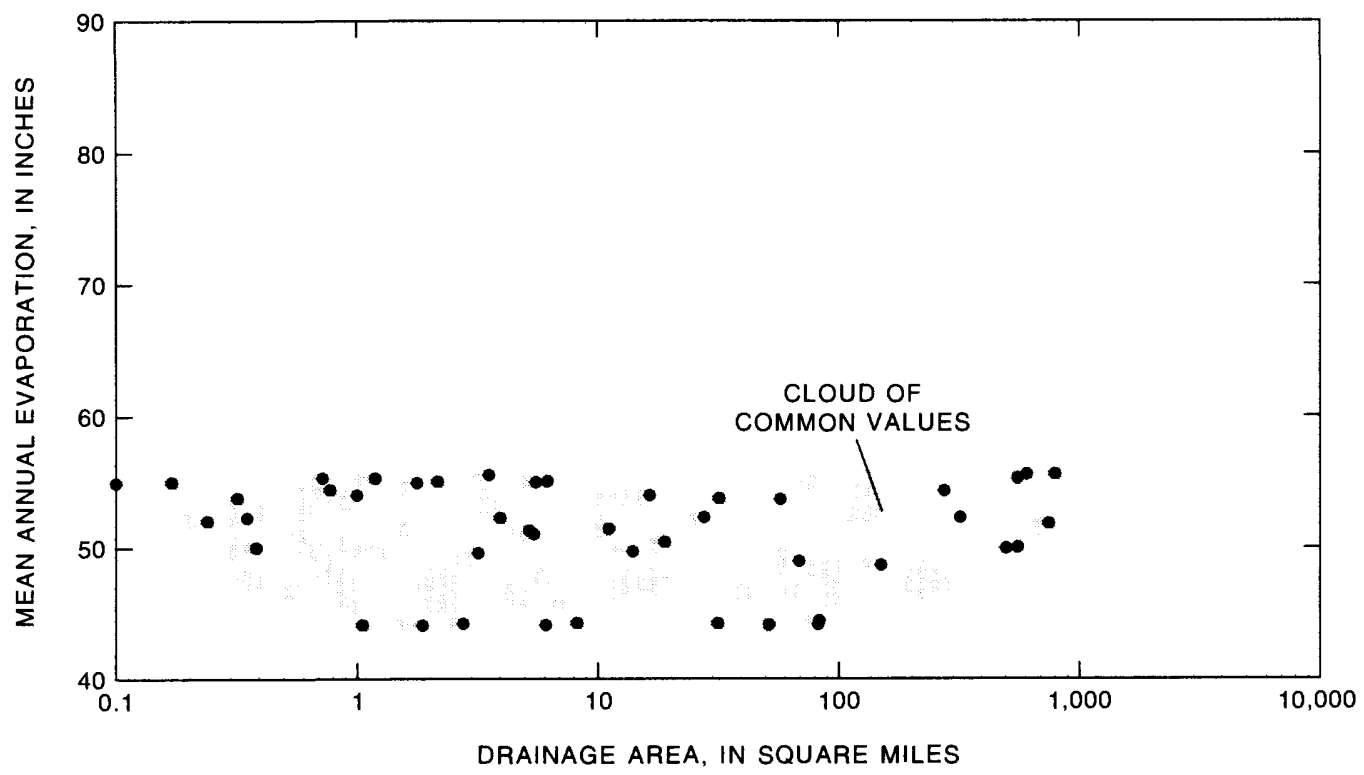

Figure 38. Joint distribution of mean annual evaporation and drainage area for gaged sites in the Northeastern Arizona Region 11.

Table 15. Hybrid equations for estimating regional flood-frequency relations for the Northeastern Arizona Region 11 Equation: Q, peak discharge, in cubic feet per second; AREA, drainage area, in square miles; and EVAP, mean annual evaporation, in inches. Data were based on $\mathbf{4 6}$ stations. Average number of years of systematic record is 20 .

Estimated average standard error of regression for the hybrid method includes much of the within-station residual variance and therefore is not comparable to standard error of estimate from an ordinary least-squares regression. See section entitled "Hybrid Method" for explanation of error.

\begin{tabular}{cccc}
\hline $\begin{array}{c}\text { Recurrence } \\
\text { Interval, In years }\end{array}$ & Equation & $\begin{array}{c}\text { Estlmatod } \\
\text { average } \\
\text { standard error of } \\
\text { regresslon, In } \\
\text { log units }\end{array}$ & $\begin{array}{c}\text { Equlvalent } \\
\text { years of } \\
\text { record }\end{array}$ \\
\hline 2 & $Q=26 \mathrm{AREA}^{0.62}$ & 0.609 & 0.428 \\
5 & $Q=130 \mathrm{AREA}^{0.56}$ & .309 & 2.79 \\
10 & $Q=0.10 \mathrm{AREA}^{0.52} \mathrm{EVAP}^{20}$ & .296 & 4.63 \\
25 & $Q=0.17 \mathrm{AREA}^{0.52} \mathrm{EVAP}^{20}$ & .191 & 17.1 \\
50 & $Q=0.24 \mathrm{AREA}^{0.54} \mathrm{EVAP}^{20}$ & .294 & 9.20 \\
100 & $Q=0.27 \mathrm{AREA}^{0.58} \mathrm{EVAP}^{20}$ & .863 & 1.32 \\
\hline
\end{tabular}




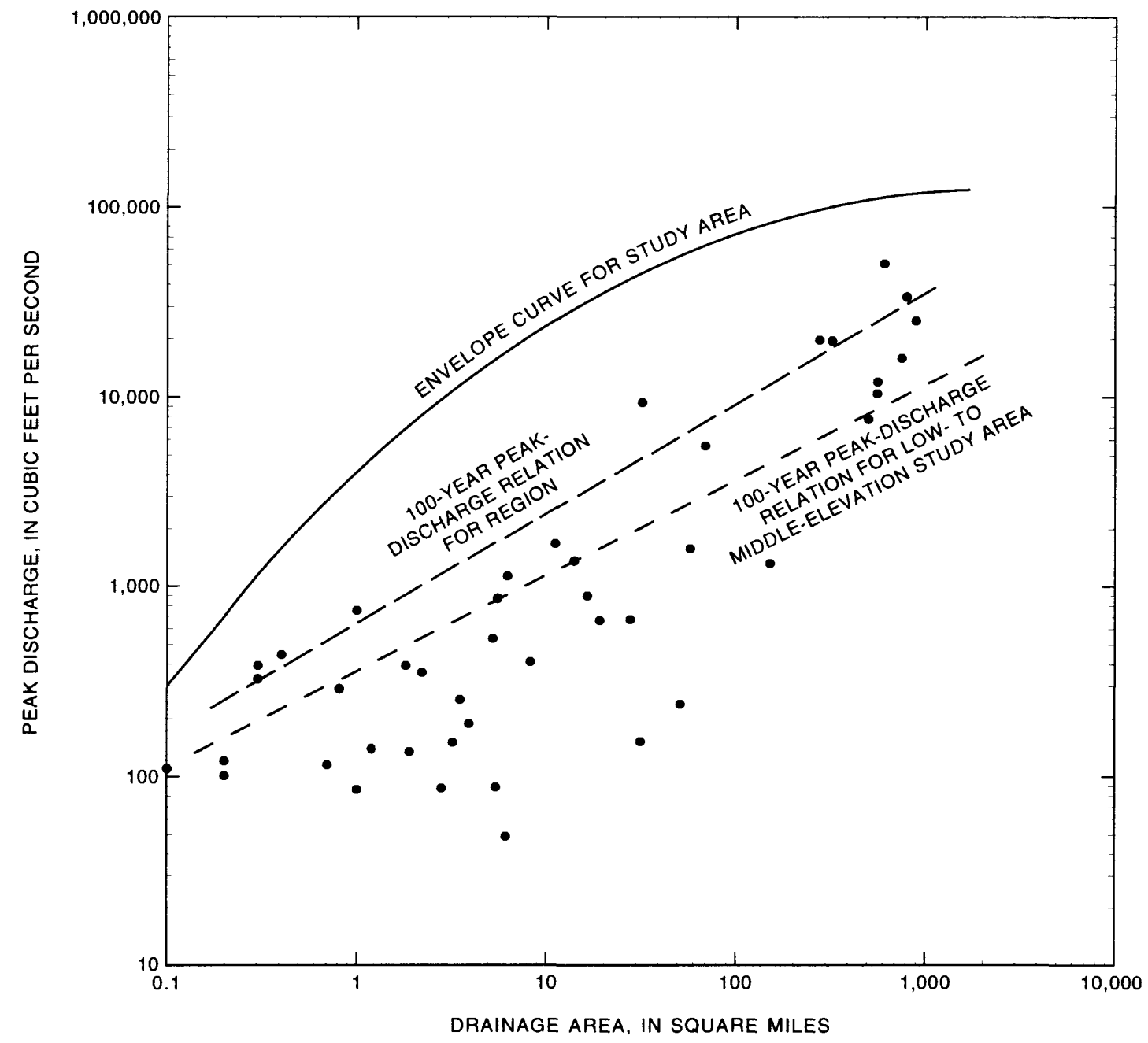

Figure 39. Relations between 100-year peak discharge and drainage area and plot of maximum peak discharge of record and drainage area for gaged sites in the Northeastern Arizona Region 11. 


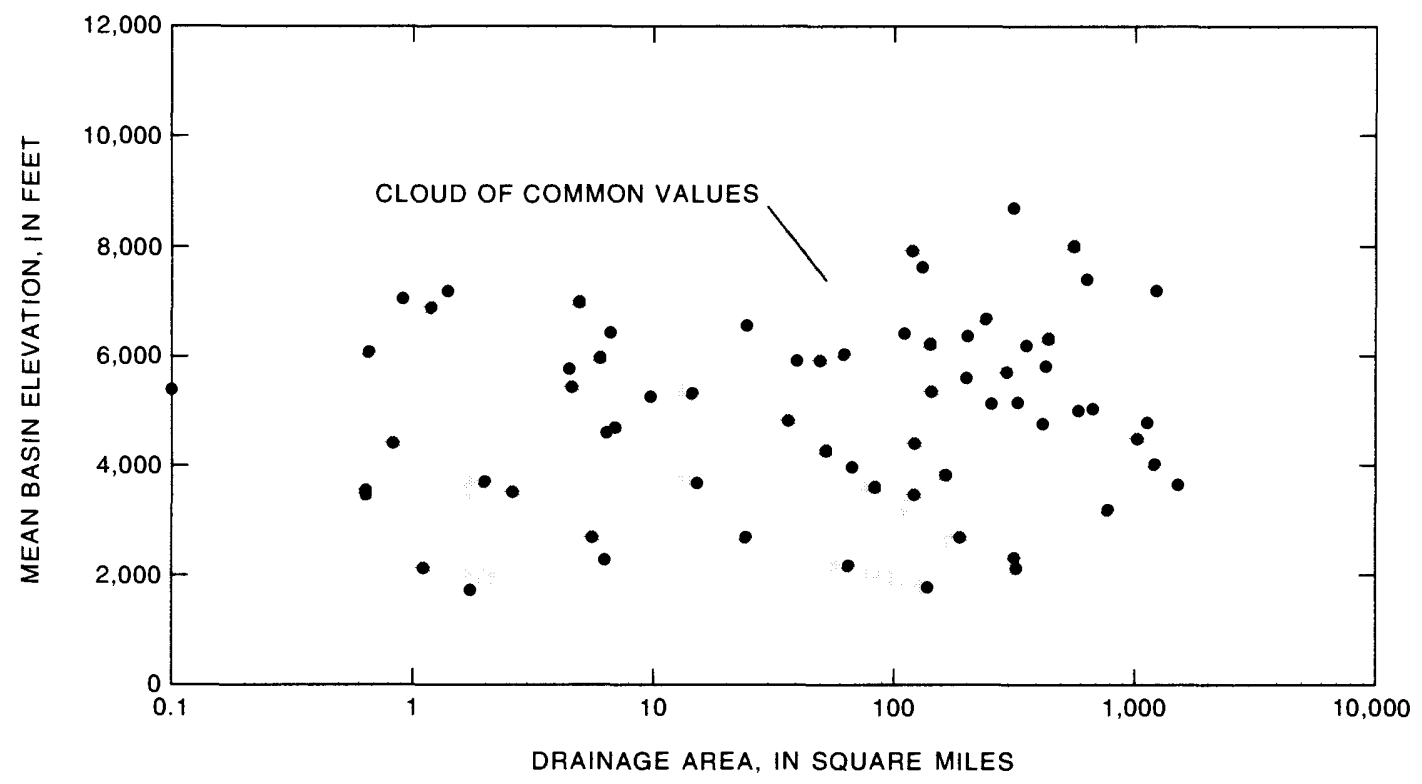

Figure 40. Joint distribution of mean basin elevation and drainage area for gaged sites in the Central Arizona Region 12.

Table 16. Generalized least-squares regression equations for estimating regional flood-frequency relations for the Central Arizona Region 12

Equation: $Q$, peak discharge, in cubic feet per second; AREA, drainage area, in square miles; and ELEV, mean basin elevation, in feet. Data were based on 68 stations. Average number of years of systematic record is 21 .

\begin{tabular}{cccc}
\hline $\begin{array}{c}\text { Recurrence } \\
\text { Interval, in } \\
\text { years }\end{array}$ & Equation & $\begin{array}{c}\text { Average } \\
\text { standard error } \\
\text { of prediction, in } \\
\text { percent }\end{array}$ & $\begin{array}{c}\text { Equivalent } \\
\text { years of } \\
\text { record }\end{array}$ \\
\hline 2 & $Q=41.1 \mathrm{AREA}^{0.629}$ & 105 & 0.23 \\
5 & $Q=238 \mathrm{AREA}^{0.687}(\mathrm{ELEV} / 1,000)^{-0.358}$ & 68 & 1.90 \\
10 & $Q=479 \mathrm{AREA}^{0.661}(\mathrm{ELEV} / 1,000)^{-0.398}$ & 52 & 6.24 \\
25 & $Q=942 \mathrm{AREA}^{0.630}(\mathrm{ELEV} / 1,000)^{-0.383}$ & 40 & 17.8 \\
50 & $Q=10^{\left(7.36-4.17 \mathrm{AREA}^{-0.08}\right)}(\mathrm{ELEV} / 1000)^{-0.440}$ & 37 & 27.5 \\
100 & $Q=10^{\left(6.55-3.17 \mathrm{AREA}^{-0.11}\right)}\left(\mathrm{ELEV}^{-1,000)^{-0.454}}\right.$ & 39 & 32.1 \\
\hline
\end{tabular}




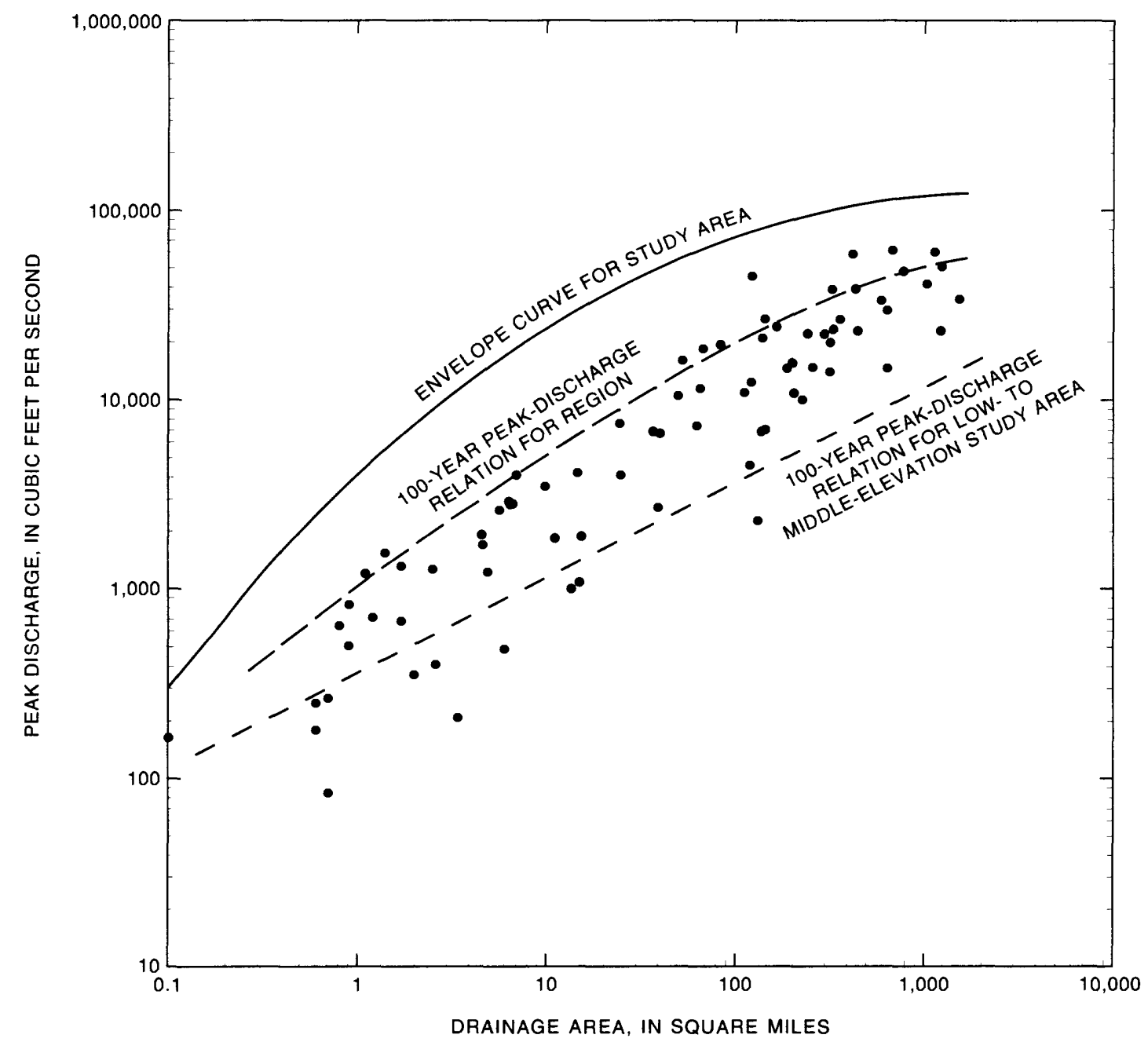

Figure 41. Relations between 100-year peak discharge and drainage area and plot of maximum peak discharge of record and drainage area for gaged sites in the Central Arizona Region 12. 


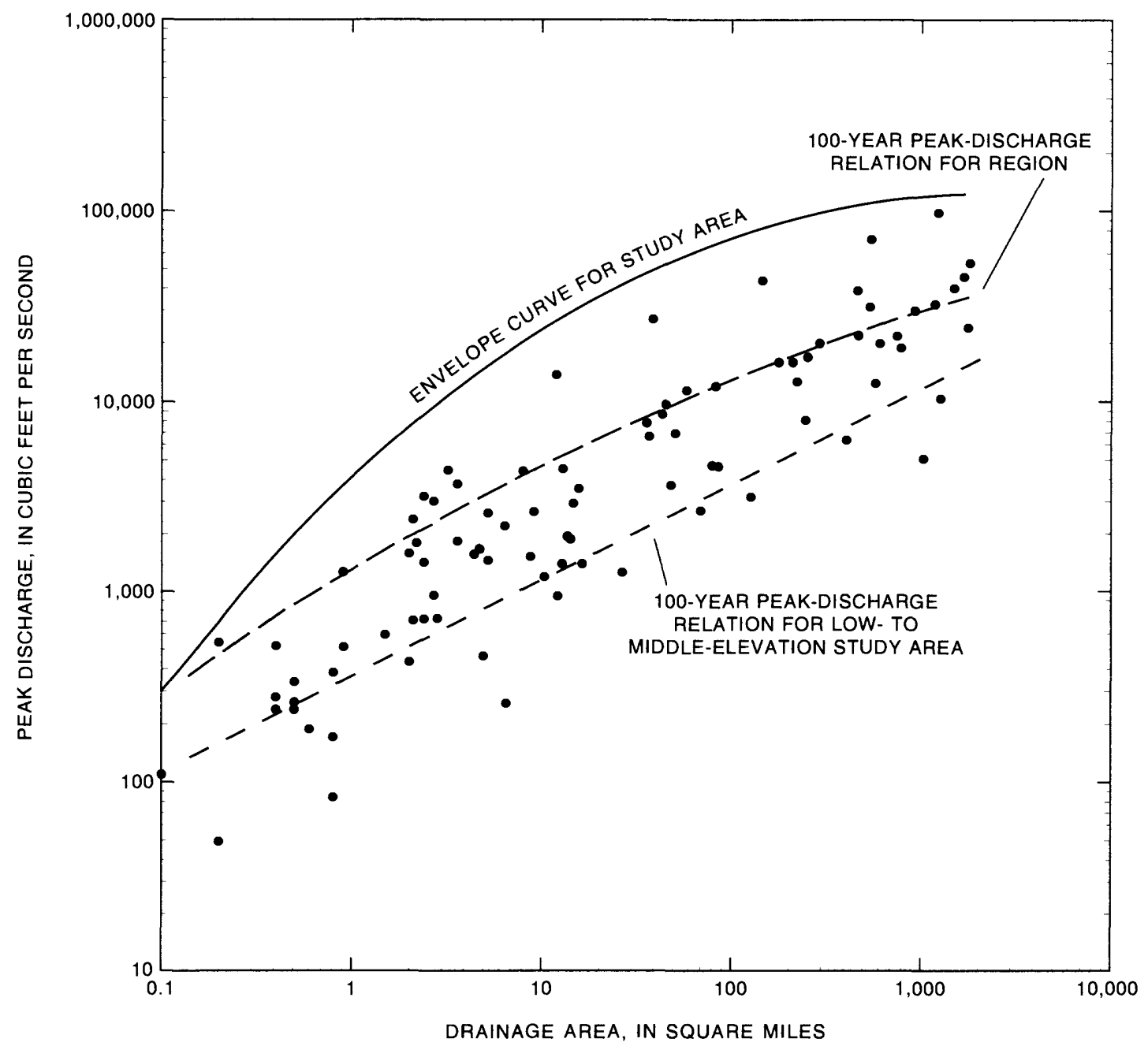

Figure 42. Relations between 100-year peak discharge and drainage area and plot of maximum peak discharge of record and drainage area for gaged sites in the Southern Arizona Region 13.

Table 17. Generalized least-squares regression equations for estimating regional flood-frequency relations for the Southern Arizona Region 13

Equation: Q, peak discharge, in cubic feet per second; and AREA, drainage area, in square miles. Data were based on 73 stations. Average number of years of systematic record is 21 .

\begin{tabular}{cccc}
\hline $\begin{array}{c}\text { Recurrence } \\
\text { intervai, in } \\
\text { years }\end{array}$ & Equation & $\begin{array}{c}\text { Average } \\
\text { standard orror } \\
\text { of predictlon, in } \\
\text { percent }\end{array}$ & $\begin{array}{c}\text { Equivaient } \\
\text { years of } \\
\text { rocord }\end{array}$ \\
\hline 2 & $Q=10^{\left(6.38-4.29 \mathrm{AREA}^{-0.05}\right.}$ & 57 & 2.0 \\
5 & $Q=10^{\left(5.78-3.31 \mathrm{AREA}^{-0.08}\right)}$ & 40 & 6.25 \\
10 & $Q=10^{\left(5.68-3.02 \mathrm{AREA}^{-0.09}\right)}$ & 37 & 11.1 \\
25 & $Q=10^{\left(5.64-2.78 \mathrm{AREA}^{-0.19}\right.}$ & 39 & 15.0 \\
50 & $Q=10^{\left(5.57-2.59 \mathrm{AREA}^{-0.11}\right)}$ & 43 & 15.9 \\
100 & $Q=10^{\left(5.52-2.42 \mathrm{AREA}^{-0.12}\right)}$ & 48 & 16.1 \\
\hline
\end{tabular}




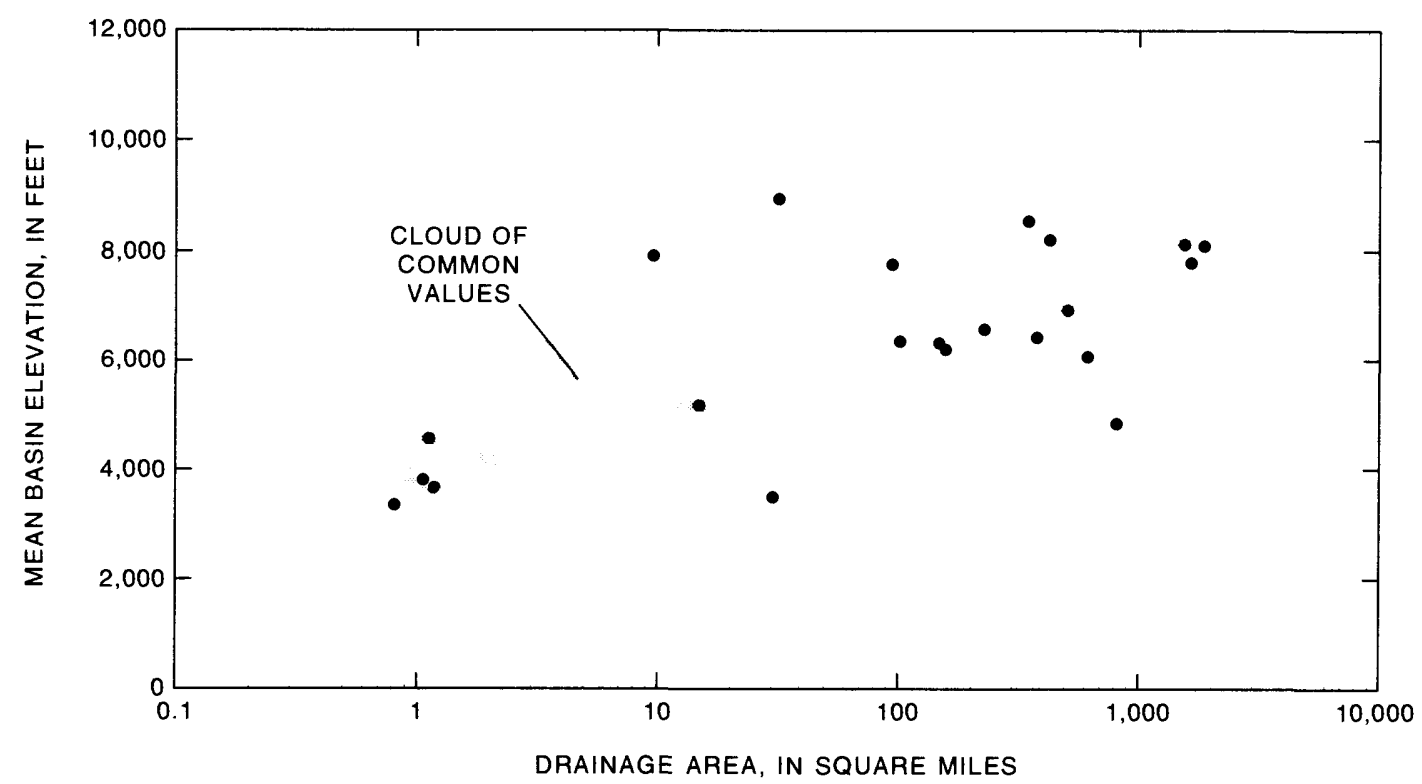

Figure 43. Joint distribution of mean basin elevation and drainage area for gaged sites in the Upper Gila Basin Region 14.

Table 18. Generalized least-squares regression equations for estimating regional flood-frequency relations for the Upper Gila Basin Region 14

Equation: Q, peak discharge, in cubic feet per second; AREA, drainage area, in square miles; and ELEV, mean basin elevation, in feet. Data were based on 22 stations. Average number of years of systematic record is 26.

\begin{tabular}{cccc}
\hline $\begin{array}{c}\text { Recurrence } \\
\text { interval, in years }\end{array}$ & Equation & $\begin{array}{c}\text { Average } \\
\text { standard error of } \\
\text { prediction, in } \\
\text { percent }\end{array}$ & $\begin{array}{c}\text { Equivalent } \\
\text { years of } \\
\text { record }\end{array}$ \\
\hline 2 & $Q=583 \mathrm{AREA}^{0.588}\left(\mathrm{ELEV}^{-1,000}\right)^{-1.3}$ & 74 & 1.69 \\
5 & $Q=618 \mathrm{AREA}^{0.524}\left(\mathrm{ELEV}^{-11,000)^{-0.70}}\right.$ & 63 & 3.54 \\
10 & $Q=361 \mathrm{AREA}^{0.464}$ & 65 & 4.95 \\
25 & $Q=581 \mathrm{AREA}^{0.462}$ & 63 & 7.75 \\
50 & $Q=779 \mathrm{AREA}^{0.462}$ & 64 & 9.65 \\
100 & $Q=1,010 \mathrm{AREA}^{0.463}$ & 66 & 11.2 \\
\hline
\end{tabular}




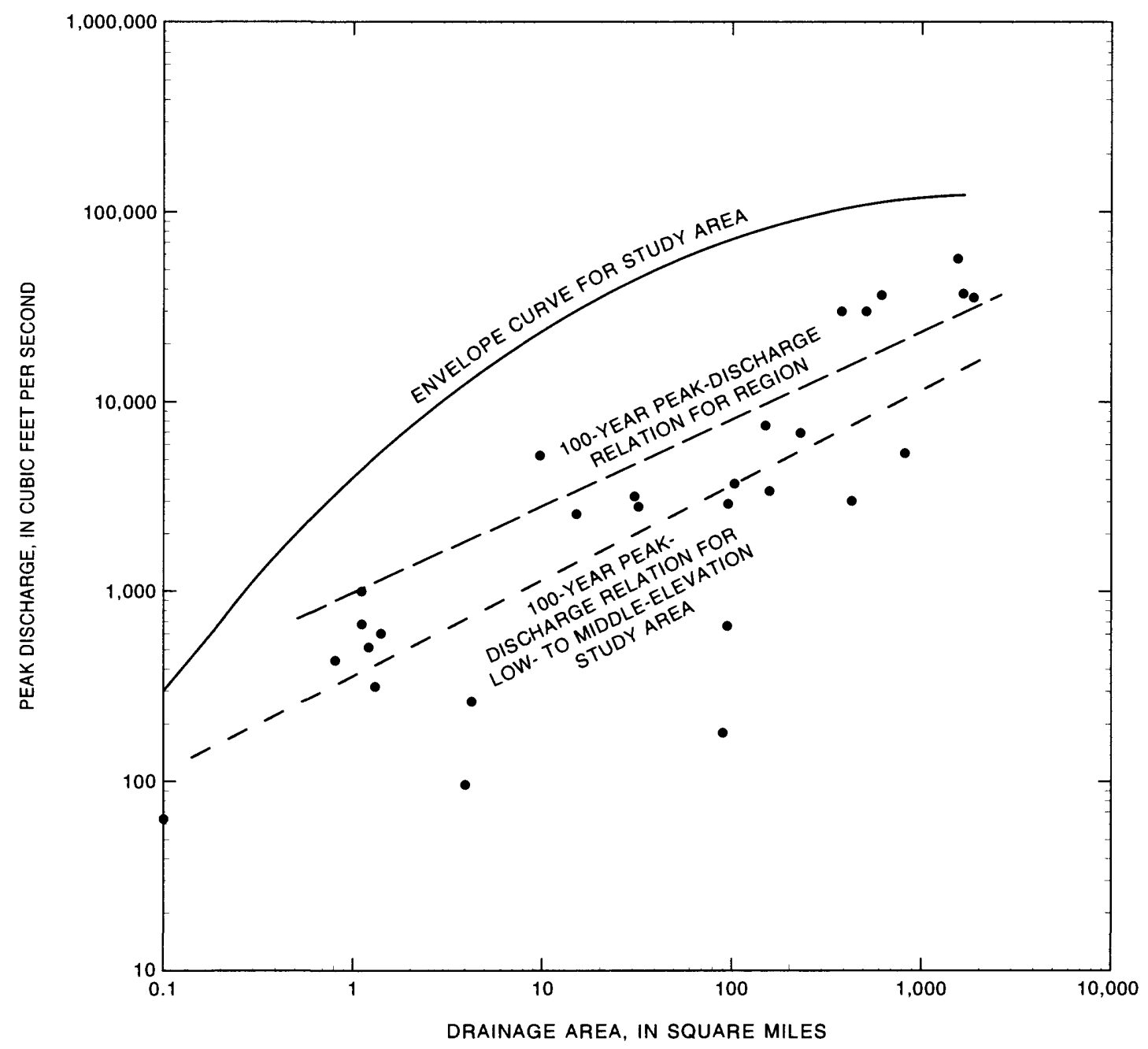

Figure 44. Relations between 100-year peak discharge and drainage area and plot of maximum peak discharge of record and drainage area for gaged sites in the Upper Gila Basin Region 14. 


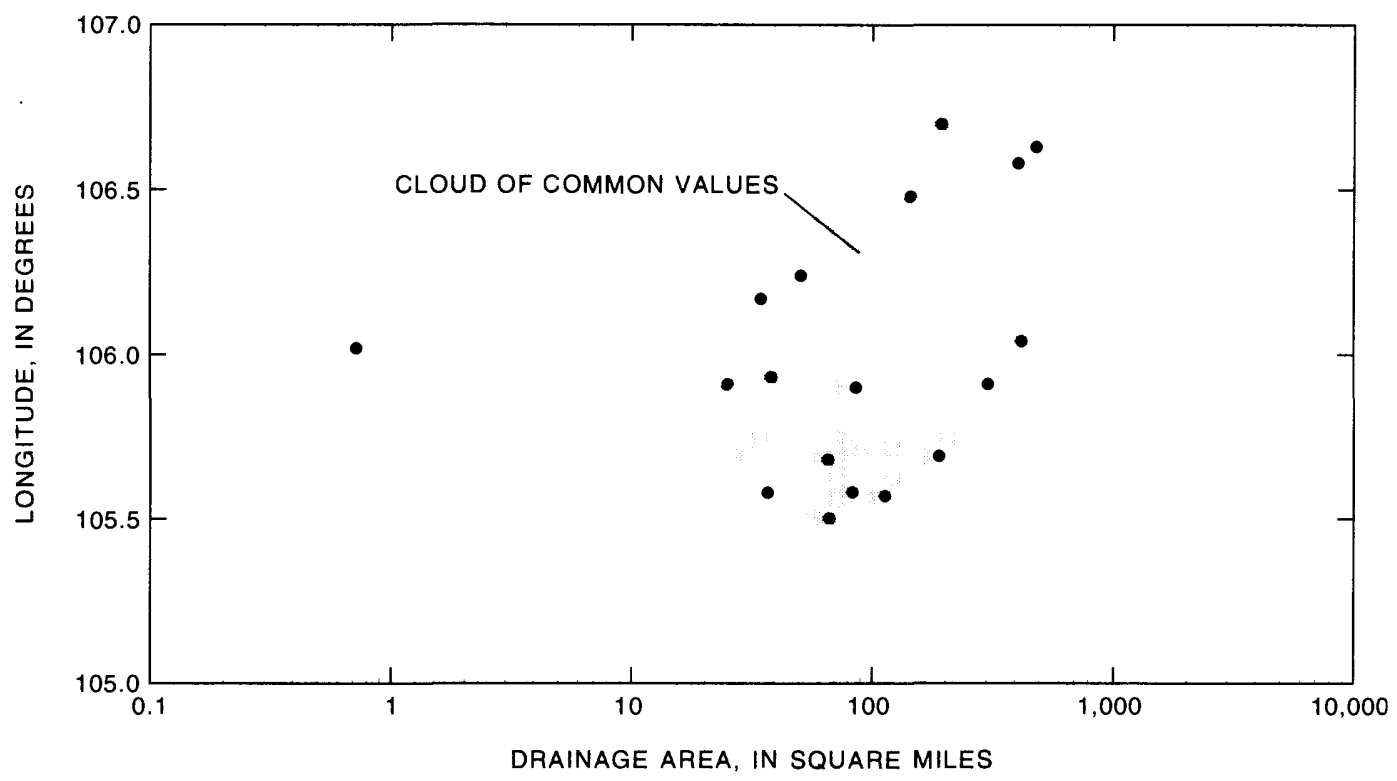

Figure 45. Joint distribution of longitude and drainage area for gaged sites in the Upper Rio Grande Basin Region 15.

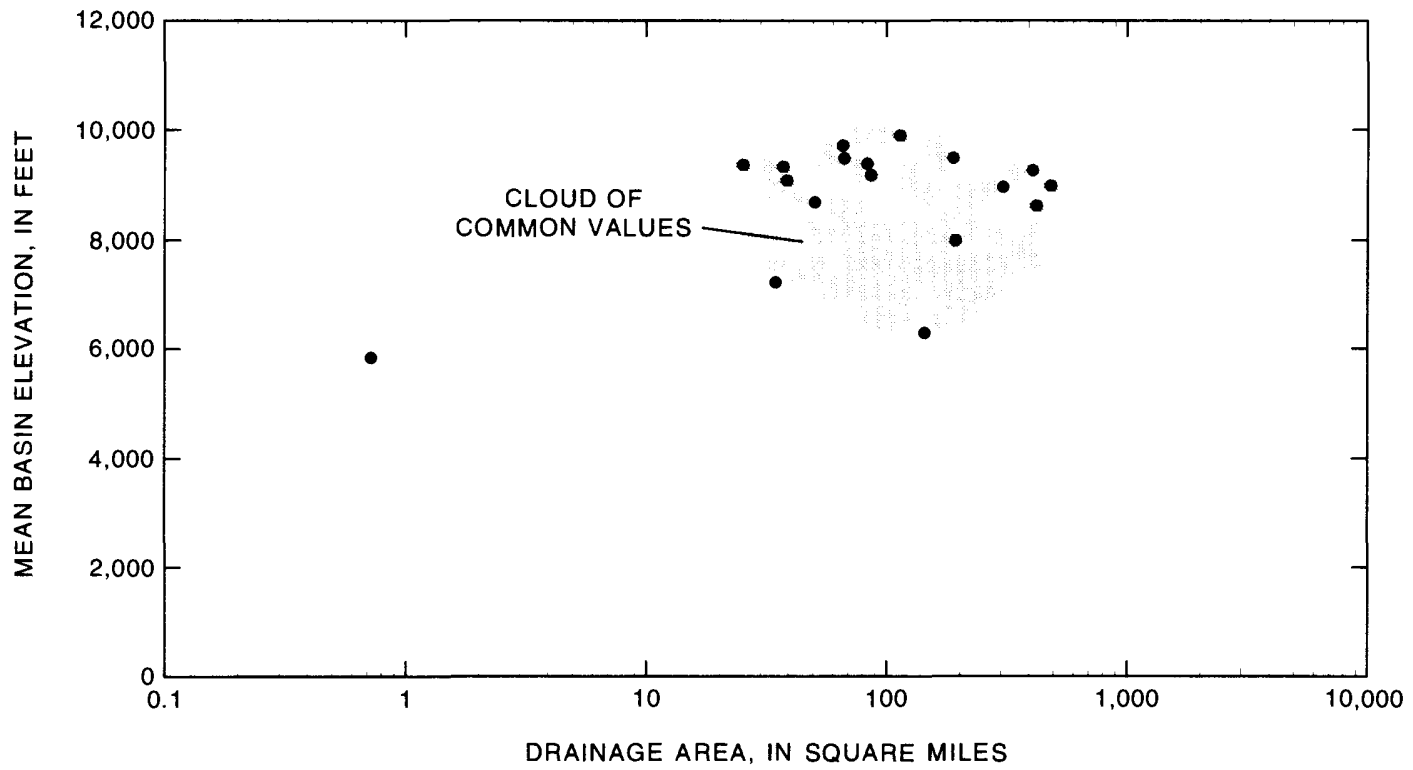

Figure 46. Joint distribution of mean basin elevation and drainage area for gaged sites in the Upper Rio Grande Basin Region 15. 


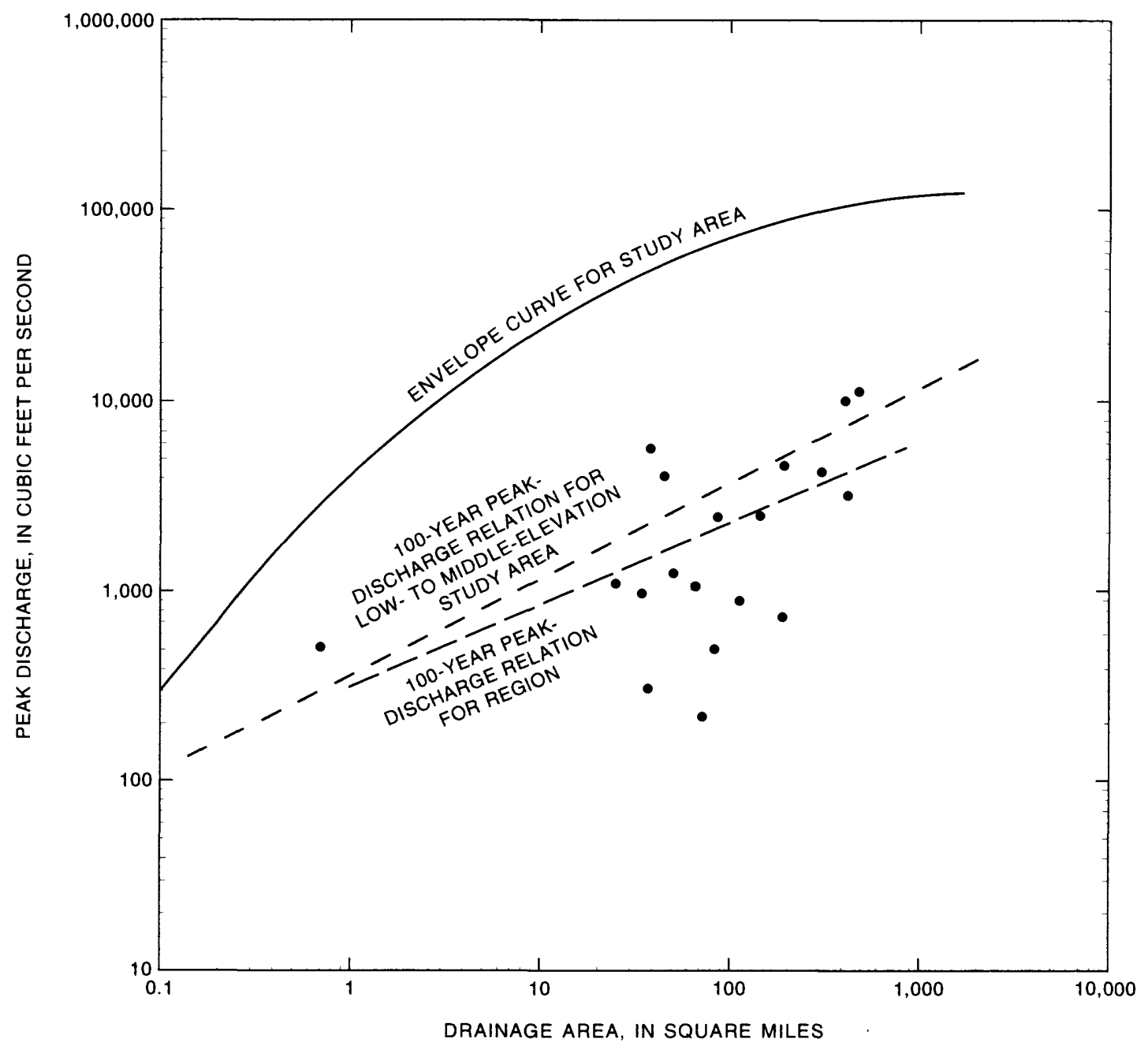

Figure 47. Relations between 100-year peak discharge and drainage area and plot of maximum peak discharge of record and drainage area for gaged sites in the Upper Rio Grande Basin Region 15.

Table 19. Generalized least-squares regression equations for estimating regional flood-frequency relations for the Upper Rio Grande Basin Region 15

Equation: Q, peak discharge, in cubic feet per second; AREA, drainage area, in square miles; ELEV, mean basin elevation, in feet; and LONG, longitude of site, in decimal degrees. Data were based on 17 stations. Average number of years of systematic record is 35.

\begin{tabular}{clcc}
\hline $\begin{array}{c}\text { Recurrence } \\
\text { interval, in years }\end{array}$ & Equation & $\begin{array}{c}\text { Average } \\
\text { standard error of } \\
\text { prediction, in } \\
\text { percent }\end{array}$ & $\begin{array}{c}\text { Equivalent } \\
\text { years of } \\
\text { record }\end{array}$ \\
\hline 2 & $\left.Q=18,700 \mathrm{AREA}^{0.730}(\mathrm{ELEV} / 1,000)^{-2.86}[(\mathrm{LONG}-99) / 10)\right]^{2.8}$ & 64 & 0.13 \\
5 & $\left.Q=31,700 \mathrm{AREA}^{0.646}(\mathrm{ELEV} / 1,000)^{-2.67}[(\mathrm{LONG}-99) / 10)\right]^{27}$ & 66 & .64 \\
10 & $\left.Q=26,000 \mathrm{AREA}^{0.582}(\mathrm{ELEV} / 1,000)^{-2.27}[(\mathrm{LONG}-99) / 10)\right]^{27}$ & 68 & 1.24 \\
25 & $\left.Q=34,800 \mathrm{AREA}^{0.532}(\mathrm{ELEV} / 1,000)^{-2.15}[(\mathrm{LONG}-99) / 10)\right]^{26}$ & 71 & 2.04 \\
50 & $\left.Q=44,200 \mathrm{AREA}^{0.501}(\mathrm{ELEV} / 1,000)^{-2.11}[(\mathrm{LONG}-99) / 10)\right]^{2.5}$ & 73 & 2.60 \\
100 & $\left.Q=91,800 \mathrm{AREA}^{0.439}(\mathrm{ELEV} / 1,000)^{-2.22}[(\mathrm{LONG}-99) / 10)\right]^{2.5}$ & 76 & 3.12 \\
\hline
\end{tabular}




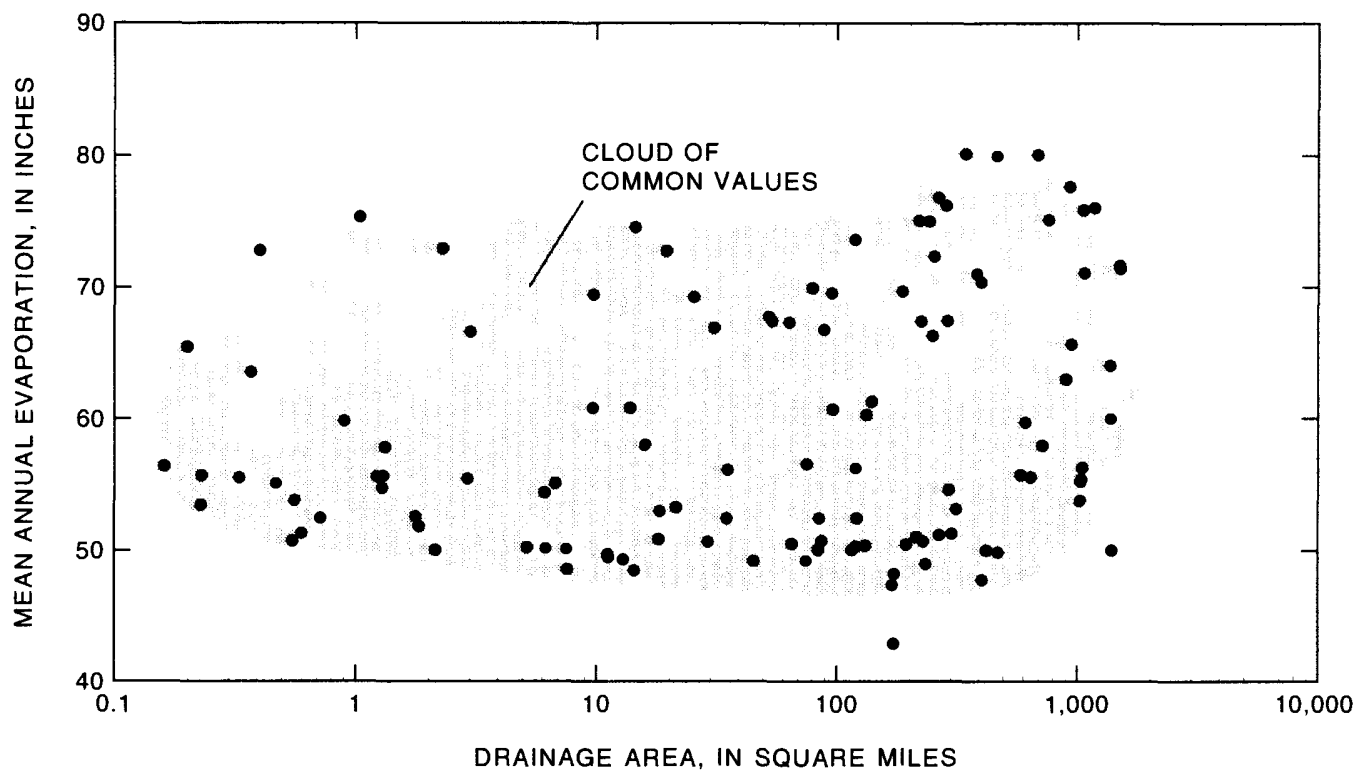

Figure 48. Joint distribution of mean annual evaporation and drainage area for gaged sites in the Southeast Region 16.

Table 20. Hybrid equations for estimating regional flood-frequency relations for the Southeast Region 16

Equation: Q, peak discharge, in cubic feet per second; AREA, drainage area, in square miles; and EVAP, mean annual evaporation, in inches. Data were based on 120 stations. Average number of years of systematic record is 30 .

Estimated average standard error of regression includes much of the within-station residual variance and therefore is not comparable to standard error of estimate from an ordinary least-squares regression. See section entitled "Hybrid Method" for explanation of error.

\begin{tabular}{|c|c|c|c|}
\hline $\begin{array}{c}\text { Recurrence } \\
\text { Interval, in years }\end{array}$ & Equation & $\begin{array}{l}\text { Estimated } \\
\text { average } \\
\text { standard error of } \\
\text { regresslon, in } \\
\text { log units }\end{array}$ & $\begin{array}{l}\text { Equivalent } \\
\text { years of } \\
\text { record }\end{array}$ \\
\hline 2 & $Q=14$ AREA ${ }^{0.51}\left(\text { EVAP }^{-32}\right)^{0.55}$ & 0.664 & 0.410 \\
\hline 5 & $Q=37$ AREA $^{0.48}\left(\text { EVAP }^{-32}\right)^{0.63}$ & .269 & 3.77 \\
\hline 10 & $Q=52$ AREA $^{0.47}\left(\text { EVAP }^{-32}\right)^{0.67}$ & .177 & 12.6 \\
\hline 25 & $Q=70$ AREA $^{0.48}\left(\text { EVAP }^{-32}\right)^{0.74}$ & .425 & 3.20 \\
\hline 50 & $Q=110$ AREA $^{0.47}(\text { EVAP }-34)^{0.74}$ & .367 & 5.38 \\
\hline 100 & $Q=400$ AREA $^{0.50}\left(\text { EVAP }^{-37}\right)^{0.45}$ & .442 & 4.54 \\
\hline
\end{tabular}




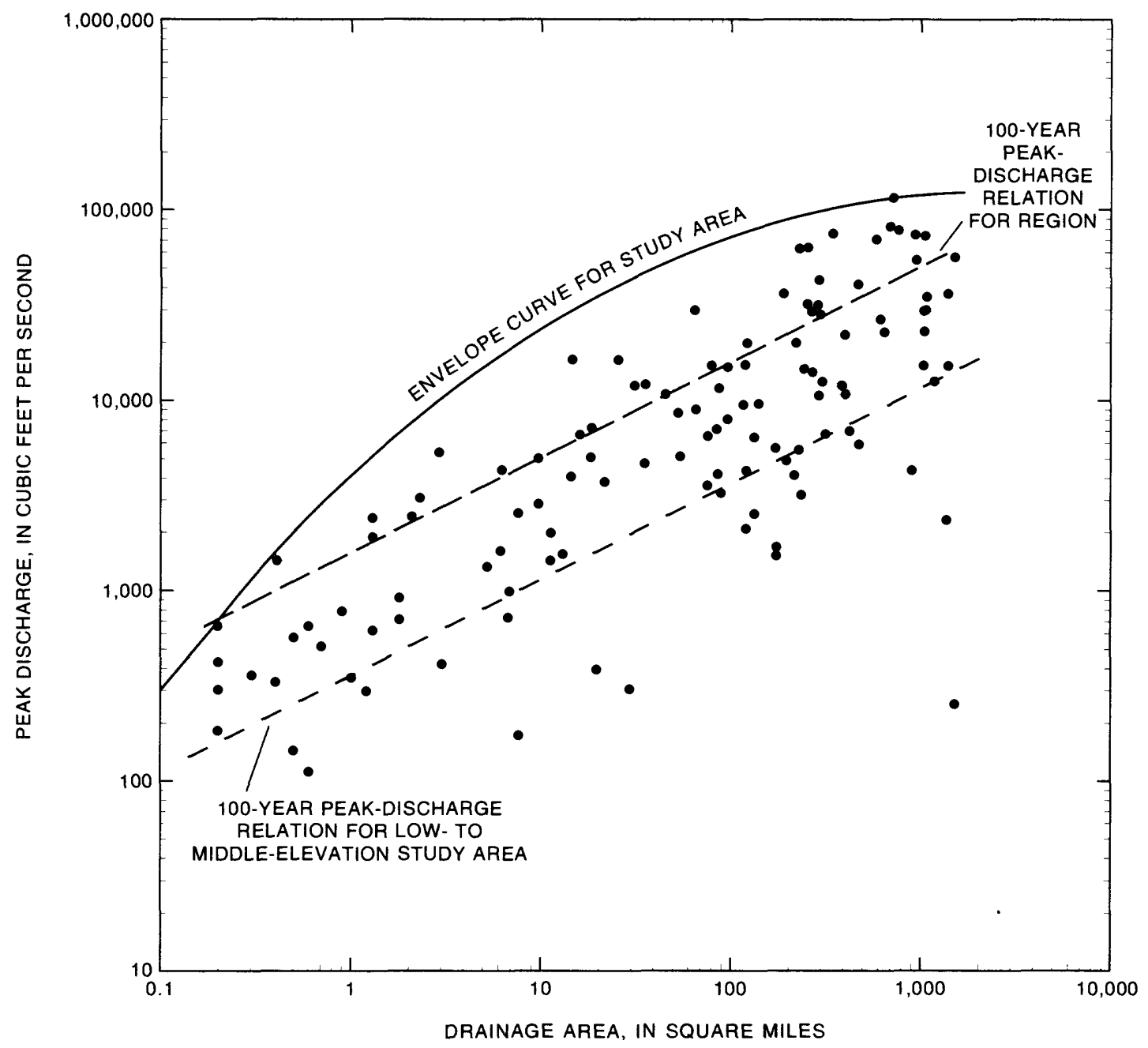

Figure 49. Relations between 100-year peak discharge and drainage area and plot of maximum peak discharge of record and drainage area for gaged sites in the Southeast Region 16. 


\section{Alternative Methods}

The methods in this study apply to streams with flow unaffected by works of man and are based on a sample of gaging stations on streams draining areas of less than 2,000 $\mathrm{mi}^{2}$. Existing flood-frequency relations in the referenced reports can be used for sites with flow affected by works of man and for large drainage areas. In the unusual situations where the described methods of this report do not apply, many alternative methods can be used to estimate flood-frequency relations. Most of the alternative methods require an estimate of rainfall intensity for a specific probability. Runoff characteristics for the estimate of rainfall are then estimated using a deterministic model of rainfall-runoff relations (Crawford and Linsley, 1966; Leavesley and others, 1983), an empirical relation such as the rational method (Chow, 1964, p. 14-6 to 14-8), or a model such as the unit hydrograph (Chow, 1964, p. 14-13 to 14-34). A nationwide comparison of alternative methods for estimating flood-frequency relations on ungaged streams is provided by the U.S. Water Resources Council (1981).

The channel-geometry method is applicable to many natural stream channels; however, a visit to the study site is required. Estimates from channel-geometry methods are based on the concept that the size and shape of an alluvial channel are a measure of the discharge of water and transport of sediment. Reports describing channel-geometry methods within the study area are shown in table 1. A review of channel-geometry methods was made by Wahl (1984).

The methods presented in this report, the rainfall-runoff models, and the channel-geometry method are applicable to streams on tributary systems of channels. Floodflow is much more difficult to estimate on alluvial fans or distributary-flow areas (Dawdy, 1979; McGinn, 1980; Hjalmarson and Kemna, 1991).

\section{Assumptions and Limitations of Methods}

It is important to recognize the assumptions and limitations inherent in the statistical methods used to estimate flood-frequency relations. The flood-information transfer method used in this study for most regions has two main components. Flood-frequency relations are first estimated from the series of annual peak discharges at streamflow-gaging stations. Information then is transferred to ungaged sites by relating the peak discharges at specific recurrence intervals at gaged sites to explanatory variables by using multiple-regression techniques. In this approach, the flood-frequency relations determined for gaged sites are the foundation.

\section{Flood-Frequency Relations at Gaged Sites}

Flood-frequency relations at gaged sites were estimated by fitting a probability distribution to the gaging-station records. In this study, the log-Pearson Type III distribution was fit to the data using the method of moments. The assumptions for applying a probability distribution to a set of streamflow records are that the record at the gaged site is representative of the population of floods that can occur at the site, and that the annual peak discharges are independent, homogeneous, and random.

The population of annual peak discharges is defined as the whole class of possible occurrences of annual peak discharges in the past, present, and future. A sample is used that is an observed part of the population to describe and make inferences about this population. The annual peak discharges generally are independent and random; however, homogeneity may be a problem and needs careful examination. The factors that affect the annual peak discharges generally should remain constant to assure a homogeneous sample or population. Thus, watershed conditions should be constant during the period of record for the sample and for the period for which flood frequency is to be estimated. Cover conditions of the watershed such as vegetation, soil, and extent of urban areas generally should be constant. The streamflow regime should not change significantly because of urbanization, channelization, or construction of reservoirs, diversions, and levees. If all the assumptions are met, the relations of magnitude and frequency for past floods are assumed to be applicable to future floods and therefore are used to predict the future magnitude and frequency of floods. 
An unbiased and accurate record of annual peak discharges is needed for a flood-frequency analysis made on the basis of gaged data. Methods used in this study to ensure record accuracy include analysis of the accuracy of measurements of peak discharges, addition of historical and paleoflood information to records, comparisons of systematic records and frequency estimates to envelope curves of maximum measured floods, comparison of records to droughts and wet periods, and stationarity analysis.

\section{Regional Flood-Frequency Relations}

The multiple-regression method that was used for determination of most of the regional flood-frequency relations provides a means of estimating design-flood magnitudes at ungaged sites. The regional relations are based on a sample of gaged streams that is assumed to represent the population of flood events and streams in the study area. Thus, any errors or uncertainty contained in the estimates of flood-frequency relations from records of gaged sites are transferred to the estimates for ungaged sites. A potentially large problem with an individual relation at a gaged site is the time-sampling error, which is the error caused by having a sample that does not represent the population of floods at the site. This time-sampling error, however, is partially reduced by the combining and averaging of station flood-frequency relations in the regression method.

Flood magnitudes at ungaged sites in Regions $6,10,11$, and 16 were estimated using a new hybrid method. As in the multiple-regression method the hybrid regional relations are based on a sample of gaged streams that is assumed to represent the population of flood events and streams in the study area. The hybrid regional relations are subject to a time-sampling error associated with the sample of gaged sites used to represent the regional population of floods.

Use of regional relations with values of explanatory variables outside the range of the sample that is used to define the relations can result in unreliable estimates of peak discharge. Average standard errors of prediction for the regional equations in this report are for the average of the explanatory variables. For values of variables that are much different from the average, errors may be much greater than the average standard error of prediction. For explanatory variables with a large exponent, small departures from the average value of the variable can have corresponding large errors. Application of a regional relation where two or more of the values of the explanatory variables are near the limits of the range of sample values may result in a combination of values that is outside the sample range. Such extrapolations are subject to large potential errors, and the results may be misleading.

Predicted floods from regression models are an average for an entire area; therefore, a particular site may have smaller or larger floods depending on basin, climatic, and channel characteristics that are not used in the regression equations. The user of the regression models should be aware of the characteristics of the basin to which the model is applied. Because of the averaging characteristic of the regression models in this study, another limitation of their application is that estimated peak discharges near many of the flood-region boundaries may be quite different using two adjacent regional models.

\section{APPLICATION OF METHODS}

To estimate flood-frequency relations at a study site, the user should use the following steps. Examples are given for sites in one region and for sites near flood-region boundaries.

1. Using latitude and elevation of the study site, determine if the study site is in High Elevation Region 1 or in a low- to middle-elevation region (fig. 5). If the study site is in a low- to middle-elevation region, determine the flood region of the study site using figures 6-16.

2. Using the flood region and the data section, determine if the study site is on a gaged stream.

3. If the study site is at a gaged site, use the listed weighted flood-frequency values for that site in the data section. 
4. If the study site is near a gaged site on the same stream, use the method described in the section entitled "Sites Near Gaged Sites on the Same Stream."

5. If the study site is on an ungaged stream, use the method described in the section entitled "Ungaged Sites."

\section{Sites Near Gaged Sites on the Same Stream}

Flood-frequency relations for sites near gaged sites on the same stream can be computed using the drainage-area ratio of ungaged site to gaged site. If the ratio is between 0.5 and 1.5 and the ungaged and gaged sites are draining similar basins, equation 2 should be used to compute the required peak discharges. If the ratio is outside that range or the basins are significantly different, the method for ungaged sites should be used. Flood-frequency relations for sites between gaged sites on the same stream can be determined by interpolating between values of drainage areas for gaged sites in the data section.

The following is an example of determination of the 10- and 100-year peak discharges for the Pecos River in New Mexico at an ungaged site. The drainage area $\left(A_{u}\right)$ is $165 \mathrm{mi}^{2}$. In the data section, the station, 08378500 Pecos River near Pecos, New Mexico (drainage area $A_{g}=189 \mathrm{mi}^{2}$ ), is in High Elevation Region 1 and is downstream from the study site.

1. Check that the drainage-area ratio $A_{u} / A_{g}$ is between 0.5 and 1.5. That ratio is as follows:

$$
A_{u} / A_{g}=\frac{165 m i^{2}}{189 m i^{2}}=0.87,
$$

which meets the ratio requirement. Equation 2 is used.

$$
Q_{T(u)}=Q_{T(g)}\left(A_{u} / A_{g}\right)^{x},
$$

where

$$
\begin{aligned}
& Q_{T(g)}=\text { weighted discharge from the } \\
& \text { data section, and }
\end{aligned}
$$

$$
\begin{aligned}
x= & 0.8 \text { for the High-Elevation } \\
& \text { Region. }
\end{aligned}
$$

2. Obtain the weighted discharges at the gaged site from the data section:

$$
\begin{aligned}
Q_{10(g)} & =1,480 \mathrm{ft}^{3} / \mathrm{s}, \text { and } \\
Q_{100(g)} & =3,250 \mathrm{ft}^{3} / \mathrm{s} .
\end{aligned}
$$

3. Compute the discharges at the ungaged site:

$$
\begin{aligned}
& Q_{10(u)}=1,480\left(\frac{165}{189}\right)^{0.8}=1,330 \mathrm{ft}^{3} / \mathrm{s}, \\
& Q_{100(u)}=3,250\left(\frac{165}{189}\right)^{0.8}=2,920 \mathrm{ft}^{3} / \mathrm{s} .
\end{aligned}
$$

The computed 100-year peak discharge appears reasonable in comparison to the plot of maximum-peak discharge of record and drainage area for the region (fig. 19).

\section{Ungaged Sites}

Flood-frequency relations at ungaged sites can be determined using one of the following procedures, depending on the location of the site and its relation to the flood-region boundaries. The first procedure is for sites with a drainage area in one region. The second procedure is for sites with a drainage area in two low- to middle-elevation regions. The third procedure is for sites in a low- to middle-elevation region with an elevation that is within $700 \mathrm{ft}$ of the boundary of High-Elevation Region 1.

Use the following step-by-step procedure to compute flood-frequency relations at ungaged sites.

1. If the drainage area of the study site is entirely within one flood region, compute the required information for one region. If the drainage area of the study site is in two low- to middle-elevation regions or if the elevation of the study site is within 700 feet below the boundary of the HighElevation Region, a weighted flood- 
frequency relation is needed and the required information for the two adjacent regions should be computed.

2. Use table 4 and the flood region(s) of the study site to find the tables and figures containing the required information. The explanatory variables required for each region are in column 3 . The numbers of the tables of equations for estimating regional flood-frequency relations are in column 4. Figures showing the relation between maximum-peak discharges of record and drainage area are in column 5. Figures showing plots of explanatory variables and their cloud of common values are in column 6 .

3. Compute the required explanatory variables using the methods described on pages 17 and 18.

4. Determine if the values of explanatory variables are within the cloud(s) of common values shown in the figures listed in column 6 of table 4 . If they are within the cloud(s) of common values, then proceed to step 5 . If they are outside the cloud(s), the methods are not defined for the study site, and the methods should be used with extreme caution.

5. Use the equations for the appropriate region(s) (tables 5-20) to compute the flood-frequency relation at the study site. See the following examples for sites using equations for one region or two regions.

\section{Site With a Drainage Area in One Flood Region}

The first example is the use of the regression equations with the model described by equation 3 . Determine the peak discharges for recurrence intervals of 10 and 100 years for an ungaged site in the Northeast Region 4 (fig. 6 and tables 4 and 8). The required basin characteristics are drainage area (AREA), in square miles, and mean basin elevation (ELEV), in feet. Using the procedures described in the section entitled "Explanatory Variables," the drainage area is computed as $35 \mathrm{mi}^{2}$ and the mean basin elevation is $7,500 \mathrm{ft}$. The drainage area and mean basin elevation are in the cloud of common values for the region (fig. 24). The characteristics are inserted into the appropriate equations as follows:

$$
\begin{aligned}
& Q_{10}=1.26(A R E A)^{0.674}\left(\frac{E L E V}{1,000}\right)^{1.64} \\
& =1.26(35)^{0.674}(7.5)^{1.64}=377 \mathrm{ft}^{3} / \mathrm{s},
\end{aligned}
$$

and

$$
\begin{aligned}
& Q_{100}=11.8(A R E A)^{0.662}\left(\frac{E L E V}{1,000}\right)^{0.835} \\
& =11.8(35)^{0.662}(7.5)^{0.835}=668 \mathrm{ft}^{3} / \mathrm{s} .
\end{aligned}
$$

The computed 100-year peak discharge appears reasonable in comparison to the plot of maximum peak discharge of record and drainage area for the region (fig. 25).

The second example is for the use of the regression equations with the model described by equation 4. Determine the peak discharges for recurrence intervals of 50 and 100 years for an ungaged site in Central Arizona Region 12 (fig. 6 and tables 4 and 16). The required basin characteristics are drainage area (AREA), in square miles, and mean basin elevation (ELEV), in feet. Using the procedures in the section "Explanatory Variables," the drainage area is computed as 110 $\mathrm{mi}^{2}$, and the mean basin elevation is $5,900 \mathrm{ft}$. The drainage area and mean basin elevation are in the cloud of common values for the region (fig. 40).

The characteristics are inserted into the appropriate equations as follows:

$$
\begin{aligned}
Q_{50} & =10^{\left(7.36-4.17(A R E A)^{-0.08}\right.}\left(\frac{E L E V}{1,000}\right)^{-0.440} \\
& =10^{\left(7.36-4.17(110)^{-0.08}\right)}(5.90)^{-0.440} \\
& =14,400 \mathrm{ft}^{3} / \mathrm{s},
\end{aligned}
$$

and 


$$
\begin{aligned}
Q_{100} & =10^{\left(6.55-3.17(A R E A)^{-0.11}\right)}\left(\frac{E L E V}{1,000}\right)^{-0.454} \\
& =10^{\left(6.55-3.17(110)^{-0.11}\right)}(5.90)^{-0.454} \\
& =20,400 \mathrm{ft}^{3} / 8 .
\end{aligned}
$$

The computed 100-year peak discharge appcars reasonable in comparison to the plot of maximum-peak discharge of record and drainage area for the region (fig. 41).

\section{Site With a Drainage Area in Two Low- to Middle-Elevation Flood Regions}

A hypothetical study site has a drainage area in the Northern and Southern Great Basin Regions (Regions 6 and 10). Thus, an averaging procedure based on the percentage of the drainage area in each region should be used. The peak discharges are estimated for each region as if the drainage area is entirely in one region. Then, a weighted peak discharge is estimated using equation 6.

An example for the use of regression equations for two regions is as follows. Determine the peak discharges for recurrence intervals of 10 and 100 years for an ungaged site with a drainage area in Northem Great Basin Region 6 and Southem Great Basin Region 10 (fig. 6 and tables 4, 10, and 14). The required basin and climatic characteristics are drainage area (AREA), in square miles and mean basin elevation (ELEV), in feet. Using the procedures discussed in "Explanatory Variables," the basin and climatic characteristics are computed as $57 \mathrm{mi}^{2}$ for drainage area and $6,500 \mathrm{ft}$ for mean basin elevation. The drainage area and mean basin elevation are within the cloud of common values for Region 6 (fig. 29), and the drainage area is within the range of drainage area for Region 10 (fig. 37). On the topographic map, the drainage area is bisected by the regional boundary at $37^{\circ}$ latitude. The northern region includes $21 \mathrm{mi}^{2}$, and the southern region includes $36 \mathrm{mi}^{2}$. The basin and climatic characteristics are inscrted into the appropriate regional equations to oblain cstimates of $T$-year discharges for each region. Then, equation 6 is used to obtain weighted estimates of T-year discharges. For the Northem Great Basin Reglon 6, the cquations are as follows:

$$
\begin{aligned}
& Q_{10}=590(A R E A)^{0.62}\left(\frac{E L E V}{1,000}\right)^{-1.6} \\
& =590\left[(57)^{0.62}\right](6.5)^{-1.6}=362 \mathfrak{f t}^{3} / 5,
\end{aligned}
$$

and

$$
\begin{aligned}
& Q_{100}=20,000(A R E A)^{0.51}\left(\frac{E L E V}{1,000}\right)^{-2.3} \\
& =20,000\left[(57)^{0.51}\right](6.5)^{-23}=2,120 \mathrm{f}^{3} / \mathrm{s}
\end{aligned}
$$

For the Southern Greal Basin Region 10, the equations are as follows:

$$
\begin{aligned}
& Q_{10}=200(A R E A)^{0.62} \\
= & 200\left[(57)^{0.62}\right]=2,450 \mathrm{rt}^{3} / \mathrm{s},
\end{aligned}
$$

and

$$
\begin{gathered}
\ell_{100}=850(\text { AREA })^{0.69} \\
=850\left[(57)^{0.69}\right]=13,800 \mathrm{n}^{3} / \mathrm{s} .
\end{gathered}
$$

The computed 100-year pcak discharges for Regions 6 and 10 appear reasonable in comparison to the plots of maximum peak discharge of record and drainage area for the regions (figs. 30 and 37).

Estimates of weighted peak discharges using equation 6 are as follows.

$$
\begin{aligned}
Q_{10(w)}= & \frac{(362 \times 21)+(2,450 \times 36)}{57} \\
& =1,680 \mathrm{fl}^{3} / \mathrm{s} .
\end{aligned}
$$

and

$$
\begin{gathered}
Q_{100(\mathrm{w})}=\frac{(2,120 \times 21)+(13,800 \times 36)}{57} \\
=9,500 \mathrm{ft}^{3} / \mathrm{s} .
\end{gathered}
$$

Low. to Middle-Elevation Site Near the High-Elevation Flood Region

A hypothetical study site is in a low- to middle-elevation flood region but the sile elevation is within $700 \mathrm{ft}$ of the boundary of High-Elevation Region 1 (fig. 5). Thus, an averaging procedure bascd on the relation between the elevation of the study site and the 700-10ot transition zone should be used. The peak discharges are cstimated for each region as if the drainage area is entirely in onc region. Then, a weighted peak discharge is estimated using equation 7. 
An example for the use of regression equations for High-Elevation Region 1 and a low- to middle-elevation region is as follows. Determine the peak discharges for recurrence intervals of 2 and 50 years for an ungaged site in the Four Corners Region 8 with a site elevation of 7,100 feet (fig. 6). The site elevation is within 700 feet of the boundary of High-Elevation Region 1, which is 7,500 feet in the latitudes of Region 8 (figs. 5 and 6). The regression equations for Region 1 are in table 5 and the equations for Region 8 are in table 12. The required basin and climatic characteristics are drainage area (AREA), in square miles, mean basin elevation (ELEV), in feet, and mean annual precipitation (PREC), in inches. Using the procedures in the section "Explanatory Variables," the drainage area is computed as $45 \mathrm{mi}^{2}$, the mean basin elevation is $8,900 \mathrm{ft}$, and the mean annual precipitation is 28 in. The drainage area and mean annual precipitation are in the cloud of common values for Region 1 (fig. 18), and the drainage area and mean basin elevation are in the cloud of common values for Region 8 (fig. 33).

Basin and climatic characteristics are inserted into the appropriate regional equations to obtain estimates of $\mathrm{T}$-year discharges for each region. Then, equation 7 is used to obtain weighted estimates of T-year discharges. For the Four Corners Region 8, the equations are as follows:

$$
\begin{gathered}
Q_{2}=598(A R E A)^{0.501}\left(\frac{E L E V}{1,000}\right)^{-1.02} \\
=598\left[(45)^{0.501}\right](8.90)^{-1.02}=433 \mathrm{ft}^{3} / \mathrm{s},
\end{gathered}
$$

and

$$
\begin{gathered}
Q_{50}=16,000(A R E A)^{0.390}\left(\frac{E L E V}{1,000}\right)^{-1.54} \\
=16,000\left[(45)^{0.390}\right](8.90)^{-1.54}=2,440 \mathrm{ft}^{3} / \mathrm{s} .
\end{gathered}
$$

For High-Elevation Region 1, the equations are as follows:

$$
\begin{gathered}
Q_{2}=0.124(A R E A)^{0.845}(P R E C)^{1.44} \\
=0.124\left[(45)^{0.845}\right](28)^{1.44}=375 \mathrm{ft}^{3} / \mathrm{s},
\end{gathered}
$$

and

$$
\begin{aligned}
& Q_{50}=4.75(A R E A)^{0.758}(P R E C)^{0.732} \\
& =4.75\left[(45)^{0.758}\right](28)^{0.732}=975 \mathrm{ft}^{3} / \mathrm{s} .
\end{aligned}
$$

Computed 50-year peak discharges for regions 1 and 8 appear reasonable in comparison to the plots of maximum peak discharge of record and drainage area for the two regions (figs. 19 and 34).

Estimates of weighted peak discharges using equation 7 are as follows.

$$
\begin{gathered}
Q_{2(w)}=433\left(\frac{7,500-7,100}{700}\right) \\
+375\left(1-\frac{7,500-7,100}{700}\right)=408 \mathrm{ft}^{3} / \mathrm{s},
\end{gathered}
$$

and

$$
\begin{gathered}
Q_{50(w)}=2,440\left(\frac{7,500-7,100}{700}\right) \\
+975\left(1-\frac{7,500-7,100}{700}\right)=1,810 \mathrm{ft}^{3} / \mathrm{s} .
\end{gathered}
$$

\section{ANALYSIS OF GAGING-STATION RECORDS}

Gaging-station records of annual peak discharges are the foundation of the data base used in this study. Records throughout the study area were selected and examined for accuracy and the required assumptions for a statistical analysis. Flood-frequency relations were computed using statistical and graphical analyses. The final best-fit individual relations then were used to develop regional flood-frequency relations using the methods described in the following section "Regional Analysis."

\section{Records Used}

Records for 1,323 gaging stations in the USGS peak-flow file were used in this analysis. The records contain the maximum peak discharge for each water year (October 1-September 30). Gaging stations selected for this study (1) are mostly within the study-area boundary, (2) have 10 or more years 
of systematic record, (3) have annual peak discharges that were not significantly affected by regulation or diversions, and (4) are on a system of tributary streams.

The systematic gaging-station records are for data collected by the USGS during 1890 to 1986 . Systematic data are the result of regular observations over a period of time. The systematic records range in length from 10 to 83 years and approximately 32,500 station years of data are included in the 1,323 records. The period of record was extended at 119 sites with historic floods and at 5 sites with paleofloods. A historic flood or paleoflood is the largest in a known period beyond the systematic record. Historic-flood records ranged from 12 to 200 years and paleoflood records ranged from 280 to 2,100 years. The historic and paleoflood information added about 7,500 station years for a total of 40,000 station years in the data base.

The gaging stations are fairly well distributed in the study area (fig. 50). Several gaging stations outside the study-area boundary in northeastern New Mexico and west-central Texas were included in the analysis to add some information to that part of the study area. The stations are most dense in the humid mountainous areas and least dense in the arid desert areas. The average systematic record length for all sites is 25 years and ranges from 19 to 35 years for the 16 flood regions defined in this study. Record length tends to increase with drainage area because most early data-collection efforts were concentrated in the larger basins for water-supply purposes (table 21).

Table 21. Drainage area and years of systematic record at gaging stations in the southwestern United States

\begin{tabular}{ccc}
\hline $\begin{array}{c}\text { Drainage area, in } \\
\text { square miles }\end{array}$ & $\begin{array}{c}\text { Number of } \\
\text { gaging } \\
\text { stations }\end{array}$ & $\begin{array}{c}\text { Average years } \\
\text { of systematic } \\
\text { record }\end{array}$ \\
\hline Less than 1 & 120 & 16.4 \\
$1-10$ & 299 & 17.3 \\
$10-100$ & 507 & 23.1 \\
$100-1,000$ & 342 & 34.2 \\
$1,000-2,000$ & 55 & 37.4 \\
\hline
\end{tabular}

The annual peak discharges, in cubic feet per second, are converted to common (base 10) logarithms for the flood-frequency analyses in this study. The average of the mean peak discharges in each record is $2.3 \mathrm{log}$ units, the average standard deviation is 0.45 , and the average skew coefficient is 0.028 .

\section{Stationarity and Trend Tests}

One of the assumptions needed for a statistical flood-frequency analysis is that the series of annual peak discharges is homogeneous. One aspect of a homogeneous series is that the annual peaks should be stationary over time. The factors that affect the annual peak discharges generally should remain constant during the period of record for the sample and for the period of time for which flood frequency is to be estimated.

The time series of annual peak discharges were examined for long-term changes using the two-sided nonparametric Kendall tau statistical test. The 340 gaging stations that had at least 30 years of record were used for the test. At least 30 years of record was considered necessary for reliable detection of trends. Eighty-two percent of the stations had no trend significant at the 5-percent level $(\alpha=0.05)$, and about an equal number of stations had positive and negative trends (table 22). The computed trend apparently is independent of drainage area because stations that had a wide range of drainage area had no trend or equal amounts of increasing and decreasing trends.

The results indicate no significant trend in time for annual peak discharge at the gaging stations in the study area. A nonuniform geographic distribution of computed trends, however, indicates a systematic effect. A negative trend of decreasing magnitudes of annual peaks for several gaging stations was detected in the southeastern part of the study area. Fourteen percent of the selected stations in Colorado and New Mexico have a decreasing trend, and only 2 percent of the selected stations have an increasing trend. In the northern part of the study area, 27 percent of the selected stations in Oregon, Idaho, and Wyoming have an increasing trend, and no decreasing trends were detected at any stations. 


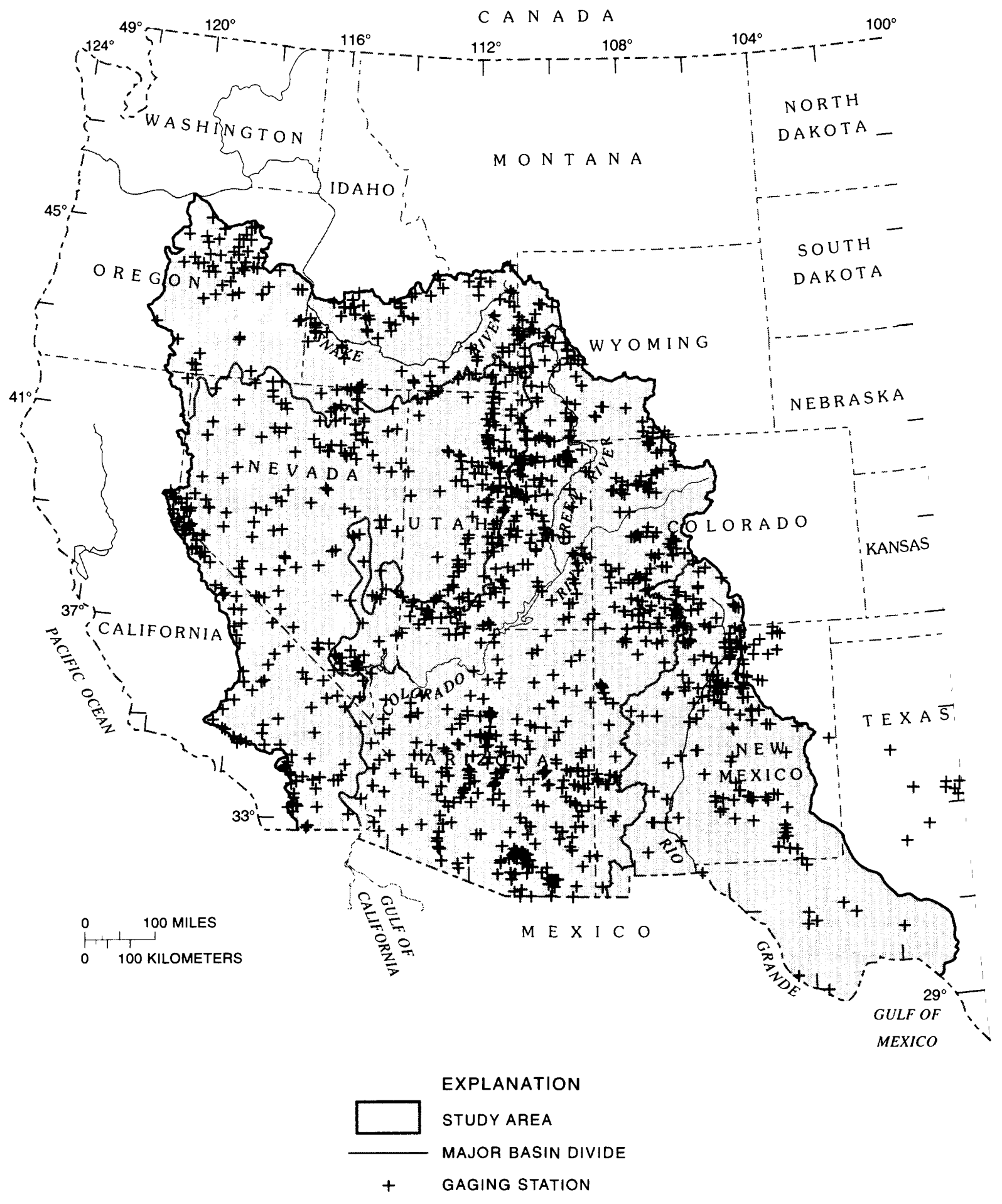

Figure 50. Gaging stations used in this study. 
Table 22. Significance of trends over time in annual peak discharges for gaging stations with at least 30 years of record in the southwestern United States

\begin{tabular}{ccccc}
\hline & \multicolumn{4}{c}{ Number of gaging stations } \\
\cline { 2 - 5 } State & $\begin{array}{c}\text { At least } \\
\text { 30 years } \\
\text { of record }\end{array}$ & \multicolumn{3}{c}{ Trend } \\
\cline { 3 - 5 } & $\begin{array}{c}\text { Posi- } \\
\text { tlve }\end{array}$ & $\begin{array}{c}\text { Nega- } \\
\text { tlve }\end{array}$ & None \\
\hline Arizona......... & 31 & 2 & 3 & 26 \\
California ...... & 24 & 1 & 1 & 22 \\
Colorado........ & 55 & 1 & 9 & 45 \\
Idaho............. & 22 & 7 & 0 & 15 \\
Nevada .......... & 17 & 3 & 0 & 14 \\
New & & & & \\
Mexico ....... & 90 & 2 & 12 & 76 \\
Oregon.......... & 15 & 5 & 0 & 10 \\
Texas ............ & 4 & 0 & 0 & 4 \\
Utah............. & 55 & 5 & 4 & 46 \\
Wyoming...... & 27 & 5 & 0 & 22 \\
\cline { 3 - 5 } Total.............. & 340 & 31 & 29 & 280 \\
\hline
\end{tabular}

Changes of the physical conditions of the basins in the northern and southeastern part of the study area that may have caused changes in the magnitude of flood peaks were unknown for this study. If the computed trends are related to climatic variation, extrapolation of the trend to the future is considered tenuous and beyond the scope of this study. An analysis of possible trends and climatic variability for the Santa Cruz River in southern Arizona showed that these factors introduce uncertainty in flood-frequency estimates (Webb and Betancourt, 1992). Adjustment of the computed flood-frequency relations was not made because there was no known physical condition in the basins that could explain the computed trends and because trends were detected at only a few of the stations in the northern and southeastern parts of the study area.

\section{Flood-Frequency Analyses}

Analyses were made to determine flood-frequency relations at 1,323 gaging stations. The relation of annual peak discharge to exceedance probability, or to recurrence interval, is referred to as a flood-frequency relation or curve. Exceedance probability is the chance that a flood will equal or exceed a given magnitude in any year. Recurrence interval is the reciprocal of the exceedance probability and is the average number of years between exceedances.

In the flood-frequency analyses, peakdischarge records were analyzed by mathematical fitting and graphical analysis. Some adjustments were made to obtain the best fit of the flood-frequency relations to the data. Individual frequency relations were defined for 1,059 sites. Relations were not defined for 264 sites because of inadequate samples and poor fits of the relations to the data. A small sample of gaging-station records with mixed populations was analyzed to estimate the effect of such populations on the frequency relations. A detailed analysis was done to estimate the regional relations of skew coefficient for the study area. The final flood-frequency relations presented in this study reflect the individual adjustments and the incorporation of the new information on regional skew coefficient.

The log-Pearson Type III probability distribution (LPIII) and the method of moments were used to define flood-frequency relations for gaging-station records (Interagency Advisory Committee on Water Data, 1982). In this method, the series of annual floods at a site is assumed to represent a random sample from a single distribution whose characteristics do not change with time. The LPIII is a three-parameter generalization of the log-normal statistical distribution that provides sufficient flexibility to approximate many observed flood distributions. To fit the LPIII to a sample of data using the method of moments, the annual floods are converted to logarithms and three statistics are computed-mean, standard deviation, and skew coefficient. The mean and standard deviation of the sample define the position and slope of a plot of the data on log-normal probability paper. Log-normal data plot as a straight line and LPIII data plot as a curve with the skew coefficient defining the amount and sense of curvature.

Detailed evaluations of the computed flood-frequency relations were made by visual examination of the fit of the LPIII probability 
distribution to the plotted annual peak discharges. The Cunnane plotting position formula was used to plot the data on logarithmic normal probability paper. The Cunnane plotting position essentially is unbiased and distribution free and provides a satisfactory visual comparison between the computed flood-frequency relation and the plotted peak discharges (Cunnane, 1978).

The shape of flood-frequency relations for sites is assumed to have limitations. The expected slope of the relations is positive because peak discharge increases with decreasing probability of occurrence. The expected shape of a relation in $\log$-probability space is a straight line or a smooth curve with no sharp breaks or discontinuities; therefore, a three-component LPIII distribution was used to fit relations. Also the fitted relation is expected to visually agree with the plotted data; for example, a persistent departure of the smaller annual peaks from the fitted relation is not considered a satisfactory fit.

The reliability of station flood-frequency relations was assessed by how well the computed relations fit the plotted peak discharges, the presence or absence of outliers, and the shape of the distribution of the plotted peaks. The assessment showed that 264 sites have a poor fit of the computed relation to the plotted peaks, odd-appearing plotted peaks, and usually a large variance. The peaks at many of these 264 sites that have inadequate flood-frequency relations were used in the hybrid analysis to estimate regional flood-frequency relations. The remaining 1,059 sites were judged to have adequate flood-frequency relations.

Examination of the plotted peaks found some similar characteristics that occurred in many of the records with defined relations (table 23). Thirty-eight percent of the sites had plotted peaks with the expected smooth shape of a LPIII distribution. The remaining sites had one or more departures from the expected shape. Adjustments to the frequency relations were made for sites with low outliers (Interagency Advisory Committee on Water Data, 1982, appendix 5). When available, historical periods were applied to sites with high outliers. Other departures from expectation, such as
Table 23. Summary of characteristics of station floodfrequency relations in the southwestern United States

\begin{tabular}{|c|c|c|}
\hline $\begin{array}{l}\text { Flood-frequency } \\
\text { characteristics }\end{array}$ & $\begin{array}{c}\text { Number } \\
\text { of } \\
\text { stations }\end{array}$ & $\begin{array}{l}\text { Percent- } \\
\text { age of } \\
\text { stations } \\
\text { with } \\
\text { defined } \\
\text { relations }\end{array}$ \\
\hline Smooth shape of plotted data... & 399 & 38 \\
\hline $\begin{array}{l}\text { Applied low-discharge } \\
\text { threshold.................................... }\end{array}$ & 512 & 48 \\
\hline High outlier ................................ & 178 & 17 \\
\hline Historical period used ................. & 124 & 12 \\
\hline $\begin{array}{l}\text { High outlier and historical } \\
\text { period used................................ }\end{array}$ & 52 & 5 \\
\hline 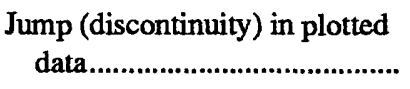 & 68 & 6 \\
\hline $\begin{array}{l}\text { Dogleg (break in slope) } \\
\text { in plotted data...................... }\end{array}$ & 100 & 9 \\
\hline
\end{tabular}

sites with discontinuities (jumps) or sharp breaks (doglegs) in the plotted peaks were coded, but no adjustments were made.

The percentage of gaged sites with low outliers, high outliers, doglegs, and jumps in their plotted peaks was compared to the basin and climatic characteristics of the sites (table 24). The gaged sites were placed into three incremental classes of the characteristics, and an analysis of variance (ANOVA) was performed to test if there is a significant difference in the percentages between the three classes. The ANOVA was performed by coding the gaged sites with a 1 if the attribute is present and a 0 if the attribute is absent. Thus, the mean of the 1's and 0's in each class of basin or climatic characteristic is the percentage of the attributes in each class. The following three sections discuss the results of these comparisons.

\section{Low Outliers and Low-Discharge Threshold}

Low outliers can have an adverse effect on computed flood-frequency relations for gaged sites by causing a large negative skew coefficient that can distort the frequency relation by flattening the 
Table 24. Characteristics of station flood-frequency relations compared to basin and climatic characteristics in the southwestern United States

[ANOVA, analysis of variance significance level. The gaging stations were coded with a 1 if the attribute is present and a 0 if the attribute is not present. The mean of the 1's and 0's in each class of basin or climatic characteristic is the percentage of the attributes in each class. ANOVA was performed on the three classes to test if a significant difference in means (percentages) exists between the three groups (three classes of basin or climatic characteristic). Dogleg in plotted data is indicated by a sharp break or dogleg appearance. The data fit into two segments with different slopes. Jump in plotted data is indicated by a discontinuity or jump where two or more segments are displaced vertically]

\begin{tabular}{|c|c|c|c|c|c|c|c|c|c|}
\hline \multirow[b]{2}{*}{ Class } & \multirow{2}{*}{$\begin{array}{l}\text { Num- } \\
\text { ber } \\
\text { of } \\
\text { sta- } \\
\text { tions }\end{array}$} & \multicolumn{8}{|c|}{$\begin{array}{l}\text { Percentage of streamflow-gaging stations with speclfied characterlstic and } \\
\text { ANOVA signiflcance level }\end{array}$} \\
\hline & & $\begin{array}{l}\text { Low dis- } \\
\text { charge } \\
\text { thres- } \\
\text { hoid }\end{array}$ & ANOVA & $\begin{array}{l}\text { High } \\
\text { outlier }\end{array}$ & ANOVA & $\begin{array}{l}\text { Dogleg } \\
\text { in } \\
\text { piotted } \\
\text { data }\end{array}$ & ANOVA & $\begin{array}{l}\text { Jump } \\
\text { In } \\
\text { plotted } \\
\text { data }\end{array}$ & ANOVA \\
\hline \multicolumn{10}{|c|}{ Drainage area, in square miles } \\
\hline Less than 50 & 536 & 48 & & 17 & & 7 & & 6 & \\
\hline 50 to 200 & 268 & 48 & 0.83 & 12 & 0.02 & 9 & 0.01 & 9 & 0.18 \\
\hline More than 200 & 255 & 49 & & 21 & & 14 & & 5 & \\
\hline \multicolumn{10}{|c|}{ Latitude, in degrees } \\
\hline Less than 37 & 409 & 53 & & 14 & & 11 & & 6 & \\
\hline 37 to 41 & 404 & 46 & .09 & 19 & .10 & 6 & .03 & 8 & .35 \\
\hline More than 41 & 246 & 45 & & 18 & & 11 & & 5 & \\
\hline \multicolumn{10}{|c|}{ Mean basin elevation, in feet } \\
\hline Less than 6,000 & 287 & 55 & & 17 & & 11 & & 7 & \\
\hline 6,000 to 8,000 & 382 & 49 & .01 & 16 & .70 & 11 & .08 & 7 & .82 \\
\hline More than 8,000 & 361 & 43 & & 18 & & 7 & & 6 & \\
\hline \multicolumn{10}{|c|}{ Mean annual precipitation, in inches } \\
\hline Less than 16 & 358 & 56 & & 18 & & 11 & & 8 & \\
\hline 16 to 25 & 408 & 45 & .01 & 16 & .45 & 9 & .17 & 7 & .03 \\
\hline More than 25 & 254 & 43 & & 15 & & 7 & & 3 & \\
\hline \multicolumn{10}{|c|}{ Mean annual evaporation, in inches } \\
\hline Less than 40 & 383 & 45 & & 16 & & 9 & & 6 & \\
\hline 40 to 55 & 429 & 47 & .02 & 19 & .42 & 9 & .78 & 8 & .10 \\
\hline More than 55 & 247 & 56 & & 15 & & 10 & & 4 & \\
\hline
\end{tabular}


upper end of the relation. Low outliers are small peak discharges that depart from the low end of a fitted flood-frequency relation. In addition, zero-flow years in gaged records are low outliers. For many sites, the departure of the small peaks from the fitted relation may be related to characteristics of the basin or stream channel. This type of departure should be called a hydrologic low outlier to emphasize that it is defined by hydrologic considerations rather than by statistical tests. Hydrologic low outliers often define a different relation than the midrange and large peaks. A peak-discharge record with characteristics of a hydrologic low outlier may be evidence that the smaller peaks are from a different flood population than the larger peaks. Meteorologic processes and watershed characteristics may affect small flood peaks differently than large peaks.

Small peaks that are identified as low outliers using a statistical test and zero-flow years are truncated, and a conditional probability adjustment is made to obtain the final frequency relation in the procedure recommended by the Interagency Advisory Committee on Water Data (1982, p. 17-19 and Appendix 5). The statistical procedure detects the smallest peaks; however, many small peaks that depart from the fitted relation are not identified as outliers. In this study, therefore, a low-discharge threshold was used to adjust for those small peaks that depart from the fitted relation but are not detected by the statistical test. Application of this low-discharge threshold also used the conditional probability adjustment to obtain the final frequency relation. The statistical procedure (Interagency Advisory Committee on Water Data, 1982) generally is successful in making appropriate adjustments for low outliers; however, computed results need to be examined for hydrologic low outliers if the procedure is not successful.

The low-discharge threshold was applied to sites primarily on the basis of the visual fit of the computed relation to annual peak discharges using the Cunuane plotting positions. At many sites, the plot of annual peak discharges has a segment of small peaks that curves steeply downward. The low-discharge threshold was commonly set at a sharp downward break in the relation and always was set at a probability greater than 0.7 , which is a recurrence interval of less than 1.4 years. The low-discharge threshold was applied to 48 percent of the sites with defined flood-frequency relations (table 23), and many of those sites have a statistical low outlier. The stations with an applied low-discharge threshold are identified in the data table under the heading "Relation Characteristics." With few exceptions, the use of the low-discharge threshold resulted in better fits between the relations and the plotted peak discharges.

Another method used to select the appropriate low-discharge threshold was to examine the effect on skew coefficient and T-year discharges as successive increments of peaks were truncated. The threshold was selected when computed skew coefficient and $T$-year discharge stabilized (changed less than about 1 percent). At a few sites with a departure of the smaller peaks from the fitted relation, the application of the low-discharge threshold did not result in a satisfactory fit. As the threshold was successively raised to the point of departure, a new fitted relation was computed and a new departure of additional peaks with an apparent higher threshold occurred. Relations for these sites had a negative skew coefficient, and the skew coefficient would not stabilize as the threshold was successively increased. For these sites, the lower peaks may be a part of the entire population of peaks, and no threshold was used. The unadjusted computed relation that was used, however, did not appear to be an ideal fit to the smaller peaks.

In this study, the interest is on the midrange and larger peaks of a sample (2- to 100-year floods). Using the method of truncation with a low-discharge threshold at a recurrence interval of less than 1.4 years, the magnitude and frequency of the midrange and larger peaks are used to fit the frequency relation. The existence and frequency of the small peaks are used for the conditional probability adjustment; however, the magnitude, which does not fit the relation defined by the other peaks, is not used.

A geographic pattern is not apparent in the distribution of sites with a low-discharge threshold (fig. 51). The percentage of sites with an applied low-discharge threshold was compared to basin and 

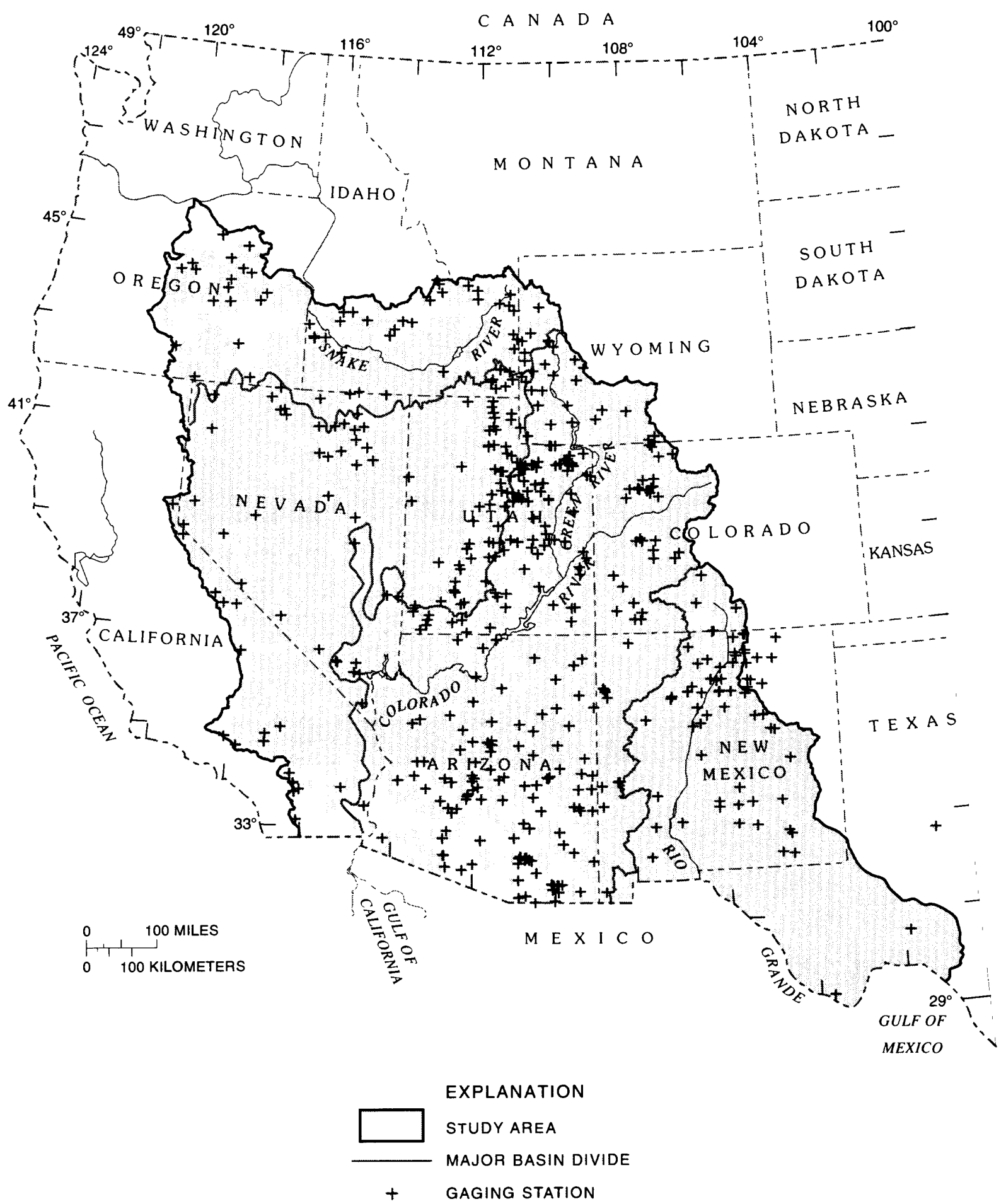

Figure 51. Gaging stations with an applied low-discharge threshold. 
climatic characteristics (table 24). In general, low-discharge thresholds were used at more sites in arid areas in the southern latitudes. The sites were at lower elevations, had smaller amounts of mean annual precipitation, and had larger amounts of mean annual evaporation. Many intermittent and ephemeral streams in the southwestern United States have characteristics that indicate a low-discharge threshold. Plots of samples of annual peaks at many of these streams have a segment of small peaks that curves steeply downward. The cause of this steep lower segment in the plotted peaks often is the large infiltration losses of the smaller annual peaks.

The following two examples of gaging-station records with low outliers show the effect on computed relations of using all peaks in the record compared to using the low-discharge threshold. At streamflow-gaging station, 09480000, Santa Cruz River near Lochiel, Arizona, the 100-year peak discharge for an unadjusted relation is $5,200 \mathrm{ft}^{3} / \mathrm{s}$, which is about one-half of the discharge for the relation with the low-discharge threshold adjustment (fig. 52). The unadjusted relation is far below the two largest annual peaks. No known physical characteristic of the drainage basin can explain the flattening of the flood-frequency relation for large floods. Also, the unadjusted relation has a 100 -year discharge that is about one-quarter of the discharge using a regional estimation procedure (Reich, 1988, p. 30). The use of the low-discharge threshold of $450 \mathrm{ft}^{3} / \mathrm{s}$, which is greater than 5 of the 41 annual peaks, results in a flood-frequency relation that better fits the data using a Cunnane plotting position. The default statistical adjustment for this station produced a satisfactory relation for the 2- to 100-year floods (Interagency Advisory Committee on Water Data, 1982, appendix 5); however, the computed skew coefficient was considered too negative, and the low-discharge threshold of $450 \mathrm{ft}^{3} / \mathrm{s}$ was used.

At streamflow-gaging station, 09513910, New River near Glendale, Arizona, use of a low-discharge threshold of $2,500 \mathrm{ft}^{3} / \mathrm{s}$ results in a change in the 100-year peak discharge from 75,100 $\mathrm{ft}^{3} / \mathrm{s}$ to $58,800 \mathrm{ft}^{3} / \mathrm{s}$ (fig. 53). The channel bed is permeable sand, and a large percentage of small peaks is lost to infiltration. No peaks were below the statistical threshold for the unadjusted relation and six peaks were below the low-discharge threshold of $2,500 \mathrm{ft}^{3} / \mathrm{s}$ for the adjusted relation. The adjusted relation more closely fits the large annual peaks including the historic peak that was outside the period of systematic record.

\section{High Outliers and Historical Periods}

High outliers can have a significant effect on computed flood-frequency relations at gaged sites. High outliers are large peak discharges that depart from the high end of a fitted flood-frequency relation. Gaging-station records with high outliers usually have a large positive skew coefficient and a large variance. Many large peaks that are part of the systematic record at gaging stations are high outliers because the large peak is the maximum for an extended period of time that is much longer than the period of systematic record. Flood-frequency relations fit to those samples often have large computed discharges for the infrequent floods and may not represent the true flood population. Large peaks that are considered high outliers can be adjusted by use of a historical period for which the peak is a maximum.

Seventeen percent or 178 of the gaged sites with defined flood-frequency relations had high outliers (table 23). The stations with a high outlier are identified in the data table under the heading "Relation Characteristics." Most of these outliers were statistically identified (Interagency Advisory Committee on Water Data, 1982, p. 17-19); however, about 10 percent of the outliers were defined visually by the observed departure from the fitted flood-frequency relation. Available information that often defines an extended period during which the high outlier floods are known to be maximum flows are included in the analysis. For example, if the outlier peak was the largest known flood for the past 75 years on the basis of reliable newspaper accounts, a historical period of 75 years would be used. A historical period was estimated for 124 (12 percent) gaged sites.

No pattern is apparent in the geographic distribution of gaging stations with high outliers (fig. 54). The percentage of high outliers in gaging-station records was compared to basin and 


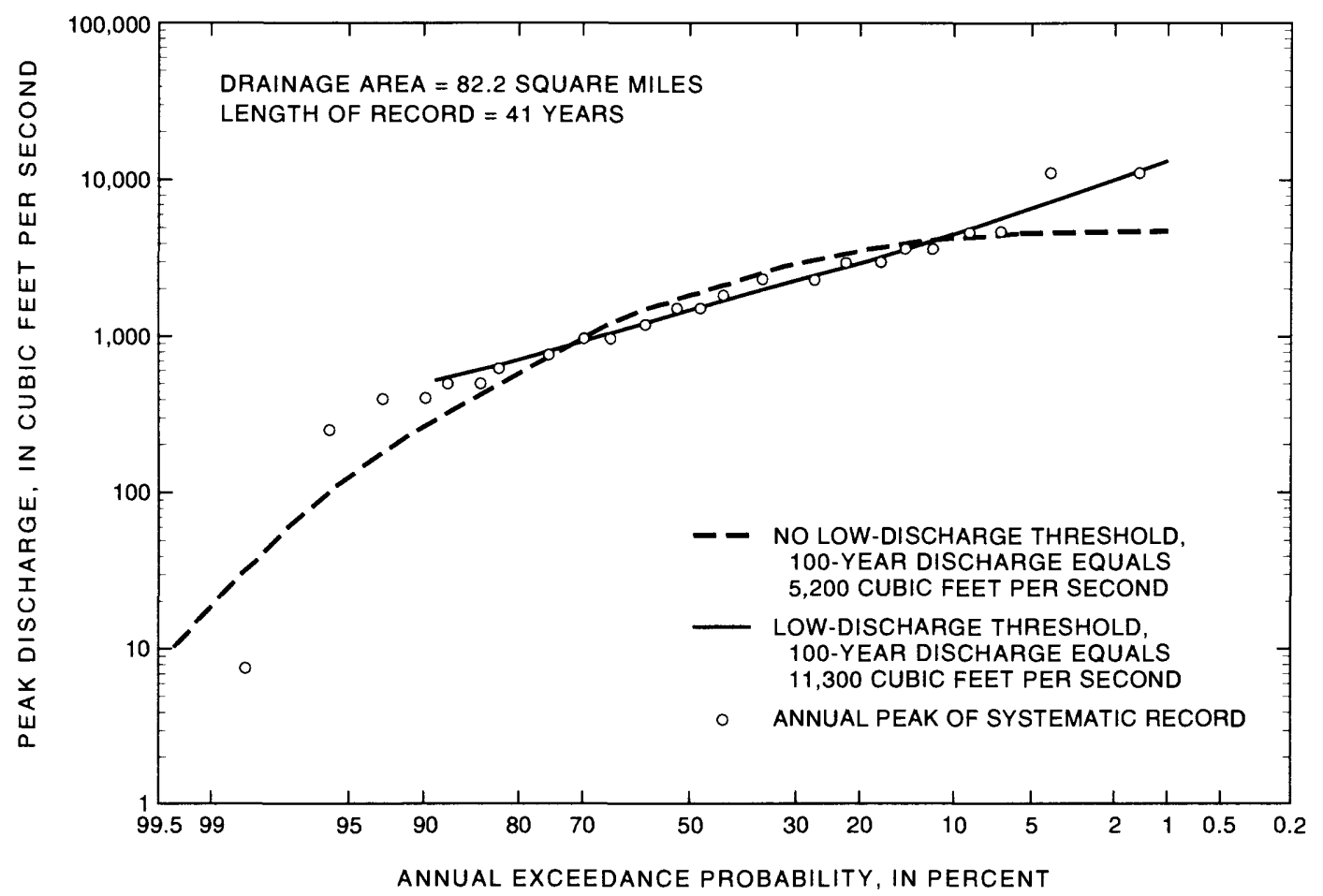

Figure 52. Flood-frequency relations for Santa Cruz River near Lochiel, Arizona (09480000).

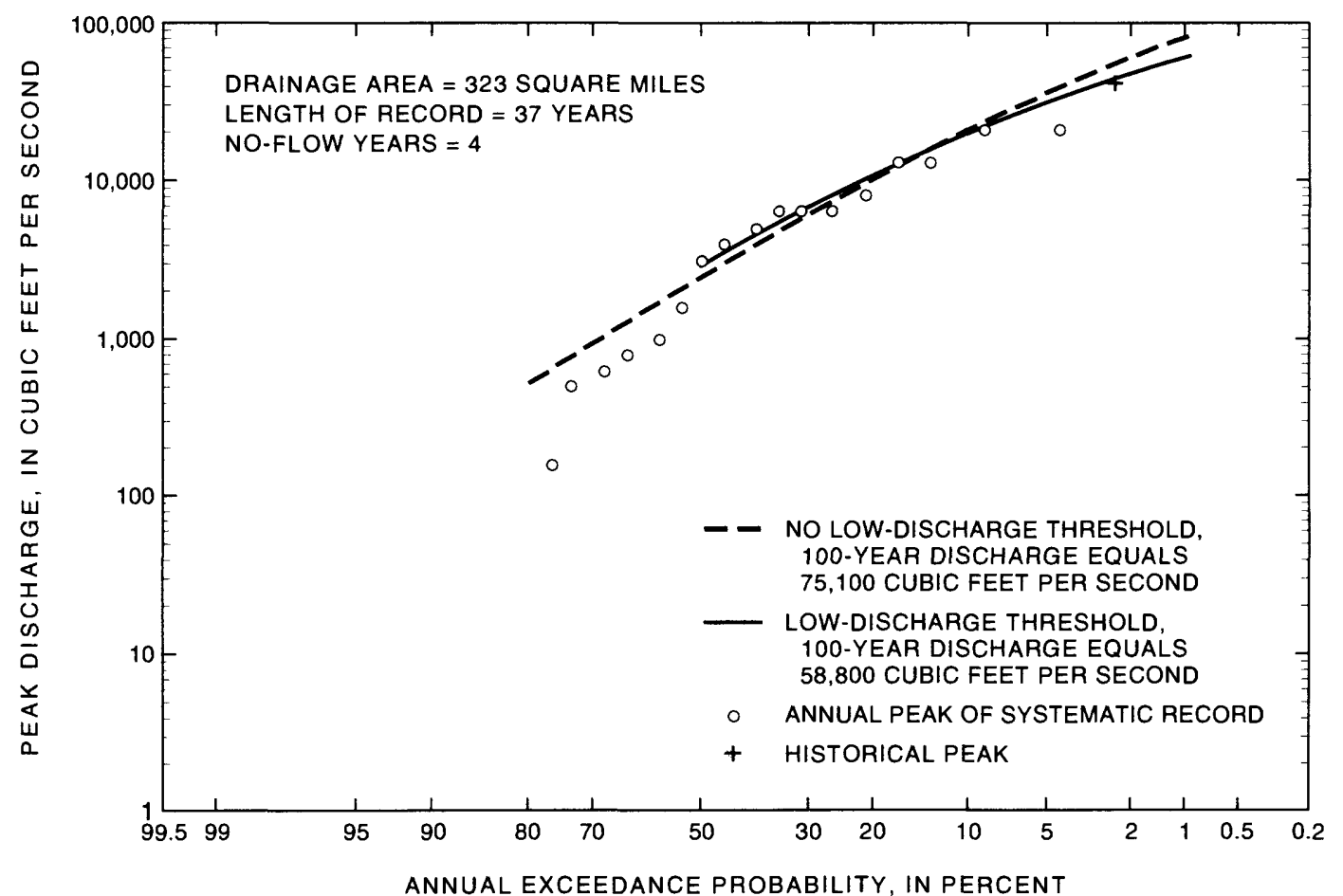

Figure 53. Flood-frequency relations for New River near Glendale, Arizona (09513910). 


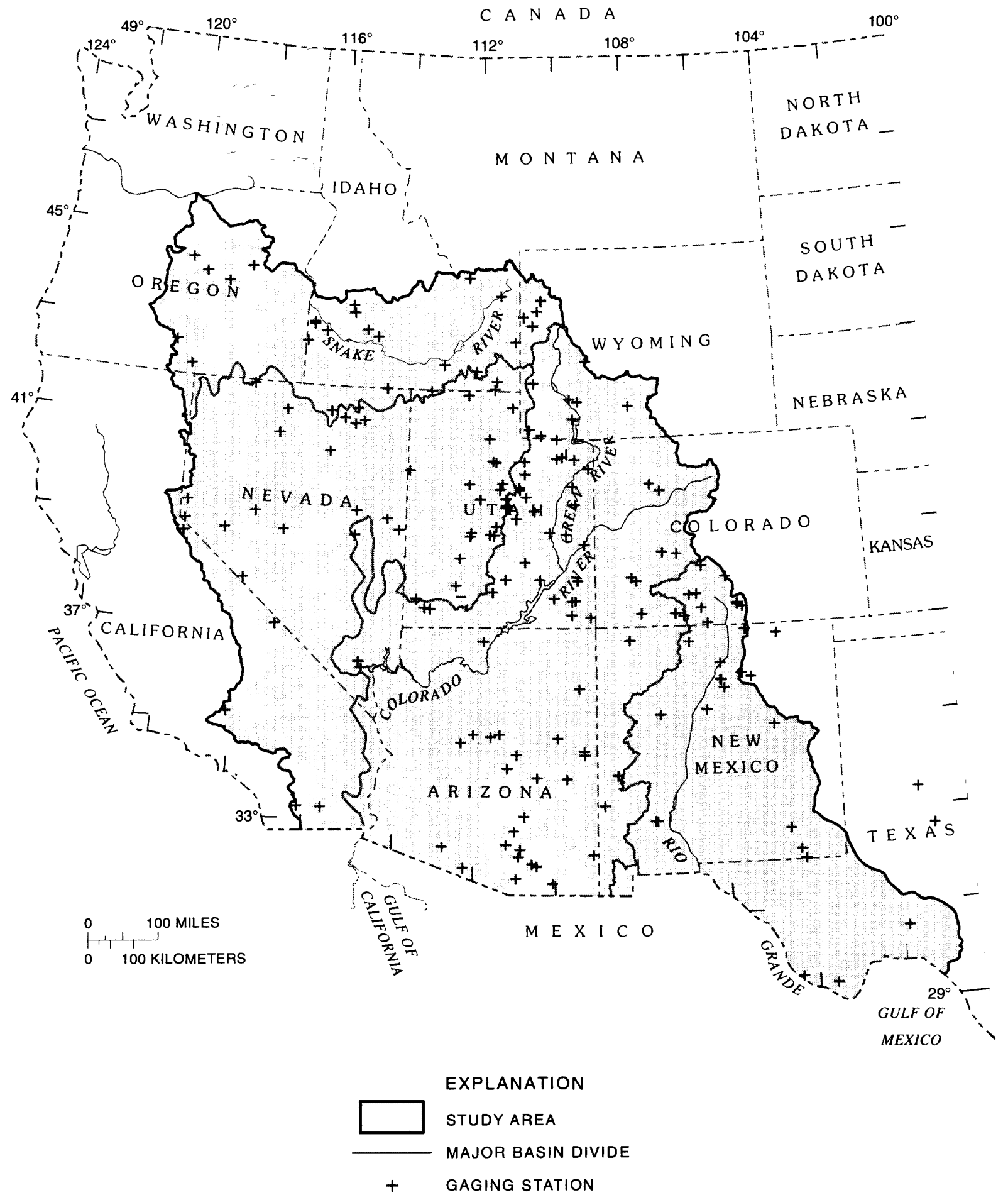

Figure 54. Gaging stations with a high outlier. 
climatic characteristics (table 24). Only drainage area had a significant relation $(\alpha=0.02)$, and that has no linear trend as seen by the percentage of stations for the three strata of drainage areas (table 24). High outliers, therefore, appear to be random and not related to some of the more important variables that are related to the magnitudes of floods.

Use of historical flood information, such as the historical or extended period outside the period of systematic record for outlier peaks, commonly is assumed to add information and improve the accuracy of flood-frequency relations. In this study, the exclusion of the outlier peaks would have had a significant effect on the regional relations. If the high outlier peaks are excluded, the average computed 100-year discharge for the 178 records is 38 percent smaller than the average computed 100 -year discharge with the high outliers included. The overall effect of the high outliers and the use of historical periods on the regional analysis were not investigated. Clearly, if the high outliers were excluded from the 178 records, estimated regional 100 -year discharges would be smaller than the estimated discharges using the high outliers; however, the magnitude of the effect on the regional relations is unknown. The high outliers were not excluded because of the recommendation to retain high outliers by Interagency Advisory Committee on Water Data (1982, p. 17).

\section{Sharp Breaks or Discontinuities in Plotted Peaks}

For most gaged sites in the study area, the series of annual peak discharges displayed on logarithmic normal probability paper were a straight line or a smooth curve. Two departures from this expected shape were identified in about 16 percent of the sites with defined flood-frequency relations. These sites had sharp breaks or discontinuities in the plot of peak discharges. One hundred sites had plotted peaks with a sharp break or dogleg appearance (table 23). A site with a sharp break, or "dogleg," in the plotted peaks has a lower and upper segment; the lower segment generally has a steeper slope than the upper segment. Thus, a sharp break is shown at the intersection of the two slopes. Sixty-eight sites had plotted peaks with a substantial discontinuity, or "jump," in the plotted peak discharges where two or more segments are displaced vertically (table 23 and fig. 55). The stations with a dogleg or jump in the plotted peaks are identified in the data table under the heading "Relation characteristics."

When plotted peaks have a dogleg shape and only a few small peaks are included in the lower segment, the small peaks can be truncated with the low-discharge threshold and a uniform relation can be fit to the data. The 100 sites classified as dogleg, however, either have the break in plotted peaks at a recurrence interval greater than 1.4 years, which is the limit for truncation with low-discharge threshold that was defined in this study, or a successive incremental application of a low-discharge threshold did not change the dogleg shape.

The cause of doglegs and jumps may be related to physical characteristics of the stream channel or drainage basin, types of storms causing floods, and instability of small sample sizes. Because of the nature of statistical samples, some of the log-normal probability plots for sites with short records might be expected to substantially depart from an expected smoother curve. As the sample size is increased, smoother plots might be expected. Therefore, the frequency of doglegs and jumps was compared to record length, but no significant relation was found for the sites in this study area.

Dogleg shapes may be caused by attenuation of peak discharge because of stream-channel characteristics, such as channels with bed material that have high infiltration rates, or wide channels, or small channels with wide flood plains. Causes of jumps in a record may be mixed flood populations, such as floods from snowmelt or summer thunderstorms, and different flood populations caused by the different effects of the watershed on small or large peaks.

No pattern is apparent in the geographic distribution of gaging stations with doglegs and jumps (fig. 56). The percentage of doglegs or jumps in station records was compared to basin and climatic characteristics (table 24). The percentage of doglegs increases with increasing size of drainage area, possibly because of the increasing 


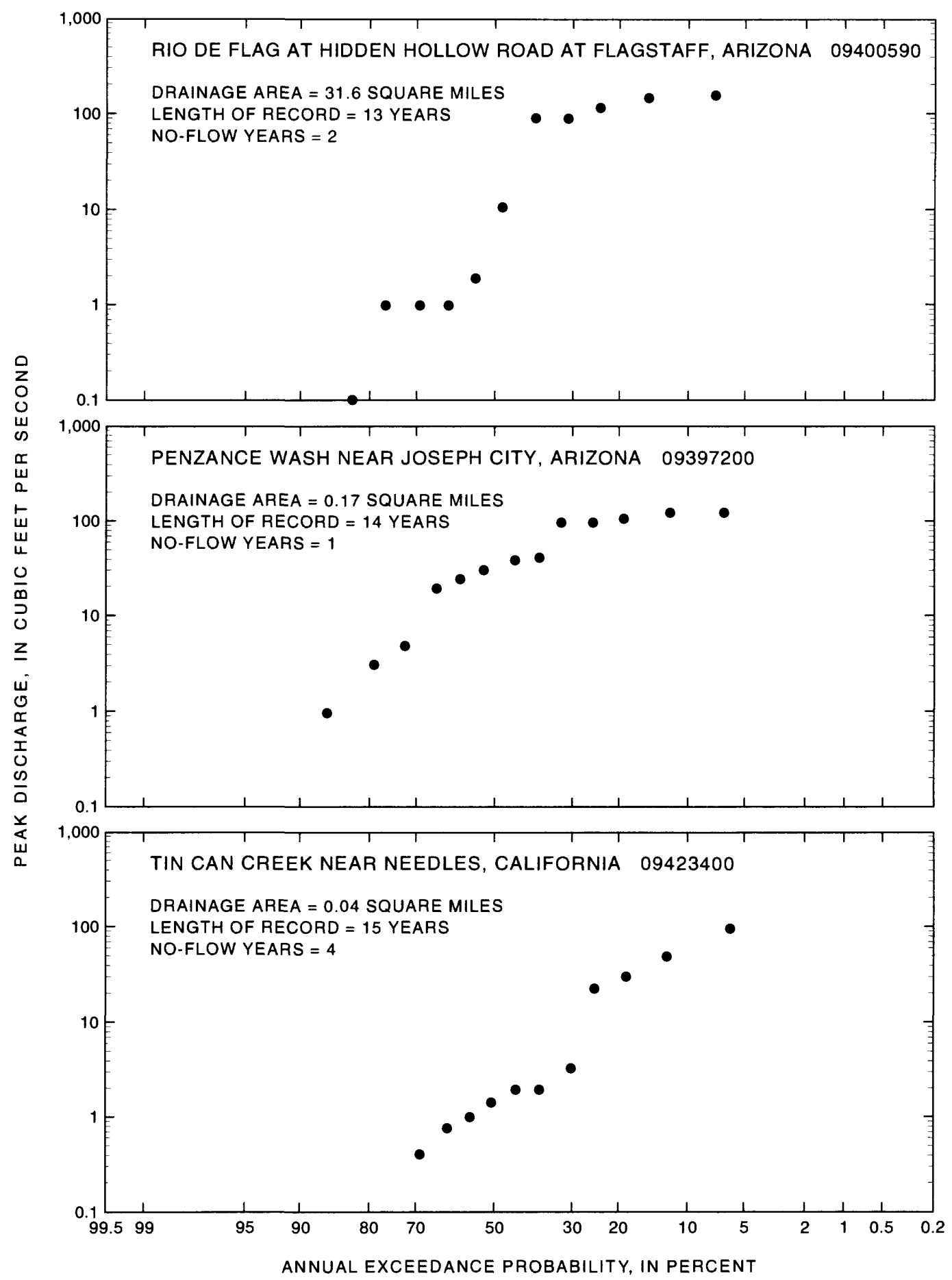

Figure 55. Examples of gaging-station records with sharp breaks or discontinuities in their plotted peaks. 


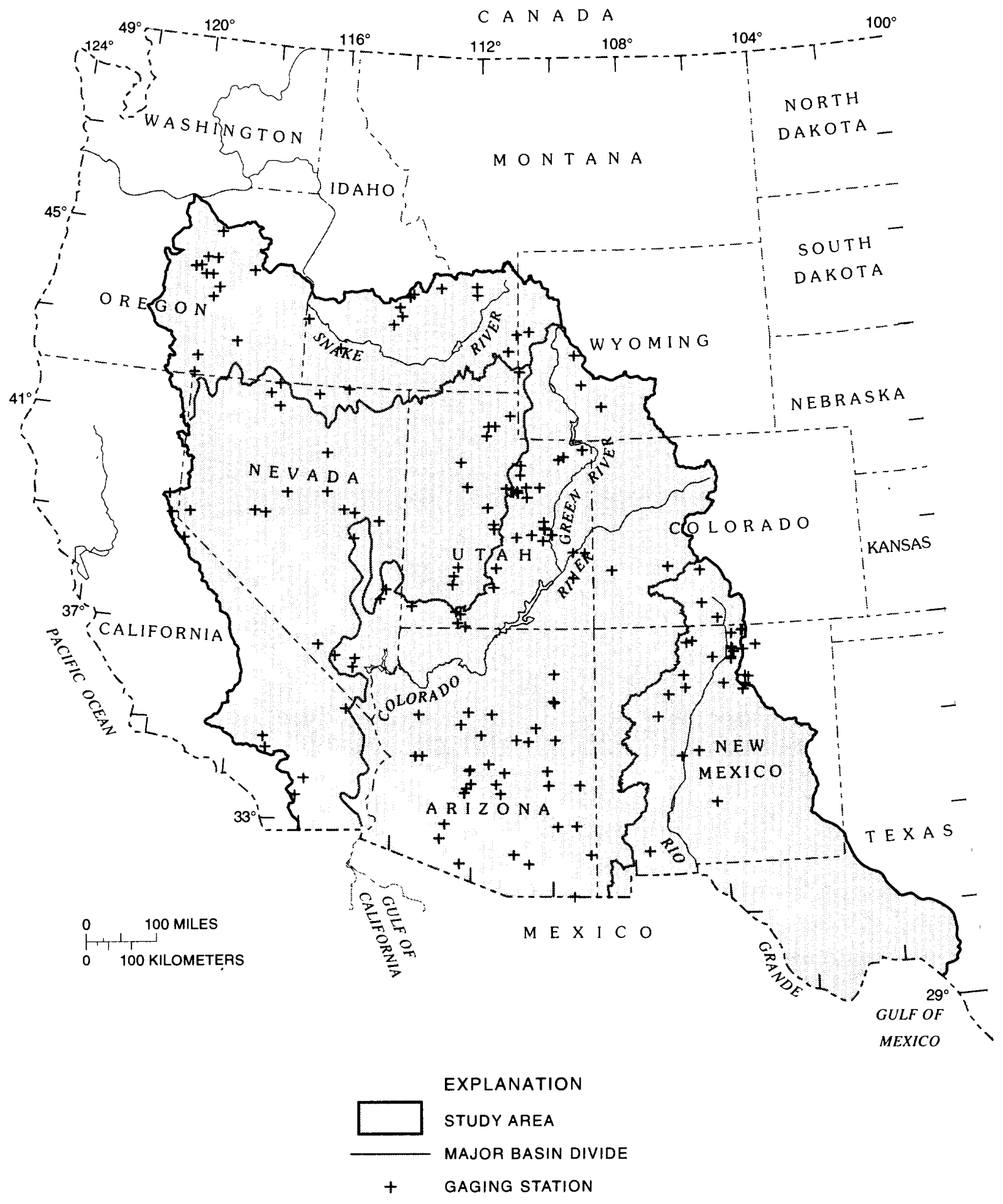

Figure 56. Gaging stations with sharp breaks or discontinuities in their plotted peaks. 
opportunity for attenuation of small peaks. The percentage of jumps decreases with increasing amounts of mean annual precipitation. This relation may be a function of mixed populations. Stations in areas with mean annual precipitation of greater than 25 in. usually have frequency relations dominated by snowmelt runoff and little influence of mixed populations. The percentage of doglegs also is smaller in the middle latitudes although the reason is unknown. Evaluation of the reliability of a flood-frequency relation fit to a gaged record with plotted peak discharges that have dogleg or jump shapes is difficult. The records, therefore, were identified and used in the regional flood-frequency analysis.

The accuracy of the annual peak-discharge data was examined for several stations with plots of peaks that had the largest departures from an expected smooth shape. For most of these stations, the stage-discharge relations used to determine peak discharges were poorly defined. Several of the ratings were for unstable channel controls, or were improperly fitted to the measurements of discharge, or the measurements of discharge used to define the rating appeared to be inaccurate. For some stations, a discontinuity of the rating curve coincided with a discontinuity of the plot of annual peak discharges on logarithmic normal probability paper. For other stations, the indirect measurements of peak discharge used to define the rating were made in unstable channels that probably scoured during the peak and subsequently filled when the measurement was made. For a few stations, indirect measurements of peak discharge may have been made for debris flows. For one station, a wide inundated flood plain that was beyond the end of the measuring cableway was incorrectly assumed to have negligible flow velocity. Twelve stations were excluded from this study because a significant number of annual peaks were considered unreliable. Those stations are 08351500, 09279100, 09336000, 09355000, 09371000, 09419660, 09482000, 10241600, $10253350,10255810,13027500$, and 13061100 .

\section{Gaged Sites with Inadequate Samples or Non-Log-Pearson Type III Distribution}

Detailed investigations were made of the flood-frequency relations computed for the 1,323 gaging-station records. For 264 station records, a visual examination showed extremely poor fits of the LPIII probability distribution to the plotted annual peak discharges. Four examples of these poor fits are shown in figure 57. Flood-frequency relations computed from the data do not fit the plotted data, and the relations are much different from regional relations computed for the sites. The variability of the annual peak discharges is extremely large at most of these stations. The average standard deviation for the 264 records is $0.88 \mathrm{log}$ units. The average standard deviation of the 1,059 stations with defined relations is $0.37 \mathrm{log}$ units. An additional problem in defining relations is a short average record length of 17 years. The relations that were computed for the annual series of peak discharges are unreliable especially for extrapolations to the 100-year flood. The computed 95-percent confidence interval typically is 2 to 3 orders of magnitude for these stations.

Most of these sites that had no defined flood-frequency relations are in the most arid parts of the study area including most of Nevada, southeastern California, and southwestern Arizona (fig. 58). Of 264 stations, 42 percent had more than 25 percent of the years with no flow, and 15 percent had more than 50 percent of the years with no flow. The procedures defined in Interagency Advisory Committee on Water Data (1982, p. 5-1) for computing flood-frequency relations are not recommended when more than 25 percent of a gaged record has no flow.

The percentage of gaging stations with undefined flood-frequency relations was compared to basin and climatic characteristics (table 25). Significantly more $(\alpha<0.01)$ undefined relations were found at sites with smaller drainage areas, sites in the lower latitudes, sites with lower elevations, sites with lower mean annual precipitation, and sites with higher mean annual evaporation. At the 264 undefined sites, no convincing evidence exists that the plot of annual peak discharges can be fit by the LPIII probability distribution. The records may be insufficient in length and too unstable to define a relation. The sites, therefore, are classified as having inadequate samples or non-LPIII distribution. Flood-frequency relations for these sites are considered unreliable and were not used in the standard regional 

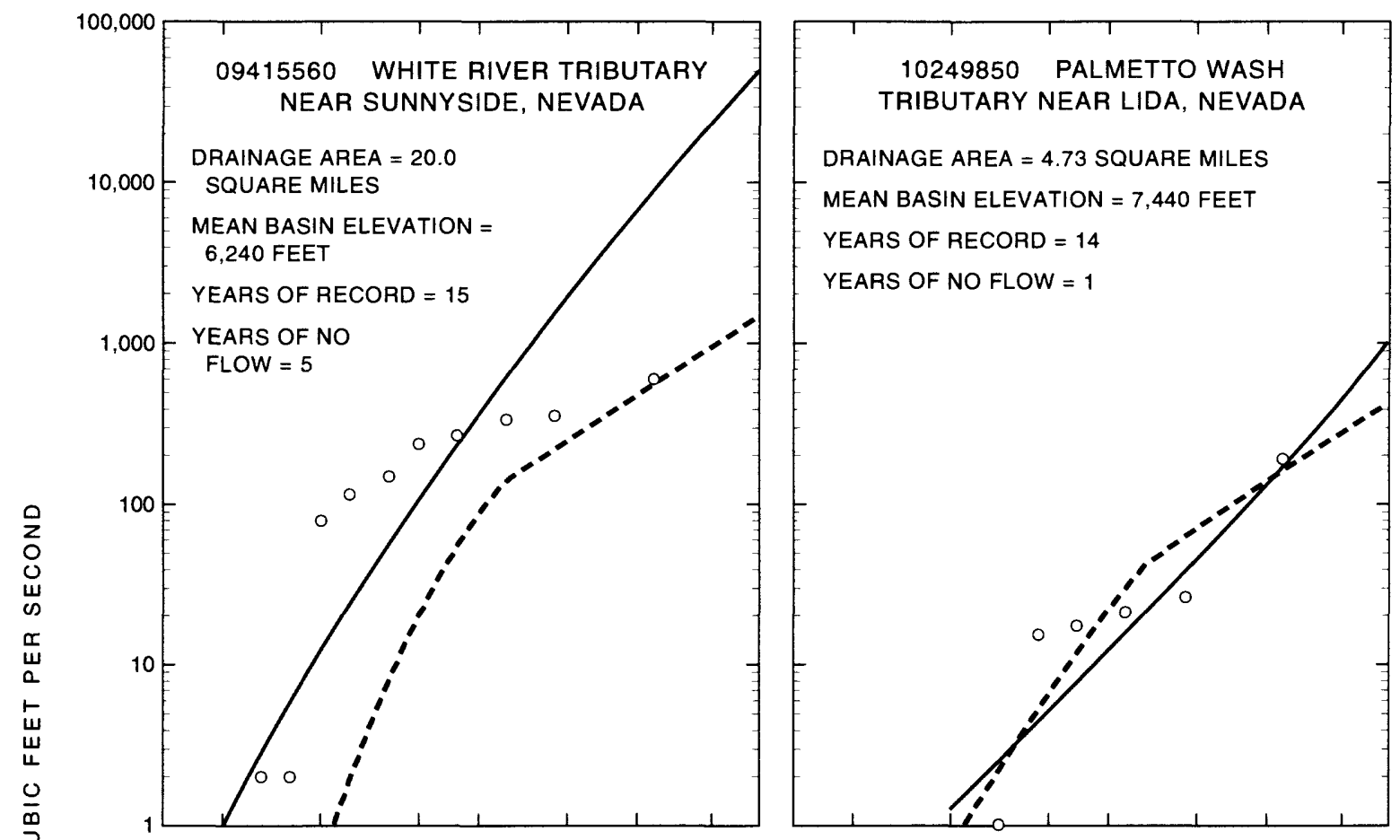

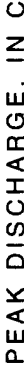
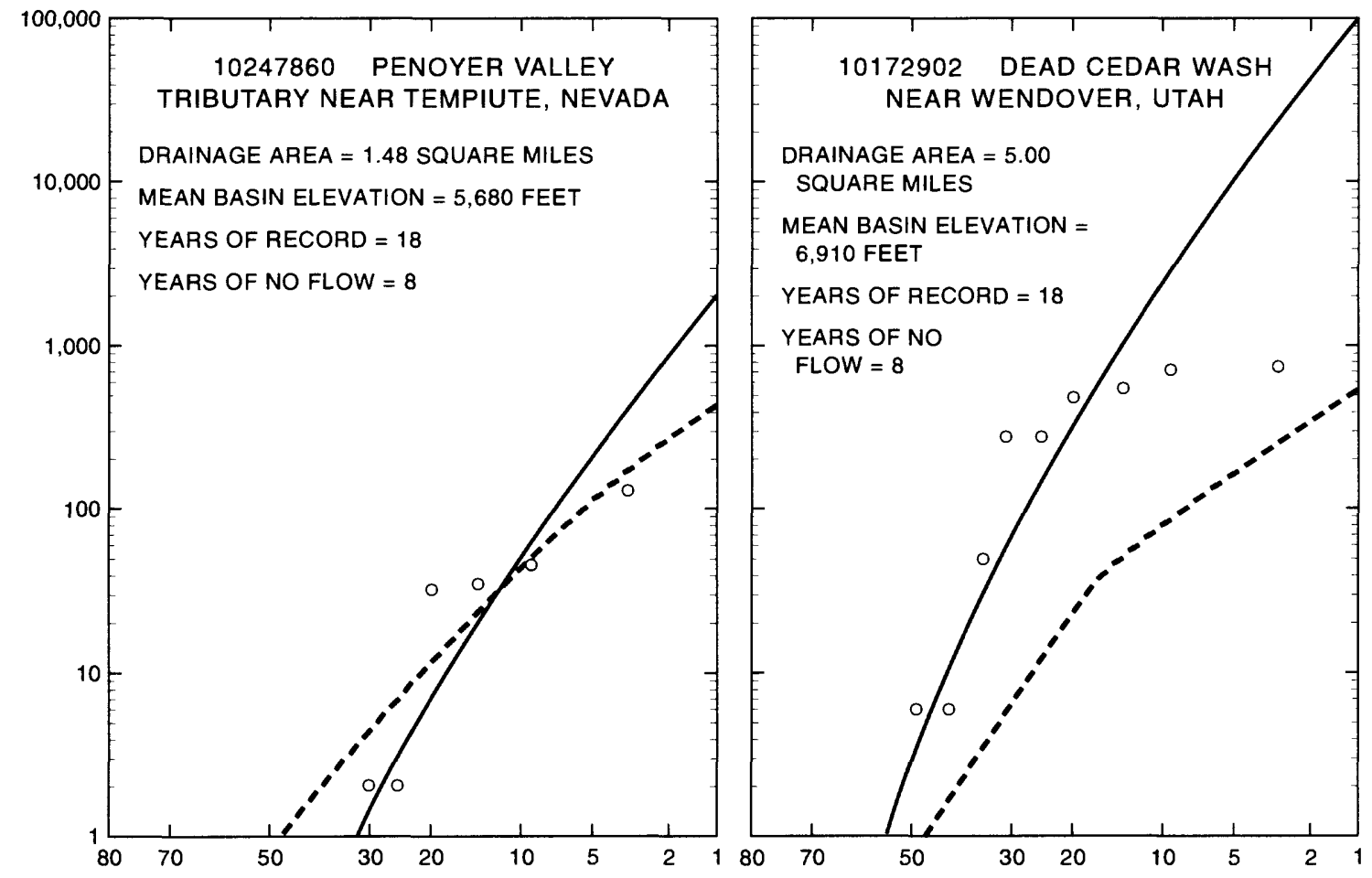

ANNUAL EXCEEDANCE PROBABILITY, IN PERCENT

EXPLANATION

$$
\begin{aligned}
& \text { LOG-PEARSON TYPE III FITTED } \\
& \text { RELATION-Interagency Advisory } \\
& \text { Committee on Water Data (1982) }
\end{aligned}
$$

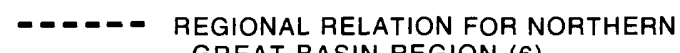
GREAT BASIN REGION (6)

Figure 57. Examples of plotted peaks for gaging stations with samples that are inadequate to define a flood-frequency relation. 

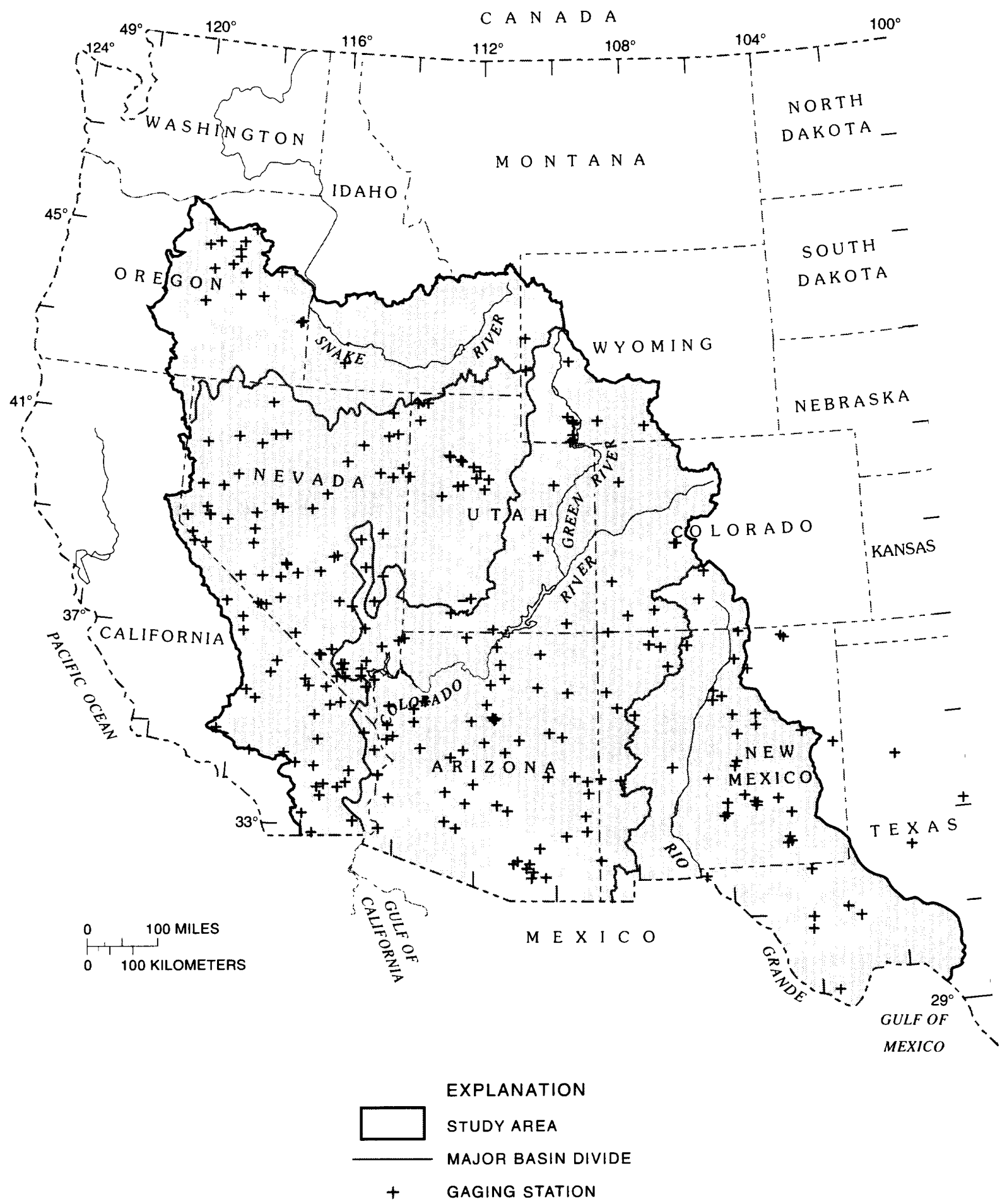

Figure 58. Gaging stations with samples that are inadequate to define a flood-frequency relation. 
Table 25. Percentage of gaging stations with undefined flood-frequency relations compared to basin and climatic characteristics in the southwestern United States

[ANOVA, analysis of variance significance level. The gaging stations were coded with a 1 if the attribute is present and a 0 if the attribute is not present. The mean of the 1's and 0's in each class of basin or climatic characteristic is the percentage of the attributes in each class. An ANOVA was performed on the three classes to test if there is a significant difference in means (percentages) between the three groups (three classes of basin or climatic characteristic)]

\begin{tabular}{|c|c|c|c|}
\hline Class & $\begin{array}{c}\text { Number of } \\
\text { statlons }\end{array}$ & $\begin{array}{l}\text { Percent- } \\
\text { age of sta- } \\
\text { tlons with } \\
\text { undeflned } \\
\text { flood- } \\
\text { frequency } \\
\text { relatlons }\end{array}$ & $\begin{array}{c}\text { ANOVA } \\
\text { sIgnifl- } \\
\text { cance } \\
\text { level }\end{array}$ \\
\hline \multicolumn{4}{|c|}{ Drainage area, in square miles } \\
\hline Less than 50 & 756 & 29 & \\
\hline 50 to 200 & 293 & 9 & $<0.01$ \\
\hline More than 200 & 274 & 7 & \\
\hline \multicolumn{4}{|c|}{ Latitude, in degrees } \\
\hline Less than 37 & 559 & 27 & \\
\hline 37 to 41 & 482 & 16 & $<.01$ \\
\hline More than 41 & 282 & 13 & \\
\hline \multicolumn{4}{|c|}{ Mean basin elevation, in feet } \\
\hline Less than 6,000 & 408 & 30 & \\
\hline 6,000 to 8,000 & 471 & 19 & .01 \\
\hline More than 8,000 & 381 & 5 & \\
\hline \multicolumn{4}{|c|}{ Mean annual precipitation, in inches } \\
\hline Less than 16 & 535 & 33 & \\
\hline 16 to 25 & 442 & 8 & $<.01$ \\
\hline More than 25 & 266 & 5 & \\
\hline \multicolumn{4}{|c|}{ Mean annual evaporation, in inches } \\
\hline Less than 40 & 421 & 9 & \\
\hline 40 to 55 & 541 & 21 & $<.01$ \\
\hline More than 55 & 361 & 32 & \\
\hline
\end{tabular}

regression analysis. Data from many of these sites, however, were used in the hybrid analysis, which developed regional relations for Regions 6, 10, 11, and 16.

\section{Mixed Populations}

More than 80 percent of the sites in the study area have a mixed population of floods. Populations of floods were identified by the time of year that the annual floods occurred. A mixed population of floods is an aggregation of floods that are caused by two or more distinct and generally independent hydrometeorologic conditions. Populations in the study area include floods caused by snowmelt, rainfall, and rainfall on snow. Rainfall is caused by summer thunderstorms, winter midlatitudecyclonic storms, winter upper-level low-pressure systems, or tropical cyclones.

When a sample of annual peaks contains a mixed population, a single flood-frequency relation can be much different from a compositional relation (Webb and Betancourt, 1992). The computed differences in the mean, variance, and skew (moments) of each population cause this distortion. Differences in moments between two populations in a gaging-station record may result in relations with abnormally large skew coefficients and abnormal slope changes when plotted on logarithmic normal-probability paper (Interagency Advisory Committee on Water Data, 1982, p. 16). A method that can be used to account for mixed populations is the composite-probability analysis.

In a composite-probability analysis, an annual peak discharge is determined for each population and a separate flood-frequency relation is computed for each population. The relations are combined using a formula for the probability distribution of the maximum of independent random variables. The formula for computing a composite relation for two populations of floods is as follows (Crippen, 1978):

$$
P_{C}(x)=P_{A}(x)+P_{B}(x)-P_{A}(x) P_{B}(x),
$$

where

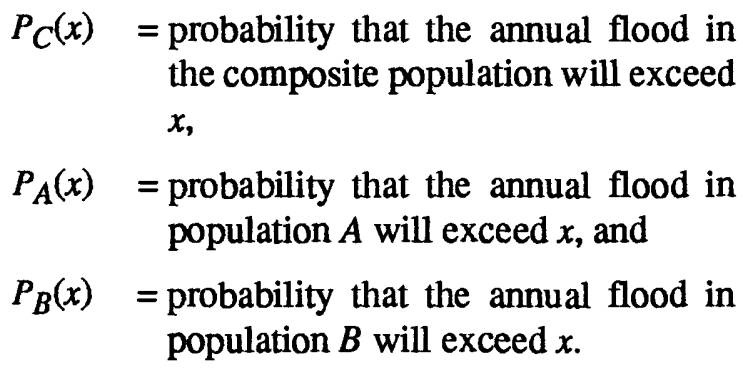

The significance of mixed populations on the flood-frequency relations computed for sites in the study area is uncertain. At some sites with a certain combination of samples of populations, the 
composite relation will be significantly different from the relation computed from the annual maximum peaks (mixed population); however, at many sites, the two relations will be similar.

To estimate the significance of the mixed-population problem, composite analyses were made of many representative sites with a combination of floods caused by snowmelt and floods caused by rainfall from summer thunderstorms. The snowmelt and summer thunderstorm populations were selected for analysis because that combination is the most common in the study area. Jarrett and Costa (1982) and Thomas (1985) found that a composite flood-frequency relation for that combination may be significantly different from the relation based on annual maximum peaks (mixed population).

About 50 percent of the sites in the study area have a mixed population of floods caused by snowmelt and summer thunderstorms. These sites occur throughout the study area mostly in an elevation zone (fig. 59) between mountainous areas and the plains or plateau areas. Above the elevation zone, flood characteristics are dominated by snowmelt runoff; below the elevation zone, flood characteristics are dominated by thunderstorms (McCain and Jarrett, 1976, p. 31; Thomas, 1985, p. 382). The upper-elevation limit for sites with mixed populations is near or above the previously estimated upper limit for large thunderstorm-caused floods. The elevation zone of the mixed population in the southern latitudes is about 6,200 to $8,200 \mathrm{ft}$. In the northern latitudes, the elevation zone decreased to about 4,500 to $6,500 \mathrm{ft}$. About 35 percent of the sites in the study area are in this mixed-population elevation zone.

The elevation zone for the mixed population contains most of the sites that have the potential for significantly different composite and annual maximum flood-frequency relations. Within and neartheelevation zone, 51 gaged sites with more than 20 years of record that had drainage areas that ranged from 2 to $1,100 \mathrm{mi}^{2}$ were selected (table 26, fig. 60). Composite relations were computed for the 51 sites, which are about 14 percent of the sites in the elevation zone. Most of the sites are in northerm and central New Mexico, southwestern Colorado, and Utah.

In the composite analysis, the rainfall peaks were estimated from the annual peak-discharge records with peaks above a base. Missing peaks were accounted for by using a conditional probability adjustment. Snowmelt peaks were estimated from the same records, and peaks below the base discharge were estimated as mean daily discharges from historical records. The relations for rainfall, snowmelt, and annual maximum peaks were computed using a station skew coefficient. The Interagency Advisory Committee on Water Data (1982) recommends weighting the station skew with a generalized skew when computing station flood-frequency relations. The purposes of this study, however, which were to compare differences in composite and mixed relations, are adequately served by using station skews.

Typical differences in flood-frequency relations between sites above, in, and below the mixed-population elevation zone are described in the following three examples. A typical high-elevation site with snowmelt runoff is South Fork of Rock Creek near Hanna, Utah (09278000), which has a drainage area of $15.7 \mathrm{mi}^{2}$ and a site elevation of $7,860 \mathrm{ft}$ (fig. 61). Floods caused by snowmelt represent 90 percent of the record. In the frequency relations, the magnitude of the snowmelt relation is greater than the rainfall relation until a recurrence interval of greater than 100 years (exceedance probability of 0.01 ) where the curves would cross. The computed relation using the array of annual maximum peaks is adequate until the curves intersect. Thus, estimates of floods with recurrence intervals of greater than 100 years may need a composite relation.

A middle-elevation site that has a mixed population of rainfall and snowmelt peaks is Big Creek near Randolf, Utah (10023000), which has a drainage area of $52.2 \mathrm{mi}^{2}$ and a site elevation of $6,410 \mathrm{ft}$ (fig. 62). The magnitudes and distributions of the rainfall and snowmelt peaks are mixed with 31 percent caused by rainfall and 69 percent caused by snowmelt. About one-half of the largest 25 percent of the peaks were caused by rainfall and the largest peak was caused by rainfall. The composite 


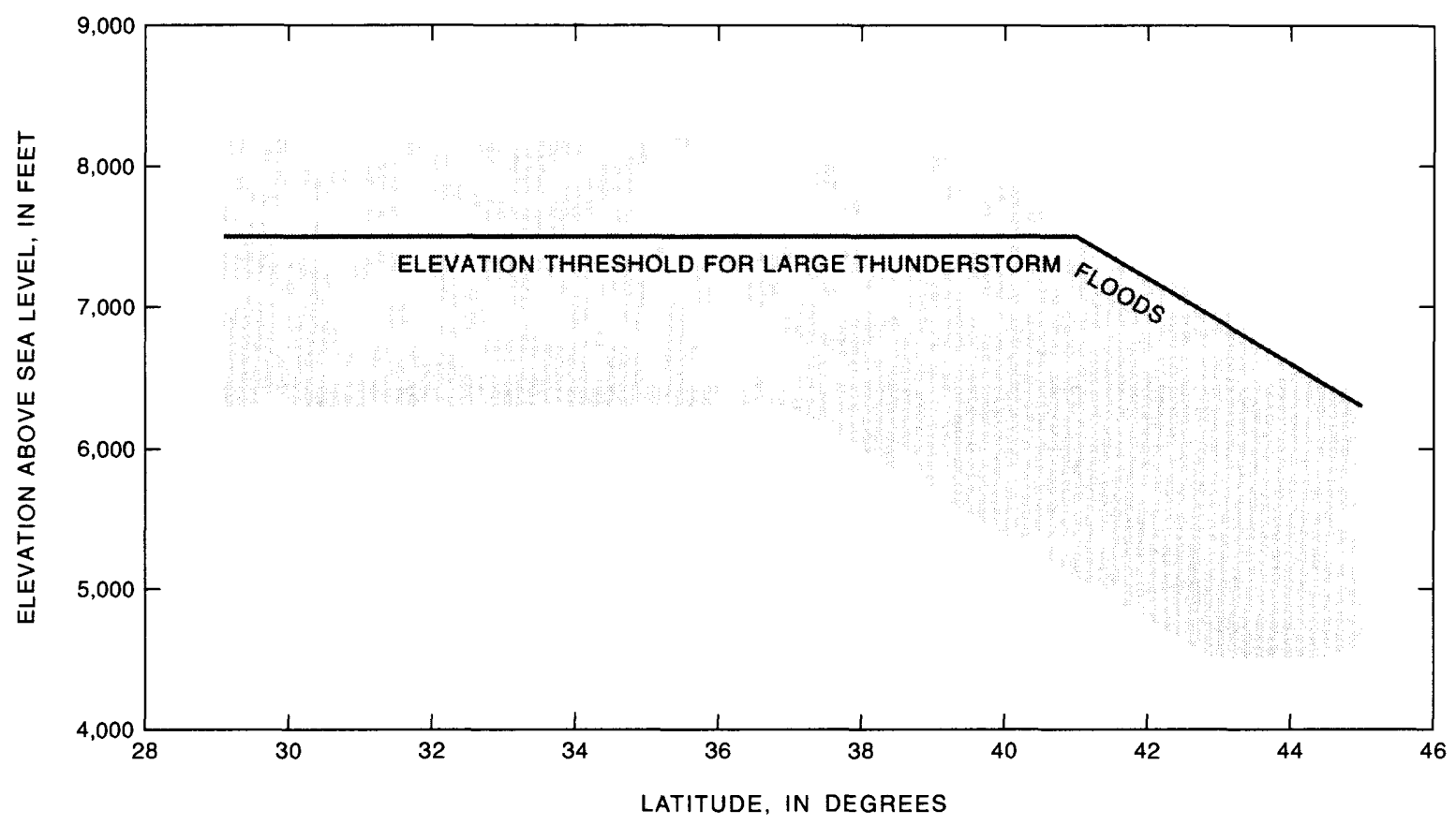

Figure 59. Elevation zone for mixed population of floods caused by thunderstorms and snowmelt in the southwestern United States.

100 -year peak is 26 percent larger than the 100 -year peak based on annual maximum peaks. In this particular case, the composite relation is a more accurate depiction of the flood characteristics than the annual maximum relation.

A typical low-elevation site that had runoff dominated by rainfall is Mill Creek near Moab, Utah (09184000), which has a drainage area of 74.9 $\mathrm{mi}^{2}$ and a site elevation of $4,240 \mathrm{ft}$ (fig. 63). Peaks caused by rainfall represent 84 percent of the record. The rainfall and composite relation are mostly coincident and are greater than the snowmelt relation for all recurrence intervals. The composite relation is not needed for such low-elevation sites.

The ratio of the 100-year composite peak to the 100-year annual maximum peak (mixed) for the 51 analyzed sites was used to evaluate the significance of the composite analysis. A significant difference between the composite relation and mixed relation may be at the 50- to 100-year recurrence intervals where there is a greater influence of the potential difference in mean, variance, and skew of the two populations. The difference between relations usually is not significant for the 2- to 25-year recurrence intervals. The 100-year composite peak discharges were greater than the annual maximum peak discharges for 36 sites. Statistics for the composite to annual maximum ratio are a mean of 1.08 , median of 1.04 , and a standard deviation of 0.13 . The composite 100-year peaks, although systematically larger than the annual maximum 100-year peaks, are only an average of 8 percent larger. This difference is considered small because of all the uncertainties inherent in flood-frequency analysis.

Jarrett (1987) examined 29 streamflow-gaging station records for mixed populations in the Colorado River basin (part of this study area). The average ratio of composite 100 -year peak to annual maximum 100-year peak for the 29 stations was 1.12 and is similar to the average ratio of 1.08 in this 

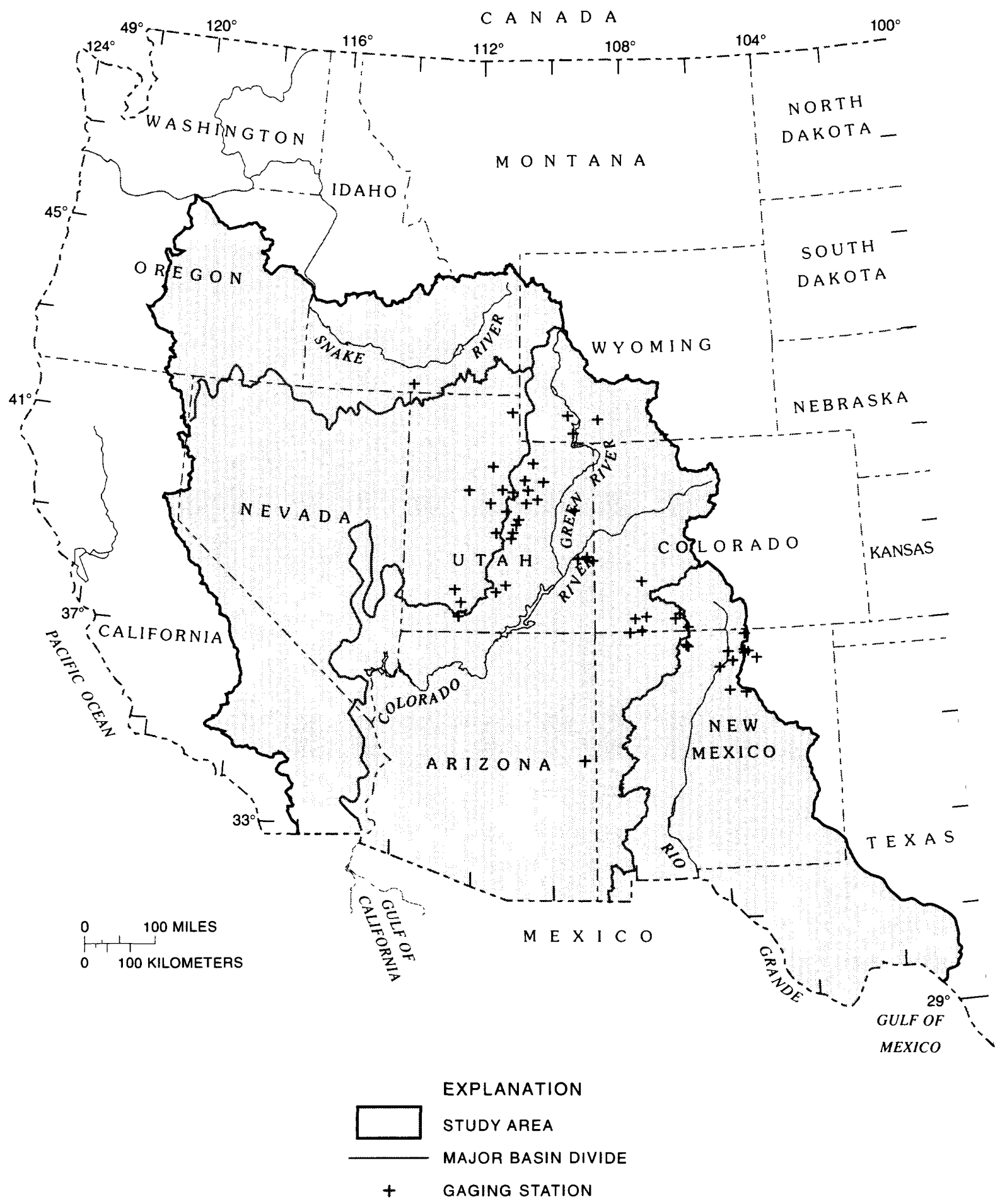

Figure 60. Gaging stations with an analysis for a mixed population of floods caused by thunderstorms and snowmelt. 
Table 26. Summary of analyses of mixed-population flood records in the southwestern United States

\begin{tabular}{|c|c|c|c|c|c|c|c|}
\hline \multirow{2}{*}{$\begin{array}{l}\text { Station } \\
\text { number }\end{array}$} & \multirow{2}{*}{$\begin{array}{c}\text { Drain- } \\
\text { age area, } \\
\text { in square } \\
\text { miles }\end{array}$} & \multirow{2}{*}{$\begin{array}{c}\text { Site } \\
\text { elevation, in } \\
\text { feet }\end{array}$} & \multicolumn{4}{|c|}{ 100-year peak discharge, in cubic foet per second } & \multirow{2}{*}{$\begin{array}{c}\text { Ratio of } \\
\text { composite to } \\
\text { annual } \\
\text { maximum }\end{array}$} \\
\hline & & & Rainfall & Snowmelt & $\begin{array}{l}\text { Com- } \\
\text { posite }\end{array}$ & $\begin{array}{c}\text { Annual } \\
\text { maximum }\end{array}$ & \\
\hline 07204000 & 73.8 & 8,197 & 301 & 234 & 320 & 298 & 1.07 \\
\hline 07204500 & 56.0 & 8,195 & 650 & 650 & 760 & 741 & 1.03 \\
\hline 07206400 & 7.4 & 7,860 & 240 & 65 & 240 & 186 & 1.29 \\
\hline 07208500 & 65.0 & 6,720 & 3,060 & 1,260 & 3,300 & 3,000 & 1.10 \\
\hline 08252500 & 25.1 & 9,429 & 1,140 & 308 & 1,140 & 1,070 & 1.07 \\
\hline 08268500 & 65.6 & 6,670 & 1,290 & 706 & 1,290 & 1,250 & 1.03 \\
\hline 08275600 & 37.0 & 7,223 & 590 & 447 & 680 & 572 & 1.19 \\
\hline 08279000 & 305.0 & 5,859 & 3,710 & 2,400 & 3,710 & 3,740 & .99 \\
\hline 08284300 & 45.0 & 7,189 & 4,820 & 2,300 & 4,820 & 4,500 & 1.07 \\
\hline 08284500 & 193.0 & 6,945 & 3,890 & 4,750 & 5,500 & 5,450 & 1.01 \\
\hline 08378500 & 189.0 & 7,503 & 3,070 & 2,390 & 3,400 & 3,400 & 1.00 \\
\hline 08381000 & 87.0 & 6,675 & 7,100 & 1,750 & 7,100 & 6,070 & 1.17 \\
\hline 09146400 & 14.1 & 8,400 & 349 & 160 & 349 & 295 & 1.18 \\
\hline 09177500 & 12.0 & 8,120 & 882 & 811 & 1,060 & 959 & 1.11 \\
\hline 09182000 & 7.6 & 7,070 & 47 & 37 & 51 & 51 & 1.00 \\
\hline 09184000 & 74.9 & 4,240 & 12,000 & 1,200 & 12,000 & 12,500 & .96 \\
\hline 09216600 & 7.9 & 6,300 & 1,020 & 135 & 1,020 & 982 & 1.04 \\
\hline 09224820 & 3.6 & 6,200 & 763 & 36 & 763 & 770 & .99 \\
\hline 09225200 & 6.6 & 6,200 & 839 & 325 & 860 & 865 & .99 \\
\hline 09278000 & 15.7 & 7,860 & 200 & 240 & 250 & 250 & 1.00 \\
\hline 09288000 & 140.0 & 6,670 & 1,000 & 1,020 & 1,250 & 1,320 & .95 \\
\hline 09288150 & 56.1 & 6,790 & 3,530 & 988 & 3,530 & 3,170 & 1.11 \\
\hline 09288500 & 950.0 & 5,512 & 2,810 & 3,720 & 3,900 & 3,850 & 1.01 \\
\hline 09307500 & 297.0 & 6,000 & 2,450 & 500 & 2,450 & 2,410 & 1.02 \\
\hline 09308500 & 32.0 & 7,190 & 1,830 & 1,290 & 2,220 & 2,410 & .92 \\
\hline 09313000 & 415.0 & 6,000 & 9,570 & 2,610 & 9,700 & 9,330 & 1.04 \\
\hline 09318000 & 190.0 & 6,210 & 2,920 & 1,700 & 2,920 & 2,620 & 1.11 \\
\hline 09324500 & 208.0 & 6,050 & 5,620 & 2,760 & 5,620 & 4,860 & 1.16 \\
\hline 09326500 & 138.0 & 6,210 & 4,370 & 2,050 & 4,370 & 3,920 & 1.11 \\
\hline 09330500 & 105.0 & 6,400 & 3,520 & 2,430 & 4,100 & 4,110 & 1.00 \\
\hline 09337000 & 68.1 & 6,400 & 1,700 & 493 & 1,700 & 1,790 & .95 \\
\hline 09338500 & 1.9 & 8,600 & 957 & 267 & 957 & 774 & 1.24 \\
\hline 09340000 & 86.9 & 7,598 & 2,250 & 2,340 & 2,650 & 2,620 & 1.01 \\
\hline 09342500 & 298.0 & 7,052 & 15,700 & 7,280 & 15,700 & 15,600 & 1.01 \\
\hline 09344000 & 69.8 & 7,941 & 1,460 & 1,360 & 1,500 & 1,650 & .91 \\
\hline 09363000 & 97.4 & 7,302 & 3,440 & 2,370 & 3,440 & 3,340 & 1.03 \\
\hline 09363500 & 1,090 & 5,960 & 13,300 & 15,100 & 15,800 & 15,700 & 1.01 \\
\hline 09365500 & 37.0 & 8,105 & 1,850 & 1,430 & 1,940 & 1,800 & 1.08 \\
\hline 09366500 & 331.0 & 5,975 & 6,620 & 2,140 & 6,620 & 5,900 & 1.12 \\
\hline 09384000 & 747.0 & 6,010 & 12,100 & 4,090 & 12,100 & 10,700 & 1.13 \\
\hline 09404450 & 69.2 & 5,900 & 1,610 & 895 & 1,800 & 1,490 & 1.21 \\
\hline 10023000 & 52.2 & 6,410 & 444 & 221 & 444 & 352 & 1.26 \\
\hline 10146000 & 95.6 & 5,280 & 1,010 & 754 & 1,120 & 1,090 & 1.03 \\
\hline 10148200 & 19.4 & 6,120 & 990 & 126 & 1,000 & 1,020 & .98 \\
\hline 10148500 & 490.0 & 5,027 & 1,250 & 1,600 & 1,700 & 1,730 & .98 \\
\hline 10165500 & 9.8 & 5,320 & 685 & 365 & 685 & 570 & 1.20 \\
\hline 10172700 & 25.0 & 6,200 & 1,500 & 470 & 1,500 & 870 & 1.72 \\
\hline 10210000 & 16.4 & 6,760 & 2,660 & 436 & 2,660 & 2,160 & 1.23 \\
\hline 10216400 & 59.4 & 6,000 & 2,120 & 993 & 2,120 & 1,740 & 1.22 \\
\hline 10241400 & 15.8 & 6,740 & 1,150 & 286 & 1,150 & 1,240 & .93 \\
\hline 13083000 & 53.7 & 4,820 & 210 & 141 & 245 & 241 & 1.02 \\
\hline
\end{tabular}




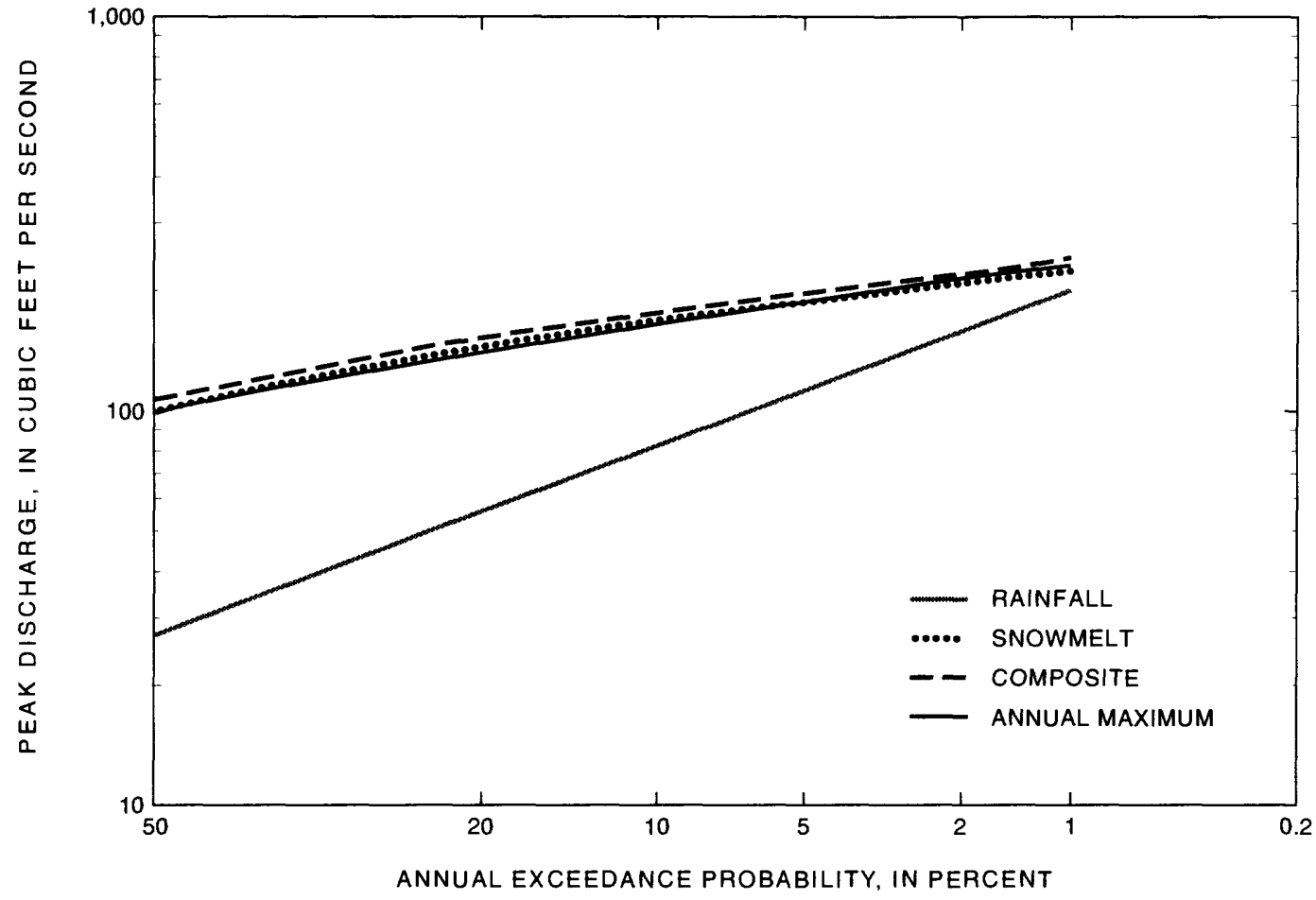

Figure 61. Flood-frequency relations for South Fork of Rock Creek near Hanna, Utah (09278000).

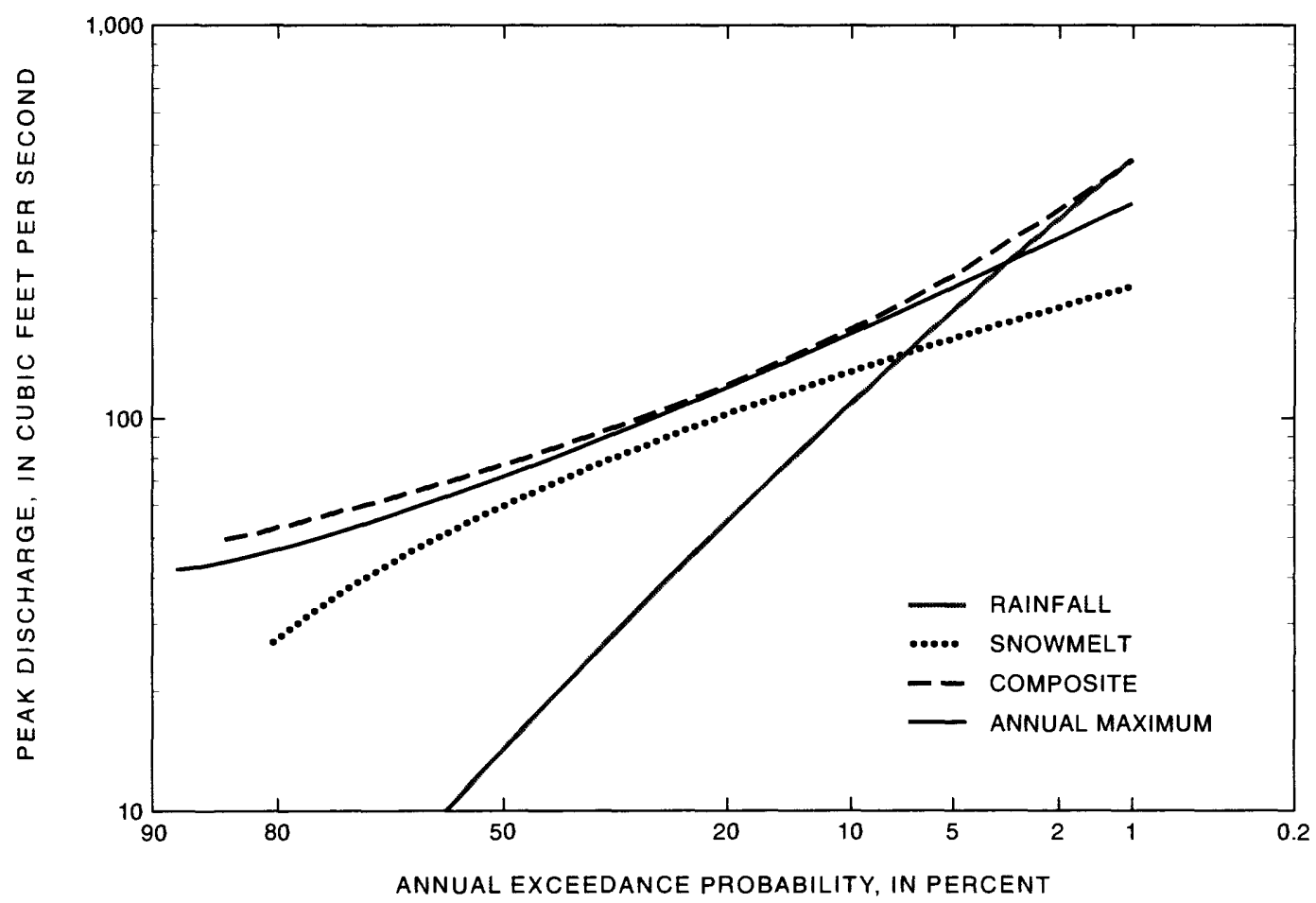

Figure 62. Flood-frequency relations for Big Creek near Randolf, Utah (10023000). 


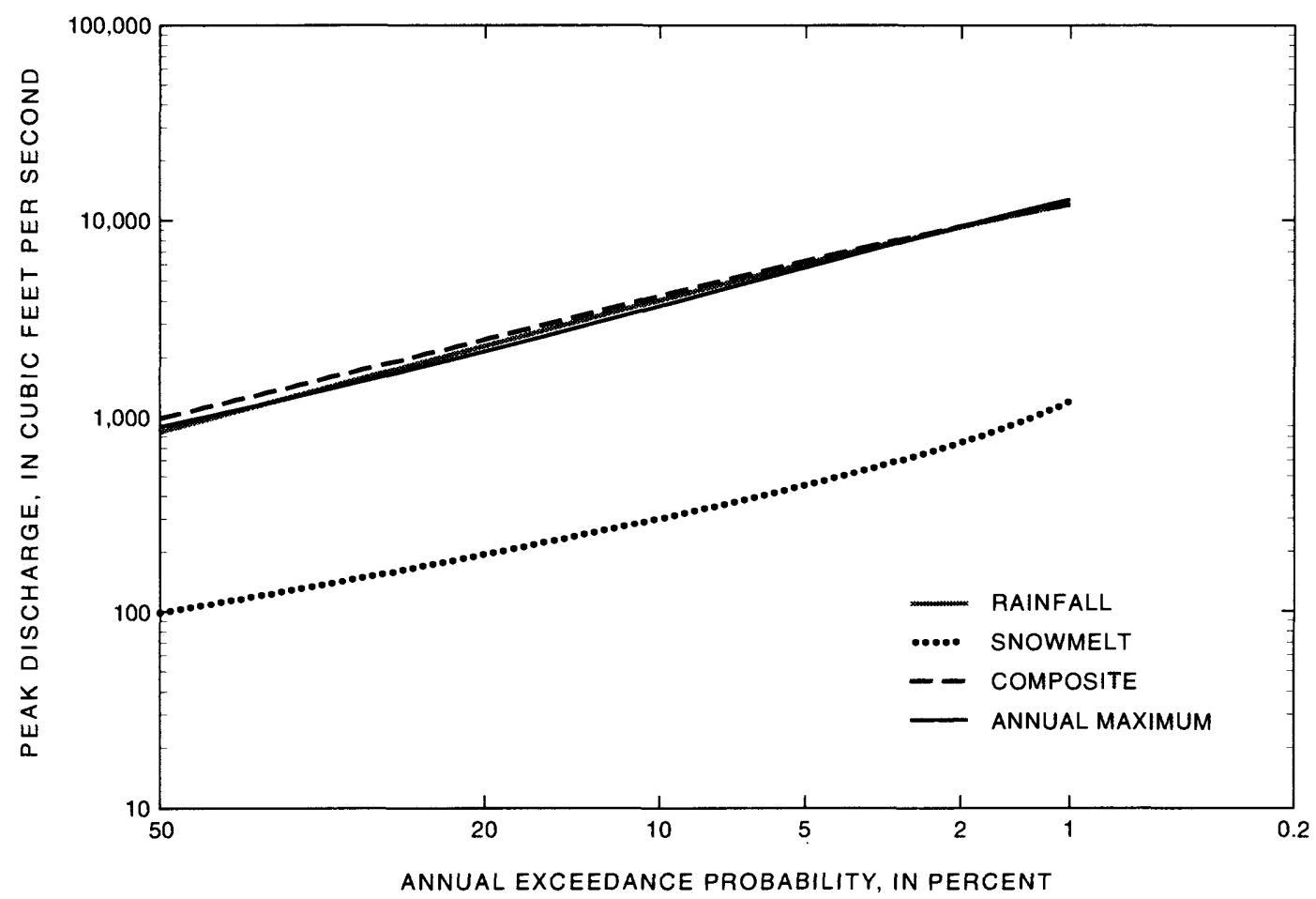

Figure 63. Flood-frequency relations for Mill Creek near Moab, Utah (09184000).

study. The potential problem of mixed populations of floods caused by rainfall and snowmelt, therefore, does not appear to be significant in the study area for estimating floods of as much as the 100 -year peak discharge.

The ratio of composite to annual maximum 100-year peak discharge was compared to size of drainage area, site elevation, mean basin elevation, and geographic area. No relations were found except for geographic area, where some concentrations of higher ratios were found in south-central Utah and northern New Mexico (fig. 60).

In conclusion, analysis of the mixed population of floods caused by snowmelt and summer thunderstorms indicates that flood-frequency relations computed from the mixed populations apparently are adequate descriptions of the flood characteristics for the 100-year flood and less. Separation of populations and a composite analysis for 51 sites did not appear to significantly change the flood-frequency relations. Sites identified with the greatest potential for a significant composite relation are in middle elevations. For some ungaged streams that drain basins in the middle elevations, the regional relations for estimating the 100-year peak discharge may be about 10 percent too small.

\section{Regional Skew Coefficient}

The method of moments was used to fit the LPIII probability distribution to the series of annual peak discharges at gaged sites. In this method, an estimate of skew coefficient is required. An accurate estimate of skew coefficient is difficult to obtain from samples of less than 50 data points because of its sensitivity to extreme events (Viessman and others, 1977, p. 169). Thus, skew coefficients estimated from the peak-discharge records in this study area are often unreliable because the average record length is 27 years and only 10 percent of the sites have more than 50 years of record. The estimate of station skew coefficient is improved by weighting the station skew with a 
regional skew (Interagency Advisory Committee on Water Data, 1982, p. 10-12).

An analysis was made of regional skew coefficient for the series of annual peak discharges at gaging stations in the study area. The study hypothesis was that regional relations for skew coefficient cannot be defined, and therefore, the regional skew is equal to the mean value of zero for the sample with an associated error equal to the sample variance of 0.31 . That is, the logarithms of peak discharges at individual sites do have skewed distributions, but there is no definable regional pattern to the variation of skew among sites. The model for regional site-tosite variation of skew is a regional mean value plus a random component that is uncorrelated with any definable site characteristic. Alternative hypothesis A was that regional relations of skew coefficient can be defined. Alternative hypothesis B was that the gaging-station records fit the log-normal distribution, and therefore, station and regional skew equal zero.

Data and methods.-A sample of 1,061 gaging-station records was used to estimate relations of regional skew coefficient for the study area. A station skew coefficient was computed for the logarithms of the series of annual peak discharges at each gaged site. A skew computed from a sample by the method of moments is a biased estimate of the population skew; therefore, the computed skew was multiplied by a correction factor of $1+(6 / N)$, in which $\mathbf{N}$ is sample size, to obtain a nearly unbiased estimate (Tasker and Stedinger, 1986). The adjusted skew coefficient was used for all sites.

A cumulative distribution plot of the skew coefficients was a straight line on an arithmetic-normal scale, but the line had a sharp break at a skew of about 1.5. Nineteen sites with a skew greater than 1.5 were considered to represent a different population and therefore were deleted from the regional analysis. All the sites with skews greater than 1.5 had a peak discharge that is a high outlier in their individual sample; therefore, those 19 sites were considered to be contaminated by the high outliers. The final sample of 1,042 adjusted skew coefficients has a cumulative distribution that plots as a straight line, a mean of 0.028 , a median of 0.011 , and a variance of 0.31 . Thus, the distribution is considered normal with a mean of about zero.

Seven regional skew relations were tested in this analysis; one relation for the study hypothesis, five relations for hypothesis $\mathrm{A}$, and one relation for hypothesis B.

1. Regional relations of skew coefficient cannot be defined. The regional skew is equal to the mean value of zero for the sample with an associated error equal to the sample variance of 0.31 (study hypothesis).

2. Spatial relations for hypothesis A were tested using a published geographic isoline map of skew coefficient (Interagency Advisory Committee on Water Data, 1982, plate 1).

3. Spatial relations for hypothesis A were tested by determining new geographic isoline maps of skew coefficient.

4. Spatial relations for hypothesis A were tested by dividing the study area into geographic regions of uniform skew coefficient.

5. Relations between skew coefficient and basin and climatic characteristics for hypothesis A were tested using multiple-regression analysis.

6. Relations between skew coefficient and basin and climatic characteristics and geographic regions of uniform skew for hypothesis A were tested together using multiple-regression analysis.

7. Gaging-station records fit the log-normal distribution, and therefore, regional and station skew are equal to zero (hypothesis B).

The overall accuracy of the estimated regional skew relations was evaluated by comparing the computed mean-square error of each relation. A split-sample approach was used to estimate the 
mean-square error. The sample of gaged sites was split into 695 sites to develop the regional relations for estimating skew coefficient and the relations were applied to the remaining 347 sites to estimate the mean-square error. The mean-square error is the variance of the difference between skew estimated from the regional relation and the at-site skew. The sites were listed numerically by station number and then assigned alternately to the first or second group. The procedure resulted in two samples with similar basin and climatic characteristics.

Another method used to evaluate the accuracy of the different regional skew relations was to apply the estimated regional skews to predictions of regional 100-year peak discharges. For the regional relations with a station skew coefficient, 100-year peak discharges were computed for each station using skew coefficients weighted by the associated errors of the station skew and each regional skew (Interagency Advisory Committee on Water Data, 1982 , p. 10-14). For the relation of a log-normal distribution, 100-year peak discharges were computed by fitting the log-normal distribution to the station records. Regional regression relations were then developed for the 100-year peak discharge for each regional skew. To reduce the large variation in flood characteristics for the study area and provide a more homogeneous sample for a comparison of regional skews, the study area was divided into 23 regions with similar flood characteristics. Regional regression equations were developed for those 23 regions, which were preliminary and are not the final flood regions used in the report. The 23 regions were delineated during the procedure to estimate geographic regions of uniform skew. All the regression relations used for comparison among the different regional skew relations had the same explanatory variables.

Application of the relations for regional skew to the estimation of regional 100-year peak discharges was evaluated by comparing a weighted average standard error of estimate of the regression relations. The weighted average standard error of estimate is the average standard error of estimate for the 23 regions weighted by the number of gaged sites in each region.
Study hypothesis. - The study hypothesis is that regional relations of skew coefficient cannot be defined, and therefore, the regional skew is equal to the mean value of zero for the sample. For a comparison with the other regional skew relations, the sample variance of 0.31 can be considered analogous to a mean-square error. The application of the regional skew to a regression of 100 -year peak discharge in 23 regions resulted in a weighted average standard error of estimate of $0.29 \mathrm{log}$ units.

Published isoline map.-The Interagency Advisory Committee on Water Data (1982, plate I) developed an isoline map using peak-discharge records from about 3,000 gaging stations throughout the United States. The isoline map has an overall mean-square error of 0.30 , which is similar to the mean-square error computed for the other methods used in this analysis. The application of regional skews obtained from the isoline map to a regression of 100-year peak discharge in 23 regions resulted in a weighted average standard error of estimate of $0.29 \mathrm{log}$ units.

Isoline maps.-An isoline map of skew coefficient was developed using a kriging procedure where the study area was divided into a uniform grid of 33 rows and 33 columns. Thus, the square cells are about one-half degree on a side. The magnitude of estimated isolines ranged from -0.4 to 0.3 , with an estimated mean skew of zero. The kriged map had a mean-square error of 0.31 and application of the kriged isoline regional skew to a regression of 100-year peak discharge in 23 regions resulted in a weighted average standard error of estimate of $0.29 \log$ units.

An isoline map also was developed using a geographic-information system procedure. No grid was used and the isolines were estimated from the irregularly spaced gaged-site locations using a two-variable five-step interpolation method. The magnitude of the estimated isolines ranged from -0.6 to 0.5 , with an estimated mean skew of zero. The mean-square error from that map is $0.29 \mathrm{log}$ units.

Geographic regions of uniform skew coefficient.-The optimum number of geographic regions with a uniform skew coefficient was determined using the following procedure. 
Twenty-five regions were first delineated using boundaries of drainage-basin divides and large rivers. The regions were selected on the basis of similar flood characteristics and potentially similar skew coefficients. The second step was to examine the uniformity of skew coefficient within each region. Skew coefficient was plotted against latitude and longitude, and the magnitudes and areal trends in skew coefficient were compared to adjacent regions. Several region boundaries were moved to ensure uniformity of skew coefficient within each region. These initial adjustments resulted in a reduction in the number of regions to 22.

Statistical tests were used to evaluate if the populations of skew coefficient in adjacent regions were significantly different. The mean was used as the primary measure of central tendency of skew coefficient for a region because the majority of regions have a normal distribution of skew coefficient. Thus, a t-test was the primary test used to evaluate the difference between means of regions. A nonparametric Mann-Whitney test was a secondary test used to evaluate the difference between medians of regions.

The two statistical tests were performed on all adjacent regions, and in all comparisons, the Mann-Whitney test gave the same results as the t-test. If two adjacent regions did not have significantly different skew coefficients, the regions were combined. During consolidation of the regions, the new combined regions were tested against adjacent regions each time a new combined region was made. The final number of significantly different regions was nine, and the range in values of mean skew coefficient was -0.22 to 0.18 .

Regression analysis was used as a further test of significance of the regions and to estimate the mean-square errors of the uniform-region method. The nine regions were grouped into four regions of uniform skew for the regression analysis. The nine regions are needed for a geographical representation because some areas of similar skew coefficient are separated by an area of different skew coefficient and could not be combined in the two-dimensional space. The mean skew coefficients of the four regions are $-0.20,-0.062$, 0.078 , and 0.17 .
Three dummy variables were used to represent the four regions in the regression analysis. The variables were coded as follows:

\begin{tabular}{cccc}
\hline \multirow{2}{*}{ Region } & \multicolumn{3}{c}{ Variable } \\
\cline { 2 - 4 } & RA & RB & RC \\
\hline A & 1 & 0 & 0 \\
B & 0 & 1 & 0 \\
C & 0 & 0 & 1 \\
D & 0 & 0 & 0 \\
\hline
\end{tabular}

The three dummy variables and regression constant are all significant at better than the 0.05 level. The regression equation representing the four regions has a $R^{2}$ value of 5.2 percent and a mean-square error of 0.32 . Thus, the four regions only explain 5.2 percent of the variation in skew coefficient, and the mean-square error is about the same as the variance of the sample of 1,042 gaged sites, which is 0.31 . The application of the four regions of uniform skew to a regression of 100 -year peak discharge in 23 regions resulted in a weighted average standard error of estimate of $0.29 \mathrm{log}$ units.

Relation between skew coefficient and basin and climatic characteristics.-Multipleregression analysis was used to investigate the relation between skew coefficient and basin and climatic characteristics. Investigated characteristics were drainage area, in square miles; stream length, in miles; main channel slope, in feet per mile; mean basin elevation, in feet; site elevation, in feet; mean annual precipitation, in inches; precipitation intensity for 24 hours and 100-year recurrence interval (124_100), in inches; and mean minimum January temperature, in degrees Fahrenheit.

The regression analysis used both log-transformed and untransformed independent variables, and generally the log-transformed values had more significant relations. Several combinations of the $\log$ of mean annual precipitation, mean basin elevation, and I24_100 are significant at better than the 0.05 level. The largest $R^{2}$ value of combinations of those variables, however, is 3 percent. Thus, only 3 percent of the variation in skew coefficient can be explained by the investigated explanatory variables. The smallest mean-square error from the regression models is 
0.31 , which is the same value as the variance of the sample of 1,042 gaged sites. The application of the best skew-prediction equation of regional skew to a regression of 100-year peak discharge in 23 regions resulted in a weighted average standard error of estimate of $0.29 \mathrm{log}$ units.

Relation between skew coefficient and basin and climatic characteristics and uniform regions.-Multiple-regression analysis was used to investigate the relations between skew coefficient, basin and climatic characteristics, and the four regions of uniform skew. The model for this evaluation was to log-transform all independent variables and use the three dummy variables to represent the four regions of uniform skew.

The four uniform regions formed the best three-variable model with a $R^{2}$ of 5.2 percent and a mean-square error of 0.32 . Adding drainage area, 24-hour precipitation intensity for 100-year recurrence interval, and stream length to the equation increases the $R^{2}$ to 6.6 and reduces the mean-square error to 0.30 . Thus, the six-variable model is a small improvement over the three-variable model, but none of the models explain a sufficient portion of the variation in skew coefficient to be accurate or reliable.

Log-normal distribution. - This hypothesis is that the gaging-station records fit the log-normal distribution, and therefore station and regional skew equal zero. Comparison to the other regional skew relations cannot be made using mean-square error because no prediction of skew is made. Also, this relation has no station skew and thus no variance of skews. One comparison can be made and that is by using the 100 -year peak discharges computed from fitting the log-normal distribution to the records at each site and applying the regional regression relations for the 23 regions. This application resulted in a weighted average standard error of estimate of $0.29 \mathrm{log}$ units.

Discussion.-The analysis of regional skew coefficient failed to reject the study hypothesis. The study hypothesis was that regional relations of skew coefficient cannot be defined and the regional skew is equal to the mean value of zero for the sample with an associated error equal to the sample variance of 0.31 . Five methods were used to predict regional skew and test hypothesis $\mathrm{A}$-that regional relations of skew can be defined. The five methods are a published isoline map, new isoline maps, geographic regions of uniform skew, relation between skew and basin and climatic characteristics, and relation between skew and basin and climatic characteristics and geographic regions of uniform skew. These methods have mean-square errors of between 0.30 and 0.32 , therefore they all failed to improve on the mean skew of zero for the sample.The second test of applying the predicted regional skews to a regional regression of 100 -year peak discharge also showed that the prediction methods offer no improvement in accuracy compared to using a mean regional skew of zero. The weighted average standard errors of estimate from the regression analyses were 0.29 $\log$ units for the study hypothesis and all the predicted regional skews.

Results of the analyses support the study hypothesis that the regional skew is zero for the study area. The methods and results, however, did not provide conclusive evidence that hypothesis B is more or less accurate than the study hypothesis. Hypothesis B is that the gaging-station records fit the log-normal distribution, and therefore station and regional skew equal zero. Application of hypothesis B to prediction of regional 100-year peak discharges had the same average accuracy (weighted average standard error of estimate of 0.29 ) as the other regional skews. This similarity in accuracy does provide some evidence that many of the sites in the study area may have a log-normal distribution of annual peak discharges. However, classification of all sites as having a log-normal distribution cannot be made, because many sites with long records have a clearly skewed distribution of the peaks plotted on log-normal probability paper. Characteristics of basin soils, storage capacity of the basin, stream channel size, and flood-plain width may cause a skewed distribution by having different effects on peak discharge, depending on the magnitude and frequency of the discharge. In addition, some samples of mixed populations of floods also may cause a skewed distribution.

The regional skew coefficient used in this study was zero with an associated mean-square error equal to the sample variance of 0.31 . The 
weighted skew coefficients for station floodfrequency relations computed with this regional skew, thus, allow individual variations in skew according to the mean-square error of the station record and the regional skew. Although this study did not prove the log-normal distribution is applicable to many sites in the southwestern United States, the study results do justify further investigation of this hypothesis.

\section{Summary of Analyses}

Flood-frequency analyses were made of records at 1,323 gaging stations. The reliability of station flood-frequency relations was assessed by visual examination of how well the computed relations fit the plotted peak discharges, the presence or absence of outliers, and the shape exhibited by the plotted peaks. This examination resulted in defining flood-frequency relations at 1,059 gaged sites. The remaining 264 undefined sites were classified as having unreliable relations because of extremely poor fits of the computed relations to the peak-discharge data. The sites may have inadequate samples to define a relation or a non-LPIII distribution.

Sites with defined flood-frequency relations were classified as having plots of data that exhibit certain characteristics (table 23). Some sites have more than one characteristic. The expected smooth shape of an LPIII distribution was found at 38 percent of the sites. At 48 percent of the sites, a low-discharge threshold was used to truncate peaks identified as low outliers and a conditionalprobability adjustment was used to compute the flood-frequency relation. High outliers were identified at 17 percent of the sites. Historical periods were used to extend the period of record at 12 percent of all sites. A jump or dogleg in the plotted peaks was identified at 16 percent of the sites, and no adjustments were made to the frequency relations for these departures from the expected smooth shape.

The percentage of sites with plots of data that departed from the expected smooth shape was compared to incremental classes of some basin and climatic characteristics (table 24). Generally, the departures were not related to basin and climatic characteristics of the gaged sites. The few significant relations were: low-discharge thresholds increased in more arid areas, doglegs increased as drainage area increased, and jumps decreased as mean annual precipitation increased.

An analysis was made of the mixed population of annual peaks caused by snowmelt and summer thunderstorms. A small sample of 51 gaging-station records was selected at sites expected to have a potential difference in flood-frequency relations computed from the mixed population and computed by separating the peaks, computing separate relations, and combining the relations into a composite relation. The average ratio of composite 100-year peak-discharge relation to mixed relation for the 51 sites was 1.08. That difference is considered small because of all the uncertainties inherent in flood-frequency analysis. Thus, the flood-frequency relations computed from the mixed populations apparently are adequate and no adjustments were made for this condition.

An analysis of regional skew coefficient was made for the study area. The methods of attempting to define a regional skew by spatial variation or by regression with basin and climatic characteristics all failed to improve on a uniform value of zero for the study area. The regional skew used in the study, therefore, was a value of zero, which was the mean of all the station skews analyzed with an associated error equal to the sample variance of $0.31 \mathrm{log}$ units.

\section{REGIONAL ANALYSIS}

Multiple-regression analysis was used to relate flood-frequency relations that could be determined at gaged sites to basin and climatic characteristics. Ordinary least-squares (OLS) and generalized least-squares (GLS) regression analyses were used. A hybrid analysis (Hjalmarson and Thomas, 1992) of the station-year method and multiple regression developed during this study also was applied and used for areas where the standard multiple-regression method was judged to be inadequate. The final regional flood-frequency relations were defined for 12 regions (regions 1-5, $7-9,12-15)$ using GLS regression and for four 
regions (regions $6,10,11,16$ ) using hybrid analysis. All 12 regions with GLS relations had less than 20 percent of their gaging stations with undefined flood-frequency relations and all 4 regions with hybrid relations had more than 30 percent undefined station relations. Results of these analyses are the regional equations for estimating floodfrequency relations at ungaged sites (tables 5-20).

\section{Multiple Regression}

The multiple-regression analysis consisted of an investigation of geographic variation of flood magnitudes, different forms of models, and the significance of available explanatory variables. The geographic variation of flood characteristics is not linear or consistent. Incorporation of geographic variables into the regression equations, therefore, is not practical, and the study area was divided into geographic regions of similar flood characteristics. The objective was to obtain the smallest number of geographic regions with predictive equations that are accurate, physically reasonable, and efficient for the user.

OLS and GLS regression analyses were used in this study. OLS analysis was used for preliminary analyses of delineation of flood regions, investigation of models, and selection of significant explanatory variables. GLS analysis was used for refinement and to compute the final regression models.

GLS regression is considered to be a more appropriate method for developing regional regression models of streamflow characteristics than is OLS regression (Stedinger and Tasker, 1985). Regional regression models of streamflow characteristics, such as flood-frequency relations, are commonly developed by regressing gaged-site flood-frequency relations on basin and climatic characteristics. Using flood-frequency relations at gaged sites as a response variable may violate two assumptions of OLS regression. Those assumptions are that the response variable at each site is independent and has equal variance. Peak discharges for nearby watersheds may be correlated as a result of similar climatic events. Streamflow records have different lengths and at-site variability, and therefore, the computed flood-frequency relations have unequal variances. GLS takes into account the possible cross-correlation and unequal variance of flood-frequency estimates at gaged sites.

\section{Models Investigated}

Several model forms were investigated. The objective was to find the model form that has the best fit for the relations of flood characteristics compared to basin and climatic characteristics. The model should be intrinsically linear in order to perform standard linear-regression techniques. Many previous studies have shown that the multiplicative model (all variables are log transformed) is applicable to regional flood-frequency studies. When the response and explanatory variables are log-transformed, the resulting model commonly is linear. That model was used as the base method, and other models were investigated and evaluated. Polynomial models were tested, dummy variables were used, and various transformation-s of the explanatory and response variables such as reciprocals, interaction terms, and fractional exponents (Draper and Smith, 1981, p. 218-225) were tested.

\section{Explanatory Variables Investigated}

Nineteen explanatory variables were investigated as possible predictors of $T$-year discharges. The following list shows the variables, units of measurement, and number of sites with the variable measured:

1. Drainage area, in square miles $(1,059)$;

2. Main channel slope, in feet per mile (1,027);

3. Main channel length, in miles $(1,018)$;

4. Mean basin elevation, in feet above sea level $(1,031)$;

5. Elevation of gage datum, in feet above sea level (963);

6. Forested area, in percent $(1,010)$;

7. Latitude of gaged site, in decimal degrees (1,059); 
8. Longitude of gaged site, in decimal degrees $(1,059)$;

9. Mean annual precipitation, in inches $(1,020)$;

10. 100-year, 24-hour maximum precipitation, in inches $(1,043)$;

11. Mean annual free water-surface evaporation, in inches $(1,054)$;

12. Distance from major moisture source, Gulf of Mexico, in hundreds of miles $(1,059)$;

13. Distance from major moisture source, Gulf of California, in hundreds of miles $(1,059)$;

14. Relation of gaged site to major orographic barriers, attribute dimensionless (1,059);

15. Basin shape, length squared divided by drainage area, dimensionless $(1,018)$;

16. Potential vegetation at gaged site, in discrete units $(1,059)$;

17. Field-measured channel geometry, active channel width, in feet (59);

18. Channel slope of lower one-third stream length, in feet per mile (126);

19. Isoerodent factor, dimensionless (220).

Variables $1-8,15$, and 18 were determined from the largest-scale topographic maps available. Mean annual precipitation was determined from 1:500,000-scale maps of normal annual precipitation published by the U.S. Weather Bureau (1963) for each State. The distance from major moisture sources was determined by measuring the distance from gaged sites to points selected near the Texas coast for the Gulf of Mexico (28 $8^{\circ}$ latitude and $97^{\circ}$ longitude) and in the northern part of the Gulf of California ( $29^{\circ}$ latitude and $113^{\circ}$ longitude). The 100-year 24-hour maximum precipitation (Miller and others, 1973a-i), mean annual free water-surface evaporation (Farnsworth and others, 1982), and relation to orographic barriers were determined at gaged sites using geographic-information systems techniques.
The relation of gaged site to major orographic barriers was determined in several steps. First the major orographic barriers were selected and outlined on a map of the study area. Such barriers include the Cascade-Sierra Mountains of eastern California and the mountains of central Arizona. Windward and leeward sides of the barriers were delineated on the basis of dominant directions of moisture or storm movement. The sites on the windward side were assigned positive numbers and sites on the leeward side were assigned negative numbers. A scale of -3 to +3 was used. The largest numbers were assigned to the highest and most continuous barriers. The angle of moisture movement also was factored in with right angles receiving larger numbers and obtuse angles receiving smaller numbers.

A map of potential natural vegetation (Kuchler, 1964) was examined for possible use as an explanatory variable in the study area. The locations of the 1,059 gaged sites were plotted on the map. The types of vegetation were grouped into two major classes: (1) forests and dense shrubs and (2) shrubs and grasslands. Differences of the standardized values of the 100-year peak discharge $\left(\mathrm{Q}_{100} / \mathrm{AREA}^{0.5}\right)$ for the two general vegetation types at the gaging stations were examined visually and using statistical tests of subsamples.

A partial sample of 59 field measurements of channel geometry were obtained from Hedman and Osterkamp (1982). The channel slope of the lower one-third stream length was measured from the largest scale topographic map available for a small sample of gaged sites (26 sites) in southern Arizona and for about one-half the sites with a drainage area of greater than $200 \mathrm{mi}^{2}$ throughout the study area (126 sites). An isoerodent factor (Fletcher and others, 1977) was determined for 220 gaged sites in New Mexico using a geographic-information system technique.

\section{Results}

Flood regions.-A single regression equation for the entire study area does not adequately explain the variation in flood characteristics. The OLS standard errors of estimate for T-year discharges 
were more than 100 percent for all attempted single models. In addition, except for a high-elevation region, a single relation for a stratum of an explanatory variable was not found. The study area, therefore, was divided into 16 flood regions, and separate regression equations were developed for each region. Use of the 16 flood regions removes some of the variation in the system not explained by available explanatory variables and thus makes the subsequent equations simpler. The flood regions were delineated on the basis of general magnitudes of floods, the meteorologic cause of floods (snowmelt, summer thunderstorms, or cyclonic rainfall), elevation of the sites, and geographic patterns in residuals from the regression analysis. No obvious, consistent geographic patterns in residuals were found; therefore, an explanatory variable could not be developed that could explain the study-wide geographic variation. Geographic clusters of residuals from study-wide regressions were used to help delineate boundaries of the regions.

The first stratification was into High-Elevation Region 1, which occurs throughout the entire study area. Sixteen percent of the gaged sites were placed in this region. A regression of 100 -year peak discharge on drainage area was made for all sites in the study area, and 90 percent of the residuals for the high-elevation sites were negative. The high-elevation region is dominated by floods caused by snowmelt (table 4). Thunderstorms occur in this region, although large floods caused by thunderstorms are rare. The lower boundary of the high-elevation region coincides with the estimated elevation threshold for large floods caused by thunderstorms (fig. 5). To determine if a study site fits in the high-elevation region, the elevation of the study site is used-not the mean basin elevation. The elevation threshold remains constant at $7,500 \mathrm{ft}$ for all sites south of $41^{\circ}$ latitude, and the threshold decreases north of that latitude. North of $41^{\circ}$ latitude, the threshold is approximately a flat plane that slopes about $300 \mathrm{ft}$ for each increment of $1^{\circ}$ of latitude.

The second stratification of data was into 15 geographic low- to middle-elevation flood regions where the elevations of the gaged sites are below the boundary of the high-elevation region. The boundaries of these regions are based mainly on drainage divides.

Models. -The model that best describes most regional flood-frequency relations for this study is the multiplicative model (equation $3 \mathrm{~A}$ and $3 \mathrm{~B}$ ), where all variables are log transformed. The most significant explanatory variable is drainage area, and in most flood regions, the log of drainage area is linearly related to the log of the T-year discharge. In two flood regions (Regions 12, and 13), however, a plot of $\log$ T-year peak discharge and $\log$ of drainage area indicates a slightly curvilinear relation. Eychaner (1984) found this relation for a region in southern Arizona and fit the data using a second-order polynomial described by the following equation:

$$
\log Q_{T}=a+b_{1} \log A R E A+b_{2}(\log A R E A)^{2},
$$

where

$$
\begin{aligned}
Q_{T}= & \text { peak discharge, in cubic feet per } \\
& \text { second, for T-year recurrence in- } \\
& \text { terval; } \\
A R E A= & \text { drainage area, in square miles; } \\
\text { and } & \\
a, b_{1} \text { and } b_{2}= & \text { regression coefficients. }
\end{aligned}
$$

That model fits the two regions with curvilinear relations in this study. Tasker and others (1986), however, used a transformation other than logs to account for the nonlinearity for the same data as Eychaner (1984). The transformation consisted of raising drainage area to a negative fractional power. The equation used in Tasker and others (1986, p. 112) is shown as equation 4 in this report and is repeated here for just one explanatory variable:

$$
\log Q_{T}=a+b A R E A^{X} .
$$

The model suggested by Tasker and others (1986) was used in this study to fit the nonlinear relations for T-year discharge and drainage area in the two flood regions. The equations were fit by iteratively selecting an exponent for drainage area, performing a regression analysis with $\log$-transformations for all other variables, and comparing the standard 
error of estimate and plotting until the plot appeared linear. Illustrations of the two models and how they fit the data in the Southern Arizona Region 13 are shown in figures 64 (equation 9) and 65 (equation 4).

A third model (equation 5) was used in the Southeast Region 16. In the Southeast Region, drainage area and mean annual evaporation are significant explanatory variables using equation 3. The plot of $\log Q_{T}$ and $\log A R E A$ appears linear. A plot of the residuals from that relation and the log of mean annual evaporation, however, exhibits a slight curvilinear relation with more curvature and smaller residuals for large values of mean annual evaporation. In addition, the sample of gaged sites in the region has few sites with small drainage areas and large values of mean annual evaporation. To account for the apparent curvilinear relation of the residual from the $Q_{T}$ and drainage-area relation and the poor definition of the relation for small drainage areas with large mean annual evaporation, equation 5B was fit to the data:

$$
\log Q_{T}=\log a+b \log A R E A+c \log (E V A P-d) .
$$

This relation has the best fit for larger values of $A R E A$ and smaller values of $E V A P$. For large values of $E V A P$, the relation is an average of the relation between $\log Q_{T}$ and $\log A R E A$ and the nonlinear relation between $\log Q_{T}$ and $\log A R E A$ and $\log E V A P$. Averaging where EVAP is large produced the most reliable overall relation; the distribution of residuals about the relation is more random in appearance and homoscedastic.

\section{Significance of explanatory variables. -}

The explanatory variables used in the predictive equations for the 16 flood regions are drainage area, mean basin elevation, mean annual precipitation, mean annual evaporation, latitude, and longitude. In the study area, the ranges for these variables are drainage area, 0.01 to $1,990 \mathrm{mi}^{2}$; mean basin elevation, 350 to $12,000 \mathrm{ft}$; mean annual precipitation, 2 to 68 in.; mean annual evaporation, 29 to 100 in.; latitude, 29 to $45^{\circ}$; and longitude, 100 to $121^{\circ}$. The range of values for explanatory variables in each of the 16 flood regions is shown in the plots of explanatory variables used in the 16 sets of regional flood-frequency relations. The figure numbers of these plots are referenced in column 6 of table 4 .
The range of values in a region can be large or quite small depending on the available data. For example, the range of drainage area for gaging stations in region 7 is about 6 to $350 \mathrm{mi}^{2}$, and the range of drainage area in region 12 is about 0.6 to $1,500 \mathrm{mi}^{2}$.

All the explanatory variables investigated in this study except potential vegetation were significantly related to $T$-year discharge in regressions for the entire study area. Only six variables were used in the regional regression equations because the other variables were correlated to those six variables or the other variables were not significant in the reduced variability within the 16 individual flood regions.

The explanatory variables that were measured for at least 90 percent of the gaged sites were investigated as possible predictors of $\mathrm{T}$-year discharges in all 16 flood regions. These 15 variables are numbered 1 to 15 on page 100 and 101. Routines, such as all possible regressions and stepwise regressions, were used to select the best possible models for each region. Drainage area was always the most significant variable and the first variable selected in all models. Multiple-variable models were used only if the second or third variable reduced the standard error of prediction by at least 5 percent and the coefficients of the additional variables were reasonable; that is, the sign and magnitude matched the conceptual model of flood characteristics.

Potential natural vegetation (Kuchler, 1964) was not included in the regression analysis because an initial investigation showed it had no significant relation to flood characteristics. The variable was examined by plotting the gaged-site locations on the map and grouping the vegetation in two major classes. Differences of the standardized values of the 100-year peak discharge $\left(Q_{100} / A R E A^{05}\right)$ for the two general vegetation types at the gaging stations were examined visually and using statistical tests of subsamples. The coefficient of variation was nearly 1 for the standardized flood values and no difference between the mean of the standardized flood values for the two general types of potential vegetation was detected at the 5-percent significance level $(\alpha<0.05)$. 


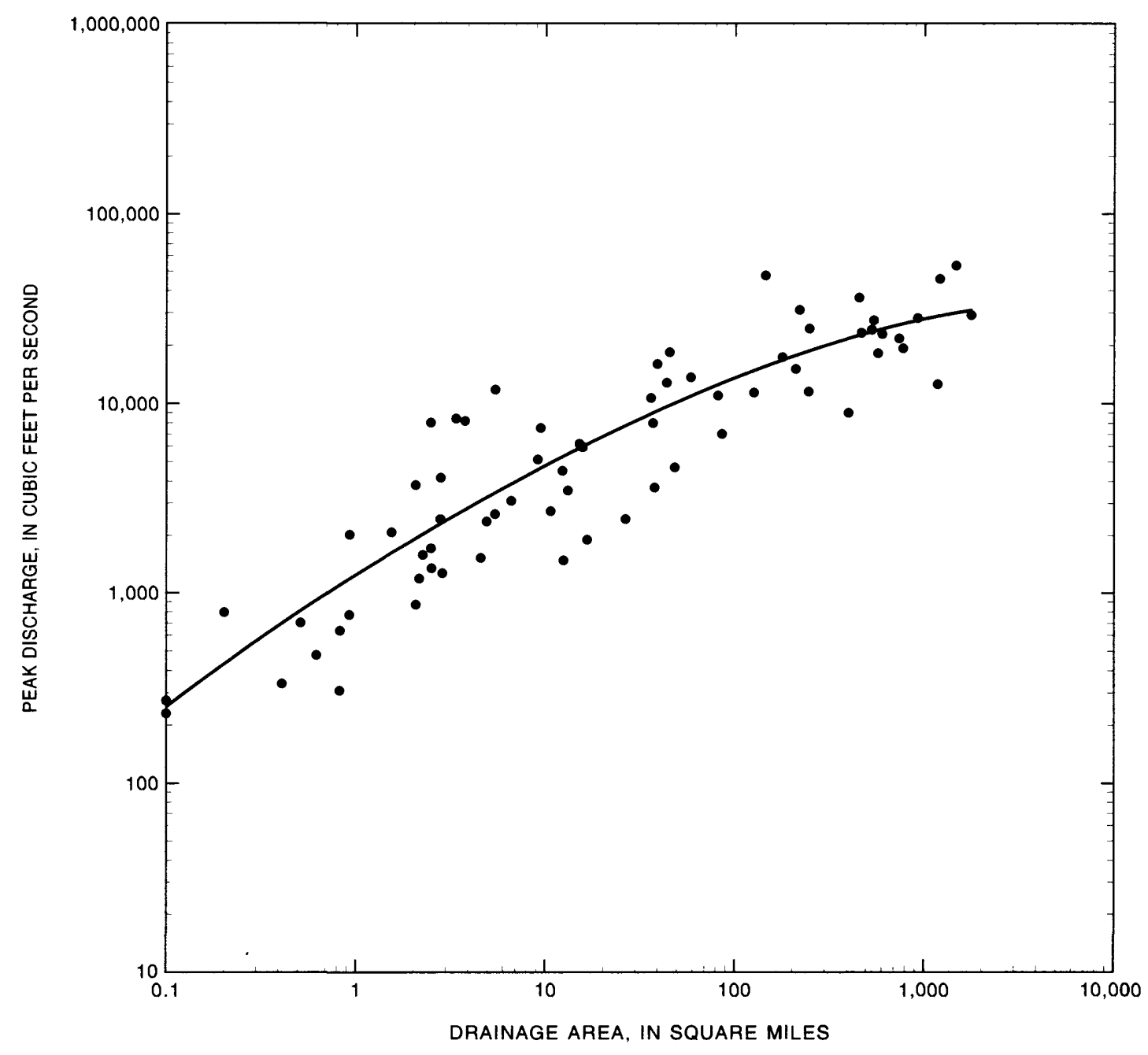

Figure 64. Relation between 100-year peak discharge and drainage area for Southern Arizona Region 13. 


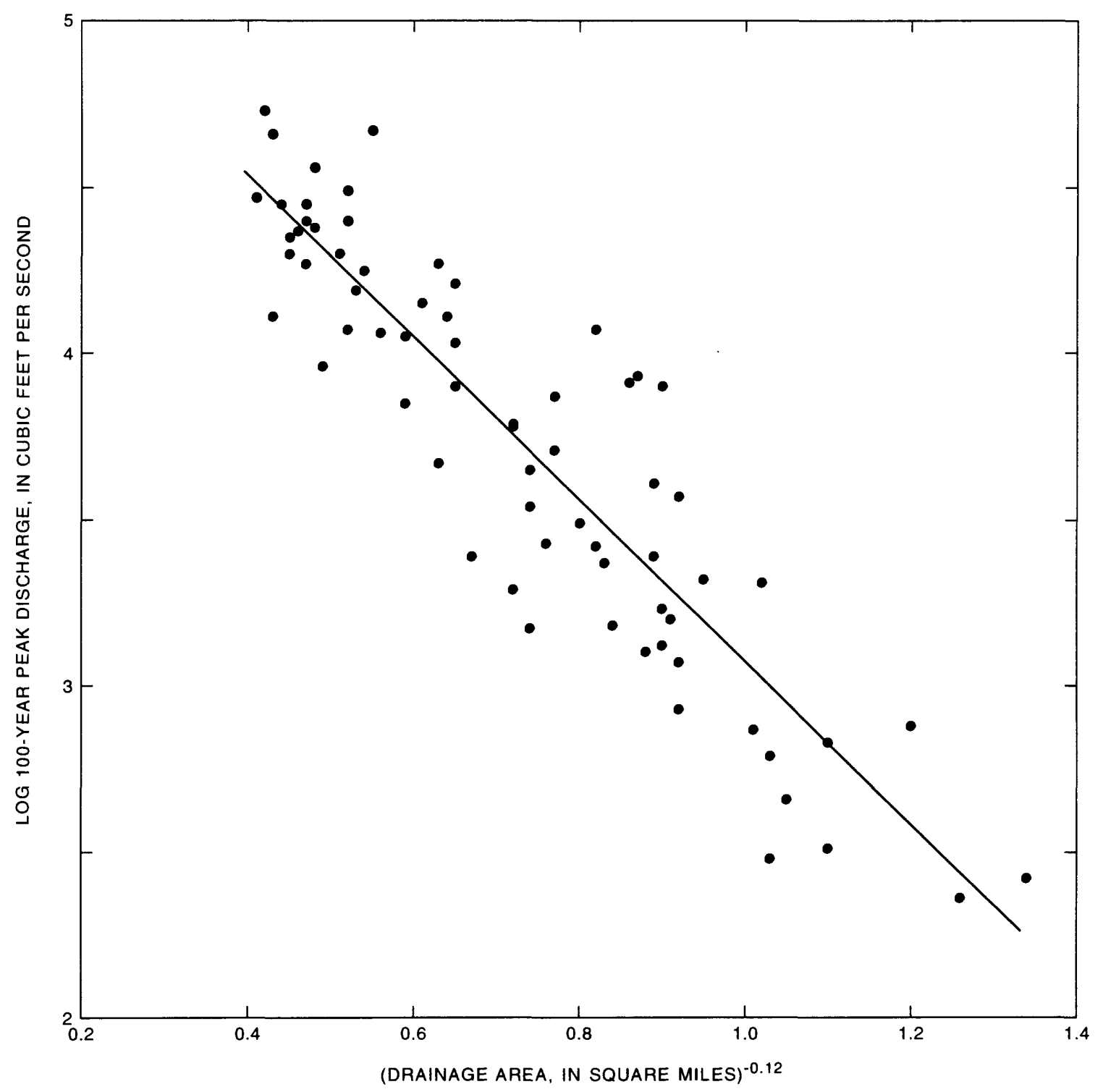

Figure 65. Relation between logarithm of 100-year peak discharge and drainage area for Southern Arizona Region 13. 
Potential natural vegetation at a gaged site as an explanatory variable has limited application for regional flood-frequency analysis. For large basins, the vegetation at the gaged site may be much different from the vegetation in the basin. Because the basin boundaries for the gaging stations have not been digitized, a comprehensive examination of vegetation as an explanatory variable was not made.

Three additional explanatory variables that were measured for only a small sample of the gaged sites were field-measured channel geometry, channel slope of lower one-third stream length, and the isoerodent factor (items $17-19$, p. 101). A sample of 59 field measurements of channel geometry was obtained from a published report (Hedman and Osterkamp, 1982). Previous studies indicated that field measurements of channel geometry are effective predictors of flood characteristics (Wahl, 1983). Although field measurement of channel geometry is a valid method, the method was rejected as an explanatory variable for this study. Regression analyses of the sample of gaged sites indicated that adding a channel-geometry variable to regression equations with basin characteristics did not significantly improve the accuracy of the estimating equations. Other reasons for rejecting channel geometry are the requirement of field visits, the required field training, and a question of stationarity at some sites.

The channel slope of the lower one-third stream length was examined for a small sample of gaged sites ( 26 sites) in southern Arizona and for about one-half the sites with a drainage area of greater than $200 \mathrm{mi}^{2}$ throughout the study area (126 sites). Attenuation of peak discharge was previously estimated for streams in southern Arizona by Eychaner (1984, p. 39) who recognized the difficulty of quantifying attenuation. The channel slope of the lower one-third stream length can be consistently measured, and this variable could be a measure of the lateral spreading and attenuation of peak discharge. A significant relation $(\alpha<0.05)$ between $\mathrm{T}$-year discharges and slope of the lower one-third of the stream channel was found for the sample of streams in southern Arizona $(n=26)$, where attenuation of peak discharges has been observed at many sites. The estimation of
T-year discharge, however, was not improved using the lower one-third slope variable for a sample of sites with large drainage areas $(n=126)$ for much of the study area. The relation for the streams in southern Arizona may have been significant because of the influence of other factors such as reduced tributary inflow from distributary-flow areas that are common in southern Arizona. Because there was no improvement in regression relations for the sample of sites with large drainage basins, this variable was not determined for all the sites in the study area.

The isoerodent factor that was determined for 220 sites in New Mexico was a significant explanatory variable in a nationwide flood study by Fletcher and others (1977). That factor was rejected in this study because it is highly correlated with the T-year maximum precipitation intensity. The 100-year, 24-hour maximum precipitation is considered a more reliable variable than the isoerodent factor. The 100-year, 24-hour maximum precipitation factor was determined for all sites in the study area. In addition, the isoerodent factor is not an accurate indicator of flood characteristics in middle- to high-elevation areas. In the middle- to high-elevation areas, the isoerodent factor increases as the magnitude of peak discharge decreases.

Regression relations.-Study-wide relations of flood characteristics are discussed in this section. Two correlation matrices were computed for low- to middle-elevation sites and high-elevation sites (table 27). The correlation matrices show the degree of correlation between all pairs of explanatory variables that were determined for more than 90 percent of the sites and between the 100-year peak discharge and each of the explanatory variables. The coefficients reflect the degree of correlation between pairs of variables but do not take into account the fact that other variables can affect the simple two-way correlation.

Some important information contained in the correlation matrices is the degree of correlation between explanatory variables. Using highly correlated variables in a regression relation can cause multicollinearity, which can cause unrealistic and unstable regression coefficients. Highly 


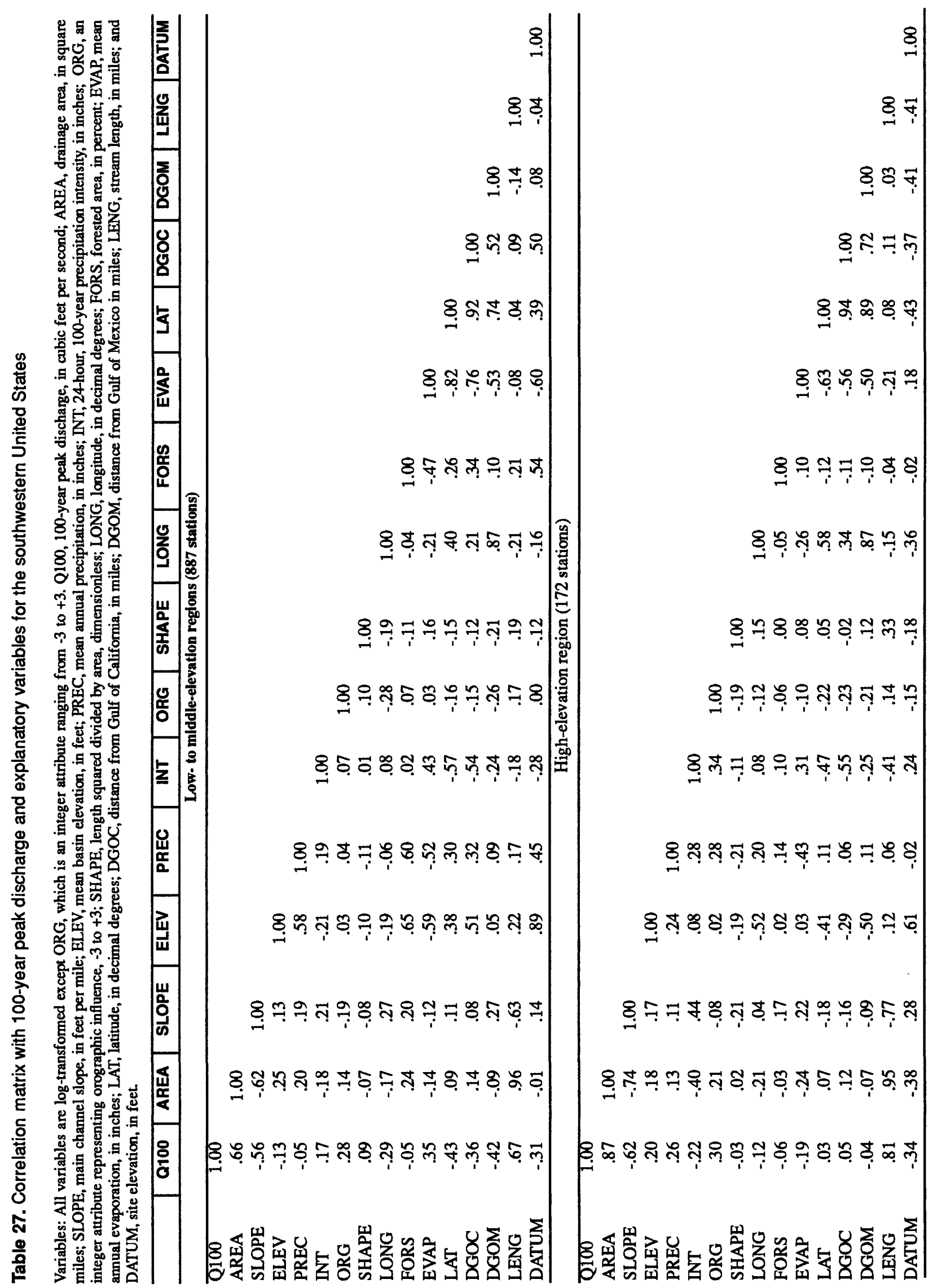


correlated explanatory variables $(r>0.7)$, therefore, should not be used in the same regression equation. The selection of which correlated variable to use in a predictive equation in this study was based on the regression error associated with the variable and the relative ease of determining the particular variable.

To obtain a general picture of the relative importance of the explanatory variables in the study area, a stepwise regression was performed on all sites in the low- to middle-elevation group for the 10- and 100-year peak discharges (table 28). The stepwise regression was based on an F-statistic criterion $(F>4)$ in which each variable is added according to the largest partial correlation, and variables already in the equation can be removed (Minitab, 1988, p. 121-127). All variables shown in table 28 are significant at better than the 5-percent significance level. A stepwise regression also was developed for the high-elevation region, and drainage area and mean annual precipitation were the most significant variables (table 5). For the 100-year peak discharge in the low- to middle-elevation regions, the most significant explanatory variables in order of importance were drainage area, latitude, orographic influence, mean basin elevation, basin shape, precipitation intensity, mean annual precipitation, and distance from the Gulf of Mexico. The 10-year peak-discharge relation is similar to the 100 -year relation in the significant variables and order of importance of variables.

An example of two highly correlated variables is latitude and mean annual evaporation, where latitude appears in the study-wide stepwise regression and mean annual evaporation appears in regional relations for two flood regions. The correlation coefficient between those variables is -0.82. In the flood regions where flood characteristics are more homogeneous and relations are more reliable, mean annual evaporation is a better predictor of $\mathrm{T}$-year discharge than latitude.

The magnitude and signs of the coefficients of the explanatory variables in the study-wide relations provide some information about the study area (table 28). The coefficient or exponent for drainage

Table 28. Stepwise ordinary least-squares regression of T-year discharge and basin and climatic characteristics for the entire low- to middle-elevation study area

[The stepwise-regression equations are based on 819 gaged sites. All variables are log-transformed except ORG. AREA, drainage area, in square miles; LAT, latitude of gaged site, in decimal degrees minus 28; ORG, orographic factor is an integer attribute ranging from -3 to +3 ; ELEV, mean basin elevation, in thousands of feet; DGOM, distance from Gulf of Mexico, in miles; PREC, mean annual precipitation, in inches; SHAPE, shape factor of drainage basin, dimensionless; and INT, precipitation intensity for 24-hour, 100-year recurrence interval, in inches]

\begin{tabular}{|c|c|c|c|c|c|c|c|c|c|c|}
\hline \multirow{2}{*}{$\begin{array}{l}\text { Recur- } \\
\text { rence } \\
\text { interval } \\
\text { (years) }\end{array}$} & \multicolumn{9}{|c|}{ Regression coefflcients } & \multirow{2}{*}{$\begin{array}{l}\text { Standard } \\
\text { error of } \\
\text { estimate } \\
\text { (percent) }\end{array}$} \\
\hline & $\begin{array}{l}\text { Con- } \\
\text { stant }\end{array}$ & AREA & LAT & ORG & SHAPE & ELEV & DGOM & INT & PREC & \\
\hline \multirow{7}{*}{10} & 113 & 0.56 & ----- & ------ & -.---- & -.----- & -...-- & ------ & ------- & 133 \\
\hline & 3,520 & .60 & -1.6 & ----- & --.--- & -.......- & ----- & ----- & ------ & 99 \\
\hline & 3,050 & .58 & -1.5 & 0.083 & $-\cdots---$ & ------ & ------ & ----- & ------ & 97 \\
\hline & 2,100 & .59 & -1.5 & .077 & 0.21 & ----- & $-\cdots-$ & ----- & ------ & 96 \\
\hline & 2,640 & .60 & -1.4 & .082 & .20 & -0.31 & ------ & --.--- & ------ & 95 \\
\hline & 10,900 & .60 & -.98 & .069 & .17 & -.47 & -0.81 & -.--.. & --.---. & 94 \\
\hline & 6,650 & .60 & -.58 & .065 & .18 & -.59 & -1.2 & 0.51 & ------ & 93 \\
\hline \multirow{8}{*}{100} & 352 & .52 & - & $-\cdots$ & $-\cdots$ & ----- & ----- & - --- & $\overline{-\cdots}$ & 165 \\
\hline & 25,900 & .56 & -2.0 & ------ & --.--. & -.----- & -..--.- & --.--- & ------ & 113 \\
\hline & 22,200 & .54 & -1.9 & .088 & --.--- & -..-.- & -ב-ב- & -..-- & -...- & 110 \\
\hline & 31,100 & .56 & -1.7 & .096 & ------- & -.48 & ------- & -..-- & ‥-- & 108 \\
\hline & 22,400 & .56 & -1.7 & .091 & .18 & -.47 & ------ & ------ & ------- & 107 \\
\hline & 10,500 & .57 & -1.5 & .091 & .20 & -.50 & ------ & .34 & -..-.- & 107 \\
\hline & 10,000 & .58 & -1.4 & .092 & .19 & -.30 & ----- & .63 & -0.35 & 106 \\
\hline & 23,200 & .58 & -1.0 & .082 & .18 & -.44 & -.65 & .78 & -.37 & 106 \\
\hline
\end{tabular}


area averages about 0.6 . The coefficient for latitude is negative, which indicates that peak discharges decrease in magnitude in a northward direction. Orographic influence is significant, and that influence is incorporated in the geographic boundaries of the 15 low- to middle-elevation flood regions. The coefficient for mean basin elevation is negative, which indicates that peak discharges decrease in magnitude as elevation increases. The coefficient for distance from the Gulf of Mexico is negative, which indicates decreased peak discharge with increased distance. Basin shape and precipitation intensity (100-year, 24-hour recurrence interval) coefficients have positive signs, which indicate increased discharge with increased magnitude of the variable.

Mean annual precipitation was one of the least significant variables in the 100 -year discharge equation for the entire low- to middle-elevation study area (table 28). The negative coefficient for mean annual precipitation does not agree with the positive coefficients determined for Regions 1 and 3 (tables 5 and 7). This disagreement shows one of the limitations in attempting to define a single peak-discharge relation for a heterogeneous area such as the arid southwestern United States.

The flood regions have vastly different flood characteristics. Some similarities are apparent, however, when the regions are grouped into areas on the basis of latitude. The relations between 100 -year peak discharge and drainage area were compared for three groups of regions (fig. 66). The northern regions $(2-4)$ have an average regression constant of 61 and an average exponent for drainage area of 0.69 . The middle regions $(5-9,15)$ have an average regression constant of 400 and an average exponent for area of 0.45 . The southern regions $(10-14,16)$ have an average regression constant of 970 and an average exponent for area of 0.54.

The 100-year peak-discharge relations for the northern regions have a small variability among regions, small peak discharges for small drainage areas, and a generally steep slope of the relations (fig. 66). The relations for the middle regions have a large variability among regions, moderate magnitude peak discharges for small drainage areas, and a moderate slope of the relations. The magnitude of peak discharges estimated for large drainage areas is similar for the northern and middle regions. The relations for the southern regions have a moderate variability among regions, consistently large peak discharges for all size drainage areas, and a moderate slope of the relations.

Stratification of the data into increments of explanatory variables was evaluated. The final flood regions and models are stratified by elevation, where all sites above a specified elevation are placed in a single high-elevation flood region. The remaining low- to middle-elevation sites are placed into 15 geographic regions. A stratification based on drainage area was tested. In each flood region, sites were placed into two groups depending on whether drainage area was less than or greater than $50 \mathrm{mi}^{2}$. A multiple-regression analysis was performed on each group, and results were compared with the relations for nonstratified sites. The standard errors and regression coefficients for the unstratified and stratified samples were about the same. There tended to be larger standard errors for the small drainage-area group and smaller standard errors for the large drainage-area group but the differences in errors were small. Significant improvement in regression relations, however, was not made with the drainage-area stratification.

A total of 41 gaging stations were considered to have flood-frequency relations that were regional outliers in the regression analyses. The stations were deleted from the computation of the final GLS regression relations. The outliers are 5 percent of the total stations in the 12 flood regions for which GLS regression equations were derived. One region-Western Colorado 9-had 14 percent, two regions had about 7 percent, and the remaining regions had less than 5 percent of the stations deleted. The stations were deleted on the basis of visual examination of the plots of residuals. About two-thirds of the outliers were more than two standard deviations from the mean of the residuals.

Because of their extreme values in a sample, outliers can cause spurious correlations, mask legitimate correlations, or add important information to the sample. Therefore, the change in regression relations caused by deleting outliers needs to be examined. The deletion of outliers in this study 


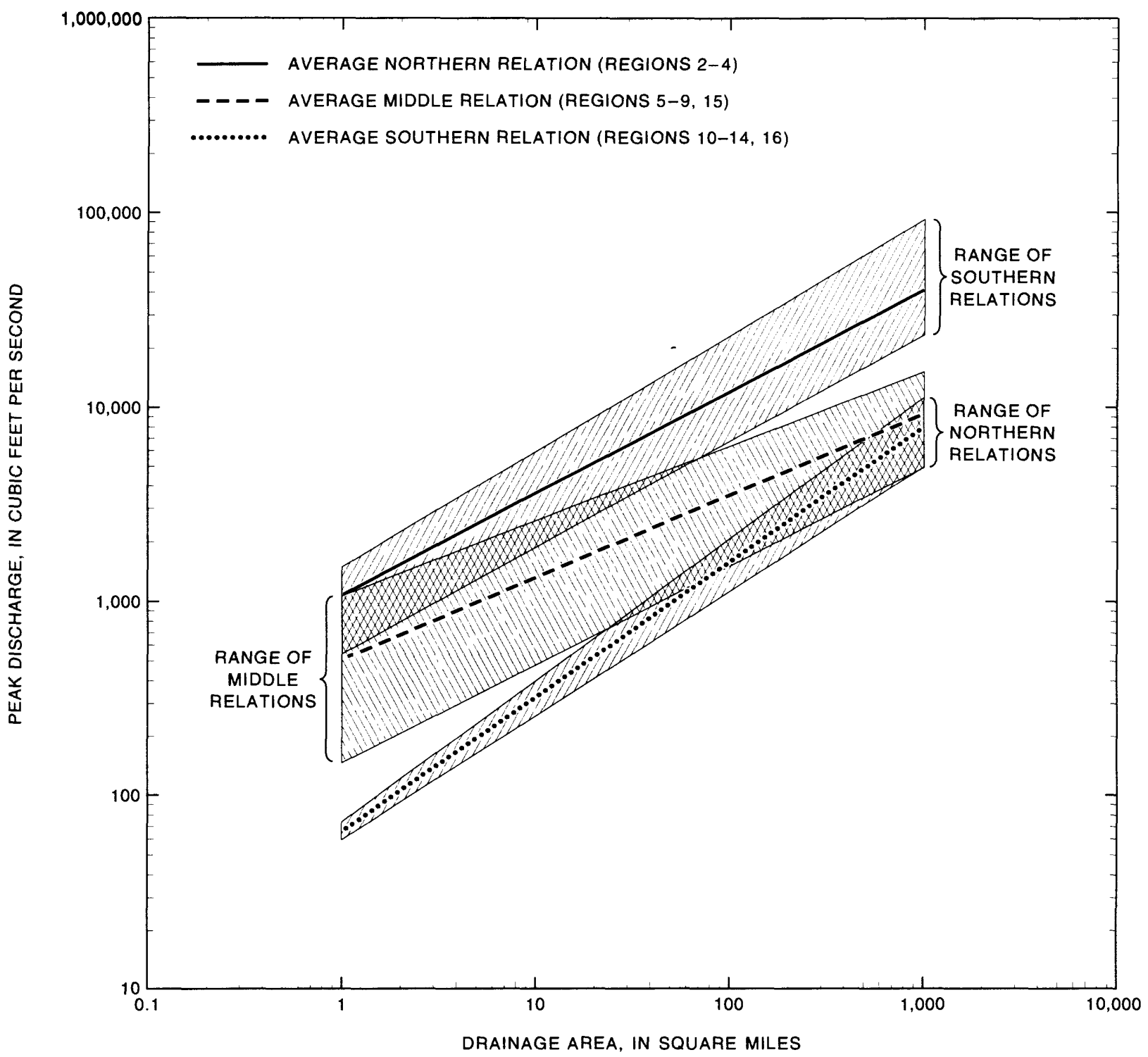

Figure 66. Relation between 100-year peak discharge and drainage area for the northern, middle, and southern parts of the study area. 
caused an average decrease of about 15 percent in the prediction errors for the 100-year peak-discharge equations-a significant improvement in accuracy. The deletion of outliers caused small changes in the regression exponent for drainage area. For the 100 -year peak-discharge equations, the average change in the exponent for drainage area was about 6 percent. The deletion of outliers had a larger effect on the second variable in the 100-year peak-discharge equations, where the average change in exponent was about 20 percent. This change matched the conceptual model for that variable in all the regions, and in 70 percent of the regions, the second explanatory variable became more significant when the outliers were deleted.

Many of the outlier stations have basin or stream-channel characteristics that are not defined by available explanatory variables and that do not fit the population of streams represented by the majority of the sample of stations. These characteristics such as basins with large areas of permeable rocks or distributary flow, or stream channels that cause a large quantity of floodflow attentuation, were described in the section entitled "Excluded Streams and Distributary-Flow Areas." The regional models in this study may not apply to streams with such characteristics.

Accuracy and split-sample analysis.-The accuracy of the GLS regression models was determined by the average standard error of prediction, which is a measure of how well regression models estimate the response variable at the calibration sites (tables 5-20). The process of determining the best regression equation is often called calibration. Another method of assessing accuracy that was used in this study was to estimate the prediction error using a split-sample technique, which is a measure of how well regression models estimate the response variable at sites other than calibration sites.

When a split-sample analysis is used to estimate prediction error, the data are split into two parts; one part is used to calibrate a new predictive model, and the other part is used to evaluate or validate the new model's performance. The new calibrated model is applied to the validation data set to estimate the average prediction error and to evaluate the significance of the explanatory variables. If the sample contains a wide range and even distribution of the explanatory variables and the new model is well calibrated, the explanatory variables that were significant in the original model will be significant in the split-sample analysis.

A split-sample analysis was made for the predictive equations for the 12 flood regions with GLS regional equations (table 29). For each region, the gaging-station records were divided into one group with two-thirds of the data used for calibration of a new model. The second group with the remaining one-third of the data was used for validation and estimation of prediction error. The stations were ordered by station number and assigned alternately to each group. This procedure resulted in the calibration group and validation group having similar basin and climatic characteristics.

The new regression models developed for the split-sample analysis had coefficients that were very similar to the original models (tables 5-20). In a few of the new models, some of the explanatory variables were not significant at the 5-percent level; however, to estimate prediction error, all new models used the same explanatory variables as the original models.

Most split-sample prediction errors are larger than the corresponding GLS prediction errors. Split-sample prediction errors estimated for Regions 3, 5, 7, 9, 14, and 15 are questionable because of the small sample size: less than 15 stations had data for error estimation. For example, the average computed split-sample prediction error for the six recurrence-interval peak discharges is smaller than the average GLS prediction error in Regions 3 and 14 . The average split-sample prediction error for the six regions with more than 20 stations for error estimation is about 8 percent larger than the average GLS prediction error.

In addition to the split-sample analysis, another method was used to assess the accuracy or validity of the regression relations of 100-year peak discharges for the 16 flood regions. Design-probability theory (Riggs, 1968, p. 13) was used to compare the computed 100 -year relations to the plotted maximum 
Table 29. Summary of estimated prediction errors of generalized least-squares regional models

[Recurrence interval, in years: PE, the estimated average standard error of prediction from calibration of generalized least-squares model, in percent. PES, the estimated average prediction error from split-sample analysis, in percent. Number of stations is the total number of stations in region used for regression analysis]

\begin{tabular}{|c|c|c|c|c|c|c|c|c|c|c|c|c|c|}
\hline \multirow{3}{*}{ Region } & \multirow{3}{*}{$\begin{array}{l}\text { Number } \\
\text { of } \\
\text { stations }\end{array}$} & \multicolumn{12}{|c|}{ Recurrence interval, in years } \\
\hline & & \multicolumn{2}{|c|}{2} & \multicolumn{2}{|c|}{5} & \multicolumn{2}{|c|}{10} & \multicolumn{2}{|c|}{25} & \multicolumn{2}{|c|}{50} & \multicolumn{2}{|c|}{100} \\
\hline & & PE & PES & PE & PES & PE & PES & PE & PES & PE & PES & PE & PES \\
\hline 1 & 165 & 59 & 64 & 52 & 55 & 48 & 52 & 46 & 52 & 46 & 52 & 46 & 54 \\
\hline 2 & 108 & 72 & 76 & 66 & 65 & 61 & 65 & 61 & 68 & 64 & 70 & 68 & 74 \\
\hline 3 & 35 & 86 & 74 & 83 & 67 & 80 & 64 & 78 & 62 & 77 & 61 & 78 & 62 \\
\hline 4 & 108 & 64 & 66 & 57 & 56 & 53 & 54 & 51 & 53 & 52 & 53 & 53 & 54 \\
\hline 5 & 37 & 135 & 151 & 101 & 123 & 84 & 115 & 87 & 109 & 91 & 107 & 95 & 105 \\
\hline 7 & 28 & 56 & 75 & 45 & 64 & 45 & 62 & 49 & 52 & 53 & 52 & 59 & 55 \\
\hline 8 & 108 & 72 & 81 & 62 & 69 & 57 & 65 & 54 & 61 & 53 & 60 & 53 & 60 \\
\hline 9 & 43 & 68 & 87 & 55 & 60 & 52 & 51 & 53 & 48 & 57 & 48 & 59 & 53 \\
\hline 12 & 68 & 105 & 88 & 68 & 57 & 52 & 50 & 40 & 50 & 37 & 58 & 39 & 63 \\
\hline 13 & 73 & 57 & 51 & 40 & 36 & 37 & 38 & 39 & 47 & 43 & 55 & 48 & 64 \\
\hline 14 & 22 & 74 & 51 & 63 & 34 & 65 & 28 & 63 & 29 & 64 & 25 & 66 & 25 \\
\hline 15 & 17 & 64 & 75 & 66 & 80 & 68 & 84 & 71 & 93 & 73 & 101 & 76 & 111 \\
\hline
\end{tabular}

peak discharges of record (figs. 19,21,23,25,28, 30, $32,34,36,37,39,41,42,44,47,49)$. Using the average length of independent station records in a region, the percentage of stations that should nothave a 100-year peak discharge can be estimated. For example, design probability indicates that for a number of independent 20 -year records about 82 percent should not have a 100-year peak discharge. For all the flood regions, the number of annual maximum peak discharges that plotted below the relation for the 100 -year flood closely agreed with the number expected from the design-probability method.

\section{Hybrid Method}

The hybrid method was developed as part of this study to define regional flood-frequency relations for Regions $6,10,11$, and 16 where many of the station flood-frequency relations appear unreliable. Flood-frequency relations could not be determined for more than 30 percent of the gaging stations in those regions because there were too few years with flow or the plot of the series of annual peaks could not be reliably fit by a LPII probability distribution. The plots of the annual series of peaks frequently do not appear to define a smooth curve, and no basis exists for using a LPIII distribution or any other three-parameter relation to estimate the flood-frequency characteristics at these stations.

The hybrid method combines all the records of annual peaks at all the gaging stations in a region as in the station-year approach (Fuller, 1914) to produce regional flood-frequency relations. The station-year method is based on the assumption that independent records of annual peak discharge from a region can be combined to form one long composite record if the peaks of the individual records can be reduced to a common base. In previous applications of a station-year approach (Carrigan, 1971; Wahl, 1982), annual flood records were reduced to a common base by dividing each peak from a particular record by the mean of that record. The standardized peaks are assumed to be from the same flood population (the coefficient of variation is constant at all stations); therefore, a single-probability distribution can be fit to the composite record. In the hybrid and station-year methods, spatial sampling is assumed to be equivalent to time sampling if the records are 
independent. Thus, a combination of 10 records, each with 10 years of record, results in a 100 -year composite record. A complete description of the hybrid method and associated assumptions is given in Hjalmarson and Thomas (1992).

The hybrid method incorporates the station-year approach to produce regional flood-frequency relations based on basin and climatic characteristics. Wahl's (1982) application of a modified station-year approach to a semiarid region in Wyoming standardized the logarithms of annual peak discharges by dividing by the mean of the logarithms of the peaks. Wahl (1982) noted, however, that in a record containing many years of no flow, the average becomes a meaningless statistic and a new standardization technique is needed. The hybrid method addresses the problem of no-flow years in flood records, a common problem in the southwestern United States. The method reduces flood records to a common base by dividing annual peaks by a function of common hydrologic characteristics.

In the hybrid method, records of annual peak discharges from gaging stations are combined into three or more levels of a common basin characteristic, such as drainage area. For this study, each level had at least 100 annual peaks to avoid extrapolation to the 100 -year flood and to allow for application of the Weibull plotting-position formula. Annual peak discharges within each level are standardized using an approximate factor and combined to form a single composite record as in the station-year method. The standardizing factor is refined with an iterative technique that uses regression and flood-frequency analysis. Standardized flood-frequency relations are determined for eachbasin-characteristic level at each iteration, and regional flood-frequency relations using basin and climatic characteristics are determined at the final iteration.

Drainage area is the first characteristic used for the iterative technique, and additional characteristics are individually added using the same iterative technique to yield the final regional relation. Additional characteristics are added only if they significantly $(\alpha<0.05)$ reduce the standard error of regression of the regional relation. The explanatory variables used in the four regions with hybrid relations (Regions 6, 10,11, and 16) are drainage area, mean basin elevation, and mean annual evaporation.

A major advantage of the hybrid method is that no extrapolation is needed for the flood probability of interest, assuming independence of peakdischarge data, and elementary plotting-position formulas can be used to define flood-frequency relations. Because little is known about how to obtain valid estimates of probability for the many ephemeral streams of the more arid regions of this study, the probabilities were simply computed using the Weibull plotting-position formula. The use of the Weibull method with the compositing of records avoids the problem of attempting to fit a smooth curve through the data.

In the application of the hybrid method to a particular region, three assumptions need to be evaluated; the annual peaks at gaging stations should be independent, and the explanatory variables should be independent and normally distributed. The sample of gaging stations and peak discharges in the four arid regions with hybrid relations in this study $(6,10,11$, and 16$)$ appear to meet the assumption of independence. Significant floods did not tend to occur in the same years at most sites. The gaged sites generally are far apart, and most have small drainage areas. The median drainage area of the gaged sites is about $11 \mathrm{mi}^{2}$, and about two thirds of the sites have a drainage area of less than $50 \mathrm{mi}^{2}$. Smaller drainage areas would be less likely to experience the same storms that produce the annual peaks. About 60 percent of the annual peaks are caused by summer thunderstorms, which generally have a small areal extent and occur in an erratic fashion. Independence of the samples of log-transformed explanatory variables is indicated because of small correlation coefficients $(r)$; drainage area and mean basin elevation in region 6 have an $r$ value of 0.19 , drainage area and mean annual evaporation in region 11 have an $r$ value of -0.06 , and drainage area and mean annual evaporation in region 16 have an $r$ value of 0.21 . The explanatory variables are distributed fairly evenly through their range of values (figs. 29, 37, 
38 , and 48), and boxplots of the log-transformed variables appear normal.

For regions where most station flood-frequency relations can be defined, the hybrid method and the station-relation regression method (GLS) produce regional relations with similar coefficients, but the standard errors of estimate are computed differently and thus the magnitudes of the errors are different. Standard errors for GLS relations are similar to the well-known OLS standard errors, and the differences between OLS and GLS errors are explained in Stedinger and Tasker (1985). A discussion of how hybrid error is computed is found in Hjalmarson and Thomas (1992), and a brief explanation is given here.

The standard errors of the hybrid relations for regions $6,10,11$, and 16 are much larger than the standard errors of GLS relations for the remaining regions. The ratio of the average hybrid error to the average error of the GLS relations is more than 10 for region 6 , about 6 for region 10, and less than 2 for regions 11 and 16. Two basic reasons for this difference are that the two methods have computational differences and are applied to regions with different flood characteristics.

The average standard error of regression in the hybrid method is estimated using a variation of a direct assessment procedure where subsets of station records are randomly selected without replacement, estimates of $T$-year discharge are made for each subset of stations, the sample variance of the estimates of T-year discharge is computed, and the population variance or standard error is computed using a relation between the variance about the mean value of $\mathrm{T}$-year discharge for a region and the variance about the mean value of $T$-year discharge for a sample. In this study, thirty subsets of stations were selected for each step of the error analysis.

The hybrid errors are larger than the GLS errors because the hybrid errors include much of the within-station residual variance, which is the variance of annual peak discharges about the flood-frequency relation that is fitted to the record at a particular gaging station. The GLS method takes into account the fact that stations in a region have unequal lengths of record, which results in estimates of $\mathrm{T}$-year discharges with unequal variances; however, all the variance associated with the fitting of a relation to peak discharges at a particular gaging station is not taken into account in GLS errors.

The hybrid errors are larger than the GLS errors in this report because the hybrid relations are applied to four regions with more variable flood characteristics than the 12 GLS regions. The magnitude of the hybrid errors is closely related to the variability of the annual peak discharges and the percentage of undefined station flood-frequency relations in a region. The largest hybrid errors are in regions 6 and 10, and the hybrid errors for regions 11 and 16 are of moderate magnitude. The average standard deviation of peak discharges in gagingstation records is about $0.9 \log$ units for regions 6 and 10, $0.5 \log$ units for regions 11 and 16 , and 0.4 $\log$ units for the 12 GLS regions. The average percentage of undefined station flood-frequency relations is about 55 percent for regions 6 and 10, 30 percent for regions 11 and 16 , and 11 percent for the 12 GLS regions. The hybrid relations are developed from all station records in the regions, and the GLS relations are developed from only the stations with defined flood-frequency relations.

The large errors of the hybrid relations in regions 6 and 10 indicate that much of the variation in flood characteristics remains unexplained by the relations; therefore, those relations must be considered as only rough estimates. The magnitude of the errors is too large to have much meaning, but it does show the relative differences between relations for the different recurrence intervals. GLS relations were not determined in those regions because they would be based on less than half the available peak-discharge information.

\section{Transition Zones}

At most ungaged sites in the study area, flood-frequency relations can be estimated using the single set of regression equations for the flood region in which the site is located. When a site is near a regional boundary, however, a weighted estimate of peak discharge may be more appropriate. Computed peak discharges from the equations of two adjacent regions may be quite different for a site near a boundary. Two transition zones are defined in this report where methods are 
provided to weight estimated flood-frequency relations: (1) sites with a drainage area in two low- to middle-elevation regions and (2) sites in a low- to middle-elevation flood region where the basin is near the boundary of the high-elevation region.

Weighted flood-frequency relations for sites with a drainage area in two low- to middle-elevation regions are computed using the percentage of the drainage area in each region (equation 6). Peak discharges are estimated for each region as if the drainage area were entirely in one region, then the weighted average of these discharges is computed.

Weighted flood-frequency relations for sites in a low- to middle-elevation flood region with an elevation that is within $700 \mathrm{ft}$ of the boundary of the high-elevation region are computed using equation 7. Equation 7 is an averaging procedure based on how the elevation of the study site fits into the elevation boundaries of the 700-foot transition zone. Peak discharges are estimated for each region as if the drainage area were entirely in one region, then the weighted average discharge is computed. The weighted discharges are close to the low- to middle-elevation models near the lower part of the transition zone and close to the high-elevation model near the upper part of the transition zone.

The selection of the 700 -foot transition zone was made by comparing residuals computed from the low- to middle-elevation and high-elevation regional models. Gaged sites were placed into four groups with gaged-site elevations between the boundary of the high-elevation region and 500,700, 1,000 , and $1,200 \mathrm{ft}$ below that boundary. The 100-year peak-discharge equations for the appropriate low- to middle-elevation regions and the high-elevation region were then used to compute residuals for each site (table 30 ). The mean and median of the residuals should ideally be zero which would indicate no bias, and the magnitude of the standard deviation indicates the accuracy. The low- to middle-elevation models have a slight positive bias for all groups, and the high-elevation model has a slight negative bias for all groups. As the transition zone becomes larger and more lower elevation sites are added to the groups, the bias becomes smaller and the standard deviation remains the same for the low- to middle-elevation models. Bias and standard deviation become larger for the high-elevation model. These comparisons indicate that as the transition zone gets larger, the low- to middle-elevation models get slightly better; however, the high-elevation model becomes more biased and less accurate.

The criterion for selecting the most appropriate size of a transition zone was based on the composite residuals in table 30 . For each site, an average predicted 100-year peak discharge was computed using the predicted discharges from the appropriate low- to middle-elevation model and the highelevation model. The composite residual is the average predicted discharge minus the station value of the discharge. The best transition zone, therefore, has the smallest bias and smallest dispersion of composite residuals. The transition zone of 700 feet was selected for this study because the mean and median composite residuals are closest to zero and the standard deviation of the composite residuals is similar to the other three transition zones (table 30).

Two statistical tests were made to compare the central tendency or bias of the composite residuals in the four transition zones. The hypothesis that the mean is equal to zero was tested with a t-test, and the mean of the residuals is significantly different than zero for the zones of 1,000 and $1,200 \mathrm{ft}$ $(\alpha<0.05)$. The hypothesis that the median is equal to zero was tested with a Wilcoxon signed rank procedure. None of the transition zones had a median that was significantly different than zero. The 700-foot zone, however, has the largest alpha value; the alphas for the zones are 0.23 for $500 \mathrm{ft}$, 0.87 for $700 \mathrm{ft}, 0.15$ for $1,000 \mathrm{ft}$, and 0.06 for 1,200 ft (Minitab, 1988, p. 97, 191-192).

\section{ADDITIONAL DATA AND STUDY NEEDS}

A better understanding of flood characteristics is needed for flood-frequency studies in the southwestern United States. Because streamflow is extremely variable, data obtained from the sparse areal distribution of gaging stations and the short records at many stations commonly result in samples that do not represent the populations of 
Table 30. Summary of residuals from low- to middle-elevation regional models, high-elevation model, and composite model for gaged sites in a transition zone

Transition zone-The zone includes gaged sites with elevations between the boundary of the high-elevation region and 500,700,1,000, and 1,200 feet below that boundary.

Composite model-A composite 100-year peak discharge is computed by taking the average of the predicted discharge from the appropriate lowto middle-elevation model and the high-elevation model. The composite residual is the composite discharge, in log units, minus the station discharge, in $\log$ units.

\begin{tabular}{|c|c|c|c|c|c|c|c|c|c|c|}
\hline \multirow{3}{*}{$\begin{array}{l}\text { Transi- } \\
\text { tion } \\
\text { zone, in } \\
\text { feet }\end{array}$} & \multirow{3}{*}{$\begin{array}{l}\text { Num- } \\
\text { ber of } \\
\text { sites }\end{array}$} & \multicolumn{9}{|c|}{ Regression residuals from 100-year peak-discharge models, In log units } \\
\hline & & \multicolumn{3}{|c|}{ Low- to middie-elevation models } & \multicolumn{3}{|c|}{ High-eievation modei } & \multicolumn{3}{|c|}{ Composite model } \\
\hline & & Mean & Median & $\begin{array}{l}\text { Stan- } \\
\text { dard } \\
\text { devia- } \\
\text { tion }\end{array}$ & Mean & Median & $\begin{array}{c}\text { Stan- } \\
\text { dard } \\
\text { devia- } \\
\text { tion }\end{array}$ & Mean & Median & $\begin{array}{c}\text { Stan- } \\
\text { dard } \\
\text { devia- } \\
\text { tion }\end{array}$ \\
\hline 500 & 64 & 0.14 & 0.10 & 0.36 & -0.08 & -0.02 & 0.45 & 0.03 & 0.04 & 0.35 \\
\hline 700 & 100 & .11 & .07 & .36 & -.15 & -.03 & .50 & -.02 & .00 & .38 \\
\hline 1,000 & 162 & .09 & .06 & .35 & -.23 & -.10 & .53 & -.07 & -.02 & .39 \\
\hline 1,200 & 198 & .09 & .06 & .34 & -.24 & -.10 & .54 & -.08 & -.02 & .39 \\
\hline
\end{tabular}

floods that occur in the area. More streamflow- and crest-stage gaging stations throughout the study area that have longer records would provide an improved data base. Crest-stage stations are an efficient method for obtaining records of annual maximum peak discharges, and more peak-discharge information is needed especially in the low- to middle-elevation areas where streamflow is more variable. Existing peak-discharge records could be augmented by historical information. Historical information is obtained from newspapers and other cultural information, from observation of mudlines after peak flows, from records of bridge and culvert construction, and from paleoflood investigations.

Statistical and probability analyses commonly are used to estimate flood-frequency relations at gaged and ungaged sites. More research is needed on which probability distributions are applicable to streams in arid areas. The analysis of regional skew coefficient in this study indicated that the log-normal distribution may be applicable to many sites in the study area.

The hybrid method developed during this study uses elementary plotting-position formulas to estimate regional flood-frequency relations. Thus, it avoids the potential problem of fitting an incorrect probability distribution to the data. The method combines elements of the station-year method and multiple-regression analysis to determine regional relations directly from the peak-discharge data. The method, however, assumes independence of the peak discharges, and the explanatory variables should be independent and normally distributed. More evaluation of the potential effects of dependence or nonnormality on hybrid coefficients and errors is needed.

The large errors of the hybrid relations in regions 6 and 10 indicate that much of the variation in flood characteristics remains unexplained by the relations. These two regions have the most arid climate in the study area. Reliable flood-frequency relations are difficult to define at many gaging stations because the available records have many years with no flow and a large variability of the peak discharges. More studies are needed in those regions to find alternative methods of estimating flood-frequency relations. Commonly used statistical methods that are based on station flood-frequency relations do not appear to be well suited to such areas. The hybrid method, which does not use station flood-frequency relations, needs to be developed and refined. Other new methods with perhaps a multidiscipline approach need to be investigated.

Two methods are commonly used for estimating flood-frequency relations at ungaged 
sites-(1) transferring flood-frequency relations from gaged to ungaged sites by multiple-regression or index-flow techniques, and (2) estimating runoff by applying a rainfall intensity of a specific probability to a deterministic or empirical rainfall-runoff model. Both methods would benefit from additional precipitation data, especially in middle- to high-elevation areas. A definition of precipitation intensity for specific recurrence intervals could be obtained from such data. Additional data and information that are needed for the information-transfer method used in this report include more explanatory variables to define the variation in basin and flood characteristics of the southwestern United States. Some potentially significant basin characteristics include soils, geologic material, vegetation, and drainage network.

The technologyused in geographic-information systems has a potential for determining new explanatory variables. In this study, values of maximum precipitation intensity, mean annual evaporation, potential natural vegetation, and orographic influence were determined for gaged-site locations using geographic-information system technology, and all characteristics except potential natural vegetation were significantly related to flood characteristics. When drainage-area boundaries for the gaging stations are defined in a geographic-information system, significant information would be available to develop future studies and models. The use of geographic-information system technology to more uniformly redefine explanatory variables, such as mean basin elevation and mean annual precipitation, also has potential for improving regional flood-frequency relations.

The sample of gaging stations used in this study did not represent some of the hydrologic conditions that exist in the study area. Streams in permeable volcanic or limestone terrain, distributary-flow areas, such as active alluvial fans, and playas were not adequately sampled. Transferring flood information from gaged to ungaged sites may be inadequate in low- or middle-elevation sites in deserts where the drainage area is large and where a large peak-discharge attenuation often occurs. Investigations of flood-frequency characteristics in the areas where flood magnitude decreases along the stream as drainage area increases would add significantly to future studies.

Peaks at miscellaneous sites were excluded from this study because some extreme peaks at ungaged sites in the study area have been found to be erroneous. Some extreme peaks in the arid southwestern United States that were estimated using indirect methods such as the slope-area method probably were debris flows. The slope-area method is inappropriate for these non-Newtonian flows and commonly greatly overestimates the peak discharge. The drainage-basin area for some miscellaneous sites was determined several years ago from small-scale topographic maps and these computed areas may have large errors. A review of indirect measurements for the extreme peaks including an examination of photographs for evidence of debris flows and recomputation of the drainage basins using the latest topographic maps is needed.

\section{SUMMARY}

The general magnitude of peak discharges in the southwestern United States decreases in a northward direction. In the southern part of the area (between $29^{\circ}$ and $37^{\circ}$ latitude), the mean maximum unit peak discharge of record is $316\left(\mathrm{ft}^{3} / \mathrm{s}\right) / \mathrm{mi}^{2}$. In contrast, the mean maximum unit peak discharge of record is $26\left(\mathrm{ft}^{3} / \mathrm{s}\right) / \mathrm{mi}^{2}$ in the northern part of the area (between $41^{\circ}$ and $45^{\circ}$ latitude).

An elevation threshold exists in the study area where large floods caused by thunderstorms rarely occur above that threshold. For sites between $29^{\circ}$ and $41^{\circ}$ latitude, the elevation threshold is approximately $7,500 \mathrm{ft}$ above sea level. Between $41^{\circ}$ and $45^{\circ}$ latitude, the elevation threshold decreases in a northward direction at a rate of about $300 \mathrm{ft}$ for each degree of latitude. For example, at $42^{\circ}$ latitude, the threshold is $7,200 \mathrm{ft}$ and at $43^{\circ}$ latitude, the threshold is $6,900 \mathrm{ft}$.

Detailed flood-frequency analyses were made of more than 1,300 gaging stations with a combined 40,000 station years of annual peak discharges. The LPIII probability distribution and the method of 
moments were used to define flood-frequency relations for most gaging-station records. The reliability of station flood-frequency relations was assessed by visual examination of how well the computed relations fit the plotted peak discharges, the presence or absence of outliers, and the shape exhibited by the plotted peaks.

Generally, the computed flood-frequency relations agreed well with the plotted peak discharges. A low-discharge threshold was applied to about one-half the sites to adjust the relations for low outliers. With few exceptions, the use of the low-discharge threshold resulted in markedly better appearing fits between the relations and the peak-discharge data. About one-third of the sites had a high outlier, or an odd-appearing shape of the plotted peaks such as a discontinuity or a sharp break; however, these sites were judged to have adequate fits and the computed relations were used. The individual flood-frequency relations for 264 of the sites were judged to be unreliable because of extremely poor fits of the computed relations to the peak-discharge data. The sites may have had inadequate samples to define a relation or non-log-Pearson Type III probability distributions; therefore, the computed relations at these sites were not used in the standard regional analysis on the basis of station flood-frequency relations. Peak-discharge records at the 264 sites that had unreliable relations are extremely variable and had an average standard deviation of $0.88 \mathrm{log}$ units. Most of the 264 sites were from extremely arid areas. One hundred and twelve ( 42 percent) of the sites had more than 25 percent of the annual records with no flow.

The hybrid method developed during this study was used to define regional relations in the arid regions where there were many years of no flow at the gaging stations and where many of the station relations were unreliable. A major advantage of the new hybrid method, which has no extrapolation to the recurrence interval of interest assuming independence of the data, is that elementary plotting-position formulas can be used to define the regional flood-frequency relations. The hybrid method uses all of the available peak-discharge data in the extremely arid regions while the standard method that is based on station flood-frequency relations uses only the defined station relations. Data in station records with undefined flood-frequency relations are not used.

A mixed-population analysis was performed on a sample of 51 gaging stations with peaks caused by snowmelt and summer thunderstorms. Significant differences were not found between flood-frequency relations computed from the mixed populations and from composite relations computed by separating the peaks, computing separate relations, and combining the separate relations.

An analysis of regional skew coefficient was made for the study area. The methods of attempting to define the variation in skew by geographic areas or by regression with basin and climatic characteristics all failed to improve on a mean of zero for the sample. The regional skew used in the study, therefore, was the mean of zero with an associated error equal to the sample variance of $0.31 \log$ units.

The regional analysis consisted of an investigation of different forms of models, the significance of all available explanatory variables, and geographic variation of flood magnitudes at selected recurrence intervals. The geographic variation of flood characteristics was explained by dividing the study area into 16 flood regions. A high-elevation region was defined for the entire study area with the lower boundary coinciding with the elevation threshold for large floods caused by thunderstorms.

The model that best describes most regional flood-frequency relations for this study area is the multiplicative model, where all variables are log transformed. Eighteen of the 19 investigated explanatory variables were significantly related to flood characteristics in some part of the study area; however, only drainage area, mean basin elevation, mean annual precipitation, mean annual evaporation, latitude, and longitude are needed to use the regional models.

GLS regression was used to define the regression models in 12 regions where sufficient data allowed a reasonable regional model to be developed using the flood-frequency relations at 
gaged sites. Four regions had more than 30 percent of the gaged sites with no defined relations; therefore, the regression method was not used because of the large amount of missing information. The hybrid analysis was used in those four regions because the method does not use station flood-frequency relations and the method uses all the data from gaging stations in a region. The average standard error of prediction in the 12 regions with GLS models ranged from 39 to 95 percent for the 100-year peak discharge, and only three of those models have errors of greater than 70 percent. The estimated average standard error in the four regions with hybrid models, computed differently than GLS errors, ranged from 0.44 to 1.8 $\log$ units for the 100 -year peak discharge.

Descriptions are provided for estimating flood-frequency relations at gaged and ungaged sites. Flood-frequency relations and selected basin and climatic characteristics are summarized for more than 1,300 gaging stations in the southwestern United States.

\section{REFERENCES CITED}

Baker, V.R., 1984, Paleoflood hydrologic techniques for the extension of streamflow records: Washington, D.C., National Research Council, Transportation Research Record 922, p. 18-23.

Baker, V.R., Ely, L.L., O'Connor, J.E., and Partridge, J.B., 1987, Paleoflood hydrology and design applications, central Arizona, in Proceedings of the International Symposium on Flood Frequency and Risk Analysis, Baton Rouge, Louisiana State University, May 14-17, 1986: Boston, Massachusetts, D. Reidel Publishing Co., p. 339-353.

Benson, M.A., 1964, Factors affecting the occurrence of floods in the Southwest: U.S. Geological Survey Water-Supply Paper 1580-D, 72 p.

Boughton, W.C., and Renard, K.G., 1984, Flood-frequency characteristics of some Arizona watersheds: American Water Resources Association, Water Resources Bulletin, v. 20, no. 5, p. 761-769.

Burkham, D.E., 1988, Methods for delineating flood-prone areas in the Great Basin of Nevada and adjacent States: U.S. Geological Survey Water-Supply Paper 2316, 20 p.

Butler, Elmer, and Cruff, R.W., 1971, Floods of Utah, magnitude and frequency characteristics through 1969: U.S. Geological Survey unnumbered open-file report, $34 \mathrm{p}$.

Butler, E.B., Reid, J.K., and Berwick, V.K., 1966, Magnitude and frequency of floods in the United States, Part 10. The Great Basin: U.S. Geological Survey Water-Supply Paper 1684, 256 p.

Carrigan, P.H., Jr., 1971, A flood-frequency relation based on regional record maxima: U.S. Geological Survey Professional Paper 434-F, 22 p.

Chow, V.T., ed., 1964, Handbook of applied hydrology: New York, McGraw-Hill Book Company, 1050 p.

Christenson, R.C., Johnson, E.B., and Plantz, G.G., 1985, Manual for estimating selected streamflow characteristics of natural-flow streams in the Colorado River Basin in Utah: U.S. Geological Survey Water-Resources Investigations Report $85-4297,39 \mathrm{p}$.

Costa, J.E., 1987, A comparison of the largest rainfall-runoff floods in the United States with those of the People's Republic of China and the world: Journal of Hydrology, v. 96, no. 1-4, p. 101-115.

Craig, G.S., Jr., and Rankl, J.G., 1978, Analysis of runoff from small drainage basins in Wyoming: U.S. Geological Survey Water-Supply Paper 2056, 70 p.

Crawford, N.H., and Linsley, R.K., 1966, Digital simulation in hydrology-Stanford Watershed Model IV: Palo Alto, California, Stanford University Department of Civil Engineering Technical Report 39, 210 p.

Crippen, J.R., 1978, Composite log-Pearson Type III frequency-magnitude curve of annual floods: U.S. Geological Survey Open-File Report 78-352, 5 p.

Crippen, J.F., and Bue, C.D., 1977, Maximum floodflows in the conterminous United States: U.S. Geological Survey Water-Supply Paper 1887, $52 \mathrm{p}$.

Cunnane, C., 1978, Unbiased plotting positions-A review: Journal of Hydrology, v. 37, p. 205-222.

Dawdy, D.R., 1979, Flood frequency estimates on alluvial fans: American Society of Civil Engineers, Journal of the Hydraulics Division, v. 105, no. HY11, p. 1407-1413.

Draper, N.R., and Smith, H., 1981, Applied regression analysis, second edition: New York, John Wiley and Sons, Inc., 709 p. 
Ely, L.L., and Baker, V.R., 1985, Reconstructing paleoflood hydrology with slackwater deposits-Verde River, Arizona: Physical Geography, v. 6, no. 2, p. 103-126.

Eychaner, J.H., 1976, Estimating runoff volumes and flood hydrographs in the Colorado River basin, southern Utah: U.S. Geological Survey Water-Resources Investigations Report 76-102, 18 p.

1984, Estimation of magnitude and frequency of floods in Pima County, Arizona, with comparisons of alternative methods: U.S. Geological Survey Water-Resources Investigations Report 84-4142, $69 \mathrm{p}$.

Farnsworth, R.K., Thompson, E.S., and Peck, E.L., 1982, Evaporation atlas for the contiguous 48 United States: National Oceanic and Atmospheric Administration Technical Report NWS 33, 26 p.

Fenneman, N.M., 1931, Physiography of Western United States: New York, McGraw-Hill Book Company, $534 \mathrm{p}$.

Fields, F.K., 1975, Estimating streamflow characteristics for streams in Utah using selected channel-geometry parameters: U.S. Geological Survey WaterResources Investigations Report 74-34, 19 p.

Fletcher, J.E., Huber, A.L., Haws, F.W., and Clyde, C.G., 1977, Runoff estimates for small rural watersheds and development of a sound design method, volume II, Recommendations for preparing design manuals and appendices B, C, D, E, F, G, and $\mathrm{H}$ : Federal Highway Administration Report FHWA-RD-77-159, 368 p.

Fuller, J.E., 1987, Paleoflood hydrology of the alluvial Salt River, Tempe, Arizona: Tucson, Arizona, University of Arizona, master's thesis, $70 \mathrm{p}$.

Fuller, W.E., 1914, Flood flows: American Society of Civil Engineers, Transactions, v. 77, no. 1293, p. 564-617.

Hardison, C.H., 1971, Prediction error of regression estimates of streamflow characteristics at ungaged sites: U.S. Geological Survey Professional Paper 750-C, p. C228-C236.

Harenberg, W.A., 1980, Using channel geometry to estimate flood flows at ungaged sites in Idaho: U.S. Geological Survey Water-Resources Investigations Report 80-32, 39 p.

Harris, D.D., and Hubbard, L.E., 1982, Magnitude and frequency of floods in eastern Oregon: U.S.
Geological Survey Water-Resources Investigations Report 82-4078, 45 p.

Hedman, E.R., and Osterkamp, W.R., 1982, Streamflow characteristics related to channel geometry of streams in western United States: U.S. Geological Survey Water-Supply Paper 2193, 17 p.

Hedman, E.R., Moore, D.O., and Livingston, R.K., 1972, Selected streamflow characteristics as related to channel geometry of perennial streams in Colorado: U.S. Geological Survey Open-File Report 72-1060, $24 \mathrm{p}$.

Hejl, H.R., Jr., 1984, Use of selected basin characteristics to estimate mean annual runoff and peak discharges for ungaged streams in drainage basins containing strippable coal resources, northwestern New Mexico: U.S. Geological Survey Water-Resources Investigations Report 84-4260, $17 \mathrm{p}$.

Hjalmarson, H.W., 1991, Flood hydrology of arid basins in southwestern United States, in Kirby, W.H., and Tan, W.Y., compilers, Proceedings of the United States-People's Republic of China Bilateral Symposium on droughts and arid-region hydrology, September 16-20, 1991, Tucson, Arizona: U.S. Geological Survey Open-File Report 91-244, p. 59-64.

Hjalmarson, H.W., and Kemna, S.P., 1991, Flood hazards of distributary-flow areas in southwestern Arizona: U.S. Geological Survey Water-Resources Investigations Report 91-4171, 58 p.

Hjalmarson, H.W., and Thomas, B. E., 1992, A new look at regional flood-frequency relations for arid lands: American Society of Civil Engineers, Journal of Hydraulic Engineering, v. 118, no. 6, p. 868-886.

Hulsing, H., and Kallio, N.A., 1964, Magnitude and frequency of floods in the United States-Part 14. Pacific slope basins in Oregon and lower Columbia River basin: U.S. Geological Survey Water-Supply Paper 1689, 320 p.

Interagency Advisory Committee on Water Data, 1982, Guidelines for determining flood flow frequency: Washington, D.C., Interagency Advisory Committee on Water Data, Hydrology Subcommittee Bulletin 17B, 183 p.

Jarrett, R.D., 1987, Flood hydrology of foothill and mountain streams in Colorado: Fort Collins, Colorado, Colorado State University, doctoral dissertation, $239 \mathrm{p}$. 
Jarrett, R.D., and Costa, J.E., 1982, Multidisciplinary approach to the flood hydrology of foothills streams in Colorado, in Johnson, A.I., and Clark, R.A., eds., International Symposium on Hydrometeorology: Bethesda, Maryland, American Water Resources Association, p. 565-569.

Kircher, J.E., Choquette, A.F., and Richter, B.D., 1985, Estimation of natural streamflow characteristics in Western Colorado: U.S. Geological Survey Water-Resources Investigations Report 85-4086, $28 \mathrm{p}$.

Kjelstrom, L.C., and Moffatt, R.L., 1981, Method of estimating flood-frequency parameters for streams in Idaho: U.S. Geological Survey Open-File Report 81-909, $101 \mathrm{p}$.

Kochel, R.C., 1980, Interpretation of flood paleohydrology using slackwater deposits, lower Pecos and Devils Rivers, southwestern Texas: Austin, Texas, University of Texas doctoral dissertation, $364 \mathrm{p}$.

Kuchler, A.W., 1964, Potential natural vegetation of the conterminous United States: American Geographical Society Special Publication 36, 116 p.

Leavesley, G.H., Lichty, R.W., Troutman, B.M., and Saindon, L.G., 1983, Precipitation-runoff modeling system-User's manual: U.S. Geological Survey Water-Resources Investigations Report 83-4238, $207 \mathrm{p}$.

Lowham, H.W., 1976, Techniques for estimating flow characteristics of Wyoming streams: U.S. Geological Survey Water-Resources Investigations Report 76-112, 83 p.

1988, Streamflows in Wyoming: U.S. Geological Survey Water-Resources Investigations Report $88-4045,84$ p.

Massey, B.C., and Schroeder, E.E., 1977, Application of a rainfall-runoff model in estimating flood peaks for selected small natural drainage basins in Texas: U.S. Geological Survey Open-File Report 77-792, 34 p.

McCain, J.F., and Jarrett, R.D., 1976, Manual for estimating flood characteristics of natural-flow streams in Colorado: Colorado Water Conservation Board,Technical Manual No.1, 68 p.

McGinn, R.A., 1980, Discussion of flood frequency estimates on alluvial fans: American Society of Civil Engineers, Journal of the Hydraulics Division, v. 106, no. HY10, p. 1718-1720.
Miller, J.F., Frederick, R.H., and Tracey, R.J., 1973a, Precipitation-frequency atlas of the Western United States-Volume II, Wyoming: National Oceanic and Atmospheric Administration NOAA Atlas 2, $43 \mathrm{p}$.

1973b, Precipitation-frequency atlas of the Western United States-Volume III, Colorado: National Oceanic and Atmospheric Administration NOAA Atlas 2, $43 \mathrm{p}$.

1973c, Precipitation-frequency atlas of the Western United States-Volume IV, New Mexico: National Oceanic and Atmospheric Administration NOAA Atlas 2, $43 \mathrm{p}$.

1973d, Precipitation-frequency atlas of the Western United States-Volume V, Idaho: National Oceanic and Atmospheric Administration NOAA Atlas 2, 43 p.

1973e, Precipitation-frequency atlas of the Western United States-Volume VI, Utah: National Oceanic and Atmospheric Administration NOAA Atlas 2,67 p.

1973f, Precipitation-frequency atlas of the Western United States-Volume VII, Nevada: National Oceanic and Atmospheric Administration NOAA Atlas 2, $43 \mathrm{p}$.

1973g, Precipitation-frequency atlas of the Western United States-Volume VIII, Arizona: National Oceanic and Atmospheric Administration NOAA Atlas 2, $41 \mathrm{p}$.

1973h, Precipitation-frequency atlas of the Western United States-Volume X, Oregon: National Oceanic and Atmospheric Administration NOAA Atlas 2, $43 \mathrm{p}$.

1973i, Precipitation-frequency atlas of the Western United States-Volume XI, California: National Oceanic and Atmospheric Administration NOAA Atlas 2, $71 \mathrm{p}$.

Minitab, 1988, Minitab reference manual-Release 6.1: State College, Pennsylvania, Minitab, Inc., 341 p.

Moore, D.O., 1974, Estimating flood discharges in Nevada using channel-geometry measurements: Nevada Highway Department Hydrologic Report No. $1,43 \mathrm{p}$.

1976, Estimating peak discharges from small drainages in Nevada according to basin areas within elevation zones: Nevada Highway Department Hydrologic Report No. 3, 17 p.

O'Connor, J.E., Fuller, J.E., and Baker, V.R., 1986, Late Holocene flooding within the Salt River basin, 
central Arizona: Tucson, University of Arizona, Department of Geosciences paper, $84 \mathrm{p}$.

O'Connor, J.E., Webb, R.H., and Baker, V.R., 1986, Paleohydrology of pool- and riffle-pattern development: Boulder Creek, Utah, Geologic Society of American Bulletin, v. 97, p. 410-420.

Partridge, J.B., and Baker, V.R., 1987, Paleoflood hydrology of the Salt River, Arizona: Earth Surface Processes and Landforms, v. 12, p. 109-125.

Patterson, J.L., 1965, Magnitude and frequency of floods in the United States-Part 8. Western Gulf of Mexico basins: U.S. Geological Survey Water-Supply Paper 1682, $506 \mathrm{p}$.

Patterson, J.L. and Somers, W.P., 1966, Magnitude and frequency of floods in the United States-Part 9. Colorado River basin: U.S. Geological Survey Water-Supply Paper $1683,475 \mathrm{p}$.

Reich, B.M., 1988, Flood frequency methods for Arizona streams: Arizona Department of Transportation Report FHWA-AZ88-801, 56 p.

Riggs, H.C., 1968, Frequency curves: U.S. Geological Survey Techniques of Water-Resources Investigations, book 4, chap. A2, 15 p.

Riggs, H.C., and Harenburg, W.A., 1976, Flood characteristics of streams in Owyee County, Idaho: U.S. Geological Survey Water-Resources Investigations Report 76-88, $14 \mathrm{p}$.

Roberts, L.K., 1987, Paleohydrologic reconstruction, hydraulics, and frequency-magnitude relationships of large flood events along Aravaipa Creek, Arizona: Tucson, University of Arizona master's thesis, $63 \mathrm{p}$.

Roeske, R.H., 1978, Methods for estimating the magnitude and frequency of floods in Arizona: Arizona Department of Transportation Report ADOT-RS-15-121, $82 \mathrm{p}$.

Sauer, V.B., 1974, Flood characteristics of Oklahoma streams: U.S. Geological Survey Water-Resources Investigations Report 52-73, $301 \mathrm{p}$.

Schroeder, E.E., and Massey, B.C., 1977, Technique for estimating the magnitude and frequency of floods in Texas: U.S. Geological Survey Water-Resources Investigations Report 77-110.

Scott, A.G., 1971, Preliminary flood-frequency relations and summary of maximum discharges in New Mexico-A progress report: U.S. Geological Survey Open-File Report 71-251, 76 p.
Scott, A.G., and Kunkler, J.L., 1976, Flood discharges of streams in New Mexico as related to channel geometry: U.S. Geological Survey Open-File Report 76-414, 38 p.

Stedinger, J.R., and Tasker, G.D., 1985, Regional hydrologic analysis 1. Ordinary, weighted and generalized least-squares compared: American Geophysical Union, Water Resources Research, v. 21 , no. 9 , p. 1421-1432.

Tasker, G.D., and Stedinger, J.R., 1986, Regional skew with weighted LS regression: Journal of Water Resources Planning and Management, v. 122, no. 2 , p. 225-237.

Tasker, G.D., Eychaner, J.H., and Stedinger, J.R., 1986, Application of generalized least-squares in regional hydrologic regression analysis: U.S. Geological Survey Water-Supply Paper 2310, p. 107-115.

Thomas, B.E., 1985, Problems with statistical flood-frequency analyses of streams in Utah, in Bowles, D.S., ed., Delineation of landslide, flash flood, and debris-flow hazards in Utah: Logan, Utah, Utah State University, Water Research Laboratory Report UWRL/G-85/03, p. 379-393.

Thomas, B.E., and Lindskov, K.L., 1983, Methods for estimating peak discharge and flood boundaries of streams in Utah: U.S. Geological Survey Water-Resources Investigations Report 83-4129, $77 \mathrm{p}$.

Thomas, C.A., Broom, H.C., and Cummans, J.E., 1963, Magnitude and frequency of floods in the United States-Part 13. Snake River Basin: U.S. Geological Survey Water-Supply Paper 1688, $250 \mathrm{p}$.

Thomas, C.A., Harenburg, W.A., and Anderson, J.M., 1973, Magnitude and frequency of floods in small drainage basins in Idaho: U.S. Geological Survey Open-File Report 73-276, 61 p.

Thomas, R.P., and Gold, R., 1982, Techniques for estimating flood discharges for New Mexico streams: U.S. Geological Survey Water-Resources Investigations Report 82-24, 42 p.

Trewartha, G.T., 1954, An introduction to climate: New York, McGraw-Hill Book Company, 402 p.

Tunnell, L., 1991, Summertime precipitation in the high elevations of Colorado: Association of State Floodplain Managers, 15th Annual Conference Proceedings, p. 179-182. 
U.S. Water Resources Council, 1981, Estimating peak flow frequencies for natural ungaged watersheds-A proposed nationwide test: Water Resources Council, Hydrology Committee report, $346 \mathrm{p}$.

U.S. Weather Bureau, 1959-61, Climates of the States: U.S. Department of Commerce, Weather Bureau, Climatography of the United States, no. 60 [section for each State].

1963, Normal annual precipitation (1931-60) for the States of Arizona, Colorado, New Mexico, Utah: U.S. Department of Commerce, Weather Bureau maps, scale, 1:500,000.

Viessman, Warren, Jr., Knapp, J.W., Lewis, G.L., and Harbaugh, T.E., 1977, Introduction to hydrology, 2d ed: New York, Harper and Row, 704 p.

Waananen, A.O., and Crippen, J.R., 1977, Magnitude and frequency of floods in California: U.S. Geological Survey Water-Resources Investigations Report 77-21, 96 p.

Wahl, K.L., 1982, Simulation of regional floodfrequency curves based on peaks of record, in Biswas, M.R., and Biswas, A.K., eds, Alternative
Strategies for Desert Development and Management: New York, Pergamon Press, v. 3, p. $760-769$.

1984, Evolution of the use of channel cross-section properties for estimating streamflow characteristics: U.S. Geological Survey Water-Supply Paper 2262, p. 53-66.

Waltemeyer, S.D., 1986, Techniques for estimating flood-flow frequency for unregulated streams in New Mexico: U.S. Geological Survey Water-Resources Investigations Report 86-4104, $56 \mathrm{p}$.

Webb, R.H., and Betancourt, J.L., 1992, Climatic variability and flood frequency of the Santa Cruz River, Pima County, Arizona: U.S. Geological Survey Water-Supply Paper 2379, 40 p.

Webb, R.H., O'Connor, J.E., and Baker, V.R., 1988, Paleohydrologic reconstruction of flood frequency on the Escalante River, south-central Utah, in Baker, V.R., Kochel, R.C., and Patton, P.C., eds., Flood Geomorphology: New York; John Wiley and Sons, p. $403-418$. 
124 
BASIN, CLIMATIC, AND FLOOD CHARACTERISTICS FOR STREAMFLOWGAGING STATIONS IN SOUTHWESTERN UNITED STATES

To obtain diskettes containing the following data table and the annual peak-discharge data used in this study, contact:

\author{
U.S. Geological Survey \\ National Water Data Exchange (NAWDEX) \\ 421 National Center \\ 12201 Sunrise Valley Drive \\ Reston, VA 22092 \\ Telephone: (703) 648-5676 \\ Telefax: (703)648-5704 \\ Email: cilewis@qvarsa.er.usgs.gov \\ ATTN: Carol Lewis
}


Peak discharge: First line, station value used In regression enalysis, and second line, value weighted with station and regtonal value. For stations with no defined relation, second line, reglonal value of peak discharge.

Dashes indicate no data.

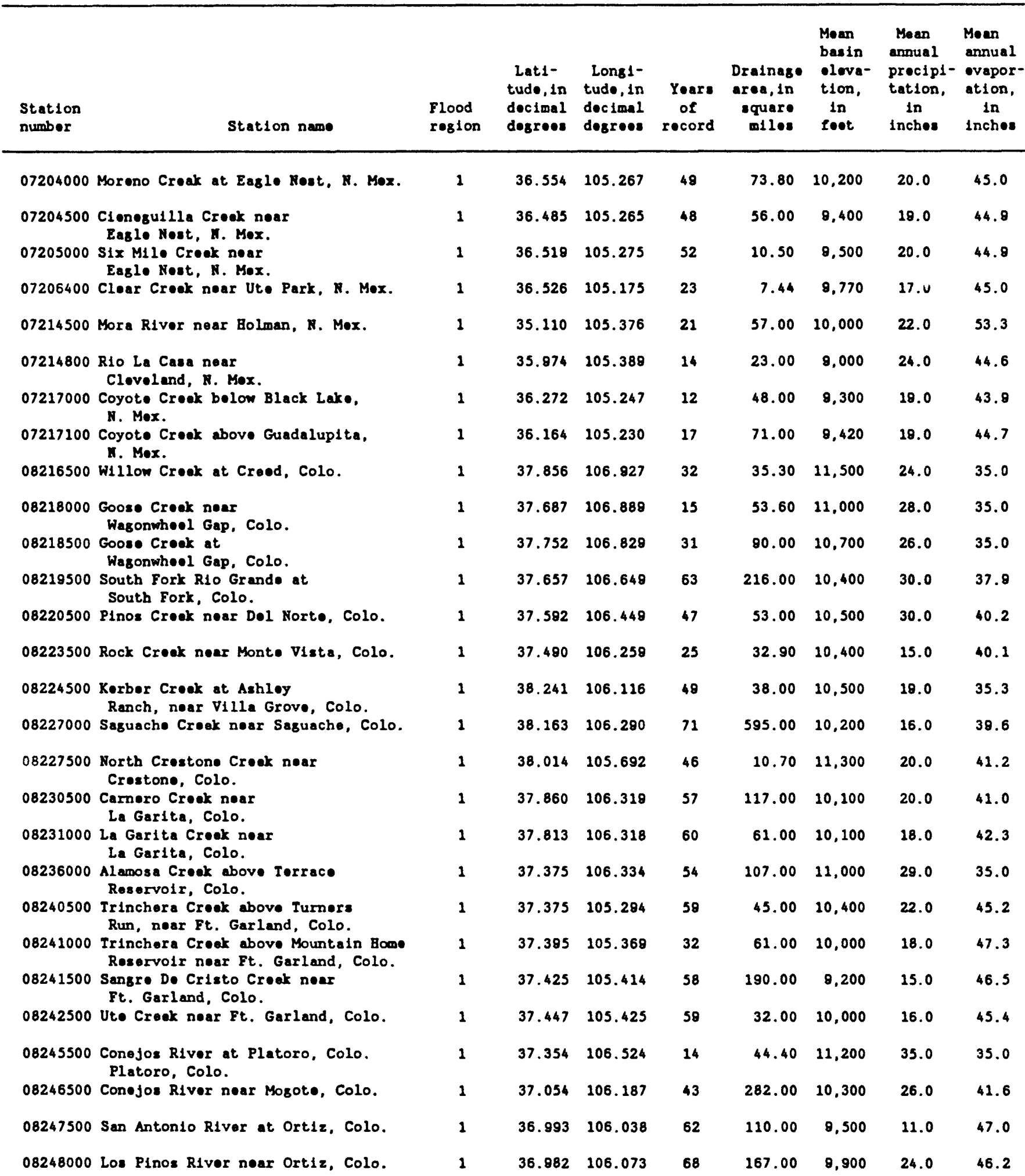


Relation characteristic: L, low-discharga threshold used to compute station relation; B, hich outliar detected in station record; D, relation fit through the plotted anpual peak flow has the appearance of a dogleg or jump; $O$, station is regional outlior doloted fron senoralized lanst-squares regression analysis; U, relation was undefined. 1, code applies; 0 , codo does not apply; and -, code 1s not applicable.

\begin{tabular}{|c|c|c|c|c|c|c|c|c|c|c|c|c|}
\hline \multirow[b]{2}{*}{$\begin{array}{l}\text { Station } \\
\text { number }\end{array}$} & \multicolumn{5}{|c|}{$\begin{array}{c}\text { Rolation } \\
\text { character lette }\end{array}$} & \multicolumn{3}{|c|}{$\begin{array}{l}\text { Pouk discharge (cublc } \\
\text { Indicated recurrence }\end{array}$} & \multicolumn{3}{|c|}{$\begin{array}{l}\text { Leet per second) for } \\
\text { intervel (rears) }\end{array}$} & \multirow{2}{*}{$\begin{array}{l}\text { Maximu } \\
\text { poak discharge } \\
\text { of record } \\
\text { (cubic loet } \\
\text { par second) }\end{array}$} \\
\hline & $\frac{c l}{L}$ & $\frac{17}{\mathbf{B}}$ & $\frac{C+0}{D}$ & & & 2 & 5 & 10 & 25 & 50 & 100 & \\
\hline 07204000 & 1 & 0 & 0 & 1 & 0 & $\begin{array}{l}71 \\
72\end{array}$ & $\begin{array}{l}121 \\
127\end{array}$ & $\begin{array}{l}159 \\
175\end{array}$ & $\begin{array}{l}212 \\
248\end{array}$ & $\begin{array}{l}256 \\
311\end{array}$ & $\begin{array}{l}302 \\
378\end{array}$ & 240 \\
\hline 07204500 & 1 & 0 & 1 & 0 & 0 & $\begin{array}{l}122 \\
122\end{array}$ & $\begin{array}{l}243 \\
245\end{array}$ & $\begin{array}{l}345 \\
351\end{array}$ & $\begin{array}{l}497 \\
509\end{array}$ & $\begin{array}{l}626 \\
642\end{array}$ & $\begin{array}{l}768 \\
786\end{array}$ & 505 \\
\hline 07205000 & 0 & 0 & 0 & 0 & 0 & $\begin{array}{l}28 \\
28\end{array}$ & $\begin{array}{l}55 \\
56\end{array}$ & $\begin{array}{l}79 \\
81\end{array}$ & $\begin{array}{l}117 \\
121\end{array}$ & $\begin{array}{l}151 \\
157\end{array}$ & $\begin{array}{l}190 \\
198\end{array}$ & 128 \\
\hline 07206400 & 0 & 0 & 0 & 0 & 0 & $\begin{array}{l}20 \\
20\end{array}$ & $\begin{array}{l}45 \\
45\end{array}$ & $\begin{array}{l}68 \\
70\end{array}$ & $\begin{array}{l}106 \\
110\end{array}$ & $\begin{array}{l}142 \\
146\end{array}$ & $\begin{array}{l}184 \\
187\end{array}$ & 151 \\
\hline 07214500 & 0 & 0 & 0 & 1 & 0 & $\begin{array}{l}560 \\
558\end{array}$ & $\begin{array}{l}1,630 \\
1,600\end{array}$ & $\begin{array}{l}2,860 \\
2,730\end{array}$ & $\begin{array}{l}5,230 \\
4,760\end{array}$ & $\begin{array}{l}7,720 \\
6,790\end{array}$ & $\begin{array}{r}11,000 \\
8,360\end{array}$ & 4,700 \\
\hline 07214800 & 0 & 1 & 0 & 0 & 0 & $\begin{array}{l}193 \\
193\end{array}$ & $\begin{array}{r}449 \\
442\end{array}$ & $\begin{array}{l}717 \\
685\end{array}$ & $\begin{array}{l}1,210 \\
1,100\end{array}$ & $\begin{array}{l}1,710 \\
1,480\end{array}$ & $\begin{array}{l}2,350 \\
1,950\end{array}$ & 2,260 \\
\hline 07217000 & 1 & 0 & 0 & 0 & 0 & $\begin{array}{l}42 \\
45\end{array}$ & $\begin{array}{l}178 \\
188\end{array}$ & $\begin{array}{l}394 \\
405\end{array}$ & $\begin{array}{l}952 \\
901\end{array}$ & $\begin{array}{l}1,710 \\
1,500\end{array}$ & $\begin{array}{l}2,940 \\
2,410\end{array}$ & 913 \\
\hline 07217100 & - & - & - & - & 1 & 316 & 531 & 685 & $---\overline{8}$ & 1,040 & 1,190 & 1,820 \\
\hline 08216500 & 0 & 0 & 0 & 0 & 0 & $\begin{array}{l}190 \\
190\end{array}$ & $\begin{array}{l}301 \\
303\end{array}$ & $\begin{array}{l}377 \\
382\end{array}$ & $\begin{array}{l}476 \\
487\end{array}$ & $\begin{array}{l}550 \\
567\end{array}$ & $\begin{array}{l}624 \\
647\end{array}$ & 430 \\
\hline 08218000 & 0 & 0 & 0 & 0 & 0 & $\begin{array}{l}418 \\
418\end{array}$ & $\begin{array}{l}701 \\
699\end{array}$ & $\begin{array}{l}820 \\
810\end{array}$ & $\begin{array}{l}1,230 \\
1,190\end{array}$ & $\begin{array}{l}1,490 \\
1,420\end{array}$ & $\begin{array}{l}1,760 \\
1,650\end{array}$ & 1,170 \\
\hline 08218500 & 0 & 0 & 0 & 0 & 0 & $\begin{array}{l}371 \\
372\end{array}$ & $\begin{array}{l}559 \\
566\end{array}$ & $\begin{array}{l}691 \\
709\end{array}$ & $\begin{array}{l}863 \\
901\end{array}$ & $\begin{array}{r}995 \\
1,050\end{array}$ & $\begin{array}{l}1,130 \\
1,200\end{array}$ & 878 \\
\hline 08219500 & 0 & 1 & 0 & 0 & 0 & $\begin{array}{l}1,510 \\
1,510\end{array}$ & $\begin{array}{l}2,350 \\
2,350\end{array}$ & $\begin{array}{l}2,970 \\
2,960\end{array}$ & $\begin{array}{l}3,820 \\
3,790\end{array}$ & $\begin{array}{l}4,510 \\
4,450\end{array}$ & $\begin{array}{l}5,240 \\
5,140\end{array}$ & 8,000 \\
\hline 08220500 & 1 & 0 & 0 & 0 & 0 & $\begin{array}{l}176 \\
177\end{array}$ & $\begin{array}{l}304 \\
309\end{array}$ & $\begin{array}{l}402 \\
414\end{array}$ & $\begin{array}{l}538 \\
563\end{array}$ & $\begin{array}{l}648 \\
682\end{array}$ & $\begin{array}{l}763 \\
806\end{array}$ & 720 \\
\hline 08223500 & 0 & 0 & 1 & 0 & 0 & $\begin{array}{l}86 \\
86\end{array}$ & $\begin{array}{l}148 \\
150\end{array}$ & $\begin{array}{l}182 \\
187\end{array}$ & $\begin{array}{l}249 \\
263\end{array}$ & $\begin{array}{l}292 \\
315\end{array}$ & $\begin{array}{l}335 \\
369\end{array}$ & 190 \\
\hline 08224500 & 0 & 0 & 0 & 0 & 0 & $\begin{array}{l}93 \\
94\end{array}$ & $\begin{array}{l}156 \\
158\end{array}$ & $\begin{array}{l}206 \\
212\end{array}$ & $\begin{array}{l}277 \\
290\end{array}$ & $\begin{array}{l}336 \\
356\end{array}$ & $\begin{array}{l}401 \\
428\end{array}$ & 407 \\
\hline 08227000 & 1 & 0 & 0 & 1 & 0 & $\begin{array}{l}326 \\
329\end{array}$ & $\begin{array}{l}529 \\
545\end{array}$ & $\begin{array}{l}668 \\
714\end{array}$ & $\begin{array}{l}850 \\
955\end{array}$ & $\begin{array}{r}986 \\
1,150\end{array}$ & $\begin{array}{l}1,120 \\
1,350\end{array}$ & 790 \\
\hline 08227500 & 0 & 1 & 0 & 0 & 0 & $\begin{array}{l}84 \\
84\end{array}$ & $\begin{array}{l}149 \\
149\end{array}$ & $\begin{array}{l}208 \\
207\end{array}$ & $\begin{array}{l}304 \\
299\end{array}$ & $\begin{array}{l}395 \\
386\end{array}$ & $\begin{array}{l}505 \\
488\end{array}$ & 735 \\
\hline 08230500 & 0 & 0 & 0 & 0 & 0 & $\begin{array}{l}139 \\
140\end{array}$ & $\begin{array}{l}322 \\
328\end{array}$ & $\begin{array}{l}501 \\
514\end{array}$ & $\begin{array}{l}803 \\
826\end{array}$ & $\begin{array}{l}1,090 \\
1,120\end{array}$ & $\begin{array}{l}1,430 \\
1,450\end{array}$ & 1,600 \\
\hline 08231000 & 0 & 0 & 0 & 0 & 0 & $\begin{array}{l}158 \\
158\end{array}$ & $\begin{array}{l}291 \\
293\end{array}$ & $\begin{array}{l}395 \\
399\end{array}$ & $\begin{array}{l}540 \\
548\end{array}$ & $\begin{array}{l}658 \\
670\end{array}$ & $\begin{array}{l}781 \\
797\end{array}$ & 530 \\
\hline 08236000 & 0 & 1 & 0 & 0 & 0 & $\begin{array}{l}944 \\
944\end{array}$ & $\begin{array}{l}1,400 \\
1,400\end{array}$ & $\begin{array}{l}1,730 \\
1,720\end{array}$ & $\begin{array}{l}2,180 \\
2,160\end{array}$ & $\begin{array}{l}2,550 \\
2,510\end{array}$ & $\begin{array}{l}2,930 \\
2,870\end{array}$ & 5,200 \\
\hline 08240500 & 0 & 1 & 0 & 0 & 0 & $\begin{array}{l}114 \\
114\end{array}$ & $\begin{array}{l}217 \\
219\end{array}$ & $\begin{array}{l}305 \\
310\end{array}$ & $\begin{array}{l}441 \\
452\end{array}$ & $\begin{array}{l}560 \\
574\end{array}$ & $\begin{array}{l}695 \\
710\end{array}$ & 689 \\
\hline 08241000 & 0 & 0 & 0 & 0 & 0 & $\begin{array}{l}114 \\
115\end{array}$ & $\begin{array}{l}228 \\
232\end{array}$ & $\begin{array}{l}322 \\
332\end{array}$ & $\begin{array}{l}457 \\
478\end{array}$ & $\begin{array}{l}568 \\
599\end{array}$ & $\begin{array}{l}686 \\
725\end{array}$ & 421 \\
\hline 08241500 & 0 & 1 & 0 & 0 & 0 & $\begin{array}{l}158 \\
159\end{array}$ & $\begin{array}{l}350 \\
356\end{array}$ & $\begin{array}{l}536 \\
551\end{array}$ & $\begin{array}{l}847 \\
876\end{array}$ & $\begin{array}{l}1,140 \\
1,180\end{array}$ & $\begin{array}{l}1,500 \\
1,540\end{array}$ & 1,520 \\
\hline 08242500 & 1 & 1 & 0 & 0 & 0 & $\begin{array}{l}143 \\
143\end{array}$ & $\begin{array}{l}215 \\
215\end{array}$ & $\begin{array}{l}267 \\
268\end{array}$ & $\begin{array}{l}335 \\
338\end{array}$ & $\begin{array}{l}389 \\
395\end{array}$ & $\begin{array}{l}445 \\
454\end{array}$ & 630 \\
\hline 08245500 & 0 & 0 & 0 & 0 & 0 & $\begin{array}{l}1,030 \\
1,020\end{array}$ & $\begin{array}{l}1,220 \\
1,200\end{array}$ & $\begin{array}{l}1,330 \\
1,290\end{array}$ & $\begin{array}{l}1,460 \\
1,390\end{array}$ & $\begin{array}{l}1,550 \\
1,470\end{array}$ & $\begin{array}{l}1,630 \\
1,540\end{array}$ & 1,380 \\
\hline 08246500 & 0 & 1 & 0 & 0 & 0 & $\begin{array}{l}2,640 \\
2,640\end{array}$ & $\begin{array}{l}3,660 \\
3,640\end{array}$ & $\begin{array}{l}4,400 \\
4,350\end{array}$ & $\begin{array}{l}5,420 \\
5,300\end{array}$ & $\begin{array}{l}6,240 \\
6,060\end{array}$ & $\begin{array}{l}7,110 \\
6,840\end{array}$ & 9,000 \\
\hline 08247500 & 1 & 0 & 0 & 0 & 0 & $\begin{array}{l}505 \\
504\end{array}$ & $\begin{array}{l}810 \\
815\end{array}$ & $\begin{array}{l}1,040 \\
1,030\end{array}$ & $\begin{array}{l}1,350 \\
1,330\end{array}$ & $\begin{array}{l}1,580 \\
1,550\end{array}$ & $\begin{array}{l}1,820 \\
1,780\end{array}$ & 1,750 \\
\hline 08248000 & 1 & 0 & 0 & 0 & 0 & $\begin{array}{l}1,380 \\
1,380\end{array}$ & $\begin{array}{l}1,900 \\
1,900\end{array}$ & $\begin{array}{l}2,230 \\
2,220\end{array}$ & $\begin{array}{l}2,650 \\
2,630\end{array}$ & $\begin{array}{l}2,960 \\
2,930\end{array}$ & $\begin{array}{l}3,270 \\
3,230\end{array}$ & 3,160 \\
\hline
\end{tabular}




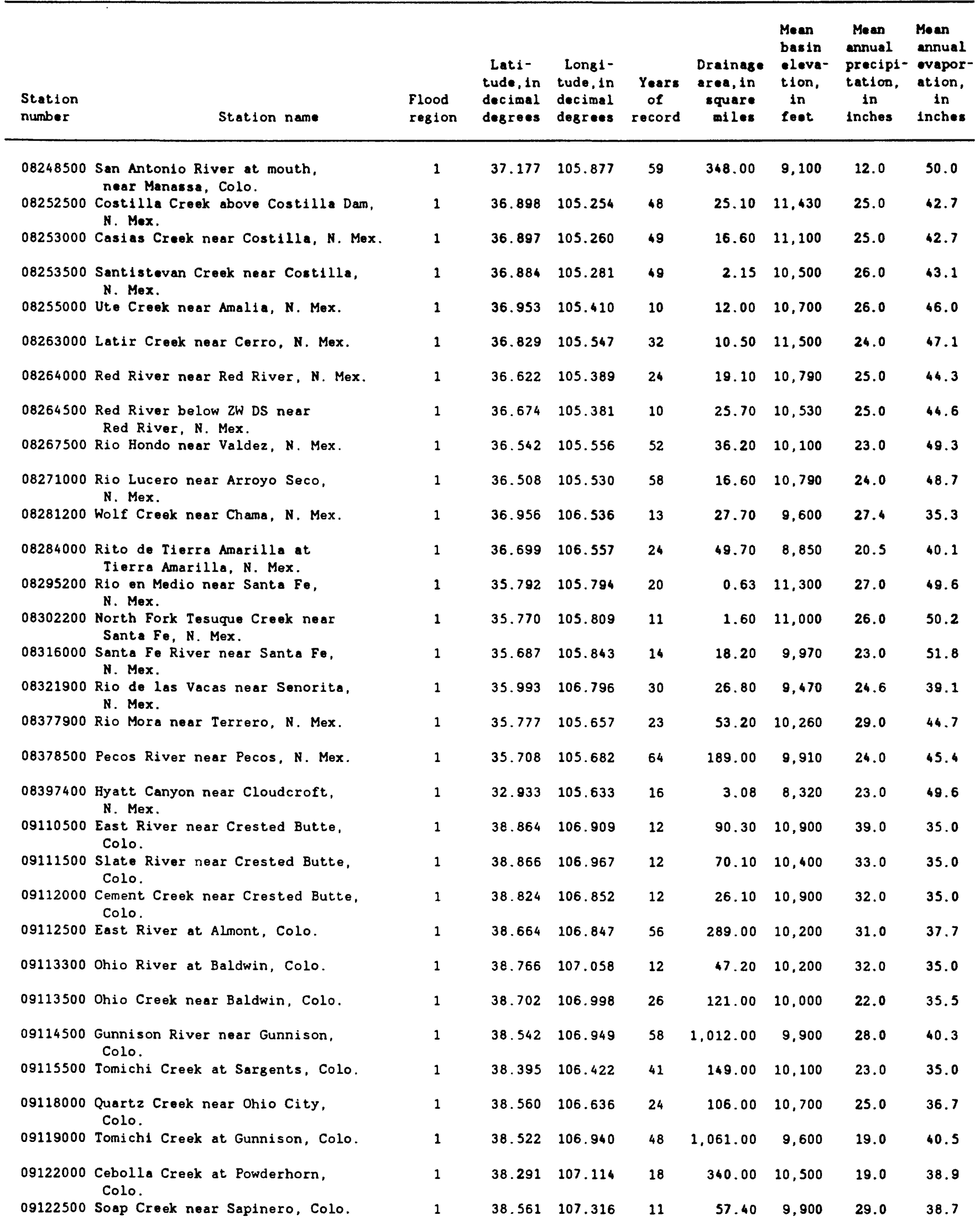




\begin{tabular}{|c|c|c|c|c|c|c|c|c|c|c|c|c|}
\hline \multirow{2}{*}{$\begin{array}{l}\text { Station } \\
\text { number }\end{array}$} & \multicolumn{5}{|c|}{$\begin{array}{c}\text { Relation } \\
\text { characteristi }\end{array}$} & \multicolumn{3}{|c|}{$\begin{array}{l}\text { Peak discharge (cubic } \\
\text { Indicated recurrence }\end{array}$} & \multicolumn{3}{|c|}{$\begin{array}{l}\text { Leet per second) for } \\
\text { interval (years) }\end{array}$} & \multirow{2}{*}{$\begin{array}{l}\text { Maximum } \\
\text { peak discharge } \\
\text { of record } \\
\text { (cublc feet } \\
\text { per second) }\end{array}$} \\
\hline & $\mathrm{L}$ & $\mathrm{B}$ & $D$ & 0 & U & 2 & 5 & 10 & 25 & so & 100 & \\
\hline \multirow[t]{2}{*}{08248500} & 0 & 0 & 1 & 0 & 0 & 816 & 1,440 & 1,860 & 2,370 & 2,740 & 3,080 & 2,620 \\
\hline & & & & & & 815 & 1,440 & 1,850 & 2,360 & 2,730 & 3,070 & \\
\hline \multirow[t]{2}{*}{08252500} & 1 & 1 & 0 & 0 & 0 & 62 & 139 & 225 & 397 & 588 & 854 & 3,870 \\
\hline & & & & & & 62 & 141 & 230 & 402 & 587 & 838 & \\
\hline \multirow[t]{2}{*}{08253000} & 1 & 0 & 1 & 0 & 0 & 61 & 101 & 129 & 167 & 195 & 223 & 181 \\
\hline & & & & & & 62 & 103 & 133 & 176 & 210 & 243 & \\
\hline \multirow[t]{2}{*}{08253500} & 1 & 0 & 1 & 1 & 0 & 9 & 13 & 16 & 19 & 21 & 23 & 18 \\
\hline & & & & & & 9 & 13 & 17 & 22 & 26 & 30 & \\
\hline \multirow[t]{2}{*}{08255000} & - & - & - & - & 1 & $\cdots$ & $\cdots$ & $\ldots$ & $\ldots$ & $\ldots$ & $\cdots$ & 88 \\
\hline & & & & & & 110 & 180 & 229 & 292 & 339 & 385 & \\
\hline \multirow[t]{2}{*}{08263000} & 1 & 0 & 1 & 0 & 0 & 48 & 79 & 102 & 132 & 156 & 180 & 126 \\
\hline & & & & & & 48 & 80 & 106 & 140 & 169 & 197 & \\
\hline 08264000 & 0 & 0 & 0 & 0 & 0 & 107 & 166 & 208 & 263 & 305 & 348 & 264 \\
\hline & & & & & & 107 & 168 & 214 & 276 & 325 & 375 & \\
\hline 08264500 & 0 & 0 & 0 & 0 & 0 & 96 & 160 & 206 & 267 & 315 & 363 & 216 \\
\hline & & & & & & 97 & 169 & 229 & 315 & 384 & 452 & \\
\hline 08267500 & 0 & 0 & 1 & 0 & 0 & 163 & 272 & 354 & 467 & 558 & 653 & 541 \\
\hline & & & & & & 163 & 273 & 357 & 474 & 568 & 665 & \\
\hline 08271000 & 1 & 0 & 1 & 0 & 0 & 127 & 190 & 232 & 286 & 326 & 365 & 310 \\
\hline & & & & & & 127 & 190 & 233 & 289 & 331 & 372 & \\
\hline 08281200 & 0 & 0 & 0 & 0 & 0 & 558 & 920 & 1,210 & 1,650 & 2,020 & 2,440 & 1,900 \\
\hline & & & & & & 554 & 895 & 1.140 & 1,480 & 1,740 & 2,030 & \\
\hline 08284000 & 0 & 0 & 1 & 0 & 0 & 281 & 547 & 757 & 1,060 & 1,300 & 1,550 & 1,000 \\
\hline & & & & & & 281 & 544 & 746 & 1,030 & 1,240 & 1,460 & \\
\hline 08295200 & 0 & 0 & 1 & 0 & 0 & 8 & 14 & 19 & 25 & 30 & 35 & 20 \\
\hline & & & & & & $B$ & 14 & 19 & 26 & 31 & 37 & \\
\hline 08302200 & 0 & 0 & 0 & 0 & 0 & 9 & 15 & 20 & 29 & 36 & 45 & 33 \\
\hline & & & & & & 9 & 16 & 23 & 35 & 45 & 56 & \\
\hline 08316000 & 0 & 1 & 0 & 0 & 0 & 94 & 232 & 388 & 695 & 1,030 & 1,490 & 1,500 \\
\hline & & & & & & 94 & 231 & 379 & 645 & 913 & 1,260 & \\
\hline 08321900 & 0 & 0 & 1 & 0 & 0 & 259 & 407 & 504 & 625 & 711 & 795 & 530 \\
\hline & & & & & & 259 & 405 & 500 & 617 & 700 & 781 & \\
\hline 08377900 & 0 & 0 & 0 & 0 & 0 & 228 & 389 & 515 & 697 & 848 & 1,010 & 820 \\
\hline & & & & & & 230 & 397 & 532 & 727 & 885 & 1,050 & \\
\hline 08378500 & 1 & 0 & 0 & 0 & 0 & 601 & 1,070 & 1,470 & 2,090 & 2,640 & 3,270 & 4,500 \\
\hline & & & & & & 602 & 1,070 & 1,480 & 2,100 & 2,640 & 3,250 & \\
\hline 08397400 & 1 & 0 & 0 & 0 & 0 & 37 & 58 & 72 & 92 & 107 & 123 & 86 \\
\hline & & & & & & 37 & 57 & 72 & 92 & 108 & 124 & \\
\hline 09110500 & - & - & - & - & 1 & $\cdots$ & $\ldots$ & $\ldots$ & $\ldots$ & $\ldots$ & $\cdots$ & 1,270 \\
\hline & & & & & & 1,090 & 1,440 & 1,650 & 1,910 & 2,110 & 2,300 & \\
\hline 09111500 & - & - & - & - & 1 & $\cdots$ & $\cdots$ & $\cdots$ & $\cdots$ & $\cdots$ & $\cdots$ & 1,240 \\
\hline & & & & & & 691 & 975 & 1,150 & 1,370 & 1,140 & 1,700 & \\
\hline 09112000 & 0 & 0 & 0 & 0 & 0 & 209 & 271 & 311 & 361 & 396 & 431 & 358 \\
\hline & & & & & & 210 & 279 & 331 & 407 & 465 & 525 & \\
\hline 09112500 & 1 & 0 & 0 & 0 & 0 & 2,280 & 3,160 & 3.790 & 4.650 & 5,320 & 6.030 & 6,500 \\
\hline & & & & & & 2,280 & 3,160 & 3,780 & 4,620 & 5,260 & 5,940 & \\
\hline 09113300 & 0 & 0 & 0 & 0 & 0 & 364 & 524 & 631 & 768 & 870 & 972 & 683 \\
\hline & & & & & & 365 & 532 & 650 & 806 & 924 & 1,040 & \\
\hline 09113500 & 0 & 0 & 0 & 0 & 0 & 664 & 965 & 1,150 & 1,370 & 1,520 & 1,670 & 1,260 \\
\hline & & & & & & 664 & 965 & 1,150 & 1,380 & 1,540 & 1,710 & \\
\hline 09114500 & 1 & 0 & 0 & 0 & 0 & 3,900 & 5,640 & 6,790 & 8,230 & 9,290 & 10,300 & 11,400 \\
\hline & & & & & & 3,900 & 5,650 & 6,820 & 8,280 & 9,350 & 10,400 & \\
\hline 09115500 & 0 & 0 & 0 & 0 & 0 & 350 & 547 & 677 & 840 & 958 & 1,070 & 804 \\
\hline & & & & & & 352 & 557 & 702 & 897 & 1,040 & 1,190 & \\
\hline 09118000 & 0 & 0 & 0 & 0 & 0 & 361 & 503 & 591 & 697 & 771 & 843 & 640 \\
\hline & & & & & & 363 & 515 & 624 & 773 & 888 & 1,000 & \\
\hline 09119000 & 0 & 1 & 0 & 0 & 0 & 777 & 1,290 & 1,690 & 2,260 & 2,730 & 3.250 & 4,620 \\
\hline & & & & & & 785 & 1,330 & 1.800 & 2,500 & 3,080 & 3,710 & \\
\hline 09122000 & 0 & 0 & 1 & 0 & 0 & 658 & 1,150 & 1.550 & 2,120 & 2,590 & 3,110 & 2,150 \\
\hline & & & & & & 663 & 1,170 & 1,610 & 2,220 & 2,720 & 3,250 & \\
\hline 09122500 & 0 & 1 & 0 & 0 & 0 & 451 & 613 & 728 & 881 & 1,000 & 1,130 & 1,000 \\
\hline & & & & & & 451 & 619 & 743 & 914 & 1,050 & 1,190 & \\
\hline
\end{tabular}


Station

number
Station name

\section{Flood}

Lati- Longitude, in tude, in decimal decimal

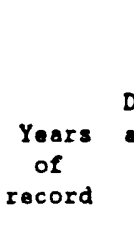

09124500 Lake Fork at Gateview, Colo.

09125000 Curecanti Creek near Sapinero, Colo.

09126000 Cimarron River near Cimarron. Colo.

09127500 Crystal Creek near Maher, Colo.

09130600 West Muddy Creek near Ragsed Mountain, Colo.

09132900 West Hubbard Creek near Paonia, Colo.

09140700 Cottonwood Creek near Grand Mesa, Colo.

09143000 Surface Creek near Cedaredge, Colo.

09145000 Uncompahgre River at Ouray, Colo.

09146000 Uncompahgre River below Ouray, Colo.

09146400 West Fork Dallas Creek near Ridgway, Colo.

09146500 East Fork Dallas Creek near Ridgway, Colo.

09146600 Pleasant Valley Creek near Noel, Colo.

09147100 Cow Creek near Ridgway, Colo.

09165000 Dolores River below Rico, Colo.

09172000 Fall Creek near Fall Creek, Colo.

09175000 West Naturita Creek near Norwood, Colo.

09177500 Taylor Creek near Gateway, Colo.

09188500 Green River at Warren Branch near Daniel, Wyo.

09189500 Borse Creek at Sherman Ranger Station, Wyo.

09196500 Pine Creek above Fremont Lake, Wyo.

09198500 Pole Creek below Balf Moon Lake near Pinedale, Wyo.

09199500 Fall Creek near Pinedale, Wyo.

09203000 East Fork River near Big Sandy, Wyo.

09204000 Silver Creek near Big Sandy, Wyo.

09204700 Sand Springs Draw Tributary near Boulder, Wyo.

09205500 North Piney Creek near Mason, Wyo.

09208000 La Barge Creek near La Barge MDWS Ranger Station, Wyo.

$09212500 \mathrm{Big}$ Sandy River at Lechie Ranch near Bis Sandy, Wyo.

09217900 Blacks Fork near Robertson, Wyo.

09218500 Blacks Fork near Millburne, Wyo.

\begin{tabular}{|c|c|c|c|c|c|c|c|}
\hline 1 & 38.299 & 107.229 & 48 & 334.00 & 10,900 & 24.0 & 39.5 \\
\hline 1 & 38.488 & 107.414 & 27 & 35.00 & 9,700 & 22.0 & 40.2 \\
\hline 1 & 38.262 & 107.544 & 15 & 66.60 & 10,900 & 31.0 & 39.3 \\
\hline 1 & 38.552 & 107.506 & 21 & 42.20 & 9,600 & 25.0 & 40.1 \\
\hline 1 & 39.131 & 107.575 & 10 & 7.42 & 9,400 & 38.0 & 40.0 \\
\hline 1 & 39.032 & 107.613 & 13 & 2.34 & 10,300 & 38.0 & 39.7 \\
\hline 1 & 38.927 & 107.950 & 11 & 2.15 & 9,200 & 23.0 & 39.9 \\
\hline 1 & 38.985 & 107.854 & 47 & 27.40 & 9,700 & 36.0 & 39.5 \\
\hline 1 & 38.019 & 107.676 & 14 & 42.00 & 11,400 & 30.0 & 35.1 \\
\hline 1 & 38.031 & 107.674 & 16 & 75.20 & 11,300 & 32.0 & 35.3 \\
\hline 1 & 38.074 & 107.851 & 15 & 14.10 & 10,200 & 35.0 & 38.1 \\
\hline 1 & 38.093 & 107.813 & 16 & 16.80 & 10.800 & 32.0 & 38.2 \\
\hline 1 & 38.146 & 107.919 & 12 & 7.98 & 9,100 & 20.0 & 39.9 \\
\hline 1 & 38.149 & 107.644 & 18 & 45.40 & 10,700 & 29.0 & 38.8 \\
\hline 1 & 37.639 & 108.060 & 35 & 105.00 & 10,600 & 31.0 & 35.2 \\
\hline 1 & 37.958 & 108.005 & 18 & 33.40 & 10,000 & 32.0 & 38.4 \\
\hline 1 & 37.976 & 108.327 & 12 & 53.00 & 8,500 & 31.0 & 42.1 \\
\hline 1 & 38.519 & 109.109 & 23 & 15.40 & 9.000 & 17.0 & 44.6 \\
\hline 1 & 43.019 & 110.117 & 55 & 468.00 & 9,320 & 22.0 & 36.6 \\
\hline 1 & 42.944 & 110.389 & 20 & 43.00 & 8,880 & 20.0 & 37.2 \\
\hline 1 & 43.031 & 109.769 & 32 & 75.80 & 10,200 & 23.0 & 35.0 \\
\hline 1 & 42.883 & 109.717 & 33 & 87.50 & 11,000 & 22.0 & 35.7 \\
\hline 1 & 42.856 & 109.720 & 33 & 37.20 & 9,460 & 20.0 & 35.9 \\
\hline 1 & 42.667 & 109.417 & 48 & 79.20 & 9,580 & 22.0 & 37.0 \\
\hline 1 & 42.750 & 109.517 & 30 & 45.40 & 9,750 & 20.0 & 36.0 \\
\hline 1 & 42.585 & 109.623 & 18 & 2.77 & 7,300 & 10.0 & 39.0 \\
\hline 1 & 42.658 & 110.342 & 43 & 58.00 & 8,920 & 18.0 & 38.8 \\
\hline 1 & 42.508 & 110.669 & 33 & 6.30 & 8,970 & 25.0 & 38.0 \\
\hline 1 & 42.571 & 109.283 & 47 & 94.00 & 9,250 & 20.0 & 37.4 \\
\hline 1 & 40.965 & 110.577 & 22 & 130.00 & 10,640 & 20.0 & 34.5 \\
\hline 1 & 41.032 & 110.579 & 31 & 152.00 & 10,270 & 19.0 & 34.6 \\
\hline
\end{tabular}




\begin{tabular}{|c|c|c|c|c|c|c|c|c|c|c|c|c|}
\hline \multirow{2}{*}{$\begin{array}{l}\text { Station } \\
\text { number }\end{array}$} & \multicolumn{5}{|c|}{$\begin{array}{c}\text { Relation } \\
\text { charactoristic }\end{array}$} & \multicolumn{6}{|c|}{$\begin{array}{l}\text { Peak discharge (cubic feet per second) for } \\
\text { indicated recurrence interval (years) }\end{array}$} & \multirow{2}{*}{$\begin{array}{l}\text { Maximus } \\
\text { poak discharge } \\
\text { of record } \\
\text { (cubic leet } \\
\text { per second) }\end{array}$} \\
\hline & $\frac{1}{L}$ & B & $D$ & 0 & U & 2 & 5 & 10 & 25 & 50 & 100 & \\
\hline 09124500 & 0 & 0 & 0 & 0 & 0 & $\begin{array}{l}1,680 \\
1,680\end{array}$ & $\begin{array}{l}2,200 \\
2,200\end{array}$ & $\begin{array}{l}2,520 \\
2,530\end{array}$ & $\begin{array}{l}2,900 \\
2,930\end{array}$ & $\begin{array}{l}3,160 \\
3,210\end{array}$ & $\begin{array}{l}3,420 \\
3,500\end{array}$ & 2.720 \\
\hline 09125000 & 0 & 0 & 0 & 0 & 0 & $\begin{array}{l}252 \\
252\end{array}$ & $\begin{array}{l}350 \\
350\end{array}$ & $\begin{array}{l}410 \\
412\end{array}$ & $\begin{array}{l}483 \\
491\end{array}$ & $\begin{array}{l}536 \\
550\end{array}$ & $\begin{array}{l}583 \\
608\end{array}$ & 480 \\
\hline 09126000 & 0 & 0 & 0 & 0 & 0 & $\begin{array}{l}826 \\
824\end{array}$ & $\begin{array}{l}1,180 \\
1,170\end{array}$ & $\begin{array}{l}1,430 \\
1,400\end{array}$ & $\begin{array}{l}1,770 \\
1,700\end{array}$ & $\begin{array}{l}2,050 \\
1,930\end{array}$ & $\begin{array}{l}2,330 \\
2,160\end{array}$ & 1,790 \\
\hline 09127500 & 1 & 0 & 0 & 0 & 0 & $\begin{array}{l}282 \\
282\end{array}$ & $\begin{array}{l}407 \\
409\end{array}$ & $\begin{array}{l}486 \\
492\end{array}$ & $\begin{array}{l}582 \\
599\end{array}$ & $\begin{array}{l}651 \\
679\end{array}$ & $\begin{array}{l}717 \\
758\end{array}$ & 542 \\
\hline 09130600 & 0 & 0 & 0 & 0 & 0 & $\begin{array}{l}85 \\
86\end{array}$ & $\begin{array}{l}158 \\
160\end{array}$ & $\begin{array}{l}218 \\
219\end{array}$ & $\begin{array}{l}307 \\
300\end{array}$ & $\begin{array}{l}384 \\
366\end{array}$ & $\begin{array}{l}669 \\
433\end{array}$ & 260 \\
\hline 09132900 & 0 & 0 & 0 & 0 & 0 & $\begin{array}{l}46 \\
46\end{array}$ & $\begin{array}{l}61 \\
61\end{array}$ & $\begin{array}{l}71 \\
73\end{array}$ & $\begin{array}{l}84 \\
89\end{array}$ & $\begin{array}{r}94 \\
101\end{array}$ & $\begin{array}{l}106 \\
114\end{array}$ & 93 \\
\hline 09140700 & 1 & 0 & 0 & 0 & 0 & $\begin{array}{l}24 \\
24\end{array}$ & $\begin{array}{l}34 \\
34\end{array}$ & $\begin{array}{l}40 \\
41\end{array}$ & $\begin{array}{l}47 \\
52\end{array}$ & $\begin{array}{l}52 \\
60\end{array}$ & $\begin{array}{l}57 \\
68\end{array}$ & 38 \\
\hline 09143000 & 1 & 0 & 0 & 0 & 0 & $\begin{array}{l}296 \\
296\end{array}$ & $\begin{array}{l}429 \\
430\end{array}$ & $\begin{array}{l}526 \\
528\end{array}$ & $\begin{array}{l}656 \\
659\end{array}$ & $\begin{array}{l}759 \\
762\end{array}$ & $\begin{array}{l}868 \\
870\end{array}$ & 824 \\
\hline 09145000 & 0 & 0 & 0 & 0 & 0 & $\begin{array}{l}966 \\
960\end{array}$ & $\begin{array}{l}1,360 \\
1,330\end{array}$ & $\begin{array}{l}1,650 \\
1,570\end{array}$ & $\begin{array}{l}2.050 \\
1,870\end{array}$ & $\begin{array}{l}2.360 \\
2.090\end{array}$ & $\begin{array}{l}2.690 \\
2,320\end{array}$ & 2,000 \\
\hline 09146000 & 0 & 0 & 0 & 0 & 0 & $\begin{array}{l}1,440 \\
1,430\end{array}$ & $\begin{array}{l}1,920 \\
1,890\end{array}$ & $\begin{array}{l}2,220 \\
2,140\end{array}$ & $\begin{array}{l}2,590 \\
2.430\end{array}$ & $\begin{array}{l}2,860 \\
2,640\end{array}$ & $\begin{array}{l}3,120 \\
2,840\end{array}$ & 2,400 \\
\hline 09146400 & 0 & 0 & 0 & 0 & 0 & $\begin{array}{l}81 \\
82\end{array}$ & $\begin{array}{l}126 \\
132\end{array}$ & $\begin{array}{l}159 \\
174\end{array}$ & $\begin{array}{l}206 \\
237\end{array}$ & $\begin{array}{l}264 \\
287\end{array}$ & $\begin{array}{l}284 \\
338\end{array}$ & 200 \\
\hline 09146500 & 0 & 0 & 0 & 0 & 0 & $\begin{array}{l}173 \\
173\end{array}$ & $\begin{array}{l}230 \\
233\end{array}$ & $\begin{array}{l}266 \\
274\end{array}$ & $\begin{array}{l}307 \\
326\end{array}$ & $\begin{array}{l}336 \\
366\end{array}$ & $\begin{array}{l}366 \\
407\end{array}$ & 297 \\
\hline 09146600 & 0 & 0 & 0 & 0 & 0 & $\begin{array}{l}150 \\
149\end{array}$ & $\begin{array}{l}282 \\
273\end{array}$ & $\begin{array}{l}388 \\
362\end{array}$ & $\begin{array}{l}543 \\
479\end{array}$ & $\begin{array}{l}671 \\
569\end{array}$ & $\begin{array}{l}810 \\
662\end{array}$ & 500 \\
\hline 09167100 & 0 & 0 & 0 & 0 & 0 & $\begin{array}{l}640 \\
638\end{array}$ & $\begin{array}{l}894 \\
884\end{array}$ & $\begin{array}{l}1,070 \\
1,050\end{array}$ & $\begin{array}{l}1.300 \\
1.250\end{array}$ & $\begin{array}{l}1,480 \\
1,410\end{array}$ & $\begin{array}{l}1,670 \\
1,570\end{array}$ & 1,360 \\
\hline 09165000 & 1 & 0 & 0 & 0 & 0 & $\begin{array}{l}1,270 \\
1,270\end{array}$ & $\begin{array}{l}1,690 \\
1.680\end{array}$ & $\begin{array}{l}1,960 \\
1,940\end{array}$ & $\begin{array}{l}2,270 \\
2,240\end{array}$ & $\begin{array}{l}2,490 \\
2.450\end{array}$ & $\begin{array}{l}2,700 \\
2,650\end{array}$ & 2,170 \\
\hline 09172000 & 0 & 1 & 0 & 0 & 0 & $\begin{array}{l}198 \\
199\end{array}$ & $\begin{array}{l}392 \\
396\end{array}$ & $\begin{array}{l}575 \\
578\end{array}$ & $\begin{array}{l}882 \\
867\end{array}$ & $\begin{array}{l}1,170 \\
1,120\end{array}$ & $\begin{array}{l}1,530 \\
1,420\end{array}$ & 1,390 \\
\hline 09175000 & 1 & 0 & 0 & 0 & 0 & $\begin{array}{l}384 \\
386\end{array}$ & $\begin{array}{l}598 \\
604\end{array}$ & $\begin{array}{l}753 \\
765\end{array}$ & $\begin{array}{l}963 \\
978\end{array}$ & $\begin{array}{l}1.130 \\
1.160\end{array}$ & $\begin{array}{l}1,300 \\
1,310\end{array}$ & 963 \\
\hline 09177500 & 0 & 0 & 0 & 0 & 0 & $\begin{array}{l}111 \\
111\end{array}$ & $\begin{array}{l}264 \\
261\end{array}$ & $\begin{array}{l}407 \\
395\end{array}$ & $\begin{array}{l}636 \\
598\end{array}$ & $\begin{array}{l}862 \\
773\end{array}$ & $\begin{array}{r}1,080 \\
967\end{array}$ & 555 \\
\hline 09188500 & 1 & 0 & 0 & 0 & 0 & $\begin{array}{l}2,880 \\
2,880\end{array}$ & $\begin{array}{l}3,620 \\
3,610\end{array}$ & $\begin{array}{l}4,100 \\
4,090\end{array}$ & $\begin{array}{l}4.680 \\
4.660\end{array}$ & $\begin{array}{l}5,110 \\
5,090\end{array}$ & $\begin{array}{l}5,560 \\
5,530\end{array}$ & 5,490 \\
\hline 09189500 & 0 & 0 & 0 & 0 & 0 & $\begin{array}{l}1.090 \\
1.080\end{array}$ & $\begin{array}{l}1,390 \\
1,360\end{array}$ & $\begin{array}{l}1,590 \\
1,520\end{array}$ & $\begin{array}{l}1,840 \\
1,710\end{array}$ & $\begin{array}{l}2,040 \\
1,850\end{array}$ & $\begin{array}{l}2,230 \\
1,990\end{array}$ & 1,860 \\
\hline 09196500 & 0 & 0 & 0 & 0 & 0 & $\begin{array}{l}1,720 \\
1,710\end{array}$ & $\begin{array}{l}2,030 \\
2,010\end{array}$ & $\begin{array}{l}2,220 \\
2,170\end{array}$ & $\begin{array}{l}2,450 \\
2,350\end{array}$ & $\begin{array}{l}2.610 \\
2.480\end{array}$ & $\begin{array}{l}2,770 \\
2,610\end{array}$ & 2,550 \\
\hline 09198500 & 0 & 0 & 0 & 0 & 0 & $\begin{array}{l}937 \\
935\end{array}$ & $\begin{array}{l}1,130 \\
1,120\end{array}$ & $\begin{array}{l}1,240 \\
1,230\end{array}$ & $\begin{array}{l}1,360 \\
1,350\end{array}$ & $\begin{array}{l}1.460 \\
1.430\end{array}$ & $\begin{array}{l}1,510 \\
1,510\end{array}$ & 1.300 \\
\hline 09199500 & 0 & 0 & 0 & 0 & 0 & $\begin{array}{l}425 \\
424\end{array}$ & $\begin{array}{l}550 \\
546\end{array}$ & $\begin{array}{l}622 \\
615\end{array}$ & $\begin{array}{l}703 \\
693\end{array}$ & $\begin{array}{l}757 \\
748\end{array}$ & $\begin{array}{l}807 \\
801\end{array}$ & 707 \\
\hline 09203000 & 0 & 0 & 0 & 0 & 0 & $\begin{array}{l}1.290 \\
1,290\end{array}$ & $\begin{array}{l}1,570 \\
1,560\end{array}$ & $\begin{array}{l}1,720 \\
1,700\end{array}$ & $\begin{array}{l}1,880 \\
1,840\end{array}$ & $\begin{array}{l}1.980 \\
1.930\end{array}$ & $\begin{array}{l}2,070 \\
2,020\end{array}$ & 2,330 \\
\hline 09204000 & 1 & 0 & 1 & 0 & 0 & $\begin{array}{l}725 \\
722\end{array}$ & $\begin{array}{l}880 \\
870\end{array}$ & $\begin{array}{l}970 \\
950\end{array}$ & $\begin{array}{l}1,070 \\
1,040\end{array}$ & $\begin{array}{l}1,150 \\
1,110\end{array}$ & $\begin{array}{l}1,210 \\
1,170\end{array}$ & 1,030 \\
\hline 09204700 & 0 & 0 & 0 & 0 & 0 & $\begin{array}{l}10 \\
10\end{array}$ & $\begin{array}{l}27 \\
27\end{array}$ & $\begin{array}{l}46 \\
45\end{array}$ & $\begin{array}{l}81 \\
76\end{array}$ & $\begin{array}{l}115 \\
106\end{array}$ & $\begin{array}{l}157 \\
140\end{array}$ & 82 \\
\hline 09205500 & 1 & 0 & 0 & 0 & 0 & $\begin{array}{l}396 \\
395\end{array}$ & $\begin{array}{l}523 \\
522\end{array}$ & $\begin{array}{l}602 \\
601\end{array}$ & $\begin{array}{l}698 \\
700\end{array}$ & $\begin{array}{l}766 \\
773\end{array}$ & $\begin{array}{l}831 \\
844\end{array}$ & 767 \\
\hline 09208000 & 1 & 0 & 0 & 0 & 0 & $\begin{array}{l}129 \\
129\end{array}$ & $\begin{array}{l}164 \\
163\end{array}$ & $\begin{array}{l}185 \\
183\end{array}$ & $\begin{array}{l}209 \\
206\end{array}$ & $\begin{array}{l}225 \\
223\end{array}$ & $\begin{array}{l}241 \\
240\end{array}$ & 196 \\
\hline 09212500 & 1 & 1 & 0 & 0 & 0 & $\begin{array}{l}928 \\
926\end{array}$ & $\begin{array}{l}1,220 \\
1,210\end{array}$ & $\begin{array}{l}1,410 \\
1,400\end{array}$ & $\begin{array}{l}1,660 \\
1,620\end{array}$ & $\begin{array}{l}1,800 \\
1,770\end{array}$ & $\begin{array}{l}1,960 \\
1,920\end{array}$ & 2,030 \\
\hline 09217900 & 0 & 0 & 0 & 0 & 0 & $\begin{array}{l}1,640 \\
1,630\end{array}$ & $\begin{array}{l}2,130 \\
2,100\end{array}$ & $\begin{array}{l}2,420 \\
2,350\end{array}$ & $\begin{array}{l}2,760 \\
2,630\end{array}$ & $\begin{array}{l}2,990 \\
2,820\end{array}$ & $\begin{array}{l}3,200 \\
3,000\end{array}$ & 2,480 \\
\hline 09218500 & 0 & 0 & 0 & 0 & 0 & $\begin{array}{l}1,460 \\
1,460\end{array}$ & $\begin{array}{l}1,830 \\
1,810\end{array}$ & $\begin{array}{l}2,070 \\
2,040\end{array}$ & $\begin{array}{l}2,380 \\
2,320\end{array}$ & $\begin{array}{l}2,600 \\
2,530\end{array}$ & $\begin{array}{l}2,820 \\
2,730\end{array}$ & 2,530 \\
\hline
\end{tabular}




\begin{tabular}{|c|c|c|c|c|c|c|c|c|c|}
\hline $\begin{array}{l}\text { Station } \\
\text { number }\end{array}$ & Station name & $\begin{array}{l}\text { Flood } \\
\text { region }\end{array}$ & $\begin{array}{l}\text { Lat1- } \\
\text { tude, in } \\
\text { decimal } \\
\text { degrees }\end{array}$ & $\begin{array}{l}\text { Long1- } \\
\text { tude, in } \\
\text { decimal } \\
\text { degrees }\end{array}$ & $\begin{array}{l}\text { Years } \\
\text { of } \\
\text { record }\end{array}$ & $\begin{array}{c}\text { Drainage } \\
\text { area, in } \\
\text { square } \\
\text { miles }\end{array}$ & $\begin{array}{l}\text { Moan } \\
\text { basin } \\
\text { lova- } \\
\text { tion, } \\
\text { in } \\
\text { leet }\end{array}$ & $\begin{array}{l}\text { Mean } \\
\text { annual } \\
\text { prectpi- } \\
\text { tation, } \\
\text { in } \\
\text { inches }\end{array}$ & $\begin{array}{l}\text { Mean } \\
\text { amnual } \\
\text { erapor- } \\
\text { ation, } \\
\text { in } \\
\text { inches }\end{array}$ \\
\hline 09220000 & $\begin{array}{l}\text { East Fort of Smith Fork near } \\
\text { Robertson, Wyo. }\end{array}$ & 1 & 41.054 & 110.398 & 40 & 53.00 & 10,250 & 20.0 & 34.7 \\
\hline 09220500 & $\begin{array}{l}\text { West Fork of Smith Fork near } \\
\text { Robertson, Wyo. }\end{array}$ & 1 & 41.022 & 110.479 & 42 & 37.20 & 9,790 & 20.0 & 35.0 \\
\hline 09223000 & $\begin{array}{l}\text { Bans Fork below Pole Creek near } \\
\text { Frontier, Wyo. }\end{array}$ & 1 & 42.111 & 110.709 & 34 & 128.00 & 8,380 & 25.0 & 38.1 \\
\hline 09226000 & Henrys Fork near Lonetree, Wyo. & 1 & 41.006 & 110.270 & 30 & 56.00 & 10,270 & 23.0 & 34.7 \\
\hline 09226500 & $\begin{array}{l}\text { Middle Fork Beaver Creek near } \\
\text { Lonetree, Wyo. }\end{array}$ & 1 & 40.944 & 110.179 & 22 & 28.00 & 10,480 & 30.5 & 34.2 \\
\hline 09227500 & $\begin{array}{l}\text { West Fork Beaver Creek near } \\
\text { Lonetree, Wys. }\end{array}$ & 1 & 40.947 & 110.217 & 14 & 23.00 & 10,490 & 32.0 & 35.0 \\
\hline 09228500 & Burnt Fork near Burntfork, Wyo. & 1 & 40.946 & 110.066 & 32 & 52.80 & 10,300 & 29.3 & 34.3 \\
\hline 09235600 & $\begin{array}{l}\text { Pot Creek above Diversions, near } \\
\text { Vernal, Utah }\end{array}$ & 1 & 40.768 & 109.318 & 28 & 25.00 & 8,167 & 19.6 & 34.5 \\
\hline 09244500 & Elkhead Creek near Clark, Colo. & 1 & 40.732 & 107.169 & 15 & 45.60 & 8,600 & 27.0 & 40.1 \\
\hline 09251800 & $\begin{array}{l}\text { North Fork Little Snake River near } \\
\text { Encampment, Wyo. }\end{array}$ & 1 & 41.050 & 106.958 & 10 & 9.64 & 9,470 & 30.0 & 39.8 \\
\hline 09253400 & Battle Creek near Encampment, Wro. & 1 & 41.133 & 107.064 & 10 & 12.80 & 9,590 & 40.0 & 40.0 \\
\hline 09264000 & $\begin{array}{l}\text { Ashley Creek below Trout Creok } \\
\text { near Vernal, Utah }\end{array}$ & 1 & 40.733 & 109.678 & 11 & 27.00 & 9.930 & 28.0 & 34.4 \\
\hline 09264500 & $\begin{array}{l}\text { South Fork Asheley Creek } \\
\text { near Vernal, Utah }\end{array}$ & 1 & 40.733 & 109.703 & 12 & 20.00 & 10,480 & 30.3 & 34.8 \\
\hline 09268000 & $\begin{array}{l}\text { Dry Fork above Sinks, near Dry } \\
\text { Fork, Utah }\end{array}$ & 1 & 40.626 & 109.819 & 37 & 44.40 & 10,240 & 29.7 & 34.6 \\
\hline 09268500 & $\begin{array}{l}\text { North Fork of Dry Fork near } \\
\text { Dry Fork, Utah }\end{array}$ & 1 & 40.643 & 109.810 & 41 & 8.62 & 10,122 & 29.6 & 34.6 \\
\hline 09268900 & $\begin{array}{l}\text { Brownte Canyton above Sinks, } \\
\text { near Dry Fork, Utah }\end{array}$ & 1 & 40.659 & 109.750 & 26 & 8.24 & 10,107 & 28.0 & 34.3 \\
\hline 09269000 & $\begin{array}{l}\text { East Fork of Dry Fork near } \\
\text { Dry Fork, Utah }\end{array}$ & 1 & 40.650 & 109.761 & 18 & 12.00 & 9,360 & 28.6 & 36.2 \\
\hline 09273000 & $\begin{array}{l}\text { Duchesne River at Provo } \\
\text { River Trail, near Hanna Utah }\end{array}$ & 1 & 40.625 & 110.889 & 21 & 39.00 & 9,730 & 35.9 & 35.0 \\
\hline 09275000 & $\begin{array}{l}\text { West Fork Duchesne River, } \\
\text { Dry Hollow near Banna, Utah }\end{array}$ & 1 & 40.449 & 110.975 & 26 & 43.80 & 9,100 & 28.5 & 35.0 \\
\hline 09276000 & $\begin{array}{l}\text { Wolf Creek above Rhodes Canyon, } \\
\text { near Hanna, Utah }\end{array}$ & 1 & 40.471 & 110.918 & 38 & 10.60 & 9,040 & 26.6 & 35.0 \\
\hline 09277800 & $\begin{array}{l}\text { Rock Creek above South Fork } \\
\text { near Henna, Utah }\end{array}$ & 1 & 40.557 & 110.697 & 19 & 98.90 & 10,360 & 35.5 & 35.0 \\
\hline 09278000 & $\begin{array}{l}\text { South Fork Rock Creek near Hanna, } \\
\text { Utah }\end{array}$ & 1 & 40.548 & 110.694 & 32 & 15.70 & 10,000 & 30.8 & 35.0 \\
\hline 09278500 & Rock Creek near Hanna, Utah & 1 & 40.546 & 110.656 & 32 & 122.00 & 10,200 & 32.9 & 35.0 \\
\hline 09280400 & $\begin{array}{l}\text { Hobble Creek at Daniels Summit } \\
\text { near Wallsbur8, Utah }\end{array}$ & 1 & 40.298 & 111.264 & 21 & 2.89 & 9,060 & 29.3 & 34.8 \\
\hline 09287000 & $\begin{array}{l}\text { Currant Creek Below Red Leg } \\
\text { Hollow, near Fruitland, Utah }\end{array}$ & 1 & 40.324 & 111.045 & 32 & 50.10 & 8,880 & 27.8 & 35.0 \\
\hline 09289500 & $\begin{array}{l}\text { Lake Fork River above Moon Lake } \\
\text { near Mountain Home, Utah }\end{array}$ & 1 & 40.607 & 110.526 & 38 & 77.90 & 10,800 & 35.4 & 35.0 \\
\hline 09302450 & Lost Creek near Buford, Colo. & 1 & 40.050 & 107.468 & 22 & 21.50 & 8,960 & 27.5 & 40.0 \\
\hline 09302500 & Mervine Creek near Buford, Colo. & 1 & 40.038 & 107.487 & 12 & 59.70 & 9,780 & 32.2 & 40.0 \\
\hline 09303300 & $\begin{array}{l}\text { South Fork White River at } \\
\text { Budges Resort, Colo. }\end{array}$ & 1 & 39.843 & 107.334 & 11 & 52.30 & 10,569 & 40.0 & 40.0 \\
\hline 09303320 & $\begin{array}{l}\text { Wagonwheel Creek at Budges Resort, } \\
\text { Colo. }\end{array}$ & 1 & 39.843 & 107.336 & 11 & 7.36 & 10,640 & 40.0 & 40.0 \\
\hline 09303400 & South Fork White River near & 1 & 39.864 & 107.533 & 11 & 128.00 & 10,250 & 40.0 & 40.0 \\
\hline
\end{tabular}




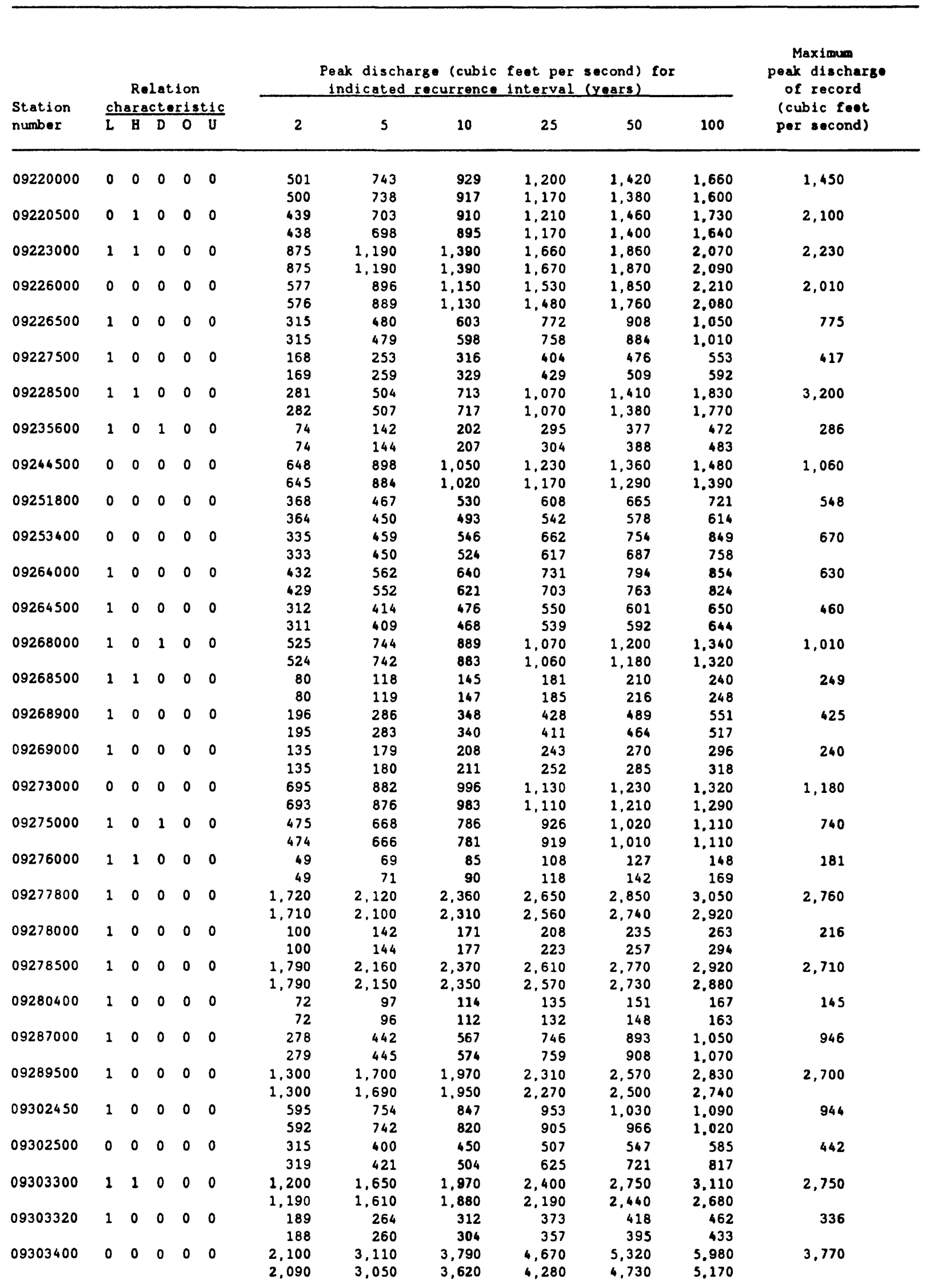




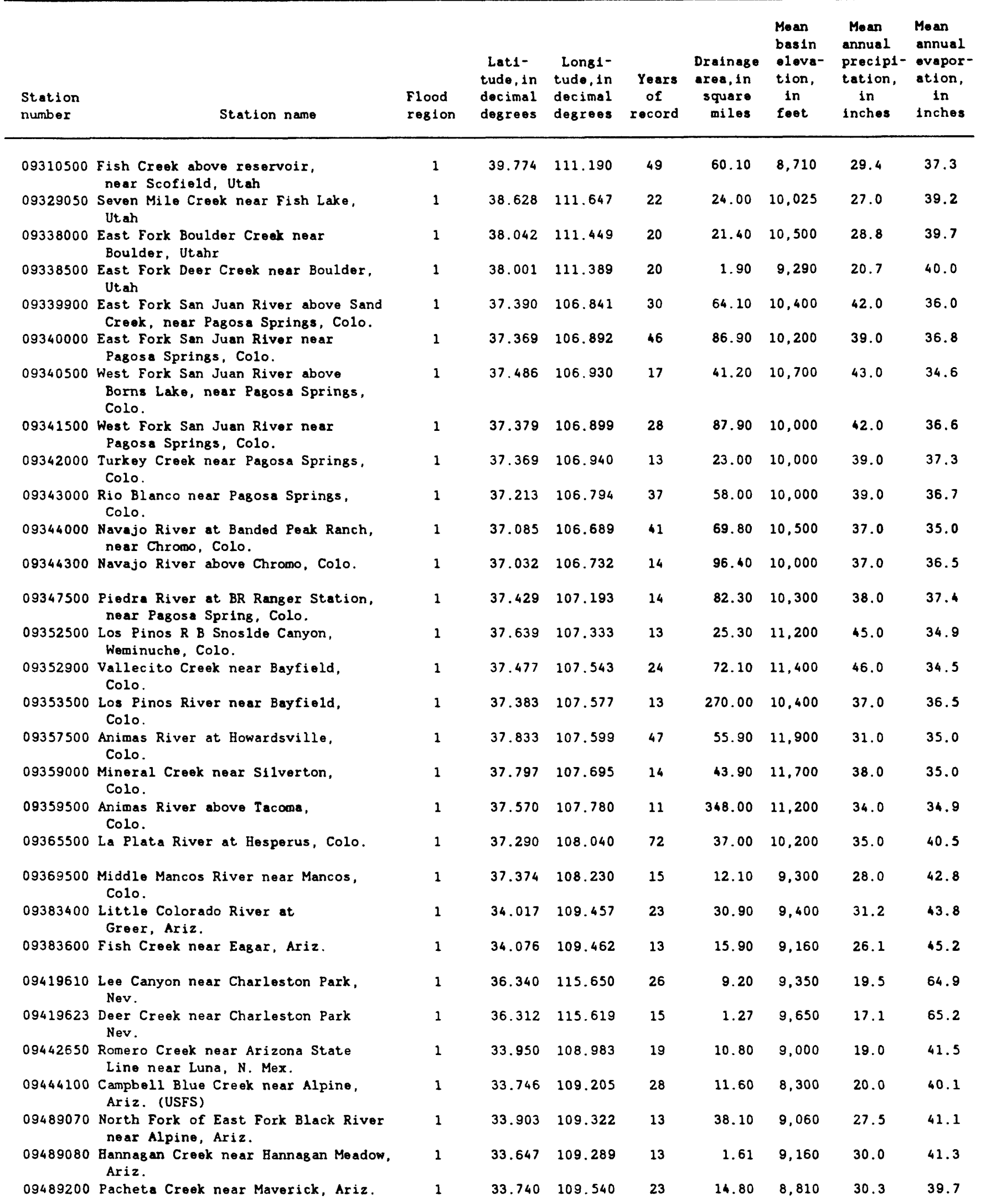




\begin{tabular}{|c|c|c|c|c|c|c|c|c|c|c|c|c|}
\hline \multirow{2}{*}{$\begin{array}{l}\text { Station } \\
\text { number }\end{array}$} & \multicolumn{5}{|c|}{$\begin{array}{c}\text { Relation } \\
\text { characteristic }\end{array}$} & \multicolumn{3}{|c|}{$\begin{array}{l}\text { Peak discharge (cubic } \\
\text { indicated recurrence }\end{array}$} & \multicolumn{3}{|c|}{$\begin{array}{l}\text { foet per second) for } \\
\text { interval (years) }\end{array}$} & \multirow{2}{*}{$\begin{array}{l}\text { Maximum } \\
\text { peak discharge } \\
\text { of record } \\
\text { (cubic feet } \\
\text { per second) }\end{array}$} \\
\hline & $L$ & H & D & 0 & $\bar{U}$ & 2 & 5 & 10 & 25 & 50 & 100 & \\
\hline \multirow[t]{2}{*}{09310500} & 1 & 0 & 0 & 0 & 0 & 595 & 828 & 985 & 1,190 & 1,340 & 1,500 & 1,450 \\
\hline & & & & & & 595 & 827 & 983 & 1,190 & 1,340 & 1,490 & \\
\hline 09329050 & 1 & 0 & 0 & 0 & 0 & 180 & 243 & 284 & 335 & 371 & 408 & 369 \\
\hline \multirow[t]{2}{*}{09338000} & 0 & 0 & 0 & 0 & & 180 & 245 & 291 & 353 & 400 & 449 & \\
\hline & & & & & 0 & $\begin{array}{l}199 \\
199\end{array}$ & 303 & 375 & 467 & 536 & 606 & 483 \\
\hline \multirow{2}{*}{09338500} & 0 & 1 & 0 & 1 & 0 & $\begin{array}{r}199 \\
20\end{array}$ & 304 & 376 & 470 & 540 & 611 & \\
\hline & & & & & & $\begin{array}{l}20 \\
20\end{array}$ & $\begin{array}{l}64 \\
63\end{array}$ & $\begin{array}{l}122 \\
117\end{array}$ & $\begin{array}{l}248 \\
227\end{array}$ & 352 & $\begin{array}{l}515 \\
523\end{array}$ & 350 \\
\hline 09339900 & 0 & 0 & 0 & 0 & 0 & 665 & 1,010 & 1,270 & 1.630 & 1.930 & 2,250 & 2,260 \\
\hline \multirow[t]{2}{*}{09340000} & 0 & 0 & 0 & 0 & 0 & $\begin{array}{l}666 \\
922\end{array}$ & 1,010 & 1.270 & 1,620 & 1,910 & 2,200 & \\
\hline & & & & & & $\begin{array}{l}922 \\
922\end{array}$ & $\begin{array}{l}1.350 \\
1.350\end{array}$ & 1,640 & 2.020 & 2,320 & 2,620 & 2,460 \\
\hline \multirow{2}{*}{09340500} & 0 & 0 & 0 & 0 & 0 & $\begin{array}{l}922 \\
733\end{array}$ & $\begin{array}{r}1,350 \\
978\end{array}$ & 1,640 & 2,010 & 2,300 & 2,590 & \\
\hline & & & & & & 732 & 974 & $\begin{array}{l}1,140 \\
1,130\end{array}$ & 1,350 & 1,510 & 1,670 & 1,290 \\
\hline \multirow[t]{2}{*}{09341500} & 0 & 0 & 0 & 0 & 0 & 1,310 & 1,830 & 2,180 & 2,630 & $\begin{array}{l}1,470 \\
2,970\end{array}$ & 3,320 & 2,330 \\
\hline & & & & & & 1,310 & 1,820 & 2,160 & 2,580 & 2.890 & 3,200 & 2,000 \\
\hline 09342000 & 0 & 0 & 0 & 0 & 0 & 335 & 521 & 659 & 849 & 1,000 & 1,160 & 860 \\
\hline & & & & & & 335 & 519 & 650 & 820 & 948 & 1,080 & \\
\hline 09343000 & 0 & 1 & 0 & 0 & 0 & 851 & 1,200 & 1,450 & 1,780 & 2,040 & 2,310 & 2,500 \\
\hline & & & & & & 851 & 1,200 & 1,440 & 1,750 & 2.000 & 2,240 & \\
\hline 09344000 & 0 & 0 & 0 & 0 & 0 & 649 & 897 & 1,070 & 1,290 & 1.460 & 1,630 & 1,480 \\
\hline & & & & & & 650 & 900 & 1,080 & 1,300 & 1,480 & 1,650 & \\
\hline 09344300 & 0 & 0 & 0 & 0 & 0 & 716 & 984 & 1,170 & 1.420 & 1.620 & 1,830 & 1,400 \\
\hline & & & & & & 720 & 1.000 & 1,210 & 1,500 & 1,720 & 1.950 & \\
\hline 09347500 & 0 & 0 & 0 & 0 & 0 & 876 & 1.270 & 1,560 & 1,940 & 2,250 & 2,560 & 1.800 \\
\hline & & & & & & 877 & 1,270 & 1,550 & 1,910 & 2,190 & 2.460 & \\
\hline 09352500 & 0 & 0 & 0 & 0 & 0 & 322 & 517 & 659 & 849 & 999 & 1,150 & 650 \\
\hline 09352900 & - & - & - & - & 1 & $\begin{array}{r}324 \\
-\ldots-\end{array}$ & $\begin{array}{r}521 \\
-\ldots-\end{array}$ & $\begin{array}{r}662 \\
-\ldots .\end{array}$ & $\begin{array}{r}842 \\
\ldots . .\end{array}$ & $\begin{array}{r}977 \\
-\ldots\end{array}$ & 1,110 & 050 \\
\hline & & 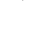 & & & 1 & 1,140 & 1,450 & 1,620 & 1.840 & 2,010 & 2,170 & 1,050 \\
\hline 09353500 & 0 & 0 & 0 & 0 & 0 & 2,310 & 3,250 & 3,860 & 4,610 & 5.170 & 5.710 & 13,800 \\
\hline & & & & & & 2,310 & 3,250 & 3,850 & 4,550 & 5,060 & 5,550 & \\
\hline 09357500 & 0 & 0 & 0 & 0 & 0 & 979 & 1,270 & 1,460 & 1,690 & 1,860 & 2,020 & 1,980 \\
\hline & & & & & & 977 & 1,260 & 1,450 & 1,660 & 1,820 & 1.970 & \\
\hline 09359000 & 0 & 0 & 0 & 0 & 0 & 827 & 1,100 & 1,300 & 1,560 & 1,760 & 1,980 & 1,700 \\
\hline & & & & & & 824 & 1.090 & 1,270 & 1,490 & 1,650 & 1.830 & \\
\hline 09359500 & 0 & 0 & 0 & 0 & 0 & 5,370 & 7,300 & 8.540 & 10,100 & 11,100 & 12,200 & 9.500 \\
\hline & & & & & & 5,330 & 7,110 & 8.070 & 9,120 & 9,740 & 10,400 & \\
\hline 09365500 & 1 & 0 & 0 & 0 & 0 & 450 & 756 & 986 & 1,300 & 1,560 & 1.820 & 1.880 \\
\hline & & & & & & 450 & 755 & 981 & 1,290 & 1,540 & 1,780 & \\
\hline 09369500 & - & - & - & 0 & 1 & $\ldots$ & $\ldots$ & $\cdots$ & $\cdots$ & $\ldots$ & $\ldots$ & 297 \\
\hline & & & & & & 124 & 196 & 247 & 312 & 360 & 407 & \\
\hline 09383400 & 0 & 0 & 0 & 0 & 0 & 174 & 316 & 427 & 586 & 715 & 854 & 615 \\
\hline & & & & & & 175 & 320 & 435 & 597 & 725 & 859 & \\
\hline 09383600 & 1 & 0 & 0 & 0 & 0 & 73 & 158 & 230 & 336 & 423 & 518 & 236 \\
\hline & & & & & & 74 & 161 & 235 & 340 & 423 & 508 & \\
\hline 09419610 & 1 & 0 & 1 & 1 & 0 & 11 & 85 & 249 & 769 & 1,580 & 3.020 & 880 \\
\hline & & & & & & 11 & 86 & 246 & 718 & 1,420 & 2,640 & \\
\hline 09419623 & 1 & 0 & 0 & 0 & 0 & 4 & 16 & 32 & 66 & 105 & 158 & 50 \\
\hline & & & & & & 4 & 16 & 32 & 62 & 94 & 135 & \\
\hline 09442650 & - & - & - & - & 1 & --- & --- & $\cdots$ & $\ldots$ & $\cdots$ & $-\cdots$ & 480 \\
\hline & & & & & & 64 & 116 & 156 & 209 & 249 & 289 & \\
\hline 09444100 & 1 & 0 & 0 & 0 & 0 & 43 & 113 & 195 & 357 & 535 & 778 & 619 \\
\hline & & & & & & 43 & 113 & 194 & 347 & 507 & 718 & \\
\hline 09489070 & - & - & - & - & 1 & --- & -.- & -... & $\cdots$ & $\cdots$ & --- & 1,070 \\
\hline & & & & & & 318 & 486 & 598 & 741 & 848 & 951 & \\
\hline 09489080 & - & - & - & - & 1 & -.. & $\ldots$ & --- & $\ldots$ & $\cdots$ & $\cdots$ & 70 \\
\hline & & & & & & 25 & 42 & 56 & 70 & 82 & 94 & \\
\hline 09489200 & 1 & 0 & 0 & 0 & 0 & 105 & 179 & 235 & 313 & 376 & 442 & 323 \\
\hline & & & & & & 105 & 181 & 239 & 320 & 385 & 451 & \\
\hline
\end{tabular}




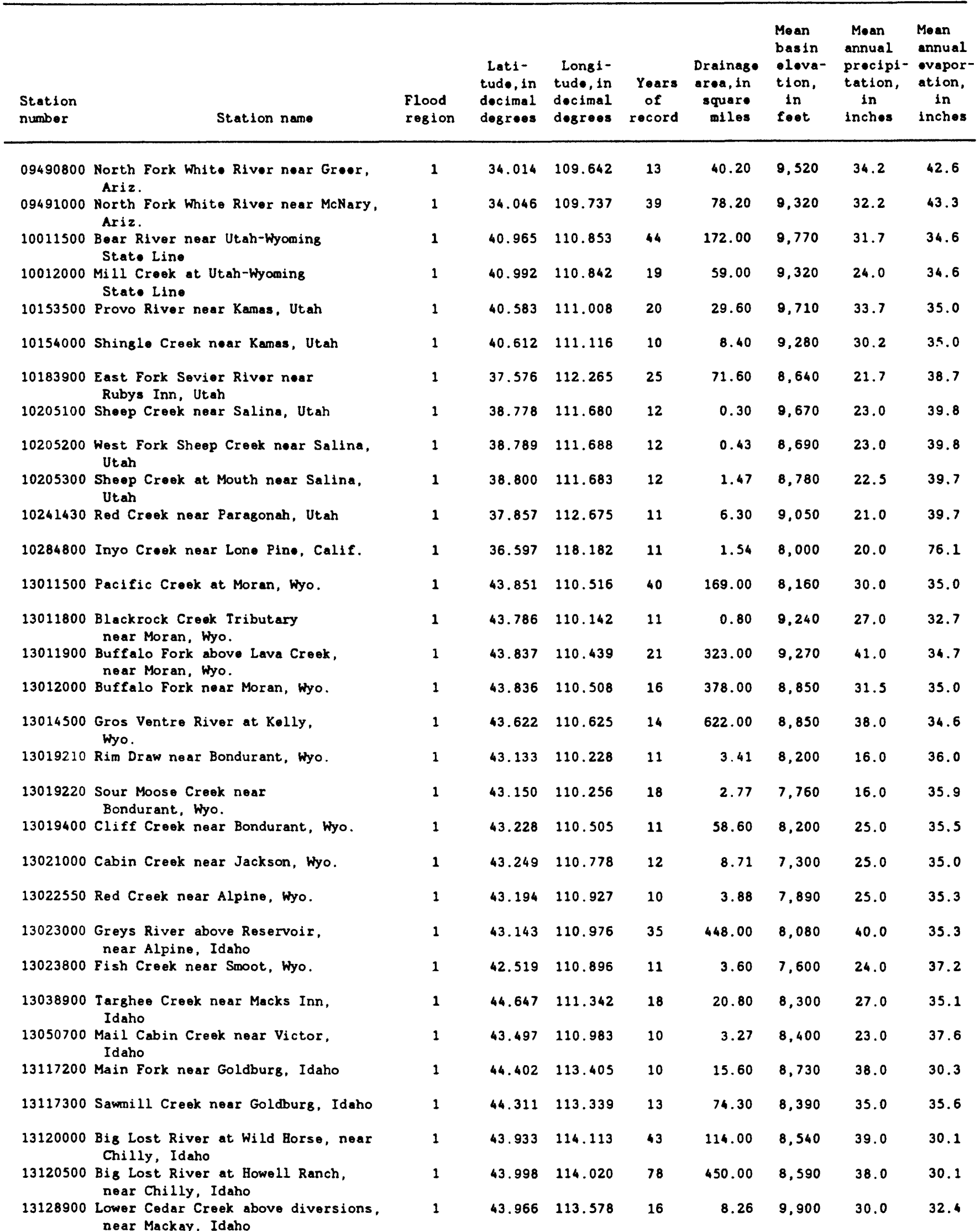




\begin{tabular}{|c|c|c|c|c|c|c|c|c|c|c|c|c|}
\hline \multirow{2}{*}{$\begin{array}{l}\text { Station } \\
\text { number }\end{array}$} & \multicolumn{5}{|c|}{$\begin{array}{c}\text { Relation } \\
\text { characteristic }\end{array}$} & \multicolumn{3}{|c|}{$\begin{array}{l}\text { Peak discharge (cubic } \\
\text { indicated recurrence }\end{array}$} & \multicolumn{3}{|c|}{$\begin{array}{l}\text { Eot per second) for } \\
\text { interval (yoars) }\end{array}$} & \multirow{2}{*}{$\begin{array}{l}\text { Maximum } \\
\text { peak discharse } \\
\text { of record } \\
\text { (cubic feot } \\
\text { per second) }\end{array}$} \\
\hline & $L$ & $\mathrm{H}$ & $D$ & 0 & $v$ & 2 & $s$ & 10 & 25 & so & 100 & \\
\hline \multirow[t]{2}{*}{09490800} & - & - & - & - & 1 &.-- & --- & $\ldots$ & $\cdots$ & $\cdots$ & --- & 510 \\
\hline & & & & & & 455 & 648 & 769 & 922 & 1,040 & 1,150 & \\
\hline \multirow[t]{2}{*}{09491000} & 0 & 0 & 0 & 0 & 0 & 404 & 740 & 1,030 & 1,480 & 1,890 & 2,350 & 2,310 \\
\hline & & & & & & 405 & 745 & 1,040 & 1,480 & 1.870 & 2,300 & \\
\hline \multirow[t]{2}{*}{10011500} & 0 & 0 & 0 & 0 & 0 & 1,880 & 2,410 & 2,720 & 3,080 & 3,340 & 3,580 & 3,230 \\
\hline & & & & & & 1,880 & 2,400 & 2,710 & 3,060 & 3,310 & 3.550 & \\
\hline \multirow[t]{2}{*}{10012000} & 0 & 0 & 0 & 0 & 0 & 387 & 543 & 646 & 776 & 872 & 967 & 690 \\
\hline & & & & & & 387 & 545 & 652 & 794 & 902 & 1,010 & \\
\hline \multirow{2}{*}{10153500} & 1 & 0 & 0 & 0 & 0 & 503 & 633 & 711 & 806 & 868 & 930 & 825 \\
\hline & & & & & & 502 & 629 & 704 & 795 & 860 & 925 & \\
\hline \multirow[t]{2}{*}{10154000} & 0 & 0 & 0 & 0 & 0 & 178 & 203 & 218 & 235 & 247 & 258 & 238 \\
\hline & & & & & & 177 & 200 & 216 & 238 & 258 & 278 & \\
\hline 10183900 & 0 & 0 & 0 & 0 & 0 & 112 & 196 & 267 & 377 & 475 & 588 & 448 \\
\hline & & & & & & 114 & 206 & 293 & 433 & 555 & 691 & \\
\hline 10205100 & 0 & 0 & 0 & 0 & 0 & 4 & 9 & 13 & 19 & 25 & 33 & 17 \\
\hline & & & & & & 4 & 9 & 13 & 19 & 24 & 30 & \\
\hline 10205200 & 0 & 0 & 0 & 0 & 0 & 3 & 8 & 13 & 20 & 27 & 34 & 12 \\
\hline & & & & & & 3 & 8 & 13 & 20 & 26 & 33 & \\
\hline 10205300 & 0 & 0 & 0 & 0 & 0 & 12 & 23 & 33 & 47 & 59 & 72 & 32 \\
\hline & & & & & & 12 & 24 & 34 & 48 & 60 & 72 & \\
\hline 10241430 & 1 & 1 & 0 & 0 & 0 & 15 & 24 & 31 & 42 & 52 & 62 & 48 \\
\hline & & & & & & 15 & 27 & 40 & 62 & 81 & 102 & \\
\hline 10284800 & 0 & 0 & 0 & 0 & 0 & 7 & 21 & 36 & 63 & 90 & 123 & 42 \\
\hline & & & & & & 7 & 21 & 36 & 61 & 83 & 108 & \\
\hline 13011500 & 1 & 1 & 0 & 0 & 0 & 2,480 & 3,130 & 3.540 & 4,050 & 4,420 & 4,780 & 5,350 \\
\hline & & & & & & 2,480 & 3,110 & 3,490 & 3,960 & 4,290 & 4,620 & \\
\hline 13011800 & 0 & 0 & 0 & 0 & 0 & 42 & 63 & 78 & 100 & 118 & 137 & 110 \\
\hline & & & & & & 42 & 60 & 73 & 88 & 101 & 114 & \\
\hline 13011900 & 0 & 0 & 0 & 0 & 0 & 4,260 & 5,080 & 5,600 & 6,240 & 6,710 & 7.170 & 6,540 \\
\hline & & & & & & 4,250 & 5,060 & 5,550 & 6,140 & 6.580 & 7.000 & \\
\hline 13012000 & 0 & 1 & 0 & 0 & 0 & 4,060 & 4,650 & 5,000 & 5,420 & 5,710 & 5,980 & 5,960 \\
\hline & & & & & & 4,050 & 4,610 & 4,930 & 5.340 & 5,650 & 5,950 & \\
\hline 13014500 & 0 & 1 & 0 & 0 & 0 & 3,200 & 3,980 & 4,510 & 5,200 & 5,730 & 6,270 & 6,960 \\
\hline & & & & & & 3,220 & 4,090 & 4,760 & 5,660 & 6,350 & 7,040 & \\
\hline 13019210 & 1 & 0 & 0 & 1 & 0 & 14 & 16 & 17 & 18 & 19 & 20 & 18 \\
\hline & & & & & & 14 & 17 & 21 & 29 & 36 & 45 & \\
\hline 13019220 & 1 & 0 & 0 & 0 & 0 & 15 & 20 & 24 & 28 & 31 & 34 & 26 \\
\hline & & & & & & 15 & 20 & 25 & 32 & 39 & 45 & \\
\hline 13019400 & 0 & 0 & 0 & 0 & 0 & 600 & 832 & 994 & 1.210 & 1.370 & 1,550 & 1,150 \\
\hline & & & & & & 597 & 821 & 969 & 1,160 & 1.310 & 1,460 & \\
\hline 13021000 & 0 & 0 & 1 & 0 & 0 & 127 & 163 & 184 & 208 & 226 & 239 & 167 \\
\hline & & & & & & 126 & 162 & 183 & 210 & 232 & 254 & \\
\hline 13022550 & - & - & - & - & 1 & $-\cdots$ & $-\cdots$ & $\cdots$ & $\cdots$ & $\cdots$ &.-- & 44 \\
\hline & & & & & & 40 & 69 & 91 & 119 & 140 & 161 & \\
\hline 13023000 & 1 & 0 & 0 & 0 & 0 & 3,420 & 4,520 & 5,230 & 6,130 & 6.790 & 7,450 & 7,230 \\
\hline & & & & & & 3,420 & 4,540 & 5,260 & 6.170 & 6,830 & 7,480 & \\
\hline 13023800 & - & - & - & - & 1 & $\ldots$ & $\ldots$ & -- & $\ldots$ & $\ldots$ & -..- & 81 \\
\hline & & & & & & 36 & 62 & 82 & 108 & 128 & 148 & \\
\hline 13038900 & 0 & 0 & 0 & 0 & 0 & 256 & 326 & 370 & 424 & 462 & 499 & 458 \\
\hline & & & & & & 255 & 325 & 370 & 428 & 473 & $\$ 17$ & \\
\hline 13050700 & 0 & 1 & 0 & 0 & 0 & 37 & 51 & 60 & 73 & 83 & 93 & 81 \\
\hline & & & & & & 37 & 51 & 62 & 78 & 91 & 105 & \\
\hline 13117200 & 1 & 0 & 0 & 0 & 0 & 137 & 193 & 230 & 278 & 313 & 349 & 273 \\
\hline & & & & & & 139 & 202 & 251 & 319 & 372 & 424 & \\
\hline 13117300 & 1 & 0 & 0 & 0 & 0 & 374 & 522 & 619 & 741 & 832 & 922 & 651 \\
\hline & & & & & & 379 & 548 & 680 & 864 & 1,010 & 1,150 & \\
\hline 13120000 & 0 & 0 & 1 & 0 & 0 & 753 & 1,020 & 1,200 & 1,410 & 1,570 & 1,720 & 1,440 \\
\hline & & & & & & 755 & 1,030 & 1,220 & 1,460 & 1.640 & 1,810 & \\
\hline 13120500 & 0 & 0 & 1 & 0 & 0 & 2,170 & 3,010 & 3,500 & 4,070 & 4,460 & 4.810 & 4,420 \\
\hline & & & & & & 2.170 & 3,030 & 3,540 & 4,140 & 4.570 & 4.950 & \\
\hline 13128900 & 1 & 0 & 0 & 0 & 0 & 181 & 227 & 257 & 294 & 321 & 349 & 310 \\
\hline & & & & & & 180 & 224 & 252 & 287 & 315 & 343 & \\
\hline
\end{tabular}




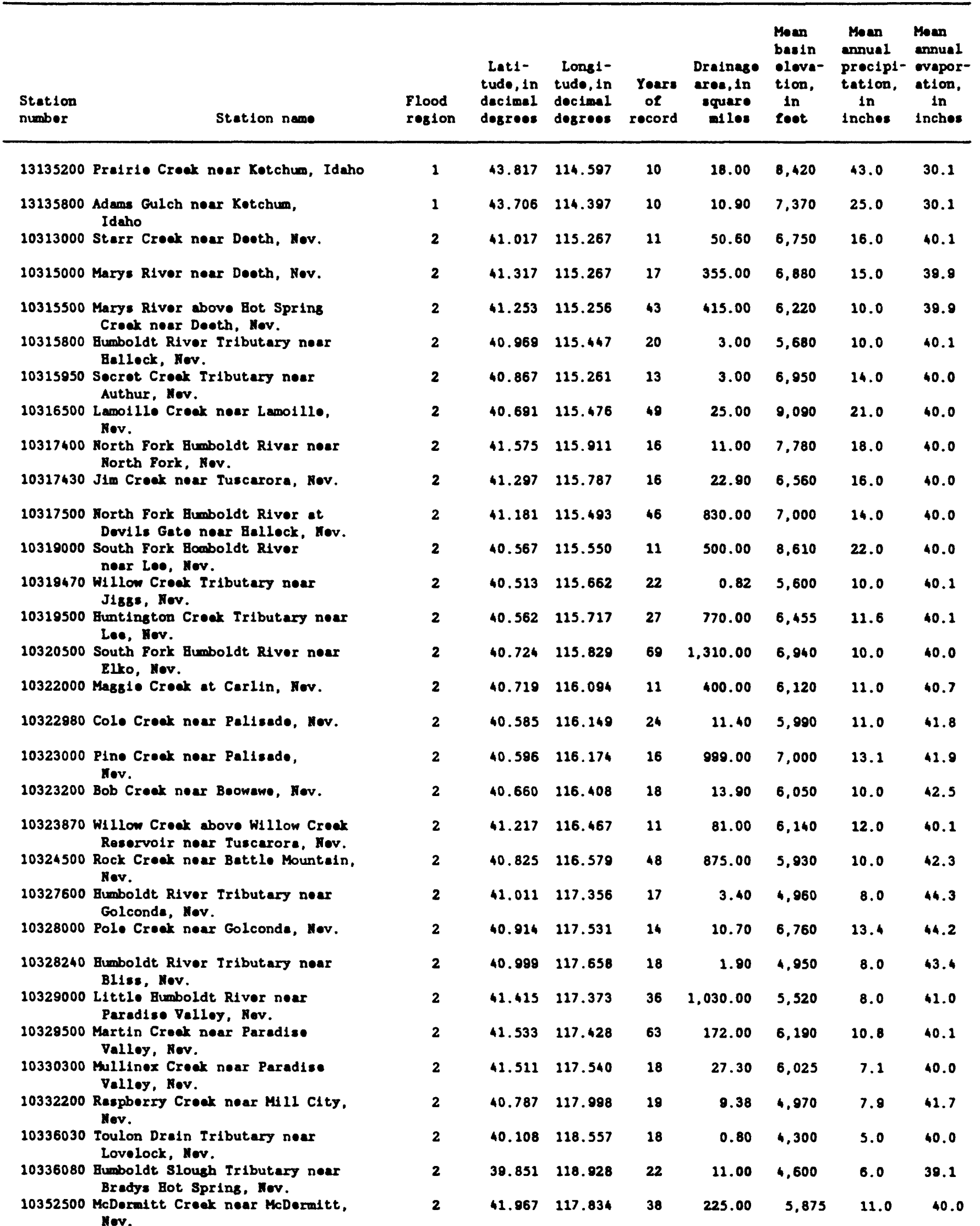




\begin{tabular}{|c|c|c|c|c|c|c|c|c|c|c|c|c|}
\hline \multirow{2}{*}{$\begin{array}{l}\text { Station } \\
\text { number }\end{array}$} & \multicolumn{5}{|c|}{ Relation } & \multicolumn{3}{|c|}{$\begin{array}{l}\text { Peak discharge (cubic } \\
\text { indicated recurrence }\end{array}$} & \multicolumn{3}{|c|}{$\begin{array}{l}\text { feet per second) for } \\
\text { interval (years) }\end{array}$} & \multirow{2}{*}{$\begin{array}{l}\text { Maximum } \\
\text { peak discharge } \\
\text { of record } \\
\text { (cubic feet } \\
\text { per second) }\end{array}$} \\
\hline & $\frac{\mathrm{cm}}{\mathrm{L}}$ & B & $D$ & 0 & $\frac{C_{1 C}}{U}$ & 2 & 5 & 10 & 25 & 50 & 100 & \\
\hline \multirow[t]{2}{*}{13135200} & 0 & 0 & 0 & 0 & 0 & 167 & 244 & 296 & 362 & 412 & 462 & 293 \\
\hline & & & & & & 169 & 255 & 321 & 409 & 476 & 541 & \\
\hline \multirow{2}{*}{13135800} & 0 & 0 & 1 & 0 & 0 & 39 & 83 & 125 & 194 & 259 & 337 & 124 \\
\hline & & & & & & 40 & 88 & 134 & 208 & 271 & 341 & \\
\hline \multirow[t]{2}{*}{10313000} & 0 & 0 & 0 & 0 & 0 & 181 & 307 & 403 & 535 & 641 & 753 & 391 \\
\hline & & & & & & 184 & 318 & 422 & 573 & 692 & 815 & \\
\hline \multirow[t]{2}{*}{10315000} & 0 & 0 & 0 & 0 & 0 & 283 & 454 & 571 & 721 & 832 & 944 & 616 \\
\hline & & & & & & 314 & 560 & 792 & 1,160 & 1,450 & 1,740 & \\
\hline \multirow[t]{2}{*}{10315500} & 1 & 1 & 0 & 0 & 0 & 422 & 738 & 1,020 & 1,490 & 1,930 & 2,460 & 4,210 \\
\hline & & & & & & 434 & 779 & 1,110 & 1.660 & 2,160 & 2,740 & \\
\hline \multirow[t]{2}{*}{10315800} & 1 & 0 & 0 & 0 & 0 & 13 & 32 & 50 & $7 \mathrm{~J}$ & 104 & 134 & 99 \\
\hline & & & & & & 14 & 34 & 52 & 80 & 104 & 131 & \\
\hline 10315950 & - & - & - & - & 1 & --- & --- & --- & --- & --- & --- & 42 \\
\hline & & & & & & 29 & 50 & 62 & 81 & 95 & 109 & \\
\hline 10316500 & 0 & 0 & 0 & 0 & 0 & 421 & 563 & 660 & 786 & 883 & 982 & 829 \\
\hline & & & & & & 415 & 551 & 637 & 748 & 835 & 925 & \\
\hline 10317400 & 0 & 0 & 0 & 0 & 0 & 94 & 134 & 160 & 191 & 214 & 236 & 170 \\
\hline & & & & & & 93 & 133 & 159 & 193 & 220 & 246 & \\
\hline 10317430 & 1 & 1 & 0 & 0 & 0 & 43 & 88 & 133 & 214 & 296 & 401 & 541 \\
\hline & & & & & & 48 & 101 & 157 & 250 & 334 & 434 & \\
\hline 10317500 & 1 & 1 & 0 & 0 & 0 & 624 & 1.350 & 2,030 & 3,170 & 4,240 & 5,510 & 10,400 \\
\hline & & & & & & 644 & 1.410 & 2,140 & 3,350 & 4,460 & 5,740 & \\
\hline 10319000 & 0 & 0 & 0 & 0 & 0 & 596 & 760 & 861 & 981 & 1,070 & 1,150 & 935 \\
\hline & & & & & & 566 & 709 & 776 & 875 & 960 & 1,040 & \\
\hline 10319470 & - & - & - & - & 1 & --- & --- & ---- & ---- & ---- & --- & 15 \\
\hline & & & & & & 11 & 19 & 26 & 34 & 40 & 47 & \\
\hline 10319500 & 0 & 0 & 0 & 0 & 0 & 299 & 711 & 1,100 & 1,720 & 2,270 & 2,920 & 2,160 \\
\hline & & & & & & 340 & 838 & 1,360 & 2,200 & 2.930 & 3.740 & \\
\hline 10320500 & 1 & 0 & 0 & 0 & 0 & 1,010 & 1,410 & 1,680 & 2,050 & 2,340 & 2,630 & 2,830 \\
\hline & & & & & & 1.030 & 1,480 & 1.830 & 2,370 & 2,820 & 3,270 & \\
\hline 10322000 & 0 & 0 & 0 & 0 & 0 & 138 & 376 & 643 & 1,150 & 1,690 & 2,400 & 2,440 \\
\hline & & & & & & 202 & 563 & 1.000 & 1,750 & 2,430 & 3.200 & \\
\hline 10322980 & 0 & 1 & 0 & 0 & 0 & 9 & 54 & 136 & 361 & 670 & 1.160 & 1,090 \\
\hline & & & & & & 11 & 59 & 140 & 340 & 597 & 992 & \\
\hline 10323000 & 1 & 0 & 1 & 0 & 0 & 137 & 545 & 1,130 & 2,460 & 4.080 & 6,440 & 3,140 \\
\hline & & & & & & 231 & 824 & 1,630 & 3,230 & 4.880 & 7.020 & \\
\hline 10323200 & 1 & 0 & 0 & 0 & 0 & 34 & 66 & 94 & 135 & 172 & 212 & 130 \\
\hline & & & & & & 36 & 74 & 109 & 162 & 207 & 253 & \\
\hline 10323870 & 1 & 0 & 0 & 0 & 0 & 325 & 562 & 746 & 1,010 & 1,230 & 1,460 & 820 \\
\hline & & & & & & 323 & 559 & 740 & 1,000 & 1,220 & 1.440 & \\
\hline 10324500 & 0 & 0 & 0 & 0 & 0 & 462 & 1.320 & 2,240 & 3,880 & 5,490 & 7,470 & 4,800 \\
\hline & & & & & & 485 & 1.380 & 2,350 & 4.040 & 5,660 & 7,590 & \\
\hline 10327600 & - & - & - & - & 1 & $\ldots$ & -- & $\ldots$ & --- & --- & -.. & 1 \\
\hline & & & & & & 31 & 54 & 77 & 104 & 124 & 146 & \\
\hline 10328000 & 0 & 1 & 0 & 1 & 0 & 66 & 226 & 458 & 1.020 & 1,770 & 2,960 & 4,000 \\
\hline & & & & & & 66 & 214 & 404 & 818 & 1,340 & 2,150 & \\
\hline 10328240 & - & - & - & - & 1 & --- & --- & $\ldots$ & --- & $\ldots$ &.-- & 113 \\
\hline & & & & & & 21 & 36 & 51 & 67 & 81 & 94 & \\
\hline 10329000 & 1 & 1 & 0 & 1 & 0 & 116 & 308 & 534 & 988 & 1,500 & 2,200 & 2,380 \\
\hline & & & & & & 161 & 454 & 863 & 1,640 & 2,400 & 3,330 & \\
\hline 10329500 & 1 & 0 & 0 & 0 & 0 & 423 & 1.100 & 1,890 & 3,420 & 5,110 & 7,390 & 9,000 \\
\hline & & & & & & 424 & 1,100 & 1,860 & 3,300 & 4.870 & 6,960 & \\
\hline 10330300 & 1 & 0 & 1 & 0 & 0 & 248 & 585 & 899 & 1,400 & 1,840 & 2,350 & 1,320 \\
\hline & & & & & & 242 & 554 & 816 & 1,200 & 1,540 & 1,920 & \\
\hline 10332200 & - & - & - & - & 1 & --- & --- & --- & -- &.- & --- & 25 \\
\hline & & & & & & 65 & 113 & 161 & 218 & 265 & 312 & \\
\hline 10336030 & - & - & - & - & 1 & --- & --- & ---- & --- & --- & -- & 350 \\
\hline & & & & & & 11 & 19 & 28 & 38 & 45 & 53 & \\
\hline 10336080 & - & - & - & - & 1 & 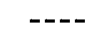 & ---- & --- &.-- & --- & --- & 710 \\
\hline & & & & & & 72 & 127 & 186 & 254 & 310 & 368 & \\
\hline 10352500 & 0 & 0 & 0 & 0 & 0 & 564 & 1,340 & 2,060 & 3,220 & 4,260 & 5,460 & 3,970 \\
\hline & & & & & & 565 & 1,330 & 2,020 & 3,100 & 4,050 & 5,140 & \\
\hline
\end{tabular}




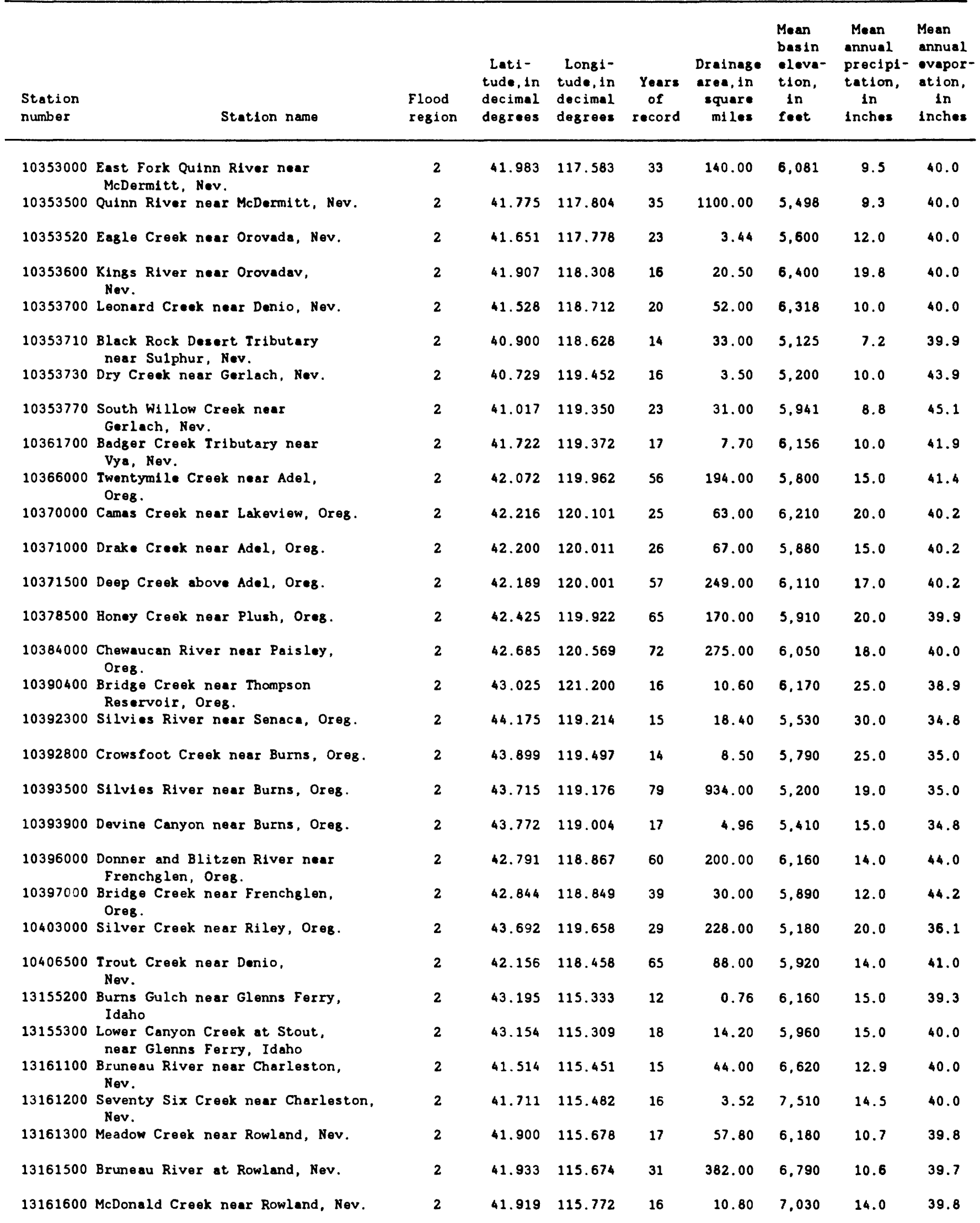




\begin{tabular}{|c|c|c|c|c|c|c|c|c|c|c|c|c|}
\hline \multirow{2}{*}{$\begin{array}{l}\text { Station } \\
\text { number }\end{array}$} & \multicolumn{5}{|c|}{$\begin{array}{c}\text { Relation } \\
\text { characteristic }\end{array}$} & \multicolumn{6}{|c|}{$\begin{array}{l}\text { Peak discharge (cubic feet per second) for } \\
\text { indicated recurrence interval (years) }\end{array}$} & \multirow{2}{*}{$\begin{array}{l}\text { Maximum } \\
\text { peak discharse } \\
\text { of record } \\
\text { (cubic feet } \\
\text { per second) }\end{array}$} \\
\hline & $\mathrm{L}$ & H & $D$ & 0 & U & 2 & 5 & 10 & 25 & 50 & 100 & \\
\hline 10353000 & 1 & 0 & 1 & 0 & 0 & $\begin{array}{l}425 \\
426\end{array}$ & $\begin{array}{l}658 \\
665\end{array}$ & $\begin{array}{l}828 \\
849\end{array}$ & $\begin{array}{l}1,060 \\
1,110\end{array}$ & $\begin{array}{l}1,260 \\
1,320\end{array}$ & $\begin{array}{l}1.440 \\
1.550\end{array}$ & 1,270 \\
\hline 10353500 & 1 & 0 & 1 & 0 & 0 & $\begin{array}{l}255 \\
300\end{array}$ & $\begin{array}{l}686 \\
826\end{array}$ & $\begin{array}{l}1,100 \\
1,410\end{array}$ & $\begin{array}{l}1,740 \\
2,360\end{array}$ & $\begin{array}{l}2,310 \\
3,190\end{array}$ & $\begin{array}{l}2.960 \\
4.070\end{array}$ & 1,580 \\
\hline 10353520 & - & - & - & - & 1 & 32 & 55 & 74 & 99 & 118 & 137 & 10 \\
\hline 10353600 & 0 & 1 & 0 & 0 & 0 & $\begin{array}{l}46 \\
50\end{array}$ & $\begin{array}{l}122 \\
130\end{array}$ & $\begin{array}{l}212 \\
220\end{array}$ & $\begin{array}{l}394 \\
384\end{array}$ & $\begin{array}{l}597 \\
551\end{array}$ & $\begin{array}{l}878 \\
770\end{array}$ & 770 \\
\hline 10353700 & 0 & 0 & 0 & 0 & 0 & $\begin{array}{l}79 \\
86\end{array}$ & $\begin{array}{l}194 \\
210\end{array}$ & $\begin{array}{l}312 \\
339\end{array}$ & $\begin{array}{l}521 \\
554\end{array}$ & $\begin{array}{l}727 \\
751\end{array}$ & $\begin{array}{l}985 \\
985\end{array}$ & 612 \\
\hline 10353710 & - & - & - & - & 1 & 158 & 281 & 397 & 545 & 666 & 790 & 3,940 \\
\hline 10353730 & - & - & - & - & 1 & 32 & 55 & 77 & 104 & 124 & 145 & 736 \\
\hline 10353770 & 1 & 0 & 0 & 0 & 0 & $\begin{array}{l}40 \\
45\end{array}$ & $\begin{array}{l}207 \\
211\end{array}$ & $\begin{array}{l}489 \\
474\end{array}$ & $\begin{array}{l}1,230 \\
1,110\end{array}$ & $\begin{array}{l}2,260 \\
1,920\end{array}$ & $\begin{array}{l}3.860 \\
3.200\end{array}$ & 1,730 \\
\hline 10361700 & 1 & 0 & 0 & 0 & 0 & $\begin{array}{l}14 \\
17\end{array}$ & $\begin{array}{l}54 \\
58\end{array}$ & $\begin{array}{l}108 \\
111\end{array}$ & $\begin{array}{l}226 \\
214\end{array}$ & $\begin{array}{l}366 \\
327\end{array}$ & $\begin{array}{l}566 \\
480\end{array}$ & 230 \\
\hline 10366000 & 1 & 0 & 1 & 0 & 0 & $\begin{array}{l}1,460 \\
1.450\end{array}$ & $\begin{array}{l}3,020 \\
2,960\end{array}$ & $\begin{array}{l}4,470 \\
4,310\end{array}$ & $\begin{array}{l}6,840 \\
6,460\end{array}$ & $\begin{array}{l}9,050 \\
8,450\end{array}$ & $\begin{array}{l}11.700 \\
10.800\end{array}$ & 3,670 \\
\hline 10370000 & 0 & 1 & 0 & 0 & 0 & $\begin{array}{l}472 \\
464\end{array}$ & $\begin{array}{l}821 \\
796\end{array}$ & $\begin{array}{l}1.130 \\
1.070\end{array}$ & $\begin{array}{l}1,640 \\
1,510\end{array}$ & $\begin{array}{l}2,110 \\
1,910\end{array}$ & $\begin{array}{l}2,670 \\
2,370\end{array}$ & 3,190 \\
\hline 10371000 & 0 & 0 & 0 & 0 & 0 & $\begin{array}{l}482 \\
476\end{array}$ & $\begin{array}{l}1.270 \\
1.220\end{array}$ & $\begin{array}{l}2,140 \\
1,980\end{array}$ & $\begin{array}{l}3,780 \\
3,340\end{array}$ & $\begin{array}{l}5,490 \\
4,720\end{array}$ & $\begin{array}{l}7,710 \\
6,490\end{array}$ & 6,210 \\
\hline 10371500 & 0 & 0 & 0 & 0 & 0 & $\begin{array}{l}1,280 \\
1,270\end{array}$ & $\begin{array}{l}2,570 \\
2,530\end{array}$ & $\begin{array}{l}3,700 \\
3,590\end{array}$ & $\begin{array}{l}5,460 \\
5,220\end{array}$ & $\begin{array}{l}7,010 \\
6,640\end{array}$ & $\begin{array}{l}8.780 \\
8.250\end{array}$ & 9,420 \\
\hline 10378500 & 0 & 0 & 1 & 0 & 0 & $\begin{array}{l}465 \\
466\end{array}$ & $\begin{array}{l}1.200 \\
1,190\end{array}$ & $\begin{array}{l}1.950 \\
1.920\end{array}$ & $\begin{array}{l}3,280 \\
3,180\end{array}$ & $\begin{array}{l}4,590 \\
4,400\end{array}$ & $\begin{array}{l}6,190 \\
5,880\end{array}$ & 11,000 \\
\hline 10384000 & 1 & 1 & 0 & 0 & 0 & $\begin{array}{l}955 \\
952\end{array}$ & $\begin{array}{l}1,580 \\
1,570\end{array}$ & $\begin{array}{l}2,110 \\
2.100\end{array}$ & $\begin{array}{l}2,910 \\
2,880\end{array}$ & $\begin{array}{l}3,620 \\
3,570\end{array}$ & $\begin{array}{l}4,430 \\
4,360\end{array}$ & 6,490 \\
\hline 10390400 & 0 & 0 & 0 & 0 & 0 & $\begin{array}{l}66 \\
66\end{array}$ & $\begin{array}{l}110 \\
111\end{array}$ & $\begin{array}{l}147 \\
150\end{array}$ & $\begin{array}{l}205 \\
208\end{array}$ & $\begin{array}{l}256 \\
257\end{array}$ & $\begin{array}{l}316 \\
312\end{array}$ & 218 \\
\hline 10392300 & 1 & 0 & 0 & 0 & 0 & $\begin{array}{l}72 \\
74\end{array}$ & $\begin{array}{l}105 \\
113\end{array}$ & $\begin{array}{l}127 \\
148\end{array}$ & $\begin{array}{l}156 \\
200\end{array}$ & $\begin{array}{l}178 \\
241\end{array}$ & $\begin{array}{l}201 \\
283\end{array}$ & 152 \\
\hline 10392800 & 0 & 0 & 1 & 0 & 0 & $\begin{array}{l}49 \\
50\end{array}$ & $\begin{array}{l}72 \\
76\end{array}$ & $\begin{array}{l}87 \\
97\end{array}$ & $\begin{array}{l}106 \\
127\end{array}$ & $\begin{array}{l}120 \\
150\end{array}$ & $\begin{array}{l}136 \\
174\end{array}$ & 88 \\
\hline 10393500 & 1 & 0 & 0 & 0 & 0 & $\begin{array}{l}1,340 \\
1,350\end{array}$ & $\begin{array}{l}2,220 \\
2,240\end{array}$ & $\begin{array}{l}2,910 \\
2,970\end{array}$ & $\begin{array}{l}3,880 \\
4,020\end{array}$ & $\begin{array}{l}4,680 \\
4,900\end{array}$ & $\begin{array}{l}5,550 \\
5,840\end{array}$ & 4,960 \\
\hline 10393900 & - & - & - & - & 1 & 41 & 71 & 98 & 132 & 157 & 184 & 28 \\
\hline 10396000 & 0 & 0 & 1 & 0 & 0 & $\begin{array}{l}1,380 \\
1,370\end{array}$ & $\begin{array}{l}2,170 \\
2,140\end{array}$ & $\begin{array}{l}2,690 \\
2.630\end{array}$ & $\begin{array}{l}3.330 \\
3.230\end{array}$ & $\begin{array}{l}3,780 \\
3,660\end{array}$ & $\begin{array}{r}4,230 \\
4,100\end{array}$ & 4,270 \\
\hline 10397000 & 1 & 0 & 0 & 0 & 0 & $\begin{array}{l}108 \\
109\end{array}$ & $\begin{array}{l}174 \\
178\end{array}$ & $\begin{array}{l}221 \\
231\end{array}$ & $\begin{array}{l}281 \\
302\end{array}$ & $\begin{array}{l}327 \\
358\end{array}$ & $\begin{array}{l}373 \\
414\end{array}$ & 301 \\
\hline 10403000 & 1 & 0 & 1 & 0 & 0 & $\begin{array}{l}611 \\
612\end{array}$ & $\begin{array}{l}1,020 \\
1,030\end{array}$ & $\begin{array}{l}1,310 \\
1.340\end{array}$ & $\begin{array}{l}1,690 \\
1,770\end{array}$ & $\begin{array}{l}1,980 \\
2,110\end{array}$ & $\begin{array}{l}2,270 \\
2.460\end{array}$ & 1,810 \\
\hline 10406500 & 1 & 0 & 0 & 0 & 0 & $\begin{array}{l}119 \\
122\end{array}$ & $\begin{array}{l}193 \\
203\end{array}$ & $\begin{array}{l}253 \\
276\end{array}$ & $\begin{array}{l}342 \\
389\end{array}$ & $\begin{array}{l}420 \\
487\end{array}$ & $\begin{array}{l}507 \\
593\end{array}$ & 470 \\
\hline 13155200 & 0 & 0 & 0 & 0 & 0 & $\begin{array}{l}6 \\
6\end{array}$ & $\begin{array}{l}12 \\
13\end{array}$ & $\begin{array}{l}18 \\
19\end{array}$ & $\begin{array}{l}27 \\
28\end{array}$ & $\begin{array}{l}36 \\
36\end{array}$ & $\begin{array}{l}46 \\
45\end{array}$ & 22 \\
\hline 13155300 & 0 & 1 & 0 & 0 & 0 & $\begin{array}{l}93 \\
93\end{array}$ & $\begin{array}{l}161 \\
160\end{array}$ & $\begin{array}{l}221 \\
219\end{array}$ & $\begin{array}{l}315 \\
307\end{array}$ & $\begin{array}{l}401 \\
384\end{array}$ & $\begin{array}{l}502 \\
472\end{array}$ & 500 \\
\hline 13161100 & 1 & 1 & 0 & 0 & 0 & $\begin{array}{l}26 \\
36\end{array}$ & $\begin{array}{l}125 \\
149\end{array}$ & $\begin{array}{l}297 \\
323\end{array}$ & $\begin{array}{l}780 \\
738\end{array}$ & $\begin{array}{l}1,490 \\
1,290\end{array}$ & $\begin{array}{l}2,690 \\
2,160\end{array}$ & 1.890 \\
\hline 13161200 & 0 & 0 & 0 & 0 & 0 & $\begin{array}{l}22 \\
23\end{array}$ & $\begin{array}{l}49 \\
49\end{array}$ & $\begin{array}{l}71 \\
71\end{array}$ & $\begin{array}{l}105 \\
101\end{array}$ & $\begin{array}{l}133 \\
125\end{array}$ & $\begin{array}{l}165 \\
152\end{array}$ & 89 \\
\hline 13161300 & 0 & 0 & 0 & 0 & 0 & $\begin{array}{l}198 \\
200\end{array}$ & $\begin{array}{l}432 \\
431\end{array}$ & $\begin{array}{l}639 \\
627\end{array}$ & $\begin{array}{l}959 \\
916\end{array}$ & $\begin{array}{l}1,240 \\
1,160\end{array}$ & $\begin{array}{l}1,550 \\
1,430\end{array}$ & 940 \\
\hline 13161500 & 1 & 0 & 1 & 0 & 0 & $\begin{array}{l}784 \\
788\end{array}$ & $\begin{array}{l}1,290 \\
1,310\end{array}$ & $\begin{array}{l}1.670 \\
1.710\end{array}$ & $\begin{array}{l}2,180 \\
2,280\end{array}$ & $\begin{array}{l}2,580 \\
2,730\end{array}$ & $\begin{array}{l}3,000 \\
3,200\end{array}$ & 2,140 \\
\hline 13161600 & 0 & 0 & 0 & 0 & 0 & $\begin{array}{l}43 \\
45\end{array}$ & $\begin{array}{l}63 \\
69\end{array}$ & $\begin{array}{l}76 \\
89\end{array}$ & $\begin{array}{r}93 \\
119\end{array}$ & $\begin{array}{l}105 \\
141\end{array}$ & $\begin{array}{l}118 \\
163\end{array}$ & 85 \\
\hline
\end{tabular}




\begin{tabular}{|c|c|c|c|c|c|c|c|c|c|}
\hline $\begin{array}{l}\text { Station } \\
\text { number }\end{array}$ & Station name & $\begin{array}{l}\text { Flood } \\
\text { region }\end{array}$ & $\begin{array}{l}\text { Lati- } \\
\text { tude, in } \\
\text { decimal } \\
\text { degrees }\end{array}$ & $\begin{array}{l}\text { Longi- } \\
\text { tude, in } \\
\text { decimal } \\
\text { degrees }\end{array}$ & $\begin{array}{l}\text { Years } \\
\text { of } \\
\text { record }\end{array}$ & $\begin{array}{l}\text { Drainage } \\
\text { area, in } \\
\text { square } \\
\text { miles }\end{array}$ & $\begin{array}{l}\text { Moan } \\
\text { basin } \\
\text { oleva- } \\
\text { tion, } \\
\text { In } \\
\text { feet }\end{array}$ & $\begin{array}{l}\text { Mean } \\
\text { ennual } \\
\text { precipi- } \\
\text { tation. } \\
\text { in } \\
\text { inches }\end{array}$ & $\begin{array}{l}\text { Mean } \\
\text { annual } \\
\text { evapor- } \\
\text { ation, } \\
\text { in } \\
\text { inches }\end{array}$ \\
\hline 13162200 & Jarbidge River at Jarbidge, Nev. & 2 & 41.862 & 115.428 & 15 & 22.60 & 7,950 & 18.4 & 40.0 \\
\hline 13162400 & Buck Creek near Jarbidge, Nev. & 2 & 41.979 & 115.432 & 16 & 20.20 & 6.990 & 13.2 & 40.0 \\
\hline 13162500 & $\begin{array}{l}\text { East Fork Jarbidge River near } \\
\text { Three Creek, Idaho }\end{array}$ & 2 & 42.033 & 115.372 & 22 & 84.60 & 7,600 & 19.0 & 39.8 \\
\hline 13162600 & Columbet Creek near Jarbidge, Nev. & 2 & 41.967 & 115.485 & 16 & 3.37 & 7.020 & 14.2 & 40.0 \\
\hline 13169500 & $\begin{array}{l}\text { Big Jacks Creek near Bruneau, } \\
\text { Idaho }\end{array}$ & 2 & 42.785 & 115.983 & 33 & 253.00 & 5,150 & 13.0 & 39.3 \\
\hline 13170000 & $\begin{array}{l}\text { Little Jacks Creek near Bruneau, } \\
\text { Idaho }\end{array}$ & 2 & 42.833 & 116.000 & 11 & 100.00 & 5,020 & 12.0 & 39.5 \\
\hline 13170100 & $\begin{array}{l}\text { Sugar Creek Tributary near Grasmere, } \\
\text { Idaho }\end{array}$ & 2 & 42.564 & 115.907 & 19 & 4.50 & 4,860 & 12.0 & 40.0 \\
\hline 13172200 & Fossil Creek near Oreana, Idaho & 2 & 43.094 & 116.449 & 17 & 19.70 & 3,920 & 12.0 & 43.0 \\
\hline 13172666 & $\begin{array}{l}\text { West Fork Reynolds Creek near } \\
\text { Reymolds, Idaho }\end{array}$ & 2 & 43.070 & 116.760 & 14 & 0.20 & 6,880 & 41.0 & 43.0 \\
\hline 13172668 & $\begin{array}{l}\text { East Fork Reynolds Creek near } \\
\text { Reynolds, Idaho }\end{array}$ & 2 & 43.070 & 116.750 & 16 & 0.16 & 6,800 & 41.0 & 43.0 \\
\hline 13172680 & $\begin{array}{l}\text { Reynolds Creek at Tollgate Weir, } \\
\text { near Reynolds, Idaho }\end{array}$ & 2 & 43.100 & 116.770 & 13 & 21.00 & 5,940 & 31.0 & 43.1 \\
\hline 13172720 & Macks Creek near Reynolds, Idaho & 2 & 43.230 & 116.790 & 15 & 12.30 & 4,860 & 19.0 & 43.7 \\
\hline 13172735 & Salmon Creek near Reynolds, Idaho & 2 & 43.270 & 116.790 & 15 & 14.00 & 4,870 & 19.0 & 43.8 \\
\hline 13172740 & $\begin{array}{l}\text { Reynolds Creek at outlet weir, } \\
\text { near Reynolds, Idaho }\end{array}$ & 2 & 43.180 & 116.760 & 16 & 90.00 & 5,000 & 20.0 & 43.5 \\
\hline 13172800 & $\begin{array}{l}\text { L Squaw Creek Tributary near } \\
\text { Marsing, Idaho }\end{array}$ & 2 & 43.364 & 116.921 & 19 & 1.81 & 4,440 & 13.0 & 44.1 \\
\hline 13175900 & Reed Creek near Owyhee, Nev. & 2 & 41.896 & 116.061 & 17 & 6.51 & 6,400 & 12.0 & 39.8 \\
\hline 13176600 & $\begin{array}{l}\text { Taylor Canyon Tributary near } \\
\text { Tuscarora, Nev. }\end{array}$ & 2 & 41.236 & 116.036 & 13 & 1.20 & 6,600 & 16.0 & 40.0 \\
\hline 13176900 & $\begin{array}{l}\text { Jack Creek below Schoonover Creek, } \\
\text { near Tuscarora, Nev. }\end{array}$ & 2 & 41.508 & 116.072 & 16 & 19.80 & 7,450 & 14.2 & 40.0 \\
\hline 13177000 & Jack Creek near Tuscarora, Nev. & 2 & 41.500 & 116.100 & 13 & 31.00 & 6,890 & 12.0 & 40.0 \\
\hline 13177200 & $\begin{array}{l}\text { South Fork Owyhee River at Spanish } \\
\text { RA near Tuscarora, Nev. }\end{array}$ & 2 & 41.428 & 116.178 & 16 & 330.00 & 6,170 & 12.0 & 40.0 \\
\hline 13177800 & $\begin{array}{l}\text { South Fork Owyhee River near } \\
\text { Whiterock, Nev. }\end{array}$ & 2 & 41.800 & 116.483 & 26 & $1,080.00$ & 6,060 & 9.4 & 40.0 \\
\hline 13178000 & $\begin{array}{l}\text { Jordan Creek above LN Tree Creek, } \\
\text { near Jordan Valley, Oreg. }\end{array}$ & 2 & 42.874 & 116.953 & 24 & 440.00 & 5,780 & 15.0 & 42.1 \\
\hline 13182100 & Dago Gulch near Rockville, Oreg. & 2 & 43.294 & 117.254 & 12 & 3.09 & 4,560 & 12.0 & 43.3 \\
\hline 13182150 & Long Gulch near Rockville, Oreg. & 2 & 43.321 & 117.195 & 10 & 1.38 & 5,030 & 12.0 & 43.6 \\
\hline 13184200 & $\begin{array}{l}\text { Roaring River near Rocky Bar, } \\
\text { Idaho }\end{array}$ & 2 & 43.706 & 115.464 & 17 & 23.30 & 7,200 & 43.0 & 29.4 \\
\hline 13184800 & Beaver Creek near Lowman, Idaho & 2 & 43.972 & 115.608 & 10 & 9.30 & 5,860 & 45.0 & 30.0 \\
\hline 13185000 & $\begin{array}{l}\text { Boise River near Iwin Springs, } \\
\text { Idaho }\end{array}$ & 2 & 43.659 & 115.726 & 76 & 830.00 & 6,350 & 42.0 & 33.8 \\
\hline 13185500 & $\begin{array}{l}\text { Cottonwood Creek at Arrowrock } \\
\text { Reservoir, Idaho }\end{array}$ & 2 & 43.632 & 115.824 & 11 & 20.90 & 5,180 & 23.0 & 36.4 \\
\hline 13186000 & $\begin{array}{l}\text { South Fork Boise River near } \\
\text { Featherville, Idaho }\end{array}$ & 2 & 43.494 & 115.306 & 42 & 635.00 & 6,840 & 37.0 & 35.2 \\
\hline 13186500 & Lime Creek near Bennett, Idaho & 2 & 43.417 & 115.267 & 11 & 131.00 & 6,140 & 23.0 & 35.7 \\
\hline 13187000 & $\begin{array}{l}\text { Fall Creek near Anderson Ranch } \\
\text { Dam, Idaho }\end{array}$ & 2 & 43.433 & 115.386 & 12 & 55.30 & 6,070 & 26.0 & 35.4 \\
\hline
\end{tabular}




\begin{tabular}{|c|c|c|c|c|c|c|c|c|c|c|c|c|}
\hline \multirow{2}{*}{$\begin{array}{l}\text { Station } \\
\text { number }\end{array}$} & \multicolumn{5}{|c|}{$\begin{array}{c}\text { Relation } \\
\text { characteristic } \\
\end{array}$} & \multicolumn{6}{|c|}{$\begin{array}{l}\text { Peak discharge (cubic feet per second) for } \\
\text { indicated recurrence interval (years) }\end{array}$} & \multirow{2}{*}{$\begin{array}{l}\text { Maximum } \\
\text { peak discharge } \\
\text { of record } \\
\text { (cubic feet } \\
\text { per second) }\end{array}$} \\
\hline & L & $\mathrm{H}$ & $D$ & 0 & U & 2 & 5 & 10 & 25 & 50 & 100 & \\
\hline \multirow[t]{2}{*}{13162200} & 0 & 0 & 0 & 0 & 0 & 306 & 477 & 597 & 756 & 878 & 1,000 & 700 \\
\hline & & & & & & 295 & 449 & 539 & 658 & 751 & 845 & \\
\hline \multirow[t]{2}{*}{13162400} & 1 & 0 & 0 & 0 & 0 & 85 & 164 & 234 & 344 & 443 & 558 & 380 \\
\hline & & & & & & 86 & 167 & 236 & 341 & 430 & 530 & \\
\hline \multirow[t]{2}{*}{13162500} & 0 & 0 & 0 & 0 & 0 & 449 & 623 & 732 & 864 & 958 & 1,050 & 798 \\
\hline & & & & & & 443 & 618 & 726 & 873 & 986 & 1,100 & \\
\hline \multirow[t]{2}{*}{13162600} & 0 & 0 & 0 & 0 & 0 & 12 & 24 & 34 & 50 & 63 & 79 & 46 \\
\hline & & & & & & 13 & 27 & 39 & 58 & 74 & 89 & \\
\hline \multirow[t]{2}{*}{13169500} & 1 & 0 & 1 & 0 & 0 & 230 & 493 & 749 & 1.190 & 1,610 & 2,130 & 2,100 \\
\hline & & & & & & 243 & 531 & 834 & 1,340 & 1,810 & 2,370 & \\
\hline \multirow[t]{2}{*}{13170000} & 0 & 0 & 0 & 0 & 0 & 143 & 423 & 739 & 1,330 & 1,940 & 2,720 & 908 \\
\hline & & & & & & 160 & 451 & 773 & 1,310 & 1,810 & 2,410 & \\
\hline \multirow[t]{2}{*}{13170100} & - & - & - & - & 1 & --- & --- & --- & --- & --- & $-\cdots$ & 105 \\
\hline & & & & & & 38 & 66 & 95 & 128 & 155 & 182 & \\
\hline 13172200 & 1 & 1 & 0 & 0 & 0 & 43 & 196 & 456 & 1,170 & 2,190 & 3,920 & 2,860 \\
\hline & & & & & & 47 & 196 & 432 & 1.010 & 1,780 & 3,060 & \\
\hline 13172666 & 1 & 0 & 0 & 0 & 0 & 5 & 9 & 11 & 15 & 18 & 21 & 14 \\
\hline & & & & & & 5 & 9 & 11 & 14 & 17 & 19 & \\
\hline 13172668 & 1 & 0 & 0 & 0 & 0 & 5 & 6 & 8 & 10 & 11 & 13 & 11 \\
\hline & & & & & & 5 & 6 & 8 & 10 & 11 & 13 & \\
\hline 13172680 & 1 & 0 & 0 & 0 & 0 & 201 & 273 & 320 & 380 & 424 & 468 & 404 \\
\hline & & & & & & 195 & 264 & 311 & 376 & 429 & 483 & \\
\hline 13172720 & 0 & 1 & 0 & 0 & 0 & 97 & 264 & 451 & 801 & 1,160 & 1,640 & 1,200 \\
\hline & & & & & & 96 & 250 & 408 & 675 & 938 & 1,280 & \\
\hline 13172735 & 0 & 1 & 0 & 0 & 0 & 81 & 213 & 355 & 617 & 887 & 1,230 & 1,007 \\
\hline & & & & & & 82 & 206 & 332 & 541 & 746 & 999 & \\
\hline 13172740 & 0 & 0 & 0 & 0 & 0 & 438 & 1,090 & 1,780 & 3,030 & 4,280 & 5,880 & 3,801 \\
\hline & & & & & & 432 & 1.040 & 1,630 & 2,610 & 3,550 & 4,730 & \\
\hline 13172800 & 1 & 0 & 1 & 0 & 0 & 13 & 32 & 52 & 87 & 121 & 163 & 93 \\
\hline & & & & & & 13 & 32 & 52 & 83 & 112 & 147 & \\
\hline 13175900 & 0 & 0 & 0 & 0 & 0 & 23 & 49 & 73 & 109 & 140 & 176 & 95 \\
\hline & & & & & & 24 & 53 & 79 & 118 & 149 & 184 & \\
\hline 13176600 & 1 & 0 & 0 & 0 & 0 & 4 & 7 & 10 & 14 & 17 & 20 & 12 \\
\hline & & & & & & 4 & 9 & 14 & 21 & 27 & 32 & \\
\hline 13176900 & 0 & 0 & 0 & 0 & 0 & 168 & 239 & 286 & 345 & 390 & 434 & 325 \\
\hline & & & & & & 165 & 234 & 279 & 339 & 386 & 434 & \\
\hline 13177000 & 0 & 0 & 0 & 0 & 0 & 200 & 299 & 371 & 468 & 545 & 626 & 465 \\
\hline & & & & & & 197 & 295 & 365 & 465 & 545 & 629 & \\
\hline 13177200 & 0 & 1 & 0 & 0 & 0 & 615 & 1,310 & 1,950 & 2.970 & 3,900 & 4,990 & 4,130 \\
\hline & & & & & & 627 & 1,330 & 1,960 & 2,920 & 3,770 & 4,720 & \\
\hline 13177800 & 1 & 0 & 1 & 0 & 0 & 1,540 & 2,460 & 3.100 & 3,950 & 4,610 & 5,270 & 3,830 \\
\hline & & & & & & 1,550 & 2,530 & 3,270 & 4.350 & 5,240 & 6,140 & \\
\hline 13178000 & 0 & 1 & 0 & 0 & 0 & 1,940 & 3,010 & 3,790 & 4.870 & 5,740 & 6,650 & 7,530 \\
\hline & & & & & & 1,900 & 2,930 & 3,640 & 4.650 & 5,480 & 6,350 & \\
\hline 13182100 & - & - & - & - & 1 & --- & $\cdots$ & --- & --- & --- & --- & 46 \\
\hline & & & & & & 29 & 51 & 74 & 100 & 121 & 143 & \\
\hline 13182150 & - & - & - & - & 1 & --- & --- & --- & --- & --- & --- & 18 \\
\hline & & & & & & 16 & 28 & 40 & 53 & 63 & 73 & \\
\hline 13184200 & 0 & 0 & 0 & 0 & 0 & 330 & 453 & 529 & 620 & 684 & 745 & 575 \\
\hline & & & & & & 319 & 431 & 490 & 565 & 623 & 680 & \\
\hline 13184800 & 0 & 0 & 0 & 0 & 0 & 102 & 149 & 181 & 223 & 256 & 288 & 195 \\
\hline & & & & & & 99 & 143 & 174 & 216 & 251 & 286 & \\
\hline 13185000 & 1 & 1 & 0 & 0 & 0 & 6,760 & 9,310 & 11.000 & 13,200 & 14,900 & 16,600 & 18,800 \\
\hline & & & & & & 6,700 & 9,160 & 10,700 & 12,700 & 14,300 & 16,000 & \\
\hline 13185500 & 0 & 0 & 0 & 0 & 0 & 91 & 191 & 284 & 436 & 577 & 745 & 330 \\
\hline & & & & & & 93 & 193 & 284 & 422 & 542 & 678 & \\
\hline 13186000 & 1 & 0 & 0 & 0 & 0 & 4,620 & 5,970 & 6,800 & 7,770 & 8,460 & 9,120 & 7,960 \\
\hline & & & & & & 4,550 & 5,820 & 6,550 & 7,420 & 8,090 & 8,750 & \\
\hline 13186500 & 0 & 0 & 0 & 0 & 0 & 659 & 964 & 1.170 & 1,420 & 1,610 & 1,800 & 1,180 \\
\hline & & & & & & 640 & 935 & 1,140 & 1.410 & 1,640 & 1,870 & \\
\hline 13187000 & 0 & 0 & 0 & 0 & 0 & 509 & 706 & 849 & 1,040 & 1,200 & 1,360 & 1,150 \\
\hline & & & & & & 488 & 667 & 787 & 956 & 1,110 & 1,260 & \\
\hline
\end{tabular}




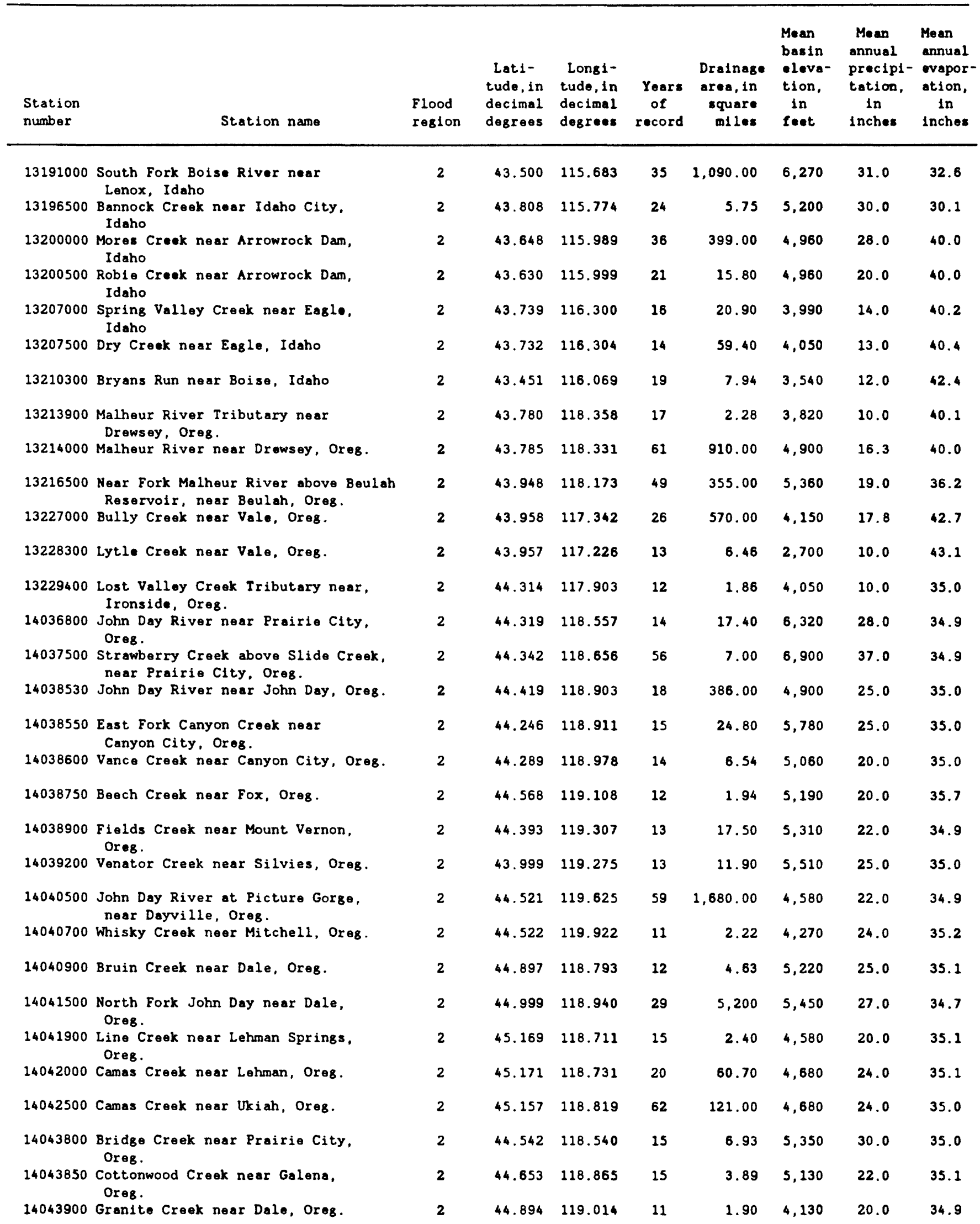




\begin{tabular}{|c|c|c|c|c|c|c|c|c|c|c|c|c|}
\hline \multirow{2}{*}{$\begin{array}{l}\text { Station } \\
\text { number }\end{array}$} & \multicolumn{5}{|c|}{$\begin{array}{c}\text { Relation } \\
\text { characteristic } \\
\end{array}$} & \multicolumn{6}{|c|}{$\begin{array}{l}\text { Peak discharge (cubic feet per second) for } \\
\text { indicated recurrence interval (years) }\end{array}$} & \multirow{2}{*}{$\begin{array}{l}\text { Maximum } \\
\text { peak discharge } \\
\text { of record } \\
\text { (cubic feet } \\
\text { per second) }\end{array}$} \\
\hline & $\mathrm{L}$ & $\mathrm{H}$ & D & 0 & $\frac{U}{U}$ & 2 & 5 & 10 & 25 & 50 & 100 & \\
\hline 13191000 & 0 & 1 & 0 & 0 & 0 & $\begin{array}{l}4,900 \\
4,820\end{array}$ & $\begin{array}{l}7.540 \\
7.340\end{array}$ & $\begin{array}{l}9,520 \\
9,130\end{array}$ & $\begin{array}{l}12,300 \\
11,600\end{array}$ & $\begin{array}{l}14,600 \\
13,700\end{array}$ & $\begin{array}{l}17,000 \\
15,900\end{array}$ & 9.550 \\
\hline \multirow[t]{2}{*}{13196500} & 0 & 0 & 0 & 1 & 0 & 13 & 24 & 34 & 47 & 58 & 72 & 46 \\
\hline & & & & & & 14 & 28 & 42 & 64 & 82 & 100 & \\
\hline 13200000 & 1 & 0 & 0 & 0 & 0 & $\begin{array}{l}1.820 \\
1.800\end{array}$ & $\begin{array}{l}2,900 \\
2,840\end{array}$ & $\begin{array}{l}3,700 \\
3,600\end{array}$ & $\begin{array}{l}4.770 \\
4.620\end{array}$ & $\begin{array}{l}5,610 \\
5,440\end{array}$ & $\begin{array}{l}6.490 \\
6.310\end{array}$ & 5,440 \\
\hline \multirow[t]{2}{*}{13200500} & 0 & 0 & 0 & 0 & 0 & 61 & 103 & 137 & 186 & 227 & 272 & 274 \\
\hline & & & & & & 62 & 108 & 150 & 210 & 261 & 315 & \\
\hline \multirow[t]{2}{*}{13207000} & 0 & 0 & 0 & 0 & 0 & 52 & 129 & 206 & 335 & 457 & 601 & 244 \\
\hline & & & & & & 55 & 136 & 223 & 357 & 478 & 614 & \\
\hline \multirow[t]{2}{*}{13207500} & 0 & 0 & 0 & 0 & 0 & 94 & 237 & 383 & 636 & 880 & 1,180 & 373 \\
\hline & & & & & & 103 & 259 & 433 & 710 & 960 & 1,250 & \\
\hline \multirow[t]{2}{*}{13210300} & 1 & 0 & 0 & 0 & 0 & 74 & 164 & 248 & 381 & 502 & 642 & 420 \\
\hline & & & & & & 73 & 158 & 236 & 350 & 452 & 568 & \\
\hline \multirow[t]{2}{*}{13213900} & - & - & - & - & 1 & -..- & $\cdots$ & $-\cdots$ & $-\cdots$ &.-- & $\cdots$ & 100 \\
\hline & & & & & & 24 & 41 & 63 & 86 & 105 & 126 & \\
\hline 13214000 & 1 & 0 & 0 & 0 & 0 & 2,080 & 3,890 & 5.400 & 7,680 & 9,640 & 11,800 & 12.000 \\
\hline & & & & & & 2,070 & 3,870 & 5.360 & 7,590 & 9,510 & 11.600 & \\
\hline 13216500 & 1 & 0 & 0 & 0 & 0 & 939 & 1.490 & 1.910 & 2.500 & 2.880 & 3,500 & 3.970 \\
\hline & & & & & & 938 & 1,490 & 1.930 & 2.550 & 3,070 & 3,620 & \\
\hline 13227000 & 0 & 0 & 0 & 0 & 0 & 835 & 2,330 & 3,880 & 6.540 & 9,050 & 12,000 & 8,980 \\
\hline & & & & & & 848 & 2,320 & 3,830 & 6.290 & 8,560 & 11,200 & \\
\hline 13228300 & 0 & 0 & 0 & 0 & 0 & 101 & 191 & 269 & 388 & 494 & 615 & 497 \\
\hline & & & & & & 97 & 178 & 247 & 343 & 429 & 527 & \\
\hline 13229400 & - & - & - & - & 1 & ---- & --- & --- & $\cdots$ & --- & --- & 41 \\
\hline & & & & & & 20 & 35 & 53 & 73 & 88 & 104 & \\
\hline 14036800 & 0 & 0 & 1 & 0 & 0 & 73 & 115 & 144 & 181 & 208 & 235 & 155 \\
\hline & & & & & & 74 & 122 & 160 & 213 & 254 & 294 & \\
\hline 14037500 & 1 & 1 & 0 & 0 & 0 & 90 & 134 & 167 & 216 & 258 & 304 & 354 \\
\hline & & & & & & 90 & 133 & 164 & 211 & 251 & 295 & \\
\hline 14038530 & 1 & 0 & 0 & 0 & 0 & 1,730 & 2,800 & 3.650 & 4.900 & 5,960 & 7.140 & 5,830 \\
\hline & & & & & & 1.690 & 2.700 & 3,470 & 4,590 & 5,570 & 6.640 & \\
\hline 14038550 & - & - & - & - & 1 &.-- & $-\ldots$ & $\ldots$ &.-- & -.. & $\ldots$ & 285 \\
\hline & & & & & & 129 & 228 & 310 & 419 & 506 & 594 & \\
\hline 14038600 & 0 & 0 & 0 & 0 & 0 & 18 & 28 & 35 & 45 & 53 & 61 & 39 \\
\hline & & & & & & 20 & 35 & 51 & 75 & 94 & 114 & \\
\hline 14038750 & - & - & - & - & 1 & --- & $-\cdots$ & --- & --- & $-\cdots$ & --- & 28 \\
\hline & & & & & & 21 & 36 & 50 & 67 & 80 & 93 & \\
\hline 14038900 & - & - & - & - & 1 & --- & $-\cdots$ & --- & --- & --- & --- & 240 \\
\hline & & & & & & 101 & 177 & 248 & 336 & 407 & 480 & \\
\hline 14039200 & 1 & 1 & 0 & 0 & 0 & 56 & 73 & 84 & 98 & 109 & 120 & 108 \\
\hline & & & & & & 57 & 80 & 103 & 138 & 165 & 194 & \\
\hline 14040500 & 0 & 0 & 1 & 0 & 0 & 2,820 & 4,580 & 5,880 & 7,650 & 9,060 & 10,500 & 8,170 \\
\hline & & & & & & 2,820 & 4,590 & 5,950 & 7.850 & 9,410 & 11,000 & \\
\hline 14040700 & 0 & 0 & 1 & 0 & 0 & 33 & 75 & 115 & 179 & 239 & 308 & 143 \\
\hline & & & & & & 33 & 70 & 103 & 150 & 192 & 240 & \\
\hline 14040900 & 1 & 0 & 0 & 0 & 0 & 34 & 44 & 51 & 60 & 67 & 73 & 57 \\
\hline & & & & & & 34 & 47 & 60 & 79 & 94 & 109 & \\
\hline 14041500 & 0 & 0 & 0 & 0 & 0 & 3,080 & 4,500 & 5.410 & 6,530 & 7,340 & 8,120 & 8,170 \\
\hline & & & & & & 3,020 & 4,360 & 5,170 & 6,190 & 6,980 & 7,770 & \\
\hline 14041900 & - & - & - & - & 1 & $\ldots$ & $--\cdot$ & --- & $\ldots$ & $\ldots$ & $\ldots$ & 90 \\
\hline & & & & & & 24 & 42 & 62 & 83 & 100 & 118 & \\
\hline 14042000 & 0 & 0 & 0 & 0 & 0 & 632 & 993 & 1,280 & 1,690 & 2.040 & 2,430 & 1.880 \\
\hline & & & & & & 614 & 947 & 1,200 & 1,540 & 1,840 & 2,170 & \\
\hline 14042500 & 0 & 0 & 0 & 0 & 0 & 1.060 & 1,600 & 2.010 & 2,560 & 3,010 & 3.480 & 3.840 \\
\hline & & & & & & 1.050 & 1.580 & 1,970 & 2,490 & 2,920 & 3.370 & \\
\hline 14043800 & 0 & 0 & 0 & 0 & 0 & 39 & 59 & 73 & 91 & 105 & 121 & 98 \\
\hline & & & & & & 40 & 62 & 82 & 109 & 131 & 155 & \\
\hline 14043850 & 0 & 0 & 0 & 0 & 0 & 47 & 68 & 82 & 100 & 114 & 128 & 98 \\
\hline & & & & & & 47 & 67 & 82 & 103 & 120 & 137 & \\
\hline 14043900 & - & - & - & - & 1 & --- & $\cdots$ & --- & -- & $\cdots$ & $\cdots$ & 66 \\
\hline & & & & & & 21 & 36 & 54 & 73 & 88 & 105 & \\
\hline
\end{tabular}




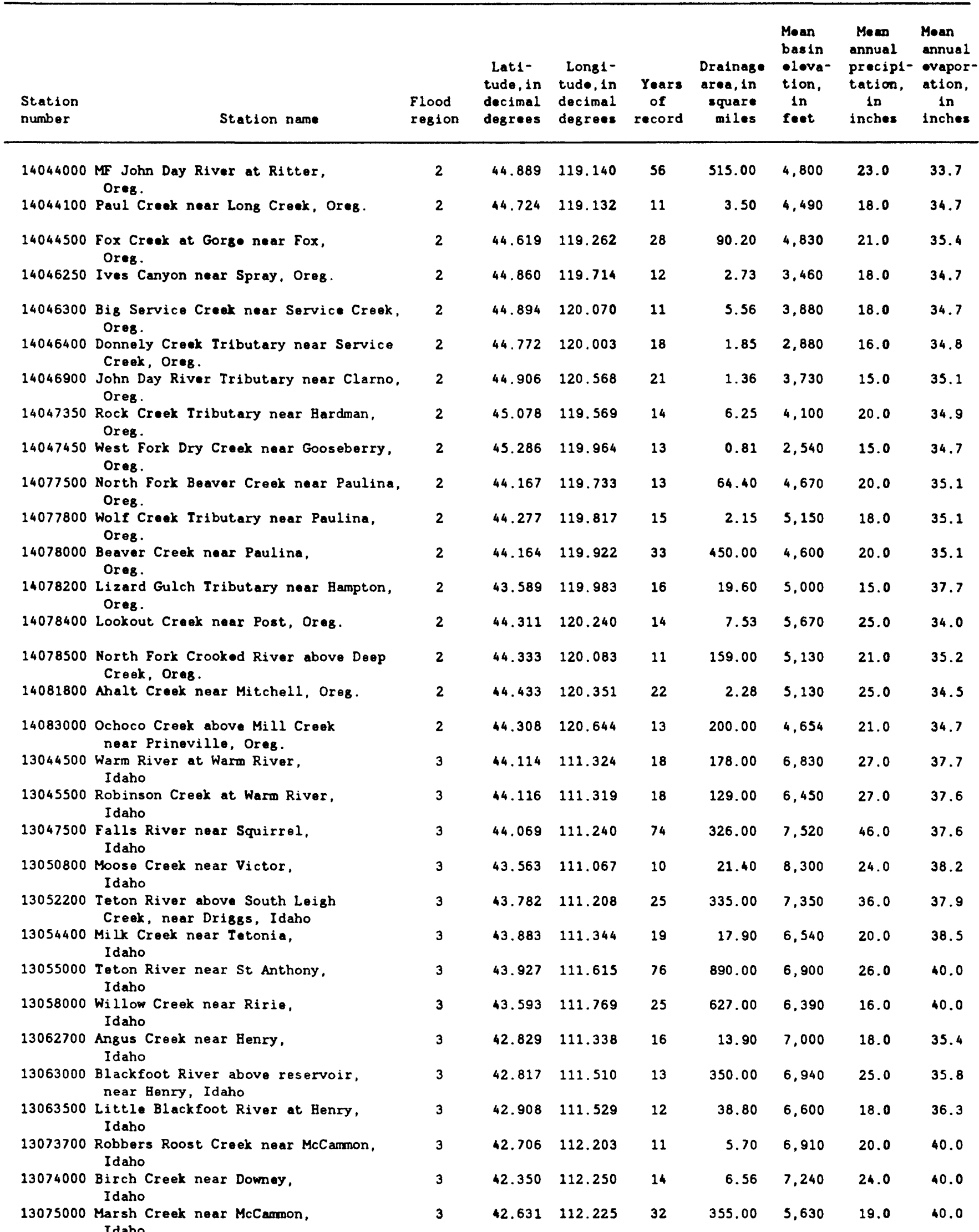




\begin{tabular}{|c|c|c|c|c|c|c|c|c|c|c|c|c|}
\hline \multirow[b]{2}{*}{$\begin{array}{l}\text { Station } \\
\text { number }\end{array}$} & \multicolumn{5}{|c|}{$\begin{array}{c}\text { Relation } \\
\text { characteristic }\end{array}$} & \multicolumn{6}{|c|}{$\begin{array}{l}\text { Peak discharge (cubic feet per second) for } \\
\text { indicated recurrence interval (years) }\end{array}$} & \multirow{2}{*}{$\begin{array}{l}\text { Maximum } \\
\text { peak di scharge } \\
\text { of record } \\
\text { (cubic foet } \\
\text { per second) }\end{array}$} \\
\hline & $\frac{\mathrm{ch}}{\mathrm{L}}$ & $\frac{\arg }{\mathrm{B}}$ & $\frac{\text { cte }}{D}$ & $\frac{18}{0}$ & & 2 & 5 & 10 & 25 & 50 & 100 & \\
\hline 14044000 & 0 & 0 & 0 & 0 & 0 & $\begin{array}{l}1,650 \\
1,640\end{array}$ & $\begin{array}{l}2,430 \\
2,420\end{array}$ & $\begin{array}{l}2,970 \\
2.970\end{array}$ & $\begin{array}{l}3,650 \\
3,700\end{array}$ & $\begin{array}{l}4,170 \\
4,280\end{array}$ & $\begin{array}{l}4.700 \\
4.870\end{array}$ & 4,730 \\
\hline 14044100 & - & - & - & - & 1 & 32 & 55 & 81 & 110 & 134 & 158 & 56 \\
\hline 14044500 & 1 & 0 & 0 & 0 & 0 & $\begin{array}{l}410 \\
407\end{array}$ & $\begin{array}{l}798 \\
785\end{array}$ & $\begin{array}{l}1,150 \\
1,120\end{array}$ & $\begin{array}{l}1,700 \\
1,630\end{array}$ & $\begin{array}{l}2,210 \\
2,090\end{array}$ & $\begin{array}{l}2,810 \\
2,620\end{array}$ & 1,860 \\
\hline 14046250 & - & - & - & - & 1 & 27 & 46 & 75 & 103 & 127 & 153 & 86 \\
\hline 14046300 & 0 & 0 & 0 & 1 & 0 & $\begin{array}{l}4 \\
7\end{array}$ & $\begin{array}{r}7 \\
17\end{array}$ & $\begin{array}{r}9 \\
33\end{array}$ & $\begin{array}{l}12 \\
58\end{array}$ & $\begin{array}{l}14 \\
77\end{array}$ & $\begin{array}{l}17 \\
97\end{array}$ & 11 \\
\hline 14046400 & - & - & - & - & 1 & 20 & 35 & 60 & 84 & 104 & 127 & 42 \\
\hline 14046900 & 0 & 0 & 0 & 0 & 0 & $\begin{array}{l}30 \\
30\end{array}$ & $\begin{array}{l}49 \\
47\end{array}$ & $\begin{array}{l}62 \\
60\end{array}$ & $\begin{array}{l}79 \\
76\end{array}$ & $\begin{array}{l}92 \\
88\end{array}$ & $\begin{array}{l}105 \\
101\end{array}$ & 83 \\
\hline 14047350 & 1 & 0 & 1 & 0 & 0 & $\begin{array}{l}57 \\
56\end{array}$ & $\begin{array}{l}89 \\
88\end{array}$ & $\begin{array}{l}111 \\
114\end{array}$ & $\begin{array}{l}139 \\
148\end{array}$ & $\begin{array}{l}159 \\
175\end{array}$ & $\begin{array}{l}180 \\
203\end{array}$ & 117 \\
\hline 14047450 & - & - & - & - & 1 & 11 & 19 & 34 & 48 & 60 & 73 & 134 \\
\hline 14077500 & 0 & 0 & 1 & 0 & 0 & $\begin{array}{l}612 \\
587\end{array}$ & $\begin{array}{l}781 \\
741\end{array}$ & $\begin{array}{l}885 \\
844\end{array}$ & $\begin{array}{r}1,010 \\
989\end{array}$ & $\begin{array}{l}1,100 \\
1,120\end{array}$ & $\begin{array}{l}1,180 \\
1,240\end{array}$ & 955 \\
\hline 14077800 & - & - & - & - & 1 & 23 & 39 & 54 & 73 & 87 & 101 & 300 \\
\hline 14078000 & 0 & 1 & 1 & 0 & 0 & $\begin{array}{l}1,370 \\
1,360\end{array}$ & $\begin{array}{l}2,750 \\
2,700\end{array}$ & $\begin{array}{l}4,060 \\
3,950\end{array}$ & $\begin{array}{l}6,270 \\
5,980\end{array}$ & $\begin{array}{l}8,400 \\
7,910\end{array}$ & $\begin{array}{l}11,000 \\
10,200\end{array}$ & 12,800 \\
\hline 14078200 & - & - & - & - & 1 & 109 & 193 & 275 & 375 & 457 & 542 & 177 \\
\hline 14078400 & 1 & 0 & 1 & 0 & 0 & $\begin{array}{l}49 \\
49\end{array}$ & $\begin{array}{l}71 \\
74\end{array}$ & $\begin{array}{l}86 \\
94\end{array}$ & $\begin{array}{l}103 \\
121\end{array}$ & $\begin{array}{l}116 \\
142\end{array}$ & $\begin{array}{l}129 \\
164\end{array}$ & 85 \\
\hline 14078500 & 0 & 0 & 1 & 0 & 0 & $\begin{array}{l}1,390 \\
1,320\end{array}$ & $\begin{array}{l}1,780 \\
1,650\end{array}$ & $\begin{array}{l}2,040 \\
1.870\end{array}$ & $\begin{array}{l}2,370 \\
2,180\end{array}$ & $\begin{array}{l}2,620 \\
2,460\end{array}$ & $\begin{array}{l}2,870 \\
2,770\end{array}$ & 2,500 \\
\hline 14081800 & 1 & 1 & 0 & 0 & 0 & $\begin{array}{l}39 \\
38\end{array}$ & $\begin{array}{l}57 \\
56\end{array}$ & $\begin{array}{l}71 \\
70\end{array}$ & $\begin{array}{l}92 \\
89\end{array}$ & $\begin{array}{l}108 \\
105\end{array}$ & $\begin{array}{l}127 \\
122\end{array}$ & 122 \\
\hline 14083000 & 1 & 0 & 0 & 0 & 0 & $\begin{array}{l}356 \\
371\end{array}$ & $\begin{array}{l}540 \\
600\end{array}$ & $\begin{array}{l}671 \\
834\end{array}$ & $\begin{array}{r}845 \\
1,190\end{array}$ & $\begin{array}{r}982 \\
1,490\end{array}$ & $\begin{array}{l}1.120 \\
1.790\end{array}$ & 821 \\
\hline 13044500 & 0 & 0 & 0 & 0 & 0 & $\begin{array}{l}460 \\
462\end{array}$ & $\begin{array}{l}628 \\
635\end{array}$ & $\begin{array}{l}738 \\
753\end{array}$ & $\begin{array}{l}875 \\
910\end{array}$ & $\begin{array}{r}976 \\
1,030\end{array}$ & $\begin{array}{l}1.080 \\
1.160\end{array}$ & 900 \\
\hline 13045500 & 1 & 0 & 0 & 0 & 0 & $\begin{array}{l}639 \\
636\end{array}$ & $\begin{array}{l}805 \\
803\end{array}$ & $\begin{array}{l}910 \\
910\end{array}$ & $\begin{array}{l}1,040 \\
1,050\end{array}$ & $\begin{array}{l}1,130 \\
1,150\end{array}$ & $\begin{array}{l}1,220 \\
1,260\end{array}$ & 1,140 \\
\hline 13047500 & 0 & 0 & 0 & 0 & 0 & $\begin{array}{l}3,550 \\
3,540\end{array}$ & $\begin{array}{l}4,450 \\
4,440\end{array}$ & $\begin{array}{l}5,010 \\
4,990\end{array}$ & $\begin{array}{l}5,700 \\
5,660\end{array}$ & $\begin{array}{l}6,190 \\
6,140\end{array}$ & $\begin{array}{l}6,680 \\
6,620\end{array}$ & 7,060 \\
\hline 13050800 & 0 & 0 & 0 & 0 & 0 & $\begin{array}{l}278 \\
274\end{array}$ & $\begin{array}{l}338 \\
332\end{array}$ & $\begin{array}{l}373 \\
365\end{array}$ & $\begin{array}{l}415 \\
407\end{array}$ & $\begin{array}{l}445 \\
440\end{array}$ & $\begin{array}{l}473 \\
474\end{array}$ & 390 \\
\hline 13052200 & 1 & 0 & 0 & 0 & 0 & $\begin{array}{l}1,510 \\
1,510\end{array}$ & $\begin{array}{l}1,910 \\
1,910\end{array}$ & $\begin{array}{l}2,160 \\
2,160\end{array}$ & $\begin{array}{l}2,470 \\
2,480\end{array}$ & $\begin{array}{l}2,700 \\
2,730\end{array}$ & $\begin{array}{l}2,920 \\
2.970\end{array}$ & 2,460 \\
\hline 13054400 & 1 & 0 & 0 & 0 & 0 & $\begin{array}{l}82 \\
82\end{array}$ & $\begin{array}{l}244 \\
242\end{array}$ & $\begin{array}{l}445 \\
435\end{array}$ & $\begin{array}{l}865 \\
828\end{array}$ & $\begin{array}{l}1,350 \\
1,270\end{array}$ & $\begin{array}{l}2,020 \\
1,870\end{array}$ & 1,350 \\
\hline 13055000 & 1 & 1 & 0 & 0 & 0 & $\begin{array}{l}3,370 \\
3,360\end{array}$ & $\begin{array}{l}4.540 \\
4.530\end{array}$ & $\begin{array}{l}5,340 \\
5,320\end{array}$ & $\begin{array}{l}6,370 \\
6,330\end{array}$ & $\begin{array}{l}7.170 \\
7.120\end{array}$ & $\begin{array}{l}7,980 \\
7,910\end{array}$ & 11,000 \\
\hline 13058000 & 0 & 0 & 0 & 0 & 0 & $\begin{array}{l}1,730 \\
1,720\end{array}$ & $\begin{array}{l}2.550 \\
2.520\end{array}$ & $\begin{array}{l}3,110 \\
3,060\end{array}$ & $\begin{array}{l}3,830 \\
3,750\end{array}$ & $\begin{array}{l}4.380 \\
4.270\end{array}$ & $\begin{array}{l}4,930 \\
4,780\end{array}$ & 5,080 \\
\hline 13062700 & 0 & 0 & 1 & 0 & 0 & $\begin{array}{l}274 \\
270\end{array}$ & $\begin{array}{l}511 \\
499\end{array}$ & $\begin{array}{l}715 \\
689\end{array}$ & $\begin{array}{r}1.030 \\
971\end{array}$ & $\begin{array}{l}1,320 \\
1,220\end{array}$ & $\begin{array}{l}1,640 \\
1,500\end{array}$ & 1,060 \\
\hline 13063000 & 0 & 0 & 0 & 0 & 0 & $\begin{array}{l}1,040 \\
1,040\end{array}$ & $\begin{array}{l}1,520 \\
1,510\end{array}$ & $\begin{array}{l}1,840 \\
1,830\end{array}$ & $\begin{array}{l}2,250 \\
2,230\end{array}$ & $\begin{array}{l}2,550 \\
2,540\end{array}$ & $\begin{array}{l}2,850 \\
2.840\end{array}$ & 2,150 \\
\hline 13063500 & 0 & 0 & 0 & 0 & 0 & $\begin{array}{l}140 \\
140\end{array}$ & $\begin{array}{l}209 \\
210\end{array}$ & $\begin{array}{l}257 \\
259\end{array}$ & $\begin{array}{l}321 \\
327\end{array}$ & $\begin{array}{l}370 \\
382\end{array}$ & $\begin{array}{l}420 \\
439\end{array}$ & 292 \\
\hline 13073700 & 0 & 0 & 0 & 1 & 0 & $\begin{array}{l}14 \\
15\end{array}$ & $\begin{array}{l}21 \\
23\end{array}$ & $\begin{array}{l}26 \\
31\end{array}$ & $\begin{array}{l}33 \\
42\end{array}$ & $\begin{array}{l}37 \\
52\end{array}$ & $\begin{array}{l}42 \\
63\end{array}$ & 24 \\
\hline 13074000 & 0 & 1 & 0 & 0 & 0 & $\begin{array}{l}24 \\
25\end{array}$ & $\begin{array}{l}38 \\
40\end{array}$ & $\begin{array}{l}49 \\
52\end{array}$ & $\begin{array}{l}65 \\
73\end{array}$ & $\begin{array}{l}78 \\
90\end{array}$ & $\begin{array}{r}94 \\
110\end{array}$ & 95 \\
\hline 13075000 & 0 & 0 & 0 & 0 & 0 & $\begin{array}{l}322 \\
324\end{array}$ & $\begin{array}{l}475 \\
482\end{array}$ & $\begin{array}{l}588 \\
603\end{array}$ & $\begin{array}{l}743 \\
776\end{array}$ & $\begin{array}{l}869 \\
920\end{array}$ & $\begin{array}{l}1,000 \\
1,070\end{array}$ & 1,120 \\
\hline
\end{tabular}




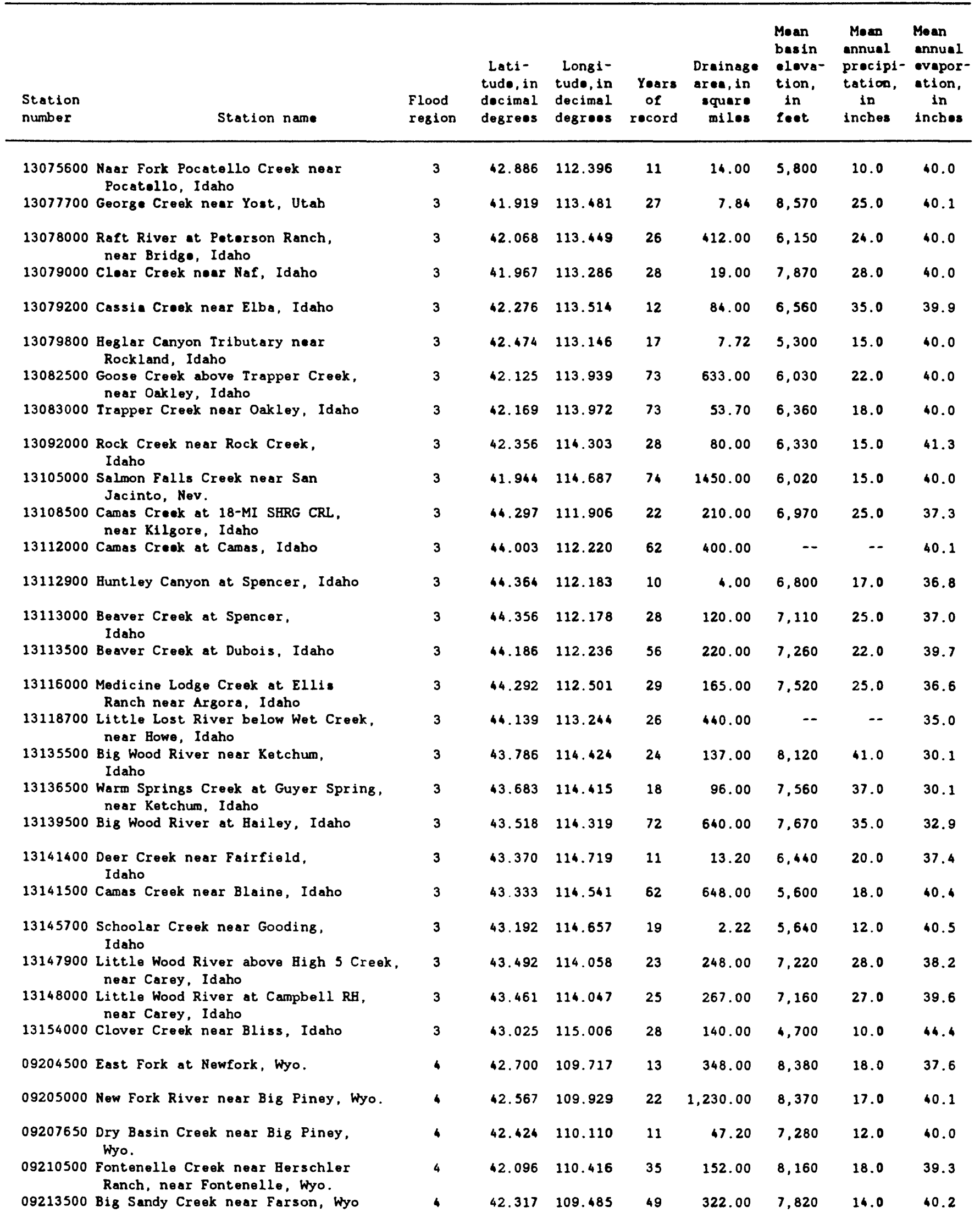


Maxtmum

peak discharge

of record

(cublc feet

per second)

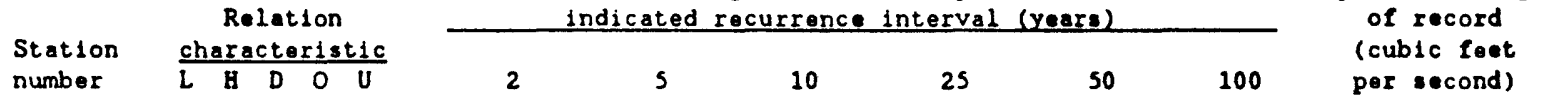

\begin{tabular}{|c|c|c|c|c|c|c|c|c|c|c|c|c|}
\hline \multirow[t]{2}{*}{13075600} & 0 & 0 & 0 & 0 & 0 & 22 & 38 & so & 68 & 83 & 99 & 57 \\
\hline & & & & & & 23 & 39 & 53 & 74 & 92 & 112 & \\
\hline \multirow[t]{2}{*}{13077700} & 0 & 1 & 0 & 0 & 0 & 73 & 115 & 148 & 196 & 236 & 281 & 295 \\
\hline & & & & & & 73 & 115 & 148 & 196 & 235 & 280 & \\
\hline \multirow[t]{2}{*}{13078000} & 0 & 0 & 0 & 0 & 0 & 149 & 316 & 483 & 782 & 1,080 & 1,470 & 2,060 \\
\hline & & & & & & 157 & 335 & 518 & 845 & 1,170 & 1.580 & \\
\hline \multirow[t]{2}{*}{13079000} & 0 & 0 & 0 & 0 & 0 & 117 & 182 & 231 & 299 & 353 & 412 & 386 \\
\hline & & & & & & 117 & 183 & 232 & 302 & 357 & 418 & \\
\hline \multirow[t]{2}{*}{13079200} & 0 & 0 & 0 & 0 & 0 & 192 & 401 & 592 & 903 & 1,180 & 1,530 & 982 \\
\hline & & & & & & 199 & 413 & 609 & 922 & 1,200 & 1,520 & \\
\hline \multirow[t]{2}{*}{13079800} & 1 & 1 & 0 & 0 & 0 & 154 & 305 & 453 & 713 & 974 & 1,310 & 1,930 \\
\hline & & & & & & 152 & 298 & 437 & 673 & 904 & 1,200 & \\
\hline \multirow[t]{2}{*}{13082500} & 0 & 0 & 0 & 0 & 0 & 255 & 552 & 856 & 1,400 & 1,960 & 2,670 & 3,240 \\
\hline & & & & & & 258 & 559 & 869 & 1,420 & 1,990 & 2,700 & \\
\hline \multirow[t]{2}{*}{13083000} & 0 & 0 & 0 & 0 & 0 & 53 & 88 & 116 & 157 & 193 & 233 & 270 \\
\hline & & & & & & 54 & 89 & 119 & 162 & 201 & 244 & \\
\hline \multirow[t]{2}{*}{13092000} & 0 & 0 & 0 & 0 & 0 & 187 & 301 & 379 & 478 & 552 & 625 & 461 \\
\hline & & & & & & 187 & 301 & 379 & 480 & 557 & 634 & \\
\hline \multirow[t]{2}{*}{13105000} & 1 & 1 & 0 & 0 & 0 & 734 & 1.230 & 1,590 & 2,100 & 2,500 & 2,920 & 3,860 \\
\hline & & & & & & 736 & 1.230 & 1,600 & 2,120 & 2,530 & 2,960 & \\
\hline \multirow[t]{2}{*}{13108500} & 0 & 0 & 0 & 0 & 0 & 791 & 1,300 & 1.710 & 2,290 & 2.770 & 3,300 & 2,590 \\
\hline & & & & & & 788 & 1,290 & 1,690 & 2,250 & 2,700 & 3,200 & \\
\hline \multirow[t]{2}{*}{13112000} & 1 & 0 & 1 & 0 & 0 & 441 & 751 & 959 & 1,220 & 1,400 & 1,570 & 1,320 \\
\hline & & & & & & $\cdots$ & $\cdots$ & $-\cdots$ & $\cdots$ & $\cdots$ & --- & \\
\hline 13112900 & 0 & 0 & 0 & 0 & 0 & 9 & 17 & 24 & 35 & 44 & 55 & 36 \\
\hline & & & & & & 10 & 19 & 27 & 41 & 53 & 67 & \\
\hline 13113000 & 0 & 0 & 0 & 0 & 0 & 340 & 547 & 711 & 950 & 1,150 & 1,370 & 1,190 \\
\hline & & & & & & 341 & 549 & 714 & 954 & 1,160 & 1,370 & \\
\hline 13113500 & 1 & 0 & 1 & 0 & 0 & 267 & 454 & 601 & 813 & 989 & 1,180 & 858 \\
\hline & & & & & & 268 & 457 & 607 & 825 & 1,010 & 1,200 & \\
\hline 13116000 & 1 & 1 & 0 & 1 & 0 & 105 & 154 & 192 & 245 & 289 & 337 & 361 \\
\hline & & & & & & 109 & 164 & 213 & 287 & 352 & 425 & \\
\hline 13118700 & 1 & 0 & 1 & 0 & 0 & 345 & 405 & 441 & 483 & 513 & 542 & 509 \\
\hline & & & & & & $\cdots$ & $\cdots$ & $-\cdots$ & ---- & $-\cdots$ & $\cdots$ & \\
\hline 13135500 & 0 & 0 & 0 & 0 & 0 & 914 & 1.290 & 1.530 & 1,840 & 2,070 & 2,300 & 1,690 \\
\hline & & & & & & 912 & 1.290 & 1.530 & 1.830 & 2,070 & 2,300 & \\
\hline 13136500 & 0 & 0 & 0 & 0 & 0 & 488 & 653 & 765 & 909 & 1,020 & 1,130 & 961 \\
\hline & & & & & & 489 & 657 & 775 & 932 & 1,060 & 1,180 & \\
\hline 13139500 & 1 & 0 & 1 & 0 & 0 & 2,410 & 3,470 & 4.210 & 5,180 & 5,930 & 6,690 & 6,150 \\
\hline & & & & & & 2,410 & 3,460 & 4,200 & 5,160 & 5,900 & 6.650 & \\
\hline 13141400 & 0 & 0 & 0 & 0 & 0 & 53 & 87 & 114 & 153 & 186 & 223 & 150 \\
\hline & & & & & & 53 & 88 & 117 & 159 & 195 & 236 & \\
\hline 13141500 & 1 & 0 & 1 & 0 & 0 & 3,300 & 5,260 & 6,670 & 8,560 & 10,000 & 11,600 & 9,780 \\
\hline & & & & & & 3,290 & 5,230 & 6,610 & 8,440 & 9,820 & 11,300 & \\
\hline 13145700 & 1 & 0 & 0 & 0 & 0 & 26 & 38 & 46 & 57 & 65 & 74 & 68 \\
\hline & & & & & & 26 & 38 & 46 & 56 & 65 & 74 & \\
\hline 13147900 & 1 & 0 & 0 & 0 & 0 & 1,070 & 1,550 & 1,890 & 2,330 & 2,670 & 3,010 & 2,480 \\
\hline & & & & & & 1,070 & 1,540 & 1,880 & 2,300 & 2,640 & 2,970 & \\
\hline 13148000 & 0 & 0 & 0 & 0 & 0 & 861 & 1,400 & 1,830 & 2,440 & 2,960 & 3,530 & 3,110 \\
\hline & & & & & & 860 & 1,400 & 1,820 & 2,410 & 2,910 & 3.460 & \\
\hline 13154000 & 0 & 1 & 0 & 1 & 0 & 1,580 & 3,190 & 4,700 & 7.230 & 9,640 & 12,500 & 4,500 \\
\hline & & & & & & 1,570 & 3,140 & 4,580 & 6,950 & 9,160 & 11,700 & \\
\hline 09204500 & - & - & - & - & 1 & $\ldots$ & $--\cdot$ & $\ldots$ & $\ldots$ & $\ldots$ & --- & 2,940 \\
\hline & & & & & & 1,190 & 1,740 & 2,130 & 2,590 & 3,000 & 3,350 & \\
\hline 09205000 & 0 & 0 & 0 & 0 & 0 & 5,310 & 6,940 & 7,900 & 8,990 & 9,740 & 10,400 & 9,190 \\
\hline & & & & & & 5,270 & 6.820 & 7,680 & 8,630 & 9,320 & 9,930 & \\
\hline 09207650 & 1 & 0 & 0 & 0 & 0 & 136 & 269 & 376 & 531 & 659 & 797 & 450 \\
\hline & & & & & & 138 & 274 & 385 & 540 & 667 & 796 & \\
\hline 09210500 & 1 & 0 & 0 & 0 & 0 & 492 & 680 & 799 & 944 & 1,050 & 1,150 & 907 \\
\hline & & & & & & 493 & 687 & 816 & 983 & 1,110 & 1,240 & \\
\hline 09213500 & 1 & 0 & 0 & 0 & 0 & 843 & 1.160 & 1,350 & 1,600 & 1,770 & 1,940 & 1,890 \\
\hline & & & & & & 844 & 1,170 & 1,370 & 1,640 & 1,840 & 2.030 & \\
\hline
\end{tabular}




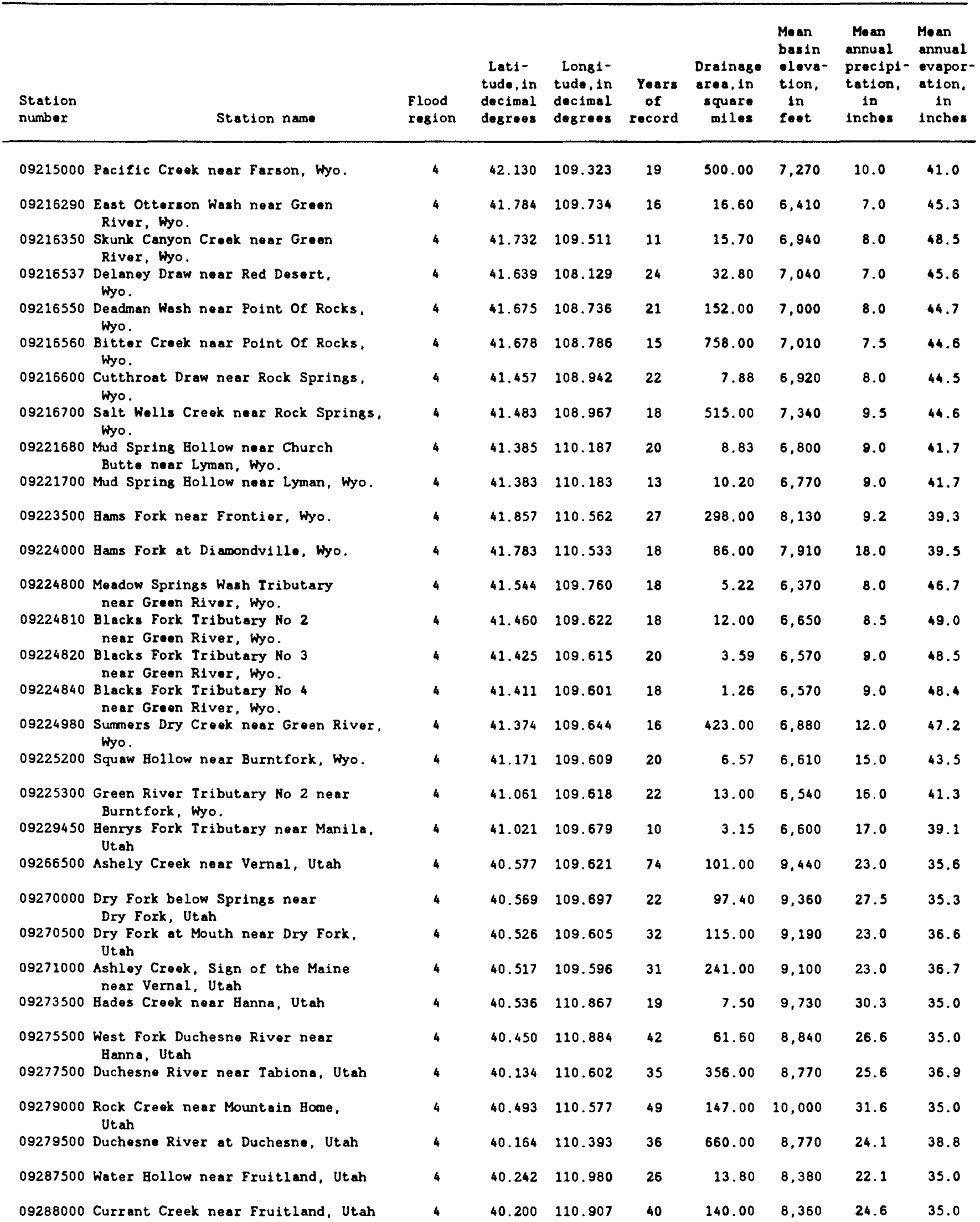




\begin{tabular}{|c|c|c|c|c|c|c|c|c|c|c|c|c|}
\hline \multirow{2}{*}{$\begin{array}{l}\text { Station } \\
\text { number }\end{array}$} & \multicolumn{5}{|c|}{$\begin{array}{c}\text { Relation } \\
\text { characteristic } \\
\end{array}$} & \multicolumn{6}{|c|}{$\begin{array}{l}\text { Peak discharge (cubic feet per second) for } \\
\text { indicated recurrence interval (yesrs) }\end{array}$} & \multirow{2}{*}{$\begin{array}{l}\text { Maximum } \\
\text { peak discharge } \\
\text { of record } \\
\text { (cublc feet } \\
\text { per second) }\end{array}$} \\
\hline & $\frac{C D}{L}$ & $\frac{a x a}{B}$ & $\frac{C l e}{D}$ & 0 & $\frac{C_{1} \mathrm{c}}{\mathrm{U}}$ & 2 & 5 & 10 & 25 & 50 & 100 & \\
\hline 09215000 & 0 & 0 & 1 & 0 & 0 & $\begin{array}{l}259 \\
274\end{array}$ & $\begin{array}{l}556 \\
609\end{array}$ & $\begin{array}{l}805 \\
919\end{array}$ & $\begin{array}{l}1.170 \\
1.390\end{array}$ & $\begin{array}{l}1,470 \\
1,780\end{array}$ & $\begin{array}{l}1,800 \\
2,190\end{array}$ & 972 \\
\hline 09216290 & 1 & 1 & 0 & 0 & 0 & $\begin{array}{l}161 \\
159\end{array}$ & $\begin{array}{l}350 \\
337\end{array}$ & $\begin{array}{l}535 \\
499\end{array}$ & $\begin{array}{l}852 \\
755\end{array}$ & $\begin{array}{r}1,160 \\
992\end{array}$ & $\begin{array}{l}1,540 \\
1,270\end{array}$ & 791 \\
\hline 09216350 & 0 & 1 & 0 & 0 & 0 & $\begin{array}{l}15 \\
17\end{array}$ & $\begin{array}{l}43 \\
51\end{array}$ & $\begin{array}{l}81 \\
97\end{array}$ & $\begin{array}{l}174 \\
192\end{array}$ & $\begin{array}{l}295 \\
301\end{array}$ & $\begin{array}{l}487 \\
452\end{array}$ & 600 \\
\hline 09216537 & 1 & 1 & 0 & 0 & 0 & $\begin{array}{l}91 \\
91\end{array}$ & $\begin{array}{l}267 \\
266\end{array}$ & $\begin{array}{l}482 \\
471\end{array}$ & $\begin{array}{l}923 \\
868\end{array}$ & $\begin{array}{l}1,420 \\
1,300\end{array}$ & $\begin{array}{l}2,100 \\
1,860\end{array}$ & 1,260 \\
\hline 09216550 & 0 & 0 & 0 & 0 & 0 & $\begin{array}{l}397 \\
397\end{array}$ & $\begin{array}{l}728 \\
726\end{array}$ & $\begin{array}{l}996 \\
989\end{array}$ & $\begin{array}{l}1,390 \\
1,370\end{array}$ & $\begin{array}{l}1,710 \\
1,670\end{array}$ & $\begin{array}{l}2,070 \\
2,000\end{array}$ & 1,320 \\
\hline ك6د 609216 & 1 & 0 & 1 & 0 & 0 & $\begin{array}{l}466 \\
485\end{array}$ & $\begin{array}{r}956 \\
1,020\end{array}$ & $\begin{array}{l}1.380 \\
1.520\end{array}$ & $\begin{array}{l}2,040 \\
2,280\end{array}$ & $\begin{array}{l}2,620 \\
2,940\end{array}$ & $\begin{array}{l}3,270 \\
3,640\end{array}$ & 1.650 \\
\hline 09216600 & - & - & - & - & 1 & 48 & 88 & 121 & 163 & $\begin{array}{r}199 \\
19 .\end{array}$ & 233 & 700 \\
\hline 09216700 & 1 & 0 & 0 & 0 & 0 & $\begin{array}{l}1,120 \\
1,120\end{array}$ & $\begin{array}{l}2,180 \\
2,160\end{array}$ & $\begin{array}{l}3,020 \\
2,950\end{array}$ & $\begin{array}{l}4,190 \\
4,000\end{array}$ & $\begin{array}{l}5,140 \\
4,830\end{array}$ & $\begin{array}{l}6,140 \\
5,680\end{array}$ & 3.750 \\
\hline 09221680 & 1 & 0 & 0 & 0 & 0 & $\begin{array}{l}63 \\
63\end{array}$ & $\begin{array}{l}194 \\
189\end{array}$ & $\begin{array}{l}342 \\
325\end{array}$ & $\begin{array}{l}619 \\
560\end{array}$ & $\begin{array}{l}903 \\
790\end{array}$ & $\begin{array}{l}1,260 \\
1,070\end{array}$ & 557 \\
\hline 09221700 & 1 & 0 & 0 & 0 & 0 & $\begin{array}{l}94 \\
93\end{array}$ & $\begin{array}{l}178 \\
173\end{array}$ & $\begin{array}{l}251 \\
238\end{array}$ & $\begin{array}{l}366 \\
333\end{array}$ & $\begin{array}{l}469 \\
414\end{array}$ & $\begin{array}{l}589 \\
505\end{array}$ & 406 \\
\hline 09223500 & 0 & 0 & 0 & 0 & 0 & $\begin{array}{l}1,150 \\
1,150\end{array}$ & $\begin{array}{l}1.620 \\
1,620\end{array}$ & $\begin{array}{l}1,910 \\
1,910\end{array}$ & $\begin{array}{l}2,250 \\
2,250\end{array}$ & $\begin{array}{l}2,500 \\
2,520\end{array}$ & $\begin{array}{l}2,730 \\
2,760\end{array}$ & 2.450 \\
\hline 09224000 & 1 & 0 & 0 & 0 & 0 & $\begin{array}{l}1,550 \\
1,540\end{array}$ & $\begin{array}{l}2,140 \\
2,120\end{array}$ & $\begin{array}{l}2,550 \\
2,510\end{array}$ & $\begin{array}{l}3,080 \\
3,010\end{array}$ & $\begin{array}{l}3,490 \\
3,410\end{array}$ & $\begin{array}{l}3,910 \\
3,810\end{array}$ & 3.250 \\
\hline 09224800 & - & - & - & - & 1 & 28 & 56 & 80 & 112 & 139 & 165 & 170 \\
\hline 09224810 & - & - & - & - & 1 & --- & 108 & 150 & 206 & 253 & 297 & 180 \\
\hline 09224820 & 1 & 0 & 0 & 0 & 0 & $\begin{array}{l}23 \\
23\end{array}$ & $\begin{array}{l}73 \\
72\end{array}$ & $\begin{array}{l}138 \\
132\end{array}$ & $\begin{array}{l}278 \\
253\end{array}$ & $\begin{array}{l}445 \\
391\end{array}$ & $\begin{array}{l}687 \\
582\end{array}$ & 245 \\
\hline 09224840 & - & - & - & - & 1 & 11 & 23 & 32 & 45 & 56 & $\begin{array}{r}-.- \\
66\end{array}$ & 47 \\
\hline 09224980 & 0 & 1 & 0 & 0 & 0 & $\begin{array}{l}624 \\
627\end{array}$ & $\begin{array}{l}1.640 \\
1,620\end{array}$ & $\begin{array}{l}2,650 \\
2,560\end{array}$ & $\begin{array}{l}4,370 \\
4,040\end{array}$ & $\begin{array}{l}5,980 \\
5,360\end{array}$ & $\begin{array}{l}7,880 \\
6.830\end{array}$ & 13,900 \\
\hline 09225200 & - & - & - & - & 1 & 37 & 71 & 99 & 137 & 169 & 199 & 620 \\
\hline 09225300 & - & - & - & - & 1 & 58 & $\begin{array}{r}--- \\
111\end{array}$ & 154 & 212 & 262 & 309 & 3,360 \\
\hline 09229450 & - & - & - & - & 1 & -- & --- & 60 & 83 & 103 & 122 & 588 \\
\hline 09266500 & 1 & 0 & 0 & 0 & 0 & $\begin{array}{l}1.070 \\
1.070\end{array}$ & $\begin{array}{l}1,560 \\
1,550\end{array}$ & $\begin{array}{l}1,910 \\
1,890\end{array}$ & $\begin{array}{l}2,380 \\
2,340\end{array}$ & $\begin{array}{l}2.750 \\
2.690\end{array}$ & $\begin{array}{l}3,140 \\
3,050\end{array}$ & 3,500 \\
\hline 09270000 & 1 & 0 & 0 & 0 & 0 & $\begin{array}{l}521 \\
524\end{array}$ & $\begin{array}{l}761 \\
767\end{array}$ & $\begin{array}{l}922 \\
934\end{array}$ & $\begin{array}{l}1,130 \\
1.150\end{array}$ & $\begin{array}{l}1,280 \\
1,300\end{array}$ & $\begin{array}{l}1,430 \\
1,460\end{array}$ & 974 \\
\hline 09270500 & 1 & 0 & 0 & 0 & 0 & $\begin{array}{l}547 \\
549\end{array}$ & $\begin{array}{l}900 \\
902\end{array}$ & $\begin{array}{l}1,170 \\
1,170\end{array}$ & $\begin{array}{l}1.540 \\
1.530\end{array}$ & $\begin{array}{l}1.850 \\
1.820\end{array}$ & $\begin{array}{l}2,180 \\
2,120\end{array}$ & 1,920 \\
\hline 09271000 & 1 & 1 & 0 & 0 & 0 & $\begin{array}{l}1,400 \\
1,400\end{array}$ & $\begin{array}{l}2,000 \\
1,990\end{array}$ & $\begin{array}{l}2,430 \\
2,400\end{array}$ & $\begin{array}{l}3,010 \\
2,940\end{array}$ & $\begin{array}{l}3,460 \\
3,360\end{array}$ & $\begin{array}{l}3,930 \\
3,790\end{array}$ & 4,110 \\
\hline 09273500 & 1 & 0 & 0 & 0 & 0 & $\begin{array}{l}81 \\
82\end{array}$ & $\begin{array}{l}105 \\
108\end{array}$ & $\begin{array}{l}121 \\
128\end{array}$ & $\begin{array}{l}142 \\
156\end{array}$ & $\begin{array}{l}157 \\
177\end{array}$ & $\begin{array}{l}173 \\
198\end{array}$ & 156 \\
\hline 09275500 & 1 & 0 & 0 & 0 & 0 & $\begin{array}{l}486 \\
485\end{array}$ & $\begin{array}{l}607 \\
607\end{array}$ & $\begin{array}{l}677 \\
679\end{array}$ & $\begin{array}{l}756 \\
764\end{array}$ & $\begin{array}{l}809 \\
825\end{array}$ & $\begin{array}{l}858 \\
884\end{array}$ & 758 \\
\hline 09277500 & 1 & 0 & 0 & 0 & 0 & $\begin{array}{l}1,400 \\
1,400\end{array}$ & $\begin{array}{l}1,800 \\
1,800\end{array}$ & $\begin{array}{l}2,050 \\
2,060\end{array}$ & $\begin{array}{l}2,340 \\
2,380\end{array}$ & $\begin{array}{l}2,550 \\
2,610\end{array}$ & $\begin{array}{l}2,750 \\
2,840\end{array}$ & 5,260 \\
\hline 09279000 & 1 & 0 & 0 & 0 & 0 & $\begin{array}{l}1,640 \\
1,640\end{array}$ & $\begin{array}{l}2,050 \\
2,040\end{array}$ & $\begin{array}{l}2,310 \\
2,290\end{array}$ & $\begin{array}{l}2,630 \\
2,580\end{array}$ & $\begin{array}{l}2,870 \\
2,810\end{array}$ & $\begin{array}{l}3,110 \\
3,030\end{array}$ & 2,920 \\
\hline 09279500 & 1 & 0 & 0 & 0 & 0 & $\begin{array}{l}2,780 \\
2,770\end{array}$ & $\begin{array}{l}3,410 \\
3,400\end{array}$ & $\begin{array}{l}3,800 \\
3,790\end{array}$ & $\begin{array}{l}4,250 \\
4,250\end{array}$ & $\begin{array}{l}4,570 \\
4,590\end{array}$ & $\begin{array}{r}4,880 \\
4,930\end{array}$ & 4.420 \\
\hline 09287500 & 0 & 0 & 1 & 0 & 0 & $\begin{array}{l}28 \\
30\end{array}$ & $\begin{array}{l}60 \\
65\end{array}$ & $\begin{array}{r}90 \\
100\end{array}$ & $\begin{array}{l}161 \\
158\end{array}$ & $\begin{array}{l}188 \\
209\end{array}$ & $\begin{array}{l}245 \\
268\end{array}$ & 133 \\
\hline 09288000 & 1 & 1 & 0 & 0 & 0 & $\begin{array}{l}323 \\
326\end{array}$ & $\begin{array}{l}496 \\
506\end{array}$ & $\begin{array}{l}634 \\
656\end{array}$ & $\begin{array}{l}838 \\
878\end{array}$ & $\begin{array}{l}1,010 \\
1,070\end{array}$ & $\begin{array}{l}1,100 \\
1,280\end{array}$ & 1,260 \\
\hline
\end{tabular}




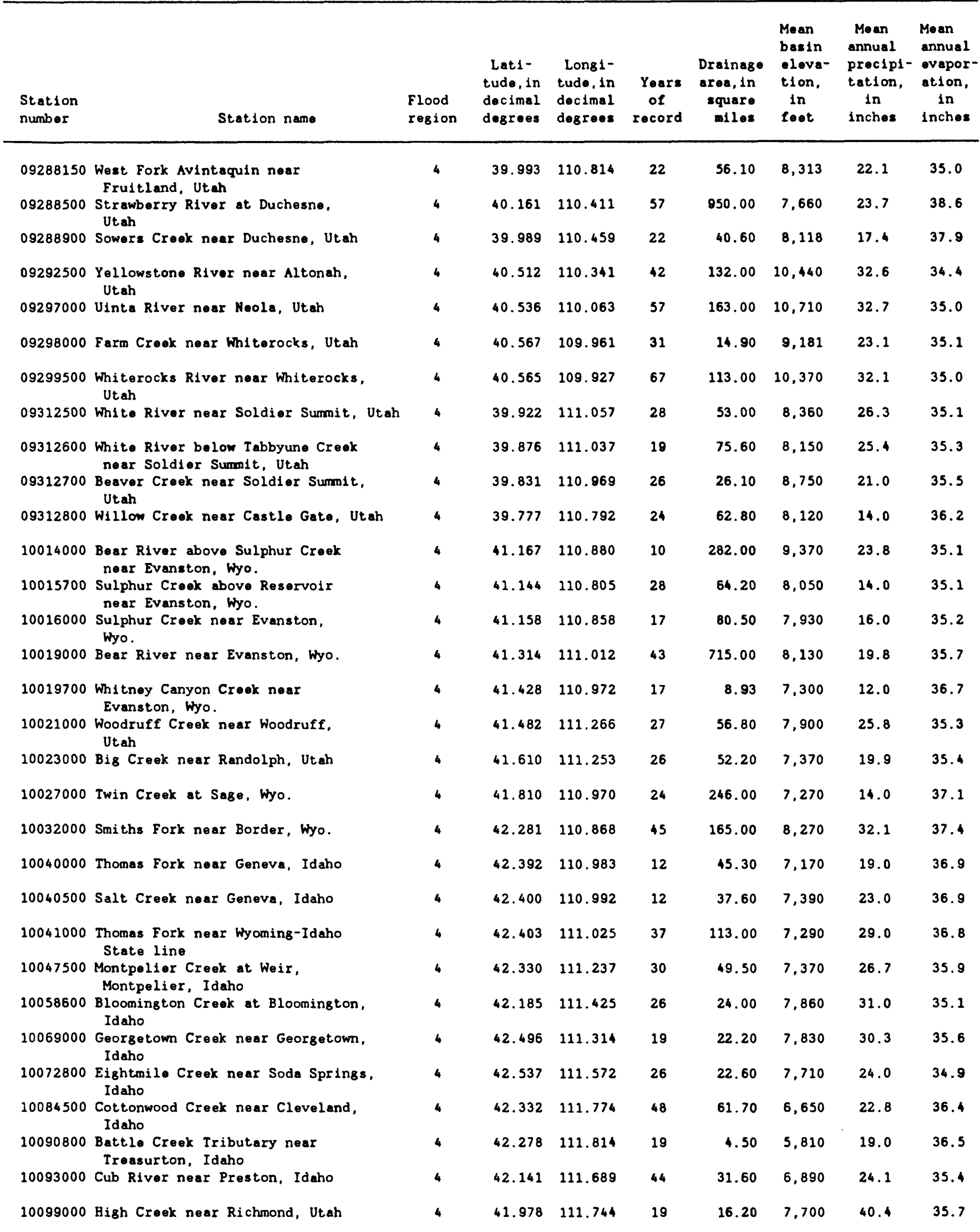




\begin{tabular}{|c|c|c|c|c|c|c|c|c|c|c|c|c|}
\hline \multirow{2}{*}{$\begin{array}{l}\text { Station } \\
\text { number }\end{array}$} & \multicolumn{5}{|c|}{$\begin{array}{c}\text { Relation } \\
\text { characteristic }\end{array}$} & \multicolumn{6}{|c|}{$\begin{array}{l}\text { Peak discharge (cuble feet per second) for } \\
\text { indicated recurrence interval (years) }\end{array}$} & \multirow{2}{*}{$\begin{array}{l}\text { Maximum } \\
\text { peak discharge } \\
\text { of record } \\
\text { (cublc feet } \\
\text { per second) }\end{array}$} \\
\hline & $\mathrm{L}$ & 日 & $D$ & 0 & $\bar{U}$ & 2 & 5 & 10 & 25 & 50 & 100 & \\
\hline 09288150 & 1 & 0 & 1 & 0 & 0 & $\begin{array}{l}291 \\
292\end{array}$ & $\begin{array}{l}670 \\
663\end{array}$ & $\begin{array}{l}1.040 \\
1.010\end{array}$ & $\begin{array}{l}1,680 \\
1,570\end{array}$ & $\begin{array}{l}2,300 \\
2,090\end{array}$ & $\begin{array}{l}3,050 \\
2,690\end{array}$ & 1,830 \\
\hline 09288500 & 1 & 0 & 0 & 0 & 0 & $\begin{array}{l}1,090 \\
1.100\end{array}$ & $\begin{array}{l}1,640 \\
1,660\end{array}$ & $\begin{array}{l}2,060 \\
2,110\end{array}$ & $\begin{array}{l}2,660 \\
2,750\end{array}$ & $\begin{array}{l}3,150 \\
3.290\end{array}$ & $\begin{array}{l}3,690 \\
3,870\end{array}$ & 3,490 \\
\hline 09288900 & 1 & 0 & 1 & 0 & 0 & $\begin{array}{l}55 \\
59\end{array}$ & $\begin{array}{l}158 \\
167\end{array}$ & $\begin{array}{l}276 \\
291\end{array}$ & $\begin{array}{l}508 \\
518\end{array}$ & $\begin{array}{l}757 \\
768\end{array}$ & $\begin{array}{l}1.090 \\
1.040\end{array}$ & 451 \\
\hline 09292500 & 0 & 0 & 0 & 0 & 0 & $\begin{array}{l}1.030 \\
1.030\end{array}$ & $\begin{array}{l}1,380 \\
1,380\end{array}$ & $\begin{array}{l}1,620 \\
1,620\end{array}$ & $\begin{array}{l}1.920 \\
1.910\end{array}$ & $\begin{array}{l}2,150 \\
2,240\end{array}$ & $\begin{array}{l}2,390 \\
2,360\end{array}$ & 2,240 \\
\hline 09297000 & 1 & 1 & 0 & 0 & 0 & $\begin{array}{l}1,390 \\
1,390\end{array}$ & $\begin{array}{l}2,080 \\
2,070\end{array}$ & $\begin{array}{l}2,590 \\
2570\end{array}$ & $\begin{array}{l}3.290 \\
3.230\end{array}$ & $\begin{array}{l}3,850 \\
3,750\end{array}$ & $\begin{array}{l}4,440 \\
4.290\end{array}$ & 5,000 \\
\hline 09298000 & 1 & 0 & 1 & 0 & 0 & $\begin{array}{l}88 \\
89\end{array}$ & $\begin{array}{l}167 \\
169\end{array}$ & $\begin{array}{l}231 \\
234\end{array}$ & $\begin{array}{l}325 \\
328\end{array}$ & $\begin{array}{l}403 \\
403\end{array}$ & $\begin{array}{l}487 \\
482\end{array}$ & 350 \\
\hline 09299500 & 1 & 1 & 0 & 0 & 0 & $\begin{array}{l}1,140 \\
1.140\end{array}$ & $\begin{array}{l}1,740 \\
1,730\end{array}$ & $\begin{array}{l}2.160 \\
2.140\end{array}$ & $\begin{array}{l}2,730 \\
2,680\end{array}$ & $\begin{array}{l}3,160 \\
3,080\end{array}$ & $\begin{array}{l}3,620 \\
3,510\end{array}$ & 4.640 \\
\hline 09312500 & 1 & 1 & 1 & 0 & 0 & $\begin{array}{l}174 \\
176\end{array}$ & $\begin{array}{l}294 \\
300\end{array}$ & $\begin{array}{l}398 \\
410\end{array}$ & $\begin{array}{l}559 \\
576\end{array}$ & $\begin{array}{l}704 \\
723\end{array}$ & $\begin{array}{l}873 \\
886\end{array}$ & 1,120 \\
\hline 09312600 & 1 & 1 & 1 & 0 & 0 & $\begin{array}{l}314 \\
315\end{array}$ & $\begin{array}{l}486 \\
490\end{array}$ & $\begin{array}{l}622 \\
631\end{array}$ & $\begin{array}{l}819 \\
831\end{array}$ & $\begin{array}{l}986 \\
998\end{array}$ & $\begin{array}{l}1,170 \\
1,170\end{array}$ & 962 \\
\hline 09312700 & 1 & 0 & 0 & 0 & 0 & $\begin{array}{l}48 \\
51\end{array}$ & $\begin{array}{l}87 \\
96\end{array}$ & $\begin{array}{l}121 \\
139\end{array}$ & $\begin{array}{l}173 \\
205\end{array}$ & $\begin{array}{l}219 \\
264\end{array}$ & $\begin{array}{l}271 \\
325\end{array}$ & 204 \\
\hline 09312800 & 1 & 0 & 1 & 0 & 0 & $\begin{array}{l}225 \\
227\end{array}$ & $\begin{array}{l}407 \\
411\end{array}$ & $\begin{array}{l}565 \\
570\end{array}$ & $\begin{array}{l}812 \\
810\end{array}$ & $\begin{array}{l}1,030 \\
1.020\end{array}$ & $\begin{array}{l}1,290 \\
1,250\end{array}$ & 836 \\
\hline 10014000 & 0 & 0 & 0 & 0 & 0 & $\begin{array}{l}1,900 \\
1,880\end{array}$ & $\begin{array}{l}2,340 \\
2,300\end{array}$ & $\begin{array}{l}2,620 \\
2,560\end{array}$ & $\begin{array}{l}2,960 \\
2,860\end{array}$ & $\begin{array}{l}3,160 \\
3,090\end{array}$ & $\begin{array}{l}3,380 \\
3,320\end{array}$ & 2,970 \\
\hline 10015700 & 1 & 1 & 0 & 0 & 0 & $\begin{array}{l}406 \\
405\end{array}$ & $\begin{array}{l}815 \\
805\end{array}$ & $\begin{array}{l}1,230 \\
1,200\end{array}$ & $\begin{array}{l}1,980 \\
1,870\end{array}$ & $\begin{array}{l}2,760 \\
2,540\end{array}$ & $\begin{array}{l}3,760 \\
3,380\end{array}$ & 8,400 \\
\hline 10016000 & 0 & 0 & 0 & 0 & 0 & $\begin{array}{l}512 \\
509\end{array}$ & $\begin{array}{l}782 \\
771\end{array}$ & $\begin{array}{l}966 \\
943\end{array}$ & $\begin{array}{l}1,200 \\
1,160\end{array}$ & $\begin{array}{l}1,380 \\
1,320\end{array}$ & $\begin{array}{l}1,560 \\
1,490\end{array}$ & 1,220 \\
\hline 10019000 & 1 & 0 & 0 & 0 & 0 & $\begin{array}{l}1,940 \\
1,940\end{array}$ & $\begin{array}{l}2,560 \\
2,560\end{array}$ & $\begin{array}{l}2.950 \\
2.960\end{array}$ & $\begin{array}{l}3,430 \\
3,470\end{array}$ & $\begin{array}{l}3,760 \\
3,840\end{array}$ & $\begin{array}{l}4,090 \\
4,210\end{array}$ & 2,690 \\
\hline 10019700 & 0 & 0 & 0 & 0 & 0 & $\begin{array}{l}43 \\
44\end{array}$ & $\begin{array}{l}83 \\
85\end{array}$ & $\begin{array}{l}118 \\
120\end{array}$ & $\begin{array}{l}172 \\
175\end{array}$ & $\begin{array}{l}219 \\
221\end{array}$ & $\begin{array}{l}274 \\
272\end{array}$ & 160 \\
\hline 10021000 & 1 & 0 & 1 & 0 & 0 & $\begin{array}{l}261 \\
261\end{array}$ & $\begin{array}{l}342 \\
346\end{array}$ & $\begin{array}{l}395 \\
406\end{array}$ & $\begin{array}{l}460 \\
486\end{array}$ & $\begin{array}{l}509 \\
552\end{array}$ & $\begin{array}{l}558 \\
617\end{array}$ & 528 \\
\hline 10023000 & 1 & 1 & 0 & 0 & 0 & $\begin{array}{l}75 \\
77\end{array}$ & $\begin{array}{l}123 \\
132\end{array}$ & $\begin{array}{l}162 \\
182\end{array}$ & $\begin{array}{l}219 \\
261\end{array}$ & $\begin{array}{l}268 \\
330\end{array}$ & $\begin{array}{l}323 \\
404\end{array}$ & 337 \\
\hline 10027000 & 0 & 0 & 0 & 0 & 0 & $\begin{array}{l}219 \\
225\end{array}$ & $\begin{array}{l}502 \\
522\end{array}$ & $\begin{array}{l}748 \\
788\end{array}$ & $\begin{array}{l}1.120 \\
1.190\end{array}$ & $\begin{array}{l}1,420 \\
1,510\end{array}$ & $\begin{array}{l}1,760 \\
1,860\end{array}$ & 853 \\
\hline 10032000 & 1 & 0 & 0 & 0 & 0 & $\begin{array}{l}978 \\
975\end{array}$ & $\begin{array}{l}1,310 \\
1,300\end{array}$ & $\begin{array}{l}1,530 \\
1,520\end{array}$ & $\begin{array}{l}1,800 \\
1,780\end{array}$ & $\begin{array}{l}2,000 \\
1,980\end{array}$ & $\begin{array}{l}2,210 \\
2,190\end{array}$ & 2,100 \\
\hline 10040000 & 1 & 0 & 0 & 0 & 0 & $\begin{array}{l}144 \\
145\end{array}$ & $\begin{array}{l}249 \\
254\end{array}$ & $\begin{array}{l}331 \\
342\end{array}$ & $\begin{array}{l}445 \\
466\end{array}$ & $\begin{array}{l}539 \\
569\end{array}$ & $\begin{array}{l}638 \\
673\end{array}$ & 418 \\
\hline 10040500 & 0 & 0 & 0 & 0 & 0 & $\begin{array}{l}162 \\
162\end{array}$ & $\begin{array}{l}293 \\
293\end{array}$ & $\begin{array}{l}393 \\
392\end{array}$ & $\begin{array}{l}531 \\
525\end{array}$ & $\begin{array}{l}640 \\
631\end{array}$ & $\begin{array}{l}753 \\
736\end{array}$ & 382 \\
\hline 10041000 & 0 & 0 & 1 & 0 & 0 & $\begin{array}{l}477 \\
476\end{array}$ & $\begin{array}{l}916 \\
908\end{array}$ & $\begin{array}{l}1,240 \\
1,220\end{array}$ & $\begin{array}{l}1,660 \\
1,610\end{array}$ & $\begin{array}{l}1,980 \\
1,910\end{array}$ & $\begin{array}{l}2,300 \\
2,200\end{array}$ & 1,860 \\
\hline 10047500 & 1 & 0 & 0 & 0 & 0 & $\begin{array}{l}97 \\
98\end{array}$ & $\begin{array}{l}141 \\
147\end{array}$ & $\begin{array}{l}172 \\
188\end{array}$ & $\begin{array}{l}211 \\
247\end{array}$ & $\begin{array}{l}241 \\
296\end{array}$ & $\begin{array}{l}271 \\
346\end{array}$ & 224 \\
\hline 10058600 & 1 & 0 & 0 & 0 & 0 & $\begin{array}{l}152 \\
152\end{array}$ & $\begin{array}{l}195 \\
197\end{array}$ & $\begin{array}{l}222 \\
228\end{array}$ & $\begin{array}{l}253 \\
268\end{array}$ & $\begin{array}{l}274 \\
300\end{array}$ & $\begin{array}{l}295 \\
332\end{array}$ & 249 \\
\hline 10069000 & 1 & 0 & 0 & 0 & 0 & $\begin{array}{l}51 \\
53\end{array}$ & $\begin{array}{l}81 \\
88\end{array}$ & $\begin{array}{l}104 \\
120\end{array}$ & $\begin{array}{l}137 \\
170\end{array}$ & $\begin{array}{l}164 \\
213\end{array}$ & $\begin{array}{l}193 \\
256\end{array}$ & 162 \\
\hline 10072800 & 1 & 0 & 0 & 0 & 0 & $\begin{array}{l}122 \\
122\end{array}$ & $\begin{array}{l}171 \\
173\end{array}$ & $\begin{array}{l}205 \\
211\end{array}$ & $\begin{array}{l}249 \\
262\end{array}$ & $\begin{array}{l}283 \\
305\end{array}$ & $\begin{array}{l}318 \\
347\end{array}$ & 310 \\
\hline 10084500 & 1 & 0 & 0 & 0 & 0 & $\begin{array}{l}374 \\
372\end{array}$ & $\begin{array}{l}562 \\
558\end{array}$ & $\begin{array}{l}690 \\
682\end{array}$ & $\begin{array}{l}854 \\
840\end{array}$ & $\begin{array}{l}976 \\
959\end{array}$ & $\begin{array}{l}1,100 \\
1,080\end{array}$ & 1,090 \\
\hline 10090800 & 1 & 0 & 0 & 0 & 0 & $\begin{array}{l}51 \\
50\end{array}$ & $\begin{array}{l}87 \\
85\end{array}$ & $\begin{array}{l}113 \\
109\end{array}$ & $\begin{array}{l}147 \\
139\end{array}$ & $\begin{array}{l}173 \\
163\end{array}$ & $\begin{array}{l}199 \\
187\end{array}$ & 152 \\
\hline 10093000 & 1 & 1 & 0 & 0 & 0 & $\begin{array}{l}592 \\
588\end{array}$ & $\begin{array}{l}713 \\
703\end{array}$ & $\begin{array}{l}789 \\
770\end{array}$ & $\begin{array}{l}882 \\
852\end{array}$ & $\begin{array}{l}950 \\
913\end{array}$ & $\begin{array}{r}1,020 \\
978\end{array}$ & 1,070 \\
\hline 10099000 & 0 & 1 & 0 & 0 & 0 & $\begin{array}{l}234 \\
231\end{array}$ & $\begin{array}{l}338 \\
330\end{array}$ & $\begin{array}{l}417 \\
401\end{array}$ & $\begin{array}{l}529 \\
498\end{array}$ & $\begin{array}{l}622 \\
577\end{array}$ & $\begin{array}{l}724 \\
662\end{array}$ & 702 \\
\hline
\end{tabular}




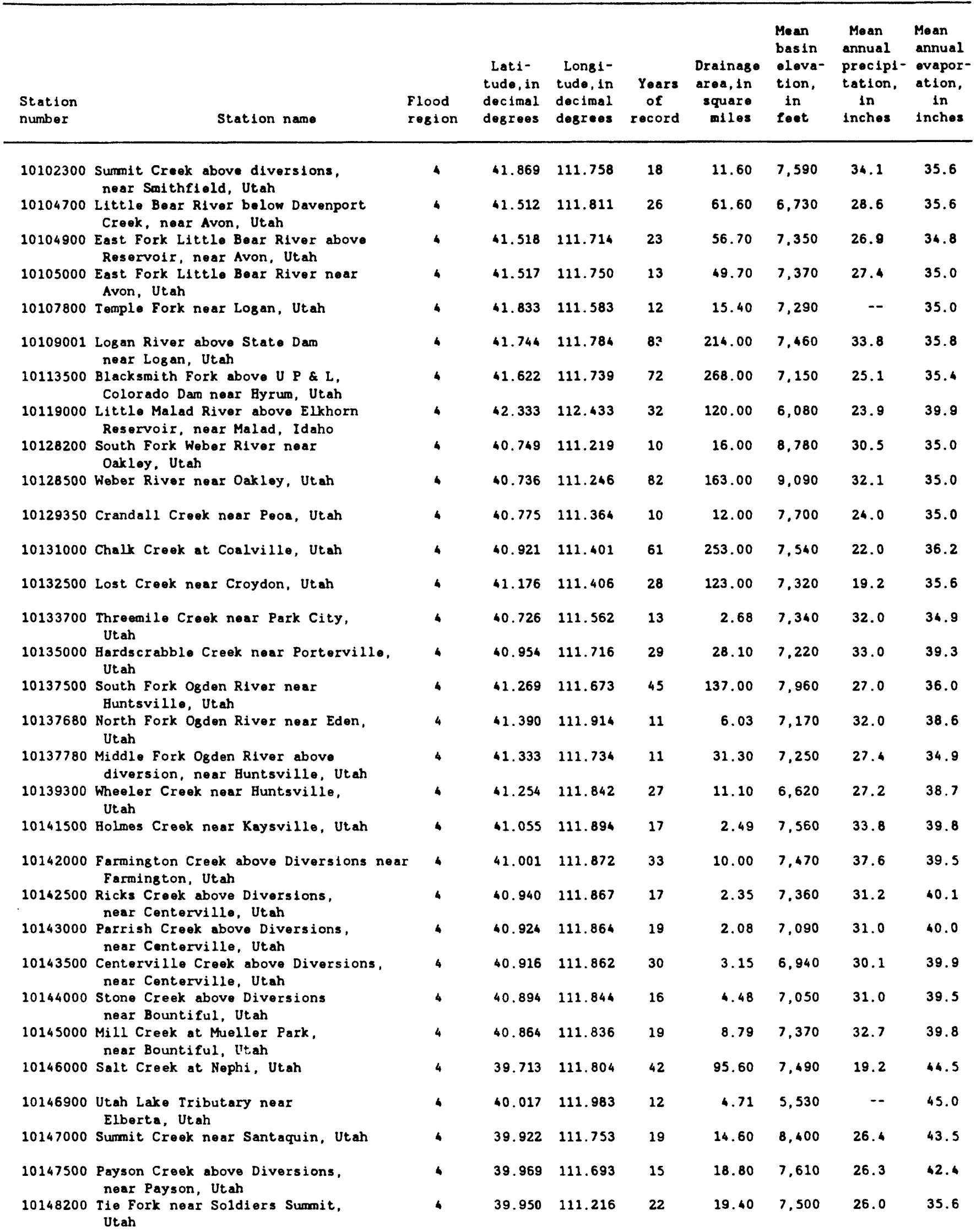




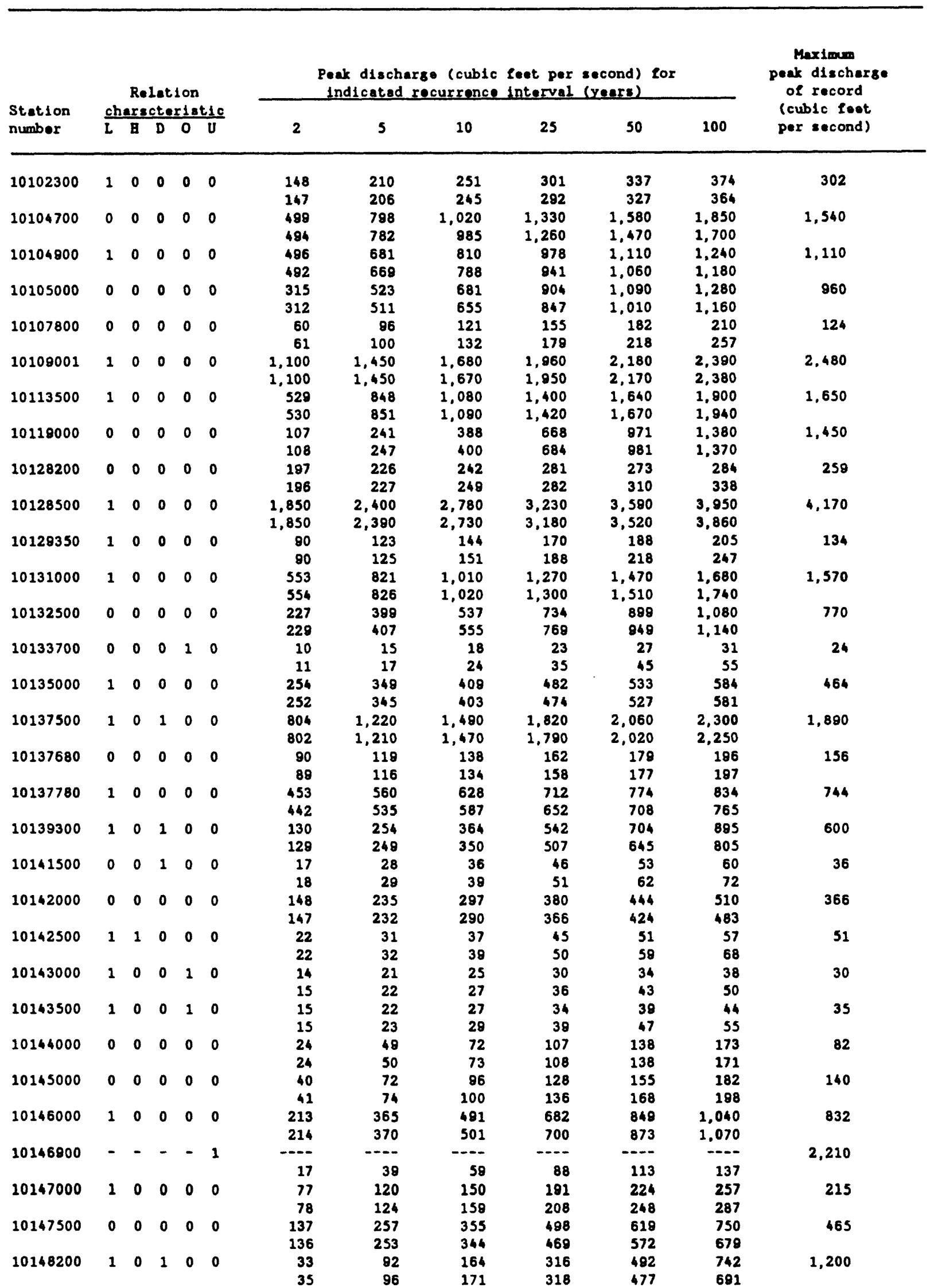




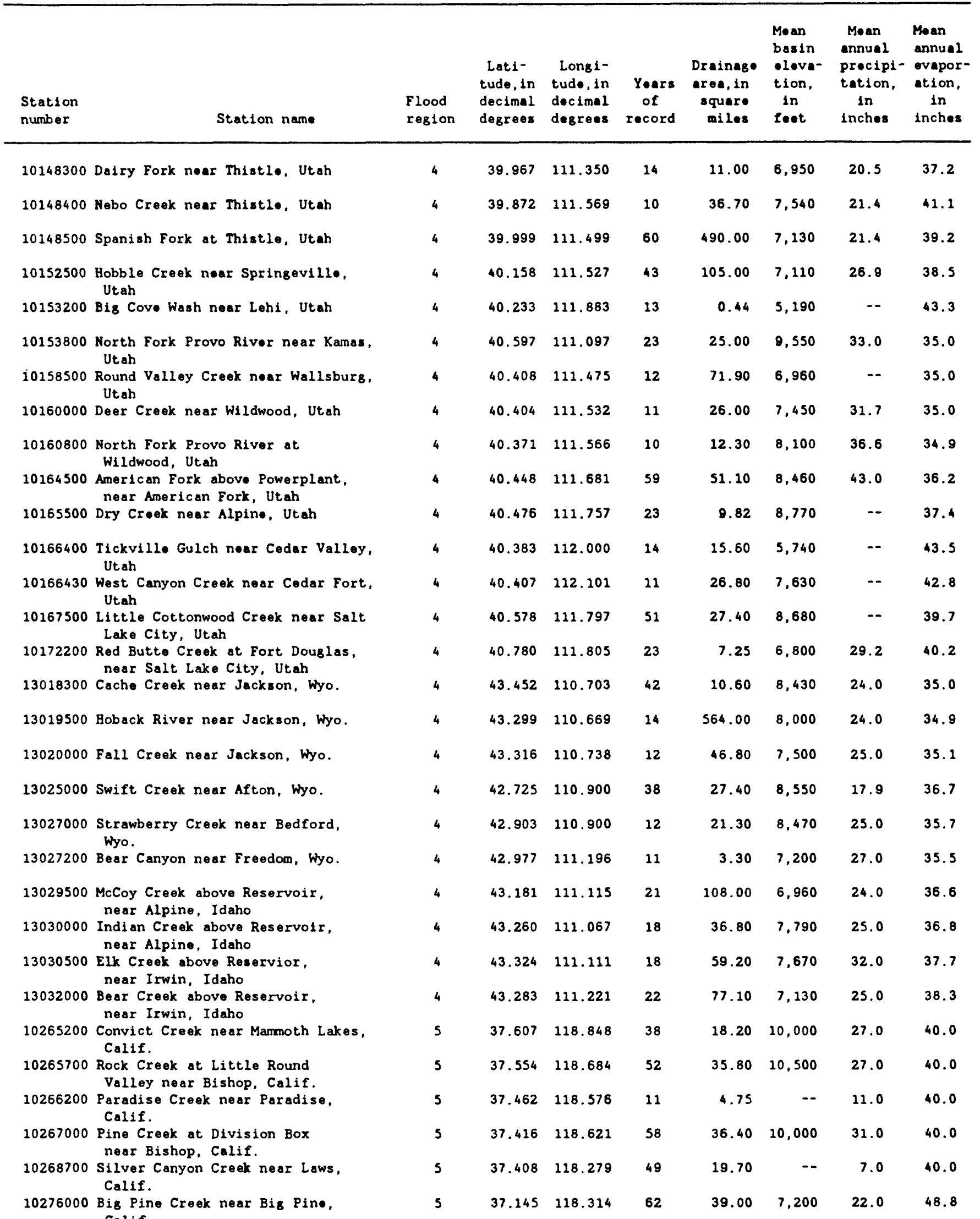


Maximum

Peak discharge (cubic feet per second) for Relation
number $\quad \frac{\begin{array}{c}\text { characteristic } \\ \text { L H D O U }\end{array}}{}$ indicated recurrence interval (years)

$\begin{array}{llllllll}10148300 & 1 & 0 & 1 & 1 & 0 & & 1 \\ 10148400 & 0 & 1 & 0 & 0 & 0 & & 1 \\ 10148500 & 1 & 1 & 0 & 0 & 0 & & 5 \\ 10152500 & 1 & 0 & 0 & 0 & 0 & & 258 \\ 10153200 & - & - & - & - & 1 & & -\end{array}$

101538001000000

10158500

1000000

10160000100000

$10160800 \quad 0 \quad 0 \quad 0 \quad 000$

10164500110000

$10165500 \quad 0 \quad 1 \quad 0 \quad 0 \quad 0$

$10166400 \quad 0 \quad 0 \quad 0000$

$10166430-\quad-\quad-1$

$10167500 \quad 0 \quad 0 \quad 0000$

$10172200 \quad 0 \quad 0 \quad 0000$

$13018300 \quad 0 \quad 0 \quad 0000$

$13019500 \quad 0 \quad 000000$

13020000110000

130250001000000

1302700011000000

130272001110000

$13029500 \quad 1001000$

$13030000 \quad 0 \quad 0 \quad 0000$

$13030500 \quad 0 \quad 0 \quad 0000$

$13032000 \quad 1 \quad 0 \quad 0 \quad 000$

$\begin{array}{llllll}10265200 & 1 & 0 & 0 & 0 & 0\end{array}$

$10265700 \quad 0 \quad 0 \quad 0000$

$10266200-\quad-\quad-1$

10267000100000

$\begin{array}{llllll}10268700 & 1 & 0 & 0 & 0 & 0\end{array}$

$10276000 \quad 0 \quad 0 \quad 0000$ $\begin{array}{lll}2 & 5 & 10\end{array}$

152405

$112 \quad 216$

$518 \quad 763$

$521 \quad 776$

258

259

40 !

405

116

120

64
66

66
104

104

350

350

198

197

28
28

28
-150

385

384

38
19

20

80

80

3,810

3,750

380

375

502

499

260

257

45
45

842
832

200

200

463

459

514

510

105

105

114

115

115

239

239

2

184

184

\section{4}

466

7

524

518

155

173

86

98
147

149

481

481

278

274

78

79

248

512

509

38

40

119

120

4.850

4. 680

508

496

622

615

320

316

78
76

1,190

1,160

258

261

592

584

672

663

155

152

172

170

$-\cdots$

313

310

4
256

256
253
$150 \quad 386$
10

25

so

100

peak discharge

of record

(cubic feet

per second)

\begin{tabular}{|c|c|c|c|c|}
\hline 691 & 1.240 & 1,830 & 2,610 & 980 \\
\hline 631 & 1.060 & 1,490 & 2,030 & \\
\hline 294 & 429 & 549 & 689 & 478 \\
\hline 309 & 447 & 565 & 690 & \\
\hline 948 & 1,210 & 1,430 & 1,660 & 1,800 \\
\hline 980 & 1,280 & 1,540 & 1,810 & \\
\hline 624 & 852 & 1,040 & 1,240 & 1,250 \\
\hline 628 & 858 & 1,050 & 1,250 & \\
\hline--- & $\cdots$ & ---- & ---- & 8 \\
\hline 11 & 17 & 22 & 27 & \\
\hline 599 & 690 & 756 & 822 & 728 \\
\hline 588 & 671 & 733 & 794 & \\
\hline 181 & 214 & 238 & 263 & 201 \\
\hline 227 & 315 & 393 & 472 & \\
\hline 100 & 116 & 127 & 138 & 99 \\
\hline 128 & 176 & 218 & 259 & \\
\hline 178 & 220 & 253 & 288 & 225 \\
\hline 183 & 231 & 270 & 310 & \\
\hline 571 & 687 & 776 & 866 & 1.000 \\
\hline 572 & 689 & 780 & 872 & \\
\hline 335 & 411 & 472 & 536 & 597 \\
\hline 326 & 393 & 446 & 501 & \\
\hline 132 & 231 & 331 & 455 & 236 \\
\hline 133 & 226 & 315 & 420 & \\
\hline--- & --- & --- & --- & 1.660 \\
\hline 324 & 417 & 497 & 568 & \\
\hline 596 & 704 & 785 & 868 & 762 \\
\hline 590 & 692 & 770 & 849 & \\
\hline 55 & 84 & 111 & 144 & 105 \\
\hline 59 & 92 & 122 & 156 & \\
\hline 145 & 179 & 203 & 228 & 225 \\
\hline 147 & 184 & 211 & 239 & \\
\hline 5,490 & 6.270 & 6.830 & 7,380 & 6,160 \\
\hline 5,180 & 5,760 & 6,200 & 6,650 & \\
\hline 598 & 716 & 809 & 905 & 780 \\
\hline 580 & 691 & 784 & 878 & \\
\hline 697 & 788 & 854 & 919 & 793 \\
\hline 684 & 766 & 827 & 888 & \\
\hline 356 & 399 & 429 & 458 & 396 \\
\hline 353 & 401 & 440 & 479 & \\
\hline 106 & 148 & 186 & 228 & 180 \\
\hline 101 & 137 & 168 & 200 & \\
\hline 1,410 & 1,660 & 1,840 & 2,000 & 1.670 \\
\hline 1,360 & 1,570 & 1,730 & 1,880 & \\
\hline 294 & 337 & 368 & 398 & 350 \\
\hline 305 & 364 & 414 & 463 & \\
\hline 670 & 762 & 826 & 886 & 870 \\
\hline 660 & 755 & 829 & 902 & \\
\hline 768 & 878 & 955 & 1.030 & 784 \\
\hline 755 & 866 & 952 & 1,040 & \\
\hline 189 & 234 & 269 & 304 & 290 \\
\hline 192 & 238 & 274 & 310 & \\
\hline 212 & 263 & 301 & 339 & 312 \\
\hline 219 & 273 & 314 & 354 & \\
\hline$-\cdots$ & --- & ---- & $-\cdots$ & 238 \\
\hline 80 & $-\cdots$ & $\ldots$ & $-\cdots$ & \\
\hline 358 & 412 & 450 & 486 & 509 \\
\hline 360 & 415 & 455 & 492 & \\
\hline 5 & 6 & 7 & 9 & 10 \\
\hline 13 & ---- & ---- & ---- & \\
\hline 304 & 365 & 409 & 454 & 458 \\
\hline 306 & 376 & 432 & 491 & \\
\hline
\end{tabular}




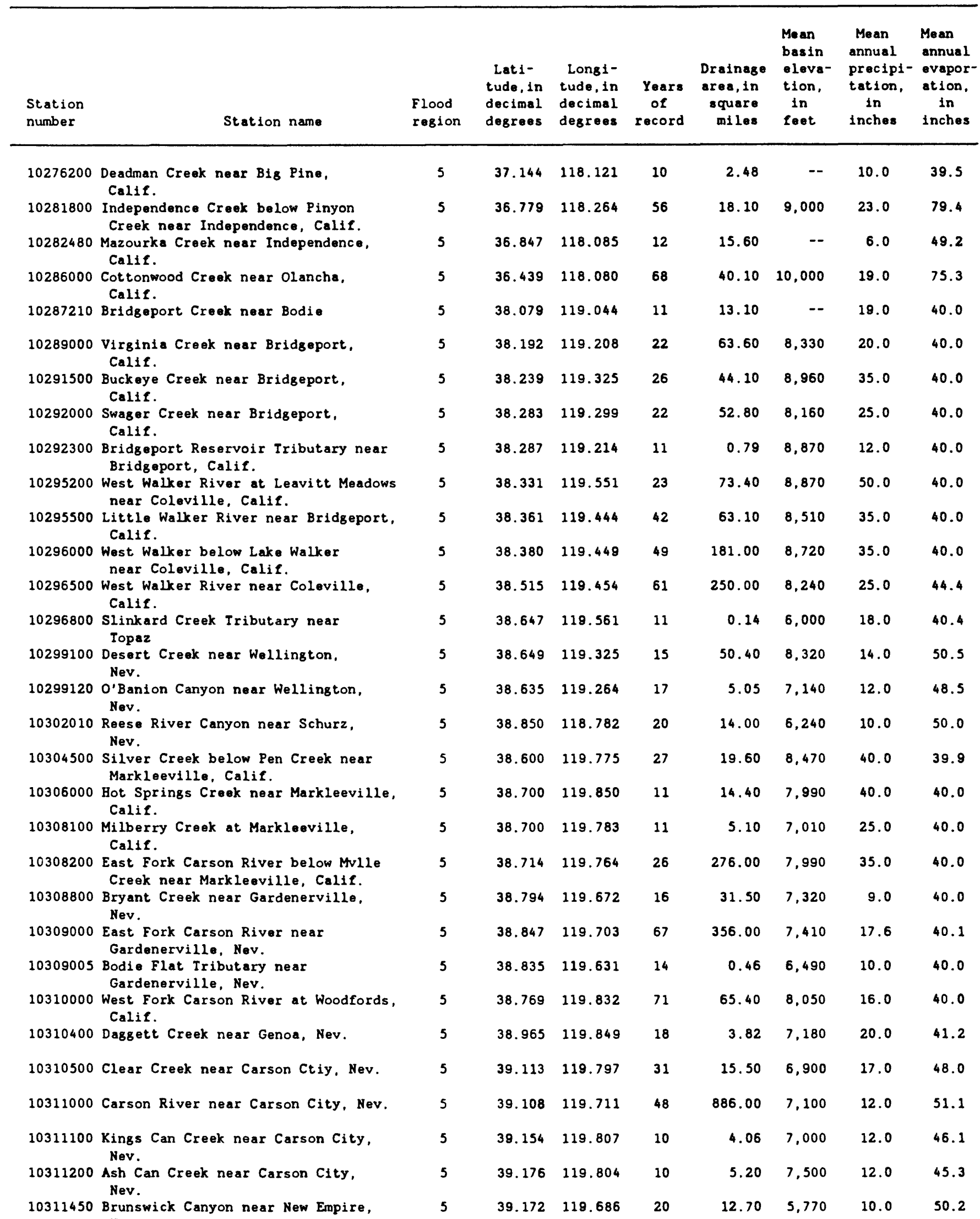


Maximum

Peak discharge (cubic feet per second) for indicated recurrence interval (years)

\begin{tabular}{|c|c|c|c|c|c|c|c|c|c|c|c|c|}
\hline \multirow[b]{2}{*}{$\begin{array}{l}\text { Station } \\
\text { number }\end{array}$} & \multirow{2}{*}{\multicolumn{5}{|c|}{$\begin{array}{c}\text { Relation } \\
\text { characteristic }\end{array}$}} & \multicolumn{6}{|c|}{ indicated recurrence interval (years) } & \multirow{2}{*}{$\begin{array}{l}\text { of record } \\
\text { (cubic feet } \\
\text { per second) }\end{array}$} \\
\hline & & & & & & 2 & 5 & 10 & 25 & 50 & 100 & \\
\hline \multirow[t]{2}{*}{10276200} & - & - & - & - & 1 & 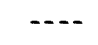 & ---- & --- & --- & $\cdots$ & $\cdots-$ & 4 \\
\hline & & & & & & --- & 4 & 40 & $\cdots$ & $-\infty$ & $m-n$ & \\
\hline \multirow[t]{2}{*}{10281800} & 0 & 0 & 0 & 0 & 0 & 53 & 86 & 108 & 137 & 157 & 177 & 169 \\
\hline & & & & & & 53 & 85 & 110 & 141 & 163 & 185 & \\
\hline \multirow[t]{2}{*}{10282480} & - & - & - & - & 1 & --- & ---- & $\cdots$ & --- & ---- & --- & 1,300 \\
\hline & & & & & & --- & 14 & 160 & --- & $\cdots$ & --- & \\
\hline \multirow[t]{2}{*}{10286000} & 1 & 0 & 0 & 0 & 0 & 120 & 208 & 275 & 368 & 444 & 525 & 520 \\
\hline & & & & & & 120 & 206 & 275 & 366 & 440 & 517 & \\
\hline \multirow[t]{2}{*}{10287210} & 0 & 0 & 0 & 0 & 0 & 8 & 33 & 68 & 147 & 238 & 367 & 115 \\
\hline & & & & & & --- & 32 & 91 & --- & $m-$ & --- & \\
\hline \multirow[t]{2}{*}{10289000} & 0 & 0 & 0 & 0 & 0 & 101 & 261 & 449 & 827 & 1,250 & 1,840 & 1,300 \\
\hline & & & & & & 103 & 255 & 484 & 878 & 1.300 & 1,850 & \\
\hline \multirow[t]{2}{*}{10291500} & 0 & 0 & 0 & 0 & 0 & 390 & 577 & 707 & 877 & 1,010 & 1,140 & 947 \\
\hline & & & & & & 390 & 563 & 707 & 880 & 1,020 & 1,160 & \\
\hline 10292000 & 0 & 0 & 0 & 0 & 0 & 86 & 207 & 332 & 558 & 785 & 1.070 & 585 \\
\hline & & & & & & 88 & 203 & 368 & 626 & 877 & 1,180 & \\
\hline 10292300 & 0 & 0 & 0 & 1 & 0 & 4 & 28 & 75 & 208 & 396 & 702 & 98 \\
\hline & & & & & & 4 & 26 & 68 & 177 & 322 & 547 & \\
\hline 10295200 & 0 & 0 & 0 & 0 & 0 & 1,180 & 1,580 & 1,850 & 2,210 & 2,490 & 2,780 & 2,810 \\
\hline & & & & & & 1,170 & 1,530 & 1,800 & 2,130 & 2,400 & 2,670 & \\
\hline 10295500 & 0 & 0 & 0 & 0 & 0 & 336 & 568 & 756 & 1,030 & 1,270 & 1,540 & 1,510 \\
\hline & & & & & & 336 & 560 & 765 & 1,050 & 1,300 & 1,580 & \\
\hline 10296000 & 0 & 0 & 0 & 0 & 0 & 1.850 & 2,830 & 3,560 & 4,550 & 5,340 & 6.180 & 6,220 \\
\hline & & & & & & 1,850 & 2,790 & 3,520 & 4,480 & 5,240 & 6,050 & \\
\hline 10296500 & 0 & 0 & 0 & 0 & 0 & 1,800 & 2.620 & 3,180 & 3,900 & 4,450 & 5,000 & 6,500 \\
\hline & & & & & & 1,800 & 2,590 & 3,180 & 3,930 & 4.510 & 5,100 & \\
\hline 10296800 & - & - & - & - & 1 & $\cdots$ & $--\cdot$ & --- & ---- & --- & --- & 640 \\
\hline & & & & & & 1 & 1 & 7 & 16 & 26 & 40 & \\
\hline 10299100 & 0 & 0 & 0 & 0 & 0 & 66 & 130 & 186 & 272 & 350 & 438 & 262 \\
\hline & & & & & & 70 & 128 & 262 & 426 & 579 & 749 & \\
\hline 10299120 & - & - & - & - & 1 & $-\cdots$ & --- & $\cdots$ & ---- & --- & ---- & 336 \\
\hline & & & & & & 33 & 12 & 139 & 238 & 336 & 454 & \\
\hline 10302010 & 1 & 1 & 0 & 0 & 0 & 34 & 145 & 320 & 768 & 1.370 & 2,330 & 1,870 \\
\hline & & & & & & 34 & 141 & 322 & 759 & 1,320 & 2,200 & \\
\hline 10304500 & 0 & 0 & 1 & 0 & 0 & 425 & 749 & 1,040 & 1,520 & 1,960 & 2,500 & 2,220 \\
\hline & & & & & & 423 & 730 & 1,000 & 1,440 & 1,830 & 2,300 & \\
\hline 10306000 & 0 & 1 & 0 & 0 & 0 & 409 & 684 & 917 & 1,280 & 1,600 & 1,970 & 1,740 \\
\hline & & & & & & 403 & 643 & 840 & 1.130 & 1,390 & 1,680 & \\
\hline 10308100 & 0 & 0 & 0 & 0 & 0 & 25 & 159 & 393 & 993 & 1.770 & 2.930 & 291 \\
\hline & & & & & & 25 & 150 & 360 & 850 & 1,450 & 2,300 & \\
\hline 10308200 & 0 & 0 & 0 & 0 & 0 & 2,890 & 5,800 & 8,400 & 12,500 & 16,200 & 20.500 & 15,100 \\
\hline & & & & & & 2,880 & 5,650 & 8,130 & 11,900 & 15,200 & 19.000 & \\
\hline 10308800 & 0 & 0 & 0 & 0 & 0 & 76 & 219 & 385 & 709 & 1.060 & 1,520 & 975 \\
\hline & & & & & & 78 & 212 & 412 & 763 & 1,130 & 1.600 & \\
\hline 10309000 & 0 & 0 & 0 & 0 & 0 & 2.610 & 4.730 & 6.630 & 9,710 & 12,600 & 16,000 & 17,600 \\
\hline & & & & & & 2,610 & 4,680 & 6,590 & 9,640 & 12,500 & 15,800 & \\
\hline 10309005 & - & - & - & - & 1 & $\cdots$ & $\cdots$ & $-\cdots$ & $\cdots$ & --- & --- & 3 \\
\hline & & & & & & 4 & 2 & 21 & 41 & 63 & 94 & \\
\hline 10310000 & 1 & 0 & 0 & 0 & 0 & 858 & 1,440 & 1,960 & 2,830 & 3,650 & 4.640 & 4,890 \\
\hline & & & & & & 857 & 1,430 & 1,940 & 2,790 & 3,590 & 4.540 & \\
\hline 10310400 & 1 & 1 & 0 & 1 & 0 & 17 & 27 & 35 & 47 & 58 & 70 & 63 \\
\hline & & & & & & 17 & 26 & 43 & 69 & 96 & 130 & \\
\hline 10310500 & 0 & 0 & 0 & 0 & 0 & 29 & 67 & 103 & 162 & 217 & 282 & 170 \\
\hline & & & & & & 30 & 66 & 120 & 207 & 297 & 408 & \\
\hline 10311000 & 0 & 0 & 0 & 0 & 0 & 2,630 & 5,780 & 9.050 & 15,000 & 21,200 & 29,100 & 30,000 \\
\hline & & & & & & 2,630 & 5,710 & 9,150 & 15,200 & 21,500 & 29,300 & \\
\hline 10311100 & 0 & 0 & 0 & 0 & 0 & 20 & 52 & 86 & 147 & 208 & 285 & 48 \\
\hline & & & & & & 21 & 49 & 94 & 168 & 245 & 344 & \\
\hline 10311200 & - & - & - & - & 1 & $\cdots$ & $-\cdots$ & $\cdots$ & $\cdots-$ & $-\cdots$ & $\cdots$ & 584 \\
\hline & & & & & & 47 & 15 & 176 & 286 & 394 & 524 & \\
\hline 10311450 & 0 & 0 & 1 & 0 & 0 & 6 & 47 & 128 & 350 & 649 & 1.100 & 90 \\
\hline & & & & & & 6 & 46 & 147 & 400 & 734 & 1,220 & \\
\hline
\end{tabular}




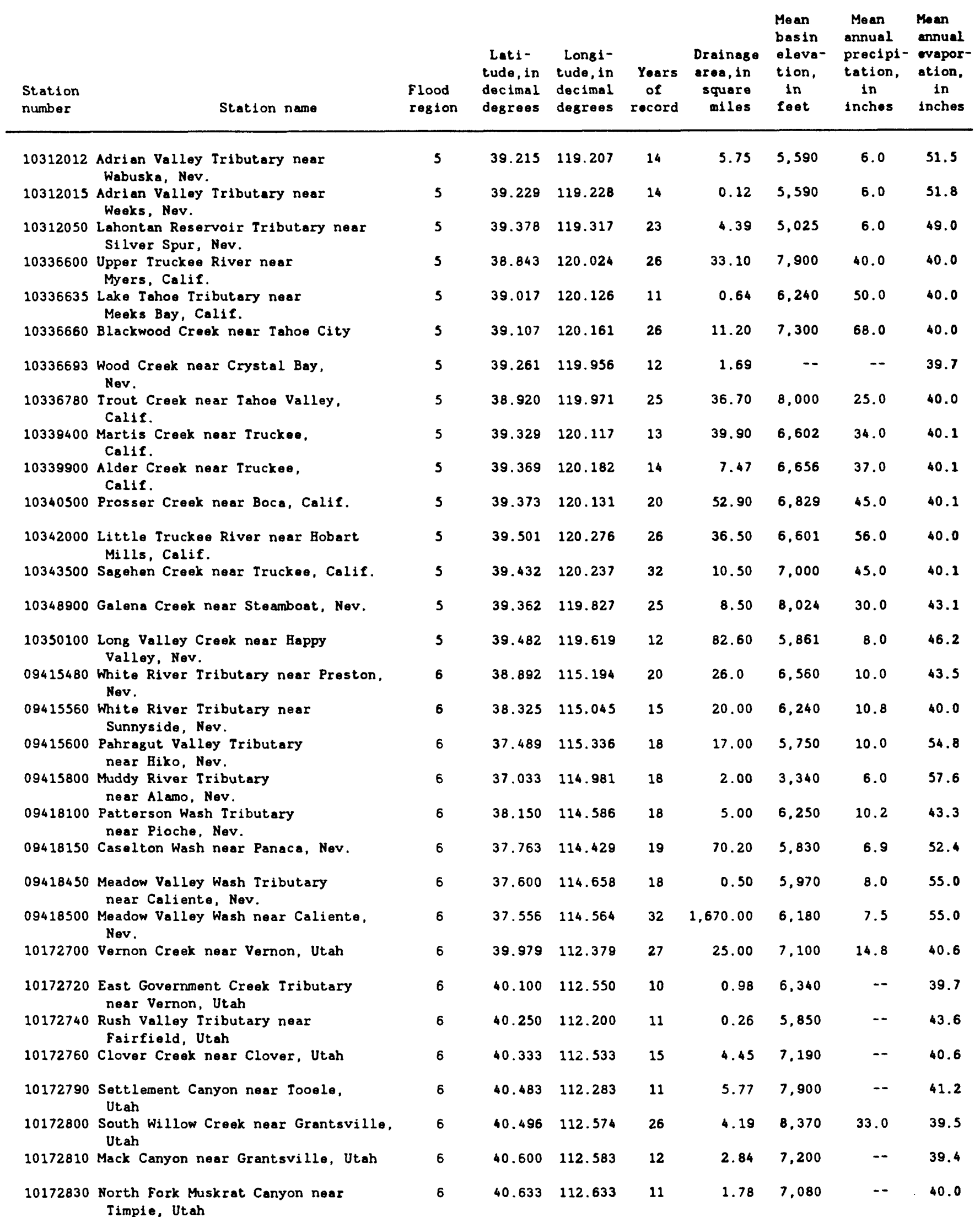




\begin{tabular}{|c|c|c|c|c|c|c|c|c|c|c|c|c|}
\hline \multirow{2}{*}{$\begin{array}{l}\text { Station } \\
\text { number }\end{array}$} & \multicolumn{5}{|c|}{$\begin{array}{c}\text { Relation } \\
\text { characteristic }\end{array}$} & \multicolumn{6}{|c|}{$\begin{array}{l}\text { Poak d1scharge (cuble foet per second) for } \\
\text { indicated recurrence interval (years) }\end{array}$} & \multirow{2}{*}{$\begin{array}{l}\text { Maxime } \\
\text { poek dischergo } \\
\text { of record } \\
\text { (cublc font } \\
\text { por secood) }\end{array}$} \\
\hline & $\frac{C B}{L}$ & B & D & $\frac{100}{0}$ & $\frac{\mathrm{Cl}}{\mathrm{U}}$ & 2 & 5 & 10 & 25 & 50 & 100 & \\
\hline 10312012 & - & - & - & - & 1 & 24 & --- & 194 & ---- & $-\overline{716}$ & 1,090 & 1 \\
\hline 10312015 & - & - & - & - & 1 & --- & -- & 8 & 19 & 33 & 53 & 1 \\
\hline 10312050 & - & - & - & - & 1 & --- & 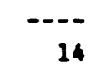 & 166 & 418 & 738 & 1,190 & 920 \\
\hline 10336600 & 0 & 0 & 0 & 0 & 0 & $\begin{array}{l}698 \\
694\end{array}$ & $\begin{array}{l}1,240 \\
1,210\end{array}$ & $\begin{array}{l}1,670 \\
1,610\end{array}$ & $\begin{array}{l}2,300 \\
2,100\end{array}$ & $\begin{array}{l}2,830 \\
2,670\end{array}$ & $\begin{array}{l}3,410 \\
3,200\end{array}$ & 2,550 \\
\hline 10336635 & 0 & 0 & 0 & 0 & 0 & $\begin{array}{l}8 \\
8\end{array}$ & $\begin{array}{l}16 \\
16\end{array}$ & $\begin{array}{l}24 \\
25\end{array}$ & $\begin{array}{l}38 \\
42\end{array}$ & $\begin{array}{l}50 \\
61\end{array}$ & $\begin{array}{l}66 \\
85\end{array}$ & 43 \\
\hline 10336660 & 0 & & 1 & 0 & 0 & $\begin{array}{l}497 \\
494\end{array}$ & $\begin{array}{l}1,060 \\
1,030\end{array}$ & $\begin{array}{l}1,600 \\
1,520\end{array}$ & $\begin{array}{l}2,500 \\
2,320\end{array}$ & $\begin{array}{l}3,350 \\
3,060\end{array}$ & $\begin{array}{l}4,390 \\
3,960\end{array}$ & 2,100 \\
\hline 10336693 & 0 & 0 & 0 & 0 & 0 & $\begin{array}{r}16 \\
---\end{array}$ & $\begin{array}{l}30 \\
28\end{array}$ & 40 & $\begin{array}{r}53 \\
--\end{array}$ & 63 & $\begin{array}{r}73 \\
---\end{array}$ & 40 \\
\hline 10336780 & 0 & 0 & 0 & 0 & 0 & $\begin{array}{l}154 \\
155\end{array}$ & $\begin{array}{l}280 \\
274\end{array}$ & $\begin{array}{l}384 \\
410\end{array}$ & $\begin{array}{l}539 \\
600\end{array}$ & $\begin{array}{l}672 \\
769\end{array}$ & $\begin{array}{l}820 \\
961\end{array}$ & 535 \\
\hline 10338400 & 0 & 0 & 0 & 0 & 0 & $\begin{array}{l}392 \\
389\end{array}$ & $\begin{array}{l}833 \\
793\end{array}$ & $\begin{array}{l}1,230 \\
1,200\end{array}$ & $\begin{array}{l}1,880 \\
1,870\end{array}$ & $\begin{array}{l}2,460 \\
2,500\end{array}$ & $\begin{array}{l}3,150 \\
3,260\end{array}$ & 1,880 \\
\hline 10338900 & 1 & 0 & 0 & 0 & 0 & $\begin{array}{l}87 \\
86\end{array}$ & $\begin{array}{l}231 \\
221\end{array}$ & $\begin{array}{l}397 \\
382\end{array}$ & $\begin{array}{l}727 \\
687\end{array}$ & $\begin{array}{l}1,090 \\
1,020\end{array}$ & $\begin{array}{l}1,580 \\
1,450\end{array}$ & 730 \\
\hline 10340500 & 0 & 0 & 0 & 0 & 0 & $\begin{array}{l}622 \\
619\end{array}$ & $\begin{array}{l}1,310 \\
1,270\end{array}$ & $\begin{array}{l}2,000 \\
1,950\end{array}$ & $\begin{array}{l}3,250 \\
3,130\end{array}$ & $\begin{array}{r}4,520 \\
4,330\end{array}$ & $\begin{array}{l}6,150 \\
5,850\end{array}$ & 4,560 \\
\hline 10342000 & 0 & 0 & 1 & 0 & 0 & $\begin{array}{l}966 \\
960\end{array}$ & $\begin{array}{l}2,310 \\
2,250\end{array}$ & $\begin{array}{l}3,830 \\
3,660\end{array}$ & $\begin{array}{l}6,800 \\
6,340\end{array}$ & $\begin{array}{r}10,000 \\
9,180\end{array}$ & $\begin{array}{l}14,500 \\
13,100\end{array}$ & 7,910 \\
\hline 10343500 & 0 & 0 & 0 & 0 & 0 & $\begin{array}{l}116 \\
116\end{array}$ & $\begin{array}{l}259 \\
254\end{array}$ & $\begin{array}{l}396 \\
394\end{array}$ & $\begin{array}{l}622 \\
620\end{array}$ & $\begin{array}{l}833 \\
835\end{array}$ & $\begin{array}{l}1,080 \\
1,090\end{array}$ & 765 \\
\hline 10348900 & 0 & 1 & 0 & 0 & 0 & $\begin{array}{l}96 \\
96\end{array}$ & $\begin{array}{l}290 \\
282\end{array}$ & $\begin{array}{l}559 \\
542\end{array}$ & $\begin{array}{l}1,200 \\
1,130\end{array}$ & $\begin{array}{l}2,020 \\
1,850\end{array}$ & $\begin{array}{l}3,320 \\
2,980\end{array}$ & 4,730 \\
\hline 10350100 & 1 & 0 & 0 & 0 & 0 & $\begin{array}{l}45 \\
49\end{array}$ & $\begin{array}{l}412 \\
398\end{array}$ & $\begin{array}{l}1,270 \\
1,350\end{array}$ & $\begin{array}{l}4,130 \\
4,100\end{array}$ & $\begin{array}{l}8,710 \\
8,160\end{array}$ & $\begin{array}{l}16,900 \\
15,000\end{array}$ & 2,560 \\
\hline 09415480 & - & - & - & - & 1 & 0 & 125 & ---- & ---- & 821 & 1,390 & 218 \\
\hline 09415560 & - & - & - & - & 1 & 0 & 105 & 202 & --- & $-\overline{-171}$ & 1,370 & 600 \\
\hline 09415600 & - & - & - & - & 1 & 0 & 97 & 208 & 471 & 825 & 1,520 & 162 \\
\hline 08415800 & - & - & - & - & 1 & $-\cdots$ & --- & 132 & ---- & --- & 1,780 & 77 \\
\hline 09418100 & - & - & - & - & 1 & 0 & $---\overline{35}$ & 85 & --- & 316 & 671 & 49 \\
\hline 09418150 & 1 & 0 & 1 & 0 & 0 & $\begin{array}{l}256 \\
221\end{array}$ & $\begin{array}{l}814 \\
808\end{array}$ & $\begin{array}{l}1,450 \\
1,410\end{array}$ & $\begin{array}{l}2,610 \\
2,430\end{array}$ & $\begin{array}{l}3,790 \\
3,640\end{array}$ & $\begin{array}{l}5,240 \\
5,150\end{array}$ & 1,710 \\
\hline 09418450 & 0 & 0 & 0 & 0 & 0 & $\begin{array}{l}0 \\
0\end{array}$ & $\begin{array}{l}2 \\
2\end{array}$ & $\begin{array}{l}5 \\
5\end{array}$ & $\begin{array}{l}15 \\
19\end{array}$ & $\begin{array}{l}31 \\
36\end{array}$ & $\begin{array}{l}63 \\
70\end{array}$ & 26 \\
\hline 09418500 & 0 & 0 & 1 & 0 & 0 & $\begin{array}{l}490 \\
448\end{array}$ & $\begin{array}{l}1,270 \\
1,290\end{array}$ & $\begin{array}{l}2,010 \\
2,040\end{array}$ & $\begin{array}{l}3,210 \\
3,480\end{array}$ & $\begin{array}{r}4,280 \\
4,750\end{array}$ & $\begin{array}{l}5,500 \\
5,690\end{array}$ & 2,400 \\
\hline 10172700 & 0 & 1 & 1 & 0 & 0 & $\begin{array}{l}26 \\
24\end{array}$ & $\begin{array}{l}91 \\
91\end{array}$ & $\begin{array}{l}175 \\
175\end{array}$ & $\begin{array}{l}355 \\
357\end{array}$ & $\begin{array}{l}561 \\
568\end{array}$ & $\begin{array}{l}848 \\
856\end{array}$ & 825 \\
\hline 10172720 & - & - & - & - & 1 & 0 & 9 & 30 & --- & 108 & $\begin{array}{r}---- \\
283\end{array}$ & 6 \\
\hline 10172740 & - & - & - & - & 1 & 0 & --- & $\begin{array}{r}--- \\
15\end{array}$ & --- & 55 & 173 & 49 \\
\hline 10172760 & 0 & 0 & 0 & 0 & 1 & $\begin{array}{l}14 \\
11\end{array}$ & $\begin{array}{l}35 \\
35\end{array}$ & $\begin{array}{l}56 \\
56\end{array}$ & $\begin{array}{l}92 \\
97\end{array}$ & $\begin{array}{l}125 \\
135\end{array}$ & $\begin{array}{l}166 \\
181\end{array}$ & 87 \\
\hline 10172780 & - & - & - & - & 1 & 0 & 33 & 64 & 124 & 212 & --- & 155 \\
\hline 10172800 & 1 & 0 & 1 & 0 & 0 & $\begin{array}{l}37 \\
33\end{array}$ & $\begin{array}{l}59 \\
58\end{array}$ & $\begin{array}{l}75 \\
74\end{array}$ & $\begin{array}{l}97 \\
96\end{array}$ & $\begin{array}{l}115 \\
117\end{array}$ & $\begin{array}{l}133 \\
138\end{array}$ & 92 \\
\hline 10172810 & - & - & - & - & 1 & 0 & 20 & 48 & 97 & --- & --- & 2 \\
\hline 10172830 & - & - & - & - & 1 & 0 & --- & 37 & 75 & --- & $\begin{array}{r}--- \\
288\end{array}$ & 1 \\
\hline
\end{tabular}




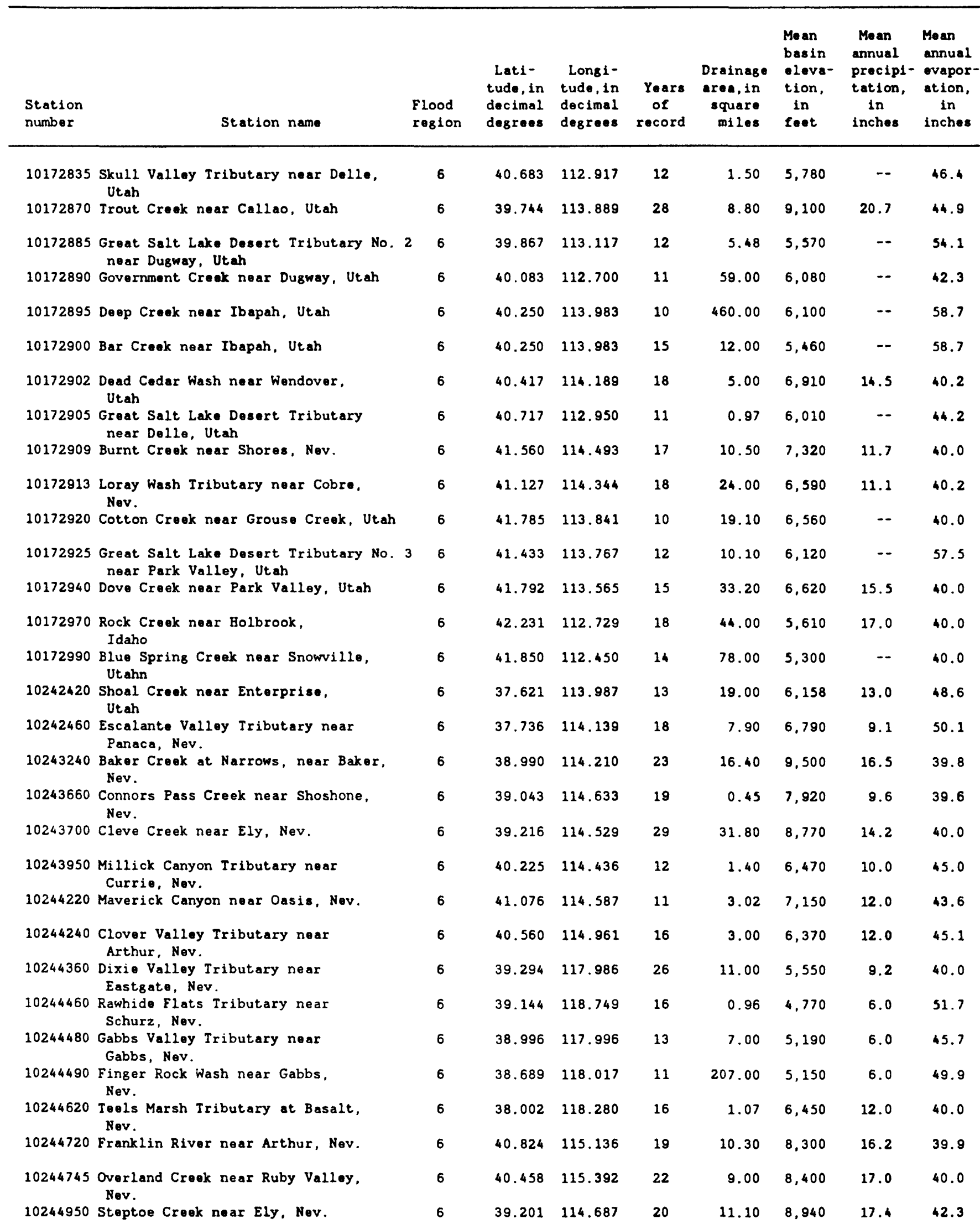




\begin{tabular}{|c|c|c|c|c|c|c|c|c|c|c|c|c|}
\hline \multirow{2}{*}{$\begin{array}{l}\text { Station } \\
\text { number }\end{array}$} & \multicolumn{5}{|c|}{$\begin{array}{c}\text { Relation } \\
\text { characteristic }\end{array}$} & \multicolumn{3}{|c|}{$\begin{array}{l}\text { Poak discharse (cublc } \\
\text { indicated recurrence }\end{array}$} & \multicolumn{3}{|c|}{$\begin{array}{l}\text { loot por second) for } \\
\text { (ntervel (rears) }\end{array}$} & \multirow{2}{*}{$\begin{array}{l}\text { Maxime } \\
\text { poak discherse } \\
\text { of record } \\
\text { (cublc leet } \\
\text { por second) }\end{array}$} \\
\hline & L & $\mathbf{B}$ & D & 0 & U & 2 & 5 & 10 & 25 & 50 & 100 & \\
\hline 10172835 & - & - & - & - & 1 & $-\cdots$ & $\ldots$ & --- & --- & $-\cdots$ & --- & 20 \\
\hline & & & & & & 0 & 14 & 46 & 103 & 173 & 435 & \\
\hline 10172870 & 1 & 0 & 0 & 0 & 0 & $\begin{array}{l}50 \\
45\end{array}$ & $\begin{array}{l}89 \\
88\end{array}$ & $\begin{array}{l}119 \\
118\end{array}$ & $\begin{array}{l}163 \\
158\end{array}$ & $\begin{array}{l}199 \\
199\end{array}$ & $\begin{array}{l}238 \\
242\end{array}$ & 177 \\
\hline 10172885 & - & - & - & - & 1 & 0 & 40 & 109 & 249 & 427 & 917 & 1,720 \\
\hline 10172890 & - & - & - & - & 1 & 0 & 254 & 412 & 905 & 1,630 & 2,520 & 370 \\
\hline 10172895 & - & - & - & - & 1 & 0 & 1,310 & 1,460 & 3,210 & 6,020 & 7,130 & 1,250 \\
\hline 10172800 & 1 & 1 & 0 & 0 & 0 & $\begin{array}{l}73 \\
61\end{array}$ & $\begin{array}{l}368 \\
364\end{array}$ & $\begin{array}{l}850 \\
818\end{array}$ & $\begin{array}{l}2,060 \\
1,830\end{array}$ & $\begin{array}{l}3,650 \\
3,350\end{array}$ & $\begin{array}{l}6,070 \\
5,840\end{array}$ & 2,690 \\
\hline 10172902 & - & - & - & - & 1 & 0 & 32 & 73 & 150 & 256 & 533 & 752 \\
\hline 10172905 & - & - & - & - & 1 & 0 & 10 & 33 & 73 & 120 & 318 & 80 \\
\hline 10172909 & - & - & - & - & 1 & 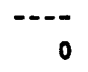 & 56 & 105 & 210 & 365 & 681 & 35 \\
\hline 10172913 & - & - & - & - & 1 & 0 & 117 & 207 & 438 & 773 & 1,320 & 220 \\
\hline 10172920 & - & - & - & - & 1 & 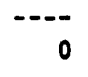 & --- & $\overline{181}$ & ---- & ---- & 1,190 & 91 \\
\hline 10172925 & - & - & - & - & 1 & 0 & 62 & --- & 299 & 519 & 1,010 & 420 \\
\hline 10172940 & - & - & - & - & 1 & 0 & 151 & 252 & 530 & 942 & 1.550 & 275 \\
\hline 10172970 & 0 & 0 & 0 & 0 & 0 & $\begin{array}{l}182 \\
156\end{array}$ & $\begin{array}{l}610 \\
605\end{array}$ & $\begin{array}{l}1,160 \\
1,130\end{array}$ & $\begin{array}{l}2,340 \\
2,160\end{array}$ & $\begin{array}{l}3,680 \\
3,500\end{array}$ & $\begin{array}{r}5,570 \\
5,450\end{array}$ & 1,580 \\
\hline 10172990 & 1 & 1 & 0 & 0 & 0 & $\begin{array}{r}110 \\
91\end{array}$ & $\begin{array}{l}350 \\
350\end{array}$ & $\begin{array}{l}661 \\
658\end{array}$ & $\begin{array}{l}1,330 \\
1,350\end{array}$ & $\begin{array}{l}2,120 \\
2,170\end{array}$ & $\begin{array}{l}3,240 \\
3,280\end{array}$ & 1,820 \\
\hline 10242420 & 0 & 0 & 0 & 0 & 0 & $\begin{array}{l}40 \\
32\end{array}$ & $\begin{array}{l}108 \\
108\end{array}$ & $\begin{array}{l}185 \\
186\end{array}$ & $\begin{array}{l}335 \\
352\end{array}$ & $\begin{array}{l}497 \\
529\end{array}$ & $\begin{array}{l}713 \\
751\end{array}$ & 390 \\
\hline 10242460 & 1 & 0 & 0 & 0 & 0 & $\begin{array}{l}32 \\
28\end{array}$ & $\begin{array}{l}96 \\
95\end{array}$ & $\begin{array}{l}167 \\
164\end{array}$ & $\begin{array}{l}300 \\
289\end{array}$ & $\begin{array}{l}434 \\
427\end{array}$ & $\begin{array}{l}604 \\
608\end{array}$ & 250 \\
\hline 10243240 & 0 & 1 & 0 & 0 & 0 & $\begin{array}{l}70 \\
62\end{array}$ & $\begin{array}{l}129 \\
128\end{array}$ & $\begin{array}{l}177 \\
174\end{array}$ & $\begin{array}{l}247 \\
238\end{array}$ & $\begin{array}{l}306 \\
304\end{array}$ & $\begin{array}{l}370 \\
373\end{array}$ & 400 \\
\hline 10243660 & - & - & - & - & 1 & --- & --- & --- & 25 & 41 & 114 & 2 \\
\hline 10243700 & 0 & 1 & 0 & 0 & 0 & $\begin{array}{l}45 \\
40\end{array}$ & $\begin{array}{l}88 \\
89\end{array}$ & $\begin{array}{l}130 \\
131\end{array}$ & $\begin{array}{l}201 \\
208\end{array}$ & $\begin{array}{l}270 \\
284\end{array}$ & $\begin{array}{l}356 \\
368\end{array}$ & 440 \\
\hline 10243850 & - & - & - & - & 1 & 0 & 12 & 37 & 78 & 130 & 324 & 83 \\
\hline 10244220 & - & - & - & - & 1 & 0 & 21 & 50 & 102 & ---- & 381 & 0 \\
\hline 10244240 & 1 & 0 & 0 & 0 & 0 & $\begin{array}{l}6 \\
5\end{array}$ & $\begin{array}{l}18 \\
18\end{array}$ & $\begin{array}{l}30 \\
31\end{array}$ & $\begin{array}{l}52 \\
62\end{array}$ & $\begin{array}{l}73 \\
87\end{array}$ & $\begin{array}{r}98 \\
117\end{array}$ & 43 \\
\hline 10244360 & 1 & 0 & 1 & 0 & 0 & $\begin{array}{r}10 \\
8\end{array}$ & $\begin{array}{l}81 \\
81\end{array}$ & $\begin{array}{l}245 \\
243\end{array}$ & $\begin{array}{l}815 \\
777\end{array}$ & $\begin{array}{l}1,800 \\
1,730\end{array}$ & $\begin{array}{l}3,690 \\
3,620\end{array}$ & 1,480 \\
\hline 10244460 & - & - & - & - & 1 & 0 & 11 & 47 & 117 & 194 & 539 & 52 \\
\hline 10244480 & - & - & - & - & 1 & 0 & 51 & 141 & 337 & 580 & 1,220 & 860 \\
\hline 10244490 & - & - & - & - & 1 & 0 & 773 & 1,170 & 2,700 & 5,150 & 7,000 & 2,430 \\
\hline 10244620 & - & - & - & - & 1 & 0 & 10 & 31 & ---- & 110 & 284 & 110 \\
\hline 10244720 & 1 & 0 & 0 & 0 & 0 & $\begin{array}{r}105 \\
91\end{array}$ & $\begin{array}{l}142 \\
141\end{array}$ & $\begin{array}{l}167 \\
164\end{array}$ & $\begin{array}{l}198 \\
194\end{array}$ & $\begin{array}{l}221 \\
226\end{array}$ & $\begin{array}{l}243 \\
253\end{array}$ & 197 \\
\hline 10244745 & 1 & 0 & 0 & 0 & 0 & $\begin{array}{r}109 \\
96\end{array}$ & $\begin{array}{l}148 \\
148\end{array}$ & $\begin{array}{l}175 \\
172\end{array}$ & $\begin{array}{l}208 \\
201\end{array}$ & $\begin{array}{l}233 \\
234\end{array}$ & $\begin{array}{l}259 \\
266\end{array}$ & 225 \\
\hline 10244950 & 0 & 0 & 1 & 0 & 0 & $\begin{array}{l}24 \\
21\end{array}$ & $\begin{array}{l}42 \\
42\end{array}$ & $\begin{array}{l}57 \\
58\end{array}$ & $\begin{array}{l}79 \\
86\end{array}$ & $\begin{array}{r}97 \\
109\end{array}$ & $\begin{array}{l}117 \\
129\end{array}$ & 85 \\
\hline
\end{tabular}




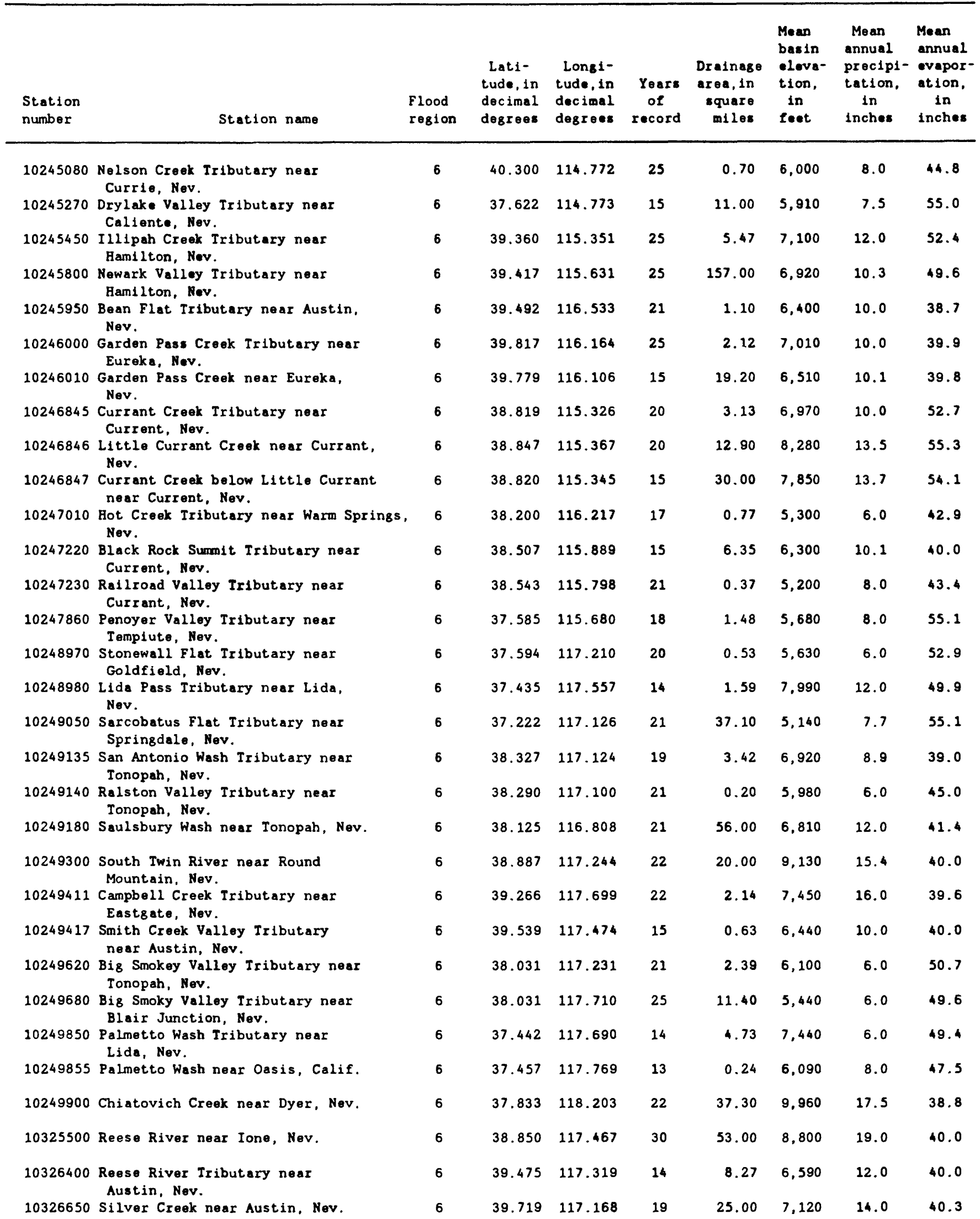




\begin{tabular}{|c|c|c|c|c|c|c|c|c|c|c|c|c|}
\hline \multirow{2}{*}{$\begin{array}{l}\text { Station } \\
\text { number }\end{array}$} & \multicolumn{5}{|c|}{$\begin{array}{c}\text { Relation } \\
\text { characteristic }\end{array}$} & \multicolumn{6}{|c|}{$\begin{array}{l}\text { Peak discharge (cublc foet per second) for } \\
\text { indicated recurrence interval (years) }\end{array}$} & \multirow{2}{*}{$\begin{array}{l}\text { Maximum } \\
\text { peak discharge } \\
\text { of record } \\
\text { (cubic foet } \\
\text { per socond) }\end{array}$} \\
\hline & $L$ & H & $D$ & 0 & U & 2 & 5 & 10 & 25 & 50 & 100 & \\
\hline 10245080 & - & - & - & - & 1 & --- & 7 & 27 & 60 & --- & 271 & 52 \\
\hline 10245270 & - & - & - & - & 1 & 0 & 67 & 152 & 339 & 589 & 1,140 & 156 \\
\hline 10245450 & 1 & 1 & 1 & 0 & 0 & $\begin{array}{l}11 \\
10\end{array}$ & $\begin{array}{l}54 \\
54\end{array}$ & $\begin{array}{l}130 \\
128\end{array}$ & $\begin{array}{l}349 \\
331\end{array}$ & $\begin{array}{l}673 \\
646\end{array}$ & $\begin{array}{l}1,230 \\
1,210\end{array}$ & 1,120 \\
\hline 10245800 & 0 & 0 & 1 & 0 & 0 & $\begin{array}{l}29 \\
26\end{array}$ & $\begin{array}{l}114 \\
118\end{array}$ & $\begin{array}{l}228 \\
239\end{array}$ & $\begin{array}{l}667 \\
540\end{array}$ & $\begin{array}{l}734 \\
838\end{array}$ & $\begin{array}{l}1,090 \\
1,150\end{array}$ & 291 \\
\hline 10245950 & - & - & - & - & 1 & 0 & 10 & 32 & 69 & 114 & 294 & 21 \\
\hline 10246000 & - & - & - & - & 1 & 0 & 16 & 42 & 85 & 164 & 333 & 190 \\
\hline 10246010 & 1 & 0 & 1 & 0 & 0 & $\begin{array}{l}21 \\
18\end{array}$ & $\begin{array}{l}113 \\
113\end{array}$ & $\begin{array}{l}265 \\
261\end{array}$ & $\begin{array}{l}648 \\
611\end{array}$ & $\begin{array}{l}1,140 \\
1.090\end{array}$ & $\begin{array}{l}1,900 \\
1,870\end{array}$ & 650 \\
\hline 10246845 & 1 & 0 & 1 & 0 & 0 & $\begin{array}{l}3 \\
2\end{array}$ & $\begin{array}{l}14 \\
14\end{array}$ & $\begin{array}{l}33 \\
34\end{array}$ & $\begin{array}{l}85 \\
88\end{array}$ & $\begin{array}{l}159 \\
161\end{array}$ & $\begin{array}{l}281 \\
286\end{array}$ & 99 \\
\hline 10246846 & 0 & 1 & 0 & 0 & 0 & $\begin{array}{l}21 \\
18\end{array}$ & $\begin{array}{l}59 \\
59\end{array}$ & $\begin{array}{l}104 \\
104\end{array}$ & $\begin{array}{l}190 \\
189\end{array}$ & $\begin{array}{l}283 \\
286\end{array}$ & $\begin{array}{l}406 \\
412\end{array}$ & 366 \\
\hline 10246847 & 1 & 0 & 0 & 0 & 0 & $\begin{array}{l}19 \\
16\end{array}$ & $\begin{array}{l}77 \\
78\end{array}$ & $\begin{array}{l}163 \\
164\end{array}$ & $\begin{array}{l}371 \\
368\end{array}$ & $\begin{array}{l}636 \\
634\end{array}$ & $\begin{array}{l}1,040 \\
1,040\end{array}$ & 604 \\
\hline 10247010 & - & - & - & - & 1 & 0 & 9 & 35 & 82 & 135 & 378 & 100 \\
\hline 10247220 & - & - & - & - & 1 & 0 & 42 & 98 & 211 & 363 & 745 & 200 \\
\hline 10247230 & - & - & - & - & 1 & 0 & 5 & 23 & 54 & 88 & 272 & 10 \\
\hline 10247860 & - & - & - & - & 1 & 0 & 14 & 67 & 106 & 177 & 450 & 130 \\
\hline 10248970 & - & - & - & - & 1 & 0 & 6 & 25 & 57 & 94 & 272 & 150 \\
\hline 10248980 & - & - & - & - & 1 & 0 & 12 & 28 & 54 & 91 & 213 & 1 \\
\hline 10249050 & 1 & 0 & 0 & 0 & 0 & $\begin{array}{l}3 \\
2\end{array}$ & $\begin{array}{l}16 \\
18\end{array}$ & $\begin{array}{l}39 \\
51\end{array}$ & $\begin{array}{r}91 \\
185\end{array}$ & $\begin{array}{l}154 \\
274\end{array}$ & $\begin{array}{l}242 \\
339\end{array}$ & 63 \\
\hline 10249135 & - & - & - & - & 1 & 0 & 24 & 57 & 118 & 200 & 438 & 660 \\
\hline 10249140 & - & - & - & - & 1 & 0 & 3 & 12 & 28 & 44 & 144 & 48 \\
\hline 10249180 & - & - & - & - & 1 & 0 & 226 & 332 & 691 & 1.240 & 1,890 & 340 \\
\hline 10249300 & 0 & 1 & 0 & 0 & 0 & $\begin{array}{l}42 \\
37\end{array}$ & $\begin{array}{l}96 \\
96\end{array}$ & $\begin{array}{l}153 \\
152\end{array}$ & $\begin{array}{l}256 \\
250\end{array}$ & $\begin{array}{l}364 \\
363\end{array}$ & $\begin{array}{l}504 \\
506\end{array}$ & 510 \\
\hline 10249411 & 0 & 0 & 1 & 0 & 0 & $\begin{array}{l}2 \\
2\end{array}$ & $\begin{array}{l}10 \\
10\end{array}$ & $\begin{array}{l}25 \\
25\end{array}$ & $\begin{array}{l}71 \\
71\end{array}$ & $\begin{array}{l}143 \\
142\end{array}$ & $\begin{array}{l}276 \\
277\end{array}$ & 179 \\
\hline 10249417 & - & - & - & - & 1 & 0 & 6 & 23 & 48 & 79 & 218 & 130 \\
\hline 10249620 & - & - & - & - & 1 & 0 & 19 & 56 & 123 & 208 & 487 & 10 \\
\hline 10249680 & - & - & - & - & 1 & 0 & 73 & 177 & 413 & 718 & 1,410 & 460 \\
\hline 10249850 & - & - & - & - & 1 & 0 & 29 & 62 & 124 & 212 & 437 & 193 \\
\hline 10249855 & - & - & - & - & 1 & 0 & 3 & 14 & 30 & 48 & --- & 30 \\
\hline 10249900 & 1 & 1 & 0 & 0 & 0 & $\begin{array}{l}24 \\
22\end{array}$ & $\begin{array}{l}55 \\
55\end{array}$ & $\begin{array}{l}87 \\
89\end{array}$ & $\begin{array}{l}149 \\
159\end{array}$ & $\begin{array}{l}216 \\
232\end{array}$ & $\begin{array}{l}306 \\
318\end{array}$ & 527 \\
\hline 10325500 & 0 & 0 & 0 & 0 & 0 & $\begin{array}{l}79 \\
71\end{array}$ & $\begin{array}{l}216 \\
216\end{array}$ & $\begin{array}{l}369 \\
365\end{array}$ & $\begin{array}{l}659 \\
638\end{array}$ & $\begin{array}{l}961 \\
947\end{array}$ & $\begin{array}{l}1,350 \\
1,340\end{array}$ & 1,000 \\
\hline 10326400 & - & - & - & - & 1 & 0 & so & 107 & 226 & 391 & 768 & 80 \\
\hline 10326650 & 0 & 0 & 1 & 0 & 0 & $\begin{array}{l}6 \\
5\end{array}$ & $\begin{array}{l}26 \\
27\end{array}$ & $\begin{array}{l}53 \\
58\end{array}$ & $\begin{array}{l}111 \\
143\end{array}$ & $\begin{array}{l}175 \\
217\end{array}$ & $\begin{array}{l}258 \\
293\end{array}$ & 52 \\
\hline
\end{tabular}




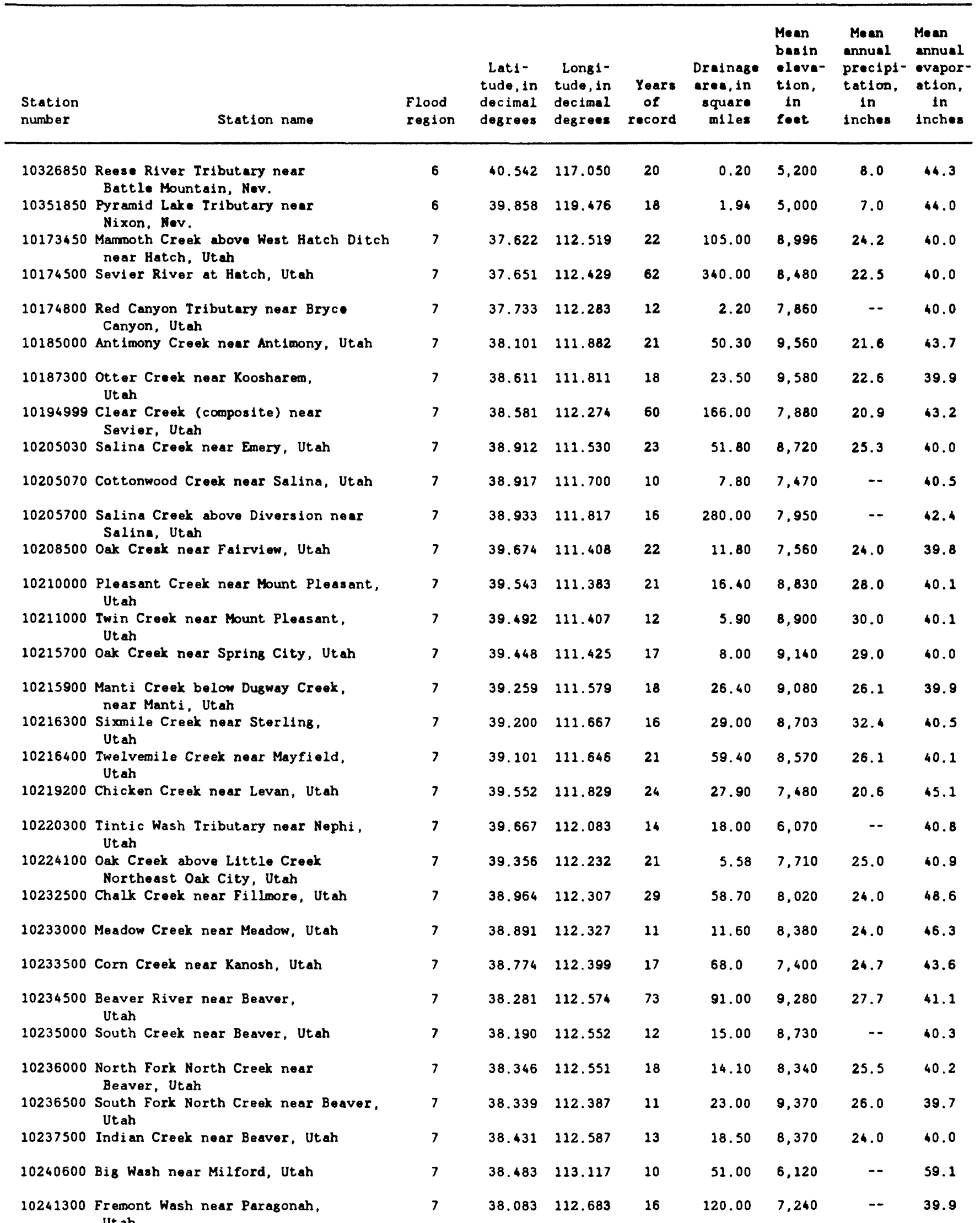




\begin{tabular}{|c|c|c|c|c|c|c|c|c|c|c|c|c|}
\hline \multirow[b]{2}{*}{$\begin{array}{l}\text { Station } \\
\text { number }\end{array}$} & \multicolumn{5}{|c|}{$\begin{array}{c}\text { Relation } \\
\text { characteristic }\end{array}$} & \multicolumn{3}{|c|}{$\begin{array}{r}\text { Peak discharge (cubic } \\
\text { indicated recurrence }\end{array}$} & \multicolumn{3}{|c|}{$\begin{array}{l}\text { Eet per second) lor } \\
\text { nterval (years) }\end{array}$} & \multirow{2}{*}{$\begin{array}{l}\text { Maximum } \\
\text { peak discharge } \\
\text { of record } \\
\text { (cubic leet } \\
\text { per second) }\end{array}$} \\
\hline & $\frac{c h}{L}$ & $\frac{\operatorname{ara}}{8}$ & $\frac{\text { cte }}{D}$ & $\frac{r 18 t}{0}$ & $\frac{\operatorname{tic}}{U}$ & 2 & 5 & 10 & 25 & 50 & 100 & \\
\hline \multirow[t]{2}{*}{10326850} & 0 & 0 & 0 & 0 & 0 & 1 & 6 & 13 & 31 & 54 & 89 & 26 \\
\hline & & & & & & 1 & 6 & 13 & 32 & 54 & 93 & \\
\hline \multirow[t]{2}{*}{10351850} & - & - & - & - & 1 & $\ldots$ & $\cdots$ & $\cdots$ & $\cdots$ & $\ldots$ & $\ldots$ & 950 \\
\hline & & & & & & 0 & 19 & 68 & 164 & 276 & 692 & \\
\hline \multirow[t]{2}{*}{10173450} & 1 & 0 & 0 & 0 & 0 & 451 & 573 & 651 & 748 & 819 & 889 & 838 \\
\hline & & & & & & 450 & 576 & 670 & 782 & 878 & 975 & \\
\hline \multirow[t]{2}{*}{10174500} & 1 & 0 & 0 & 0 & 0 & 629 & 900 & 1,090 & 1,330 & 1,510 & 1,700 & 3,000 \\
\hline & & & & & & 629 & 905 & 1,100 & 1,350 & 1,530 & 1,720 & \\
\hline \multirow[t]{2}{*}{10174800} & - & - & - & - & 1 & $\cdots$ & $\cdots$ & $\ldots$ & $\cdots$ & $\cdots$ & $\cdots$ & 365 \\
\hline & & & & & & 18 & 47 & 82 & 173 & 249 & 346 & \\
\hline \multirow[t]{2}{*}{10185000} & 1 & 0 & 0 & 0 & 0 & 250 & 383 & 481 & 615 & 722 & 834 & 669 \\
\hline & & & & & & 250 & 389 & 498 & 627 & 746 & 873 & \\
\hline 10187300 & 1 & 0 & 0 & 1 & 0 & 58 & 77 & 89 & 104 & 115 & 127 & 117 \\
\hline & & & & & & 60 & 95 & 136 & 182 & 231 & 284 & \\
\hline 10194999 & 1 & 0 & 0 & 0 & 0 & 236 & 385 & 497 & 654 & 782 & 918 & 769 \\
\hline & & & & & & 237 & 391 & 512 & 690 & 827 & 971 & \\
\hline 10205030 & 1 & 0 & 0 & 0 & 0 & 193 & 355 & 490 & 691 & 865 & 1,060 & 621 \\
\hline & & & & & & 193 & 357 & 494 & 691 & 863 & 1.050 & \\
\hline 10205070 & 1 & 1 & 0 & 0 & 0 & 27 & 101 & 208 & 459 & 776 & 1,260 & 457 \\
\hline & & & & & & 27 & 99 & 193 & 409 & 649 & 997 & \\
\hline 10205700 & 1 & 1 & 0 & 0 & 0 & 556 & 930 & 1.250 & 1,730 & 2,160 & 2,650 & 2,300 \\
\hline & & & & & & 556 & 923 & 1,220 & 1,670 & 2,030 & 2,440 & \\
\hline 10208500 & 1 & 1 & 0 & 0 & 0 & 166 & 306 & 435 & 648 & 850 & 1,100 & 1,190 \\
\hline & & & & & & 165 & 296 & 410 & 598 & 778 & 1.000 & \\
\hline 10210000 & 0 & 1 & 0 & 0 & 0 & 158 & 332 & 510 & 836 & 1,170 & 1,610 & 2,060 \\
\hline & & & & & & 157 & 323 & 482 & 761 & 1,050 & 1,410 & \\
\hline 10211000 & 0 & 1 & 0 & 0 & 0 & 67 & 132 & 194 & 300 & 402 & 529 & 488 \\
\hline & & & & & & 67 & 130 & 190 & 291 & 391 & 515 & \\
\hline 10215700 & 0 & 0 & 0 & 0 & 0 & 115 & 177 & 221 & 281 & 328 & 377 & 300 \\
\hline & & & & & & 114 & 174 & 220 & 286 & 348 & 418 & \\
\hline 10215900 & 1 & 0 & 0 & 0 & 0 & 367 & 465 & 531 & 617 & 681 & 747 & 682 \\
\hline & & & & & & 364 & 450 & 511 & 596 & 675 & 763 & \\
\hline 10216300 & 0 & 0 & 1 & 0 & 0 & 220 & 428 & 617 & 921 & 1,200 & 1,530 & 1,050 \\
\hline & & & & & & 219 & 414 & 580 & 835 & 1.070 & 1,350 & \\
\hline 10216400 & 0 & 1 & 1 & 0 & 0 & 264 & 469 & 648 & 931 & 1,190 & 1,490 & 1,350 \\
\hline & & & & & & 264 & 464 & 635 & 896 & 1.130 & 1,400 & \\
\hline 10219200 & 0 & 0 & 1 & 0 & 0 & 69 & 176 & 285 & 472 & 653 & 872 & 390 \\
\hline & & & & & & 70 & 177 & 285 & 481 & 656 & 864 & \\
\hline 10220300 & 1 & 1 & 0 & 0 & 0 & 63 & 160 & 262 & 445 & 630 & 864 & 545 \\
\hline & & & & & & 63 & 153 & 243 & 443 & 612 & 821 & \\
\hline 10224100 & 1 & 0 & 0 & 0 & 0 & 26 & 54 & 78 & 116 & 149 & 187 & 120 \\
\hline & & & & & & 27 & 56 & 85 & 142 & 191 & 249 & \\
\hline 10232500 & 0 & 1 & 0 & 0 & 0 & 237 & 425 & 587 & 838 & 1,060 & 1,320 & 1,850 \\
\hline & & & & & & 237 & 421 & 577 & 823 & 1,040 & 1,280 & \\
\hline 10233000 & 1 & 1 & 0 & 0 & 0 & 59 & 99 & 131 & 178 & 218 & 263 & 198 \\
\hline & & & & & & 59 & 105 & 151 & 231 & 302 & 382 & \\
\hline 10233500 & 1 & 0 & 0 & 0 & 0 & 145 & 352 & 571 & 974 & 1,390 & 1,920 & 1,350 \\
\hline & & & & & & 145 & 349 & 552 & 933 & 1,290 & 1,720 & \\
\hline 10234500 & 0 & 0 & 1 & 0 & 0 & 376 & 634 & 811 & 1.030 & 1,200 & 1,350 & 1,080 \\
\hline & & & & & & 376 & 634 & 810 & 1,020 & 1,190 & 1,340 & \\
\hline 10235000 & 0 & 0 & 0 & 0 & 0 & 31 & 78 & 130 & 228 & 330 & 464 & 200 \\
\hline & & & & & & 32 & 90 & 159 & 276 & 390 & 530 & \\
\hline 10236000 & 1 & 0 & 0 & 0 & 0 & 39 & 75 & 106 & 156 & 200 & 252 & 198 \\
\hline & & & & & & 40 & 82 & 126 & 204 & 271 & 349 & \\
\hline 10236500 & 0 & 0 & 0 & 0 & 0 & 164 & 460 & 801 & 1.470 & 2,190 & 3,150 & 1,550 \\
\hline & & & & & & 164 & 438 & 711 & 1.180 & 1.680 & 2,340 & \\
\hline 10237500 & 1 & 1 & 0 & 0 & 0 & 28 & 69 & 115 & 203 & 298 & 426 & 311 \\
\hline & & & & & & 29 & 82 & 147 & 265 & 377 & 515 & \\
\hline 10240600 & 1 & 0 & 0 & 0 & 0 & 168 & 331 & 468 & 671 & 844 & 1,030 & 520 \\
\hline & & & & & & 166 & 310 & 422 & 676 & 845 & 1,030 & \\
\hline 10241300 & 1 & 0 & 1 & 0 & 0 & 105 & 200 & 276 & 384 & 472 & 567 & 282 \\
\hline & & & & & & 107 & 219 & 325 & 522 & 648 & 777 & \\
\hline
\end{tabular}




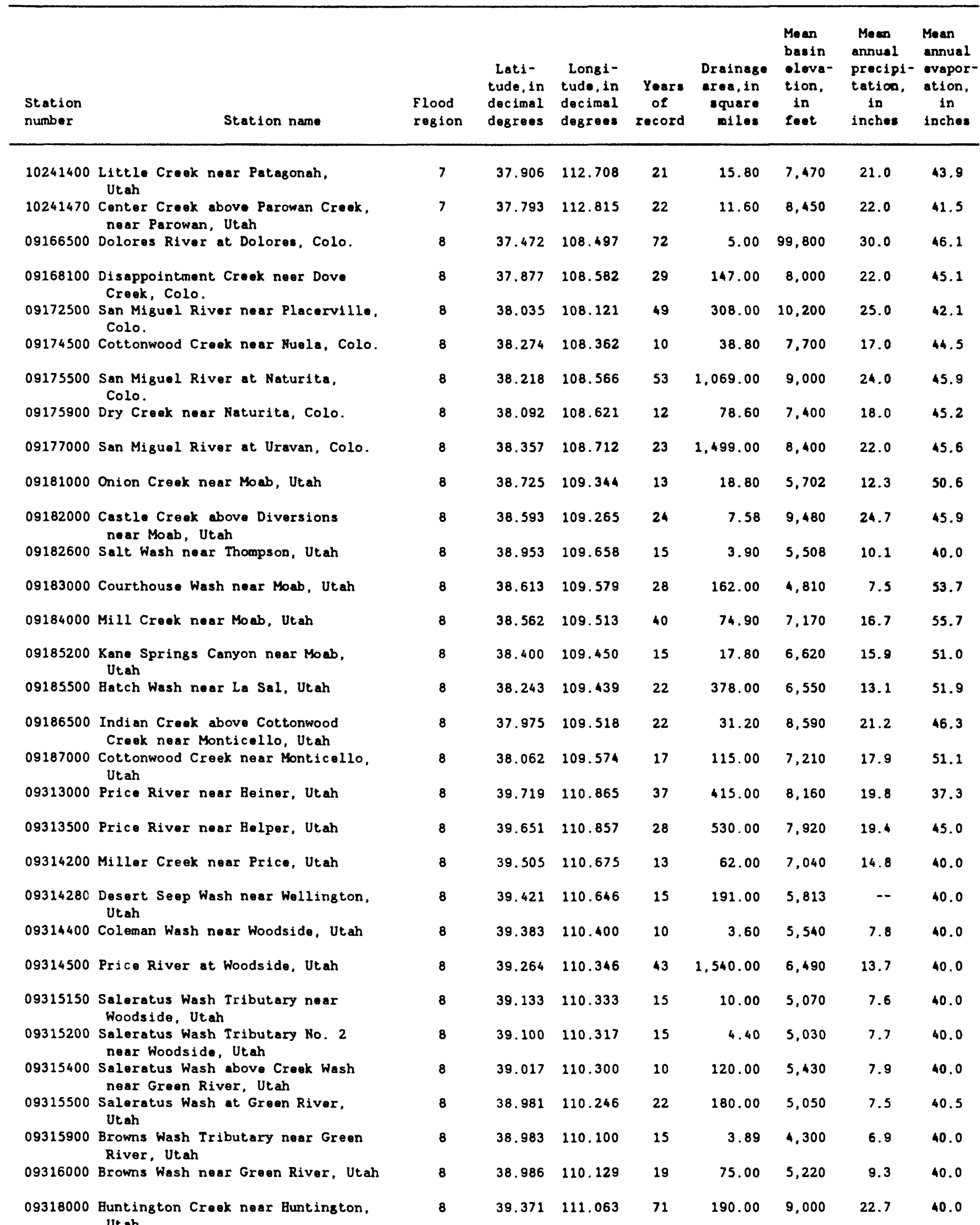




\begin{tabular}{|c|c|c|c|c|c|c|c|c|c|c|c|c|}
\hline \multirow{2}{*}{$\begin{array}{l}\text { Station } \\
\text { number }\end{array}$} & \multicolumn{5}{|c|}{$\begin{array}{c}\text { Relation } \\
\text { characteristic }\end{array}$} & \multicolumn{6}{|c|}{$\begin{array}{l}\text { Peak discharge (cublc feet per second) for } \\
\text { indicated recurrence interval (years) }\end{array}$} & \multirow{2}{*}{$\begin{array}{l}\text { Maximum } \\
\text { peak discharse } \\
\text { of record } \\
\text { (cubic feet } \\
\text { per second) }\end{array}$} \\
\hline & $\mathrm{L}$ & H & D & 0 & $\mathrm{U}$ & 2 & 5 & 10 & 25 & 50 & 100 & \\
\hline \multirow[t]{2}{*}{10241400} & 1 & 0 & 1 & 0 & 0 & 37 & 134 & 261 & 531 & 839 & 1,270 & 351 \\
\hline & & & & & & 37 & 134 & 255 & 509 & 778 & 1.150 & \\
\hline \multirow[t]{2}{*}{10241470} & 0 & 0 & 0 & 0 & 0 & 55 & 137 & 225 & 391 & 565 & 791 & 353 \\
\hline & & & & & & 55 & 138 & 225 & 385 & 548 & 755 & \\
\hline \multirow[t]{2}{*}{09166500} & 1 & 0 & 0 & 0 & 0 & 3,400 & 5,100 & 6,270 & 7,790 & 8,850 & 10.100 & 10,000 \\
\hline & & & & & & 3,390 & 5,050 & 6,150 & 7.540 & 8,620 & 9,680 & \\
\hline \multirow[t]{2}{*}{09168100} & 0 & 0 & 0 & 0 & 0 & 1,180 & 2,570 & 3,800 & 6,120 & 8,220 & 10,800 & 8,140 \\
\hline & & & & & & 1,180 & 2.530 & 3,770 & 5.710 & 7,470 & 9,540 & \\
\hline \multirow[t]{2}{*}{09172500} & 0 & 1 & 0 & 0 & 0 & 1,370 & 1,950 & 2,330 & 2,810 & 3,160 & 3.520 & 10,000 \\
\hline & & & & & & 1,370 & 1.950 & 2,330 & 2,860 & 3,300 & 3.760 & \\
\hline \multirow[t]{2}{*}{09174500} & 0 & 0 & 0 & 1 & 0 & 123 & 236 & 327 & 458 & 564 & 678 & 321 \\
\hline & & & & & & 135 & 326 & 577 & 1.070 & 1,550 & 2.090 & \\
\hline \multirow[t]{2}{*}{09175500} & 1 & 0 & 1 & 0 & 0 & 2.770 & 4,450 & 5,620 & 7,160 & 8,320 & 9,500 & 7,100 \\
\hline & & & & & & 2.770 & 4,430 & 5,580 & 7,110 & 8,310 & 9,550 & \\
\hline 09175900 & - & - & - & - & 1 & $\cdots$ & $\cdots$ & $-\cdots$ & --- & $-\cdots$ & --- & 5,660 \\
\hline & & & & & & 691 & 1,440 & 2,060 & 3,090 & 4,030 & 5,010 & \\
\hline 09177000 & 0 & 0 & 0 & 0 & 0 & 3,710 & 5.670 & 7.000 & 8,700 & 9,970 & 11,200 & 8,810 \\
\hline & & & & & & 3.690 & 5,610 & 6.890 & 8,640 & 10.100 & 11,600 & \\
\hline 09181000 & 1 & 1 & 0 & 0 & 0 & 935 & 1.280 & 1,520 & 1.840 & 2.100 & 2,360 & 2,100 \\
\hline & & & & & & 921 & 1.260 & 1,540 & 2,050 & 2,590 & 3,220 & \\
\hline 09182000 & 1 & 0 & 1 & 1 & 0 & 10 & 18 & 26 & 36 & 45 & 55 & 27 \\
\hline & & & & & & 12 & 37 & 81 & 184 & 296 & 430 & \\
\hline 09182600 & 0 & 0 & 0 & 0 & 0 & 275 & 723 & 1,190 & 2,000 & 2,780 & 3,740 & 1,380 \\
\hline & & & & & & 273 & 708 & 1,140 & 1.850 & 2,510 & 3,300 & \\
\hline 09183000 & 0 & 0 & 1 & 0 & 0 & 2,200 & 4,670 & 7.060 & 11,100 & 15,000 & 19,800 & 12,300 \\
\hline & & & & & & 2,190 & 4,610 & 6,880 & 10,600 & 14,000 & 18,100 & \\
\hline 09184000 & 0 & 0 & 0 & 0 & 0 & 694 & 1,830 & 3.080 & 5,410 & 7.840 & 11.000 & 5,110 \\
\hline & & & & & & 694 & 1.820 & 3,020 & 5,140 & 7,260 & 9,900 & \\
\hline 09185200 & 1 & 0 & 0 & 0 & 0 & 540 & 829 & 1.040 & 1,330 & 1.550 & 1,790 & 1,290 \\
\hline & & & & & & 536 & 831 & 1.080 & 1,510 & 1.920 & 2,410 & \\
\hline 09185500 & 1 & 0 & 0 & 0 & 0 & 503 & 1,200 & 1.920 & 3,250 & 4,600 & 6,340 & 4,650 \\
\hline & & & & & & 523 & 1,330 & 2.250 & 3.990 & 5,700 & 7.720 & \\
\hline 09186500 & 0 & 1 & 0 & 0 & 0 & 134 & 381 & 683 & 1,310 & 2,020 & 3,020 & 2,330 \\
\hline & & & & & & 138 & 404 & 735 & 1,390 & 2,070 & 2.950 & \\
\hline 09187000 & 0 & 0 & 1 & 0 & 0 & 390 & 1.270 & 2,330 & 4,410 & 6,640 & 9,570 & 2,200 \\
\hline & & & & & & 400 & 1,310 & 2.360 & 4,250 & 6,100 & 8,320 & \\
\hline 09313000 & 0 & 1 & 0 & 0 & 0 & 1.140 & 2,170 & 3.140 & 4.750 & 6,290 & 8,170 & 9.340 \\
\hline & & & & & & 1,140 & 2,190 & 3,180 & 4.810 & 6,350 & 8,140 & \\
\hline 09313500 & 0 & 0 & 0 & 0 & 0 & 1.880 & 3.990 & 5.950 & 9,160 & 12,100 & 15,600 & 12,000 \\
\hline & & & & & & 1,880 & 3,950 & 5,790 & 8,650 & 11,200 & 14.000 & \\
\hline 09314200 & 0 & 0 & 0 & 0 & 0 & 1,430 & 3,410 & 5,230 & 8,100 & 10,600 & 13,500 & 5,000 \\
\hline & & & & & & 1.410 & 3,220 & 4,640 & 6.600 & 8,180 & 9,940 & \\
\hline 09314280 & 1 & 1 & 0 & 1 & 0 & 534 & 860 & 1,130 & 1,530 & 1,870 & 2,270 & 2,060 \\
\hline & & & & & & 554 & 1.030 & 1,630 & 2,810 & 3,990 & 5,330 & \\
\hline 09314400 & 0 & 0 & 0 & 0 & 0 & 256 & 608 & 944 & 1,500 & 2,010 & 2,610 & 1.040 \\
\hline & & & & & & 254 & 598 & 919 & 1.460 & 1,960 & 2,550 & \\
\hline 09314500 & 1 & 0 & 1 & 0 & 0 & 4,540 & 6,480 & 7.750 & 9,320 & 10,500 & 11,600 & 9,720 \\
\hline & & & & & & 4,530 & 6,480 & 7,810 & 9,670 & 11,300 & 12,900 & \\
\hline 09315150 & 0 & 0 & 1 & 0 & 0 & 805 & 2.240 & 3.820 & 6,700 & 9,630 & 13,300 & 5,340 \\
\hline & & & & & & 794 & 2,130 & 3,440 & 5,550 & 7,500 & 9,820 & \\
\hline 09315200 & 1 & 0 & 1 & 0 & 0 & 1.060 & 2,420 & 3,630 & 5,490 & 7,110 & 8,910 & 3,720 \\
\hline & & & & & & 1,040 & 2,270 & 3,210 & 4,490 & 5,540 & 6,700 & \\
\hline 09315400 & - & - & - & - & 1 & --- & --- & --- & --- & --- & --- & 19.500 \\
\hline & & & & & & 1.170 & 2,580 & 3.800 & 5,810 & 7.650 & 9.610 & \\
\hline 09315500 & 1 & 1 & 0 & 0 & 0 & 2,490 & 4.560 & 6,390 & 9.320 & 12,000 & 15,200 & 14,200 \\
\hline & & & & & & 2,470 & 4,490 & 6,230 & 8,980 & 11,500 & 14,400 & \\
\hline 09315900 & 1 & 0 & 0 & 0 & 0 & 205 & 612 & 1,090 & 2.010 & 2,990 & 4,290 & 1,470 \\
\hline & & & & & & 206 & 623 & 1,110 & 2.030 & 2,950 & 4,110 & \\
\hline 09316000 & 0 & 0 & 1 & 0 & 0 & 1,790 & 3,750 & 5,460 & 8,090 & 10,400 & 12,900 & 5,620 \\
\hline & & & & & & 1.770 & 3,650 & 5,170 & 7,420 & 9,380 & 11,500 & \\
\hline 09318000 & 0 & 0 & 0 & 0 & 0 & 812 & 1,300 & 1.640 & 2,070 & 2,400 & 2.720 & 2,500 \\
\hline & & & & & & 812 & 1,310 & 1,670 & 2,160 & 2,570 & 3,000 & \\
\hline
\end{tabular}




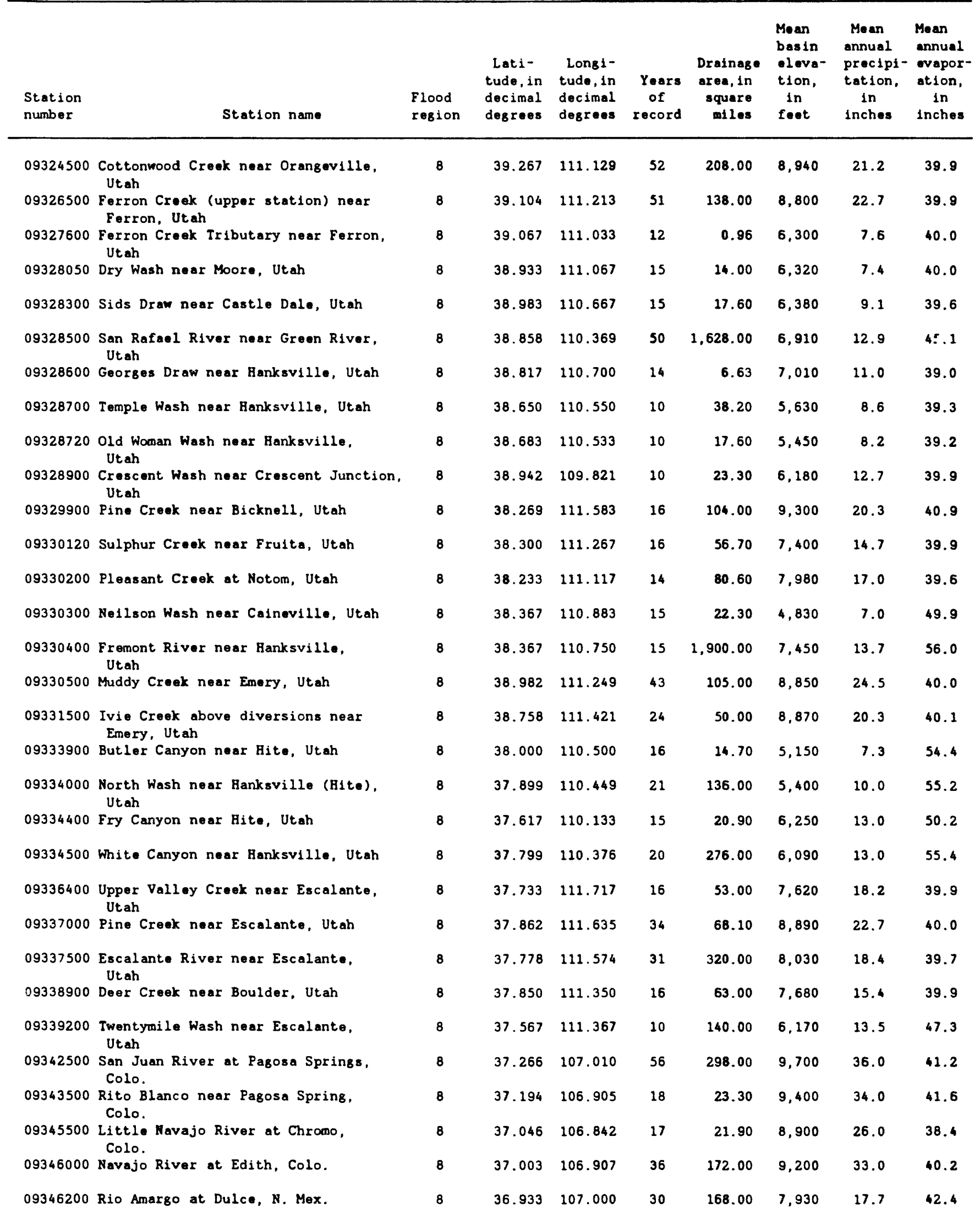




\begin{tabular}{|c|c|c|c|c|c|c|c|c|c|c|c|c|}
\hline \multirow[b]{2}{*}{$\begin{array}{l}\text { Station } \\
\text { number }\end{array}$} & \multirow{2}{*}{\multicolumn{5}{|c|}{$\begin{array}{c}\text { Relation } \\
\text { characteristic }\end{array}$}} & \multicolumn{6}{|c|}{$\begin{array}{l}\text { Peak discharge (cubic feet per second) for } \\
\text { indicated recurrence interval (years) }\end{array}$} & \multirow{2}{*}{$\begin{array}{l}\text { Maximum } \\
\text { peak discharge } \\
\text { of record } \\
\text { (cublc feet } \\
\text { per second) }\end{array}$} \\
\hline & & & & & $\frac{t 1 c}{U}$ & 2 & 5 & 10 & 25 & 50 & 100 & \\
\hline 09324500 & 0 & 1 & 0 & 0 & 0 & 1,290 & $\begin{array}{l}2,080 \\
2,070\end{array}$ & $\begin{array}{r}2,670 \\
2,660\end{array}$ & $\begin{array}{r}3,490 \\
3,490\end{array}$ & $\begin{array}{r}4,150 \\
\end{array}$ & $\begin{array}{r}4.850 \\
.830\end{array}$ & 7,220 \\
\hline 09326500 & 0 & 0 & 0 & 0 & 0 & $\begin{array}{l}903 \\
902\end{array}$ & $\begin{array}{l}1,500 \\
1,500\end{array}$ & $\begin{array}{l}1,980 \\
1,980\end{array}$ & $\begin{array}{l}2,660 \\
2,690\end{array}$ & $\begin{array}{l}3,230 \\
3,310\end{array}$ & $\begin{array}{l}3,850 \\
3,980\end{array}$ & 4,180 \\
\hline 09327600 & 0 & 0 & 0 & 0 & 0 & $\begin{array}{l}111 \\
110\end{array}$ & $\begin{array}{l}342 \\
332\end{array}$ & $\begin{array}{l}607 \\
566\end{array}$ & $\begin{array}{r}1,110 \\
971\end{array}$ & $\begin{array}{l}1,630 \\
1,360\end{array}$ & $\begin{array}{l}2,290 \\
1,830\end{array}$ & 600 \\
\hline 09328050 & 1 & 0 & 1 & 0 & 0 & $\begin{array}{l}324 \\
324\end{array}$ & $\begin{array}{l}643 \\
657\end{array}$ & $\begin{array}{l}938 \\
986\end{array}$ & $\begin{array}{l}1,420 \\
1,560\end{array}$ & $\begin{array}{l}1,880 \\
2,130\end{array}$ & $\begin{array}{l}2,430 \\
2,790\end{array}$ & 1,630 \\
\hline 09328300 & 1 & 0 & 1 & 0 & 0 & $\begin{array}{l}459 \\
457\end{array}$ & $\begin{array}{l}1,200 \\
1,170\end{array}$ & $\begin{array}{l}1,940 \\
1,840\end{array}$ & $\begin{array}{l}3,180 \\
2,890\end{array}$ & $\begin{array}{l}4,340 \\
3,840\end{array}$ & $\begin{array}{l}5,700 \\
4,900\end{array}$ & 2.150 \\
\hline 09328500 & 1 & 0 & 1 & $\iota$ & 0 & $\begin{array}{l}2,220 \\
2,230\end{array}$ & $\begin{array}{l}3,980 \\
4,040\end{array}$ & $\begin{array}{l}5,550 \\
5,700\end{array}$ & $\begin{array}{l}8,110 \\
8,450\end{array}$ & $\begin{array}{l}10,500 \\
11,000\end{array}$ & $\begin{array}{l}13,300 \\
14,000\end{array}$ & 12,000 \\
\hline 09328600 & 1 & 0 & 0 & 0 & 0 & $\begin{array}{l}210 \\
210\end{array}$ & $\begin{array}{l}592 \\
584\end{array}$ & $\begin{array}{r}1,030 \\
987\end{array}$ & $\begin{array}{l}1,860 \\
1,690\end{array}$ & $\begin{array}{l}2,740 \\
2,370\end{array}$ & $\begin{array}{l}3,890 \\
3,200\end{array}$ & 1.650 \\
\hline 09328700 & - & - & - & - & 1 & 636 & 1,470 & 2,220 & 3,470 & 4,630 & 5,900 & 1.880 \\
\hline 09328720 & 1 & 0 & 0 & 0 & 0 & $\begin{array}{l}286 \\
292\end{array}$ & $\begin{array}{l}860 \\
887\end{array}$ & $\begin{array}{l}1,520 \\
1,550\end{array}$ & $\begin{array}{l}2,750 \\
2,720\end{array}$ & $\begin{array}{l}4,030 \\
3,850\end{array}$ & $\begin{array}{l}5,660 \\
5,170\end{array}$ & 2,650 \\
\hline 09328900 & 1 & 1 & 0 & 0 & 0 & $\begin{array}{l}448 \\
448\end{array}$ & $\begin{array}{l}1,110 \\
1,100\end{array}$ & $\begin{array}{l}1,840 \\
1,780\end{array}$ & $\begin{array}{l}3,270 \\
2,990\end{array}$ & $\begin{array}{l}4,800 \\
4,160\end{array}$ & $\begin{array}{l}6,860 \\
5,590\end{array}$ & 4,160 \\
\hline 09329900 & 0 & 0 & 1 & 0 & 0 & $\begin{array}{l}74 \\
87\end{array}$ & $\begin{array}{l}232 \\
308\end{array}$ & $\begin{array}{l}422 \\
615\end{array}$ & $\begin{array}{r}799 \\
1,220\end{array}$ & $\begin{array}{l}1,210 \\
1,830\end{array}$ & $\begin{array}{l}1,750 \\
2,530\end{array}$ & 707 \\
\hline 09330120 & 0 & 0 & 0 & 0 & 0 & $\begin{array}{l}524 \\
525\end{array}$ & $\begin{array}{l}1,220 \\
1,220\end{array}$ & $\begin{array}{l}1,880 \\
1,870\end{array}$ & $\begin{array}{l}2,960 \\
2,900\end{array}$ & $\begin{array}{l}3,950 \\
3,820\end{array}$ & $\begin{array}{l}5,100 \\
4,850\end{array}$ & 2,600 \\
\hline 09330200 & 0 & 0 & 0 & 0 & 0 & $\begin{array}{l}256 \\
266\end{array}$ & $\begin{array}{l}815 \\
859\end{array}$ & $\begin{array}{l}1,460 \\
1,530\end{array}$ & $\begin{array}{l}2,680 \\
2,710\end{array}$ & $\begin{array}{l}3,930 \\
3,820\end{array}$ & $\begin{array}{l}5,520 \\
5,110\end{array}$ & 2,040 \\
\hline 09330300 & 1 & 1 & 0 & 0 & 0 & $\begin{array}{l}1,130 \\
1,120\end{array}$ & $\begin{array}{l}2,280 \\
2,210\end{array}$ & $\begin{array}{l}3,290 \\
3,110\end{array}$ & $\begin{array}{l}4,850 \\
4,490\end{array}$ & $\begin{array}{l}6,230 \\
5,740\end{array}$ & $\begin{array}{l}7.800 \\
7,170\end{array}$ & 5,450 \\
\hline 09330400 & 0 & 0 & 0 & 0 & 0 & $\begin{array}{l}4,300 \\
4,280\end{array}$ & $\begin{array}{l}7,330 \\
7,220\end{array}$ & $\begin{array}{l}9,650 \\
9,370\end{array}$ & $\begin{array}{l}12,900 \\
12,400\end{array}$ & $\begin{array}{l}15,500 \\
14,900\end{array}$ & $\begin{array}{l}18,300 \\
17,600\end{array}$ & 15,300 \\
\hline 09330500 & 1 & 0 & 0 & 0 & 0 & $\begin{array}{l}575 \\
576\end{array}$ & $\begin{array}{l}1,200 \\
1,200\end{array}$ & $\begin{array}{l}1,740 \\
1,750\end{array}$ & $\begin{array}{l}2,590 \\
2,600\end{array}$ & $\begin{array}{l}3,340 \\
3,350\end{array}$ & $\begin{array}{l}4,190 \\
4,190\end{array}$ & 3,340 \\
\hline 09331500 & 1 & 0 & 0 & 0 & 0 & $\begin{array}{l}190 \\
194\end{array}$ & $\begin{array}{l}395 \\
423\end{array}$ & $\begin{array}{l}583 \\
662\end{array}$ & $\begin{array}{r}887 \\
1.090\end{array}$ & $\begin{array}{l}1,170 \\
1,500\end{array}$ & $\begin{array}{l}1,490 \\
1,960\end{array}$ & 1,240 \\
\hline 09333900 & 1 & 1 & 0 & 0 & 0 & $\begin{array}{l}409 \\
410\end{array}$ & $\begin{array}{l}748 \\
773\end{array}$ & $\begin{array}{l}1,030 \\
1,130\end{array}$ & $\begin{array}{l}1,450 \\
1,770\end{array}$ & $\begin{array}{l}1,810 \\
2,400\end{array}$ & $\begin{array}{l}2,210 \\
3,140\end{array}$ & 1,950 \\
\hline 09334000 & 0 & 0 & 0 & 0 & 0 & $\begin{array}{l}1,180 \\
1.180\end{array}$ & $\begin{array}{l}3,070 \\
3,050\end{array}$ & $\begin{array}{l}5,020 \\
4,900\end{array}$ & $\begin{array}{l}8.420 \\
7.960\end{array}$ & $\begin{array}{l}11.700 \\
10,800\end{array}$ & $\begin{array}{l}15,800 \\
14,100\end{array}$ & 8,900 \\
\hline 09334400 & 1 & 1 & 0 & 0 & 0 & $\begin{array}{l}634 \\
629\end{array}$ & $\begin{array}{l}1,290 \\
1,270\end{array}$ & $\begin{array}{l}1,940 \\
1,870\end{array}$ & $\begin{array}{l}3,060 \\
2,870\end{array}$ & $\begin{array}{l}4.170 \\
3,820\end{array}$ & $\begin{array}{l}5,560 \\
4.960\end{array}$ & 3,500 \\
\hline 09334500 & 0 & 0 & 0 & 0 & 0 & $\begin{array}{l}2,190 \\
2,180\end{array}$ & $\begin{array}{l}4,250 \\
4,190\end{array}$ & $\begin{array}{l}5,990 \\
5,820\end{array}$ & $\begin{array}{l}8,610 \\
8,230\end{array}$ & $\begin{array}{l}10,900 \\
10,300\end{array}$ & $\begin{array}{l}13,400 \\
12,600\end{array}$ & 7,390 \\
\hline 09336400 & 0 & 1 & 0 & 0 & 0 & $\begin{array}{l}718 \\
714\end{array}$ & $\begin{array}{l}1,580 \\
1,550\end{array}$ & $\begin{array}{l}2,440 \\
2,320\end{array}$ & $\begin{array}{l}3,950 \\
3,590\end{array}$ & $\begin{array}{l}5,450 \\
4,770\end{array}$ & $\begin{array}{l}7,340 \\
6,160\end{array}$ & 5,560 \\
\hline 09337000 & 1 & 0 & 1 & 0 & 0 & $\begin{array}{l}169 \\
173\end{array}$ & $\begin{array}{l}370 \\
396\end{array}$ & $\begin{array}{l}568 \\
641\end{array}$ & $\begin{array}{r}910 \\
1,090\end{array}$ & $\begin{array}{l}1,240 \\
1,530\end{array}$ & $\begin{array}{l}1,660 \\
2,060\end{array}$ & 1,010 \\
\hline 09337500 & 1 & 0 & 0 & 0 & 0 & $\begin{array}{l}782 \\
788\end{array}$ & $\begin{array}{l}1,740 \\
1,770\end{array}$ & $\begin{array}{l}2,590 \\
2,650\end{array}$ & $\begin{array}{l}3,900 \\
4,040\end{array}$ & $\begin{array}{l}5,040 \\
5,250\end{array}$ & $\begin{array}{l}6,320 \\
6,590\end{array}$ & 3,450 \\
\hline 09338900 & 1 & 0 & 0 & 0 & 0 & $\begin{array}{l}361 \\
366\end{array}$ & $\begin{array}{l}1,180 \\
1,190\end{array}$ & $\begin{array}{l}2,170 \\
2,110\end{array}$ & $\begin{array}{l}4,160 \\
3,780\end{array}$ & $\begin{array}{l}6,320 \\
5,420\end{array}$ & $\begin{array}{l}9,200 \\
7,420\end{array}$ & 3,820 \\
\hline 09339200 & 1 & 0 & 0 & 0 & 0 & $\begin{array}{l}1,750 \\
1,730\end{array}$ & $\begin{array}{l}2,940 \\
2,870\end{array}$ & $\begin{array}{l}3,880 \\
3,770\end{array}$ & $\begin{array}{l}5,230 \\
5,190\end{array}$ & $\begin{array}{l}6,350 \\
6,490\end{array}$ & $\begin{array}{l}7,580 \\
7,930\end{array}$ & 4,620 \\
\hline 09342500 & 0 & 1 & 0 & 0 & 0 & $\begin{array}{l}2,660 \\
2,650\end{array}$ & $\begin{array}{l}4,480 \\
4,420\end{array}$ & $\begin{array}{l}6.130 \\
5,950\end{array}$ & $\begin{array}{l}8,840 \\
8,370\end{array}$ & $\begin{array}{l}11,400 \\
10,600\end{array}$ & $\begin{array}{l}14,500 \\
13,200\end{array}$ & 25,000 \\
\hline 09343500 & 0 & 0 & 0 & 0 & 0 & $\begin{array}{l}190 \\
192\end{array}$ & $\begin{array}{l}313 \\
334\end{array}$ & $\begin{array}{l}403 \\
469\end{array}$ & $\begin{array}{l}524 \\
710\end{array}$ & $\begin{array}{l}619 \\
945\end{array}$ & $\begin{array}{r}717 \\
1.210\end{array}$ & 475 \\
\hline 09345500 & 0 & 0 & 0 & 0 & 0 & $\begin{array}{l}145 \\
148\end{array}$ & $\begin{array}{l}253 \\
281\end{array}$ & $\begin{array}{l}335 \\
420\end{array}$ & $\begin{array}{l}451 \\
682\end{array}$ & $\begin{array}{l}545 \\
940\end{array}$ & $\begin{array}{r}645 \\
1.230\end{array}$ & 399 \\
\hline 09346000 & 0 & 0 & 0 & 0 & 0 & $\begin{array}{l}850 \\
850\end{array}$ & $\begin{array}{l}1,310 \\
1,320\end{array}$ & $\begin{array}{l}1,660 \\
1,690\end{array}$ & $\begin{array}{l}2.170 \\
2,290\end{array}$ & $\begin{array}{l}2,590 \\
2,820\end{array}$ & $\begin{array}{l}3,060 \\
3,410\end{array}$ & 2,840 \\
\hline 09346200 & 0 & 0 & 0 & 0 & 0 & $\begin{array}{l}1,010 \\
1,010\end{array}$ & $\begin{array}{l}1,560 \\
1,570\end{array}$ & $\begin{array}{l}1,940 \\
2,000\end{array}$ & $\begin{array}{l}2,460 \\
2,660\end{array}$ & $\begin{array}{l}2,860 \\
3,260\end{array}$ & $\begin{array}{l}3,270 \\
3,910\end{array}$ & 2,860 \\
\hline
\end{tabular}




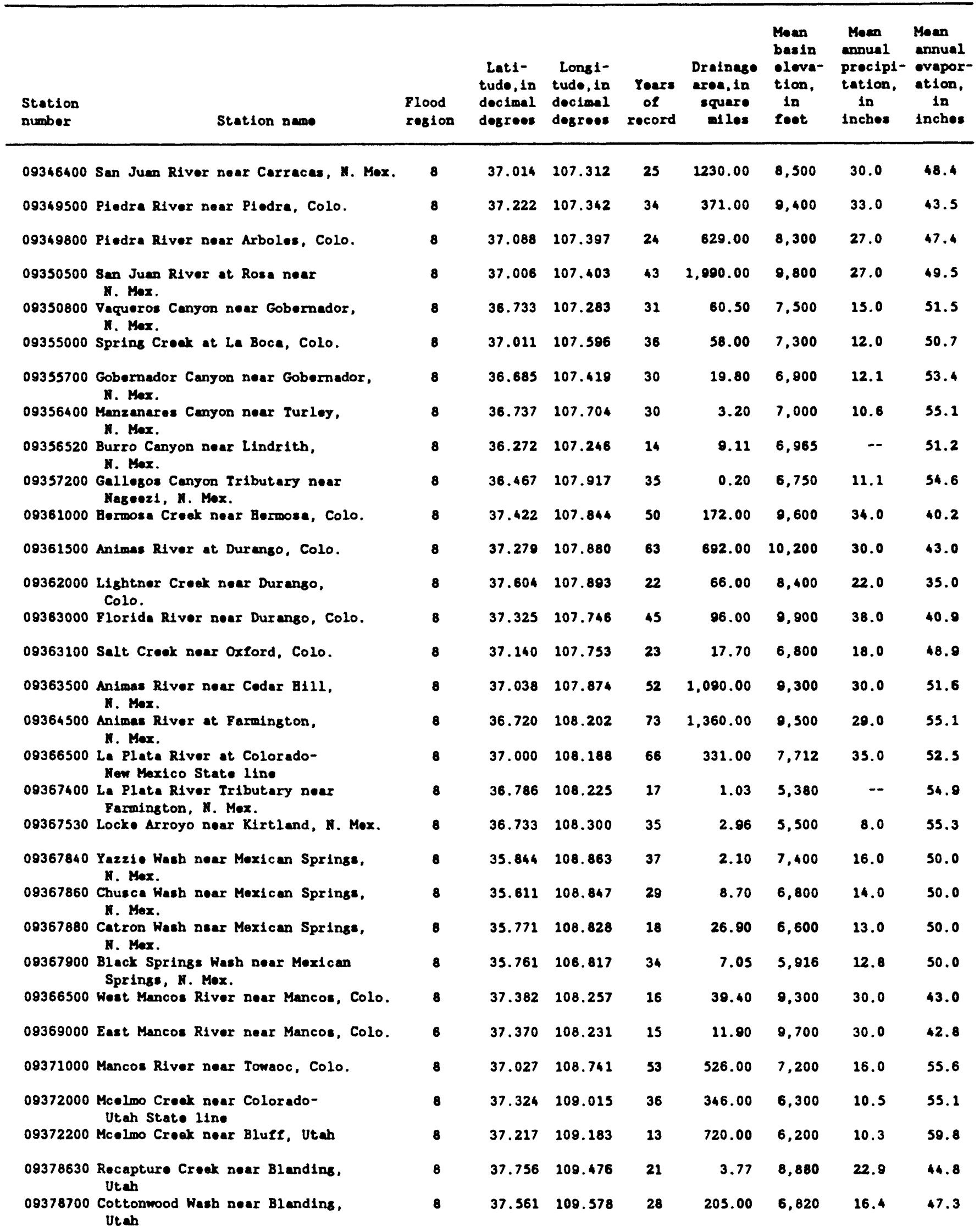




\begin{tabular}{|c|c|c|c|c|c|c|c|c|c|c|c|c|}
\hline \multirow{2}{*}{$\begin{array}{l}\text { Station } \\
\text { number }\end{array}$} & \multicolumn{5}{|c|}{ Relation } & \multicolumn{3}{|c|}{$\begin{array}{l}\text { Peak discharge (cubic } \\
\text { indicated recurrence }\end{array}$} & \multicolumn{3}{|c|}{$\begin{array}{l}\text { feet per second) for } \\
\text { interval (years) }\end{array}$} & \multirow{2}{*}{$\begin{array}{c}\text { Maximum } \\
\text { peak discharge } \\
\text { of record } \\
\text { (cubic feet } \\
\text { per second) }\end{array}$} \\
\hline & $\mathrm{L}$ & B & $D$ & 0 & $\frac{0}{0}$ & 2 & 5 & 10 & 25 & 50 & 100 & \\
\hline \multirow[t]{2}{*}{09346400} & 0 & 0 & 0 & 0 & 0 & 4.110 & 6,260 & 7,740 & 9,640 & 11,100 & 12,500 & 9.730 \\
\hline & & & & & & 4,090 & 6,150 & 7.500 & 9,280 & 10,700 & 12,200 & \\
\hline \multirow[t]{2}{*}{09349500} & 0 & 0 & 0 & 0 & 0 & 2,080 & 3,470 & 4,650 & 6.440 & 8,040 & 9,880 & 7,980 \\
\hline & & & & & & 2,070 & 3,420 & 4,510 & 6,110 & 7,510 & 8,080 & \\
\hline \multirow[t]{2}{*}{09349800} & 0 & 0 & 0 & 0 & 0 & 2,470 & 4,260 & 5,690 & 7,760 & 9,500 & 11,400 & 8,370 \\
\hline & & & & & & 2,460 & 4,200 & 5.540 & 7,440 & 9,050 & 10,800 & \\
\hline \multirow[t]{2}{*}{09350500} & 0 & 0 & 0 & 0 & 0 & 6,730 & 10,600 & 13,700 & 18,100 & 21,900 & 26,000 & 25,000 \\
\hline & & & & & & 6,700 & 10,400 & 13,200 & 16,900 & 20,000 & 23,300 & \\
\hline \multirow[t]{2}{*}{09350800} & 0 & 0 & 0 & 0 & 0 & 205 & 518 & 866 & 1,530 & 2,240 & 3,190 & 2,520 \\
\hline & & & & & & 210 & 549 & 946 & 1,710 & 2,500 & 3,480 & \\
\hline \multirow[t]{2}{*}{09355000} & - & - & - & - & 1 & ---- & --- & $-\cdots$ & $-\cdots$ & $\cdots-$ & --- & 1.980 \\
\hline & & & & & & 602 & 1.270 & 1,850 & 2.790 & 3,650 & 4,570 & \\
\hline 09355700 & - & - & - & - & 1 & -.-- & --- & --- & $-\cdots$ & $\cdots$ & --- & 3,450 \\
\hline & & & & & & 372 & 845 & 1,260 & 1,970 & 2.620 & 3,330 & \\
\hline 09356400 & - & - & - & - & 1 & --- & ---- & --- & --- & --- & --- & 2,210 \\
\hline & & & & & & 147 & 366 & 571 & 924 & 1.260 & 1,640 & \\
\hline 09356520 & - & - & - & - & 1 & --- & --- & --- & --- & $\cdots$ & --- & 725 \\
\hline & & & & & & 250 & 589 & 897 & 1.420 & 1,910 & 2,450 & \\
\hline 09357200 & 0 & 0 & 0 & 0 & 0 & 133 & 255 & 358 & 511 & 642 & 787 & 580 \\
\hline & & & & & & 132 & 250 & 345 & 485 & 609 & 750 & \\
\hline 09361000 & 1 & 0 & 0 & 0 & 0 & 986 & 1.690 & 2.230 & 3,000 & 3,620 & 4,280 & 2,980 \\
\hline & & & & & & 985 & 1,680 & 2,220 & 2,990 & 3,630 & 4,310 & \\
\hline 09361500 & 1 & 1 & 0 & 0 & 0 & 4,930 & 7,420 & 9,450 & 12,500 & 15.200 & 18,200 & 25,000 \\
\hline & & & & & & 4,910 & 7.320 & 9,180 & 11,900 & 14,200 & 16,700 & \\
\hline 09362000 & 0 & 0 & 0 & 0 & 0 & 484 & 971 & 1,410 & 2,100 & 2,740 & 3,470 & 1,850 \\
\hline & & & & & & 485 & 980 & 1,430 & 2,160 & 2,830 & 3,580 & \\
\hline 09363000 & 0 & 0 & 0 & 0 & 0 & 985 & 1,480 & 1,840 & 2,360 & 2,780 & 3,220 & 3,200 \\
\hline & & & & & & 982 & 1.470 & 1,820 & 2,340 & 2,780 & 3,250 & \\
\hline 09363100 & 0 & 0 & 0 & 0 & 0 & 214 & 392 & 535 & 742 & 913 & 1,100 & 811 \\
\hline & & & & & & 216 & 416 & 612 & 968 & 1,320 & 1,720 & \\
\hline 09363500 & 0 & 0 & 0 & 0 & 0 & 5,770 & 8,130 & 9,790 & 12,000 & 13,700 & 15.400 & 13,100 \\
\hline & & & & & & 5,740 & 8,010 & 9,520 & 11,500 & 13,000 & 14.500 & \\
\hline 09364500 & 0 & 1 & 0 & 0 & 0 & 6,070 & 9,030 & 11.100 & 13,800 & 15,900 & 18,000 & 25,000 \\
\hline & & & & & & 6,050 & 8,930 & 10,900 & 13,300 & 15,200 & 17.100 & \\
\hline 09366500 & 0 & 0 & 0 & 0 & 0 & 762 & 1,580 & 2,320 & 3,510 & 4,590 & 5.850 & 4,750 \\
\hline & & & & & & 765 & 1.600 & 2,370 & 3,640 & 4,800 & 6,120 & \\
\hline 09367400 & 1 & 0 & 0 & 0 & 0 & 92 & 253 & 435 & 778 & 1,140 & 1,600 & 1,130 \\
\hline & & & & & & 92 & 257 & 446 & 799 & 1,160 & 1,610 & \\
\hline 09367530 & 0 & 0 & 0 & 0 & 0 & 105 & 254 & 403 & 657 & 901 & 1,200 & 812 \\
\hline & & & & & & 106 & 262 & 431 & 741 & 1,050 & 1,440 & \\
\hline 09367840 & 1 & 0 & 0 & 0 & 0 & 284 & 591 & 863 & 1,290 & 1,660 & 2,090 & 1,390 \\
\hline & & & & & & 282 & 580 & 833 & 1.220 & 1.550 & 1,930 & \\
\hline 09367860 & 1 & 0 & 0 & 0 & 0 & 1,120 & 2,420 & 3,620 & 5,530 & 7,260 & 9,260 & 6,400 \\
\hline & & & & & & 1,110 & 2,340 & 3,380 & 4.880 & 6.170 & 7,620 & \\
\hline 09367880 & 1 & 0 & 0 & 0 & 0 & 1.720 & 3,040 & 4.070 & 5.540 & 6.750 & 8,050 & 4.750 \\
\hline & & & & & & 1,700 & 2,900 & 3,720 & 4.810 & 5,700 & 6,680 & \\
\hline 09367900 & - & - & - & - & 1 & --- & --- & --- & --- & --- & --- & 2,200 \\
\hline & & & & & & 260 & 647 & 1,010 & 1,630 & 2,220 & 2,880 & \\
\hline 09368500 & 0 & 0 & 0 & 0 & 0 & 316 & 584 & 808 & 1,140 & 1.430 & 1,760 & 1,080 \\
\hline & & & & & & 318 & 600 & 855 & 1,270 & 1.660 & 2,100 & \\
\hline 09369000 & - & - & - & - & 1 & 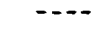 & -.. & --- & -..- & $-\ldots$ & --- & 642 \\
\hline & & & & & & 204 & 435 & 632 & 965 & 1,270 & 1,600 & \\
\hline 09371000 & - & - & - & - & 1 & --- & $-\cdots$ & ---- & ---- & --- & --- & 5,300 \\
\hline & & & & & & 1.840 & 3,490 & 4,800 & 6.920 & 8,810 & 10,700 & \\
\hline 09372000 & 0 & 0 & 0 & 0 & 0 & 958 & 1,540 & 2,000 & 2.640 & 3,180 & 3,770 & 3,040 \\
\hline & & & & & & 966 & 1,610 & 2,210 & 3.230 & 4,210 & 5,320 & \\
\hline 09372200 & 0 & 1 & 0 & 0 & 0 & $\begin{array}{l}651 \\
702\end{array}$ & $\begin{array}{l}1,800 \\
2,090\end{array}$ & $\begin{array}{l}3,200 \\
3,850\end{array}$ & $\begin{array}{l}6.170 \\
7,250\end{array}$ & $\begin{array}{r}9,610 \\
10,700\end{array}$ & $\begin{array}{l}14,500 \\
14,800\end{array}$ & 13,100 \\
\hline 09378630 & 0 & 0 & 0 & 1 & 0 & 17 & 43 & 69 & 114 & 159 & 215 & 142 \\
\hline & & & & & & 19 & 58 & 113 & 233 & 361 & 515 & \\
\hline 09378700 & 1 & 1 & 0 & 0 & 0 & 1,080 & 2,820 & 4,800 & 8,650 & 12,800 & 18,400 & 20,500 \\
\hline & & & & & & 1,080 & 2,800 & 4,680 & 8,080 & 11,500 & 15,900 & \\
\hline
\end{tabular}




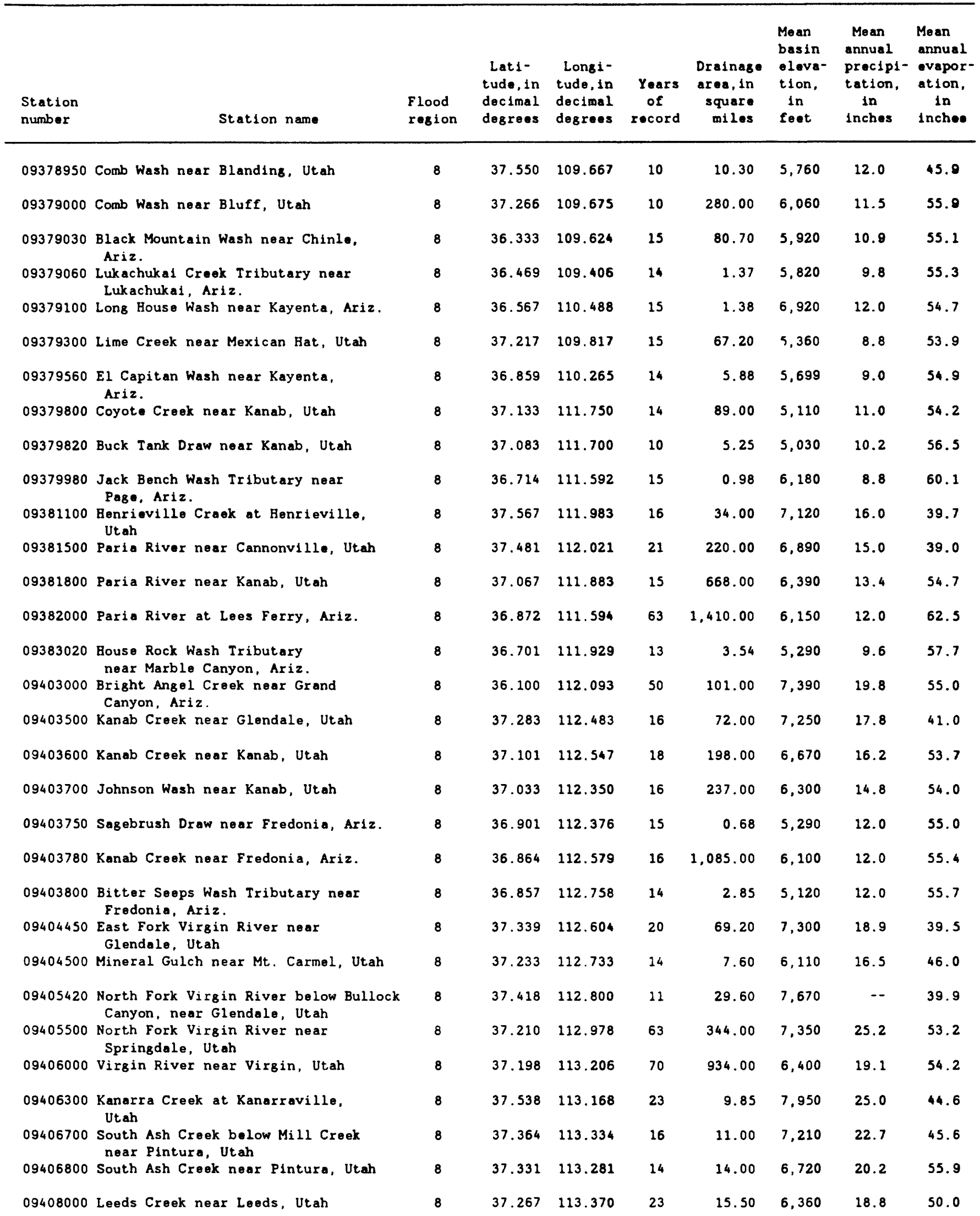




\begin{tabular}{|c|c|c|c|c|c|c|c|c|c|c|c|c|}
\hline \multirow{2}{*}{$\begin{array}{l}\text { Station } \\
\text { number }\end{array}$} & \multicolumn{5}{|c|}{$\begin{array}{c}\text { Rolation } \\
\text { characteristic }\end{array}$} & \multicolumn{6}{|c|}{$\begin{array}{l}\text { Poak discharge (cubic feet por second) for } \\
\text { indicated recurrence interval (years) }\end{array}$} & \multirow{2}{*}{$\begin{array}{l}\text { Maximum } \\
\text { peak discharge } \\
\text { of record } \\
\text { (cubic feot } \\
\text { por socond) }\end{array}$} \\
\hline & L & B & $D$ & 0 & $\mathbf{U}$ & 2 & 5 & 10 & 25 & so & 100 & \\
\hline \multirow[t]{2}{*}{09378950} & 1 & 1 & 0 & 0 & 0 & 743 & 1.450 & 2,110 & 3,210 & 4,250 & 5,500 & 3,430 \\
\hline & & & & & & 728 & 1.370 & 1.910 & 2.780 & 3,580 & 4.520 & \\
\hline \multirow[t]{2}{*}{09379000} & 1 & 1 & 0 & 0 & 0 & 1,750 & 3.200 & 4.490 & 6,590 & 8,540 & 10,900 & 8,390 \\
\hline & & & & & & 1,750 & 3,210 & 4,530 & 6,710 & 8,730 & 11,000 & \\
\hline \multirow{2}{*}{09379030} & 1 & 0 & 0 & 0 & 0 & 843 & 1,650 & 2,320 & 3,290 & 4,100 & 4,990 & 3,100 \\
\hline & & & & & & 844 & 1,670 & 2,410 & 3,570 & 4,640 & 5,840 & \\
\hline \multirow[t]{2}{*}{09379060} & 1 & 0 & 0 & 1 & 0 & 18 & 47 & 80 & 144 & 213 & 306 & 227 \\
\hline & & & & & & 20 & 71 & 154 & 346 & 556 & 820 & \\
\hline \multirow[t]{2}{*}{09379100} & - & - & - & - & 1 & -... & $\cdots$ & $\cdots$ & $\cdots$ & $\cdots$ & $\cdots$ & 2.060 \\
\hline & & & & & & 98 & 255 & 406 & 670 & 922 & 1,210 & \\
\hline \multirow[t]{2}{*}{$0: 379300$} & - & - & - & - & 1 & $\cdots$ & --- & $-\cdots$ & $\cdots$ & --- & $\cdots$ & 6,600 \\
\hline & & & & & & 888 & 2,020 & 3,030 & 4.690 & 6,220 & 7.890 & \\
\hline \multirow[t]{2}{*}{09379560} & 0 & 0 & 0 & 0 & 0 & 469 & 951 & 1,390 & 2,110 & 2,780 & 3,570 & 2,340 \\
\hline & & & & & & 463 & 922 & 1,320 & 1.970 & 2,580 & 3,290 & \\
\hline 09379800 & 1 & 0 & 0 & 0 & 0 & 1.400 & 2.760 & 3.880 & 5,540 & 6,950 & 8,490 & 4.590 \\
\hline & & & & & & 1,390 & 2.730 & 3,840 & 5,570 & 7,130 & 8,880 & \\
\hline 09379820 & - & - & - & - & 1 & $-\cdots$ & $\cdots$ & $\cdots$ & $\cdots$ & $-\cdots$ & $\cdots-$ & 680 \\
\hline & & & & & & 264 & 698 & 1,120 & 1.850 & 2,540 & 3,340 & \\
\hline 09379980 & - & - & - & - & 1 & $-\cdots$ & $\cdots$ & $\cdots$ & $-\cdots$ & $\cdots$ & $\ldots$ & 200 \\
\hline & & & & & & 92 & 252 & 411 & 690 & 961 & 1,280 & \\
\hline 09381100 & 0 & 0 & 0 & 0 & 0 & 864 & 2.060 & 3,340 & 5,670 & 8,070 & 11,200 & 7,360 \\
\hline & & & & & & 855 & 1,980 & 3,060 & 4,820 & 6,490 & 8,510 & \\
\hline 09381500 & 0 & 0 & 0 & 0 & 0 & 2.770 & 4.860 & 6,600 & 9.230 & 11,500 & 14,100 & 11,600 \\
\hline & & & & & & 2,740 & 4,720 & 6.230 & 8,400 & 10.200 & 12,300 & \\
\hline 09381800 & 0 & 0 & 0 & 0 & 0 & 2,480 & 5,290 & 7,960 & 12,400 & 16,700 & 21,800 & 15,400 \\
\hline & & & & & & 2,480 & 5,230 & 7,690 & 11,500 & 15,000 & 18,900 & \\
\hline 09382000 & 1 & 0 & 0 & 0 & 0 & 3,880 & 6,990 & 9,540 & 13,300 & 16,600 & 20,100 & 16,100 \\
\hline & & & & & & 3,880 & 6,980 & 9,520 & 13,300 & 16,600 & 20,100 & \\
\hline 09383020 & 1 & 1 & 0 & 0 & 0 & 25 & 82 & 161 & 343 & 573 & 922 & 1,610 \\
\hline & & & & & & 30 & 126 & 292 & 673 & 1.100 & 1,640 & \\
\hline 09403000 & 1 & 0 & 0 & 0 & 0 & 435 & 1,010 & 1,600 & 2,650 & 3,690 & 5,010 & 4,400 \\
\hline & & & & & & 438 & 1,030 & 1,640 & 2,730 & 3,790 & 5,090 & \\
\hline 09403500 & 1 & 0 & 1 & 0 & 0 & 701 & 1.380 & 1,920 & 2,680 & 3,290 & 3,920 & 2,100 \\
\hline & & & & & & 700 & 1,380 & 1,940 & 2.780 & 3,520 & 4,320 & \\
\hline 09403600 & 0 & 0 & 1 & 0 & 0 & 610 & 1.330 & 1,990 & 3,060 & 4,040 & 5,190 & 3,030 \\
\hline & & & & & & 622 & 1,410 & 2,200 & 3,570 & 4,840 & 6.270 & \\
\hline 09403700 & 1 & 0 & 1 & 0 & 0 & 1,230 & 1,770 & 2,140 & 2,640 & 3,030 & 3,420 & 2,750 \\
\hline & & & & & & 1,230 & 1,860 & 2,440 & 3,530 & 4,590 & 5,770 & \\
\hline 09403750 & - & - & - & - & 1 & -.. & $\cdots$ & $\cdots$ & $\ldots$ & $-\cdots$ & $\cdots-$ & 150 \\
\hline & & & & & & 90 & 261 & 438 & 751 & 1,060 & 1,430 & \\
\hline 09403780 & 1 & 0 & 0 & 0 & 0 & 875 & 1,760 & 2,610 & 4,050 & 5,440 & 7,150 & 4.630 \\
\hline & & & & & & 926 & 2,090 & 3,470 & 6,040 & 8,500 & 11.300 & \\
\hline 09403800 & 0 & 0 & 0 & 0 & 0 & 127 & 575 & 1,240 & 2,790 & 4,660 & 7,360 & 1,950 \\
\hline & & & & & & 129 & 570 & 1,170 & 2,400 & 3,720 & 5,450 & \\
\hline 09404450 & 0 & 0 & 1 & 0 & 0 & 132 & 293 & 453 & 729 & 999 & 1,330 & 640 \\
\hline & & & & & & 142 & 362 & 646 & 1,210 & 1,790 & 2,460 & \\
\hline 09404500 & 1 & 0 & 0 & 0 & 0 & 313 & 952 & 1,710 & 3,180 & 4,770 & 6.860 & 3,210 \\
\hline & & & & & & 312 & 925 & 1,590 & 2,740 & 3,870 & 5.250 & \\
\hline 09405420 & - & - & - & - & 1 & $-\cdots$ & $-\cdots$ & $--\cdot$ & $-\cdots$ & -- & --- & 1,740 \\
\hline & & & & & & 409 & 884 & 1,290 & 1,980 & 2,600 & 3,280 & \\
\hline 09405500 & 0 & 0 & 0 & 0 & 0 & 1,810 & 3,260 & 4,430 & 6.130 & 7,570 & 9.140 & 9.150 \\
\hline & & & & & & 1,810 & 3,250 & 4,410 & 6.090 & 7,530 & 9,100 & \\
\hline 09406000 & 0 & 0 & 0 & 0 & 0 & 3,820 & 7.180 & 10,100 & 14.500 & 18,400 & 22,900 & 22,800 \\
\hline & & & & & & 3,810 & 7,140 & 9,990 & 14,200 & 17,900 & 22,100 & \\
\hline 09406300 & 0 & 0 & 0 & 0 & 0 & 141 & 367 & 608 & 1.050 & 1,490 & 2.050 & 1,000 \\
\hline & & & & & & 142 & 375 & 626 & 1,080 & 1,520 & 2,050 & \\
\hline 09406700 & 1 & 1 & 0 & 0 & 0 & 218 & 531 & 859 & 1,450 & 2.050 & 2,820 & 1,910 \\
\hline & & & & & & 219 & 537 & 869 & 1.450 & 2,020 & 2,700 & \\
\hline 09406800 & 0 & 0 & 0 & 0 & 0 & 194 & 469 & 739 & 1.190 & 1,630 & 2,140 & 938 \\
\hline & & & & & & 197 & 494 & 806 & 1.360 & 1,890 & 2.500 & \\
\hline 09408000 & 1 & 0 & 0 & 0 & 0 & 361 & 1,030 & 1.750 & 3,040 & 4,300 & 5,850 & 2,980 \\
\hline & & & & & & 361 & 1,020 & 1,700 & 2.840 & 3,910 & 5,160 & \\
\hline
\end{tabular}




\begin{tabular}{|c|c|c|c|c|c|c|c|c|c|}
\hline $\begin{array}{l}\text { Station } \\
\text { number }\end{array}$ & Station name & $\begin{array}{l}\text { Flood } \\
\text { region }\end{array}$ & $\begin{array}{l}\text { Lati- } \\
\text { tude, in } \\
\text { decimal } \\
\text { degrees }\end{array}$ & $\begin{array}{l}\text { Long1- } \\
\text { tude, in } \\
\text { decimel } \\
\text { degrees }\end{array}$ & $\begin{array}{l}\text { Years } \\
\text { of } \\
\text { record }\end{array}$ & $\begin{array}{c}\text { Drainage } \\
\text { orea, in } \\
\text { square } \\
\text { miles }\end{array}$ & $\begin{array}{l}\text { Mean } \\
\text { besin } \\
\text { eleva- } \\
\text { tion, } \\
\text { in } \\
\text { feet }\end{array}$ & $\begin{array}{l}\text { Mean } \\
\text { annual } \\
\text { precipi- } \\
\text { tation, } \\
\text { in } \\
\text { inches }\end{array}$ & $\begin{array}{l}\text { Mean } \\
\text { annual } \\
\text { evapor- } \\
\text { ation, } \\
\text { in } \\
\text { inches }\end{array}$ \\
\hline 09408200 & $\begin{array}{l}\text { Fort Pierce Wash near St. George, } \\
\text { Utah }\end{array}$ & 8 & 37.060 & 113.544 & 11 & $1,650.00$ & 4.870 & 9.0 & 59.4 \\
\hline 09408400 & $\begin{array}{l}\text { Santa Clara River near Pine Valley, } \\
\text { Utah }\end{array}$ & 8 & 37.383 & 113.482 & 27 & 18.70 & 8,720 & 27.3 & 43.8 \\
\hline 09409500 & Moody Wash near Veyo, Utah & 8 & 37.433 & 113.742 & 15 & 33.00 & 6,070 & 13.7 & 45.2 \\
\hline 09410000 & $\begin{array}{l}\text { Santa Clare River above Windsor } \\
\text { Dam near Santa Clara, Utah }\end{array}$ & 8 & 37.218 & 113.776 & 30 & 338.00 & 5,900 & 15.6 & 55.2 \\
\hline 10242440 & $\begin{array}{l}\text { Cottonwood Creek near Enterprise, } \\
\text { Utah }\end{array}$ & 8 & 37.567 & 113.700 & 11 & 6.00 & 6,110 & 11.0 & 57.4 \\
\hline 09093500 & $\begin{array}{l}\text { Parachute Creek at Grand Valley. } \\
\text { Colo. }\end{array}$ & 9 & 39.453 & 108.059 & 21 & 198.00 & 7,500 & 16.0 & 40.8 \\
\hline 09095000 & Roan Creek near De Beque, Colo. & 9 & 39.453 & 108.316 & 23 & 321.00 & 7,500 & 18.0 & 40.0 \\
\hline 09128500 & Smith Fork near Crawford, Colo. & 9 & 38.728 & 107.506 & 50 & 42.80 & 9,200 & 23.0 & 40.1 \\
\hline 09130500 & $\begin{array}{l}\text { East Muddy Creek near Bardine, } \\
\text { Colo. }\end{array}$ & 9 & 39.013 & 107.358 & 19 & 133.00 & 8,700 & 26.0 & 40.8 \\
\hline 09132500 & $\begin{array}{l}\text { North Fork Gunnison River } \\
\text { near Somerset, Colo. }\end{array}$ & 9 & 38.929 & 107.448 & 52 & 526.00 & 8,900 & 25.0 & 40.2 \\
\hline 09134500 & $\begin{array}{l}\text { Leroux Creek near Cedaredge, } \\
\text { Colo. }\end{array}$ & 9 & 38.927 & 107.793 & 29 & 34.50 & 9,700 & 33.0 & 40.0 \\
\hline 09241000 & Elk River at Clark, Colo. & 9 & 40.717 & 106.915 & 58 & 216.00 & 9,000 & 37.0 & 39.1 \\
\hline 09244100 & Fish Creek near Milner, Colo. & 9 & 40.334 & 107.139 & 18 & 34.50 & 8,200 & 23.0 & 40.0 \\
\hline 09245000 & Elkhead Croek near Elkhead, Colo. & 9 & 40.670 & 107.285 & 34 & 64.20 & 8.400 & 26.0 & 40.0 \\
\hline 09245500 & $\begin{array}{l}\text { North Fork Elkhead Creek near } \\
\text { Elkhead, Colo. }\end{array}$ & 9 & 40.681 & 107.287 & 15 & 21.00 & 8.600 & 41.0 & 40.0 \\
\hline 09248600 & $\begin{array}{l}\text { East Fork of Williams Fork above } \\
\text { Willow Creek, Colo. }\end{array}$ & 9 & 40.261 & 107.294 & 16 & 108.00 & 9,600 & 29.0 & 40.0 \\
\hline 09249000 & $\begin{array}{l}\text { East Fork of Williams Fork near } \\
\text { Pagoda, Colo. }\end{array}$ & 9 & 40.312 & 107.319 & 18 & 150.00 & 9,200 & 26.0 & 40.0 \\
\hline 09249200 & $\begin{array}{l}\text { South Fork of Williams Fork near } \\
\text { Pagoda, Colo. }\end{array}$ & 9 & 40.212 & 107.442 & 13 & 46.70 & 9,200 & 32.0 & 40.0 \\
\hline 09250000 & Milk Creek near Thornburs, Colo. & 9 & 40.194 & 107.732 & 34 & 65.00 & 7,800 & 18.0 & 40.0 \\
\hline 09253000 & Little Snake River near Slater, Colo. & 9 & 40.999 & 107.143 & 40 & 285.00 & 8,600 & 31.0 & 40.0 \\
\hline 09255000 & Slater Fork near Slater, Colo. & 9 & 40.982 & 107.383 & 55 & 161.00 & 8.400 & 22.0 & 41.1 \\
\hline 09255500 & $\begin{array}{l}\text { Savery Creek at Upper Station, } \\
\text { near Savery, Wyo. }\end{array}$ & 9 & 41.218 & 107.372 & 23 & 200.00 & 7,790 & 21.0 & 41.9 \\
\hline 09256000 & Savery Creek near Savery, Wyo. & 9 & 41.098 & 107.381 & 32 & 330.00 & 7,870 & 19.0 & 41.7 \\
\hline 09257000 & $\begin{array}{l}\text { Little Snake River near Dixon, } \\
\text { Wyo. }\end{array}$ & 9 & 41.028 & 107.549 & 52 & 988.00 & 8,030 & 18.0 & 41.8 \\
\hline
\end{tabular}




\begin{tabular}{|c|c|c|c|c|c|c|c|c|c|c|c|c|}
\hline \multirow[b]{2}{*}{$\begin{array}{l}\text { Station } \\
\text { number }\end{array}$} & \multicolumn{5}{|c|}{$\begin{array}{c}\text { Relation } \\
\text { characteristic }\end{array}$} & \multicolumn{6}{|c|}{$\begin{array}{l}\text { Peak discharge (cubic feet per second) for } \\
\text { indicated recurrence interval (years) }\end{array}$} & \multirow{2}{*}{$\begin{array}{l}\text { Maximum } \\
\text { peak dischsrge } \\
\text { of record } \\
\text { (cubic feet } \\
\text { per second) }\end{array}$} \\
\hline & $\frac{c h}{L}$ & $\frac{a r e}{H}$ & $\frac{\text { tee }}{D}$ & $\frac{15}{0}$ & $\frac{t i c}{U}$ & 2 & 5 & 10 & 25 & 50 & 100 & \\
\hline 09408150 & 1 & 0 & 0 & 0 & 0 & $\begin{array}{l}5.940 \\
5.900\end{array}$ & $\begin{array}{l}10,400 \\
10,200\end{array}$ & $\begin{array}{l}13,900 \\
13,300\end{array}$ & $\begin{array}{l}19,100 \\
17,700\end{array}$ & $\begin{array}{l}23,500 \\
21,500\end{array}$ & $\begin{array}{l}28,400 \\
25,600\end{array}$ & 20,100 \\
\hline 09408200 & 1 & 0 & 0 & 0 & 0 & $\begin{array}{l}2,340 \\
2,420\end{array}$ & $\begin{array}{l}4,500 \\
5.060\end{array}$ & $\begin{array}{l}6.360 \\
7.840\end{array}$ & $\begin{array}{r}9,240 \\
12,700\end{array}$ & $\begin{array}{l}11,800 \\
17,200\end{array}$ & $\begin{array}{l}14,700 \\
22,000\end{array}$ & 8,760 \\
\hline 09408400 & 0 & 1 & 0 & 0 & 0 & $\begin{array}{l}75 \\
78\end{array}$ & $\begin{array}{l}163 \\
184\end{array}$ & $\begin{array}{l}250 \\
312\end{array}$ & $\begin{array}{l}406 \\
566\end{array}$ & $\begin{array}{l}561 \\
826\end{array}$ & $\begin{array}{r}758 \\
1,160\end{array}$ & 776 \\
\hline 09409500 & 1 & 0 & 1 & 0 & 0 & $\begin{array}{l}267 \\
274\end{array}$ & $\begin{array}{l}868 \\
900\end{array}$ & $\begin{array}{l}1,560 \\
1,610\end{array}$ & $\begin{array}{l}2,830 \\
2,860\end{array}$ & $\begin{array}{l}4,110 \\
4,040\end{array}$ & $\begin{array}{l}5,700 \\
5,410\end{array}$ & 1,810 \\
\hline 09410000 & 0 & 0 & 0 & 0 & 0 & $\begin{array}{l}940 \\
951\end{array}$ & $\begin{array}{l}2,380 \\
2,440\end{array}$ & $\begin{array}{l}3,850 \\
3,970\end{array}$ & $\begin{array}{l}6,400 \\
6,610\end{array}$ & $\begin{array}{l}8,850 \\
8,090\end{array}$ & $\begin{array}{l}11,800 \\
12,000\end{array}$ & 6,190 \\
\hline 10242000 & 1 & 0 & 0 & 0 & 0 & $\begin{array}{l}785 \\
784\end{array}$ & $\begin{array}{l}1,660 \\
1,650\end{array}$ & $\begin{array}{l}2,490 \\
2,450\end{array}$ & $\begin{array}{l}3,870 \\
3,750\end{array}$ & $\begin{array}{l}5,170 \\
4,960\end{array}$ & $\begin{array}{l}6,730 \\
6,340\end{array}$ & 4.620 \\
\hline 10242100 & 0 & 0 & 0 & 0 & 0 & $\begin{array}{l}269 \\
269\end{array}$ & $\begin{array}{l}495 \\
501\end{array}$ & $\begin{array}{l}684 \\
709\end{array}$ & $\begin{array}{r}969 \\
1.060\end{array}$ & $\begin{array}{l}1,220 \\
1,390\end{array}$ & $\begin{array}{l}1,490 \\
1,760\end{array}$ & 1,070 \\
\hline 10242440 & 1 & 1 & 0 & 0 & 0 & $\begin{array}{l}145 \\
148\end{array}$ & $\begin{array}{l}398 \\
418\end{array}$ & $\begin{array}{l}684 \\
729\end{array}$ & $\begin{array}{l}1,240 \\
1,310\end{array}$ & $\begin{array}{l}1,820 \\
1,890\end{array}$ & $\begin{array}{l}2,600 \\
2,590\end{array}$ & 1,670 \\
\hline 09093500 & 0 & 0 & 0 & 0 & 0 & $\begin{array}{l}429 \\
430\end{array}$ & $\begin{array}{l}886 \\
888\end{array}$ & $\begin{array}{l}1.290 \\
1.290\end{array}$ & $\begin{array}{l}1.920 \\
1.920\end{array}$ & $\begin{array}{l}2,490 \\
2,510\end{array}$ & $\begin{array}{l}3,130 \\
3,120\end{array}$ & 2,600 \\
\hline 09095000 & 0 & 0 & 0 & 0 & 0 & $\begin{array}{l}567 \\
568\end{array}$ & $\begin{array}{l}1,110 \\
1,110\end{array}$ & $\begin{array}{l}1,530 \\
1,540\end{array}$ & $\begin{array}{l}2,120 \\
2,160\end{array}$ & $\begin{array}{l}2,590 \\
2,680\end{array}$ & $\begin{array}{l}3,090 \\
3,190\end{array}$ & 2,020 \\
\hline 09128500 & 1 & 0 & 0 & 0 & 0 & $\begin{array}{l}375 \\
375\end{array}$ & $\begin{array}{l}578 \\
581\end{array}$ & $\begin{array}{l}734 \\
742\end{array}$ & $\begin{array}{l}956 \\
969\end{array}$ & $\begin{array}{l}1,160 \\
1,150\end{array}$ & $\begin{array}{l}1,340 \\
1,360\end{array}$ & 1,410 \\
\hline 09130500 & 0 & 0 & 0 & 0 & 0 & $\begin{array}{l}914 \\
913\end{array}$ & $\begin{array}{l}1,310 \\
1,310\end{array}$ & $\begin{array}{l}1,590 \\
1,580\end{array}$ & $\begin{array}{l}1.970 \\
1.960\end{array}$ & $\begin{array}{l}2,270 \\
2,260\end{array}$ & $\begin{array}{l}2,590 \\
2,590\end{array}$ & 2,190 \\
\hline 09132500 & 1 & 0 & 0 & 0 & 0 & $\begin{array}{l}3,590 \\
3.590\end{array}$ & $\begin{array}{l}5,060 \\
5,020\end{array}$ & $\begin{array}{l}6,060 \\
5,970\end{array}$ & $\begin{array}{l}7.350 \\
7.160\end{array}$ & $\begin{array}{l}8,320 \\
8,070\end{array}$ & $\begin{array}{l}9,300 \\
8,980\end{array}$ & 9,220 \\
\hline 09134500 & 1 & 0 & 0 & 0 & 0 & $\begin{array}{l}697 \\
696\end{array}$ & $\begin{array}{l}922 \\
919\end{array}$ & $\begin{array}{l}1,070 \\
1,070\end{array}$ & $\begin{array}{l}1,250 \\
1,240\end{array}$ & $\begin{array}{l}1,380 \\
1,360\end{array}$ & $\begin{array}{l}1,520 \\
1,510\end{array}$ & 1,310 \\
\hline 09137800 & 0 & 0 & 0 & 1 & 0 & $\begin{array}{l}44 \\
47\end{array}$ & $\begin{array}{l}68 \\
91\end{array}$ & $\begin{array}{r}84 \\
142\end{array}$ & $\begin{array}{l}104 \\
210\end{array}$ & $\begin{array}{l}118 \\
249\end{array}$ & $\begin{array}{l}132 \\
305\end{array}$ & 86 \\
\hline 09141200 & 0 & 0 & 0 & 1 & 0 & $\begin{array}{l}55 \\
57\end{array}$ & $\begin{array}{l}72 \\
91\end{array}$ & $\begin{array}{r}81 \\
133\end{array}$ & $\begin{array}{r}92 \\
193\end{array}$ & $\begin{array}{r}99 \\
232\end{array}$ & $\begin{array}{l}106 \\
283\end{array}$ & 86 \\
\hline 09238500 & 0 & 0 & 0 & 0 & 0 & $\begin{array}{l}1,380 \\
1,370\end{array}$ & $\begin{array}{l}1,830 \\
1,790\end{array}$ & $\begin{array}{l}2,110 \\
2,020\end{array}$ & $\begin{array}{l}2,460 \\
2,300\end{array}$ & $\begin{array}{l}2,710 \\
2,500\end{array}$ & $\begin{array}{l}2,960 \\
2,720\end{array}$ & 2,800 \\
\hline 09239500 & 0 & 0 & 0 & 0 & 0 & $\begin{array}{l}3,700 \\
3,700\end{array}$ & $\begin{array}{l}4,650 \\
4,630\end{array}$ & $\begin{array}{l}5,190 \\
5.150\end{array}$ & $\begin{array}{l}5,800 \\
5,740\end{array}$ & $\begin{array}{l}6.210 \\
6.140\end{array}$ & $\begin{array}{l}6,580 \\
6,510\end{array}$ & 6,820 \\
\hline 09241000 & 1 & 0 & 0 & 0 & 0 & $\begin{array}{l}2,670 \\
2,670\end{array}$ & $\begin{array}{l}3,360 \\
3,340\end{array}$ & $\begin{array}{l}3,780 \\
3,730\end{array}$ & $\begin{array}{l}4,260 \\
4,180\end{array}$ & $\begin{array}{l}4,590 \\
4,490\end{array}$ & $\begin{array}{l}4,900 \\
4,790\end{array}$ & 4.910 \\
\hline 09244100 & 0 & 0 & 0 & 0 & 0 & $\begin{array}{l}159 \\
160\end{array}$ & $\begin{array}{l}245 \\
255\end{array}$ & $\begin{array}{l}303 \\
336\end{array}$ & $\begin{array}{l}373 \\
452\end{array}$ & $\begin{array}{l}424 \\
549\end{array}$ & $\begin{array}{l}473 \\
641\end{array}$ & 342 \\
\hline 09245000 & 1 & 0 & 0 & 0 & 0 & $\begin{array}{l}1.020 \\
1.020\end{array}$ & $\begin{array}{l}1.460 \\
1.440\end{array}$ & $\begin{array}{l}1,770 \\
1,730\end{array}$ & $\begin{array}{l}2,180 \\
2,110\end{array}$ & $\begin{array}{l}2,490 \\
2,410\end{array}$ & $\begin{array}{l}2,810 \\
2,710\end{array}$ & 2,850 \\
\hline 09245500 & 0 & 0 & 0 & 0 & 0 & $\begin{array}{l}402 \\
401\end{array}$ & $\begin{array}{l}652 \\
642\end{array}$ & $\begin{array}{l}838 \\
813\end{array}$ & $\begin{array}{l}1,100 \\
1,050\end{array}$ & $\begin{array}{l}1,300 \\
1,240\end{array}$ & $\begin{array}{l}1.520 \\
1,440\end{array}$ & 1,100 \\
\hline 09248600 & 0 & 0 & 0 & 0 & 0 & $\begin{array}{l}1,010 \\
1,010\end{array}$ & $\begin{array}{l}1,290 \\
1,300\end{array}$ & $\begin{array}{l}1,460 \\
1,480\end{array}$ & $\begin{array}{l}1.650 \\
1.690\end{array}$ & $\begin{array}{l}1,790 \\
1,830\end{array}$ & $\begin{array}{l}1,930 \\
2,010\end{array}$ & 1,570 \\
\hline 09249000 & 0 & 0 & 0 & 0 & 0 & $\begin{array}{l}923 \\
924\end{array}$ & $\begin{array}{l}1,240 \\
1,250\end{array}$ & $\begin{array}{l}1,450 \\
1,480\end{array}$ & $\begin{array}{l}1,710 \\
1,770\end{array}$ & $\begin{array}{l}1,910 \\
1,980\end{array}$ & $\begin{array}{l}2,100 \\
2,210\end{array}$ & 1,620 \\
\hline 09249200 & 1 & 0 & 0 & 0 & 0 & $\begin{array}{l}628 \\
627\end{array}$ & $\begin{array}{l}766 \\
769\end{array}$ & $\begin{array}{l}850 \\
869\end{array}$ & $\begin{array}{r}950 \\
1,000\end{array}$ & $\begin{array}{l}1,020 \\
1,100\end{array}$ & $\begin{array}{l}1,090 \\
1,210\end{array}$ & 910 \\
\hline 09250000 & 1 & 0 & 0 & 0 & 0 & $\begin{array}{l}355 \\
355\end{array}$ & $\begin{array}{l}623 \\
622\end{array}$ & $\begin{array}{l}842 \\
841\end{array}$ & $\begin{array}{l}1,170 \\
1,170\end{array}$ & $\begin{array}{l}1,440 \\
1,460\end{array}$ & $\begin{array}{l}1.750 \\
1.760\end{array}$ & 1,580 \\
\hline 09253000 & 0 & 0 & 0 & 0 & 0 & $\begin{array}{l}2,250 \\
2,250\end{array}$ & $\begin{array}{l}3,050 \\
3,030\end{array}$ & $\begin{array}{l}3,550 \\
3,490\end{array}$ & $\begin{array}{l}4,140 \\
4,050\end{array}$ & $\begin{array}{l}4,550 \\
4,440\end{array}$ & $\begin{array}{l}4,960 \\
4,840\end{array}$ & 4,780 \\
\hline 09255000 & 1 & 0 & 0 & 0 & 0 & $\begin{array}{l}857 \\
857\end{array}$ & $\begin{array}{l}1,210 \\
1,210\end{array}$ & $\begin{array}{l}1.460 \\
1.460\end{array}$ & $\begin{array}{l}1.780 \\
1.790\end{array}$ & $\begin{array}{l}2,020 \\
2,040\end{array}$ & $\begin{array}{l}2,270 \\
2,310\end{array}$ & 2,250 \\
\hline 09255500 & 0 & 0 & 0 & 0 & 0 & $\begin{array}{l}459 \\
460\end{array}$ & $\begin{array}{l}837 \\
844\end{array}$ & $\begin{array}{l}1.140 \\
1.160\end{array}$ & $\begin{array}{l}1,600 \\
1,650\end{array}$ & $\begin{array}{l}1,980 \\
2,070\end{array}$ & $\begin{array}{l}2,400 \\
2,500\end{array}$ & 1,680 \\
\hline 09256000 & 1 & 0 & 0 & 0 & 0 & $\begin{array}{l}1,200 \\
1,200\end{array}$ & $\begin{array}{l}1,660 \\
1,650\end{array}$ & $\begin{array}{l}1.940 \\
1.940\end{array}$ & $\begin{array}{l}2,290 \\
2,320\end{array}$ & $\begin{array}{l}2,530 \\
2,610\end{array}$ & $\begin{array}{l}2,770 \\
2,890\end{array}$ & 2.670 \\
\hline 09257000 & 1 & 0 & 0 & 0 & 0 & $\begin{array}{l}4.680 \\
4.670\end{array}$ & $\begin{array}{l}6,160 \\
6,110\end{array}$ & $\begin{array}{l}7,070 \\
6,950\end{array}$ & $\begin{array}{l}8,170 \\
7,980\end{array}$ & $\begin{array}{l}8,960 \\
8,750\end{array}$ & $\begin{array}{l}9,710 \\
9,470\end{array}$ & 13,000 \\
\hline
\end{tabular}




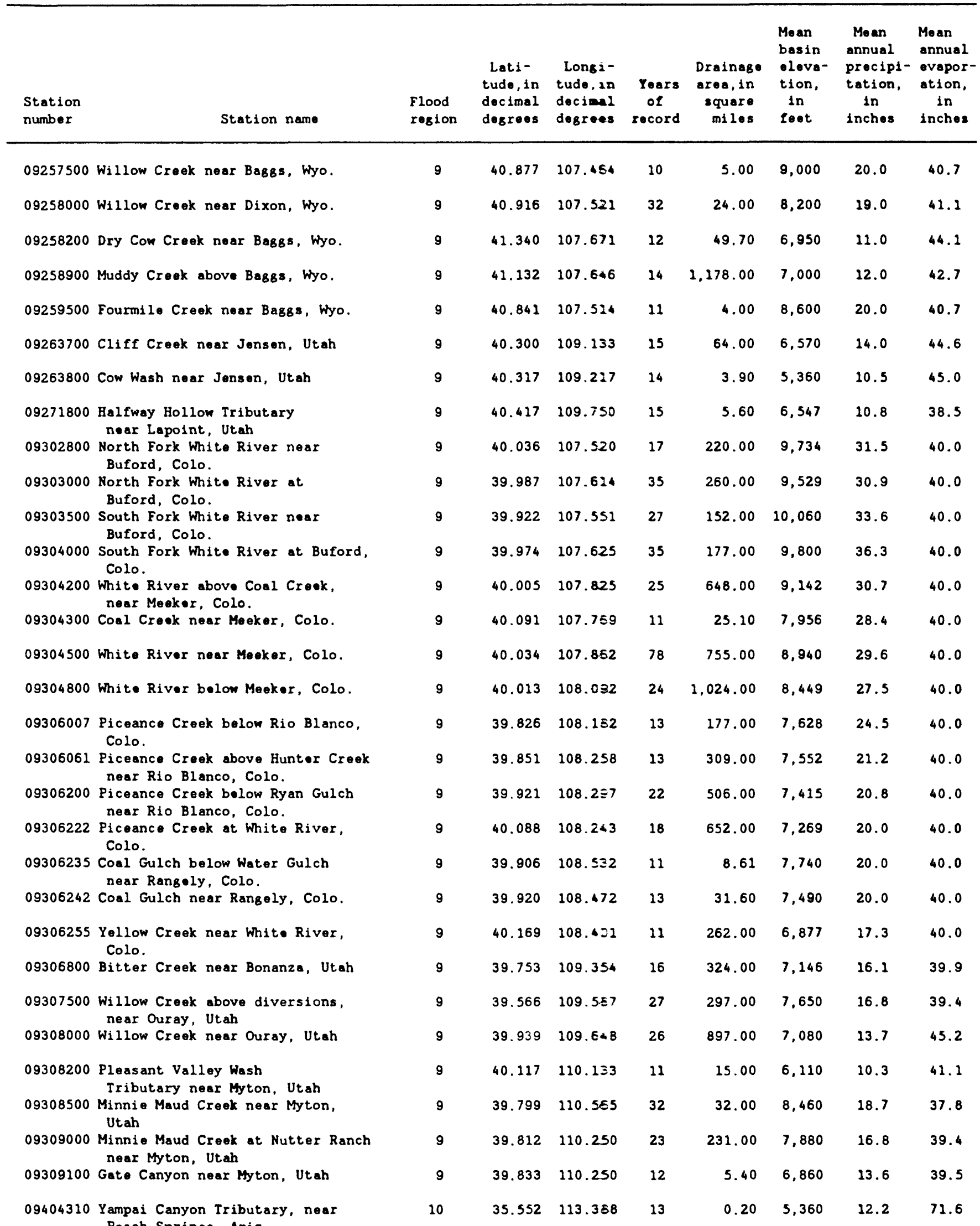




\begin{tabular}{|c|c|c|c|c|c|c|c|c|c|c|c|c|}
\hline \multirow{2}{*}{$\begin{array}{l}\text { Station } \\
\text { number }\end{array}$} & \multicolumn{5}{|c|}{$\begin{array}{c}\text { Relation } \\
\text { characteristic }\end{array}$} & \multicolumn{3}{|c|}{$\begin{array}{l}\text { Peak discharge (cubic } \\
\text { indicated recurrence }\end{array}$} & \multicolumn{3}{|c|}{$\begin{array}{l}\text { feet per second) for } \\
\text { interval (years) }\end{array}$} & \multirow{2}{*}{$\begin{array}{l}\text { Maximum } \\
\text { peak discharge } \\
\text { of record } \\
\text { (cubic feet } \\
\text { per second) }\end{array}$} \\
\hline & 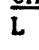 & H & D & 0 & U & 2 & 5 & 10 & 25 & 50 & 100 & \\
\hline 09257500 & 1 & 0 & 0 & 1 & 0 & $\begin{array}{l}89 \\
90\end{array}$ & $\begin{array}{l}102 \\
112\end{array}$ & $\begin{array}{l}109 \\
140\end{array}$ & $\begin{array}{l}117 \\
186\end{array}$ & $\begin{array}{l}122 \\
220\end{array}$ & $\begin{array}{l}127 \\
260\end{array}$ & 115 \\
\hline 09258000 & 1 & 0 & 0 & 0 & 0 & $\begin{array}{l}161 \\
161\end{array}$ & $\begin{array}{l}260 \\
264\end{array}$ & $\begin{array}{l}329 \\
341\end{array}$ & $\begin{array}{l}419 \\
450\end{array}$ & $\begin{array}{l}486 \\
538\end{array}$ & $\begin{array}{l}554 \\
625\end{array}$ & 476 \\
\hline 09258200 & - & - & - & - & 1 & 193 & 374 & 565 & 944 & 1,430 & 1,650 & 853 \\
\hline 09258900 & 0 & 0 & 0 & 0 & 0 & $\begin{array}{l}647 \\
654\end{array}$ & $\begin{array}{l}1,330 \\
1,360\end{array}$ & $\begin{array}{l}1,920 \\
2,000\end{array}$ & $\begin{array}{l}2,800 \\
3,030\end{array}$ & $\begin{array}{l}3,560 \\
4,020\end{array}$ & $\begin{array}{l}4,400 \\
4,920\end{array}$ & 2,650 \\
\hline 09259500 & 0 & 0 & 0 & 0 & 0 & $\begin{array}{l}81 \\
81\end{array}$ & $\begin{array}{l}131 \\
135\end{array}$ & $\begin{array}{l}167 \\
180\end{array}$ & $\begin{array}{l}214 \\
246\end{array}$ & $\begin{array}{l}250 \\
300\end{array}$ & $\begin{array}{l}286 \\
353\end{array}$ & 168 \\
\hline 09263700 & 1 & 0 & 0 & 0 & 0 & $\begin{array}{l}183 \\
183\end{array}$ & $\begin{array}{l}754 \\
735\end{array}$ & $\begin{array}{l}1,500 \\
1,410\end{array}$ & $\begin{array}{l}2,990 \\
2,680\end{array}$ & $\begin{array}{l}4,590 \\
4,040\end{array}$ & $\begin{array}{l}6,640 \\
5,640\end{array}$ & 1,360 \\
\hline 09263800 & 1 & 1 & 0 & 1 & 0 & $\begin{array}{l}311 \\
308\end{array}$ & $\begin{array}{l}770 \\
732\end{array}$ & $\begin{array}{l}1,270 \\
1,140\end{array}$ & $\begin{array}{l}2,210 \\
1,880\end{array}$ & $\begin{array}{l}3,200 \\
2,670\end{array}$ & $\begin{array}{l}4,490 \\
3,620\end{array}$ & 2,950 \\
\hline 09271800 & 1 & 0 & 0 & 0 & 0 & $\begin{array}{l}93 \\
93\end{array}$ & $\begin{array}{l}288 \\
279\end{array}$ & $\begin{array}{l}510 \\
475\end{array}$ & $\begin{array}{l}926 \\
830\end{array}$ & $\begin{array}{l}1,350 \\
1,200\end{array}$ & $\begin{array}{l}1,890 \\
1,630\end{array}$ & 702 \\
\hline 09302800 & 1 & 0 & 0 & 0 & 0 & $\begin{array}{l}1,330 \\
1,330\end{array}$ & $\begin{array}{l}1,610 \\
1,630\end{array}$ & $\begin{array}{l}1.780 \\
1.840\end{array}$ & $\begin{array}{l}1,980 \\
2.090\end{array}$ & $\begin{array}{l}2,120 \\
2,230\end{array}$ & $\begin{array}{l}2,250 \\
2,430\end{array}$ & 1,950 \\
\hline 09303000 & 1 & 1 & 0 & 0 & 0 & $\begin{array}{l}1,390 \\
1,390\end{array}$ & $\begin{array}{l}1,860 \\
1,870\end{array}$ & $\begin{array}{l}2,170 \\
2,190\end{array}$ & $\begin{array}{l}2,570 \\
2,590\end{array}$ & $\begin{array}{l}2,870 \\
2,880\end{array}$ & $\begin{array}{l}3,180 \\
3,210\end{array}$ & 3,550 \\
\hline 09303500 & 1 & 0 & 0 & 0 & 0 & $\begin{array}{l}1,870 \\
1,870\end{array}$ & $\begin{array}{l}2,380 \\
2,370\end{array}$ & $\begin{array}{l}2,710 \\
2,680\end{array}$ & $\begin{array}{l}3,110 \\
3.040\end{array}$ & $\begin{array}{l}3,410 \\
3,300\end{array}$ & $\begin{array}{l}3,700 \\
3,580\end{array}$ & 3,620 \\
\hline 09304000 & 1 & 0 & 0 & 0 & 0 & $\begin{array}{l}1,940 \\
1,940\end{array}$ & $\begin{array}{l}2,380 \\
2,370\end{array}$ & $\begin{array}{l}2.650 \\
2.630\end{array}$ & $\begin{array}{l}2,970 \\
2,930\end{array}$ & $\begin{array}{l}3,200 \\
3,140\end{array}$ & $\begin{array}{l}3,430 \\
3,380\end{array}$ & 3,150 \\
\hline 09304200 & 1 & 0 & 0 & 0 & 0 & $\begin{array}{l}3,300 \\
3,300\end{array}$ & $\begin{array}{l}4,290 \\
4,260\end{array}$ & $\begin{array}{l}4.900 \\
4.820\end{array}$ & $\begin{array}{l}5,640 \\
5,500\end{array}$ & $\begin{array}{l}6.180 \\
5.990\end{array}$ & $\begin{array}{l}6,700 \\
6.490\end{array}$ & 5,740 \\
\hline 09304300 & 0 & 0 & 0 & 1 & 0 & $\begin{array}{l}49 \\
51\end{array}$ & $\begin{array}{r}80 \\
100\end{array}$ & $\begin{array}{l}102 \\
161\end{array}$ & $\begin{array}{l}131 \\
267\end{array}$ & $\begin{array}{l}153 \\
364\end{array}$ & $\begin{array}{l}176 \\
452\end{array}$ & 102 \\
\hline 09304500 & 1 & 0 & 0 & 0 & 0 & $\begin{array}{l}3,270 \\
3,270\end{array}$ & $\begin{array}{l}4,260 \\
4,250\end{array}$ & $\begin{array}{l}4,900 \\
4,880\end{array}$ & $\begin{array}{l}5.710 \\
5,670\end{array}$ & $\begin{array}{l}6.300 \\
6.240\end{array}$ & $\begin{array}{l}6,890 \\
6,830\end{array}$ & 6,950 \\
\hline 09304800 & 1 & 0 & 0 & 0 & 0 & $\begin{array}{l}3,400 \\
3,390\end{array}$ & $\begin{array}{l}4,540 \\
4,500\end{array}$ & $\begin{array}{l}5,280 \\
5,180\end{array}$ & $\begin{array}{l}6,180 \\
6,030\end{array}$ & $\begin{array}{l}6,840 \\
6,680\end{array}$ & $\begin{array}{l}7.490 \\
7,330\end{array}$ & 6,590 \\
\hline 09306007 & 1 & 0 & 0 & 0 & 0 & $\begin{array}{l}201 \\
205\end{array}$ & $\begin{array}{l}359 \\
392\end{array}$ & $\begin{array}{l}485 \\
578\end{array}$ & $\begin{array}{l}668 \\
885\end{array}$ & $\begin{array}{r}820 \\
1,170\end{array}$ & $\begin{array}{r}986 \\
1,430\end{array}$ & 520 \\
\hline 09306061 & 0 & 0 & 0 & 0 & 0 & $\begin{array}{l}200 \\
206\end{array}$ & $\begin{array}{l}403 \\
449\end{array}$ & $\begin{array}{l}576 \\
701\end{array}$ & $\begin{array}{r}835 \\
1,120\end{array}$ & $\begin{array}{l}1,060 \\
1,510\end{array}$ & $\begin{array}{l}1,300 \\
1,860\end{array}$ & 612 \\
\hline 09306200 & 0 & 0 & 0 & 1 & 0 & $\begin{array}{l}141 \\
146\end{array}$ & $\begin{array}{l}268 \\
309\end{array}$ & $\begin{array}{l}381 \\
499\end{array}$ & $\begin{array}{l}561 \\
835\end{array}$ & $\begin{array}{r}726 \\
1,170\end{array}$ & $\begin{array}{r}919 \\
1,480\end{array}$ & 550 \\
\hline 09306222 & 0 & 0 & 0 & 1 & 0 & $\begin{array}{l}238 \\
244\end{array}$ & $\begin{array}{l}429 \\
477\end{array}$ & $\begin{array}{l}578 \\
717\end{array}$ & $\begin{array}{r}789 \\
1,130\end{array}$ & $\begin{array}{r}961 \\
1,530\end{array}$ & $\begin{array}{l}1,140 \\
1,870\end{array}$ & 625 \\
\hline 09306235 & 0 & 0 & 0 & 0 & 0 & $\begin{array}{l}15 \\
16\end{array}$ & $\begin{array}{r}97 \\
104\end{array}$ & $\begin{array}{l}256 \\
262\end{array}$ & $\begin{array}{l}717 \\
667\end{array}$ & $\begin{array}{l}1,390 \\
1,220\end{array}$ & $\begin{array}{l}2,530 \\
2,060\end{array}$ & 272 \\
\hline 09306242 & 0 & 0 & 0 & 0 & 0 & $\begin{array}{l}64 \\
65\end{array}$ & $\begin{array}{l}312 \\
315\end{array}$ & $\begin{array}{l}717 \\
696\end{array}$ & $\begin{array}{l}1.750 \\
1.590\end{array}$ & $\begin{array}{l}3,100 \\
2,700\end{array}$ & $\begin{array}{l}5,210 \\
4,310\end{array}$ & 1.780 \\
\hline 09306255 & - & - & - & - & 1 & 508 & 854 & 1,240 & 2,020 & 3,020 & 3,460 & 6,800 \\
\hline 09306800 & 0 & 0 & 0 & 0 & 0 & $\begin{array}{l}125 \\
130\end{array}$ & $\begin{array}{l}546 \\
570\end{array}$ & $\begin{array}{l}1,160 \\
1,190\end{array}$ & $\begin{array}{l}2,540 \\
2,510\end{array}$ & $\begin{array}{l}4,200 \\
4,050\end{array}$ & $\begin{array}{l}6,540 \\
6,000\end{array}$ & 1,790 \\
\hline 09307500 & 1 & 1 & 0 & 0 & 0 & $\begin{array}{l}242 \\
245\end{array}$ & $\begin{array}{l}470 \\
491\end{array}$ & $\begin{array}{l}689 \\
747\end{array}$ & $\begin{array}{l}1,070 \\
1,200\end{array}$ & $\begin{array}{l}1,440 \\
1,630\end{array}$ & $\begin{array}{l}1,900 \\
2,120\end{array}$ & 2,240 \\
\hline 09308000 & 1 & 1 & 0 & 0 & 0 & $\begin{array}{l}663 \\
666\end{array}$ & $\begin{array}{l}1,740 \\
1,740\end{array}$ & $\begin{array}{l}2,980 \\
2,950\end{array}$ & $\begin{array}{l}5,400 \\
5,230\end{array}$ & $\begin{array}{l}8,020 \\
7,700\end{array}$ & $\begin{array}{l}11,600 \\
10,900\end{array}$ & 11,000 \\
\hline 09308200 & - & - & - & - & 1 & 59 & 139 & 237 & 469 & 837 & 972 & 2,590 \\
\hline 09308500 & 0 & 0 & 0 & 0 & 0 & $\begin{array}{l}107 \\
108\end{array}$ & $\begin{array}{l}365 \\
369\end{array}$ & $\begin{array}{l}676 \\
677\end{array}$ & $\begin{array}{l}1,280 \\
1,250\end{array}$ & $\begin{array}{l}1,910 \\
1,840\end{array}$ & $\begin{array}{l}2,720 \\
2,570\end{array}$ & 1,370 \\
\hline 09309000 & 1 & 0 & 0 & 0 & 0 & $\begin{array}{l}538 \\
539\end{array}$ & $\begin{array}{l}818 \\
830\end{array}$ & $\begin{array}{l}1,030 \\
1,070\end{array}$ & $\begin{array}{l}1,320 \\
1,420\end{array}$ & $\begin{array}{l}1,560 \\
1,730\end{array}$ & $\begin{array}{l}1,810 \\
2,020\end{array}$ & 1,380 \\
\hline 09309100 & 1 & 0 & 0 & 0 & 0 & $\begin{array}{l}282 \\
279\end{array}$ & $\begin{array}{l}625 \\
594\end{array}$ & $\begin{array}{l}928 \\
836\end{array}$ & $\begin{array}{l}1,390 \\
1,190\end{array}$ & $\begin{array}{l}1,800 \\
1,520\end{array}$ & $\begin{array}{l}2,250 \\
1,850\end{array}$ & 1,000 \\
\hline 09404310 & - & - & - & - & 1 & 5 & 33 & 74 & 141 & 201 & 280 & 177 \\
\hline
\end{tabular}




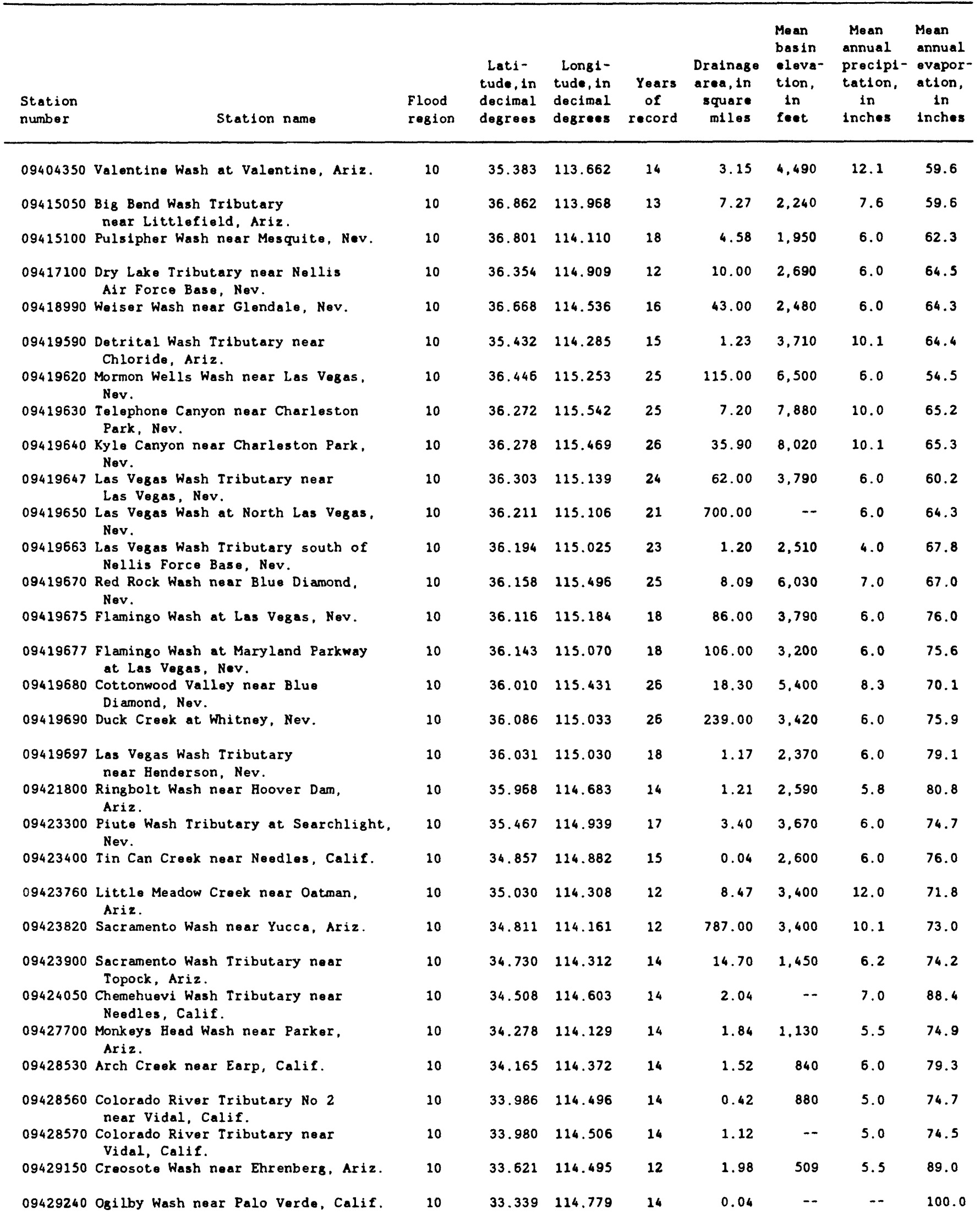




\begin{tabular}{|c|c|c|c|c|c|c|c|c|c|c|c|c|}
\hline \multirow{2}{*}{$\begin{array}{l}\text { Station } \\
\text { number }\end{array}$} & \multicolumn{5}{|c|}{$\begin{array}{c}\text { Relation } \\
\text { characteristic }\end{array}$} & \multicolumn{6}{|c|}{$\begin{array}{l}\text { Peak discharge (cubic feet per second) for } \\
\text { indicated recurrence interval (years) }\end{array}$} & \multirow{2}{*}{$\begin{array}{l}\text { Maximum } \\
\text { peak discharse } \\
\text { of record } \\
\text { (cublc leet } \\
\text { per second) }\end{array}$} \\
\hline & $\mathrm{L}$ & $\mathrm{H}$ & $D$ & 0 & U & 2 & 5 & 10 & 25 & 50 & 100 & \\
\hline \multirow[t]{2}{*}{09404350} & - & - & - & - & 1 & $-\cdots$ & $\cdots$ & $\cdots$ & $\cdots$ & $\cdots$ & $-\cdots$ & 3,800 \\
\hline & & & & & & 23 & 167 & 407 & 843 & 1.270 & 1.880 & \\
\hline \multirow[t]{2}{*}{09415050} & - & - & - & - & 1 & $\cdots$ & $\cdots$ & $\cdots$ & $\cdots$ & $\ldots$ & $\cdots$ & 250 \\
\hline & & & & & & 38 & 274 & 684 & 1,450 & 2,230 & 3,340 & \\
\hline \multirow[t]{2}{*}{09415100} & - & - & - & - & 1 & $-\cdots$ & $-\cdots$ & $\cdots$ & $\ldots$ & $\cdots$ & $\ldots$ & 1,880 \\
\hline & & & & & & 29 & 209 & 516 & 1,080 & 1,640 & 2,430 & \\
\hline \multirow[t]{2}{*}{09417100} & - & - & - & - & 1 & $-\cdots$ & --- & $\cdots$ & $\cdots$ & $\cdots$ & -.. & 180 \\
\hline & & & & & & 46 & 331 & 834 & 1.790 & 2,760 & 4,160 & \\
\hline \multirow[t]{2}{*}{09418990} & - & - & - & - & 1 & $\cdots$ & $\cdots$ & $-\ldots$ & $\cdots$ & $-\cdots$ & $\ldots$ & 584 \\
\hline & & & & & & 106 & 782 & 2,060 & 4,610 & 7,330 & 11.400 & \\
\hline \multirow[t]{2}{*}{09419590} & - & - & - & - & 1 & $-\cdots$ & --- & $\cdots$ & $\cdots$ & $\cdots$ & $\ldots$ & 670 \\
\hline & & & & & & 14 & 96 & 227 & 458 & 678 & 981 & \\
\hline \multirow[t]{2}{*}{09419620} & 0 & 0 & 0 & 0 & 0 & 12 & 71 & 171 & 432 & 773 & 1,300 & 480 \\
\hline & & & & & & 16 & 218 & 610 & 1,190 & 2,300 & 3.030 & \\
\hline 09419630 & - & - & - & - & 1 & $\cdots$ & $\cdots$ & $-\cdots$ & $\cdots$ & $\cdots$ & $\cdots$ & 2,500 \\
\hline & & & & & & 38 & 272 & 680 & 1,460 & 2.210 & 3,320 & \\
\hline 09419640 & - & - & - & - & 1 & $\cdots$ & $\cdots$ & $\cdots$ & $\ldots$ & $\ldots$ & $\ldots$ & 1,660 \\
\hline & & & & & & 96 & 703 & 1,840 & 4,100 & 6,500 & 10,100 & \\
\hline 09419647 & 1 & 0 & 1 & 0 & 0 & 46 & 304 & 825 & 2,410 & 4.850 & 9,120 & 5,130 \\
\hline & & & & & & 48 & 381 & 1,050 & 2,730 & 5,390 & 9,590 & \\
\hline 09419650 & 0 & 1 & 0 & 0 & 0 & 254 & 1,200 & 2,730 & 6,580 & 11.700 & 19,500 & 12,010 \\
\hline & & & & & & 262 & 1,570 & 3,980 & 8,880 & 16,500 & 25,100 & \\
\hline 09419663 & - & - & - & - & 1 & $\cdots$ & $\cdots$ & $\cdots$ & $\cdots$ & $\cdots$ & $\cdots$ & 296 \\
\hline & & & & & & 13 & 95 & 224 & 450 & 667 & 964 & \\
\hline 09419670 & - & - & - & - & 1 & $\ldots$ & $\cdots$ & $\cdots$ & $\cdots$ & $\ldots$ & 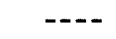 & 7,470 \\
\hline & & & & & & 40 & 292 & 731 & 1,560 & 2,390 & 3,600 & \\
\hline 09419675 & 1 & 0 & 1 & 0 & 0 & 199 & 714 & 1,370 & 2,720 & 4.220 & 6.230 & 3,910 \\
\hline & & & & & & 198 & 783 & 1,660 & 3,270 & 5.350 & 7,560 & \\
\hline 09419677 & 0 & 0 & 0 & 0 & 0 & 264 & 1,210 & 2,650 & 6,090 & 10,400 & 16,800 & 4.700 \\
\hline & & & & & & 261 & 1,230 & 2,800 & 6,360 & 10,900 & 17,300 & \\
\hline 09419680 & - & - & - & - & 1 & $-\cdots$ & $\cdots$ & $\cdots$ & $\cdots$ & $\cdots$ & $-\cdots$ & 1,100 \\
\hline & & & & & & 65 & 472 & 1,210 & 2,650 & 4,140 & 6,320 & \\
\hline 09419690 & 1 & 1 & 0 & 0 & 0 & 337 & 698 & 1,060 & 1,700 & 2,350 & 3,170 & 3,570 \\
\hline & & & & & & 336 & 854 & 1,640 & 2,780 & 4.640 & 5,850 & \\
\hline 09419697 & - & - & - & - & 1 & $\cdots$ & $\cdots$ & $\cdots$ & $\ldots$ & $\ldots$ & $\ldots$ & 1,950 \\
\hline & & & & & & 13 & 93 & 220 & 443 & 655 & 947 & \\
\hline 09421800 & - & - & - & - & 1 & $-\cdots$ & $\cdots$ & -..- & -..- & $\cdots$ & $-\cdots$ & 310 \\
\hline & & & & & & 13 & 95 & 225 & 453 & 670 & 969 & \\
\hline 09423300 & 1 & 0 & 0 & 0 & 0 & 69 & 173 & 275 & 445 & 605 & 793 & 400 \\
\hline & & & & & & 68 & 173 & 301 & 501 & 722 & 930 & \\
\hline 09423400 & - & - & - & - & 1 & $\ldots$ & $\cdots$ & $\cdots$ & $\ldots$ & $\ldots$ & $\ldots$ & 98 \\
\hline & & & & & & 2 & 13 & 27 & 49 & 68 & 92 & \\
\hline 09423760 & - & - & - & - & 1 & $\ldots$ & $\ldots$ & $\cdots$ & $\ldots$ & $\ldots$ &.-- & 869 \\
\hline & & & & & & 41 & 300 & 752 & 1,600 & 2,470 & 3,710 & \\
\hline 09423820 & - & - & - & - & 1 & $\cdots$ & $\cdots$ & $\cdots$ & $\cdots$ & $\ldots$ & $-\cdots$ & 13,000 \\
\hline & & & & & & 574 & 4,350 & 12,500 & 30,500 & 51,400 & 86.700 & \\
\hline 09423900 & - & - & - & - & 1 & $\ldots$ & $\ldots$ & $\cdots$ & $\ldots$ & $\ldots$ & $\ldots$ & 1,030 \\
\hline & & & & & & 57 & 415 & 1,060 & 2,300 & 3,570 & 5,430 & \\
\hline 09424050 & - & - & - & - & 1 & $\cdots$ & $\cdots$ & $\ldots$ & $\ldots$ & $\cdots$ & $\ldots$ & 114 \\
\hline & & & & & & 18 & 129 & 311 & 636 & 951 & 1.390 & \\
\hline 09427700 & 0 & 0 & 0 & 0 & 0 & 18 & 100 & 236 & 572 & 1,000 & 1,640 & 320 \\
\hline & & & & & & 18 & 104 & 247 & 575 & 979 & 1,590 & \\
\hline 09428530 & 0 & 0 & 0 & 0 & 0 & 25 & 193 & 526 & 1,460 & 2,750 & 4.780 & 7,160 \\
\hline & & & & & & 25 & 178 & 473 & 1,320 & 2,380 & 4.280 & \\
\hline 09428560 & - & - & - & - & 1 & $\ldots$ & $\cdots$ & $\cdots$ & $\ldots$ & $\ldots$ & $\ldots$ & 400 \\
\hline & & & & & & 7 & 51 & 117 & 228 & 330 & 467 & \\
\hline 09428570 & - & - & - & - & 1 & --- & $-\cdots$ & $\cdots$ & $\cdots$ & $\ldots$ & $\cdots$ & 460 \\
\hline & & & & & & 13 & 91 & 215 & 431 & 637 & 919 & \\
\hline 09429150 & 0 & 0 & 0 & 0 & 0 & 96 & 240 & 388 & 651 & 910 & 1,230 & 580 \\
\hline & & & & & & 92 & 217 & 370 & 646 & 915 & 1,250 & \\
\hline 09429240 & 0 & 0 & 0 & 0 & 0 & 6 & 15 & 26 & 65 & 64 & 88 & 39 \\
\hline & & & & & & 5 & 15 & 26 & 46 & 65 & 89 & \\
\hline
\end{tabular}




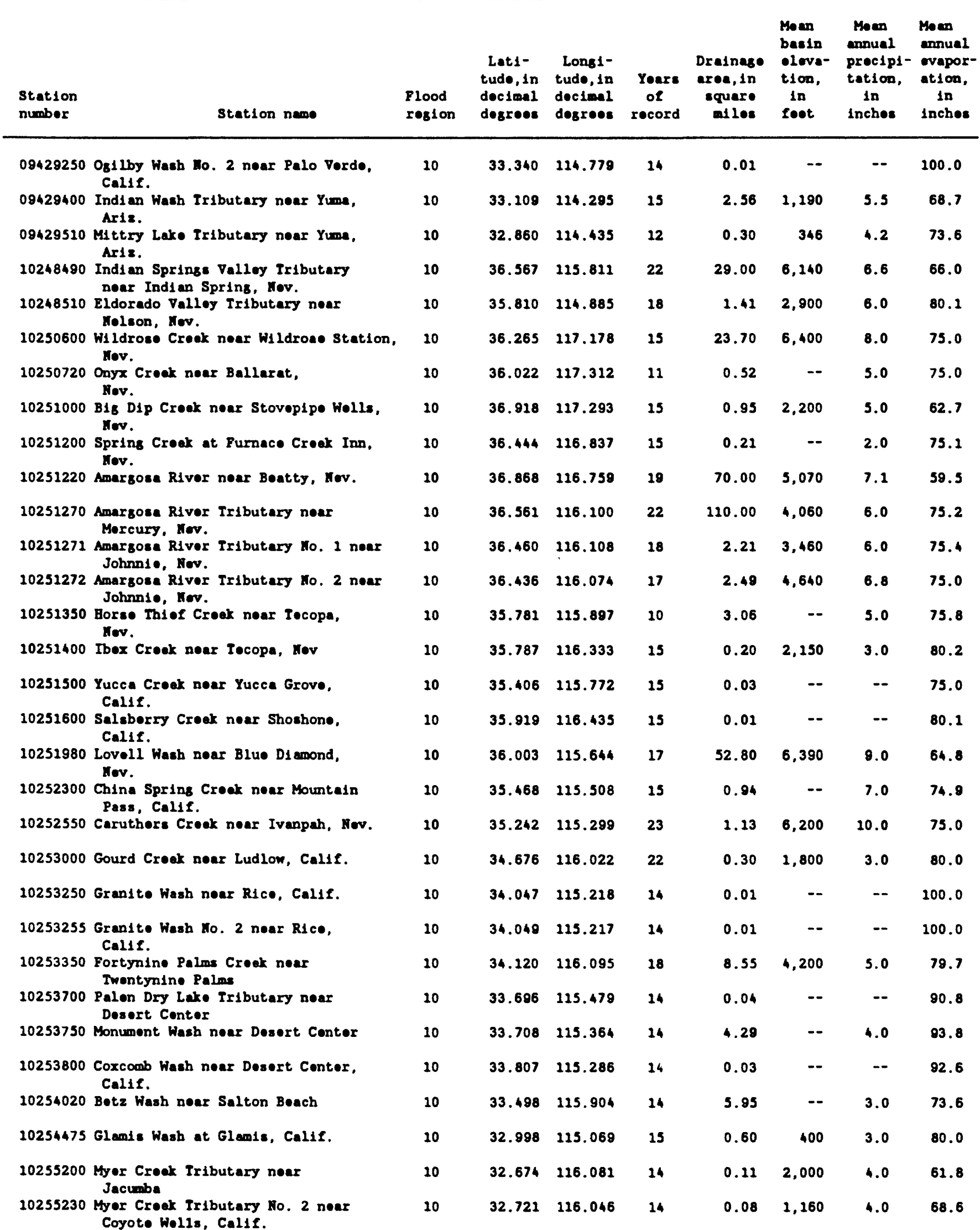




\begin{tabular}{|c|c|c|c|c|c|c|c|c|c|c|c|c|}
\hline \multirow{2}{*}{$\begin{array}{l}\text { Station } \\
\text { number }\end{array}$} & \multicolumn{5}{|c|}{$\begin{array}{c}\text { Relation } \\
\text { characterlstic }\end{array}$} & \multicolumn{6}{|c|}{$\begin{array}{l}\text { Peak discharge (cubic feet per second) for } \\
\text { indicated recurrence interval (years) }\end{array}$} & \multirow{2}{*}{$\begin{array}{l}\text { Maximum } \\
\text { peak discharge } \\
\text { of record } \\
\text { (cubic feet } \\
\text { per second) }\end{array}$} \\
\hline & L & $\mathrm{H}$ & $D$ & 0 & U & 2 & 5 & 10 & 25 & 50 & 100 & \\
\hline \multirow[t]{2}{*}{09429250} & 1 & 0 & 0 & 0 & 0 & 11 & 20 & 26 & 36 & 43 & 51 & 32 \\
\hline & & & & & & 11 & 17 & 23 & 33 & 40 & 49 & \\
\hline \multirow[t]{2}{*}{09429400} & 0 & 0 & 0 & 0 & 0 & 45 & 65 & 79 & 98 & 113 & 129 & 98 \\
\hline & & & & & & 44 & 79 & 131 & 288 & 289 & 322 & \\
\hline \multirow[t]{2}{*}{09429510} & - & - & - & - & 1 & --- & -... & $\ldots$ & $\ldots$ & $\ldots$ & $-\cdots$ & 165 \\
\hline & & & & & & 6 & 42 & 95 & 183 & 263 & 370 & \\
\hline \multirow[t]{2}{*}{10248490} & - & - & - & - & 1 & --- & ---- & --- & --- & $\cdots$ & $=--$ & 497 \\
\hline & & & & & & 85 & 620 & 1.610 & 3,570 & 5,630 & 8,680 & \\
\hline \multirow[t]{2}{*}{10248510} & - & - & - & - & 1 & $\cdots$ & $\cdots$ & $\cdots$ & $\cdots$ & $\cdots$ & $\cdots$ & 530 \\
\hline & & & & & & 15 & 104 & 247 & 500 & 743 & 1,080 & \\
\hline \multirow[t]{2}{*}{10250600} & - & - & - & - & 1 & --- & --- & $-\cdots$ & --- & --- & $-\cdots$ & 1,060 \\
\hline & & & & & & 75 & 550 & 1,420 & 3,130 & 4.920 & 7.550 & \\
\hline \multirow[t]{2}{*}{10250720} & - & - & - & - & 1 & --- & --- & -- & $-\cdots$ & $\cdots$ & --- & 24 \\
\hline & & & & & & 8 & 58 & 133 & 261 & 381 & 541 & \\
\hline 10251000 & 0 & 1 & 0 & 0 & 0 & 13 & 38 & 66 & 122 & 184 & 267 & 199 \\
\hline & & & & & & 13 & 45 & 90 & 160 & 252 & 338 & \\
\hline 10251200 & 0 & 0 & 0 & 0 & 0 & 4 & 12 & 20 & 34 & 48 & 64 & 24 \\
\hline & & & & & & 4 & 16 & 31 & so & 76 & 93 & \\
\hline 10251220 & - & - & - & - & 1 & --- & --- & $\cdots$ & $\cdots$ & $-\cdots$ & --- & 16,000 \\
\hline & & & & & & 426 & 3,210 & 9.070 & 21,800 & 36,400 & 59,300 & \\
\hline 10251270 & 1 & 0 & 1 & 0 & 0 & 35 & 272 & 805 & 2.590 & 5,540 & 11,000 & 3,430 \\
\hline & & & & & & 39 & 408 & 1,200 & 3,190 & 6,590 & 12,000 & \\
\hline 10251271 & - & - & - & - & 1 & $\ldots$ & $-\cdots$ & $-\ldots$ & $\cdots$ & $\cdots$ & $\cdots$ & 350 \\
\hline & & & & & & 19 & 136 & 327 & 670 & 1,000 & 1,470 & \\
\hline 10251272 & - & - & - & - & 1 & ---- & --- & $-\cdots$ & -.- & $-\cdots$ & --- & 125 \\
\hline & & & & & & 20 & 146 & 352 & 724 & 1,090 & 1.600 & \\
\hline 10251350 & - & - & - & - & 1 & --- & --- & --- & --- & $\cdots$ & $-\cdots$ & 850 \\
\hline & & & & & & 23 & 164 & 400 & 828 & 1,250 & 1.840 & \\
\hline 10251400 & - & - & - & - & 1 & --- & $-\cdots$ & --- & ...- & .... & $\ldots$ & 126 \\
\hline & & & & & & 5 & 33 & 74 & 141 & 201 & 280 & \\
\hline 10251500 & - & - & - & - & 1 & $-\cdots$ & --- & -- & $-\cdots$ & --- & $\ldots$ & 24 \\
\hline & & & & & & 2 & 11 & 23 & 41 & 56 & 76 & \\
\hline 10251600 & - & - & - & - & 1 & --- & --- & --- & $\cdots$ & $-\cdots$ & $-\cdots$ & 12 \\
\hline & & & & & & 1 & 6 & 12 & 20 & 27 & 35 & \\
\hline 10251980 & - & - & - & - & 1 & --- & --- & $--\cdot$ & --- & --- & --- & 4,150 \\
\hline & & & & & & 120 & 883 & 2,340 & 5.270 & 8.410 & 13,100 & \\
\hline 10252300 & - & - & - & - & 1 & --- & --- & ---- & $\cdots$ & -- & -- & 113 \\
\hline & & & & & & 12 & 82 & 192 & 384 & 566 & 814 & \\
\hline 10252550 & 0 & 0 & 1 & 0 & 0 & 35 & 235 & 605 & 1,610 & 2,960 & 5,090 & 671 \\
\hline & & & & & & 35 & 218 & 554 & 1,500 & 2,680 & 4,720 & \\
\hline 10253000 & - & - & - & - & 1 & $\cdots$ & 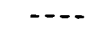 & --- & $\cdots$ & $-\cdots$ & $\cdots$ & 125 \\
\hline & & & & & & 6 & 42 & 95 & 183 & 263 & 370 & \\
\hline 10253250 & - & - & - & - & 1 & $-\cdots$ & --- & $-\cdots$ & -... & $\cdots$ & $-\cdots$ & 22 \\
\hline & & & & & & 1 & 6 & 12 & 20 & 27 & 35 & \\
\hline 10253255 & - & - & - & - & 1 & $\cdots$ & --- & $\cdots$ & $\cdots$ & --- & $-\cdots$ & 27 \\
\hline & & & & & & 1 & 6 & 12 & 20 & 27 & 35 & \\
\hline 10253350 & - & - & - & - & 1 & --- & $-\cdots$ & $-\cdots$ & $-\cdots$ & $\ldots$ & $-\cdot-$ & 1,240 \\
\hline & & & & & & 42 & 301 & 757 & 1,610 & 2,490 & 3,740 & \\
\hline 10253700 & - & - & - & - & 1 & --- & --- & $-\cdots$ & $\cdots$ & $\cdots$ & $\cdots$ & 52 \\
\hline & & & & & & 2 & 13 & 27 & 49 & 68 & 92 & \\
\hline 10253750 & 1 & 0 & 0 & 0 & 0 & 18 & 53 & 89 & 153 & 214 & 287 & 100 \\
\hline & & & & & & 19 & 80 & 169 & 286 & 467 & 565 & \\
\hline 10253800 & - & - & - & - & 1 & $-\cdots$ & --- & --- & --- & --- & $-\cdots$ & 75 \\
\hline & & & & & & 2 & 11 & 23 & 41 & 56 & 76 & \\
\hline 10254020 & - & - & - & - & 1 & $-\cdots$ & $\cdots$ & --- & $\ldots$ & --- & $\ldots$ & 133 \\
\hline & & & & & & 34 & 243 & 604 & 1,280 & 1,950 & 2,910 & \\
\hline 10254475 & - & - & - & - & 1 & $-\cdots$ & --- & --- & $\cdots$ & $-\cdots$ & -- & 86 \\
\hline & & & & & & 9 & 63 & 146 & 287 & 419 & 598 & \\
\hline 10255200 & 0 & 0 & 0 & 0 & 0 & 1 & 8 & 27 & 97 & 216 & 441 & 41 \\
\hline & & & & & & 1 & 11 & 32 & 96 & 201 & 406 & \\
\hline 10255230 & - & - & - & - & 1 & $-\cdots$ & $\cdots$ & --- & $-\ldots$ & $-\cdots$ & $--\cdot$ & 21 \\
\hline & & & & & & 3 & 19 & 42 & 77 & 109 & 149 & \\
\hline
\end{tabular}




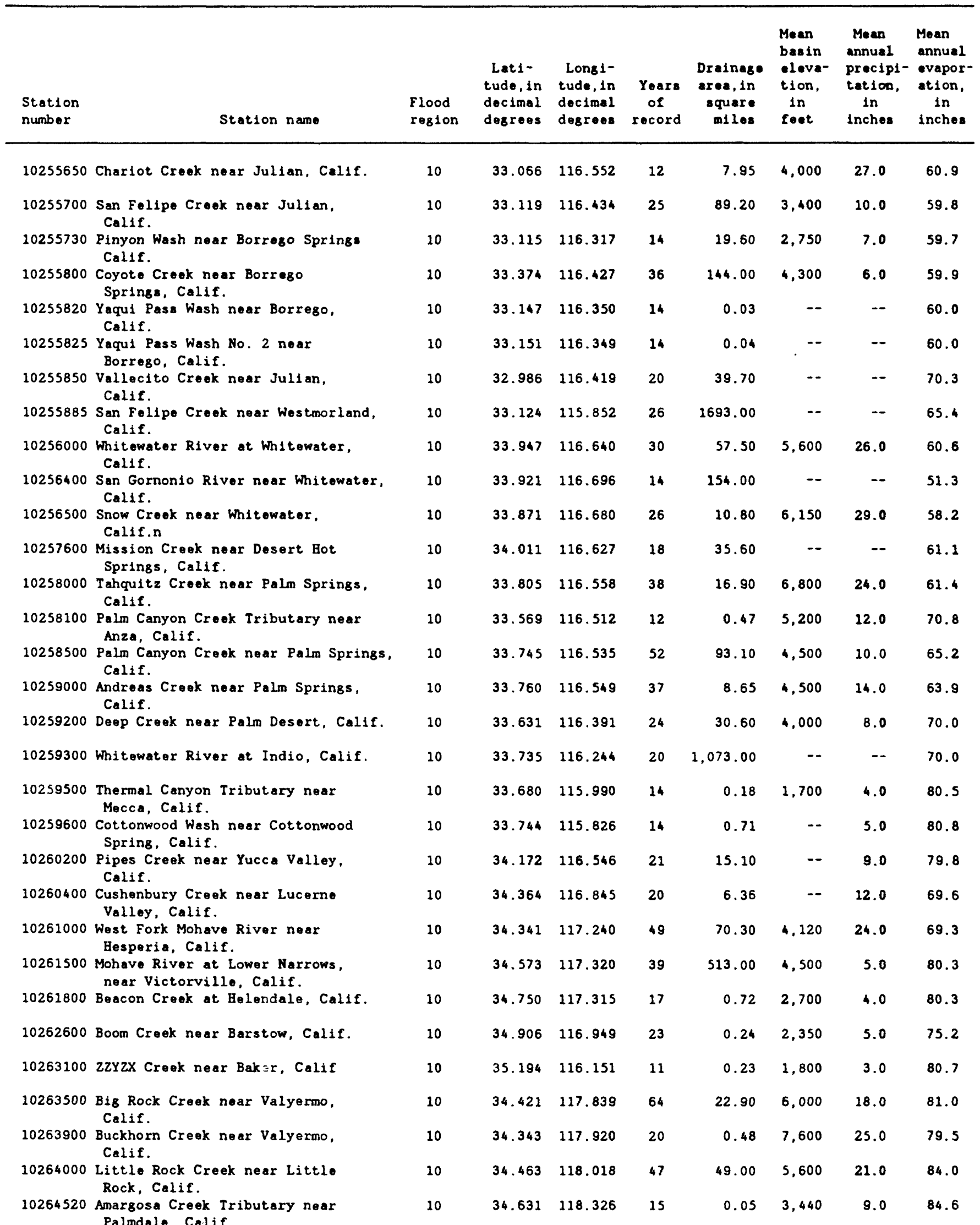




\begin{tabular}{|c|c|c|c|c|c|c|c|c|c|c|c|c|}
\hline \multirow{2}{*}{$\begin{array}{l}\text { Station } \\
\text { number }\end{array}$} & \multicolumn{5}{|c|}{$\begin{array}{c}\text { Relation } \\
\text { characteristic }\end{array}$} & \multicolumn{3}{|c|}{$\begin{array}{l}\text { Peak discharge (cubic } \\
\text { indicated recurrence }\end{array}$} & \multicolumn{3}{|c|}{$\begin{array}{l}\text { feet per second) for } \\
\text { interval (years) }\end{array}$} & \multirow{2}{*}{$\begin{array}{l}\text { Maximum } \\
\text { peak discharse } \\
\text { of record } \\
\text { (cublc feet } \\
\text { per second) }\end{array}$} \\
\hline & $\mathrm{L}$ & 日 & $D$ & 0 & U & 2 & 5 & 10 & 25 & so & 100 & \\
\hline \multirow[t]{2}{*}{10255650} & 0 & 0 & 0 & 0 & 0 & 12 & 77 & 201 & 569 & 1,120 & 2.070 & 340 \\
\hline & & & & & & 14 & 121 & 318 & 736 & 1,380 & 2.300 & \\
\hline \multirow[t]{2}{*}{10255700} & 0 & 1 & 0 & 0 & 0 & 17 & 123 & 370 & 1.280 & 2,960 & 6,460 & 6,150 \\
\hline & & & & & & 21 & 243 & 718 & 1.840 & 3,990 & 7,470 & \\
\hline \multirow[t]{2}{*}{10255730} & - & - & - & - & 1 & $\ldots$ & $\ldots$ & $\ldots$ & $\ldots$ & $\ldots$ & $\ldots$ & 19,200 \\
\hline & & & & & & 67 & 492 & 1,270 & 2.770 & 4,330 & 6,620 & \\
\hline \multirow[t]{2}{*}{10255800} & 0 & 0 & 1 & 0 & 0 & 308 & 1,350 & 2,740 & 5,560 & 8,590 & 12,500 & 3,890 \\
\hline & & & & & & 306 & 1,370 & 2,880 & 5,860 & 9,240 & 13,300 & \\
\hline \multirow[t]{2}{*}{10255820} & 0 & 0 & 0 & 0 & 0 & 2 & 11 & 27 & 68 & 121 & 199 & 38 \\
\hline & & & & & & 2 & 11 & 27 & 64 & 109 & 182 & \\
\hline \multirow[t]{2}{*}{10255825} & 0 & 0 & 0 & 0 & 0 & 2 & 10 & 21 & 45 & 73 & 111 & 25 \\
\hline & & & & & & 2 & 10 & 22 & 46 & 72 & 108 & \\
\hline 10255850 & 1 & 0 & 0 & 0 & 0 & 48 & 241 & 533 & 1,190 & 1,960 & 3,030 & 1,160 \\
\hline & & & & & & 49 & 309 & 743 & 1.540 & 2,650 & 3,800 & \\
\hline 10255885 & 0 & 1 & 0 & 0 & 0 & 2,870 & 8,790 & 16,400 & 32,700 & 52,000 & 79,700 & 100,000 \\
\hline & & & & & & 2.820 & 8,580 & 16,800 & 34.200 & 55,700 & 84,700 & \\
\hline 10256000 & 1 & 0 & 0 & 0 & 0 & 465 & 1,930 & 4.460 & 11,700 & 22,700 & 42,500 & 42,000 \\
\hline & & & & & & 458 & 1,840 & 4.250 & 11,200 & 21,400 & 40,500 & \\
\hline 10256400 & 0 & 0 & 0 & 0 & 0 & 396 & 1.790 & 3.880 & 8,760 & 14,700 & 23,400 & 7.250 \\
\hline & & & & & & 389 & 1,770 & 4,010 & 9,030 & 15,200 & 24,000 & \\
\hline 10256500 & 0 & 0 & 0 & 0 & 0 & 357 & 1,270 & 2,590 & 5.720 & 9,720 & 15,900 & 13,000 \\
\hline & & & & & & 350 & 1,170 & 2,390 & 5,380 & 8,970 & 15,000 & \\
\hline 10257600 & 0 & 0 & 0 & 0 & 0 & 40 & 377 & 1.210 & 4,160 & 9,200 & 18,800 & 1,750 \\
\hline & & & & & & 42 & 425 & 1,310 & 4,150 & 8,780 & 17.800 & \\
\hline 10258000 & 0 & 0 & 0 & 0 & 0 & 91 & 429 & 983 & 2,420 & 4,370 & 7,470 & 2,900 \\
\hline & & & & & & 91 & 431 & 997 & 2,430 & 4,340 & 7,390 & \\
\hline 10258100 & 1 & 0 & 0 & 0 & 0 & 5 & 14 & 22 & 37 & so & 66 & 28 \\
\hline & & & & & & 6 & 22 & 45 & 72 & 115 & 134 & \\
\hline 10258500 & 1 & 0 & 0 & 0 & 0 & 375 & 1,360 & 2.650 & 5,350 & 8,400 & 12,600 & 7,000 \\
\hline & & & & & & 373 & 1,350 & 2.690 & 5,450 & 8,630 & 12,900 & \\
\hline 10259000 & 1 & 0 & 0 & 0 & 0 & 76 & 251 & 490 & 1,030 & 1.700 & 2,700 & 1,960 \\
\hline & & & & & & 75 & 255 & 513 & 1.070 & 1,760 & 2,760 & \\
\hline 10259200 & 1 & 0 & 0 & 0 & 0 & 352 & 1,320 & 2,610 & 5,400 & 8,600 & 13,100 & 7,100 \\
\hline & & & & & & 345 & 1.240 & 2,490 & 5,240 & 8,270 & 12,800 & \\
\hline 10259300 & 0 & 0 & 1 & 0 & 0 & 478 & 4,400 & 13,100 & 39,800 & 79,500 & 145,000 & 14,100 \\
\hline & & & & & & 484 & 4,510 & 13,400 & 39,500 & 77,300 & 141,000 & \\
\hline 10259500 & - & - & - & - & 1 & $\cdots$ & $\ldots$ & $\ldots$ & $\cdots$ & .... & $\ldots$ & 128 \\
\hline & & & & & & 4 & 31 & 69 & 131 & 187 & 260 & \\
\hline 10259600 & - & - & - & - & 1 & $\cdots$ & $\cdots$ & $\cdots$ & $\cdots$ & $\cdots$ & $\cdots$ & 34 \\
\hline & & & & & & 10 & 69 & 162 & 320 & 469 & 671 & \\
\hline 10260200 & - & - & - & - & 1 & $\ldots$ & $\cdots$ & $\cdots$ & $\cdots$ & $\ldots$ & $\cdots$ & 640 \\
\hline & & & & & & 58 & 422 & 1.080 & 2,340 & 3,640 & 5,530 & \\
\hline 10260400 & - & - & - & - & 1 & .... & $\cdots$ & $\ldots$ & $\cdots$ & $\ldots$ & $\ldots$ & 530 \\
\hline & & & & & & 35 & 253 & 630 & 1,330 & 2,040 & 3,050 & \\
\hline 10261000 & 0 & 0 & 1 & 0 & 0 & 1,920 & 6,860 & 13,400 & 27,600 & 44,100 & 67,300 & 26,100 \\
\hline & & & & & & 1,900 & 6,510 & 12,700 & 26,600 & 42.000 & 65,100 & \\
\hline 10261500 & 1 & 0 & 1 & 0 & 0 & 1,310 & 7,610 & 18,900 & 49,300 & 91,400 & 159,000 & 70,600 \\
\hline & & & & & & 1,300 & 7,300 & 18,100 & 47,700 & 87,400 & 154,000 & \\
\hline 10261800 & 1 & 0 & 0 & 0 & 0 & 13 & 44 & 85 & 176 & 286 & 447 & 360 \\
\hline & & & & & & 13 & 48 & 98 & 195 & 316 & 474 & \\
\hline 10262600 & 1 & 0 & 0 & 0 & 0 & 24 & 49 & 70 & 103 & 132 & 165 & 125 \\
\hline & & & & & & 24 & 47 & 72 & 108 & 144 & 178 & \\
\hline 10263100 & - & - & - & - & 1 & $\cdots$ & $\cdots$ & $\cdots$ & $-\cdots$ & $\ldots$ & $\ldots$ & 46 \\
\hline & & & & & & 5 & 36 & 80 & 154 & 220 & 308 & \\
\hline 10263500 & 0 & 0 & 0 & 0 & 0 & 183 & 740 & 1.530 & 3,340 & 5,520 & 8,670 & 8,300 \\
\hline & & & & & & 182 & 731 & 1,520 & 3,330 & 5,490 & 8,630 & \\
\hline 10263900 & 0 & 0 & 0 & 0 & 0 & 18 & 64 & 123 & 244 & 380 & 564 & 169 \\
\hline & & & & & & 18 & 63 & 124 & 244 & 377 & 559 & \\
\hline 10264000 & 1 & 0 & 0 & 0 & 0 & 520 & 1,890 & 3,640 & 7,210 & 11,100 & 16,300 & 17,000 \\
\hline & & & & & & 515 & 1,830 & 3,540 & 7,100 & 10,900 & 16,100 & \\
\hline 10264520 & 1 & 0 & 0 & 0 & 0 & 5 & 9 & 13 & 18 & 23 & 29 & 19 \\
\hline & & & & & & 5 & 10 & 16 & 24 & 33 & 39 & \\
\hline
\end{tabular}




\begin{tabular}{|c|c|c|c|c|c|c|c|c|c|}
\hline 10264530 & Pine Creok near Palmdale, Calif. & 10 & 34.602 & 118.247 & 24 & 1.37 & -- & 13.0 & 85.2 \\
\hline 10264605 & $\begin{array}{l}\text { Joshua Creek near Mohave, } \\
\text { Calif. }\end{array}$ & 10 & 35.012 & 118.344 & 15 & 3.83 & 4.300 & 12.0 & 54.7 \\
\hline 10264680 & $\begin{array}{l}\text { Moscal Crook Tributary at } \\
\text { Big Pines, Calif. }\end{array}$ & 10 & 34.374 & 117.700 & 12 & 0.05 & 7,400 & 9.0 & 77.6 \\
\hline 10264700 & Peowee Creek near Randsburg, Calif. & 10 & 35.461 & 117.656 & 15 & 0.14 & -- & -- & 80.5 \\
\hline 10264878 & $\begin{array}{l}\text { Ninemile Croek near Brown, } \\
\text { Calif. }\end{array}$ & 10 & 35.843 & 117.926 & 15 & 10.40 & 5,000 & 7.0 & 71.8 \\
\hline 10264900 & $\begin{array}{l}\text { Salt Wolls Croek near Westend, } \\
\text { Calif. }\end{array}$ & 10 & 35.656 & 117.447 & 15 & 61.60 & -- & -- & 75.0 \\
\hline 10264915 & $\begin{array}{l}\text { Crust Creok near Westend, } \\
\text { Calf. }\end{array}$ & 10 & 35.690 & 117.381 & 14 & 0.13 & 1,700 & 5.0 & 75.0 \\
\hline 09383500 & $\begin{array}{l}\text { Nutrioso Creek above Nelson } \\
\text { Reservoir near Springerville, Ariz. }\end{array}$ & 11 & 34.032 & 109.186 & 17 & 83.40 & 8,550 & 20.0 & 44.4 \\
\hline 09384000 & $\begin{array}{l}\text { Littlo Colorado River above } \\
\text { Lyman Lake near St. Johns }\end{array}$ & 11 & 34.314 & 109.362 & 46 & 747.00 & 7,760 & 20.0 & 51.8 \\
\hline 09384200 & $\begin{array}{l}\text { Lyman Reservation Tributary noar } \\
\text { St. Johns, Ariz. }\end{array}$ & 11 & 34.392 & 109.380 & 14 & 0.24 & 6.100 & 11.6 & 52.1 \\
\hline 09385800 & $\begin{array}{l}\text { Littl. Colorado River Iributary } \\
\text { near St. Johns, Ariz. }\end{array}$ & 11 & 34.451 & 109.256 & 14 & 0.35 & 6,350 & 11.1 & 52.3 \\
\hline 09393500 & Silver Creek near Snowflake, Ariz. & 11 & 34.667 & 110.042 & 56 & 886.00 & 6,400 & 16.7 & 55.7 \\
\hline 09395100 & $\begin{array}{l}\text { Carr Lake Tributary near Holbrook, } \\
\text { Ariz. }\end{array}$ & 11 & 34.835 & 109.933 & 13 & 1.19 & 5,420 & 7.8 & 55.3 \\
\hline 09395400 & $\begin{array}{l}\text { Milk Rock Canyon near Ft Wingate, } \\
\text { N. Mox. }\end{array}$ & 11 & 35.432 & 108.558 & 35 & 14.00 & 8,300 & 15.5 & 49.7 \\
\hline 09395500 & Puerco River at Gallup, N. Mex. & 11 & 35.529 & 108.745 & 34 & 558.00 & 7,900 & 12.9 & 50.0 \\
\hline 09395600 & $\begin{array}{l}\text { Wagon Trail Wash near Gamerco, } \\
\text { N. Mex. }\end{array}$ & 11 & 35.650 & 108.783 & 24 & 0.38 & 6,500 & 11.5 & 50.0 \\
\hline 09395900 & Black Creek near Lupton, Ariz. & 11 & 35.452 & 109.126 & 19 & 500.00 & 7.500 & 15.8 & 49.9 \\
\hline 09396400 & $\begin{array}{l}\text { Dead Wash Tributary near Holbrook. } \\
\text { Ariz. }\end{array}$ & 11 & 35.075 & 109.750 & 13 & 1.00 & 5,740 & 7.9 & 54.0 \\
\hline 09397200 & $\begin{array}{l}\text { Penzance Wash near Joseph City, } \\
\text { Ariz. }\end{array}$ & 11 & 34.919 & 110.254 & 14 & 0.17 & 5,150 & 7.8 & 55.0 \\
\hline 09397500 & $\begin{array}{l}\text { Chevelon Creek bolow Wildcat Canyon, } \\
\text { near Winslow, Ariz. }\end{array}$ & 11 & 34.636 & 110.714 & 28 & 275.00 & 7,030 & 24.0 & 54.3 \\
\hline 09397800 & Brookbank Canyon near Heber, Ariz. & 11 & 34.472 & 110.647 & 13 & 27.60 & 6,950 & 22.1 & 52.3 \\
\hline 09398000 & Chevelon Creek near Winslow, Ariz. & 11 & 34.926 & 110.531 & 48 & 794.00 & 6,440 & 18.4 & 55.6 \\
\hline $\begin{array}{l}09398500 \\
09399000\end{array}$ & $\begin{array}{l}\text { Clear Crook below Willow Creek, } \\
\text { near Winslow, Ariz. } \\
\text { Clear Creek near Winslow, Ariz. }\end{array}$ & 11 & 34.667 & 111.007 & 39 & 321.00 & 7,100 & 25.8 & 52.3 \\
\hline
\end{tabular}




\begin{tabular}{|c|c|c|c|c|c|c|c|c|c|c|c|c|}
\hline \multirow{2}{*}{$\begin{array}{l}\text { Station } \\
\text { number }\end{array}$} & \multicolumn{5}{|c|}{$\begin{array}{c}\text { Relation } \\
\text { characteristic }\end{array}$} & \multicolumn{6}{|c|}{$\begin{array}{l}\text { Peak discharge (cubic feet per second) for } \\
\text { indicated recurrence interval (years) }\end{array}$} & \multirow{2}{*}{$\begin{array}{l}\text { Maximum } \\
\text { peak discharge } \\
\text { of record } \\
\text { (cubic feet } \\
\text { per second) }\end{array}$} \\
\hline & $\frac{C n}{L}$ & B & $\frac{C \text { e }}{D}$ & $\frac{218}{0}$ & $\frac{\tau_{12}}{U}$ & 2 & 5 & 10 & 25 & 50 & 100 & \\
\hline 10264530 & 0 & 0 & 0 & 0 & 0 & $\begin{array}{l}5 \\
6\end{array}$ & $\begin{array}{l}26 \\
35\end{array}$ & $\begin{array}{l}57 \\
80\end{array}$ & $\begin{array}{l}126 \\
160\end{array}$ & $\begin{array}{l}207 \\
269\end{array}$ & $\begin{array}{l}318 \\
381\end{array}$ & 69 \\
\hline 10264560 & - & - & - & - & 1 & 25 & 181 & 443 & 920 & 1,390 & 2,060 & 430 \\
\hline 10264605 & 0 & 1 & 0 & 0 & 0 & $\begin{array}{l}6 \\
7\end{array}$ & $\begin{array}{l}70 \\
90\end{array}$ & $\begin{array}{l}256 \\
294\end{array}$ & $\begin{array}{l}1.060 \\
1.050\end{array}$ & $\begin{array}{l}2,730 \\
2,500\end{array}$ & $\begin{array}{l}6,470 \\
5,910\end{array}$ & 2,540 \\
\hline 10264680 & - & - & - & - & 1 & 2 & 15 & 31 & 57 & 79 & 108 & 21 \\
\hline 10264700 & - & - & - & - & 1 & 4 & 27 & 59 & 111 & 158 & 219 & 1 \\
\hline 10264750 & 0 & 0 & 0 & 0 & 0 & $\begin{array}{l}42 \\
44\end{array}$ & $\begin{array}{l}442 \\
474\end{array}$ & $\begin{array}{l}1,570 \\
1,600\end{array}$ & $\begin{array}{l}6.260 \\
6.000\end{array}$ & $\begin{array}{l}15,600 \\
14.300\end{array}$ & $\begin{array}{l}35,800 \\
33,200\end{array}$ & 30,000 \\
\hline 10264840 & - & - & - & - & 1 & 12 & $\begin{array}{r}-.- \\
86\end{array}$ & 202 & 405 & 598 & 862 & 22 \\
\hline 10264878 & 0 & 0 & 0 & 0 & 0 & $\begin{array}{l}19 \\
20\end{array}$ & $\begin{array}{l}102 \\
143\end{array}$ & $\begin{array}{l}243 \\
357\end{array}$ & $\begin{array}{l}613 \\
787\end{array}$ & $\begin{array}{l}1,110 \\
1,420\end{array}$ & $\begin{array}{l}1,900 \\
2,210\end{array}$ & 437 \\
\hline 10264900 & 0 & 0 & 0 & 0 & 0 & $\begin{array}{l}42 \\
46\end{array}$ & $\begin{array}{l}184 \\
319\end{array}$ & $\begin{array}{l}383 \\
793\end{array}$ & $\begin{array}{r}818 \\
1,530\end{array}$ & $\begin{array}{l}1,320 \\
2,740\end{array}$ & $\begin{array}{l}2.000 \\
3.620\end{array}$ & 612 \\
\hline 10264915 & 0 & 0 & 0 & 0 & 0 & $\begin{array}{l}1 \\
1\end{array}$ & $\begin{array}{l}3 \\
7\end{array}$ & $\begin{array}{r}6 \\
16\end{array}$ & $\begin{array}{l}11 \\
26\end{array}$ & $\begin{array}{l}17 \\
42\end{array}$ & $\begin{array}{l}24 \\
49\end{array}$ & 9 \\
\hline 09383500 & 1 & 0 & 0 & 0 & 0 & $\begin{array}{l}107 \\
114\end{array}$ & $\begin{array}{l}257 \\
439\end{array}$ & $\begin{array}{l}411 \\
744\end{array}$ & $\begin{array}{r}681 \\
2.020\end{array}$ & $\begin{array}{r}946 \\
2,430\end{array}$ & $\begin{array}{l}1,280 \\
1,690\end{array}$ & 700 \\
\hline 09384000 & 0 & 1 & 0 & 0 & 0 & $\begin{array}{l}845 \\
852\end{array}$ & $\begin{array}{l}2,030 \\
2,220\end{array}$ & $\begin{array}{l}3,260 \\
3,730\end{array}$ & $\begin{array}{l}5,470 \\
7.850\end{array}$ & $\begin{array}{r}7,670 \\
10,200\end{array}$ & $\begin{array}{l}10,500 \\
11,100\end{array}$ & 16,000 \\
\hline 09384200 & 1 & 1 & 0 & 0 & 0 & $\begin{array}{l}42 \\
42\end{array}$ & $\begin{array}{l}62 \\
61\end{array}$ & $\begin{array}{l}75 \\
89\end{array}$ & $\begin{array}{r}92 \\
162\end{array}$ & $\begin{array}{l}106 \\
183\end{array}$ & $\begin{array}{l}119 \\
136\end{array}$ & 101 \\
\hline 09385800 & 0 & 0 & 0 & 0 & 0 & $\begin{array}{l}51 \\
50\end{array}$ & $\begin{array}{l}127 \\
118\end{array}$ & $\begin{array}{l}208 \\
196\end{array}$ & $\begin{array}{l}358 \\
309\end{array}$ & $\begin{array}{l}512 \\
457\end{array}$ & $\begin{array}{l}712 \\
685\end{array}$ & 326 \\
\hline 09386100 & 0 & 0 & 0 & 0 & 0 & $\begin{array}{l}299 \\
303\end{array}$ & $\begin{array}{l}517 \\
649\end{array}$ & $\begin{array}{r}702 \\
1.020\end{array}$ & $\begin{array}{r}988 \\
2,550\end{array}$ & $\begin{array}{l}1,240 \\
2,870\end{array}$ & $\begin{array}{l}1,540 \\
1,940\end{array}$ & 1,320 \\
\hline 09387050 & 0 & 0 & 0 & 0 & 0 & $\begin{array}{l}109 \\
110\end{array}$ & $\begin{array}{l}250 \\
286\end{array}$ & $\begin{array}{l}382 \\
488\end{array}$ & $\begin{array}{r}598 \\
1,110\end{array}$ & $\begin{array}{r}796 \\
1,310\end{array}$ & $\begin{array}{l}1.030 \\
1,150\end{array}$ & 660 \\
\hline 09390500 & 1 & 0 & 0 & 0 & 0 & $\begin{array}{l}470 \\
469\end{array}$ & $\begin{array}{l}1,630 \\
1,610\end{array}$ & $\begin{array}{l}3,090 \\
2,980\end{array}$ & $\begin{array}{l}6,040 \\
5,240\end{array}$ & $\begin{array}{l}9.250 \\
8,470\end{array}$ & $\begin{array}{l}13,500 \\
13,300\end{array}$ & 5.550 \\
\hline 09392800 & 0 & 0 & 0 & 0 & 0 & $\begin{array}{l}22 \\
24\end{array}$ & $\begin{array}{l}194 \\
219\end{array}$ & $\begin{array}{l}544 \\
565\end{array}$ & $\begin{array}{l}1,520 \\
1,250\end{array}$ & $\begin{array}{l}2,840 \\
2,270\end{array}$ & $\begin{array}{l}4.850 \\
4.550\end{array}$ & 530 \\
\hline 09393500 & 1 & 1 & 1 & 0 & 0 & $\begin{array}{l}3,000 \\
2,990\end{array}$ & $\begin{array}{l}5,690 \\
5,700\end{array}$ & $\begin{array}{l}7.990 \\
8.190\end{array}$ & $\begin{array}{l}11,500 \\
13,000\end{array}$ & $\begin{array}{l}14.500 \\
16,600\end{array}$ & $\begin{array}{l}18,000 \\
18,600\end{array}$ & 25.000 \\
\hline 09395100 & - & - & - & - & 1 & 29 & 143 & 335 & 569 & 806 & 914 & 140 \\
\hline 09395400 & - & - & - & - & 1 & 134 & 570 & 973 & 1.650 & 2.460 & 3,080 & 1,360 \\
\hline 09395500 & 0 & 0 & 0 & 0 & 0 & $\begin{array}{l}2,050 \\
2,040\end{array}$ & $\begin{array}{l}5,380 \\
5,310\end{array}$ & $\begin{array}{l}8,450 \\
8.240\end{array}$ & $\begin{array}{l}13,200 \\
12,600\end{array}$ & $\begin{array}{l}17.100 \\
17.300\end{array}$ & $\begin{array}{l}21,500 \\
21,700\end{array}$ & 12,000 \\
\hline 09395600 & 1 & 0 & 0 & 0 & 0 & $\begin{array}{l}78 \\
77\end{array}$ & $\begin{array}{l}172 \\
162\end{array}$ & $\begin{array}{l}259 \\
242\end{array}$ & $\begin{array}{l}401 \\
341\end{array}$ & $\begin{array}{l}530 \\
482\end{array}$ & $\begin{array}{l}682 \\
667\end{array}$ & 437 \\
\hline 09395900 & 1 & 0 & 0 & 0 & 0 & $\begin{array}{l}2,550 \\
2,520\end{array}$ & $\begin{array}{l}4,440 \\
4,410\end{array}$ & $\begin{array}{l}5,890 \\
5,970\end{array}$ & $\begin{array}{l}7,910 \\
9,250\end{array}$ & $\begin{array}{l}9,9540 \\
12,000\end{array}$ & $\begin{array}{l}11,300 \\
12,200\end{array}$ & 7,680 \\
\hline 09396400 & 1 & 0 & 0 & 0 & 0 & $\begin{array}{l}197 \\
192\end{array}$ & $\begin{array}{l}373 \\
330\end{array}$ & $\begin{array}{l}524 \\
463\end{array}$ & $\begin{array}{l}754 \\
607\end{array}$ & $\begin{array}{l}956 \\
850\end{array}$ & $\begin{array}{l}1,190 \\
1,150\end{array}$ & 743 \\
\hline 09397200 & - & - & - & - & 1 & $\begin{array}{r}\cdots \\
9\end{array}$ & 48 & 120 & 205 & 279 & 292 & 120 \\
\hline 09397500 & 0 & 0 & 1 & 0 & 0 & $\begin{array}{l}2,750 \\
2,720\end{array}$ & $\begin{array}{l}7.500 \\
7.090\end{array}$ & $\begin{array}{l}12,500 \\
11,500\end{array}$ & $\begin{array}{l}21,300 \\
16,800\end{array}$ & $\begin{array}{l}29,800 \\
26,100\end{array}$ & $\begin{array}{l}40,300 \\
39,400\end{array}$ & 19,900 \\
\hline 09397800 & 1 & 0 & 0 & 0 & 0 & $\begin{array}{l}145 \\
147\end{array}$ & $\begin{array}{l}314 \\
406\end{array}$ & $\begin{array}{l}464 \\
746\end{array}$ & $\begin{array}{r}697 \\
1.790\end{array}$ & $\begin{array}{r}901 \\
2,160\end{array}$ & $\begin{array}{l}1.130 \\
1.490\end{array}$ & 666 \\
\hline 09398000 & 0 & 0 & 1 & 0 & 0 & $\begin{array}{l}2,420 \\
2,410\end{array}$ & $\begin{array}{l}6,270 \\
6,230\end{array}$ & $\begin{array}{l}10,700 \\
10,600\end{array}$ & $\begin{array}{l}19,400 \\
18,700\end{array}$ & $\begin{array}{l}29.000 \\
28,700\end{array}$ & $\begin{array}{r}41,900 \\
41,900\end{array}$ & 33,600 \\
\hline 09398500 & 1 & 0 & 1 & 0 & 0 & $\begin{array}{l}2,950 \\
2,930\end{array}$ & $\begin{array}{l}7.170 \\
6.910\end{array}$ & $\begin{array}{l}11.200 \\
10.600\end{array}$ & $\begin{array}{l}17,900 \\
15,300\end{array}$ & $\begin{array}{l}24,000 \\
22,300\end{array}$ & $\begin{array}{l}31,100 \\
30,800\end{array}$ & 19,700 \\
\hline 09399000 & 1 & 0 & 0 & 0 & 0 & $\begin{array}{l}2,600 \\
2,590\end{array}$ & $\begin{array}{l}7,510 \\
7,370\end{array}$ & $\begin{array}{l}13,600 \\
13,200\end{array}$ & $\begin{array}{l}26,500 \\
23,600\end{array}$ & $\begin{array}{l}41,500 \\
38,800\end{array}$ & $\begin{array}{l}62,900 \\
62,200\end{array}$ & 50,000 \\
\hline
\end{tabular}




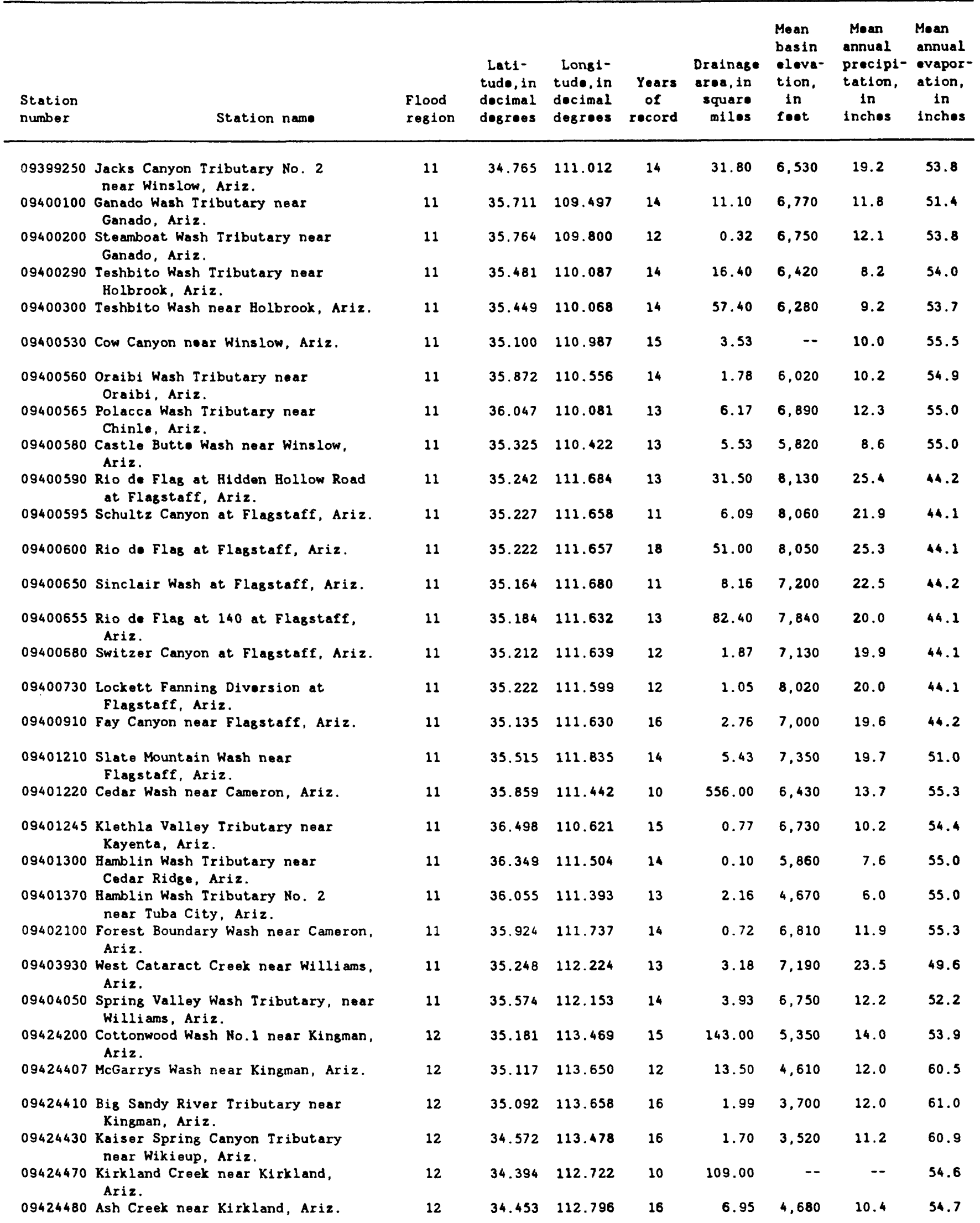




\begin{tabular}{|c|c|c|c|c|c|c|c|c|c|c|c|c|}
\hline \multirow[b]{2}{*}{$\begin{array}{l}\text { Stetion } \\
\text { number }\end{array}$} & \multicolumn{5}{|c|}{$\begin{array}{c}\text { Reletion } \\
\text { cherecterietle }\end{array}$} & \multicolumn{3}{|c|}{$\begin{array}{l}\text { Poak diecherse (cubic } \\
\text { Indicated recurrence }\end{array}$} & \multicolumn{3}{|c|}{$\begin{array}{l}\text { foot por eocond) for } \\
\text { interval (renrs) }\end{array}$} & \multirow{2}{*}{$\begin{array}{l}\text { Maximum } \\
\text { pouk diecharse } \\
\text { of record } \\
\text { (cubic foet } \\
\text { per eocond) }\end{array}$} \\
\hline & $\frac{c h}{L}$ & $\frac{r a}{B}$ & $\frac{\text { cte }}{D}$ & $\frac{1 \text { int }}{0}$ & & 2 & 5 & 10 & 25 & so & 100 & \\
\hline 09399250 & - & - & - & - & 1 & 222 & 902 & 1,750 & 2,870 & 4,490 & 5,810 & 8,330 \\
\hline 09400100 & 1 & 1 & 0 & 0 & 0 & $\begin{array}{l}238 \\
234\end{array}$ & $\begin{array}{l}533 \\
528\end{array}$ & $\begin{array}{l}820 \\
846\end{array}$ & $\begin{array}{l}1,310 \\
1,450\end{array}$ & $\begin{array}{l}1,780 \\
2,000\end{array}$ & $\begin{array}{l}2,350 \\
2,400\end{array}$ & 1,680 \\
\hline 09400200 & - & - & - & - & 1 & 13 & 69 & 160 & --- & 375 & --- & 383 \\
\hline 09400290 & 0 & 0 & 1 & 0 & 0 & $\begin{array}{l}369 \\
362\end{array}$ & $\begin{array}{l}873 \\
831\end{array}$ & $\begin{array}{l}1,310 \\
1,290\end{array}$ & $\begin{array}{l}1,970 \\
2,050\end{array}$ & $\begin{array}{l}2,510 \\
2,770\end{array}$ & $\begin{array}{l}3,090 \\
3,170\end{array}$ & 890 \\
\hline 09400300 & 1 & 0 & 1 & 0 & 0 & $\begin{array}{l}652 \\
642\end{array}$ & $\begin{array}{l}1,050 \\
1,080\end{array}$ & $\begin{array}{l}1,340 \\
1,600\end{array}$ & $\begin{array}{l}1,730 \\
2,990\end{array}$ & $\begin{array}{l}2,040 \\
3,680\end{array}$ & $\begin{array}{l}2,350 \\
2,850\end{array}$ & 1,580 \\
\hline 09400530 & 1 & 0 & 0 & 0 & 0 & $\begin{array}{l}64 \\
64\end{array}$ & $\begin{array}{l}128 \\
149\end{array}$ & $\begin{array}{l}182 \\
279\end{array}$ & $\begin{array}{l}261 \\
660\end{array}$ & $\begin{array}{l}327 \\
758\end{array}$ & $\begin{array}{l}400 \\
507\end{array}$ & 253 \\
\hline 09400560 & - & - & - & - & 1 & 37 & 180 & 407 & 692 & 989 & 1,140 & 383 \\
\hline 09400565 & 1 & 0 & 1 & 0 & 0 & $\begin{array}{l}361 \\
352\end{array}$ & $\begin{array}{l}708 \\
647\end{array}$ & $\begin{array}{l}995 \\
938\end{array}$ & $\begin{array}{l}1,410 \\
1,360\end{array}$ & $\begin{array}{l}1,770 \\
1,840\end{array}$ & $\begin{array}{l}2,150 \\
2,170\end{array}$ & 1,130 \\
\hline 09400580 & 1 & 0 & 0 & 0 & 0 & $\begin{array}{l}85 \\
85\end{array}$ & $\begin{array}{l}288 \\
287\end{array}$ & $\begin{array}{l}540 \\
591\end{array}$ & $\begin{array}{l}1,040 \\
1,160\end{array}$ & $\begin{array}{l}1,590 \\
1,690\end{array}$ & $\begin{array}{l}2,320 \\
2,310\end{array}$ & 860 \\
\hline 09400590 & - & - & - & - & 1 & 221 & 897 & 1,170 & 2,000 & 3,020 & 3,800 & 153 \\
\hline 08400585 & - & - & - & - & 1 & 80 & 358 & 497 & $---\overline{845}$ & 1,240 & 1,500 & 48 \\
\hline 09400600 & 0 & 0 & 0 & 0 & 0 & $\begin{array}{l}17 \\
24\end{array}$ & $\begin{array}{r}74 \\
222\end{array}$ & $\begin{array}{l}158 \\
433\end{array}$ & $\begin{array}{r}349 \\
1,420\end{array}$ & $\begin{array}{r}580 \\
1,700\end{array}$ & $\begin{array}{r}910 \\
1,200\end{array}$ & 240 \\
\hline 09400650 & 1 & 0 & 0 & 0 & 0 & $\begin{array}{l}73 \\
74\end{array}$ & $\begin{array}{l}167 \\
218\end{array}$ & $\begin{array}{l}261 \\
356\end{array}$ & $\begin{array}{l}424 \\
768\end{array}$ & $\begin{array}{l}583 \\
981\end{array}$ & $\begin{array}{l}780 \\
887\end{array}$ & 401 \\
\hline 09400655 & - & - & - & - & 1 & 401 & 1,540 & 1,830 & 3,280 & 5,060 & 6,780 & 421 \\
\hline 09400680 & 0 & 0 & 1 & 0 & 0 & $\begin{array}{l}38 \\
38\end{array}$ & $\begin{array}{r}96 \\
112\end{array}$ & $\begin{array}{l}152 \\
185\end{array}$ & $\begin{array}{l}245 \\
370\end{array}$ & $\begin{array}{l}331 \\
471\end{array}$ & $\begin{array}{l}430 \\
462\end{array}$ & 135 \\
\hline 09400730 & - & - & - & - & 1 & --- & --- & 189 & 338 & $-\overline{478}$ & $-\overline{539}$ & 85 \\
\hline 09400910 & 0 & 0 & 0 & 0 & 0 & $\begin{array}{r}9 \\
10\end{array}$ & $\begin{array}{l}26 \\
57\end{array}$ & $\begin{array}{r}47 \\
111\end{array}$ & $\begin{array}{r}88 \\
333\end{array}$ & $\begin{array}{l}132 \\
380\end{array}$ & $\begin{array}{l}190 \\
248\end{array}$ & 87 \\
\hline 09401210 & - & - & - & - & 1 & 74 & 335 & 628 & 1,070 & 1,560 & 1,880 & 88 \\
\hline 09401220 & 1 & 0 & 0 & 0 & 0 & $\begin{array}{l}1,500 \\
1,490\end{array}$ & $\begin{array}{l}4,550 \\
4,540\end{array}$ & $\begin{array}{l}8,070 \\
8,110\end{array}$ & $\begin{array}{l}14,800 \\
14,200\end{array}$ & $\begin{array}{l}21,900 \\
22,100\end{array}$ & $\begin{array}{l}31,000 \\
31,100\end{array}$ & 10,400 \\
\hline 09401245 & 1 & 0 & 0 & 0 & 0 & $\begin{array}{l}121 \\
118\end{array}$ & $\begin{array}{l}183 \\
180\end{array}$ & $\begin{array}{l}244 \\
247\end{array}$ & $\begin{array}{l}313 \\
380\end{array}$ & $\begin{array}{l}366 \\
461\end{array}$ & $\begin{array}{l}421 \\
442\end{array}$ & 290 \\
\hline 09401300 & - & - & - & - & 1 & --- & 36 & 91 & 155 & 208 & 214 & 110 \\
\hline 09401370 & - & - & - & - & 1 & 42 & 200 & 452 & 768 & 1,100 & 1,280 & 350 \\
\hline 09402100 & - & - & - & - & 1 & 21 & 108 & 258 & 438 & 614 & 682 & 115 \\
\hline 09403930 & 0 & 0 & 1 & 0 & 0 & $\begin{array}{l}26 \\
27\end{array}$ & $\begin{array}{r}96 \\
123\end{array}$ & $\begin{array}{l}183 \\
253\end{array}$ & $\begin{array}{l}350 \\
584\end{array}$ & $\begin{array}{l}524 \\
763\end{array}$ & $\begin{array}{l}744 \\
785\end{array}$ & 151 \\
\hline 09404050 & 1 & 0 & 0 & 0 & 0 & $\begin{array}{l}18 \\
19\end{array}$ & $\begin{array}{l}61 \\
97\end{array}$ & $\begin{array}{l}114 \\
224\end{array}$ & $\begin{array}{l}217 \\
618\end{array}$ & $\begin{array}{l}326 \\
741\end{array}$ & $\begin{array}{l}465 \\
565\end{array}$ & 190 \\
\hline 09424200 & 1 & 0 & 1 & 0 & 0 & $\begin{array}{l}3,680 \\
3,640\end{array}$ & $\begin{array}{l}5,860 \\
5,650\end{array}$ & $\begin{array}{l}7,320 \\
7,090\end{array}$ & $\begin{array}{r}9,140 \\
10,300\end{array}$ & $\begin{array}{l}10,500 \\
14,800\end{array}$ & $\begin{array}{l}11,800 \\
20,200\end{array}$ & 7,000 \\
\hline 09424407 & - & - & - & - & 1 & 211 & 823 & 1,460 & 2,700 & 4,810 & 7,380 & 1,000 \\
\hline 09424410 & 1 & 0 & 0 & 0 & 0 & $\begin{array}{l}18 \\
18\end{array}$ & $\begin{array}{l}80 \\
97\end{array}$ & $\begin{array}{l}174 \\
251\end{array}$ & $\begin{array}{l}399 \\
653\end{array}$ & $\begin{array}{r}686 \\
1,170\end{array}$ & $\begin{array}{l}1,120 \\
1,880\end{array}$ & 353 \\
\hline 09424430 & - & - & - & - & 1 & 57 & 218 & 412 & 813 & 1,330 & 2,050 & 1,310 \\
\hline 09424470 & - & - & - & - & 1 & 786 & --- & $\cdots$ & 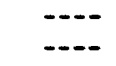 & 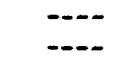 & - & 1,000 \\
\hline 09424480 & 0 & 0 & 0 & 0 & 0 & $\begin{array}{l}132 \\
132\end{array}$ & $\begin{array}{l}457 \\
464\end{array}$ & $\begin{array}{l}887 \\
800\end{array}$ & $\begin{array}{l}1,820 \\
1,790\end{array}$ & $\begin{array}{l}2,900 \\
3,040\end{array}$ & $\begin{array}{l}4,430 \\
4,700\end{array}$ & 4.000 \\
\hline
\end{tabular}




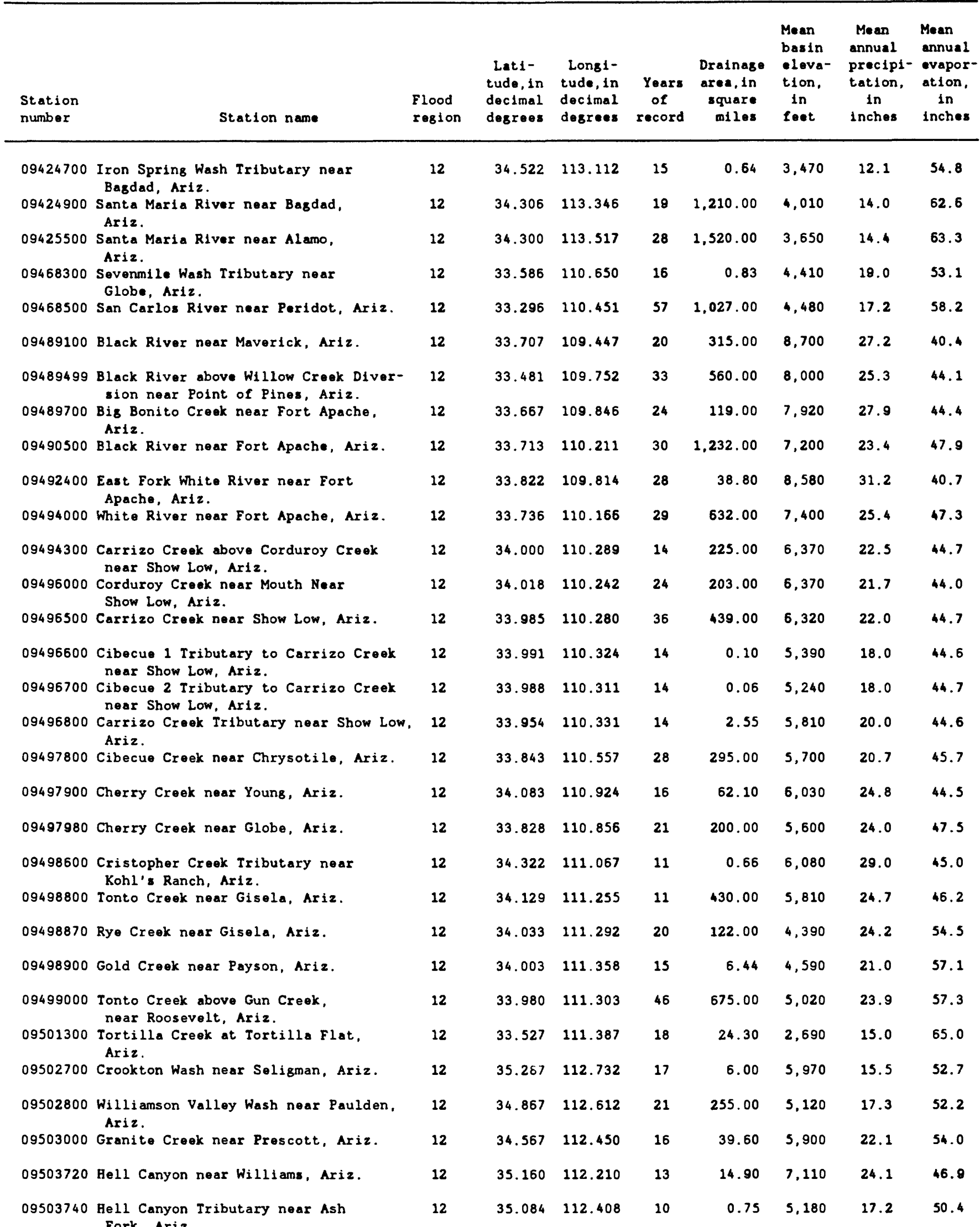




\begin{tabular}{|c|c|c|c|c|c|c|c|c|c|c|c|c|}
\hline \multirow[b]{2}{*}{$\begin{array}{l}\text { Station } \\
\text { number }\end{array}$} & \multicolumn{5}{|c|}{$\begin{array}{c}\text { Relation } \\
\text { characteristic }\end{array}$} & \multicolumn{3}{|c|}{$\begin{array}{l}\text { Peak discharge (cubic } \\
\text { indicated recurrence }\end{array}$} & \multicolumn{3}{|c|}{ feet $p \bullet r$ second) for } & \multirow{2}{*}{$\begin{array}{c}\text { Maximum } \\
\text { peak discharge } \\
\text { of record } \\
\text { (cubic leot } \\
\text { per second) }\end{array}$} \\
\hline & $\frac{c h}{L}$ & $\frac{\operatorname{arac}}{\mathrm{a}}$ & $\frac{c t e r}{D}$ & $\frac{r 15}{0}$ & $\frac{t 1 c}{v}$ & 2 & 5 & 10 & 25 & 50 & 100 & \\
\hline \multirow[t]{2}{*}{09424700} & 0 & 0 & 0 & 0 & 0 & 12 & 63 & 147 & 357 & 629 & 1,040 & 180 \\
\hline & & & & & & 13 & 69 & 168 & 403 & 631 & 975 & \\
\hline \multirow[t]{2}{*}{09424900} & 1 & 0 & 1 & 0 & 0 & 7,310 & 13,800 & 18,800 & 25,600 & 31,100 & 36,700 & 23,100 \\
\hline & & & & & & 7,270 & 14,300 & 21,600 & 36,600 & 44,600 & 55,600 & \\
\hline \multirow[t]{2}{*}{09425500} & 1 & 0 & 1 & 0 & 0 & 3,250 & 9.860 & 17,600 & 32,900 & 49,200 & 70,800 & 33,600 \\
\hline & & & & & & 3,260 & 10,700 & 21,000 & 42,600 & 55,500 & 73,400 & \\
\hline \multirow[t]{2}{*}{09468300} & 1 & 0 & 0 & 0 & 0 & 27 & 134 & 299 & 686 & 1,150 & 1,820 & 640 \\
\hline & & & & & & 27 & 133 & 281 & 575 & 864 & 1,310 & \\
\hline \multirow[t]{2}{*}{09468500} & 1 & 0 & 0 & 0 & 0 & 7,440 & 15,200 & 22,300 & 33,700 & 44,100 & 56,200 & 40,600 \\
\hline & & & & & & 7,420 & 15.200 & 22,600 & 35.600 & 45,300 & 57.500 & \\
\hline \multirow[t]{2}{*}{09489100} & 0 & 0 & 1 & 0 & 0 & $1,60 \mathrm{C}$ & 3,840 & 6.260 & 10,800 & 15.500 & 21,700 & 14,000 \\
\hline & & & & & & 1.600 & 4.000 & 6,930 & 13.000 & 18.500 & 25.300 & \\
\hline 09489499 & 0 & 0 & 0 & 0 & 0 & 2,210 & 5,390 & 8,700 & 14.600 & 20,600 & 28,100 & 17,900 \\
\hline & & & & & & 2.210 & 5,570 & 9,500 & 17,500 & 24,000 & 32,100 & \\
\hline 09489700 & 0 & 0 & 0 & 0 & 0 & 622 & 1,430 & 2,220 & 3,550 & 4,820 & 6,340 & 4,510 \\
\hline & & & & & & 624 & 1.550 & 2,780 & 5,730 & 9,280 & 13,300 & \\
\hline 09490500 & 0 & 0 & 1 & 0 & 0 & 6,860 & 19,800 & 33,500 & 57,800 & 81,500 & 110,000 & 50,000 \\
\hline & & & & & & 6,840 & 19,500 & 31,900 & 50,900 & 62,600 & 79,800 & \\
\hline 09492400 & 0 & 1 & 0 & 1 & 0 & 274 & 508 & 720 & 1,070 & 1,390 & 1.790 & 2,700 \\
\hline & & & & & & 275 & 562 & 1,010 & 2,270 & 4.110 & 6.260 & \\
\hline 09494000 & 0 & 0 & 0 & 0 & 0 & 3,400 & 6.100 & 8,390 & 11,900 & 15,000 & 18,600 & 14,00 \\
\hline & & & & & & 3,390 & 6,330 & 9,620 & 17,100 & 22.700 & 29,500 & \\
\hline 09494300 & - & - & - & - & 1 & -... & $\ldots$ & $\ldots$ & $\cdots$ & $\cdots$ & $\cdots$ & 10,000 \\
\hline & & & & & & 1,240 & 5,070 & 8,220 & 14,100 & 20,100 & 27,400 & \\
\hline 09496000 & 1 & 0 & 1 & 0 & 0 & 1,050 & 3,630 & 7,060 & 14,500 & 23,300 & 35,800 & 10,900 \\
\hline & & & & & & 1,050 & 3,710 & 7,190 & 13,900 & 21,000 & 30,300 & \\
\hline 09496500 & 1 & 0 & 0 & 0 & 0 & 3,190 & 7.430 & 11,900 & 20,000 & 28,400 & 39.100 & 23,000 \\
\hline & & & & & & 3,180 & 7,460 & 12,000 & 20.500 & 28,200 & 37,900 & \\
\hline 09496600 & 0 & 0 & 0 & 0 & 0 & 44 & 92 & 134 & 200 & 259 & 326 & 165 \\
\hline & & & & & & 43 & 84 & 109 & 152 & 157 & 193 & \\
\hline 09496700 & 1 & 0 & 0 & 0 & 0 & 43 & 69 & 89 & 118 & 162 & 168 & 120 \\
\hline & & & & & & 42 & 63 & 74 & 102 & 95 & 112 & \\
\hline 09496800 & 0 & 0 & 0 & 0 & 0 & 283 & 657 & 1030 & 1,670 & 2,290 & 3,050 & 1,260 \\
\hline & & & & & & 280 & 607 & 849 & 1,220 & 1,720 & 2,460 & \\
\hline 09497800 & 1 & 1 & 0 & 0 & 0 & 4.360 & 8,010 & 11,000 & 15,200 & 18.800 & 22,700 & 22,200 \\
\hline & & & & & & 4.340 & 7.900 & 10,900 & 16,100 & 21.400 & 27,900 & \\
\hline 09497900 & 0 & 0 & 0 & 0 & 0 & 1,380 & 3,110 & 4.710 & 7,290 & 9,620 & 12,300 & 7,290 \\
\hline & & & & & & 1,370 & 3,010 & 4,400 & 6,810 & 10,200 & 14,300 & \\
\hline 09497980. & 1 & 0 & 0 & 0 & 0 & 2,190 & 5,320 & 8.520 & 14,200 & 19.800 & 26,800 & 15,700 \\
\hline & & & & & & 2,180 & 5.290 & 8,400 & 14,000 & 19.900 & 27,300 & \\
\hline 09498600 & 0 & 1 & 0 & 0 & 0 & 30 & 69 & 111 & 188 & 269 & 374 & 265 \\
\hline & & & & & & 30 & 73 & 135 & 296 & 438 & 655 & \\
\hline 09498800 & 0 & 0 & 0 & 0 & 0 & 4,810 & 11,300 & 18,300 & 31,600 & 45,700 & 64,400 & 38,000 \\
\hline & & & & & & 4.750 & 10,800 & 16,400 & 25,600 & 33,500 & 44,500 & \\
\hline 09498870 & 0 & 1 & 0 & 0 & 0 & 2,980 & 6.250 & 9,570 & 15,500 & 21,500 & 29,300 & 44, 400 \\
\hline & & & & & & 2,960 & 6,040 & 8,810 & 13,400 & 19,100 & 26,400 & \\
\hline 09498900 & 1 & 0 & 0 & 0 & 0 & 310 & 792 & 1,300 & 2,230 & 3,160 & 4,330 & 2,800 \\
\hline & & & & & & 307 & 759 & 1,180 & 1.940 & 3.050 & 4,540 & \\
\hline 09499000 & 0 & 0 & 1 & 0 & 0 & 11,400 & 26,400 & 40,100 & 62,000 & 81,600 & 104,000 & 61,400 \\
\hline & & & & & & 11,400 & 25,800 & 37,500 & 53,300 & 65,100 & 81,100 & \\
\hline 09501300 & 1 & 0 & 1 & 0 & 0 & 1,940 & 4,290 & 6,290 & 9,270 & 11,800 & 14.500 & 7,500 \\
\hline & & & & & & 1,920 & 4,020 & 5,360 & 7,050 & 9,940 & 13,700 & \\
\hline 09502700 & 1 & 0 & 0 & 0 & 0 & 7 & 86 & 313 & 1.240 & 3,020 & 6,700 & 480 \\
\hline & & & & & & 9 & 120 & 435 & 1,360 & 2,730 & 4,890 & \\
\hline 09502800 & 0 & 0 & 0 & 0 & 0 & 1.300 & 4.070 & 7,400 & 14,000 & 21,000 & 30,300 & 14,800 \\
\hline & & & & & & 1,300 & 4,230 & 7,940 & 15,200 & 22,400 & 31,300 & \\
\hline 08503000 & 1 & 1 & 0 & 0 & 0 & 837 & 1,850 & 2,780 & 4.350 & 5,780 & 7,470 & 6,660 \\
\hline & & & & & & 831 & 1,820 & 2,760 & 4,610 & 7,310 & 10,600 & \\
\hline 09503720 & - & - & - & - & 1 & $-\cdots$ & $\cdots$ & --- & $\cdots$ & --- & -- & 1,080 \\
\hline & & & & & & 225 & 754 & 1,310 & 2,440 & 4,220 & 6,430 & \\
\hline 09503740 & 0 & 0 & 0 & 1 & 0 & 10 & 32 & 58 & 108 & 161 & 231 & 84 \\
\hline & & & & & & 11 & 44 & 115 & 307 & 483 & 740 & \\
\hline
\end{tabular}




\begin{tabular}{|c|c|c|c|c|c|c|c|c|c|}
\hline 09503750 & $\begin{array}{l}\text { Limestone Canyon near Paulden, } \\
\text { Ariz. }\end{array}$ & 12 & 34.980 & 112.401 & 11 & 14.50 & 5,310 & 15.5 & 50.6 \\
\hline 09504400 & $\begin{array}{l}\text { Munds Canyon Tributary near } \\
\text { Sedona, Ariz. }\end{array}$ & 12 & 34.922 & 111.644 & 16 & 1.19 & 6.880 & 26.0 & 44.2 \\
\hline 09504500 & Oak Creek near Cornville, Ariz. & 12 & 34.766 & 111.890 & 45 & 357.0 & 6,200 & 22.6 & 51.9 \\
\hline 09505220 & $\begin{array}{l}\text { Rocky Gulch near Stoneman Lake, } \\
\text { Ariz. (USFS) }\end{array}$ & 12 & 34.747 & 111.494 & 24 & 1.40 & 7,190 & 25.0 & 44.3 \\
\hline 09505250 & $\begin{array}{l}\text { Red Tank Draw near Rimrock, } \\
\text { Ariz. }\end{array}$ & 12 & 34.695 & 111.714 & 21 & 49.40 & 5,910 & 21.6 & 50.6 \\
\hline 09505300 & $\begin{array}{l}\text { Rattlesnake Canyon near Rimrock, } \\
\text { Ariz. }\end{array}$ & 12 & 34.767 & 111.673 & 23 & 24.60 & 6,560 & 22.8 & 46.6 \\
\hline 09505350 & $\begin{array}{l}\text { Dry Beaver Creek near Rimrock, } \\
\text { Ariz. }\end{array}$ & 12 & 34.729 & 111.775 & 26 & 142.00 & 6,220 & 23.1 & 51.3 \\
\hline 09505600 & $\begin{array}{l}\text { Dirty Neck Canyon near Clints Well, } \\
\text { Ariz. }\end{array}$ & 12 & 34.512 & 111.358 & 12 & 3.42 & 7,140 & 26.0 & 44.0 \\
\hline 09505800 & $\begin{array}{l}\text { West Clear Creek near Camp Verde, } \\
\text { Ariz. }\end{array}$ & 12 & 34.539 & 111.693 & 21 & 241.00 & 6,680 & 23.4 & 51.8 \\
\hline 09505900 & $\begin{array}{l}\text { Cottonwood Wash near Camp Verde. } \\
\text { Ariz. }\end{array}$ & 12 & 34.506 & 111.753 & 14 & 0.64 & 3,540 & 14.5 & 53.1 \\
\hline 09510070 & $\begin{array}{l}\text { West Fork Sycamore Creek above } \\
\text { McFarland Crook, noor Sunflower, Ariz. }\end{array}$ & 12 & 33.961 & 111.487 & 14 & 4.58 & 5,430 & 24.5 & 58.0 \\
\hline 09510080 & $\begin{array}{l}\text { West Fork Sycamore Creek near } \\
\text { Sunflower, Ariz. }\end{array}$ & 12 & 33.946 & 111.485 & 15 & 9.80 & 5,260 & 24.5 & 58.3 \\
\hline 09510100 & $\begin{array}{l}\text { East Fork Sycamore Creek near } \\
\text { Sunflower, Ariz. }\end{array}$ & 12 & 33.949 & 111.461 & 23 & 4.49 & 5,760 & 24.5 & 58.2 \\
\hline 09510150 & Sycamor Creek near Sunflower, Ariz. & 12 & 33.851 & 111.452 & 15 & 52.30 & 4,260 & 23.5 & 60.0 \\
\hline 09510170 & Camp Creek near Sunflower, Ariz. & 12 & 33.760 & 111.496 & 17 & 2.60 & 3,520 & 20.0 & 63.1 \\
\hline 09510180 & Rock Creek near Sunflower, Ariz. & 12 & 33.730 & 111.508 & 10 & 15.20 & 3,680 & 16.0 & 64.1 \\
\hline 09510200 & $\begin{array}{l}\text { Sycamore Creek near Fort McDowell, } \\
\text { Ariz. }\end{array}$ & 12 & 33.694 & 111.541 & 27 & 164.00 & 3,820 & 21.2 & 65.0 \\
\hline 09512100 & $\begin{array}{l}\text { Indian Bend Wash near Scottsdale, } \\
\text { Ariz. }\end{array}$ & 12 & 33.539 & 111.916 & 10 & 139.00 & 1,780 & 10.9 & 65.6 \\
\hline 09512200 & $\begin{array}{l}\text { Salt River Tributary in South Mt Park, } \\
\text { at Phoenix, Ariz. }\end{array}$ & 12 & 33.347 & 112.084 & 26 & 1.75 & 1,730 & 9.0 & 65.6 \\
\hline 09512300 & Cave Creek near Cave Creek, Ariz. & 12 & 33.783 & 112.007 & 28 & 121.00 & 3,470 & 15.7 & 62.2 \\
\hline 09512420 & $\begin{array}{l}\text { Lynx Creek Tributary near Prescott, } \\
\text { Ariz. }\end{array}$ & 12 & 34.547 & 112.399 & 10 & 0.95 & 5,900 & 16.0 & 54.2 \\
\hline 09512500 & Agua Fria River near Mayer, Ariz. & 12 & 34.315 & 112.063 & 47 & 588.00 & 5,000 & 16.7 & 60.9 \\
\hline 09512700 & $\begin{array}{l}\text { Agua Frie River Tributary No } 2 \text { near } \\
\text { Rock Springs, Ariz. }\end{array}$ & 12 & 34.033 & 112.145 & 18 & 1.11 & 2,140 & 16.2 & 60.2 \\
\hline
\end{tabular}




\begin{tabular}{|c|c|c|c|c|c|c|c|c|c|c|c|c|}
\hline \multirow{2}{*}{$\begin{array}{l}\text { Station } \\
\text { number }\end{array}$} & \multicolumn{5}{|c|}{$\begin{array}{c}\text { Relation } \\
\text { characteristic }\end{array}$} & \multicolumn{3}{|c|}{$\begin{array}{l}\text { Peak discharge (cubic } \\
\text { indicated recurrence }\end{array}$} & \multicolumn{3}{|c|}{$\begin{array}{l}\text { feet per second) for } \\
\text { interval (years) }\end{array}$} & \multirow{2}{*}{$\begin{array}{l}\text { Maximu } \\
\text { peak discharge } \\
\text { of record } \\
\text { (cubic leet } \\
\text { per second) }\end{array}$} \\
\hline & $\frac{\mathrm{L}}{\mathrm{L}}$ & 8 & $D$ & 0 & $\frac{1+10}{u}$ & 2 & 5 & 10 & 25 & 50 & 100 & \\
\hline 09503750 & 1 & 0 & 1 & 0 & 0 & $\begin{array}{l}273 \\
272\end{array}$ & $\begin{array}{l}901 \\
889\end{array}$ & $\begin{array}{l}1,710 \\
1,610\end{array}$ & $\begin{array}{l}3,420 \\
2,960\end{array}$ & $\begin{array}{l}5,400 \\
4,920\end{array}$ & $\begin{array}{l}8,170 \\
7,660\end{array}$ & 4,100 \\
\hline 09503800 & 0 & 0 & 0 & 0 & 0 & $\begin{array}{l}353 \\
362\end{array}$ & $\begin{array}{l}1,160 \\
1,410\end{array}$ & $\begin{array}{l}2,060 \\
3,080\end{array}$ & $\begin{array}{l}3,700 \\
6,860\end{array}$ & $\begin{array}{r}5,310 \\
11,100\end{array}$ & $\begin{array}{r}7.260 \\
16.000\end{array}$ & 2,300 \\
\hline 09504300 & 1 & 1 & 0 & 0 & 0 & $\begin{array}{l}2 \\
3\end{array}$ & $\begin{array}{l}23 \\
32\end{array}$ & $\begin{array}{r}67 \\
103\end{array}$ & $\begin{array}{l}189 \\
304\end{array}$ & $\begin{array}{l}351 \\
507\end{array}$ & $\begin{array}{l}597 \\
801\end{array}$ & 500 \\
\hline 09504400 & 0 & 0 & 0 & 0 & 0 & $\begin{array}{l}73 \\
73\end{array}$ & $\begin{array}{l}232 \\
222\end{array}$ & $\begin{array}{l}413 \\
367\end{array}$ & $\begin{array}{l}749 \\
619\end{array}$ & $\begin{array}{r}1,090 \\
879\end{array}$ & $\begin{array}{l}1.510 \\
1.270\end{array}$ & 705 \\
\hline 09504500 & 0 & 0 & 1 & 0 & 0 & $\begin{array}{l}5.000 \\
4,980\end{array}$ & $\begin{array}{l}12,000 \\
11,800\end{array}$ & $\begin{array}{l}18,300 \\
17,400\end{array}$ & $\begin{array}{l}28,300 \\
25,700\end{array}$ & $\begin{array}{l}36,900 \\
32,600\end{array}$ & $\begin{array}{l}46,600 \\
41,300\end{array}$ & 26,400 \\
\hline 09504800 & - & - & - & - & 1 & --- & 17 & 34 & 76 & 53 & 61 & 53 \\
\hline 09505200 & 1 & 0 & 0 & 0 & 0 & $\begin{array}{l}3,280 \\
3,260\end{array}$ & $\begin{array}{l}6,450 \\
6,210\end{array}$ & $\begin{array}{l}8,820 \\
8,090\end{array}$ & $\begin{array}{l}12,000 \\
10,700\end{array}$ & $\begin{array}{l}14,400 \\
14,200\end{array}$ & $\begin{array}{l}16.800 \\
18.500\end{array}$ & 10,900 \\
\hline 09505220 & 0 & 1 & 0 & 0 & 0 & $\begin{array}{l}45 \\
45\end{array}$ & $\begin{array}{l}152 \\
152\end{array}$ & $\begin{array}{l}297 \\
292\end{array}$ & $\begin{array}{l}629 \\
594\end{array}$ & $\begin{array}{r}1,040 \\
933\end{array}$ & $\begin{array}{l}1.640 \\
1.630\end{array}$ & 1,550 \\
\hline 09505250 & 1 & 1 & 0 & 0 & 0 & $\begin{array}{l}717 \\
716\end{array}$ & $\begin{array}{l}1,850 \\
1,850\end{array}$ & $\begin{array}{l}3,110 \\
3,110\end{array}$ & $\begin{array}{l}5,520 \\
5,540\end{array}$ & $\begin{array}{l}8,080 \\
8,770\end{array}$ & $\begin{array}{l}11,500 \\
12,800\end{array}$ & 10,500 \\
\hline 09505300 & 1 & 0 & 0 & 0 & 0 & $\begin{array}{l}865 \\
859\end{array}$ & $\begin{array}{l}1,880 \\
1,820\end{array}$ & $\begin{array}{l}2,760 \\
2,570\end{array}$ & $\begin{array}{l}4,100 \\
3,820\end{array}$ & $\begin{array}{l}5,240 \\
5,620\end{array}$ & $\begin{array}{l}6,510 \\
7,910\end{array}$ & 4,000 \\
\hline 09505350 & 1 & 0 & 0 & 0 & 0 & $\begin{array}{l}4.850 \\
4.820\end{array}$ & $\begin{array}{l}10,500 \\
10,000\end{array}$ & $\begin{array}{l}15,700 \\
13,800\end{array}$ & $\begin{array}{l}23,700 \\
18,400\end{array}$ & $\begin{array}{l}30,900 \\
23,300\end{array}$ & $\begin{array}{l}39,000 \\
29,900\end{array}$ & 26,600 \\
\hline 09505600 & - & - & - & - & 1 & 89 & 274 & 494 & 963 & 1,600 & 2,670 & 210 \\
\hline 09505800 & 1 & 0 & 0 & 0 & 0 & $\begin{array}{l}4.850 \\
4.810\end{array}$ & $\begin{array}{l}9.830 \\
9.450\end{array}$ & $\begin{array}{l}14,000 \\
12,700\end{array}$ & $\begin{array}{l}20,400 \\
17,700\end{array}$ & $\begin{array}{l}25,800 \\
22,700\end{array}$ & $\begin{array}{l}31,700 \\
29,200\end{array}$ & 22,400 \\
\hline 09505900 & 0 & 0 & 0 & 0 & 0 & $\begin{array}{l}23 \\
23\end{array}$ & $\begin{array}{l}75 \\
80\end{array}$ & $\begin{array}{l}142 \\
165\end{array}$ & $\begin{array}{l}282 \\
369\end{array}$ & $\begin{array}{l}441 \\
564\end{array}$ & $\begin{array}{l}663 \\
853\end{array}$ & 250 \\
\hline 09507600 & 0 & 0 & 0 & 0 & 0 & $\begin{array}{l}282 \\
279\end{array}$ & $\begin{array}{l}948 \\
884\end{array}$ & $\begin{array}{l}1,830 \\
1,500\end{array}$ & $\begin{array}{l}3,760 \\
2,470\end{array}$ & $\begin{array}{l}6,060 \\
3,740\end{array}$ & $\begin{array}{l}9,360 \\
5,590\end{array}$ & 2,820 \\
\hline 09507700 & 0 & 0 & 0 & 0 & 0 & $\begin{array}{l}88 \\
89\end{array}$ & $\begin{array}{l}289 \\
296\end{array}$ & $\begin{array}{l}549 \\
573\end{array}$ & $\begin{array}{l}1,110 \\
1,170\end{array}$ & $\begin{array}{l}1.750 \\
1.960\end{array}$ & $\begin{array}{l}2,670 \\
3,030\end{array}$ & 1,220 \\
\hline 09507980 & 0 & 0 & 0 & 0 & 0 & $\begin{array}{l}3,200 \\
3,190\end{array}$ & $\begin{array}{l}9,330 \\
9,170\end{array}$ & $\begin{array}{l}16,300 \\
15,300\end{array}$ & $\begin{array}{l}29,600 \\
25,300\end{array}$ & $\begin{array}{l}43,600 \\
34,700\end{array}$ & $\begin{array}{l}61,500 \\
46,900\end{array}$ & 23,500 \\
\hline 09508300 & 1 & 0 & 1 & 0 & 0 & $\begin{array}{l}1,730 \\
1.710\end{array}$ & $\begin{array}{l}4,650 \\
4,370\end{array}$ & $\begin{array}{l}7,530 \\
6,350\end{array}$ & $\begin{array}{r}12,300 \\
8,750\end{array}$ & $\begin{array}{l}16,600 \\
11,800\end{array}$ & $\begin{array}{l}21,600 \\
16,000\end{array}$ & 6,830 \\
\hline 09510070 & 0 & 0 & 0 & 0 & 0 & $\begin{array}{l}35 \\
36\end{array}$ & $\begin{array}{l}267 \\
279\end{array}$ & $\begin{array}{l}717 \\
702\end{array}$ & $\begin{array}{l}1,950 \\
1.580\end{array}$ & $\begin{array}{l}3,630 \\
2,690\end{array}$ & $\begin{array}{r}6,210 \\
4,270\end{array}$ & 1,700 \\
\hline 09510080 & 1 & 0 & 0 & 0 & 0 & $\begin{array}{r}99 \\
100\end{array}$ & $\begin{array}{l}516 \\
529\end{array}$ & $\begin{array}{l}1.210 \\
1.180\end{array}$ & $\begin{array}{l}3,000 \\
2,510\end{array}$ & $\begin{array}{l}5,350 \\
4,290\end{array}$ & $\begin{array}{l}9,000 \\
6,760\end{array}$ & 3,480 \\
\hline 09510100 & 0 & 0 & 0 & 0 & 0 & $\begin{array}{l}37 \\
38\end{array}$ & $\begin{array}{l}188 \\
201\end{array}$ & $\begin{array}{l}446 \\
488\end{array}$ & $\begin{array}{l}1.140 \\
1.180\end{array}$ & $\begin{array}{l}2,100 \\
2,110\end{array}$ & $\begin{array}{l}3,660 \\
3,450\end{array}$ & 1.940 \\
\hline 09510150 & 0 & 0 & 0 & 0 & 0 & $\begin{array}{l}1.030 \\
1.020\end{array}$ & $\begin{array}{l}4,020 \\
3,810\end{array}$ & $\begin{array}{l}8,270 \\
6,920\end{array}$ & $\begin{array}{l}18,000 \\
11,800\end{array}$ & $\begin{array}{l}29,800 \\
17,700\end{array}$ & $\begin{array}{l}47.000 \\
26,100\end{array}$ & 16,100 \\
\hline 09510170 & 0 & 0 & 0 & 0 & 0 & $\begin{array}{l}116 \\
115\end{array}$ & $\begin{array}{l}261 \\
264\end{array}$ & $\begin{array}{l}394 \\
435\end{array}$ & $\begin{array}{l}603 \\
838\end{array}$ & $\begin{array}{r}790 \\
1,420\end{array}$ & $\begin{array}{l}1,000 \\
2,180\end{array}$ & 402 \\
\hline 09510180 & 0 & 0 & 1 & 0 & 0 & $\begin{array}{l}497 \\
491\end{array}$ & $\begin{array}{l}1,360 \\
1,280\end{array}$ & $\begin{array}{l}2,170 \\
2,000\end{array}$ & $\begin{array}{l}3,550 \\
3,310\end{array}$ & $\begin{array}{l}4,820 \\
5,480\end{array}$ & $\begin{array}{l}6,280 \\
8,180\end{array}$ & 1,900 \\
\hline 09510200 & 0 & 0 & 0 & 0 & 0 & $\begin{array}{l}2,270 \\
2,260\end{array}$ & $\begin{array}{l}7,590 \\
7,410\end{array}$ & $\begin{array}{l}14,000 \\
12,900\end{array}$ & $\begin{array}{l}26,700 \\
21,700\end{array}$ & $\begin{array}{l}40,200 \\
30,700\end{array}$ & $\begin{array}{l}57,800 \\
42,700\end{array}$ & 24,200 \\
\hline 09512100 & 1 & 0 & 0 & 0 & 0 & $\begin{array}{l}375 \\
387\end{array}$ & $\begin{array}{l}1,440 \\
2,130\end{array}$ & $\begin{array}{l}2.960 \\
5,640\end{array}$ & $\begin{array}{r}6,500 \\
13,200\end{array}$ & $\begin{array}{l}10,900 \\
23,100\end{array}$ & $\begin{array}{l}17,400 \\
34,100\end{array}$ & 21,000 \\
\hline 09512200 & 0 & 0 & 0 & 0 & 0 & $\begin{array}{l}19 \\
19\end{array}$ & $\begin{array}{l}184 \\
191\end{array}$ & $\begin{array}{l}531 \\
536\end{array}$ & $\begin{array}{l}1,500 \\
1,330\end{array}$ & $\begin{array}{l}2,790 \\
2,310\end{array}$ & $\begin{array}{l}4,740 \\
3,720\end{array}$ & 670 \\
\hline 09512300 & 1 & 0 & 0 & 0 & 0 & $\begin{array}{l}1.730 \\
1,720\end{array}$ & $\begin{array}{l}4,310 \\
4,300\end{array}$ & $\begin{array}{l}6,910 \\
6,920\end{array}$ & $\begin{array}{l}11,400 \\
11,600\end{array}$ & $\begin{array}{l}15,600 \\
17,300\end{array}$ & $\begin{array}{l}20,700 \\
24,200\end{array}$ & 12,400 \\
\hline 09512420 & - & - & - & - & 1 & 40 & 122 & 228 & 462 & 682 & 1,030 & 820 \\
\hline 09512500 & 1 & 0 & 0 & 0 & 0 & $\begin{array}{l}5,850 \\
5,830\end{array}$ & $\begin{array}{l}10,200 \\
10,200\end{array}$ & $\begin{array}{l}13,900 \\
14,300\end{array}$ & $\begin{array}{l}19,300 \\
21,800\end{array}$ & $\begin{array}{l}24,000 \\
28,200\end{array}$ & $\begin{array}{l}29,300 \\
36,000\end{array}$ & 33,100 \\
\hline 09512700 & 1 & 0 & 1 & 0 & 0 & $\begin{array}{l}307 \\
304\end{array}$ & $\begin{array}{l}564 \\
529\end{array}$ & $\begin{array}{l}785 \\
681\end{array}$ & $\begin{array}{r}1130 \\
942\end{array}$ & $\begin{array}{l}1,430 \\
1,290\end{array}$ & $\begin{array}{l}1,790 \\
1,830\end{array}$ & 1,200 \\
\hline
\end{tabular}




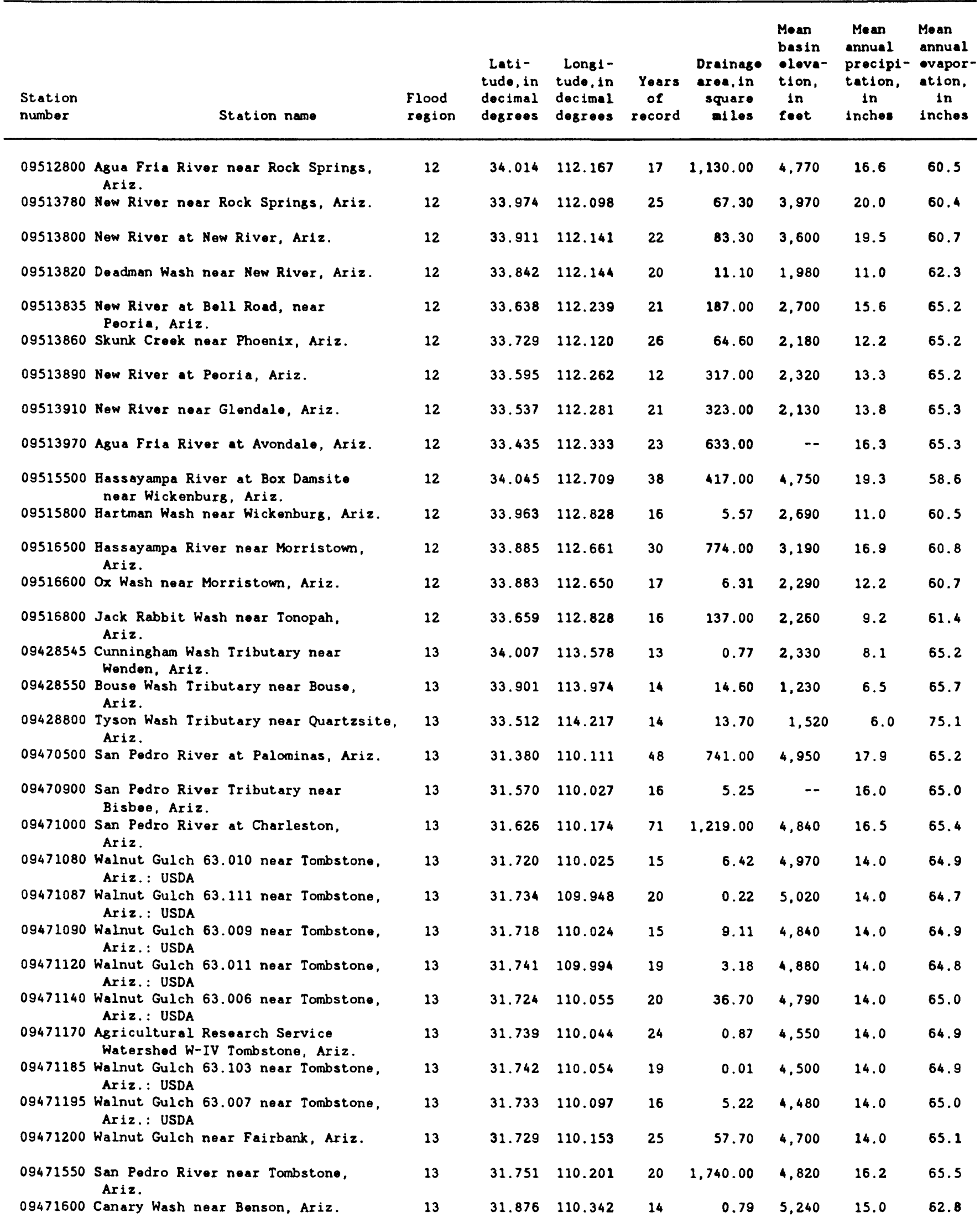




\begin{tabular}{|c|c|c|c|c|c|c|c|c|c|c|c|c|}
\hline \multirow[b]{2}{*}{$\begin{array}{l}\text { Station } \\
\text { number }\end{array}$} & \multirow{2}{*}{\multicolumn{5}{|c|}{$\begin{array}{l}\text { Relation } \\
\text { characteristic }\end{array}$}} & \multicolumn{6}{|c|}{$\begin{array}{l}\text { Peak discharge (cubic feet per second) for } \\
\text { indicated recurrence interval (years) }\end{array}$} & \multirow{2}{*}{$\begin{array}{l}\text { Maximum } \\
\text { peak discharse } \\
\text { of record } \\
\text { (cubic feet } \\
\text { per second) }\end{array}$} \\
\hline & & & & & & 2 & 5 & 10 & 25 & 50 & 100 & \\
\hline 09512800 & 0 & 0 & 1 & 0 & 0 & 7.440 & 22,800 & 42.200 & 83.300 & 131,000 & 199,000 & 59,500 \\
\hline & & & & & & 7,390 & 22,200 & 38,100 & 62.900 & 80,000 & 108,000 & \\
\hline 09513780 & 1 & 0 & 0 & 0 & 0 & $\begin{array}{l}2,380 \\
2,360\end{array}$ & $\begin{array}{l}6,580 \\
6,300\end{array}$ & $\begin{array}{r}11,100 \\
9,780\end{array}$ & $\begin{array}{l}19,100 \\
14,400\end{array}$ & $\begin{array}{l}27,100 \\
19,800\end{array}$ & $\begin{array}{l}36,900 \\
26,900\end{array}$ & 18,600 \\
\hline 09513800 & 1 & 0 & 0 & 0 & 0 & $\begin{array}{l}3,120 \\
3,100\end{array}$ & $\begin{array}{l}7,860 \\
7,490\end{array}$ & $\begin{array}{l}12,700 \\
11,100\end{array}$ & $\begin{array}{l}21,100 \\
15,800\end{array}$ & $\begin{array}{l}28,200 \\
21,500\end{array}$ & $\begin{array}{l}39,100 \\
29,100\end{array}$ & 19,500 \\
\hline 09513820 & - & - & - & - & 1 & 187 & 974 & 1,790 & 3,300 & 6,160 & 9,610 & 1,850 \\
\hline 09513835 & 1 & 0 & 1 & 0 & 0 & $\begin{array}{l}1,900 \\
1.890\end{array}$ & $\begin{array}{l}6,500 \\
6,460\end{array}$ & $\begin{array}{l}11,900 \\
11,500\end{array}$ & $\begin{array}{l}21.800 \\
19.800\end{array}$ & $\begin{array}{l}31,800 \\
28,900\end{array}$ & $\begin{array}{l}44,100 \\
40,000\end{array}$ & 14,600 \\
\hline 09513860 & 1 & 0 & 1 & 0 & 0 & $\begin{array}{l}916 \\
913\end{array}$ & $\begin{array}{l}3,510 \\
3,490\end{array}$ & $\begin{array}{r}7.040 \\
6.750\end{array}$ & $\begin{array}{l}14,800 \\
12.700\end{array}$ & $\begin{array}{l}23,800 \\
20,200\end{array}$ & $\begin{array}{l}36,500 \\
30,000\end{array}$ & 11.500 \\
\hline 09513890 & 1 & 0 & 0 & 0 & 0 & $\begin{array}{l}2,800 \\
2,780\end{array}$ & $\begin{array}{l}9,300 \\
9,290\end{array}$ & $\begin{array}{l}16,000 \\
15,800\end{array}$ & $\begin{array}{l}23,000 \\
24,600\end{array}$ & $\begin{array}{l}29,000 \\
34,600\end{array}$ & $\begin{array}{l}35,000 \\
46,100\end{array}$ & 20,000 \\
\hline 09513910 & 1 & 0 & 1 & 0 & 0 & $\begin{array}{l}1,400 \\
1,400\end{array}$ & $\begin{array}{l}8,200 \\
8,320\end{array}$ & $\begin{array}{l}15,000 \\
15,300\end{array}$ & $\begin{array}{l}23,000 \\
24,800\end{array}$ & $\begin{array}{l}30,000 \\
35,000\end{array}$ & $\begin{array}{l}37,000 \\
46,500\end{array}$ & 38,000 \\
\hline 09513970 & - & - & - & - & 1 & 2.376 & --- & --- & --- & --- & --- & 29,300 \\
\hline 09515500 & 0 & 0 & 0 & 0 & 0 & $\begin{array}{l}3,170 \\
3,160\end{array}$ & $\begin{array}{l}8,480 \\
8,490\end{array}$ & $\begin{array}{l}14,000 \\
14,000\end{array}$ & $\begin{array}{l}23,500 \\
23,400\end{array}$ & $\begin{array}{l}32,600 \\
31,900\end{array}$ & $\begin{array}{l}43,700 \\
42,400\end{array}$ & 58,000 \\
\hline 09515800 & 1 & 0 & 0 & 0 & 0 & $\begin{array}{l}216 \\
215\end{array}$ & $\begin{array}{r}794 \\
767\end{array}$ & $\begin{array}{r}1.570 \\
1.410\end{array}$ & $\begin{array}{r}3,230 \\
2,530\end{array}$ & $\begin{array}{r}5,150 \\
4,070\end{array}$ & $\begin{array}{r}7,820 \\
6,190\end{array}$ & 2,600 \\
\hline 09516500 & 1 & 0 & 0 & 0 & 0 & $\begin{array}{l}2,800 \\
2,800\end{array}$ & $\begin{array}{l}7,500 \\
7.960\end{array}$ & $\begin{array}{l}12,700 \\
14,700\end{array}$ & $\begin{array}{l}22,300 \\
28,900\end{array}$ & $\begin{array}{l}32,200 \\
40,200\end{array}$ & $\begin{array}{l}45,000 \\
54,100\end{array}$ & 47,500 \\
\hline 09516600 & 1 & 0 & 0 & 0 & 0 & $\begin{array}{l}192 \\
191\end{array}$ & $\begin{array}{l}661 \\
658\end{array}$ & $\begin{array}{l}1.250 \\
1.230\end{array}$ & $\begin{array}{l}2,460 \\
2,320\end{array}$ & $\begin{array}{l}3,790 \\
3.930\end{array}$ & $\begin{array}{l}5,570 \\
6,040\end{array}$ & 2,900 \\
\hline 09516800 & - & - & - & - & 1 & 907 & 5.220 & 8.950 & 15,300 & 24,600 & 35,000 & 6,840 \\
\hline 09428545 & 1 & 0 & 0 & 0 & 0 & $\begin{array}{l}52 \\
68\end{array}$ & $\begin{array}{l}101 \\
150\end{array}$ & $\begin{array}{l}141 \\
254\end{array}$ & $\begin{array}{l}199 \\
420\end{array}$ & $\begin{array}{l}247 \\
553\end{array}$ & $\begin{array}{l}300 \\
717\end{array}$ & 173 \\
\hline 09428550 & 1 & 0 & 0 & 0 & 0 & $\begin{array}{l}344 \\
398\end{array}$ & $\begin{array}{r}998 \\
1,090\end{array}$ & $\begin{array}{l}1,730 \\
1,860\end{array}$ & $\begin{array}{l}3,070 \\
3,170\end{array}$ & $\begin{array}{l}4,440 \\
4,410\end{array}$ & $\begin{array}{l}6.170 \\
5.990\end{array}$ & 2,920 \\
\hline 09428800 & - & - & - & - & 1 & 517 & 1.250 & 1.970 & 3.160 & 4,250 & 5.650 & 1,950 \\
\hline 09470500 & 1 & 0 & 0 & 0 & 0 & $\begin{array}{l}5,920 \\
5,630\end{array}$ & $\begin{array}{l}9,330 \\
9,030\end{array}$ & $\begin{array}{l}12,000 \\
11,700\end{array}$ & $\begin{array}{l}15,700 \\
15,800\end{array}$ & $\begin{array}{l}18,900 \\
19,400\end{array}$ & $\begin{array}{l}22,300 \\
23,400\end{array}$ & 22,000 \\
\hline 09470900 & 1 & 0 & 0 & 0 & 0 & $\begin{array}{l}451 \\
415\end{array}$ & $\begin{array}{l}903 \\
863\end{array}$ & $\begin{array}{l}1.260 \\
1.240\end{array}$ & $\begin{array}{l}1,780 \\
1,850\end{array}$ & $\begin{array}{l}2,190 \\
2,390\end{array}$ & $\begin{array}{l}2,620 \\
3,030\end{array}$ & 1,460 \\
\hline 09471000 & 1 & 1 & 0 & 0 & 0 & $\begin{array}{l}6,760 \\
6,540\end{array}$ & $\begin{array}{l}12,100 \\
11,800\end{array}$ & $\begin{array}{l}17,300 \\
16,600\end{array}$ & $\begin{array}{l}26,100 \\
24,800\end{array}$ & $\begin{array}{l}34.800 \\
32.900\end{array}$ & $\begin{array}{r}45,700 \\
42,900\end{array}$ & 98,000 \\
\hline 09471080 & 1 & 0 & 0 & 0 & 0 & $\begin{array}{l}364 \\
360\end{array}$ & $\begin{array}{l}771 \\
793\end{array}$ & $\begin{array}{l}1.150 \\
1.230\end{array}$ & $\begin{array}{l}1,790 \\
1,970\end{array}$ & $\begin{array}{l}2,380 \\
2,640\end{array}$ & $\begin{array}{l}3,080 \\
3,470\end{array}$ & 2,220 \\
\hline 09471087 & 1 & 0 & 0 & 0 & 0 & $\begin{array}{r}112 \\
98\end{array}$ & $\begin{array}{l}223 \\
196\end{array}$ & $\begin{array}{l}321 \\
266\end{array}$ & $\begin{array}{l}474 \\
380\end{array}$ & $\begin{array}{l}610 \\
483\end{array}$ & $\begin{array}{l}766 \\
609\end{array}$ & 541 \\
\hline 09471090 & 1 & 0 & 0 & 0 & 0 & $\begin{array}{l}590 \\
544\end{array}$ & $\begin{array}{l}1,570 \\
1,410\end{array}$ & $\begin{array}{l}2,550 \\
2,150\end{array}$ & $\begin{array}{l}4,190 \\
3,380\end{array}$ & $\begin{array}{l}5.710 \\
4.550\end{array}$ & $\begin{array}{l}7.490 \\
6.000\end{array}$ & 2,640 \\
\hline 09471120 & 0 & 0 & 0 & 0 & 0 & $\begin{array}{l}530 \\
464\end{array}$ & $\begin{array}{l}1.690 \\
1.420\end{array}$ & $\begin{array}{l}2,880 \\
2,150\end{array}$ & $\begin{array}{l}4,820 \\
3,340\end{array}$ & $\begin{array}{l}6,550 \\
4,450\end{array}$ & $\begin{array}{l}8,470 \\
5,770\end{array}$ & 4,390 \\
\hline 09471140 & 1 & 0 & 0 & 0 & 0 & $\begin{array}{l}1,460 \\
1,320\end{array}$ & $\begin{array}{l}2,660 \\
2,500\end{array}$ & $\begin{array}{l}3.670 \\
3.480\end{array}$ & $\begin{array}{l}5,200 \\
5,120\end{array}$ & $\begin{array}{l}6.530 \\
6.620\end{array}$ & $\begin{array}{l}8,030 \\
8,420\end{array}$ & 6,590 \\
\hline 09471170 & 0 & 0 & 0 & 0 & 0 & $\begin{array}{l}70 \\
78\end{array}$ & $\begin{array}{l}242 \\
248\end{array}$ & $\begin{array}{l}457 \\
445\end{array}$ & $\begin{array}{l}895 \\
805\end{array}$ & $\begin{array}{l}1,370 \\
1,170\end{array}$ & $\begin{array}{l}2,020 \\
1,670\end{array}$ & 1,270 \\
\hline 09471185 & 1 & 0 & 0 & 0 & 0 & $\begin{array}{l}9 \\
9\end{array}$ & $\begin{array}{l}16 \\
15\end{array}$ & $\begin{array}{l}20 \\
19\end{array}$ & $\begin{array}{l}27 \\
25\end{array}$ & $\begin{array}{l}32 \\
29\end{array}$ & $\begin{array}{l}38 \\
33\end{array}$ & 31 \\
\hline 09471195 & 0 & 0 & 0 & 0 & 0 & $\begin{array}{l}263 \\
276\end{array}$ & $\begin{array}{r}1,090 \\
997\end{array}$ & $\begin{array}{l}2,250 \\
1,820\end{array}$ & $\begin{array}{l}4,780 \\
3,400\end{array}$ & $\begin{array}{l}7,710 \\
5,150\end{array}$ & $\begin{array}{r}11,800 \\
7,600\end{array}$ & 2,590 \\
\hline 09471200 & 1 & 0 & 0 & 0 & 0 & $\begin{array}{l}1,740 \\
1,610\end{array}$ & $\begin{array}{l}3,680 \\
3,430\end{array}$ & $\begin{array}{l}5,450 \\
4,950\end{array}$ & $\begin{array}{l}8,320 \\
7,500\end{array}$ & $\begin{array}{r}11,000 \\
9,900\end{array}$ & $\begin{array}{l}14,000 \\
12,700\end{array}$ & 11,500 \\
\hline 09471550 & 1 & 0 & 0 & 0 & 0 & $\begin{array}{l}7,430 \\
6,760\end{array}$ & $\begin{array}{l}11,900 \\
11,200\end{array}$ & $\begin{array}{l}15,400 \\
14.800\end{array}$ & $\begin{array}{l}20,400 \\
20,600\end{array}$ & $\begin{array}{l}24,600 \\
25,600\end{array}$ & $\begin{array}{l}29,200 \\
31,300\end{array}$ & 24,200 \\
\hline 09471600 & - & - & - & - & 1 & 107 & ---- & 394 & --- & 817 & 1.070 & 84 \\
\hline
\end{tabular}




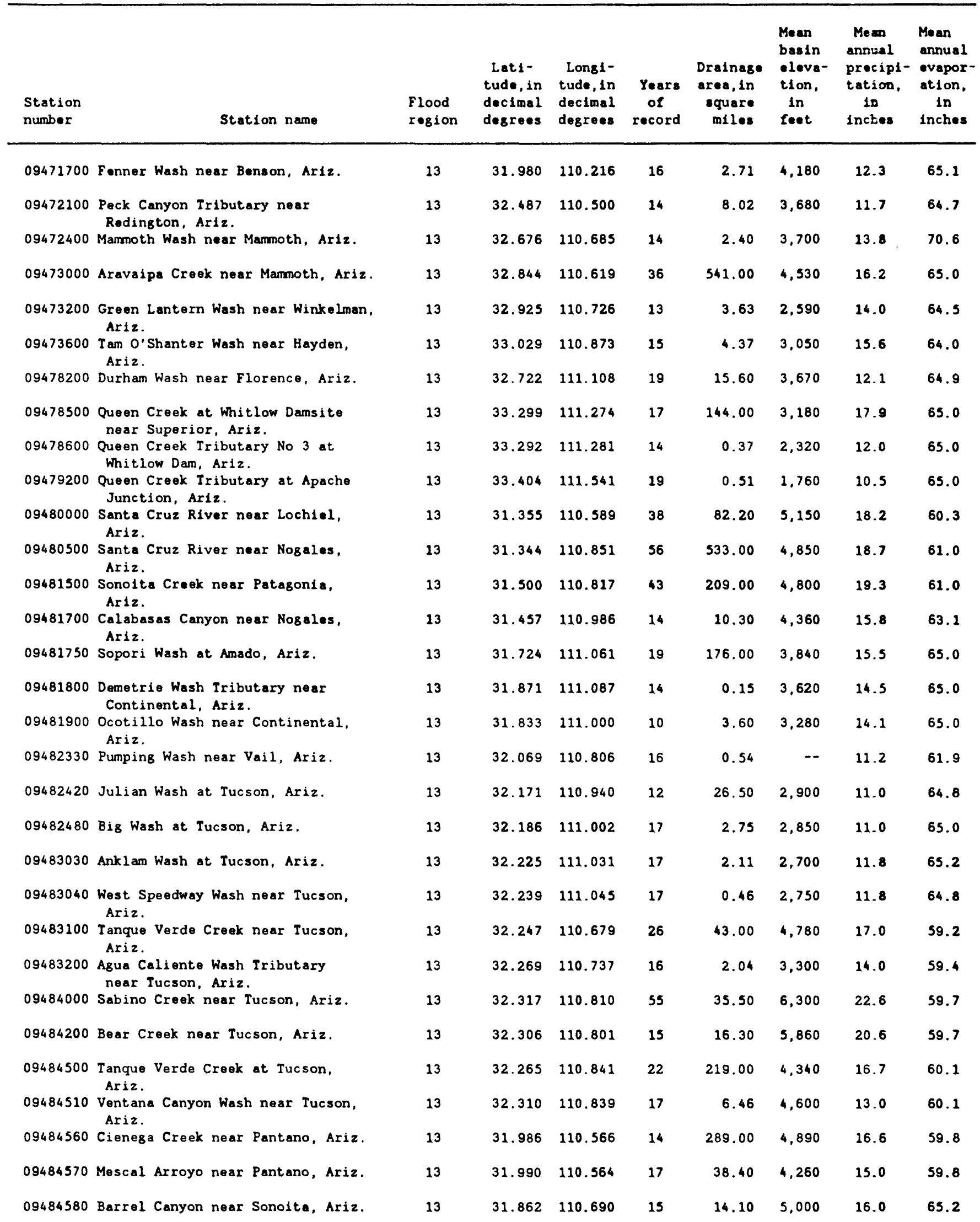




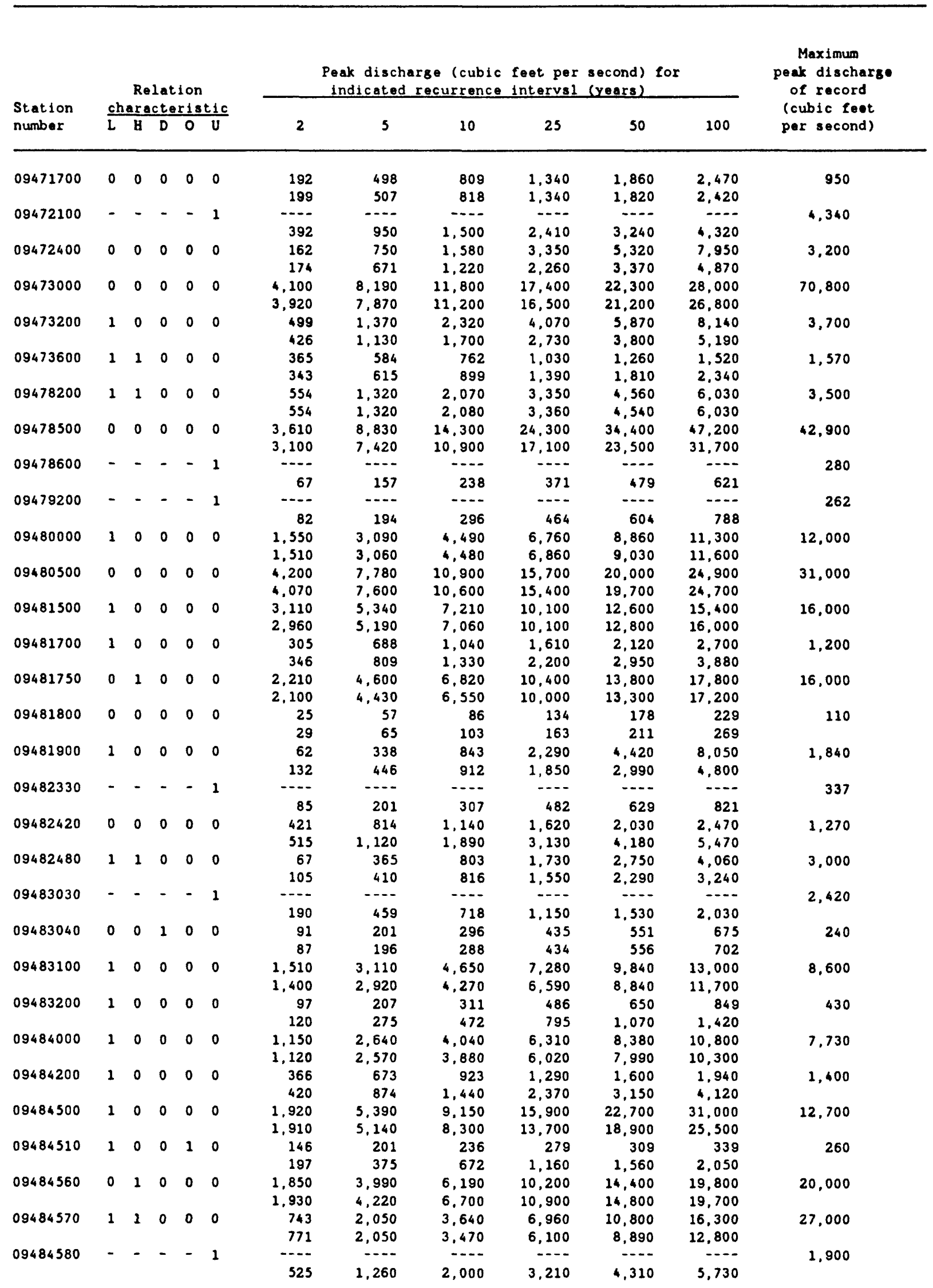




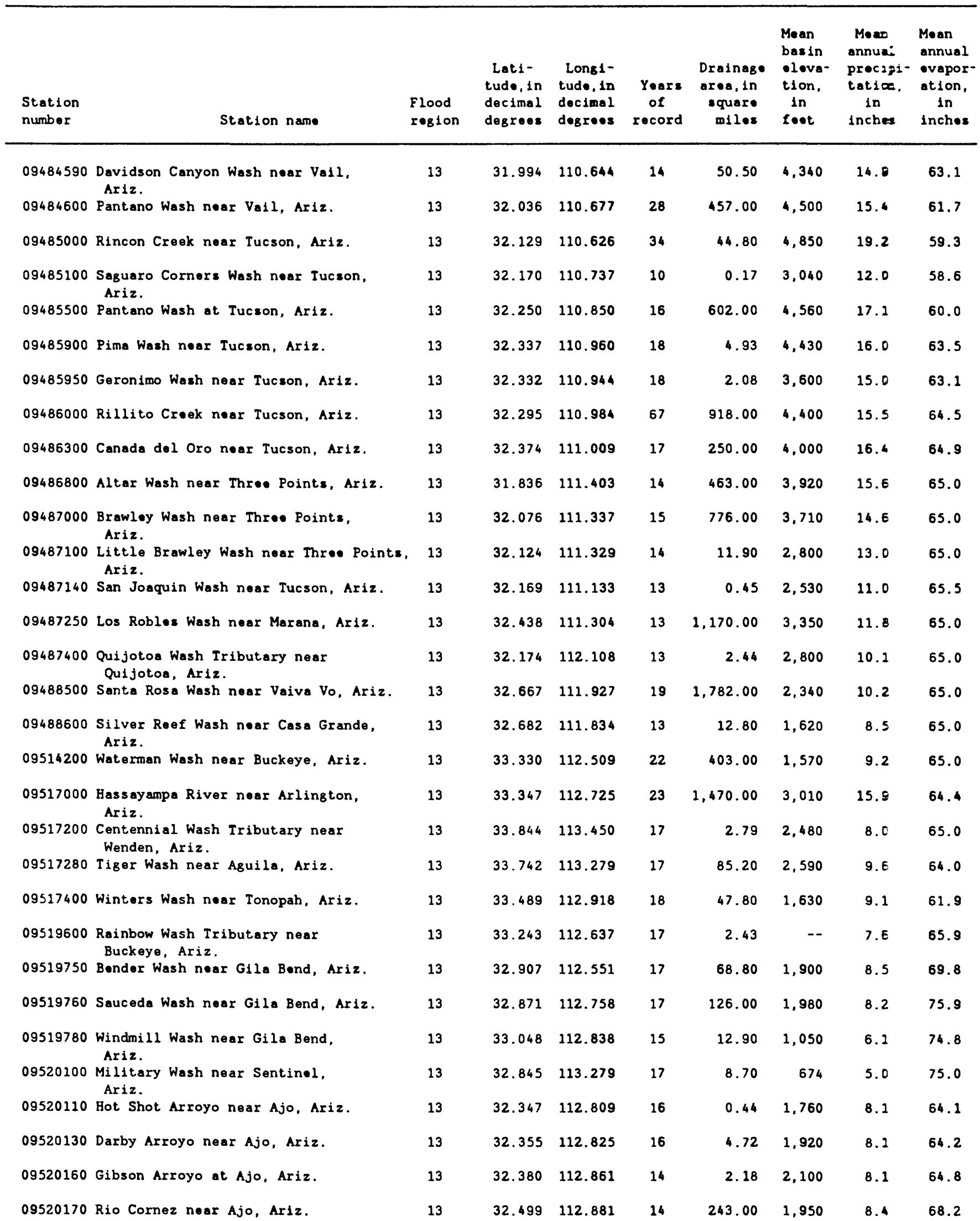




\begin{tabular}{|c|c|c|c|c|c|c|c|c|c|c|c|c|}
\hline \multirow{2}{*}{$\begin{array}{l}\text { Stat1on } \\
\text { number }\end{array}$} & \multicolumn{5}{|c|}{$\begin{array}{c}\text { Relation } \\
\text { cherecteristic }\end{array}$} & \multicolumn{6}{|c|}{$\begin{array}{l}\text { Peak discharse (cubic feet per second) for } \\
\text { indicated recurrence intervel (renrs) }\end{array}$} & \multirow{2}{*}{$\begin{array}{l}\text { Meximum } \\
\text { peak discharse } \\
\text { of record } \\
\text { (cublc feet } \\
\text { per second) }\end{array}$} \\
\hline & L & B & $D$ & 0 & $\frac{1+10}{U}$ & 2 & 5 & 10 & 25 & 50 & 100 & \\
\hline 09484590 & - & - & - & - & 1 & 976 & 2,300 & 3,620 & 5,780 & 7,720 & 10,200 & 6,860 \\
\hline 09484600 & 0 & 1 & 1 & 0 & 0 & $\begin{array}{l}3,120 \\
3,030\end{array}$ & $\begin{array}{l}7,800 \\
7,410\end{array}$ & $\begin{array}{l}12,400 \\
11,400\end{array}$ & $\begin{array}{l}20,300 \\
18,000\end{array}$ & $\begin{array}{l}27,600 \\
24,000\end{array}$ & $\begin{array}{l}36,400 \\
31,500\end{array}$ & 38,000 \\
\hline 09485000 & 0 & 0 & 0 & 0 & 0 & $\begin{array}{r}956 \\
951 \\
-\cdots-\end{array}$ & $\begin{array}{r}2,760 \\
2,670 \\
\ldots\end{array}$ & $\begin{array}{r}4,830 \\
4,490\end{array}$ & $\begin{array}{r}8,860 \\
7,830\end{array}$ & $\begin{array}{l}13,100 \\
11,300\end{array}$ & $\begin{array}{l}18,800 \\
15,900\end{array}$ & 9,660 \\
\hline 09485100 & - & - & - & - & 1 & 41 & 92 & 137 & 209 & 265 & 336 & 49 \\
\hline 09485500 & 0 & 0 & 0 & 0 & 0 & $\begin{array}{l}1,710 \\
2,010\end{array}$ & $\begin{array}{l}4,610 \\
5,070\end{array}$ & $\begin{array}{l}7,800 \\
8,420\end{array}$ & $\begin{array}{l}12,800 \\
13,800\end{array}$ & $\begin{array}{l}17,700 \\
18,600\end{array}$ & $\begin{array}{l}23,700 \\
24,300\end{array}$ & 20,000 \\
\hline 09485800 & 1 & 1 & 0 & 1 & 0 & $\begin{array}{r}73 \\
128\end{array}$ & $\begin{array}{l}177 \\
321\end{array}$ & $\begin{array}{l}272 \\
610\end{array}$ & $\begin{array}{r}423 \\
1,080\end{array}$ & $\begin{array}{r}555 \\
1,460\end{array}$ & $\begin{array}{r}703 \\
1,940\end{array}$ & 460 \\
\hline 09485850 & 1 & 0 & 0 & 0 & 0 & $\begin{array}{l}116 \\
133\end{array}$ & $\begin{array}{l}270 \\
318\end{array}$ & $\begin{array}{l}418 \\
530\end{array}$ & $\begin{array}{l}665 \\
880\end{array}$ & $\begin{array}{r}895 \\
1,190\end{array}$ & $\begin{array}{l}1,170 \\
1,570\end{array}$ & 705 \\
\hline 09486000 & 1 & 0 & 0 & 0 & 0 & $\begin{array}{l}5,090 \\
4,960\end{array}$ & $\begin{array}{l}9,520 \\
9,330\end{array}$ & $\begin{array}{l}13,200 \\
12,900\end{array}$ & $\begin{array}{l}18,600 \\
18,300\end{array}$ & $\begin{array}{l}23,200 \\
23,000\end{array}$ & $\begin{array}{l}28,300 \\
28,300\end{array}$ & 29,700 \\
\hline 09486300 & 0 & 0 & 0 & 0 & 0 & $\begin{array}{l}2,620 \\
2,470\end{array}$ & $\begin{array}{l}6,130 \\
5,690\end{array}$ & $\begin{array}{l}8,430 \\
8,460\end{array}$ & $\begin{array}{l}14,700 \\
12,900\end{array}$ & $\begin{array}{l}19,600 \\
17,100\end{array}$ & $\begin{array}{l}25,200 \\
22,100\end{array}$ & 17,000 \\
\hline 08486800 & 0 & 0 & 0 & 0 & 0 & $\begin{array}{l}4,280 \\
3,790\end{array}$ & $\begin{array}{l}7,910 \\
7,220\end{array}$ & $\begin{array}{l}11,000 \\
10,000\end{array}$ & $\begin{array}{l}15,600 \\
14,600\end{array}$ & $\begin{array}{l}18,600 \\
18,700\end{array}$ & $\begin{array}{l}24,100 \\
23,500\end{array}$ & 22,000 \\
\hline 08487000 & 0 & 0 & 0 & 0 & 0 & $\begin{array}{l}3,640 \\
3,510\end{array}$ & $\begin{array}{l}6,390 \\
6,530\end{array}$ & $\begin{array}{l}8,770 \\
8,500\end{array}$ & $\begin{array}{l}12,500 \\
14,400\end{array}$ & $\begin{array}{l}16,000 \\
18,600\end{array}$ & $\begin{array}{l}20,000 \\
23,600\end{array}$ & 19,100 \\
\hline 09487100 & 0 & 0 & 0 & 0 & 0 & $\begin{array}{l}777 \\
692\end{array}$ & $\begin{array}{l}1,450 \\
1,360\end{array}$ & $\begin{array}{l}2,010 \\
1,930\end{array}$ & $\begin{array}{l}2,870 \\
2,810\end{array}$ & $\begin{array}{l}3,610 \\
3,800\end{array}$ & $\begin{array}{l}4,450 \\
4,890\end{array}$ & 13,800 \\
\hline 09487140 & - & - & - & - & 1 & 76 & 179 &.--- & ---- & ---- & 718 & 520 \\
\hline 09487250 & 0 & 1 & 0 & 0 & 0 & $\begin{array}{l}1,130 \\
1,920\end{array}$ & $\begin{array}{l}3,090 \\
4,660\end{array}$ & $\begin{array}{l}4,930 \\
8,210\end{array}$ & $\begin{array}{r}7,790 \\
13,600\end{array}$ & $\begin{array}{l}10,200 \\
17,800\end{array}$ & $\begin{array}{l}12.900 \\
22.600\end{array}$ & 32,000 \\
\hline 09487400 & 1 & 0 & 0 & 0 & 0 & $\begin{array}{l}167 \\
179\end{array}$ & $\begin{array}{l}369 \\
411\end{array}$ & $\begin{array}{l}547 \\
655\end{array}$ & $\begin{array}{r}819 \\
1,050\end{array}$ & $\begin{array}{l}1,050 \\
1,390\end{array}$ & $\begin{array}{l}1,320 \\
1,820\end{array}$ & 715 \\
\hline 09488500 & 1 & 0 & 0 & 0 & 0 & $\begin{array}{r}805 \\
1,620\end{array}$ & $\begin{array}{l}3,160 \\
4,640\end{array}$ & $\begin{array}{l}6,270 \\
9,050\end{array}$ & $\begin{array}{l}12,800 \\
16,500\end{array}$ & $\begin{array}{l}20,000 \\
23,200\end{array}$ & $\begin{array}{l}29,600 \\
31,700\end{array}$ & 53,100 \\
\hline 09488600 & 0 & 0 & 0 & 0 & 0 & $\begin{array}{l}265 \\
336\end{array}$ & $\begin{array}{l}660 \\
837\end{array}$ & $\begin{array}{l}1,070 \\
1,450\end{array}$ & $\begin{array}{l}1,820 \\
2,480\end{array}$ & $\begin{array}{l}2,570 \\
3,420\end{array}$ & $\begin{array}{l}3,500 \\
4,590\end{array}$ & 1,400 \\
\hline 09514200 & 1 & 0 & 0 & 0 & 0 & $\begin{array}{l}1,430 \\
1,640\end{array}$ & $\begin{array}{l}2,730 \\
3,320\end{array}$ & $\begin{array}{l}3,870 \\
5,360\end{array}$ & $\begin{array}{l}5,660 \\
8,640\end{array}$ & $\begin{array}{r}7,280 \\
11,400\end{array}$ & $\begin{array}{r}9,140 \\
14,600\end{array}$ & 6,300 \\
\hline 08517000 & 1 & 0 & 0 & 0 & 0 & $\begin{array}{l}3,110 \\
3,300\end{array}$ & $\begin{array}{l}8,390 \\
8,430\end{array}$ & $\begin{array}{l}14,400 \\
13,900\end{array}$ & $\begin{array}{l}25,800 \\
23,500\end{array}$ & $\begin{array}{l}37,900 \\
32,900\end{array}$ & $\begin{array}{l}53,900 \\
45,100\end{array}$ & 39,000 \\
\hline 09517200 & 0 & 0 & 0 & 0 & 0 & $\begin{array}{l}131 \\
154\end{array}$ & $\begin{array}{l}312 \\
373\end{array}$ & $\begin{array}{l}480 \\
624\end{array}$ & $\begin{array}{r}747 \\
1,030\end{array}$ & $\begin{array}{r}986 \\
1,380\end{array}$ & $\begin{array}{l}1,260 \\
1.820\end{array}$ & 720 \\
\hline 09517280 & 1 & 0 & 0 & 0 & 0 & $\begin{array}{l}1,010 \\
1,070\end{array}$ & $\begin{array}{l}2,120 \\
2,330\end{array}$ & $\begin{array}{l}3,070 \\
3,650\end{array}$ & $\begin{array}{l}4,480 \\
5,760\end{array}$ & $\begin{array}{l}5,680 \\
7,570\end{array}$ & $\begin{array}{l}7,000 \\
0,720\end{array}$ & 4,550 \\
\hline 09517400 & 1 & 0 & 0 & 0 & 0 & $\begin{array}{l}854 \\
877\end{array}$ & $\begin{array}{l}1,540 \\
1,720\end{array}$ & $\begin{array}{l}2,120 \\
2,660\end{array}$ & $\begin{array}{l}3,000 \\
4,200\end{array}$ & $\begin{array}{l}3,770 \\
5,540\end{array}$ & $\begin{array}{l}4.640 \\
7,150\end{array}$ & 3,640 \\
\hline 09519600 & 1 & 0 & 0 & 0 & 0 & $\begin{array}{l}482 \\
413\end{array}$ & $\begin{array}{l}747 \\
680\end{array}$ & $\begin{array}{l}947 \\
881\end{array}$ & $\begin{array}{l}1,230 \\
1,240\end{array}$ & $\begin{array}{l}1,450 \\
1,550\end{array}$ & $\begin{array}{l}1,700 \\
1,850\end{array}$ & 1,430 \\
\hline 09519750 & - & - & - & - & 1 & 1,130 & 2,630 & 4.130 & 6,590 & 8,790 & 11,600 & 2,670 \\
\hline 09519760 & 1 & 0 & 1 & 0 & 0 & $\begin{array}{l}583 \\
806\end{array}$ & $\begin{array}{l}1,870 \\
2,280\end{array}$ & $\begin{array}{l}3,310 \\
4,100\end{array}$ & $\begin{array}{l}5,910 \\
7,090\end{array}$ & $\begin{array}{l}8,450 \\
8,770\end{array}$ & $\begin{array}{l}11,500 \\
13,000\end{array}$ & 3,150 \\
\hline 09519780 & - & - & - & - & 1 & 501 & 1,210 & 1,910 & 3,070 & 4,120 & 5,490 & 4,430 \\
\hline 09520100 & 0 & 0 & 0 & 0 & 0 & $\begin{array}{l}125 \\
196\end{array}$ & $\begin{array}{l}468 \\
609\end{array}$ & $\begin{array}{r}945 \\
1,180\end{array}$ & $\begin{array}{l}2,020 \\
2,250\end{array}$ & $\begin{array}{l}3,310 \\
3,340\end{array}$ & $\begin{array}{l}5,180 \\
4,850\end{array}$ & 1,530 \\
\hline 09520110 & 1 & 0 & 0 & 0 & 0 & $\begin{array}{l}136 \\
120\end{array}$ & $\begin{array}{l}191 \\
187\end{array}$ & $\begin{array}{l}226 \\
243\end{array}$ & $\begin{array}{l}267 \\
341\end{array}$ & $\begin{array}{l}297 \\
420\end{array}$ & $\begin{array}{l}325 \\
517\end{array}$ & 240 \\
\hline 09520130 & 1 & 0 & 0 & 0 & 0 & $\begin{array}{l}551 \\
485\end{array}$ & $\begin{array}{l}922 \\
865\end{array}$ & $\begin{array}{l}1,210 \\
1,180\end{array}$ & $\begin{array}{l}1,630 \\
1,720\end{array}$ & $\begin{array}{l}1,880 \\
2,210\end{array}$ & $\begin{array}{l}2,370 \\
2,810\end{array}$ & 1,670 \\
\hline 09520160 & 0 & 1 & 0 & 0 & 0 & $\begin{array}{l}239 \\
226\end{array}$ & $\begin{array}{l}463 \\
464\end{array}$ & $\begin{array}{l}661 \\
692\end{array}$ & $\begin{array}{r}974 \\
1,080\end{array}$ & $\begin{array}{l}1,260 \\
1,420\end{array}$ & $\begin{array}{l}1,580 \\
1,840\end{array}$ & 1,800 \\
\hline 09520170 & 0 & 0 & 0 & 0 & 0 & $\begin{array}{l}3,000 \\
2,710\end{array}$ & $\begin{array}{l}4.850 \\
4.720\end{array}$ & $\begin{array}{l}6,270 \\
6,540\end{array}$ & $\begin{array}{l}8,300 \\
8,610\end{array}$ & $\begin{array}{r}8,960 \\
12,300\end{array}$ & $\begin{array}{l}11,800 \\
15,400\end{array}$ & 8,030 \\
\hline
\end{tabular}




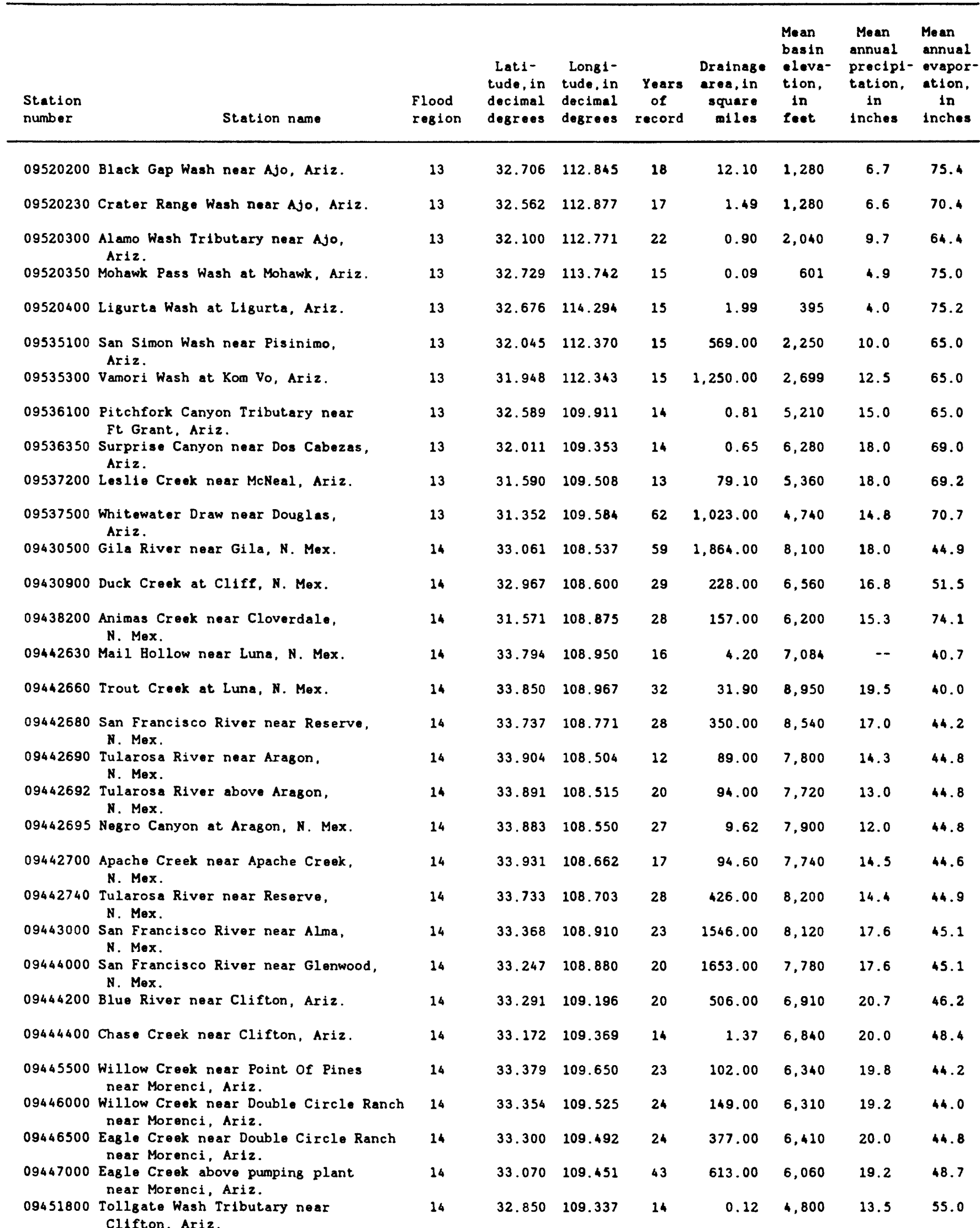




\begin{tabular}{|c|c|c|c|c|c|c|c|c|c|c|c|c|}
\hline \multirow{2}{*}{$\begin{array}{l}\text { Station } \\
\text { number }\end{array}$} & \multicolumn{5}{|c|}{ Relation } & \multicolumn{6}{|c|}{$\begin{array}{l}\text { Peak discharge (cubic feet per second) for } \\
\text { indicated recurrence interval (years) }\end{array}$} & \multirow{2}{*}{$\begin{array}{l}\text { Maximu } \\
\text { peak discharge } \\
\text { of record } \\
\text { (cublc feet } \\
\text { per second) }\end{array}$} \\
\hline & $\mathrm{L}$ & H & $D$ & 0 & U & 2 & 5 & 10 & 25 & 50 & 100 & \\
\hline 09520200 & 1 & 0 & 0 & 0 & 0 & $\begin{array}{l}392 \\
414\end{array}$ & $\begin{array}{l}672 \\
801\end{array}$ & $\begin{array}{r}868 \\
1,240\end{array}$ & $\begin{array}{l}1,120 \\
1,960\end{array}$ & $\begin{array}{l}1,300 \\
2,560\end{array}$ & $\begin{array}{l}1,480 \\
3,290\end{array}$ & 940 \\
\hline 09520230 & 0 & 0 & 1 & 0 & 0 & $\begin{array}{l}103 \\
116\end{array}$ & $\begin{array}{l}329 \\
341\end{array}$ & $\begin{array}{l}586 \\
585\end{array}$ & $\begin{array}{r}1,060 \\
999\end{array}$ & $\begin{array}{l}1,530 \\
1,390\end{array}$ & $\begin{array}{l}2,100 \\
1,870\end{array}$ & 590 \\
\hline 09520300 & 1 & 0 & 0 & 0 & 0 & $\begin{array}{l}151 \\
144\end{array}$ & $\begin{array}{l}268 \\
270\end{array}$ & $\begin{array}{l}362 \\
384\end{array}$ & $\begin{array}{l}500 \\
572\end{array}$ & $\begin{array}{l}615 \\
731\end{array}$ & $\begin{array}{l}741 \\
923\end{array}$ & 510 \\
\hline 09520350 & 0 & 0 & 0 & 0 & 0 & $\begin{array}{l}20 \\
22\end{array}$ & $\begin{array}{l}52 \\
54\end{array}$ & $\begin{array}{l}85 \\
85\end{array}$ & $\begin{array}{l}142 \\
134\end{array}$ & $\begin{array}{l}197 \\
176\end{array}$ & $\begin{array}{l}263 \\
228\end{array}$ & 117 \\
\hline 09520400 & 1 & 0 & 0 & 0 & 0 & $\begin{array}{l}185 \\
185\end{array}$ & $\begin{array}{l}551 \\
520\end{array}$ & $\begin{array}{l}971 \\
853\end{array}$ & $\begin{array}{l}1,770 \\
1,440\end{array}$ & $\begin{array}{l}2,610 \\
2,030\end{array}$ & $\begin{array}{l}3,680 \\
2,790\end{array}$ & 1,590 \\
\hline 09535100 & 1 & 0 & 1 & 0 & 0 & $\begin{array}{l}1,250 \\
1,670\end{array}$ & $\begin{array}{l}3,020 \\
3,930\end{array}$ & $\begin{array}{l}5,010 \\
6,880\end{array}$ & $\begin{array}{r}8,850 \\
11,800\end{array}$ & $\begin{array}{l}13,000 \\
16,100\end{array}$ & $\begin{array}{l}18,700 \\
21,700\end{array}$ & 12,500 \\
\hline 09535300 & 0 & 1 & 0 & 1 & 0 & $\begin{array}{r}778 \\
1,610\end{array}$ & $\begin{array}{l}1,710 \\
3,590\end{array}$ & $\begin{array}{l}2,700 \\
6,790\end{array}$ & $\begin{array}{r}4,520 \\
11,700\end{array}$ & $\begin{array}{r}6,420 \\
15,700\end{array}$ & $\begin{array}{r}8,920 \\
20,400\end{array}$ & 10,400 \\
\hline 09536100 & 1 & 0 & 0 & 0 & 0 & $\begin{array}{l}142 \\
132\end{array}$ & $\begin{array}{l}246 \\
250\end{array}$ & $\begin{array}{l}326 \\
359\end{array}$ & $\begin{array}{l}437 \\
538\end{array}$ & $\begin{array}{l}526 \\
688\end{array}$ & $\begin{array}{l}621 \\
873\end{array}$ & 375 \\
\hline 09536350 & 0 & 0 & 0 & 0 & 0 & $\begin{array}{l}44 \\
59\end{array}$ & $\begin{array}{l}112 \\
147\end{array}$ & $\begin{array}{l}176 \\
252\end{array}$ & $\begin{array}{l}275 \\
415\end{array}$ & $\begin{array}{l}362 \\
550\end{array}$ & $\begin{array}{l}457 \\
714\end{array}$ & 191 \\
\hline 09537200 & 1 & 0 & 0 & 0 & 0 & $\begin{array}{l}438 \\
668\end{array}$ & $\begin{array}{l}1,350 \\
1.820\end{array}$ & $\begin{array}{l}2,480 \\
3,360\end{array}$ & $\begin{array}{l}4,810 \\
5,980\end{array}$ & $\begin{array}{l}7,430 \\
8,460\end{array}$ & $\begin{array}{l}11,100 \\
11,700\end{array}$ & 4.600 \\
\hline 09537500 & 0 & 0 & 1 & 1 & 0 & $\begin{array}{l}1,710 \\
1,860\end{array}$ & $\begin{array}{l}2,770 \\
3,210\end{array}$ & $\begin{array}{l}3,510 \\
4,730\end{array}$ & $\begin{array}{l}4,470 \\
7,060\end{array}$ & $\begin{array}{l}5,190 \\
8,820\end{array}$ & $\begin{array}{r}5,910 \\
10,700\end{array}$ & 5,060 \\
\hline 09430500 & 0 & 0 & 0 & 0 & 0 & $\begin{array}{l}1,880 \\
1,920\end{array}$ & $\begin{array}{l}5,320 \\
5,440\end{array}$ & $\begin{array}{l}9,480 \\
9,670\end{array}$ & $\begin{array}{l}18,000 \\
18,100\end{array}$ & $\begin{array}{l}27,600 \\
27,300\end{array}$ & $\begin{array}{l}40,900 \\
39,600\end{array}$ & 35,200 \\
\hline 09430900 & 0 & 0 & 0 & 0 & 0 & $\begin{array}{l}3,660 \\
3,530\end{array}$ & $\begin{array}{l}5,510 \\
5,220\end{array}$ & $\begin{array}{l}6,700 \\
6,380\end{array}$ & $\begin{array}{l}8,170 \\
7,950\end{array}$ & $\begin{array}{l}9,220 \\
9,310\end{array}$ & $\begin{array}{l}10,200 \\
10,800\end{array}$ & 6,900 \\
\hline 09438200 & 1 & 0 & 0 & 0 & 0 & $\begin{array}{l}739 \\
757\end{array}$ & $\begin{array}{l}1,290 \\
1,420\end{array}$ & $\begin{array}{l}1,770 \\
2,070\end{array}$ & $\begin{array}{l}2,500 \\
3,260\end{array}$ & $\begin{array}{l}3,150 \\
4,410\end{array}$ & $\begin{array}{l}3,910 \\
5,790\end{array}$ & 3,400 \\
\hline 09442630 & 1 & 0 & 0 & 1 & 0 & $\begin{array}{l}54 \\
59\end{array}$ & $\begin{array}{l}106 \\
147\end{array}$ & $\begin{array}{l}151 \\
281\end{array}$ & $\begin{array}{l}219 \\
515\end{array}$ & $\begin{array}{l}278 \\
742\end{array}$ & $\begin{array}{r}344 \\
1,010\end{array}$ & 264 \\
\hline 09442660 & 0 & 0 & 0 & 0 & 0 & $\begin{array}{l}151 \\
156\end{array}$ & $\begin{array}{l}489 \\
522\end{array}$ & $\begin{array}{r}939 \\
1,050\end{array}$ & $\begin{array}{l}1,940 \\
2,120\end{array}$ & $\begin{array}{l}3,140 \\
3,310\end{array}$ & $\begin{array}{l}4,910 \\
4,940\end{array}$ & 2,790 \\
\hline 09442680 & 0 & 0 & 0 & 0 & 0 & $\begin{array}{l}871 \\
885\end{array}$ & $\begin{array}{l}2,270 \\
2,350\end{array}$ & $\begin{array}{l}3,930 \\
4,160\end{array}$ & $\begin{array}{l}7,340 \\
7,640\end{array}$ & $\begin{array}{l}11,200 \\
11,300\end{array}$ & $\begin{array}{l}16,700 \\
16,300\end{array}$ & 9,830 \\
\hline 09442690 & - & - & - & - & 1 &.--- & 1,540 & 2,900 & 4.620 & 6,200 & 8.070 & 181 \\
\hline 09442692 & 1 & 0 & 0 & 1 & 0 & $\begin{array}{r}83 \\
122\end{array}$ & $\begin{array}{l}203 \\
413\end{array}$ & $\begin{array}{l}321 \\
847\end{array}$ & $\begin{array}{r}524 \\
1,700\end{array}$ & $\begin{array}{r}716 \\
2,550\end{array}$ & $\begin{array}{r}947 \\
3,580\end{array}$ & 660 \\
\hline 09442695 & 1 & 1 & 0 & 0 & 0 & $\begin{array}{l}211 \\
207\end{array}$ & $\begin{array}{l}532 \\
526\end{array}$ & $\begin{array}{l}907 \\
926\end{array}$ & $\begin{array}{l}1.670 \\
1,670\end{array}$ & $\begin{array}{l}2,520 \\
2,440\end{array}$ & $\begin{array}{l}3,720 \\
3,470\end{array}$ & 5,200 \\
\hline 09442700 & 0 & 0 & 0 & 0 & 0 & $\begin{array}{l}290 \\
317\end{array}$ & $\begin{array}{r}962 \\
1,070\end{array}$ & $\begin{array}{l}1,770 \\
2,040\end{array}$ & $\begin{array}{l}3,370 \\
3,800\end{array}$ & $\begin{array}{l}5,070 \\
5,540\end{array}$ & $\begin{array}{l}7,280 \\
7,690\end{array}$ & 2,900 \\
\hline 09442740 & 0 & 0 & 0 & 0 & 0 & $\begin{array}{l}341 \\
397\end{array}$ & $\begin{array}{r}789 \\
1,080\end{array}$ & $\begin{array}{l}1,260 \\
1.970\end{array}$ & $\begin{array}{l}2.110 \\
3.720\end{array}$ & $\begin{array}{l}2,990 \\
5,500\end{array}$ & $\begin{array}{l}4.110 \\
7.700\end{array}$ & 3,020 \\
\hline 09443000 & 1 & 0 & 0 & 0 & 0 & $\begin{array}{l}5,110 \\
4,960\end{array}$ & $\begin{array}{l}13,000 \\
12,200\end{array}$ & $\begin{array}{l}22,000 \\
20,000\end{array}$ & $\begin{array}{l}39,400 \\
33,800\end{array}$ & $\begin{array}{l}58,100 \\
47,800\end{array}$ & $\begin{array}{l}83,400 \\
66,000\end{array}$ & 56,600 \\
\hline 09444000 & 0 & 1 & 0 & 0 & 0 & $\begin{array}{l}3,930 \\
3,870\end{array}$ & $\begin{array}{l}8,690 \\
8,460\end{array}$ & $\begin{array}{l}13,500 \\
13,100\end{array}$ & $\begin{array}{l}22,100 \\
20,900\end{array}$ & $\begin{array}{l}30,800 \\
28,600\end{array}$ & $\begin{array}{l}41,800 \\
38,000\end{array}$ & 37,100 \\
\hline 09444200 & 1 & 0 & 0 & 0 & 0 & $\begin{array}{l}4,170 \\
3,990\end{array}$ & $\begin{array}{r}10,500 \\
9,550\end{array}$ & $\begin{array}{l}17,500 \\
15,300\end{array}$ & $\begin{array}{l}30.600 \\
24.900\end{array}$ & $\begin{array}{l}44,400 \\
34,500\end{array}$ & $\begin{array}{l}62,400 \\
46,500\end{array}$ & 30,000 \\
\hline 09444400 & - & - & - & - & 1 & 58 & 190 & 418 & 672 & 901 & 1.170 & 600 \\
\hline 09445500 & 1 & 0 & 0 & 0 & 0 & $\begin{array}{l}671 \\
680\end{array}$ & $\begin{array}{l}1,360 \\
1,430\end{array}$ & $\begin{array}{l}1,980 \\
2.180\end{array}$ & $\begin{array}{l}2,960 \\
3,460\end{array}$ & $\begin{array}{l}3,840 \\
4,660\end{array}$ & $\begin{array}{l}4,860 \\
6,080\end{array}$ & 3,710 \\
\hline 09446000 & 1 & 0 & 0 & 0 & 0 & $\begin{array}{l}1,410 \\
1,380\end{array}$ & $\begin{array}{l}2,900 \\
2,830\end{array}$ & $\begin{array}{l}4,230 \\
4,140\end{array}$ & $\begin{array}{l}6.340 \\
6.220\end{array}$ & $\begin{array}{l}8,250 \\
8,140\end{array}$ & $\begin{array}{l}10,500 \\
10,400\end{array}$ & 7,500 \\
\hline 09446500 & 1 & 0 & 0 & 0 & 0 & $\begin{array}{l}2,490 \\
2,440\end{array}$ & $\begin{array}{l}5,680 \\
5,430\end{array}$ & $\begin{array}{l}8,810 \\
8.270\end{array}$ & $\begin{array}{l}14,200 \\
12,900\end{array}$ & $\begin{array}{l}19,400 \\
17,300\end{array}$ & $\begin{array}{l}25,700 \\
22,500\end{array}$ & 30,000 \\
\hline 09447000 & 0 & 0 & 0 & 0 & 0 & $\begin{array}{l}2,740 \\
2,730\end{array}$ & $\begin{array}{l}7,370 \\
7,190\end{array}$ & $\begin{array}{l}12,200 \\
11,700\end{array}$ & $\begin{array}{l}20,500 \\
19,100\end{array}$ & $\begin{array}{l}28,500 \\
26,000\end{array}$ & $\begin{array}{l}38,300 \\
34,500\end{array}$ & 36,400 \\
\hline 09451800 & - & - & - & - & 1 & 22 & 68 & 135 & 218 & 292 & 378 & 63 \\
\hline
\end{tabular}




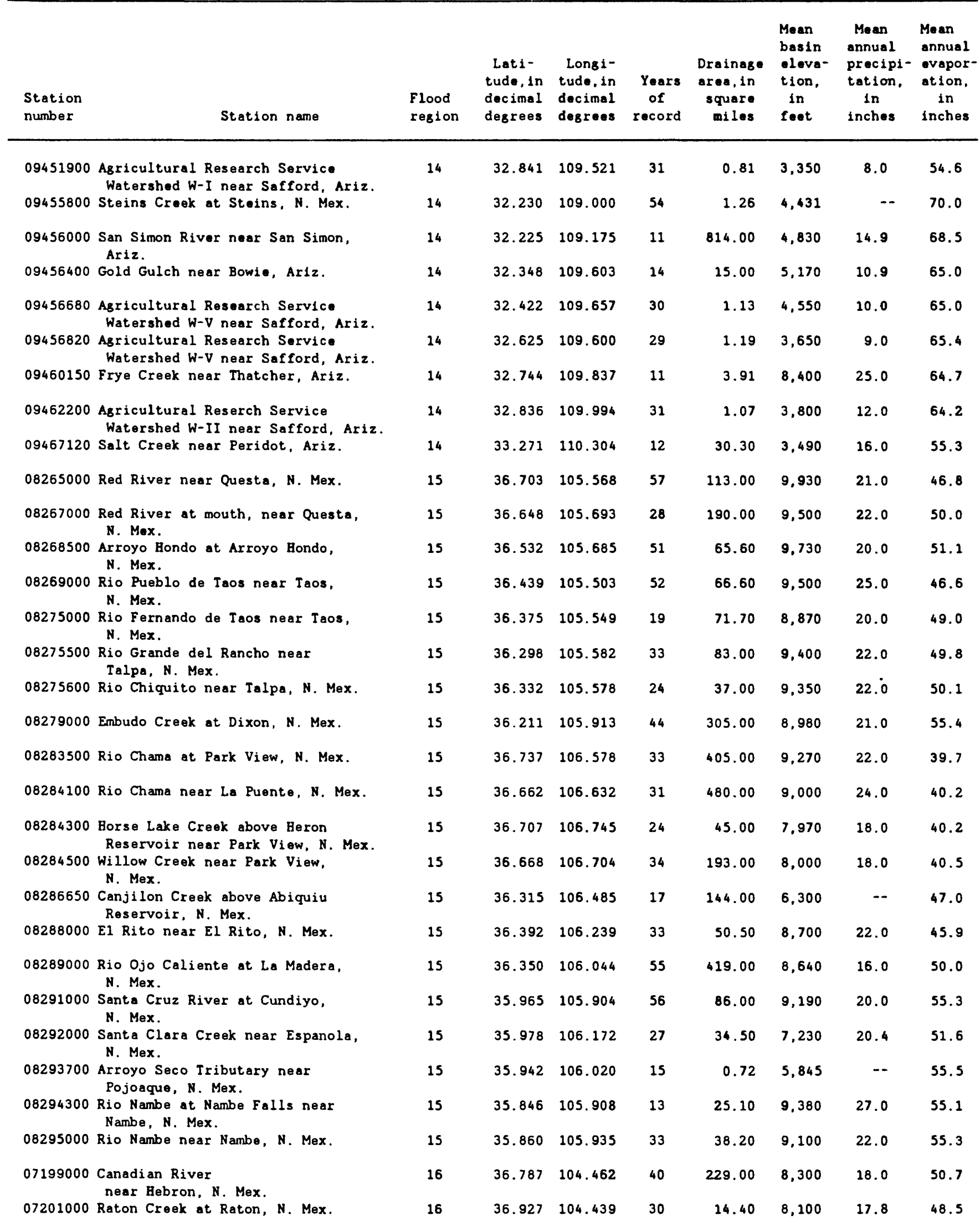




\begin{tabular}{|c|c|c|c|c|c|c|c|c|c|c|c|c|}
\hline \multirow{2}{*}{$\begin{array}{l}\text { Station } \\
\text { number }\end{array}$} & \multicolumn{5}{|c|}{$\begin{array}{c}\text { Relation } \\
\text { characteristic } \\
\end{array}$} & \multicolumn{6}{|c|}{$\begin{array}{l}\text { Peak discharge (cubic feet per second) for } \\
\text { indicated recurrence interval (years) }\end{array}$} & \multirow{2}{*}{$\begin{array}{l}\text { Maximum } \\
\text { peak discharge } \\
\text { of record } \\
\text { (cubic foet } \\
\text { per second) }\end{array}$} \\
\hline & L & $\mathrm{H}$ & $D$ & 0 & U & 2 & 5 & 10 & 25 & 50 & 100 & \\
\hline 09451900 & 0 & 0 & 1 & 0 & 0 & $\begin{array}{l}73 \\
75\end{array}$ & $\begin{array}{l}182 \\
188\end{array}$ & $\begin{array}{l}287 \\
293\end{array}$ & $\begin{array}{l}464 \\
477\end{array}$ & $\begin{array}{l}629 \\
647\end{array}$ & $\begin{array}{l}824 \\
848\end{array}$ & 434 \\
\hline 09455800 & - & - & - & - & 1 & 96 & 246 & 402 & 646 & 867 & 1,120 & 317 \\
\hline 09456000 & 1 & 1 & 1 & 0 & 0 & $\begin{array}{l}2,890 \\
3,020\end{array}$ & $\begin{array}{l}4.520 \\
5,090\end{array}$ & $\begin{array}{l}5,620 \\
6,390\end{array}$ & $\begin{array}{l}7,000 \\
9,420\end{array}$ & $\begin{array}{r}8,020 \\
12,300\end{array}$ & $\begin{array}{r}9,020 \\
15,800\end{array}$ & 5,350 \\
\hline 09456400 & 0 & 0 & 0 & 0 & 0 & $\begin{array}{l}518 \\
499\end{array}$ & $\begin{array}{l}1,180 \\
1,110\end{array}$ & $\begin{array}{l}1.810 \\
1.670\end{array}$ & $\begin{array}{l}2.860 \\
2.560\end{array}$ & $\begin{array}{l}3,840 \\
3,380\end{array}$ & $\begin{array}{l}5,010 \\
4.360\end{array}$ & 2,550 \\
\hline 09456680 & 1 & 0 & 0 & 0 & 0 & $\begin{array}{l}84 \\
84\end{array}$ & $\begin{array}{l}210 \\
212\end{array}$ & $\begin{array}{l}335 \\
342\end{array}$ & $\begin{array}{l}549 \\
562\end{array}$ & $\begin{array}{l}751 \\
769\end{array}$ & $\begin{array}{r}992 \\
1,010\end{array}$ & 671 \\
\hline 09456820 & 0 & 0 & 0 & 0 & 0 & $\begin{array}{l}68 \\
71\end{array}$ & $\begin{array}{l}148 \\
162\end{array}$ & $\begin{array}{l}222 \\
247\end{array}$ & $\begin{array}{l}344 \\
404\end{array}$ & $\begin{array}{l}456 \\
553\end{array}$ & $\begin{array}{l}587 \\
728\end{array}$ & 508 \\
\hline 09460150 & - & - & - & - & 1 & 82 & 285 & 680 & 1.090 & 1,460 & 1,900 & 96 \\
\hline 09462200 & 1 & 0 & 1 & 0 & 0 & $\begin{array}{l}247 \\
240\end{array}$ & $\begin{array}{l}650 \\
609\end{array}$ & $\begin{array}{r}1.010 \\
922\end{array}$ & $\begin{array}{l}1,560 \\
1,370\end{array}$ & $\begin{array}{l}2,020 \\
1,730\end{array}$ & $\begin{array}{l}2,510 \\
2,120\end{array}$ & 997 \\
\hline 09467120 & 0 & 0 & 0 & 0 & 0 & $\begin{array}{l}794 \\
801\end{array}$ & $\begin{array}{l}1,910 \\
1,830\end{array}$ & $\begin{array}{l}2,940 \\
2,600\end{array}$ & $\begin{array}{l}4,560 \\
3,870\end{array}$ & $\begin{array}{l}5,970 \\
4,990\end{array}$ & $\begin{array}{l}7,560 \\
6,280\end{array}$ & 3,200 \\
\hline 08265000 & 0 & 0 & 0 & 0 & 0 & $\begin{array}{l}253 \\
253\end{array}$ & $\begin{array}{l}442 \\
442\end{array}$ & $\begin{array}{l}587 \\
590\end{array}$ & $\begin{array}{l}791 \\
799\end{array}$ & $\begin{array}{l}956 \\
971\end{array}$ & $\begin{array}{l}1,130 \\
1,150\end{array}$ & 886 \\
\hline 08267000 & 0 & 0 & 0 & 0 & 0 & $\begin{array}{l}311 \\
312\end{array}$ & $\begin{array}{l}472 \\
479\end{array}$ & $\begin{array}{l}585 \\
608\end{array}$ & $\begin{array}{l}731 \\
789\end{array}$ & $\begin{array}{l}843 \\
936\end{array}$ & $\begin{array}{r}957 \\
1,090\end{array}$ & 730 \\
\hline 08268500 & 0 & 0 & 0 & 0 & 0 & $\begin{array}{l}154 \\
154\end{array}$ & $\begin{array}{l}319 \\
320\end{array}$ & $\begin{array}{l}470 \\
472\end{array}$ & $\begin{array}{l}717 \\
722\end{array}$ & $\begin{array}{l}946 \\
953\end{array}$ & $\begin{array}{l}1,220 \\
1,230\end{array}$ & 1,060 \\
\hline 08269000 & 1 & 0 & 1 & 0 & 0 & $\begin{array}{l}174 \\
174\end{array}$ & $\begin{array}{l}363 \\
363\end{array}$ & $\begin{array}{l}533 \\
534\end{array}$ & $\begin{array}{l}802 \\
803\end{array}$ & $\begin{array}{l}1,040 \\
1,040\end{array}$ & $\begin{array}{l}1,320 \\
1,320\end{array}$ & 1,050 \\
\hline 08275000 & - & - & - & - & 1 & 252 & 470 & 703 & 1,030 & 1,300 & 1,640 & 219 \\
\hline 08275500 & 1 & 0 & 1 & 0 & 0 & $\begin{array}{l}153 \\
153\end{array}$ & $\begin{array}{l}269 \\
272\end{array}$ & $\begin{array}{l}357 \\
369\end{array}$ & $\begin{array}{l}478 \\
508\end{array}$ & $\begin{array}{l}574 \\
624\end{array}$ & $\begin{array}{l}676 \\
752\end{array}$ & 497 \\
\hline 08275600 & 0 & 0 & 1 & 0 & 0 & $\begin{array}{l}71 \\
71\end{array}$ & $\begin{array}{l}155 \\
158\end{array}$ & $\begin{array}{l}232 \\
242\end{array}$ & $\begin{array}{l}355 \\
378\end{array}$ & $\begin{array}{l}466 \\
503\end{array}$ & $\begin{array}{l}593 \\
651\end{array}$ & 309 \\
\hline 08279000 & 1 & 1 & 0 & 0 & 0 & $\begin{array}{l}1,080 \\
1,080\end{array}$ & $\begin{array}{l}1,610 \\
1,610\end{array}$ & $\begin{array}{l}2,030 \\
2,030\end{array}$ & $\begin{array}{l}2,640 \\
2,630\end{array}$ & $\begin{array}{l}3,150 \\
3,140\end{array}$ & $\begin{array}{l}3.710 \\
3,690\end{array}$ & 4.200 \\
\hline 08283500 & 0 & 0 & 0 & 0 & 0 & $\begin{array}{l}4,010 \\
4,000\end{array}$ & $\begin{array}{l}5,770 \\
5,700\end{array}$ & $\begin{array}{l}6,980 \\
6,820\end{array}$ & $\begin{array}{l}8,560 \\
8,260\end{array}$ & $\begin{array}{l}9,760 \\
9.350\end{array}$ & $\begin{array}{l}11,000 \\
10,400\end{array}$ & 10,000 \\
\hline 08284100 & 0 & 0 & 0 & 0 & 0 & $\begin{array}{l}4,040 \\
4.030\end{array}$ & $\begin{array}{l}7.050 \\
6.960\end{array}$ & $\begin{array}{l}9,340 \\
9,100\end{array}$ & $\begin{array}{l}12,500 \\
12,000\end{array}$ & $\begin{array}{l}15,100 \\
14,300\end{array}$ & $\begin{array}{l}17.800 \\
16.700\end{array}$ & 11,200 \\
\hline 08284300 & - & - & - & - & 1 & 389 & 729 & 1,070 & 1,570 & 1,970 & 2,570 & 3,960 \\
\hline 08284500 & 1 & 1 & 1 & 0 & 0 & $\begin{array}{l}1,190 \\
1,190\end{array}$ & $\begin{array}{l}1.830 \\
1.830\end{array}$ & $\begin{array}{l}2,350 \\
2,350\end{array}$ & $\begin{array}{l}3,140 \\
3,150\end{array}$ & $\begin{array}{l}3,840 \\
3,850\end{array}$ & $\begin{array}{l}4,620 \\
4,630\end{array}$ & 4,500 \\
\hline 08286650 & 1 & 0 & 0 & 0 & 0 & $\begin{array}{l}866 \\
872\end{array}$ & $\begin{array}{l}1.410 \\
1.460\end{array}$ & $\begin{array}{l}1.830 \\
1.930\end{array}$ & $\begin{array}{l}2,430 \\
2,640\end{array}$ & $\begin{array}{l}2.920 \\
3.240\end{array}$ & $\begin{array}{l}3,470 \\
3,960\end{array}$ & 2,450 \\
\hline 08288000 & 1 & 0 & 0 & 0 & 0 & $\begin{array}{l}225 \\
225\end{array}$ & $\begin{array}{l}406 \\
408\end{array}$ & $\begin{array}{l}568 \\
576\end{array}$ & $\begin{array}{l}831 \\
850\end{array}$ & $\begin{array}{l}1,080 \\
1,110\end{array}$ & $\begin{array}{l}1,370 \\
1,410\end{array}$ & 1,240 \\
\hline 08289000 & 0 & 0 & 1 & 0 & 0 & $\begin{array}{l}1,040 \\
1,040\end{array}$ & $\begin{array}{l}1,710 \\
1,710\end{array}$ & $\begin{array}{l}2,160 \\
2,170\end{array}$ & $\begin{array}{l}2.740 \\
2,760\end{array}$ & $\begin{array}{l}3,170 \\
3,210\end{array}$ & $\begin{array}{l}3,600 \\
3,650\end{array}$ & 3,140 \\
\hline 08291000 & 1 & 0 & 0 & 0 & 0 & $\begin{array}{l}297 \\
297\end{array}$ & $\begin{array}{l}624 \\
623\end{array}$ & $\begin{array}{l}927 \\
925\end{array}$ & $\begin{array}{l}1,420 \\
1,410\end{array}$ & $\begin{array}{l}1,880 \\
1,860\end{array}$ & $\begin{array}{l}2,430 \\
2,400\end{array}$ & 2,420 \\
\hline 08292000 & 1 & 0 & 0 & 0 & 0 & $\begin{array}{l}94 \\
95\end{array}$ & $\begin{array}{l}229 \\
239\end{array}$ & $\begin{array}{l}373 \\
398\end{array}$ & $\begin{array}{l}642 \\
693\end{array}$ & $\begin{array}{l}921 \\
994\end{array}$ & $\begin{array}{l}1,280 \\
1,390\end{array}$ & 970 \\
\hline 08293700 & 1 & 0 & 0 & 0 & 0 & $\begin{array}{l}102 \\
101\end{array}$ & $\begin{array}{l}216 \\
211\end{array}$ & $\begin{array}{l}325 \\
312\end{array}$ & $\begin{array}{l}505 \\
476\end{array}$ & $\begin{array}{l}677 \\
632\end{array}$ & $\begin{array}{l}883 \\
843\end{array}$ & 508 \\
\hline 08294300 & 0 & 1 & 0 & 0 & 0 & $\begin{array}{l}95 \\
95\end{array}$ & $\begin{array}{l}227 \\
227\end{array}$ & $\begin{array}{l}373 \\
374\end{array}$ & $\begin{array}{l}653 \\
646\end{array}$ & $\begin{array}{l}953 \\
925\end{array}$ & $\begin{array}{l}1,360 \\
1,300\end{array}$ & 1.090 \\
\hline 08295000 & 0 & 1 & 0 & 0 & 0 & $\begin{array}{l}200 \\
200\end{array}$ & $\begin{array}{l}635 \\
629\end{array}$ & $\begin{array}{l}1,170 \\
1,150\end{array}$ & $\begin{array}{l}2,260 \\
2,180\end{array}$ & $\begin{array}{l}3,460 \\
3,280\end{array}$ & $\begin{array}{l}5,090 \\
4.770\end{array}$ & 5.580 \\
\hline 07199000 & 1 & 1 & 0 & 0 & 0 & $\begin{array}{l}3,090 \\
3,070\end{array}$ & $\begin{array}{l}6,900 \\
6,580\end{array}$ & $\begin{array}{r}10.800 \\
9.350\end{array}$ & $\begin{array}{l}17,900 \\
17,200\end{array}$ & $\begin{array}{l}25,100 \\
23,500\end{array}$ & $\begin{array}{l}34,200 \\
32,700\end{array}$ & 62,400 \\
\hline 07201000 & 0 & 0 & 0 & 0 & 0 & $\begin{array}{l}420 \\
418\end{array}$ & $\begin{array}{l}1,040 \\
1,010\end{array}$ & $\begin{array}{l}1.670 \\
1.530\end{array}$ & $\begin{array}{l}2,770 \\
2,700\end{array}$ & $\begin{array}{l}3,830 \\
3,670\end{array}$ & $\begin{array}{l}5,140 \\
5,060\end{array}$ & 3,990 \\
\hline
\end{tabular}




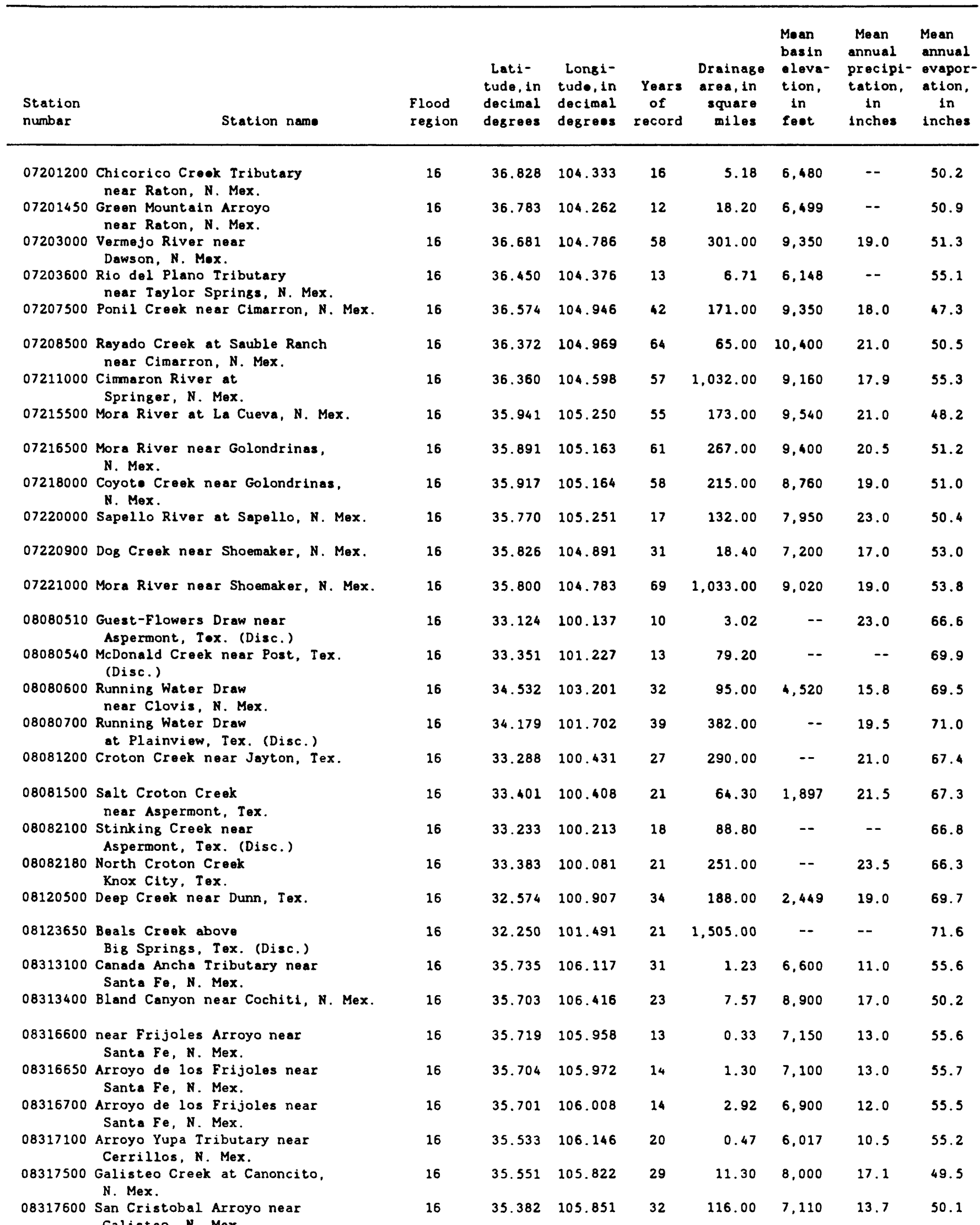




\begin{tabular}{|c|c|c|c|c|c|c|c|c|c|c|c|c|}
\hline \multirow{2}{*}{$\begin{array}{l}\text { Station } \\
\text { number }\end{array}$} & \multicolumn{5}{|c|}{$\begin{array}{c}\text { Relation } \\
\text { characteristic }\end{array}$} & \multicolumn{3}{|c|}{$\begin{array}{l}\text { Peak discharge (cubic } \\
\text { Indicated recurrence }\end{array}$} & \multicolumn{3}{|c|}{$\begin{array}{l}\text { faet per second) for } \\
\text { interval (years) }\end{array}$} & \multirow{2}{*}{$\begin{array}{l}\text { Maximum } \\
\text { peak discharge } \\
\text { of record } \\
\text { (cubic feet } \\
\text { per second) }\end{array}$} \\
\hline & L & H & D & 0 & & 2 & 5 & 10 & 25 & 50 & 100 & \\
\hline \multirow[t]{2}{*}{07201200} & - & - & - & - & 1 & --- & --- & --- & $\cdots$ & --- & $\cdots$ & 1,340 \\
\hline & & & & & & 160 & 508 & 788 & 1,320 & 1,880 & 2,910 & \\
\hline \multirow[t]{2}{*}{07201450} & - & - & - & - & 1 & --- & --- & $\cdots$ & --- & $\cdots$ & $\cdots$ & 5,030 \\
\hline & & & & & & 309 & 947 & 1,460 & 2,480 & 3,480 & 5,570 & \\
\hline \multirow[t]{2}{*}{07203000} & 0 & 0 & 0 & 0 & 0 & 1,660 & 3.250 & 4,600 & 6,640 & 8,410 & 10,400 & 12,600 \\
\hline & & & & & & 1,660 & 3,280 & 4.770 & 6,800 & 8,820 & 11,300 & \\
\hline \multirow[t]{2}{*}{07203600} & 0 & 0 & 0 & 0 & 0 & 106 & 295 & 487 & 813 & 1,120 & 1,470 & 724 \\
\hline & & & & & & 109 & 379 & 761 & 1.010 & 1,550 & 2,080 & \\
\hline \multirow[t]{2}{*}{07207500} & 0 & 0 & 1 & 0 & 0 & 452 & 1,190 & 2,000 & 3,540 & 5,150 & 7.250 & 5,630 \\
\hline & & & & & & 456 & 1,290 & 2,380 & 3,730 & 5,520 & 8.000 & \\
\hline \multirow[t]{2}{*}{07208500} & 1 & 0 & 0 & $c$ & 0 & 155 & 350 & 572 & 1,010 & 1,510 & 2,210 & 9,000 \\
\hline & & & & & & 158 & 427 & 908 & 1,180 & 1,880 & 2.750 & \\
\hline 07211000 & 1 & 0 & 0 & 0 & 0 & 785 & 2,090 & 3,610 & 6,650 & 10,000 & 14.600 & 29,500 \\
\hline & & & & & & 799 & 2,430 & 4,980 & 7.370 & 11,500 & 17.000 & \\
\hline 07215500 & 1 & 0 & 1 & 0 & 0 & 574 & 890 & 1,120 & 1.440 & 1,680 & 1.950 & 1,530 \\
\hline & & & & & & 576 & 996 & 1.620 & 1,720 & 2,320 & 2,990 & \\
\hline 07216500 & 0 & 1 & 0 & 0 & 0 & 771 & 1,620 & 2,450 & 3,910 & 5,340 & 7.130 & 14,000 \\
\hline & & & & & & 774 & 1,730 & 2,920 & 4,170 & 5,920 & 8,130 & \\
\hline 07218000 & 1 & 0 & 1 & 0 & 0 & 594 & 1,270 & 1,920 & 3,020 & 4.080 & 5,370 & 4,050 \\
\hline & & & & & & 598 & 1.380 & 2,410 & 3,290 & 4,680 & 6,380 & \\
\hline 07220000 & 1 & 0 & 1 & 0 & 0 & 2,460 & 4,200 & 5,560 & 7,510 & 9.120 & 10.900 & 6.420 \\
\hline & & & & & & 2,420 & 3,880 & 4.740 & 7,320 & 9,000 & 11.700 & \\
\hline 07220900 & 1 & 0 & 0 & 0 & 0 & 1.020 & 2,340 & 3.610 & 5,750 & 7,760 & 10,200 & 7,180 \\
\hline & & & & & & 1.010 & 2,200 & 3,020 & 5,460 & 7,180 & 9,660 & \\
\hline 07221000 & 0 & 0 & 0 & 0 & 0 & 2.220 & 5,400 & 8,390 & 13,200 & 17,500 & 22,400 & 15,200 \\
\hline & & & & & & 2.220 & 5.490 & 8,750 & 13,500 & 18,100 & 23.800 & \\
\hline 08080510 & - & - & - & - & 1 & -.-- & --- & $\cdots$ & --.- & $-\ldots$ & $\cdots$ & 410 \\
\hline & & & & & & 173 & 586 & 939 & 1,640 & 2,440 & 3,190 & \\
\hline 08080540 & 0 & 1 & 0 & 0 & 0 & 970 & 2,630 & 4,610 & 8.660 & 13,200 & 19,700 & 15,300 \\
\hline & & & & & & 970 & 2,710 & 4.620 & 8,610 & 12,900 & 19,000 & \\
\hline 08080600 & - & - & - & - & 1 & $-\cdots$ & --- & $\cdots$ & $-\cdots$ & $-\cdots$ & $-\infty$ & 8,000 \\
\hline & & & & & & 1.050 & 3,230 & 5,020 & 9,110 & 13,100 & 18,700 & \\
\hline 08080700 & - & - & - & - & 1 & $-\cdots$ & --- & $-\cdots$ & $-\cdots$ & --- & $\cdots$ & 12000 \\
\hline & & & & & & 2,180 & 6,450 & 9,890 & 18,300 & 26,000 & 38,200 & \\
\hline 08081200 & 0 & 0 & 0 & 0 & 0 & 2,730 & 6,030 & 8,760 & 12,700 & 15,800 & 19,100 & 10,600 \\
\hline & & & & & & 2,720 & 5,940 & 8,570 & 12,900 & 16,700 & 20,900 & \\
\hline 08081500 & 0 & 0 & 0 & 0 & 0 & 2,750 & 7.470 & 12.800 & 23,100 & 34,100 & 48,700 & 29,900 \\
\hline & & & & & & 2,710 & 6,730 & 9,500 & 21,000 & 29,300 & 42,700 & \\
\hline 08082100 & 0 & 0 & 0 & 0 & 0 & 589 & 1,300 & 1,990 & 3,150 & 4,250 & 5.580 & 3,260 \\
\hline & & & & & & 598 & 1.590 & 3,070 & 3.930 & 6,030 & 7.950 & \\
\hline 08082180 & 0 & 0 & 0 & 0 & 0 & 1,270 & 4,210 & 8,130 & 16.800 & 27.300 & 42,500 & 32,100 \\
\hline & & & & & & 1,280 & 4.310 & 7.880 & 16,400 & 25.700 & 40.100 & \\
\hline 08120500 & 1 & 1 & 0 & 0 & 0 & 2.330 & 4,710 & 7,220 & 11,900 & 16,800 & 23,400 & 36.400 \\
\hline & & & & & & 2,320 & 4,690 & 7.140 & 12,000 & 17.000 & 23.700 & \\
\hline 08123650 & - & - & - & - & 1 & $-\cdots$ &.--- & --- & --- & -.-- & $\cdots$ & 255 \\
\hline & & & & & & 4.420 & 12,600 & 19,100 & 35,700 & 50,200 & 76,500 & \\
\hline 08313100 & - & - & - & - & 1 & --- & --- & --- & $\cdots$ & $-\cdots$ & --- & 298 \\
\hline & & & & & & 89 & 300 & 477 & 803 & 1,180 & 1,650 & \\
\hline 08313400 & 1 & 0 & 0 & 0 & 0 & 37 & 75 & 108 & 160 & 206 & 259 & 174 \\
\hline & & & & & & 40 & 150 & 403 & 334 & 591 & 795 & \\
\hline 08316600 & 1 & 0 & 0 & 0 & 0 & 140 & 243 & 322 & 433 & 523 & 619 & 360 \\
\hline & & & & & & 137 & 224 & 290 & 432 & 556 & 681 & \\
\hline 08316650 & 1 & 0 & 0 & 0 & 0 & 508 & 1,020 & $1,4>0$ & 2,140 & 2,730 & 3,400 & 1,900 \\
\hline & & & & & & 496 & 869 & 1,010 & 1,900 & 2,310 & 2,980 & \\
\hline 08316700 & 0 & 0 & 0 & 0 & 0 & 417 & 1.650 & 3,330 & 6,980 & 11,200 & 17,100 & 5,340 \\
\hline & & & & & & 409 & 1.400 & 2,090 & 5,910 & 8,580 & 13,500 & \\
\hline 08317100 & - & - & - & - & 1 & $\cdots$ & $--\cdot$ & --- & $-\cdots$ & $-\cdots$ & $-\cdots$ & 568 \\
\hline & & & & & & 54 & 186 & 299 & 498 & 738 & 1.010 & \\
\hline 08317500 & 0 & 0 & 0 & 0 & 0 & 885 & 1,310 & 1,600 & 1,970 & 2,250 & 2,530 & 2,000 \\
\hline & & & & & & 876 & 1.240 & 1,450 & 1,960 & 2,310 & 2.750 & \\
\hline 08317600 & 1 & 0 & 0 & 0 & 0 & 1.600 & 3,270 & 4.670 & 6,750 & 8,510 & 10,400 & 9,500 \\
\hline & & & & & & 1.590 & 3,160 & 4,300 & 6,670 & 8,440 & 10,800 & \\
\hline
\end{tabular}


Station number
Station name

\section{Flood region}

Lati - Longitude, in tude, in decimal decimal degrees

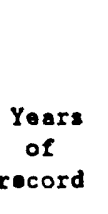

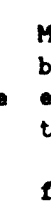

08317700 Tarhole Canyon near Galisteo, N. Max.

08317720 Canada de la Cueva near Galisteo, N. Mex.

08317800 Canada de las Minas Tributary near Santa Fe, N. Mex.

08318000 Galisteo Creek at Domingo, N. Max.

08318900 San Pedro Creek near Golden, N. Max.

08321500 Jemez River below East Fork near Jemez Springs, N. Mex.

08323000 Rio Guadalupe at Box Canyon near Jemez, N. Mex.

08324000 Jemez Rivar near Jemez, N. Mex.

08329000 Jemez River below Jemaz Canyon Dan, N. Mex.

08330500 Tijeras Arroyo at Albuquerque, N. Max.

08330600 Tijeras Arroyo near Albuquerque, N. Mex.

08331650 Canada Montoso near Scholle, N. Mex.

08331700 Abo Arroyo Tributary near Scholle, N. Mex.

08334000 Rio Puerco above Arroyo Chico near Guadalupe, N. Mex.

08340500 Arroyo Chico near Guadalupe near N. Mex.

08341300 Bluewater Creek above Bluewater Daro near Bluewater, N. Mex.

08343100 Grants Canyon at Grants, N. Mex.

08348500 Encinal Creek near Casa Blanca, N. Mex.

08353500 La Jencia Creek near Magdalena, N. Mex.

08354000 Rio Salado near San Acacia near N. Mex.

08358600 Chupadera Wash Tributary at Bingham, N. Mex.

08359400 Lumber Canyon Iributary near Monticello, N. Mex.

08360000 Alamosa Creek near Monticello near N. Mex.

08361650 Percha Creek near Kingston, N. Mex.

08361700 Percha Creek near Hillsboro, N. Mex.

08361800 Percha Creek at Caballo Dam, near Arrey, N. Mex.

08363100 Rio Grande Tributary near Radium Springs, N. Mex..

08363200 Aleman Draw at Aleman, N. Mex.

08365600 McKelligon Canyon at El Paso, Tex. (Disc.)

08374000 Alamito Creek near Presidio, Tex.

16

16

16

16

16

16

16

16

16

16

16

16

16

16

16

16

16

16

16

16

16

16

16

16

16

16

16

16

16

16

16

16

16
$35.365 \quad 105.844 \quad 34$

$35.437 \quad 106.012 \quad 16$

$\begin{array}{lll}35.607 & 105.912 \quad 29\end{array}$

$35.512 \quad 106.317 \quad 26$

$\begin{array}{lll}35.229 & 106.300 \quad 33\end{array}$

$\begin{array}{lll}35.827 & 106.647 \quad 24\end{array}$

$\begin{array}{lll}35.731 & 106.762 \quad 37\end{array}$

$35.662 \quad 106.743 \quad 42$

$35.390 \quad 106.534$

$35.061 \quad 106.478 \quad 34$

$\begin{array}{lll}35.001 & 106.655 \quad 32\end{array}$

$34.400 \quad 106.483 \quad 25$

$34.403 \quad 106.510 \quad 32$

$\begin{array}{ll}35.636 & 107.166 \quad 35\end{array}$

$35.592 \quad 107.189$

$35.267 \quad 108.114$

$35.161 \quad 107.837$

$35.143 \quad 107.465$

$34.162 \quad 107.210$

$34.297 \quad 106.900$

$33.900 \quad 106.333$

$33.400 \quad 107.267$

$33.569 \quad 107.592$

$32.918 \quad 107.649$

$32.915 \quad 107.601$

$32.900 \quad 107.317$

$32.501 \quad 106.951$

$33.000 \quad 107.006$

$31.822 \quad 106.469$

$29.521 \quad 104.294$

$29.200 \quad 103.604$
2.15

$1.796,120$

$0.567,195$

$640.00 \quad 6,000$

$45.20 \quad 6.860$

$173.00 \quad 9.070$

$235.00 \quad 8.250$

$\$ 70.00 \quad 8,400$

$1.038 .00 \quad 7.000$

$75.30 \quad 7.020$

$133.00 \quad 6,800$

$35.00 \quad 6.260$

$0.236,080$

$420.00 \quad 7.550$

43

$1,390.00$

24

25

26

30

37

26

24

40

34

27

24

31

25

20

20

52

52
Mean Mean

annual annual

precip1 - evapor-

tation, ation,

in in

inches inches

08374500 Terlingua Creek near Terlingua, Tex. 


\begin{tabular}{|c|c|c|c|c|c|c|c|c|c|c|c|c|}
\hline \multirow{2}{*}{$\begin{array}{l}\text { Station } \\
\text { number }\end{array}$} & \multicolumn{5}{|c|}{$\begin{array}{c}\text { Relation } \\
\text { characteristic }\end{array}$} & \multicolumn{6}{|c|}{$\begin{array}{l}\text { Peak discharge (cubic feet per second) for } \\
\text { indicated recurrence interval (years) }\end{array}$} & \multirow{2}{*}{$\begin{array}{l}\text { Maximum } \\
\text { peak discherge } \\
\text { of record } \\
\text { (cubic feet } \\
\text { per second) }\end{array}$} \\
\hline & L & H & $D$ & 0 & $\frac{C_{21 C}}{U}$ & 2 & 5 & 10 & 25 & so & 100 & \\
\hline 08317700 & 0 & 0 & 0 & 0 & 0 & $\begin{array}{l}330 \\
327\end{array}$ & $\begin{array}{l}745 \\
704\end{array}$ & $\begin{array}{r}1,130 \\
964\end{array}$ & $\begin{array}{l}1,770 \\
1,690\end{array}$ & $\begin{array}{l}2,340 \\
2,190\end{array}$ & $\begin{array}{l}3,020 \\
2.880\end{array}$ & 2,440 \\
\hline 08317720 & 0 & 0 & 0 & 0 & 0 & $\begin{array}{l}104 \\
104\end{array}$ & $\begin{array}{l}267 \\
279\end{array}$ & $\begin{array}{l}447 \\
478\end{array}$ & $\begin{array}{l}787 \\
801\end{array}$ & $\begin{array}{l}1,140 \\
1,170\end{array}$ & $\begin{array}{l}1.610 \\
1.660\end{array}$ & 919 \\
\hline 08317800 & - & - & - & - & 1 & 57 & 195 & 312 & 518 & 764 & 1,070 & 652 \\
\hline 08318000 & 0 & 0 & 0 & 0 & 0 & $\begin{array}{l}6,380 \\
6,310\end{array}$ & $\begin{array}{l}11,200 \\
10,500\end{array}$ & $\begin{array}{l}15,000 \\
13,000\end{array}$ & $\begin{array}{l}20,500 \\
20,000\end{array}$ & $\begin{array}{l}25,000 \\
24,500\end{array}$ & $\begin{array}{l}29,900 \\
31,100\end{array}$ & 22,800 \\
\hline 08318900 & 1 & 1 & 0 & 0 & 0 & $\begin{array}{l}926 \\
920\end{array}$ & $\begin{array}{l}1,790 \\
1,750\end{array}$ & $\begin{array}{l}2,630 \\
2,480\end{array}$ & $\begin{array}{l}4,090 \\
4,050\end{array}$ & $\begin{array}{l}5,550 \\
5,470\end{array}$ & $\begin{array}{l}7.400 \\
7.510\end{array}$ & 10,800 \\
\hline 08321500 & 1 & 0 & 0 & 0 & 0 & $\begin{array}{l}589 \\
591\end{array}$ & $\begin{array}{r}956 \\
1.100\end{array}$ & $\begin{array}{l}1,230 \\
1,810\end{array}$ & $\begin{array}{l}1,590 \\
1,980\end{array}$ & $\begin{array}{l}1,880 \\
2,680\end{array}$ & $\begin{array}{l}2,190 \\
3,700\end{array}$ & 1,700 \\
\hline 08323000 & 1 & 0 & 1 & 0 & 0 & $\begin{array}{l}425 \\
432\end{array}$ & $\begin{array}{r}840 \\
1.040\end{array}$ & $\begin{array}{l}1,210 \\
2,050\end{array}$ & $\begin{array}{l}1,780 \\
2,260\end{array}$ & $\begin{array}{l}2,300 \\
3,350\end{array}$ & $\begin{array}{l}2,890 \\
4,620\end{array}$ & 3,190 \\
\hline 08324000 & 0 & 0 & 0 & 0 & 0 & $\begin{array}{l}1,440 \\
1,440\end{array}$ & $\begin{array}{l}2,610 \\
2,750\end{array}$ & $\begin{array}{l}3.560 \\
4.230\end{array}$ & $\begin{array}{l}4,930 \\
5,380\end{array}$ & $\begin{array}{l}6,070 \\
7,120\end{array}$ & $\begin{array}{l}7,320 \\
9,280\end{array}$ & 5,900 \\
\hline 08329000 & 1 & 0 & 0 & 0 & 0 & $\begin{array}{r}4,220 \\
4,180\end{array}$ & $\begin{array}{l}8,580 \\
8,350\end{array}$ & $\begin{array}{l}12,400 \\
11,800\end{array}$ & $\begin{array}{l}18,200 \\
18,600\end{array}$ & $\begin{array}{l}23,300 \\
24,600\end{array}$ & $\begin{array}{l}29,100 \\
33,900\end{array}$ & 23,100 \\
\hline 08330500 & 1 & 0 & 0 & 0 & 0 & $\begin{array}{l}830 \\
829\end{array}$ & $\begin{array}{l}2.130 \\
2.140\end{array}$ & $\begin{array}{l}3,490 \\
3,460\end{array}$ & $\begin{array}{l}5.910 \\
5.910\end{array}$ & $\begin{array}{l}8,310 \\
8,330\end{array}$ & $\begin{array}{l}11,300 \\
11,500\end{array}$ & 6,500 \\
\hline 08330600 & 1 & 0 & 0 & 0 & 0 & $\begin{array}{l}785 \\
789\end{array}$ & $\begin{array}{l}1,270 \\
1,470\end{array}$ & $\begin{array}{l}1,650 \\
2,560\end{array}$ & $\begin{array}{l}2,200 \\
2,790\end{array}$ & $\begin{array}{l}2,660 \\
4,050\end{array}$ & $\begin{array}{l}3.170 \\
5.140\end{array}$ & 2,530 \\
\hline 08331650 & 1 & 0 & 1 & 0 & 0 & $\begin{array}{l}384 \\
385\end{array}$ & $\begin{array}{l}1,170 \\
1,200\end{array}$ & $\begin{array}{l}2.130 \\
2.120\end{array}$ & $\begin{array}{l}4,040 \\
3,990\end{array}$ & $\begin{array}{l}6.140 \\
5.950\end{array}$ & $\begin{array}{l}8,980 \\
8,850\end{array}$ & 4.700 \\
\hline 08331700 & 0 & 0 & 0 & 0 & 0 & $\begin{array}{l}85 \\
85\end{array}$ & $\begin{array}{l}144 \\
142\end{array}$ & $\begin{array}{l}192 \\
195\end{array}$ & $\begin{array}{l}266 \\
272\end{array}$ & $\begin{array}{l}331 \\
355\end{array}$ & $\begin{array}{l}406 \\
440\end{array}$ & 301 \\
\hline 08334000 & 1 & 0 & 0 & 0 & 0 & $\begin{array}{l}2,120 \\
2,110\end{array}$ & $\begin{array}{l}3,190 \\
3,280\end{array}$ & $\begin{array}{l}3,950 \\
4,540\end{array}$ & $\begin{array}{l}4,940 \\
5,430\end{array}$ & $\begin{array}{l}5,710 \\
6,900\end{array}$ & $\begin{array}{l}6.500 \\
8,740\end{array}$ & 6,940 \\
\hline 08340500 & 1 & 0 & 1 & 0 & 0 & $\begin{array}{l}4,030 \\
4,020\end{array}$ & $\begin{array}{l}6,820 \\
6,870\end{array}$ & $\begin{array}{l}9,080 \\
9,480\end{array}$ & $\begin{array}{l}12,400 \\
12,900\end{array}$ & $\begin{array}{l}15,300 \\
16,500\end{array}$ & $\begin{array}{l}18,500 \\
21,300\end{array}$ & 15,200 \\
\hline 08341300 & - & - & - & - & 1 & 607 & 1.770 & 2.670 & 4,580 & 6,290 & 10,700 & 3,570 \\
\hline 08343100 & 1 & 0 & 0 & 0 & 0 & $\begin{array}{l}253 \\
253\end{array}$ & $\begin{array}{l}549 \\
577\end{array}$ & $\begin{array}{l}844 \\
954\end{array}$ & $\begin{array}{l}1,360 \\
1,430\end{array}$ & $\begin{array}{l}1,880 \\
2,040\end{array}$ & $\begin{array}{l}2,530 \\
2,830\end{array}$ & 1,550 \\
\hline 08348500 & 0 & 1 & 1 & 0 & 0 & $\begin{array}{l}119 \\
120\end{array}$ & $\begin{array}{l}374 \\
397\end{array}$ & $\begin{array}{l}717 \\
763\end{array}$ & $\begin{array}{l}1,490 \\
1,480\end{array}$ & $\begin{array}{l}2,450 \\
2,380\end{array}$ & $\begin{array}{l}3,880 \\
3,780\end{array}$ & 4.330 \\
\hline 08353500 & - & - & - & - & 1 & 1,020 & 2,920 & 4,370 & 7,610 & 10,400 & 18,000 & 4,830 \\
\hline 08354000 & 0 & 0 & 1 & 0 & 0 & $\begin{array}{l}6,820 \\
6,780\end{array}$ & $\begin{array}{l}15,700 \\
15,100\end{array}$ & $\begin{array}{l}23,000 \\
20,800\end{array}$ & $\begin{array}{l}33,300 \\
32,800\end{array}$ & $\begin{array}{l}41,400 \\
40,800\end{array}$ & $\begin{array}{l}49,800 \\
51,000\end{array}$ & 36,200 \\
\hline 08358600 & - & - & - & - & 1 & 89 & 300 & 476 & 799 & 1.170 & 1,660 & 620 \\
\hline 08359400 & 0 & 0 & 0 & 0 & 0 & $\begin{array}{l}174 \\
172\end{array}$ & $\begin{array}{l}339 \\
332\end{array}$ & $\begin{array}{l}479 \\
472\end{array}$ & $\begin{array}{l}691 \\
701\end{array}$ & $\begin{array}{l}876 \\
928\end{array}$ & $\begin{array}{l}1.080 \\
1.160\end{array}$ & 778 \\
\hline 08360000 & 1 & 0 & 0 & 0 & 0 & $\begin{array}{l}2,080 \\
2.070\end{array}$ & $\begin{array}{l}4.420 \\
4.360\end{array}$ & $\begin{array}{l}6,450 \\
6.230\end{array}$ & $\begin{array}{l}9,550 \\
9,550\end{array}$ & $\begin{array}{l}12,200 \\
12,300\end{array}$ & $\begin{array}{l}15,200 \\
16,000\end{array}$ & 10,800 \\
\hline 08361650 & 1 & 1 & 0 & 0 & 0 & $\begin{array}{l}530 \\
528\end{array}$ & $\begin{array}{l}942 \\
959\end{array}$ & $\begin{array}{l}1,310 \\
1,420\end{array}$ & $\begin{array}{l}1,920 \\
2,010\end{array}$ & $\begin{array}{l}2,480 \\
2,710\end{array}$ & $\begin{array}{l}3,160 \\
3,560\end{array}$ & 3,740 \\
\hline 08361700 & 0 & 1 & 0 & 0 & 0 & $\begin{array}{l}1,020 \\
1,010\end{array}$ & $\begin{array}{l}2,230 \\
2,140\end{array}$ & $\begin{array}{l}3,490 \\
3,130\end{array}$ & $\begin{array}{l}5,800 \\
5,620\end{array}$ & $\begin{array}{l}8,190 \\
7,800\end{array}$ & $\begin{array}{l}11,300 \\
11,000\end{array}$ & 12,200 \\
\hline 08361800 & 0 & 0 & 0 & 0 & 0 & $\begin{array}{l}1,160 \\
1,160\end{array}$ & $\begin{array}{l}3,260 \\
3,340\end{array}$ & $\begin{array}{l}5,610 \\
5,740\end{array}$ & $\begin{array}{l}10,000 \\
10.100\end{array}$ & $\begin{array}{l}14,600 \\
14,800\end{array}$ & $\begin{array}{l}20,400 \\
20,700\end{array}$ & 15,400 \\
\hline 08363100 & 0 & 0 & 0 & 0 & 0 & $\begin{array}{l}124 \\
123\end{array}$ & $\begin{array}{l}204 \\
209\end{array}$ & $\begin{array}{l}262 \\
304\end{array}$ & $\begin{array}{l}338 \\
372\end{array}$ & $\begin{array}{l}396 \\
496\end{array}$ & $\begin{array}{l}455 \\
559\end{array}$ & 332 \\
\hline 08363200 & 1 & 0 & 0 & 0 & 0 & $\begin{array}{l}1,630 \\
1,610\end{array}$ & $\begin{array}{l}4,150 \\
3,830\end{array}$ & $\begin{array}{l}6,770 \\
5,400\end{array}$ & $\begin{array}{l}11,400 \\
10,700\end{array}$ & $\begin{array}{r}16000 \\
14,400\end{array}$ & $\begin{array}{l}21,600 \\
19,800\end{array}$ & 16,400 \\
\hline 08365600 & - & - & - & - & 1 & 165 & 572 & 925 & 1,630 & 2.450 & 3,040 & 3,060 \\
\hline 08374000 & 0 & 1 & 0 & 0 & 0 & $\begin{array}{l}7,530 \\
7,510\end{array}$ & $\begin{array}{l}12,800 \\
12,800\end{array}$ & $\begin{array}{l}17.200 \\
17.500\end{array}$ & $\begin{array}{l}23,900 \\
24,600\end{array}$ & $\begin{array}{l}29,800 \\
31,700\end{array}$ & $\begin{array}{l}36,600 \\
39,800\end{array}$ & 56,400 \\
\hline 08374500 & 1 & 0 & 0 & 0 & 0 & $\begin{array}{l}13,400 \\
13,300\end{array}$ & $\begin{array}{l}20,400 \\
19,700\end{array}$ & $\begin{array}{l}25,100 \\
23,300\end{array}$ & $\begin{array}{l}31,100 \\
31,000\end{array}$ & $\begin{array}{l}35,600 \\
36,200\end{array}$ & $\begin{array}{l}40,100 \\
42,000\end{array}$ & 34,900 \\
\hline
\end{tabular}




\begin{tabular}{|c|c|c|c|c|c|c|c|c|c|}
\hline 08379300 & $\begin{array}{l}\text { Tecolote Creek at Tecolote, } \\
\text { N. Mex. }\end{array}$ & 16 & 35.456 & 105.282 & 31 & 122.00 & 7,390 & 19.6 & 52.5 \\
\hline 08379550 & O Canon Blanco near Leyba, N. Mex. & 16 & 35.221 & 105.670 & 12 & 11.20 & 6,659 & - & 49.7 \\
\hline 08379600 & $\begin{array}{l}\text { Pecos River Tributary near } \\
\text { Dilia, N. Mex. }\end{array}$ & 16 & 35.214 & 105.081 & 33 & 0.16 & 5,450 & 14.0 & 56.4 \\
\hline 08380300 & $\begin{array}{l}\text { Sandoval Canyon at Gallinas, } \\
\text { N. Mex. }\end{array}$ & 16 & 35.689 & 105.355 & 26 & 7.60 & 7,600 & 22.6 & 48.6 \\
\hline 08382000 & $\begin{array}{l}\text { Gallinas River near Lourdes, } \\
\text { N. Mex. }\end{array}$ & 16 & 35.471 & 105.160 & 12 & 313.00 & 7,500 & 19.0 & 53.2 \\
\hline 08382500 & $\begin{array}{l}\text { Oallinas River near Colonias, } \\
\text { N. Mex. }\end{array}$ & 16 & 35.182 & 104.900 & 35 & 610.00 & 5,920 & 17.0 & 59.8 \\
\hline 08382900 & $\begin{array}{l}\text { Pecos River Tributary near } \\
\text { Pintada, N. Mex. }\end{array}$ & 16 & 34.979 & 105.094 & 23 & 16.00 & -- & -- & 58.0 \\
\hline 08383200 & $\begin{array}{l}\text { Pintada Arroyo Tributary near } \\
\text { Clines Corners, N. Mex. }\end{array}$ & 16 & 34.844 & 105.585 & 24 & 29.20 & 7.065 & 16.0 & 50.7 \\
\hline 08383210 & $\begin{array}{l}\text { Pintada Arroyo Iributary near } \\
\text { Encino, N. Mex. }\end{array}$ & 16 & 34.811 & 105.567 & 23 & 0.55 & 6,459 & -- & 50.7 \\
\hline 08383300 & $\begin{array}{l}\text { Pintada Arroyo near Santa Rosa, } \\
\text { N. Mex. }\end{array}$ & 16 & 34.889 & 104.731 & 27 & 896.00 & 6,210 & 13.5 & 63.0 \\
\hline 08383370 & $\begin{array}{l}\text { Pecos River Tributary near } \\
\text { Puerto de Luna, N. Mex. }\end{array}$ & 16 & 34.876 & 104.637 & 26 & 0.37 & 4,600 & 13.0 & 63.6 \\
\hline 08385700 & $\begin{array}{l}\text { Cloud Canyon near Gallinas, } \\
\text { N. Mex. }\end{array}$ & 16 & 34.133 & 105.667 & 30 & 1.85 & -- & 16.0 & 51.9 \\
\hline 08387000 & $\begin{array}{l}\text { Rio Ruidoso at Hollywood, } \\
\text { N. Mex. }\end{array}$ & 16 & 33.327 & 105.627 & 33 & 120.00 & 9,060 & 25.0 & 50.3 \\
\hline 08388000 & O Rio Ruidoso at Hondo, N. Mex. & 16 & 33.383 & 105.275 & 40 & 290.00 & 7,760 & 21.0 & 54.6 \\
\hline 08389000 & $\begin{array}{l}\text { Rio Bonito near Ft Stanton, } \\
\text { N. Mex. }\end{array}$ & 16 & 33.518 & 105.486 & 31 & 85.0 & 8,650 & 21.0 & 52.5 \\
\hline 08389060 & $\begin{array}{l}\text { Rio Bonito Tributary near } \\
\text { Ft Stanton, N. Mex. }\end{array}$ & 16 & 33.521 & 105.468 & 29 & 0.72 & -- & 16.0 & 52.5 \\
\hline 08389500 & Rio Bonito at Hondo, N. Mex. & 16 & 33.389 & 105.275 & 38 & 295.00 & 7,900 & 19.0 & 54.6 \\
\hline 08390050 & $\begin{array}{l}\text { Rio Hondo Tributary at Tinnie, } \\
\text { N. Mex. }\end{array}$ & 16 & 33.371 & 105.217 & 14 & 0.23 & 5,150 & -- & 55.7 \\
\hline 08390100 & Rio Bondo at Picacho, N. Mex. & 16 & 33.357 & 105.157 & 14 & 715.00 & 7,740 & 20.0 & 58.0 \\
\hline 08390150 & Gallo Canyon near Picacho, N. Mex. & 16 & 33.290 & 105.180 & 24 & 1.32 & -- & -- & 57.8 \\
\hline 08390500 & $\begin{array}{l}\text { Rio Bondo at } D i \text { amond } A \text { Ranch } \\
\text { near Roswell, N. Mex. }\end{array}$ & 16 & 33.349 & 104.851 & 47 & 947.00 & 7.400 & 18.0 & 65.6 \\
\hline 08393200 & $\begin{array}{l}\text { Rocky Arroyo above Two R } \\
\text { Reservoir near Roswell, N. Mex. }\end{array}$ & 16 & 33.285 & 104.796 & 18 & 31.00 & 4,550 & 13.4 & 66.9 \\
\hline 08393600 & $\begin{array}{l}\text { North Spring River at Roswell, } \\
\text { N. Mex. }\end{array}$ & 16 & 33.396 & 104.548 & 28 & 19.50 & 3,600 & 12.0 & 72.7 \\
\hline 08393900 & $\begin{array}{l}\text { Eight Mile Draw near Roswell, } \\
\text { N. Mex. }\end{array}$ & 16 & 33.417 & 104.650 & 35 & 397.00 & 3,740 & 14.3 & 70.4 \\
\hline
\end{tabular}




\begin{tabular}{|c|c|c|c|c|c|c|c|c|c|c|c|c|}
\hline \multirow{2}{*}{$\begin{array}{l}\text { Station } \\
\text { number }\end{array}$} & \multicolumn{5}{|c|}{$\begin{array}{c}\text { Rolution } \\
\text { characteristic }\end{array}$} & \multicolumn{6}{|c|}{$\begin{array}{l}\text { Peak discherse (cublc feet per eecond) for } \\
\text { indiceted recurrence lntervel (rears) }\end{array}$} & \multirow{2}{*}{$\begin{array}{l}\text { Meximu } \\
\text { peak discherse } \\
\text { of record } \\
\text { (cublc feet } \\
\text { per second) }\end{array}$} \\
\hline & $\frac{\mathrm{ch}}{\mathrm{L}}$ & B & $D$ & 0 & $\frac{625}{U}$ & 2 & 5 & 10 & 25 & 50 & 100 & \\
\hline 08379300 & 0 & 0 & 0 & 0 & 0 & $\begin{array}{l}1,360 \\
1,350\end{array}$ & $\begin{array}{l}3,500 \\
3,390\end{array}$ & $\begin{array}{l}5,850 \\
5,250\end{array}$ & $\begin{array}{r}10,300 \\
9,950\end{array}$ & $\begin{array}{l}14,800 \\
14,000\end{array}$ & $\begin{array}{l}21,000 \\
20,300\end{array}$ & 20,000 \\
\hline 08379500 & 1 & 0 & 0 & 0 & 0 & $\begin{array}{l}6,440 \\
6,420\end{array}$ & $\begin{array}{l}11,500 \\
11,300\end{array}$ & $\begin{array}{l}16,100 \\
15,400\end{array}$ & $\begin{array}{l}23,600 \\
23,500\end{array}$ & $\begin{array}{l}30,600 \\
30,500\end{array}$ & $\begin{array}{l}38,900 \\
38,600\end{array}$ & 73,000 \\
\hline 08379550 & - & - & - & - & 1 & 233 & 722 & 1,110 & 1,870 & 2,630 & 4,200 & 1,440 \\
\hline 08379600 & - & - & - & - & 1 & 32 & 115 & 187 & 309 & 464 & 608 & 184 \\
\hline 08380300 & 0 & 0 & 0 & 0 & 0 & $\begin{array}{l}91 \\
92\end{array}$ & $\begin{array}{l}371 \\
397\end{array}$ & $\begin{array}{l}812 \\
836\end{array}$ & $\begin{array}{l}1,950 \\
1,900\end{array}$ & $\begin{array}{l}3,500 \\
3,260\end{array}$ & $\begin{array}{l}6,010 \\
5,610\end{array}$ & 2.530 \\
\hline C8380500 & 1 & 0 & 1 & 0 & 0 & $\begin{array}{l}618 \\
618\end{array}$ & $\begin{array}{l}1,610 \\
1,630\end{array}$ & $\begin{array}{l}2,660 \\
2,700\end{array}$ & $\begin{array}{l}4,570 \\
4,590\end{array}$ & $\begin{array}{l}6,490 \\
6,520\end{array}$ & $\begin{array}{l}8,910 \\
9,080\end{array}$ & 7,120 \\
\hline 08381000 & 0 & 0 & 0 & 0 & 0 & $\begin{array}{l}480 \\
481\end{array}$ & $\begin{array}{l}1,200 \\
1,250\end{array}$ & $\begin{array}{l}1,940 \\
2,140\end{array}$ & $\begin{array}{l}3,230 \\
3,340\end{array}$ & $\begin{array}{r}4,500 \\
4,740\end{array}$ & $\begin{array}{l}6,060 \\
6,510\end{array}$ & 11,600 \\
\hline 08382000 & 0 & 0 & 0 & 0 & 0 & $\begin{array}{l}2,780 \\
2,740\end{array}$ & $\begin{array}{l}4,120 \\
4,090\end{array}$ & $\begin{array}{l}5,040 \\
5,520\end{array}$ & $\begin{array}{l}6,240 \\
7,150\end{array}$ & $\begin{array}{l}7,140 \\
8,440\end{array}$ & $\begin{array}{r}8,070 \\
12,700\end{array}$ & 6,680 \\
\hline 08382500 & 1 & 0 & 0 & 0 & 0 & $\begin{array}{l}3,410 \\
3,400\end{array}$ & $\begin{array}{l}6,450 \\
6,460\end{array}$ & $\begin{array}{l}9,090 \\
9,290\end{array}$ & $\begin{array}{l}13,200 \\
13,600\end{array}$ & $\begin{array}{l}16,900 \\
18,000\end{array}$ & $\begin{array}{l}21,200 \\
23,400\end{array}$ & 26,700 \\
\hline 08382900 & - & - & - & - & 1 & 346 & 1,090 & 1,700 & 2,950 & 4,260 & 6,300 & 6,600 \\
\hline 08383200 & 0 & 0 & 0 & 0 & 0 & $\begin{array}{l}90 \\
95\end{array}$ & $\begin{array}{l}163 \\
301\end{array}$ & $\begin{array}{l}224 \\
788\end{array}$ & $\begin{array}{l}314 \\
640\end{array}$ & $\begin{array}{r}391 \\
1,110\end{array}$ & $\begin{array}{r}477 \\
1,520\end{array}$ & 305 \\
\hline 08383210 & - & - & - & - & 1 & --- & --- & 280 & 460 & 668 & 965 & 145 \\
\hline 08383300 & 1 & 0 & 0 & 0 & 0 & $\begin{array}{l}1,940 \\
1,960\end{array}$ & $\begin{array}{l}3,270 \\
3,900\end{array}$ & $\begin{array}{l}4,180 \\
6,880\end{array}$ & $\begin{array}{l}3.300 \\
7.200\end{array}$ & $\begin{array}{r}6,110 \\
10,500\end{array}$ & $\begin{array}{r}6,880 \\
13,400\end{array}$ & 4,300 \\
\hline 08383370 & 1 & 1 & 0 & 0 & 0 & $\begin{array}{l}97 \\
97\end{array}$ & $\begin{array}{l}225 \\
222\end{array}$ & $\begin{array}{l}361 \\
351\end{array}$ & $\begin{array}{l}619 \\
612\end{array}$ & $\begin{array}{l}892 \\
884\end{array}$ & $\begin{array}{l}1,250 \\
1,220\end{array}$ & 1,450 \\
\hline 08385530 & - & - & - & - & 1 & 327 & 1,080 & 1,710 & 3,040 & 4,490 & 5,960 & 2,850 \\
\hline 08385600 & 1 & 0 & 0 & 0 & 0 & $\begin{array}{l}1,430 \\
1,440\end{array}$ & $\begin{array}{l}3,510 \\
3,710\end{array}$ & $\begin{array}{l}5,700 \\
6,450\end{array}$ & $\begin{array}{r}9,690 \\
10,200\end{array}$ & $\begin{array}{l}13,800 \\
15,000\end{array}$ & $\begin{array}{l}18,900 \\
20,400\end{array}$ & 14,800 \\
\hline 08385670 & 1 & 0 & 0 & 0 & 0 & $\begin{array}{l}478 \\
473\end{array}$ & $\begin{array}{l}791 \\
768\end{array}$ & $\begin{array}{l}1,040 \\
1,020\end{array}$ & $\begin{array}{l}1,410 \\
1,440\end{array}$ & $\begin{array}{l}1,720 \\
1,840\end{array}$ & $\begin{array}{l}2,060 \\
2,300\end{array}$ & 1,610 \\
\hline 08385690 & - & - & - & - & 1 & 55 & 187 & 297 & 490 & 714 & 1,030 & 112 \\
\hline 08385700 & - & - & - & - & 1 & 99 & 327 & 514 & 858 & 1,240 & 1,830 & 706 \\
\hline 08387000 & 1 & 0 & 0 & 0 & 0 & $\begin{array}{l}255 \\
262\end{array}$ & $\begin{array}{l}563 \\
741\end{array}$ & $\begin{array}{r}892 \\
1,600\end{array}$ & $\begin{array}{l}1,510 \\
1,910\end{array}$ & $\begin{array}{l}2,160 \\
3,010\end{array}$ & $\begin{array}{l}3,020 \\
4,350\end{array}$ & 2,120 \\
\hline 08388000 & 1 & 0 & 0 & 0 & 0 & $\begin{array}{l}944 \\
949\end{array}$ & $\begin{array}{l}2,440 \\
2,580\end{array}$ & $\begin{array}{l}4,270 \\
4,700\end{array}$ & $\begin{array}{l}8,150 \\
8,340\end{array}$ & $\begin{array}{l}12,700 \\
13,000\end{array}$ & $\begin{array}{l}19,400 \\
19,900\end{array}$ & 42,700 \\
\hline 08389000 & 0 & 0 & 0 & 0 & 0 & $\begin{array}{l}600 \\
601\end{array}$ & $\begin{array}{l}1,580 \\
1,640\end{array}$ & $\begin{array}{l}2,550 \\
2,730\end{array}$ & $\begin{array}{l}4,070 \\
4,210\end{array}$ & $\begin{array}{l}5,380 \\
5,720\end{array}$ & $\begin{array}{l}6,810 \\
7,560\end{array}$ & 4.100 \\
\hline 08389060 & - & - & - & - & 1 & $-\cdots$ & --- & 337 & 559 & 818 & 1,170 & 512 \\
\hline 08389500 & 0 & 0 & 0 & 0 & 0 & $\begin{array}{l}1,990 \\
1,980\end{array}$ & $\begin{array}{l}5,060 \\
4,970\end{array}$ & $\begin{array}{l}8,020 \\
7,540\end{array}$ & $\begin{array}{l}12,800 \\
12,600\end{array}$ & $\begin{array}{l}17,100 \\
16,800\end{array}$ & $\begin{array}{l}22,100 \\
22,400\end{array}$ & 28,200 \\
\hline 08390050 & - & - & - & - & 1 & 38 & 134 & 217 & 360 & 537 & 716 & 420 \\
\hline 08390100 & - & - & - & - & 1 & 2,400 & 6,760 & 10,100 & 18,300 & 25,400 & 42,100 & 125,000 \\
\hline 08390150 & - & - & - & - & 1 & 96 & 328 & 524 & 887 & 1,310 & 1,800 & 2,400 \\
\hline 08390500 & 0 & 0 & 0 & 0 & 0 & $\begin{array}{l}3,090 \\
3,090\end{array}$ & $\begin{array}{l}9,680 \\
9,640\end{array}$ & $\begin{array}{l}18,200 \\
17,300\end{array}$ & $\begin{array}{l}36,800 \\
36,100\end{array}$ & $\begin{array}{l}58,800 \\
56,400\end{array}$ & $\begin{array}{l}90,500 \\
87,400\end{array}$ & 54,800 \\
\hline 08393200 & 0 & 0 & 0 & 0 & 0 & $\begin{array}{l}664 \\
662\end{array}$ & $\begin{array}{l}2,450 \\
2,340\end{array}$ & $\begin{array}{l}4,760 \\
3,860\end{array}$ & $\begin{array}{l}9,520 \\
8,840\end{array}$ & $\begin{array}{l}14,800 \\
13,100\end{array}$ & $\begin{array}{l}21,800 \\
18,500\end{array}$ & 12,000 \\
\hline 08393600 & 2 & 0 & 0 & 0 & 0 & $\begin{array}{l}13 \\
20\end{array}$ & $\begin{array}{r}71 \\
251\end{array}$ & $\begin{array}{l}162 \\
893\end{array}$ & $\begin{array}{l}380 \\
805\end{array}$ & $\begin{array}{r}646 \\
1,610\end{array}$ & $\begin{array}{l}1,030 \\
2,120\end{array}$ & 387 \\
\hline 08393900 & - & - & - & - & 1 & 2,200 & 6,520 & 9,980 & 18,400 & 26,200 & 38,700 & 22,200 \\
\hline
\end{tabular}




\begin{tabular}{|c|c|c|c|c|c|c|c|c|c|}
\hline $\begin{array}{l}\text { Station } \\
\text { number }\end{array}$ & Station name & $\begin{array}{l}\text { Flood } \\
\text { region }\end{array}$ & $\begin{array}{l}\text { Lati- } \\
\text { tude, in } \\
\text { decimal } \\
\text { degroes }\end{array}$ & $\begin{array}{l}\text { Long1- } \\
\text { tude, in } \\
\text { decimal } \\
\text { degrees }\end{array}$ & $\begin{array}{l}\text { Years } \\
\text { of } \\
\text { record }\end{array}$ & $\begin{array}{l}\text { Drainage } \\
\text { area, in } \\
\text { square } \\
\text { miles }\end{array}$ & $\begin{array}{l}\text { Mean } \\
\text { basin } \\
\text { leva- } \\
\text { tion, } \\
\text { in } \\
\text { fect }\end{array}$ & $\begin{array}{l}\text { Mean } \\
\text { annual } \\
\text { precipi- } \\
\text { tation, } \\
\text { in } \\
\text { inches }\end{array}$ & $\begin{array}{l}\text { Mean } \\
\text { annual } \\
\text { evapor- } \\
\text { ation, } \\
\text { in } \\
\text { inches }\end{array}$ \\
\hline 08394500 & $\begin{array}{l}\text { Rio Felix at Old Bwy Bridge, } \\
\text { near Hagerman, N. Mex. }\end{array}$ & 16 & 33.125 & 104.344 & 56 & 932.00 & 7,070 & 16.0 & 77.6 \\
\hline 08397600 & $\begin{array}{l}\text { Rio Penasco near Dunken, } \\
\text { N. Mex. }\end{array}$ & 16 & 32.882 & 105.178 & 33 & 583.00 & 8,000 & 21.0 & 55.8 \\
\hline 08398500 & Rio Penasco at Dayton, N. Mex. & 16 & 32.743 & 104.414 & 35 & 1.060 .00 & 7.000 & 18.0 & 75.9 \\
\hline 08400000 & $\begin{array}{l}\text { Fourmile Draw near Lakewood, } \\
\text { N. Mex. }\end{array}$ & 16 & 32.672 & 104.369 & 34 & 265.00 & 4.685 & 14.0 & 76.8 \\
\hline 08401200 & $\begin{array}{l}\text { South Seven Rivers near Lakewood, } \\
\text { N. Mex. }\end{array}$ & 16 & 32.589 & 104.421 & 24 & 220.00 & 4,020 & 14.0 & 75.0 \\
\hline 08401800 & $\begin{array}{l}\text { Rocky Arroyo near Carlsbad, } \\
\text { N. Mex. }\end{array}$ & 16 & 32.467 & 104.467 & 14 & 254.00 & 4,890 & 13.2 & 72.3 \\
\hline 08401900 & $\begin{array}{l}\text { Rocky Arroyo at Bwy Bridge } \\
\text { naar Carlsbad, N. Mex. }\end{array}$ & 16 & 32.506 & 104.374 & 23 & 285.00 & 4.630 & 14.5 & 76.2 \\
\hline 08405050 & $\begin{array}{l}\text { Last Change Canyon Iributary } \\
\text { near Carlsbad Caverns, N. Mex. }\end{array}$ & 16 & 32.292 & 104.606 & 28 & 0.20 & 4,180 & 13.9 & 65.5 \\
\hline 08405100 & $\begin{array}{l}\text { Mosley Canyon near White City, } \\
\text { N. Mex. }\end{array}$ & 16 & 32.250 & 104.333 & 28 & 14.60 & 3,625 & $\cdots$ & 74.6 \\
\hline 08405500 & $\begin{array}{l}\text { Black River above Malaga, } \\
\text { N. Mex. }\end{array}$ & 16 & 32.229 & 104.151 & 41 & 343.00 & 4,540 & 15.0 & 80.2 \\
\hline 08408500 & $\begin{array}{l}\text { Delaware River near Red Bluff, } \\
\text { N. Mex. }\end{array}$ & 16 & 32.023 & 104.054 & 49 & 689.00 & 4,160 & 14.0 & 80.1 \\
\hline 08411500 & $\begin{array}{l}\text { Salt Screwbean Draw near Orla, } \\
\text { Tex. (Disc.) }\end{array}$ & 16 & 31.878 & 103.947 & 15 & 464.00 & 3,679 & 9.5 & 80.0 \\
\hline 08424500 & $\begin{array}{l}\text { Madera Canyon near Toyahvale, } \\
\text { Tex. (Disc.) }\end{array}$ & 16 & 30.868 & 103.969 & 17 & 53.80 & 5,984 & 12.0 & 67.4 \\
\hline 08431700 & Limpia Creek above Ft Davis, Tex. & 16 & 30.613 & 104.001 & 20 & 52.40 & -- & -- & 67.7 \\
\hline 08431800 & $\begin{array}{l}\text { Limpia Creok bolow Ft Davis, } \\
\text { Tex. (Disc.) }\end{array}$ & 26 & 30.681 & 103.792 & 16 & 227.00 & 5,546 & 18.0 & 67.4 \\
\hline 08435800 & $\begin{array}{l}\text { Coyanosa Draw near Ft Stockton, } \\
\text { Tex. (Disc.) }\end{array}$ & 16 & 31.041 & 103.137 & 15 & $1,180.00$ & $\cdots$ & -- & 76.0 \\
\hline 08444400 & $\begin{array}{l}\text { Three Mile Mesa Creek near } \\
\text { Ft Stockton, Tex. (Disc.) }\end{array}$ & 16 & 30.838 & 102.841 & 10 & 1.04 & -- & -- & 75.4 \\
\hline 08447020 & $\begin{array}{l}\text { Independence Creek near Sheffield, } \\
\text { Tex. }\end{array}$ & 16 & 30.452 & 101.733 & 11 & 763.00 & $\cdots$ & -- & 75.1 \\
\hline 08478500 & Mimbres River at Deming, N. Mex & 16 & 32.283 & 107.760 & 28 & 170.00 & 6,500 & 14.0 & 64.0 \\
\hline 08480650 & $\begin{array}{l}\text { Minnie Ball Draw near Three } \\
\text { Rivers, } N \text {. Mex. }\end{array}$ & 16 & 33.417 & 106.083 & 24 & 9.70 & 5,440 & 16.0 & 60.8 \\
\hline 08480700 & $\begin{array}{l}\text { Indian Creek near Three Rivers, } \\
\text { N. Mex. }\end{array}$ & 16 & 33.369 & 105.890 & 31 & 6.80 & 7,900 & 26.6 & 55.1 \\
\hline 08481000 & $\begin{array}{l}\text { Three Rivers at Three Rivers, } \\
\text { N. Mex. }\end{array}$ & 16 & 33.303 & 106.072 & 22 & 96.00 & 6,430 & 21.2 & 60.7 \\
\hline 08481100 & $\begin{array}{l}\text { Tularosa Basin Tributary } \\
\text { near Three Rivers, N. Mex. }\end{array}$ & 16 & 33.300 & 106.083 & 25 & 13.80 & 5,587 & 15.6 & 60.8 \\
\hline 08481500 & Rio Tularosa near Bent, N. Mex. & 16 & 33.145 & 105.897 & 41 & 120.00 & 7,580 & 21.0 & 56.3 \\
\hline 08482000 & $\begin{array}{l}\text { Rio Tularosa near Tularosa, } \\
\text { N. Mex. }\end{array}$ & 16 & 33.093 & 105.976 & 11 & 140.00 & 7.400 & 20.0 & 61.3 \\
\hline
\end{tabular}




\begin{tabular}{|c|c|c|c|c|c|c|c|c|c|c|c|c|}
\hline \multirow{2}{*}{$\begin{array}{l}\text { Station } \\
\text { numbor }\end{array}$} & \multicolumn{5}{|c|}{$\begin{array}{c}\text { Relation } \\
\text { characteristic }\end{array}$} & \multicolumn{6}{|c|}{$\begin{array}{l}\text { Pouk discharge (cublc loet por second) for } \\
\text { indicated recurrence interval (years) }\end{array}$} & \multirow{2}{*}{$\begin{array}{l}\text { Maxisoum } \\
\text { peat discharge } \\
\text { of record } \\
\text { (cubic leet } \\
\text { per eecond) }\end{array}$} \\
\hline & $\mathrm{L}$ & B & D & 0 & $v$ & 2 & 5 & 10 & 25 & 50 & 100 & \\
\hline 08394500 & - & - & - & - & 1 & 3.740 & 10.900 & 16700 & $-0--$ & $-2 .-$ & $6+-\overline{700}$ & 74,000 \\
\hline 08397600 & 1 & 0 & 0 & 0 & 0 & $\begin{array}{l}1,330 \\
1,340\end{array}$ & $\begin{array}{r}4,420 \\
4,560\end{array}$ & $\begin{array}{r}8,320 \\
8,420\end{array}$ & $\begin{array}{l}16,400 \\
16,300\end{array}$ & $\begin{array}{l}25,400 \\
24,800\end{array}$ & $\begin{array}{l}37,800 \\
37,600\end{array}$ & 70,000 \\
\hline 08398500 & 1 & 0 & 0 & 0 & 0 & $\begin{array}{l}2,520 \\
2,540\end{array}$ & $\begin{array}{l}7,540 \\
7,910\end{array}$ & $\begin{array}{l}13,500 \\
14,500\end{array}$ & $\begin{array}{l}25,300 \\
25,900\end{array}$ & $\begin{array}{l}38,000 \\
38,100\end{array}$ & $\begin{array}{l}55,000 \\
56,400\end{array}$ & 29,800 \\
\hline 08400000 & 1 & 1 & 0 & 0 & 0 & $\begin{array}{l}800 \\
814\end{array}$ & $\begin{array}{l}3,350 \\
3,610\end{array}$ & $\begin{array}{l}7,130 \\
7,680\end{array}$ & $\begin{array}{l}16,100 \\
16,200\end{array}$ & $\begin{array}{l}27,300 \\
26,900\end{array}$ & $\begin{array}{l}44,000 \\
42,800\end{array}$ & 29,300 \\
\hline 08401200 & - & - & - & - & 1 & 1,740 & 5,270 & 8,160 & 15,100 & 21,700 & 30,500 & 20,100 \\
\hline 08401800 & - & - & - & - & 1 & 1,800 & 5,420 & 8,360 & 15,400 & 22,100 & 31,700 & 63,300 \\
\hline 08401900 & - & - & - & - & 1 & 2,010 & 6,070 & 8,380 & 17,400 & 25,000 & 35,200 & 31,600 \\
\hline 08405050 & 1 & 0 & 0 & 0 & 0 & $\begin{array}{l}141 \\
140\end{array}$ & $\begin{array}{l}288 \\
272\end{array}$ & $\begin{array}{l}416 \\
366\end{array}$ & $\begin{array}{l}610 \\
592\end{array}$ & $\begin{array}{l}779 \\
760\end{array}$ & $\begin{array}{l}967 \\
945\end{array}$ & 683 \\
\hline 08405100 & 1 & 0 & 0 & 0 & 0 & $\begin{array}{l}1,870 \\
1,850\end{array}$ & $\begin{array}{l}3,610 \\
3,350\end{array}$ & $\begin{array}{l}5,200 \\
4,290\end{array}$ & $\begin{array}{l}7,800 \\
7,420\end{array}$ & $\begin{array}{r}10,200 \\
9,530\end{array}$ & $\begin{array}{l}13,100 \\
12,400\end{array}$ & 16,400 \\
\hline 08405500 & 0 & 1 & 0 & 0 & 0 & $\begin{array}{l}2,550 \\
2,550\end{array}$ & $\begin{array}{l}9,510 \\
8,300\end{array}$ & $\begin{array}{l}18,200 \\
16,500\end{array}$ & $\begin{array}{l}35,300 \\
34,200\end{array}$ & $\begin{array}{l}53,200 \\
50,400\end{array}$ & $\begin{array}{l}76,300 \\
72,700\end{array}$ & 74,600 \\
\hline 08408500 & 0 & 1 & 0 & 0 & 0 & $\begin{array}{l}3,790 \\
3,790\end{array}$ & $\begin{array}{l}10,600 \\
10,500\end{array}$ & $\begin{array}{l}18,800 \\
18,000\end{array}$ & $\begin{array}{c}35,400 \\
35,000\end{array}$ & $\begin{array}{l}54,100 \\
52,700\end{array}$ & $\begin{array}{l}80,000 \\
78,100\end{array}$ & 81,400 \\
\hline 08411500 & - & - & - & - & 1 & 2,700 & 8,080 & 12,500 & 23,400 & 33,500 & 46,800 & 40,600 \\
\hline 08424500 & - & - & - & - & 1 & 760 & 2,370 & 3,690 & 6,640 & 9,600 & 13,600 & 5,120 \\
\hline 08431700 & - & - & - & - & 1 & 754 & 2,350 & 3,670 & 6,600 & 9,550 & 13,500 & 8,610 \\
\hline 08431800 & 1 & 0 & 0 & 0 & 0 & $\begin{array}{l}1,930 \\
1,920\end{array}$ & $\begin{array}{l}3,010 \\
3,340\end{array}$ & $\begin{array}{l}3,820 \\
5,340\end{array}$ & $\begin{array}{l}4,970 \\
6,350\end{array}$ & $\begin{array}{l}5,900 \\
9,170\end{array}$ & $\begin{array}{r}6,910 \\
11,600\end{array}$ & 5,520 \\
\hline 08435800 & - & - & - & - & 1 & 4,140 & 12,000 & 18,200 & 34,400 & 48,600 & 71,500 & 12,600 \\
\hline 08444400 & - & - & - & - & 1 & 114 & 405 & 662 & $\overline{1,160}$ & 1,760 & 2,110 & 350 \\
\hline 08447020 & 1 & 1 & 0 & 0 & 0 & $\begin{array}{l}2,260 \\
2,300\end{array}$ & $\begin{array}{l}8,770 \\
8,980\end{array}$ & $\begin{array}{l}18,900 \\
16,600\end{array}$ & $\begin{array}{l}44,600 \\
40,700\end{array}$ & $\begin{array}{l}79,900 \\
66,500\end{array}$ & $\begin{array}{l}137,000 \\
114,000\end{array}$ & 78,100 \\
\hline 08478500 & 1 & 0 & 1 & 0 & 0 & $\begin{array}{l}666 \\
710\end{array}$ & $\begin{array}{l}1,220 \\
2,320\end{array}$ & $\begin{array}{l}1,660 \\
6,050\end{array}$ & $\begin{array}{c}2,280 \\
5,040\end{array}$ & $\begin{array}{l}2,780 \\
8,880\end{array}$ & $\begin{array}{r}3,310 \\
12,000\end{array}$ & 2,370 \\
\hline 08480650 & 1 & 0 & 0 & 0 & 0 & $\begin{array}{l}902 \\
892\end{array}$ & $\begin{array}{l}1,850 \\
1,720\end{array}$ & $\begin{array}{l}2,740 \\
2,290\end{array}$ & $\begin{array}{l}4,200 \\
4,000\end{array}$ & $\begin{array}{l}5,580 \\
5,230\end{array}$ & $\begin{array}{l}7,240 \\
6,910\end{array}$ & 4.970 \\
\hline 08480700 & - & - & - & - & 1 & 209 & 672 & 1,050 & 1,800 & 2,590 & 3,840 & 990 \\
\hline 08481000 & 0 & 0 & 0 & 0 & 0 & $\begin{array}{l}2,100 \\
2,080\end{array}$ & $\begin{array}{l}5,000 \\
4,670\end{array}$ & $\begin{array}{l}7,760 \\
6,470\end{array}$ & $\begin{array}{l}12,300 \\
11,700\end{array}$ & $\begin{array}{l}16,400 \\
15,300\end{array}$ & $\begin{array}{l}21,100 \\
20,300\end{array}$ & 15,000 \\
\hline 08481100 & 1 & 0 & 1 & 0 & 0 & $\begin{array}{l}267 \\
268\end{array}$ & $\begin{array}{l}948 \\
966\end{array}$ & $\begin{array}{l}1.760 \\
1,740\end{array}$ & $\begin{array}{l}3,280 \\
3,240\end{array}$ & $\begin{array}{r}4.820 \\
4,730\end{array}$ & $\begin{array}{l}6,750 \\
6,660\end{array}$ & 2.340 \\
\hline 08481500 & - & - & - & - & 1 & 930 & 2,750 & 4,180 & 7,380 & 10,400 & 16,600 & 4,280 \\
\hline 08462000 & - & - & - & - & 1 & 1,120 & 3,330 & 5,100 & 9,130 & 13,000 & 19,900 & 9,640 \\
\hline
\end{tabular}

